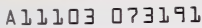

\section{GHE' NATL INST OF STANDARDS \& TECH R.I.C. (3)}

「 Joint A11103073191

QC100. U57 nce on Joint Conference on "
NBS SPECIAL PUBLICATION 584

\section{U.S. DEPARTMENT OF COMMERCE / National Bureau of Standards}

Joint Conference on Measurements and

0 Standards for Recycled Oil/Systems Performance and Durability

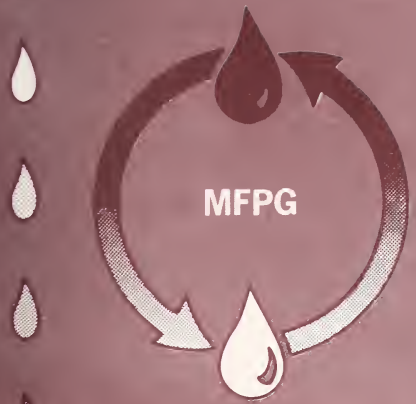

0 


\section{NATIONAL BUREAU OF STANDARDS}

The National Bureau of Standards' was established by an act of Congress on March 3, 1901. The Bureau's overall goal is to strengthen and advance the Nation's science and technology and facilitate their effective application for public benefit. To this end, the Bureau conducts research and provides: (1) a basis for the Nation's physical measurement system, (2) scientific and technological services for industry and government, (3) a technical basis for equity in trade, and (4) technical services to promote public safety. The Bureau's technical work is performed by the National Measurement Laboratory, the National Engineering Laboratory, and the Institute for Computer Sciences and Technology.

THE NATIONAL MEASUREMENT LABORATORY provides the national system of physical and chemical and materials measurement; coordinates the system with measurement systems of other nations and furnishes essential services leading to accurate and uniform physical and chemical measurement throughout the Nation's scientific community, industry, and commerce; conducts materials research leading to improved methods of measurement, standards, and data on the properties of materials needed by industry, commerce, educational institutions, and Government; provides advisory and research services to other Government agencies; develops, produces, and distributes Standard Relerence Materials; and provides calibration services. The Laboratory consists of the following centers:

Absolute Physical Quantities ${ }^{2}$ - Radiation Research - Thermodynamics and Molecular Science - Analytical Chemistry - Materials Science.

THE NATIONAL ENGINEERING LABORATORY provides technology and technical services to the public and private sectors to address national needs and to solve national problems; conducts research in engineering and applied science in support of these efforts; builds and maintains competence in the necessary disciplines required to carry out this research and technical service; develops engineering data and measurement capabilities; provides engineering measurement traceability services; develops test methods and proposes engineering standards and code changes; develops and proposes new engineering practices; and develops and improves mechanisms to transfer results of its research to the ultimate user. The Laboratory consists of the following centers:

Applied Mathematics - Electronics and Electrical Engineering ${ }^{2}$ - Mechanical

Engineering and Process Technology ${ }^{2}-$ Building Technology - Fire Research -

Consumer Product Technology — Field Methods.

THE INSTITUTE FOR COMPUTER SCIENCES AND TECHNOLOGY conducts research and provides scientific and technical services to aid Federal agencies in the selection, acquisition, application, and use of computer technology to improve effectiveness and economy in Government operations in accordance with Public Law 89-306 (40 U.S.C. 759), relevant Executive Orders, and other directives; carries out this mission by managing the Federal Information Processing Standards Program, developing Federal ADP standards guidelines, and managing Federal participation in ADP voluntary standardization activities; provides scientific and technological advisory services and assistance to Federal agencies; and provides the technical foundation for computer-related policies of the Federal Government. The Institute consists of the following centers:

Programming Science and Technology — Computer Systems Engineering.

Headquarters and Laboratories at Gaithersburg, MD, unless otherwise noted;

mailing address Washington, DC 20234.

Some divisions within the center are located at Boulder, CO 80303. 


\section{Joint Conference on Measurements and Standards for Recycled Oil/Systems Performance and Durability}

Proceedings of a Conference held at the National Bureau of Standards, DEC 151980 Gaithersburg, MD, October 23-26, 1979

Donald A. Becker, Editor

Office of Recycled Materials

National Measurement Laboratory

National Bureau of Standards

Washington, DC 20234

Sponsored by:

Recycled Oil Program

National Bureau of Standards

U.S. Department of Commerce

ASTM Technical Division P, on Recycled Petroleum Products

Mechanical Failures Prevention Group (MFPG)

Center for Materials Science. NBS

Office of Naval Research

Department of Energy

NASA/Goddard Space Flight Center

Naval Air Systems Command

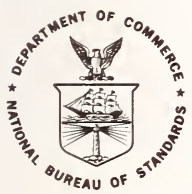

U.S. DEPARTMENT OF COMMERCE, Philip M. Klutznick, Secretary Luther H. Hodges, Jr., Deputy Secretary Jordan J. Baruch, Assistant Secretary for Productivity, Technology and Innovation NATIONAL BUREAU OF STANDARDS, Ernest Ambler, Director 
Library of Congress Catalog Card Number: 80-600159

National Bureau of Standards Special Publication 584

Nat. Bur. Stand. (U.S.), Spec. Publ. 584, 334 pages (Nov. 1980)

CODEN: XNBSAV

\section{U.S. GOVERNMENT PRINTING OFFICE}

WASHINGTON: 1980

For sale by the Superintendent of Documents, U.S. Government Printing Office, Washington, D.C. 20402 Price $\$ 8.00$

(Add 25 percent for other than U.S. mailing) 


\section{PREFACE}

On December 22, 1975, President Ford signed into law an act passed by the Congress of the United States entitled "The Energy Policy and Conservation Act of 1975" (Public Law 94-163). Section 383 of this act states that the National Bureau of Standards (NBS) shall develop test procedures "...for the determination of substantial equivalency of re-refined or otherwise processed used oil... with new oil for a particular end use." Further, NBS is to "... report such procedures to the [Federal Trade] Commission..." as soon as practicable. This NBS conference, held on October 23 through 26, 1979, is part of the continuing NBS response to this legislation.

This conference had a number of important objectives, including the following: 1) to obtain information and input to the NBS Recycled 0il Program from all relevant sources; 2) to report to you on the directions and progress being made towards the more effective re-use and utilization of our used petroleum resources; 3 ) to discuss the importance of used oil analysis in the performance of lubricating oil systems; and 4) to bring together in one place all of the different people involved with lubricating oils and their more effective utilization. From comments received during and after the conference, these objectives were achieved. Certain commercial materials and equipment are identified in this proceedings in order to specify adequately the experimental procedure. In no case does such identification imply recommendation or endorsement by the National Bureau of Standards, nor does it necessarily imply that the material or equipment identified is necessarily the best available for the purpose.

There were a total of 178 registrants at this meeting, with a breakdown as follows: 58 Government representatives (Federal Trade Commission, Department of Energy, NASA, Department of Defense, NBS, and seven States plus Puerto Rico and the province of Ontario, as well as representatives from the Canadian and West German Federal Governments); 101 representatives from private industries (engine manufacturers--8, virgin petroleum refiners and additive manufacturers--40, used $0 i 1$ re-refiners and recyclers--32 (including oil recyclers from Canada, West Germany, France, England and India), and other industry--21); and 19 attendees who were consultants or who represented consulting firms, testing laboratories, universities, or nonprofit organizations. Of the registrants described above, the foreign visitors total 24 with 13 from Canada, six from West Germany, two from England, and one each from France, India and the Netherlands.

It was felt that the conference participants again made a very important contribution to the available knowledge and understanding of the problems and opportunities in oil recycling and used oil analysis and evaluation. We plan to hold another conference on the testing and evaluation of recycled lubricating oil in the fall of 1981.

Donald A. Becker, Manager

Recycled 0 il Program 

This publication is a formal report of the Joint Conference on Measurements and Standards for Recycled 0il/Systems Performance and Durability held at the National Bureau of Standards on October 23 through 26, 1979. There were seven sessions on specific subject areas, with a total of 32 technical presentations. The subject areas were as follows: (I) Recent Developments in Recycled 0i1, (II) Engine $0 i 1$ Evaluation, (III) Lube $0 i 1$ Base Stock Characterization, (IV) $0 i 1$ Analysis for Engine Condition Monitoring, (V) Bench Tests for 0il Evaluation - I, (VI) Bench Tests for 0il Evaluation - II, and (VII) Systems Performance and Durability. Included in this report are the entire texts of the various presentations, including figures and tables.

Key words: Engine 0il; hydraulic 0i1; industrial oil; lubricating oil; oil specifications; petroleum standards; petroleum test methods; recycled oil; re-refined 0il; used oil; waste oil. 

OVERVIEW

Opening Remarks

E. Ambler

General Comments.......................... 5

P. Strigner

Brief Overview of the NBS Office of Recycled Materials (ORM) . . . . . . . . 7

H. Yakowitz

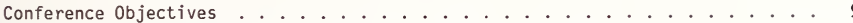

D. Becker, Recycled $0 i 1$

A. W. Ruff, MFPG

Session 1. RECENT DEVELOPMENTS IN RECYCLED OIL

Activities of the National Association of $0 i 1$ Recovery Coordinates . . . . . . 15

D. Eastep

The Maryland $0 i 1$ Recycling Legislation

C. Wiley and D. Phillips

Re-refining $0 i 1$ in India

M. Bhargava

Re-refining Waste 0i1s: Improving Acid/Clay Treatment by Using Acid Sludges

as an Additional Fuel in Cement Kilns . . . . . . . . . . . . . . . . 35

A. Rollin and L. Estaque

Session 2. ENGINE OIL EVALUATION

Status of the MIL-L-46152A Engine 0il Specification. . . . . . . . . . . . . 5 51

T. Bowen

Field Test of Re-refined Automobile Engine $0 i 1$ in RCMP Vehicles . . . . . . 55 J. Armstrong

PROP Re-refined $0 i 1$ Engine Test Performance. . . . . . . . . . . . . . . . 69

R. Linnard

Historical Perspective of Lubricant Deposit Evaluations at Southwest Research

Institute ....................... . . . . . . . . . . . . . .

J. Bowden and S. J. Lestz

Current Activities of the National Bureau of Standards Recycled 0il Program . . 97

D. Becker

Session 3. LUBE OIL BASE STOCK CHARACTERIZATION

ASTM/NBS Base Stock Consistency Study. . . . . . . . . . . . . . . . . 105 K. Frassa

Properties of Canadian Re-refined Base 0ils . . . . . . . . . . . . . 109 P. Strigner

Association of Petroleum Re-refiners Standards for Re-refined Base 0ils . . . . 123 R. Pedall 
The Viscometric Requirements for Re-refined Engine 0ils

T. Selby

Comments From a Producer of Virgin Base 0 il

D. Espey

Characterization of Lubricating Base Stocks for Automotive Crankcase 0ils

$\mathrm{S}$. Hsu

Session 4. OIL ANALYSIS FOR ENGINE CONDITION MONITORING

Wear Particle Equilibrium Measurements and Their Significance

R. D. Driver and E. R. Bowen

Used 0 il Analysis: Past, Present, and Future

C. Schwarz

Wear Particle Analysis from Grease-Lubricated Bearings . . . . . . . . . . . . . 173

W. Rosenlieb

Engine Condition Defined by 0 il Analysis

C. Salvesen

Session 5. BENCH TESTS FOR OIL EVALUATION - I.

Engine 0 il Evaluation Through Bench Testing

S. Hsu

Development of the Army Thermal Oxidation Lube 0il Tester 205

M. Valtierra and S. Lestz

Predictive Test Method for Coking and Fouling Tendency of Used

Lubricating 0 il.

G. Steele, D. Brinkman, and M. Whisman

Antioxidant Consumption and 0xidative Degradation of Lubricants.

S. Korcek, L. Mahoney, M. Johnson, and K. Otto

Application of the Antioxidant Capacity Test to Re-refined and Virgin Base

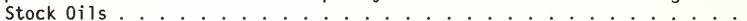

R. Rebbert

Session 6. BENCH TESTS FOR OIL EVALUATION - II.

Pin-and-V-Block and Ring-and-Block Bench Wear Tests for Engine $0 i 1$

Evaluation
L. Ives and $P$. Boyer

The Four-Ball Wear Test for Engine 0 il Evaluation.

R. Gates and S. Hsu

Application of Differential Scanning Calorimetry to the Characterization

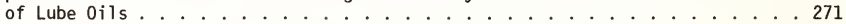

J. Walker and W. Tsang

Evaluation of Basestock and Formulated Lubes Using the Penn State

Microoxidation Test

E. Klaus, V. Krishnamachar, and H. Dang

Determination of Polychlorinated Biphenyls in Waste and

Lubricating $0 i l s$.
S. Chesler, W. May, P. White, R. Parris, and F. Guenther 
Session 7. SYSTEM PERFORMANCE AND DURABILITY

Lubricant Factors in Rolling Contact Fatigue . . . . . . . . . . . . . . . . . 301

c. Rowe

The Relationship Between Viscometric Laboratory Measurements and Field

Performance and Service. . . . . . . . . . . . . . . . . . 313

T. Selby

System Health Monitoring Through Wear Particle Analysis . . . . . . . . . . 329

P. Senholzi

Mechanical Failures and Lubrication Performance . . . . . . . . . . . . . 339

M. Peterson

LIST OF ATTENDEES . . . . . . . . . . . . . . . . . . . . . . . . . . 347 

OVERVIEW 



\section{OPENING REMARKS}

Good morning, and welcome to NBS. I am very pleased that this, the Third Recycled 0 il Conference, is co-sponsored by NBS, ASTM, and the Mechanical Failures Prevention Group. This cooperation demonstrates substantial interaction between various segments of industry, government, and academia. Together, we can make headway on the interrelated problems of lubricating oil quality and consistency, mechanical systems performance, durability and wear, energy conservation, and protection of the environment.

In my remarks at the 1976 Recycled $0 i 1$ Conference, I quoted a statement by Mr. Ted Gordon, President of the Futures Group. Mr. Gordon said:

\footnotetext{
"The use of recycling materials as a strategy to respond to increasing materials costs and uncertain availability is, of course, not new. What has changed are the equations by which the economics of such activities are evaluated."
}

In light of the petroleum situation of the last few months, these words are even more appropriate and important today. And the equations governing the economics of recycling and durability are still changing rapidly, almost always providing even stronger pressure in support of recycling. The pollution aspects of oil recovery and recycling are also gaining momentum, and the EPA hazardous waste regulations due in a few months will no doubt substantially affect these economic equations also.

The Energy Policy and Conservation Act of 1975 gave NBS some formidable technical challenges with respect to developing test procedures for the "substantial equivalency" of recycled oil to virgin 0il. The Recycled 0il Program has completed its work on Phase I, Test Procedures for Recycled $0 i 1$ Used as a Burner Fuel, and has transmitted these test procedures to the Federal Trade Commission. We are now addressing Phase II, the most difficult challenge, as well as perhaps the most important, namely test procedures for recycled oil used as motor oils. In this phase we will need the input and guidance represented by this audience.

In closing, let me once again provide some historical data. At the first Recycled 0il Conference, in 1976, there were 69 registrants. At the second Conference, 1977, there were 171 registrants. Today, at the start of this Conference, we already have over 170 registrants. It is very encouraging that all of you have taken the time from your busy schedules to be here with us. Certainly, we at NBS feel that providing for the exchange of information is a vitally important aspect of our work, and we are most pleased to co-sponsor this meeting.

Thanks again for coming, and we look forward to the contributions you will make.

Ernest Ambler

Director

National Bureau of Standards 



\title{
JOINT CONFERENCE ON MEASUREMENTS AND STANDARDS FOR RECYCLED OIL/SYSTEMS PERFORMANCE AND DURABILITY
}

\author{
P. Strigner \\ National Research Council of Canada \\ Division of Mechanical Engineering \\ Ottawa, Canada KIA OR6 \\ Introductory Remarks
}

As a joint sponsor of this conference dealing with test methods and standards for recycled oil used as automobile crankcase oil with NBS Recycled 0 il Program and MFPG, it is appropriate for me also on behalf of the officers and members of ASTM D-2, Technical Division $P$ and its sections to extend to you a warm welcome. May your presence here not only allow you to justify your journey to your employer, but also to enhance the proceedings. Judging by the program contents and the previous NBS recycled oil sessions organized by the Recycled 0il Program Manager, Don Becker, in all probability your stay here this week will meet this desirable dual objective. Unquestionably, the blend of new oil analyses and used oil monitoring for oil condition and engine or machine health is warranted.

To be fair the bulk of the credit for organizing and all of the credit for initiating this outstanding program must go to NBS and its outstanding personnel, five of whom I have had the pleasure of working with: Dr. J. J. Comeford, Dr. E. Passaglia, Dr. S. Hsu, Dr. H. Yakowitz and of course, Mr. Becker.

Touching on Technical Division $P$ activities the following points are worth mentioning:

1) Technical Division $P$ formed in December 1977 now has over 100 members. It meets twice a year at regular ASTM D-2 meetings.

2) NBS, which had a strong hand in the organization of Technical Division P, is a major contributor to its activities. Much needed basic laboratory work undertaken by the Recycled 0 il Program can very well lead to appropriate ASTM volunatry standards.

3) Contributions by the oil industry especially, but also by some additive and equipment manufacturers and users and Federal Government agencies, are super.

4) Contributions by the Association of Petroleum Re-refiners and by the re-refiners themselves need to be enlarged. Only Bob Pedall of Morco and George Booth III of Booth 0il have contributed in a large measure. One factor that could strengthen APR's contributions is an improvement in the members' own laboratory facilities, more regard for evaluation of product properties, and more verbal input and presence at Tech $P$ meetings, along with active participation in projected laboratory programs.

5) Tech $P$ acts as a strong forum bringing together producer, user, and general interest participation.

6) Regrettably, Tech $P$ is slow in the development of voluntary standard methods and specifications relating to recycled petroleum products and lubricants and/or rubber stamping existing ones relating to virgin products. Every effort will be made to speed up. One obstacle is the general absence of many ASTM standard specifications for lubricants. To meet pressures from ISO TC-28, such standards are now slowly being generated in ASTM D-2 in cooperation with other organizations.

7) To date, Tech $P$ has aided the U.S. Army in updating MIL-L-46152 to accommodate re-refined engine oils; has set up a task group in cooperation with NBS to study base stock consistency; is proposing some changes to ASTM D396 and VV-F-815d fuel specifications; is collecting virgin and recycled hydraulic fluid and industrial oil specifications; is preparing 
definitions for a number of recycled oil terms, and has asked some D-2 Research \& Development Divisions to develop a number of standard methods, e.g., for PCBs in oil and for metals in used oils and base stocks by rapid instrumental techniques. Of course, first hand information and minutes are readily available from Tech $P$ officers. 


\title{
BRIEF OVERVIEW OF THE NBS OFFICE OF RECYCLED MATERIALS (ORM)
}

\author{
Harvey Yakowitz \\ Chief, Office of Recycled Materials \\ National Bureau of Standards \\ Washington, DC 20234
}

The Office of Recycled Materials was created in the National Bureau of Standards reorganization of April 9, 1978. At present, this office consists of two programs, the Resource Conservation and Recovery Program and the Recycled 0il Program. These two efforts have existed at NBS since 1976. Both efforts were created in response to Congressional directives naming NBS to carry out specific tasks. Since you will be hearing more about the NBS Recycled $0 i 1$ Program in a few minutes, let me say a few words about the NBS Resource Recovery Program.

The Resource Conservation and Recovery Act of 1976 (PL 94-580) enacted October 21, 1976, directs the Secretary of Commerce, acting through NBS, to hold public hearings and publish guidelines (by 0ctober 21, 1978) for the development of specifications. These specifications are needed for the classification of materials which can be recovered from waste now destined for disposal. NBS is authorized to undertake work of this nature by 15, USC 272 which describes functions of the Secretary of Commerce to include "the determination of physical constants and properties of materials when such data are of great importance to scientific or manufacturing interests and are not to be obtained of sufficient accuracy elsewhere."

The nation generates about 145 million tons of municipal solid waste. Currently, over 93 percent of this waste is disposed by open dumping, "sanitary" landfilling, incineration or ocean dumping, all environmentally unsound methods. Alternatives to land disposal methods must be found since many cities in the U.S. will run out of suitable solid waste disposal sites by 1982. A method to do this is to separate metals, glass, and the organic fraction of this refuse from one another thus providing a potentially marketable set of commodities.

Large quantities of potential resources are being discarded in the waste. According to figures compiled by EPA, we annually discard about 20 percent of the nation's tin and aluminum requirements; 10 percent of its ferrous metal requirements; enough glass to replace a year's needs for glass containers; and enough organic material, which if converted to energy could provide up to 2 percent of current energy needs.

In enacting PL $94-580$, the Congress stated that:

1. Millions of tons of recoverable material which could be used are needlessly buried each year.

2. Methods are available to separate usable materials from solid waste.

3. The recovery and conservation of such materials can reduce the dependence of the United States on foreign resources and reduce the deficit in its balance of payments.

In order to carry out the program, NBS is conducting several projects to characterize recovered materials and establish the guidelines mandated in PL 94-580 and to evaluate existing, proposed and/or required specifications for these materials against the guidelines. The materials in question include ferrous metals, nonferrous metals (primarily aluminum), glass, paper, plastics, rubber, certain construction wastes, and refuse derived fuels. This provides a very short overview of the NBS Resource Recovery Program and our responsibilities there. 



\title{
CONFERENCE OBJECTIVES
}

\author{
D. A. Becker \\ Recycled 0 il Program \\ National Bureau of Standards \\ Washington, DC 20234
}

This conference is co-sponsored by ASTM Technical Division P, the Mechanical Failures Prevention Group, and the National Bureau of Standards (NBS) Recycled 0il Program. Paul Strigner has given you some insight on the workings of the ASTM Tech. $P$, and in a few minutes Bill Ruff of NBS will provide his comments on behalf of the Mechanical Failures Prevention Group. At this time, I will take several minutes to describe what the NBS Recycled 0il Program would like to see occur during this conference.

First, there are three general objectives which I discussed at our previous conferences, and which I hope will also be present at this Conference. They are as follows:

1) To obtain information and input to the NBS Recycled 0 il Program from all relevant sources;

2) To report to you on the directions and progress we are making on our legislative mandates; and

3) To bring together in one place all of the different people who are involved with the various aspects of lubricating oils--the producers, the testers, the users, the recyclers, and the regulators--to discuss new developments and recent changes in oil recycling, and the needs for measurement methods and standards for recycled oil.

During the Conference, we have tried to provide many opportunities for you, the participants, to meet and talk with the other participants--at coffee breaks, receptions, even on bus rides.

In addition to the above objectives, there is an additional objective oriented more towards the primary topic of this conference, engine oils. This objective is to provide a forum where the concerns and questions about possible widespread increased use of re-refined constituents in engine oils can be openly and objectively discussed. This conference, along with the many other NBS activities, will be important to establishing our Program as a strong, objective and technically oriented effort to establish the scientific and technical requirements for the effective reuse of re-refined oils.

In conclusion, when this Conference is concluded, I trust that we will be able to say that it has helped to provide a focal point on the subject of recycled oil--a forum in which hard technical questions can be asked, discussed, and answered, either now or after additional studies. I feel that this focus on the technical questions, rather than on political questions or emotional questions, can thus provide a strong foundation on which effective oil recycling can increase, and will provide for the optimum utilization of our limited resources of petroleum lubricating oil. 



\title{
CONFERENCE OBJECTIVES
}

\author{
A. W. Ruff \\ Mechanical Failure Prevention Group \\ National Bureau of Standards \\ Washington, DC 20234
}

Joint sponsorship of this Conference by the Mechanical Failures Prevention Group reflects the focus of MFPG technical activities on failure prevention and reliability in mechanical systems. This group, which is sponsored by NBS, ONR, NADC, DOE, and NASA, has the express purpose of stimulating voluntary cooperation among all segments of the national scientific and engineering communities to reduce the incidence of mechanical failure. The MFPG interest in oil analys is and monitoring of systems performance provides a strong common interest with the NBS Recycled 0 il Program. The MFPG operates through four technical committees as listed in the Conference Program. One of these, the Materials Durability Evaluation Committee, is responsible for the MFPG role in this Conference, particularly in organizing Sessions 4 and 7. The central theme of these invited papers is on system condition monitoring in lubricated systems, and on the related aspects of performance and durability. These are regarded as critical issues in the overall program for effective use of re-refined lubricants. 

Session 1

RECENT DEVELOPMENTS IN RECYCLED DIL 

National Bureau of Standards Special Publication 584. Proceedings of Joint Conference on Measurements and Standards for Recycled 0i1/Systems Performance and Durability held at NBS, Gaithersburg, MD, October 23-26, 1979. (Issued Nov. 1980)

\title{
ACTIVITIES OF THE NATIONAL ASSOCIATION OF OIL RECOVERY COORDINATORS
}

\author{
Don Eastep \\ National Association of 0 il Recovery Coordinators \\ Illinois Institute of Natural Resources \\ Springfield, IL 62708
}

As your first speaker of this morning, let me open by saying how happy I am that we can finally meet face-to-face. I have spoken to many of you by phone over the past year and a half, and I hope to be available tonight to go into detail with anyone on program specifics.

Last April the second, in Salt Lake City, representatives from 12 states met to discuss oil recovery. As a result of that meeting, the National Association of 0il Recovery Coordinators was formed. Membership in the Association was easy--be a member of Government and interested in the development of an oil recovery program in your state. One of our goals was to standardize our printed materials, such as posters, pamphlets, radio and TV PSA's, and news releases. This was tested during the charter meeting by making comments on the API Language that would go on the oil cans sold in New York. It was recommended that the API member present, Harold Tiffany, suggest that all motor oil sold in the U.S. be so labeled. This language was accepted by New York State and our other recommendation is being considered.

Another one of our objectives was to create an organization which would give us a voice within the industries we work with. As the association has grown to 35 states, so also has our voice become more effective.

When the Association first began, a number of the interest groups said they wanted to help, and for the most part, they just talked. They talked about incentives, promotional material, and technical assistance. It was not until we began to grow that these offers became real. In Illinois, one company donated 10000 bumper stickers. Another company offered us space in their national advertising as well as having their ad agency work with us. Public service radio spots were developed by one station which are being used now by several states. Professionally made video tape messages were prepared by the State of Oregon and have been re-edited for use by several states. Through the technical assistance program of the USEPA (Peer Match), it is possible for members to travel to other states. (This was how the Salt Lake City Meeting was funded.) The re-refining industry has been most cooperative. Companies from all around call and ask for the name of their state coordinator. I have received reports from coordinators telling of their success in getting programs started. They all say the same thing, without the cooperation of the interest groups, they would still be in a development stage instead of implementation.

Recently, I met with an inventor who had a plug for an oil pan. This would allow the do-it-yourselfer to change oil quickly and cleanly. The reason I mention this is to show that others are interested in the business of oil recovery. I can see in the next few years a new look to the re-refining industry. This will happen when the people who change oil are made aware of the value of recovery and the industry gets more aggressively involved in that recovery. We in the National Association of 0 il Recovery Coordinators are dedicated to that end. To work closely with the re-refiners, the major oil companies, the retailers of oil to the do-it-yourselfer, service stations and recycling centers, where used oil is brought in, and the scores of civic groups needed to coordinate these programs on the local level.

Let me talk a bit about the problem. How big is it and what can we do to help alleviate it. According to recent estimates ${ }^{1}$, in 1978 the total lubricant sales in the U.S. were 259100000 gallons. Of this, 1233000000 gallons went to the automotive market as crankcase oil and about 35 percent of this volume was consumed by the engine or lost through 
leakage. That gives us over 801450000 gallons of used crankcase oil. If 60 percent of the motor oil sold is through other than service stations, we have a do-it-yourself market that is responsible for 480870000 gallons of recoverable oil a year. If we add to that 50 percent of the non-SAE engine oils, such as railroad diesel, marine, and aircraft--the total is 462536000 gallons.

The general industrial lubricants sold in 1978 were 1016000000 gallons. Figuring about 60 percent recovery rate, we have another 610000000 gallons. The overall total of recoverable oil then would be more than one billion gallons.

The re-refining industry currently handles about 150000000 gallons a year (35 000000 gallons automotive, 115000000 gallons industrial). This ineans that there is more than 850000000 gallons per year not accounted for!

Where is it all going? An unknown amount of industrial oil is being recycled in-house.

A great deal of automobile oil is being dumped into sewers or just on the ground. Some of it is being burned, causing a serious environmental hazard; much of it goes to landfills. The only thing these methods have in common is that the oil is being disposed of--not recovered.

The economics of recovering this much oil is staggering. If we could recover 200 million gallons and re-refine it, we could have 150 million gallons of lube stock to place back on the market. On the other hand, based on API estimates of 1.5 percent lube stock per 42 gallons of crude, we would have to refine 238000000 barrels of crude to have the same amount $(238 \times 42$ $x 1.5 \%$ - 150 million gallons). To satisfy this segment of the market, it would cost us, in 1979 dollars, at $\$ 23.50$ a barrel, $\$ 5593000000$. When the price goes to $\$ 40.00$ a barrel, it will be $\$ 9520000000$. I realize that the rest of the barrel is also necessary. I also realize that others are working in areas dealing with the "rest of the barrel".

The President has said we will cut down on the import of crude. He has also given several guidelines as to how we can take up the slack. At this time, very little has come from Washington regarding used oil recovery as a viable alternative. Tomorrow morning I will be meeting with members of the White House Staff to discuss the possibility of a National 0 il Recovery Program. It would be premature to have any discussion of this at this time. However, I will advise the members of the Interagency Committee on Resource Recovery (ICORR) of the results.

To conclude, what can we do to help? I think the most important one thing is to educate the public; to inform them of the problem; to show them that used oil, even in quantities of one gallon, is worth something. It does not have to be dumped on roads for dust control. The farmers (one of the largest individual do-it-yourselfers) do not have to use it to kill weeds or pour it into a pit for their pigs to soak in.

I read somewhere once that it is better to have tried to do something and failed than to try nothing, and succeed. For years nothing has been done quite successfully. It is time now to try, not with the cloud of failure hanging over us, but with the idea in mind of how successful we will be. How much can we help with our energy problems--how much cleaner can we make our environment--how much money can we save? The answer is not just around the corner but it is closer now than ever before.

TJim Helms, Sun $0 i 1$ Co., The Changing Lube Market, Annual ASLE Meeting, May 1979. 
National Bureau of Standards Special Publication 584. Proceedings of Joint Conference on Measurements and Standards for Recycled 0il/Systems Performance and Durability held at NBS, Gaithersburg, MD, October 23-26, 1979. (Issued Nov. 1980)

\title{
THE MARYLAND OIL RECYCLING LEGISLATION
}

\author{
C. R. Willey and D. G. Phillips \\ Maryland Environmental Service \\ Maryland Department of Natural Resources \\ 60 West Street \\ Annapolis, MD 21401
}

\section{Introduction}

Maryland's 1978 Used 0il Recyling Act is the latest of a series of steps taken by the State to control oil and oily waste discharges into the environment. Before discussing details of this new law, and the program that evolved from it, it seems appropriate to review some of the actions that preceded its passage by the Maryland Legislature.

In the early 1970's Maryland began to recognize the magnitude of its waste oil problem $[1]^{1}$. It was estimated that some 18.5 million gallons of waste oil was generated yearly in the state, with about 7 million gallons estimated to be crankcase type oils [2], and, as a result of a decline in the oil recycling industry in the 1960's, many generators of waste oil were without means of disposal other than into the environment in one way or another. In addition, it was felt that the State needed to do more to prevent oil spills and respond to needs for oil spill cleanup.

As a result, legislation was passed granting the Department of Natural Resources broad authority to license the handling and storage of oil, to create the "Maryland $0 i 1$ Disaster Containment, Clean-up, and Contingency Fund", to promulgate regulations, develop an enforcement program to control discharges of oily wastes, and to carry out other functions necessary to prevent or control oil and oily waste contamination of both the land and waters of the State [3].

At the same time, the Maryland Environmental Service, which was then a newly formed State "waste management" agency [4], began to examine ways to improve the collection and reuse of waste oils $[2,5,6]$. The 1974 oil embargo, however, revived the oil recycling industry such that adequate collections were resumed, and plans for a State supported collection and recycling program were abandoned.

In 1975, then, with the State's regulatory and oil control program underway, waste oil collection by the recycling industry improved, and major sources of oil contamination under control, attention began to focus on "do-it-yourself" automotive crankcase waste oil, which still had no place to go but on the land, in the garbage, storm drains, and the like. Reports indicated that the numbers of people involved in this practice was increasing rapidly and that as a result several million gallons of used oil was entering the environment in Maryland each year. The need to collect and reuse this oil thus came to the attention of the State Legislature.

In 1976, after several meetings of an ad hoc task force to review proposed legislation, an oil recycling act patterned after part of the Federal Energy Administration (FEA) "Model Used 011 Act" [7] was prepared and introduced in the 1977 Maryland Legislature. Although the act was passed, it contained one requirement objectionable to the oil industry--that oil be sold in a "resealable" container. Subsequently, after a hearing, it was vetoed by the Governor of Maryland. When reintroduced in the 1978 session without this requirement, with the support of environmentalists and industry alike, the act was passed and became law in May of 1978. The primary intent of the law was environmental protection and, therefore, was made the responsibility of the Maryland Department of Natural Resources [8]. 


\section{The Maryland Used 0il Recycling Law}

Highlights of the new law are that it:

1) Requires an education program to inform the public of the needs for and the benefits of collecting and recycling used oil in order to conserve resources and preserve the environment.

2) Requires persons regularly engaged in the business of selling lubricating oil for use off the premises to post and maintain, at or near the point of display or sale, legible signs informing the public of the importance of proper collection and disposal of used oil, and how and where used oil may be disposed of.

3) Establishes a used oil information center to explain local, state, and federal laws and regulations governing used oil and to inform holders of quantities of used oil on how, where, and in what manner used oil may be properly disposed of.

4) Encourages the establishment of used oil collection and recycling programs and provides technical assistance to persons organizing these programs.

5) Encourages the use of labeling for oil containers to inform the user of the importance of proper collection and disposal of used oil.

6) Encourges State Inspection Stations, service stations, and other establishments with suitable facilities to serve as collection facilities for the deposit of used oil, with no cost to a person making the deposit. Each designated facility shall post and maintain a sign which indicates the facility is designated as a used oil disposal location. Each designated facility regularly shall remove and dispose, or have removed and disposed by used oil collectors, the accumulated oil in a manner as required by law.

7) Makes it illegal for a person to dispose or cause to be disposed any used oil by discharge, dump, or deposit into sewers, drainage systems, surfaces or ground waters, any waters in this State, or by incineration or as refuse, or onto any public or private land unless such land is designated by the State or by any of its agencies or political subdivisions as a collection facility and the used oil is placed in a receptacle or container installed or located on the property.

8) Establishes Penalties - a) Any person who violates any provision of this section of the law or any rule or regulation issued under the Act, in addition to any other penalties specifically provided by law, is subject to a civil penalty not exceeding $\$ 250$ for each violation. b) Any person who commits a second or subsequent violation, of any provision of this section or any rule or regulation issued pursuant thereto, in addition to any other penalties specifically provided by law, is guilty of a misdemeanor and, upon conviction, in a court of competent jurisdiction, is subject to a fine not exceeding $\$ 1000$ or imprisonment not exceeding two months, or both, with costs imposed at the discretion of the court.

\section{Responsibilities}

To implement the new law responsibilities were split between two agencies of the Department of Natural Resources. Enforcement became the jurisdiction of the Water Resources Administration Enforcement Program previously established to handle pollution violation. The educational program, designation of oil collection stations, and other aspects of the law were assigned to the Maryland Environmental Service to be carried out in conjunction with other waste recycling programs. 
The first step taken by the Maryland Environmental Service upon passage of the law was to provide the required "collection facilities" where used crankcase oil could be deposited. Most licensed Automobile Inspection Stations (about $1 / 3$ of the stations, garages, and car dealerships in the State) were contacted through the Automotive Safety Enforcement Division of the Maryland State Police over a two month period. Of those contacted, 410 agreed to serve as a collection facility; 493 refused. Additional survey programs were carried out by several volunteer organizations to bring the list of collection facilities up to just over 500 stations by midsummer of 1978 . (Since then, the number approaches 700. )

Step two was a letter to all 23 counties and Baltimore City to inform them of the law and request that each of them designate a person to assist with implementing the used oil recovery program.

Step three was to select a symbol that could be associated with the oil recycling program. Formation of a task force to do this was considered, as well as a contest; both were rejected because of the time involved. Instead what appeared to be an appropriate symbol was simply created. It was shown to oil industry representatives and others who had supported the legislation to determine if the symbol was acceptable, and it received their approval. The symbol and a sign created to identify used oil "collection facilities" is illustrated in figure 1 .

Step four was the preparation of a sign for display (under the law) by persons engaged in the business of selling oil for off-premise use. Various trade associations were contacted regarding the sign and it was agreed to keep the sign small. A $28 \times 34 \mathrm{~mm}$ sign, figure 2, was printed on heavy paper for distribution to major trade associations and directly to the main offices of major stores selling oil.

With the completion of these steps, a dedication ceremony was held August, 1978, as the first move bringing the program to the attention of the public. The attendance of several key elected officials helped to assure TV coverage, and press releases were sent to radio stations and newspapers throughout the State.

At the same time, an "information office" was established at the Maryland Environmental Service office to supply locations of used oil collection facilities, names of licensed oil handlers to stations needing oil pick-up service, and other information on proper disposal of 0 il.

Other steps taken have been: 1) the distribution of signs to collectors and oil retailers through county coordinators; 2) periodic meetings with county coordinators to encourage the use of the news media to publicize the Program; 3 ) distribution of brochures; 4) inclusion of introduction on proper disposal of oil and oil recycling in the Maryland Driver's Education Program; 5) inclusion of a section on oil recycling in the Maryland Driver's Handbook; and 6) the recent preparation of brochures to be distributed by the Maryland Motor Vehicle Administration to all persons renewing automobile tags at their offices.

Maryland also has joined with other States in encouraging oil companies, through the Maryland Petroleum Association-State Division of the American Petroleum Institute, to adopt the following labeling of oil:

$$
\text { "Don't Pollute - Conserve Resources - Return Used } 0 i 1 \text { to Collection Center" }
$$

\section{Evaluation of the Program}

Does the program work? Second question: how do we know?

$0 i 1$ handlers operating in Maryland are required by law to report quantities of crankcase and noncrankcase oil collected. The following amounts for crankcase oil have been reported: 


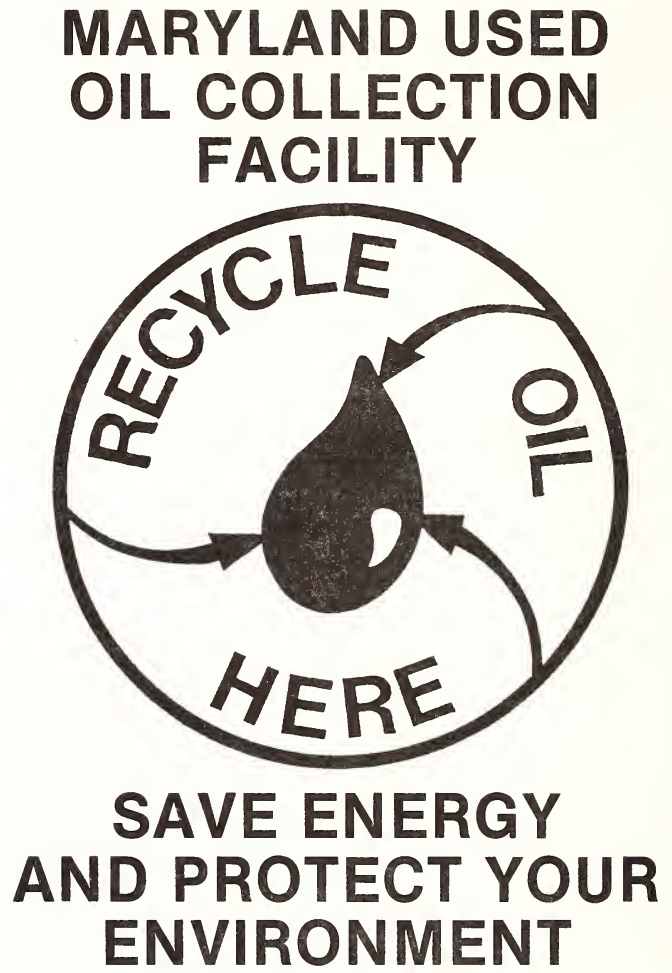

DEPT. OF NATURAL RESOURCES - MARYLAND ENVIRONMENTAL SERVICE

Figure 1. Reproduction of $40.6 \mathrm{~cm}$ (16 in) by 60.9 (24 in) metal sign used by the State of Maryland to identify used oil collection facilities. 
NOTICE TO MOTOR OIL BUYERS

DO YOU KNOW?

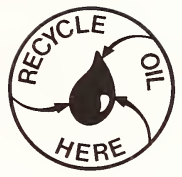

- THE STATE OF MARYLAND NOW HAS A LAW WHICH FORBIDS YOU TO DUMP USED OIL IN SEWERS, ON LAND, IN REFUSE OR IN THE WATER. FIRST TIME VIOLATORS ARE SUBJECT TO A MINIMUM OF A CIVIL PENALTY UP TO $\$ 250.00$.* $^{*}$

- YOUR USED OIL CAN BE RECYCLED TO CONSERVE ENERGY AND PROTECT THE ENVIRONMENT FROM POLLUTION.

- YOU CAN TAKE YOUR USED OIL TO THE SERVICE STATIONS AND RECYCLING CENTERS LISTED BELOW OR TO ANY FACILITY DISPLAYING THE "RECYCLE.OIL.HERE" SYMBOL SHOWN ABOVE.

FACILITIES IN THIS AREA THAT ACCEPT USED OIL FOR RECYCLING INCLUDE:

"EFFECTIVE JANUARY 1, 1979 ENFORCEMENT PROGRAM, WATER RESOURCES ADMINISTRATION, MARYLAND DEPARTMENT OF NATURAL RESOURCES.

FOR INFORMATION ON RECYCLING AND COLLECTION FACILITIES CONTACT THE MARYLAND ENVIRONMENTAL SERVICE, PHONE 301·269-3355.

Figure 2. Retyping of sign required by the State of Maryland to be posted by sellers of oil for off-premise use. (Original of sign could not be reproduced for publication.) 
January through June $1978-2.74$ million gallons

July through December 1978 - 3.69 million gallons

January through June 1979 - 4.52 million gallons

Substantial increases in the quantity reported collected have occurred during the brief period of reporting; however, it is impossible to determine what portion of the increase was the result of the recycling program, increased collection activity, or just better reporting.

In July of 1979 , a survey was made of 24 collection facilities in the Annapolis Baltimore areas of the State. Operators were asked about the numbers of people returning oil and the location of the "Recycle $0 i 1$ Here" sign (fig. 1) was checked. Answers ranged from none to 40 gallons per week with the average answer being a few gallons per week. Signs were displayed in windows or outside at $2 / 3$ of the stations contacted. A problem noted was that no one person could be counted on to know how much oil had been returned for recycling.

Stores retailing oil for off-premise use also were checked for presence of their required sign and the compliance was found to be rather poor. The problem seems to be one of educating individual store managers; although store headquarters personnel have been cooperative in the distribution of signs, it appears that not enough has been done to cause the individual stores to display the signs.

Judging from numbers of calls inquiring about oil collection facilities, people are learning about the law and the program. Progress in this respect though, has been hindered by a lack of funds. The law, unfortunately, was passed without supporting funds so that it has been necessary to manage the program with existing staff and modest support ( $\$ 10000)$ from Maryland's Energy Administration and assistance from the State's Motor Vehicle Administration. We believe we have done well with the resources available to us, but would suggest for other States of a similar size (4 million population) that to start such a program (exclusive of enforcement) that the program be provided with at least a staff of two, initially, and a budget of at least $\$ 75000$, exclusive of salaries. This amount would support the purchase of signs to identify oil recycling centers, a film for use in driver education training, production of TV and radio spots, advertising and other material for public education parts of the program.

\section{Future Plans}

The program is now seeking funds for more intensive efforts to inform the public of the law, the availability and locations of collection facilities, and the need for recycling oil. Emphasis will be placed on the energy savings aspects of recycling as well as the environmental.

There also appears to be a need for more public collection facilities. People using gas and go locations, which lack oil storage tanks for recycling, may be reluctant to drop oil at service stations they do not patronize. Collection at places such as fire departments may encourage greater participation.

A third area is communication with stations and car dealerships serving as collection facilities. Information must be made available to them to keep up their interest in the program and to continue educating new workers about the program.

\section{Conclusion}

In 1971 it was estimated that 28 percent of automotive oil was changed by the "do-ityourself" person. The estimate is now 50 percent. Based on automobile registrations and three gallons per car per year, an estimated 3.3 million gallons of waste oil, therefore, is now drained from automobiles each year. It is indeed important that we provide for the collection and reuse of this oil. 
[1] Shields, W. H. and Miles, W. A., Used 0ils: A Waste? Or a Resource?, Maryland Environmental Service and Maryland Department of Health and Mental Hygiene, p. 32 (1971).

[2] Waste 0il Recovery Practices: State of the Art, Report for Maryland Environmental Service and the U.S. Environmental Protection Agency by Environmental Quality Systems, Inc., Washington, DC, p. 250 (1972).

[3] 0 il Discharge Containment, Control, and Clean-up, Natural Resources Article, Annotated Code of Maryland, Title 8, Subtitle 14, Article 8-1411 (1974).

[4] Maryland Environmental Service Law, Natural Resources Article of the Annotated Code of Maryland (Sections 3-101 to 3-131, 1979 Supplement) (1970).

[5] State of Maryland Waste 0 il Recovery and Reuse Program, EPA Technical Report, 670-1274-013, p. 248 (NTIS No. PB-234 446/3BE) (January, 1974).

[6] Waste 0il Recovery and Reuse Program - Residue Management, Report to the Maryland Environ. mental Service and the U.S. Environmental Protection Agency by GCA Corporation, Bedford, MA, p. 131 (Apri1, 1975).

[7] A Model Used 0il Recycling Act, Prepared by W. A. Irwin, Environmental Law Institute, Washington, DC for the Federal Energy Administration (1976).

[8] Maryland Used 0il Recycling Act, Natural Resources Article of the Annotated Code of Maryl and (Section 8-1411.1, 1979 Supplement) (1978). 

National Bureau of Standards Special Publication 584. Proceedings of Joint Conference on Measurements and Standards for Recycled 0il/Systems Performance and Durability held at NBS, Gaithersburg, MD, October 23-26, 1979. (Issued Nov. 1980)

\title{
RE-REFINING IN INDIA
}

\author{
M. K. Bhargava \\ Chemoleums Private Limited \\ Thiruneermalai Road \\ Chromepet Madras 44 \\ Madras, India
}

The Indian Institute of Petroleum, Dehra Dun made available its know-how for re-refining used engine oil to about 30 entrepreneurs. Out of these only a handful are utilizing their process. However, there are about 30 members in Petroleum Re-Refiners Association of India. After the certification scheme, as announced by the Ministry of Petroleum is complete, a true picture would emerge as to the actual number of re-refiners engaged in the proper re-refining of used engine oil. There do exist a large number of backyard reclaimers whose existence becomes possible due to high price of the virgin engine oil. The cost of the virgin oils are:

Technically Equivalent

\begin{tabular}{cccc}
\hline MIL-L-2104A/ & DEF & & Series \\
DEF2101C & 21010 & MIL-L-2104B & 3 oil \\
\hline
\end{tabular}

(Rates are packed in 205 liter drum or $\sim 54$ U.S. gals.)
1. Price per liter
Rs. 6.81
Rs. 6.98
Rs. 7.23
Rs. 7.73
2. Price per U.S. gal.
Rs. 25.78
26.42
27.37
29.26
3. Price per U.S. gal.
$\$ 3.22$
$\$ 3.30$
3.42
3.66

The backyard reclaimer found a ready market for his finished product by mixing improperly reclaimed oil with virgin oil or selling it as such in bulk or packed in smaller containers of the we11-known brands.

\section{Used $0 i 1$}

The used oils are sold by large fleet owners/government state transport undertakings in open auction and by the private fleet owners and other generators of used oil negotiation.

The price of used engine oil in bulk ranges from Rs. 2/-per 1iter to Rs. 3/-per 1iter (\$1 per U.S. gal. to $\$ 1.40$ per U.S. gal.). This high price requires a larger working capital for the recognized re-refiner. Fortunately, the used engine oil in our country has a lower additive content, is void of lead and is generally monogrades, thus making the re-refining comparatively easier than the European and American used engine oils which have a higher additive content, possibly contain lead, and are generally multigrade. The draining in our country is mainly from diesel engines.

The total consumption of lubricants in India is 500000 tons of which about 5 percent maximum comes to the recognized re-refining industry and the balance is either burnt or discarded. The Government of India has been encouraging in particular the Government undertakings to set up their own captive units for re-refining but these have not been so successful and the output of captive units is used for topping up purpose.

I would conclude by saying that "Oil is Politics" and with the establishment of a re-refined engine oil specification and registration of the re-refiners in our country, it is hoped that the Government will take a more positive step in encouraging the rerefining industry in our country (see attachments 1 and 2 ). 
Indian Specification for Re-Refined Automotive Internal Combustion Engine Lubricating 0 il

\section{Introduction}

The Indian Standards Institution (ISI) was established in 1947. The main objective of the Indian Standards Institution could briefly be described as being the promotion of standardization in the country through the preparation of specifications and the administration of quality certification mark scheme for products that comply with these specifications and it is governed by the Indian Standards Institution (Certification Marks Act 1952).

\section{Specification}

Generally, British and American standards have been adopted insofar as the petroleum products are concerned. Toward the end of 1976, the Minister of Petroleum announced with a view to curb the sale of spurious lubricating oils that all lubricants sold in the country must compulsorily carry ISI Mark. This announcement naturally caused anxiety in the trade, and in particular to the smaller oil companies who immediately applied for ISI Mark. Since the current specifications did not include performance and other stringent tests it became necessary to review all the lubricating oil specifications. The Ministry of Petroleum directed ISI to do so and ad hoc study groups were formed. In 1977, the study group for automotive oils submitted its report and in respect to the re-refined oil reported that since the feed stock was obtained from different sources it was very difficult to qualify the re-refined product without full engine testing. Thereafter, based on the representation made by the Petroleum Re-Refiners Association of India to the Minister of Industries it was decided in early 1978 that ISI would give its Mark to the Re-Refined 0il and the Re-Refining Industry would be registered with the Ministry of Petroleum, and the Ministry of Petroleum in turn would make available the used oil to the re-refiners and such other virgin base oils and additives they would require.

Accordingly, after much discussion the draft Specification for Re-Refined Automotive Internal Combustion Engine Lubricating 0il was finalized. In June 1979, the Ministry of Petroleum announced a scheme for registration of the re-refining units as per details enclosed.

The specification approved for the re-refined engine oils is: 1) HD Type 1 technically equivalent to DEF 2101/MIL-L-2104A; 2) HD Type 2 technically equivalent to DEF 2101D; and 3 ) HD Type 3 technically equivalent to obsolete MIL-L-2104B. The specification requires that the re-refined base oil corresponds to the requirements as in table 1 which follows.

The physico-chemical requirements of the re-refined engine oil is as shown in table 2 which follows.

The Department of Petroleum will depute a Technical Committee consisting of six members to determine the eligibility of the re-refining units for registration. This scheme has just been initiated and the period for registration will expire on September 26, 1979, provided no further extension is granted. The implementation of the scheme can only be known after the registration is completed.

The qualification certificate would be valid for 4 years. Full specification tests, including engine tests, are required to be carried out on one batch initially. Thereafter, the following are the requirements:

1) The physico-chemical requirements on both base stock and finished oil shall be met on each batch.

2) The same additive package and dosage to meet the required performance level shall be used for all subsequent batches. 
3) One screening test for oxidation stability and bearing corrosion characteristics on Petter W1/CLR L-38 shall be conducted once in each year to the satisfaction of the qualifying authority according to the procedure laid down by it with regard to sample collection and evaluation.

The specification suffers from the following:

1) The virgin base stock should be allowed to meet the viscosity requirements for some of the grades, particularly SAE 50 .

2) The finished oil is required to be labeled as "Re-Refined Engine 0il".

\section{Marking Fee}

ISI has announced the marking fee for re-refined engine oil as:

Rs. 10.00 per unit ( 1 kilo liter) for 1500 units

Rs. $\quad 8.00$ per unit for the next 1500 units

Rs. $\quad 5.00$ per unit for the remaining units

with a minimum of Rs. $15000 /$ - for an operative period of one year. In addition, the expenses for panel members for qualification approval and other tests such as qualification of engine test, approval of blending facilities and scrutiny of engine test data, will be borne by the manufacturer.

\section{Levels of Control}

ISI has announced the following quality controls:

1) All the physico-chemical tests as contained in the enclosed tables 1 and 2 for re-refined base oil and re-refined automotive combustion engine lubricating oil are to be carried out for each batch.

2) For every fifth batch, phosphorus, chlorine, sulphur, barium, calcium, zinc, and sulphated ash test is to be carried out.

3) Once a year Petter W1/CLR L-38 test for oxidation stability and bearing corrosion characteristics is to be carried out.

4) Once in four years, engine performance tests.

\section{Reaction of Engine Builders to the Re-refined}

Engine 0 il Specification

The initial response from the two major engine builders, Messrs. Ashok Leyland, Ltd., and Tata Engineering Locomotive Company Ltd. (TELCO), in our country has been positive. They have called for samples of re-refined engine oils for evaluation in their laboratories and field tests. It is hoped, within a short time, all the engine builders will, in principle, accept the re-refined engine oils. 


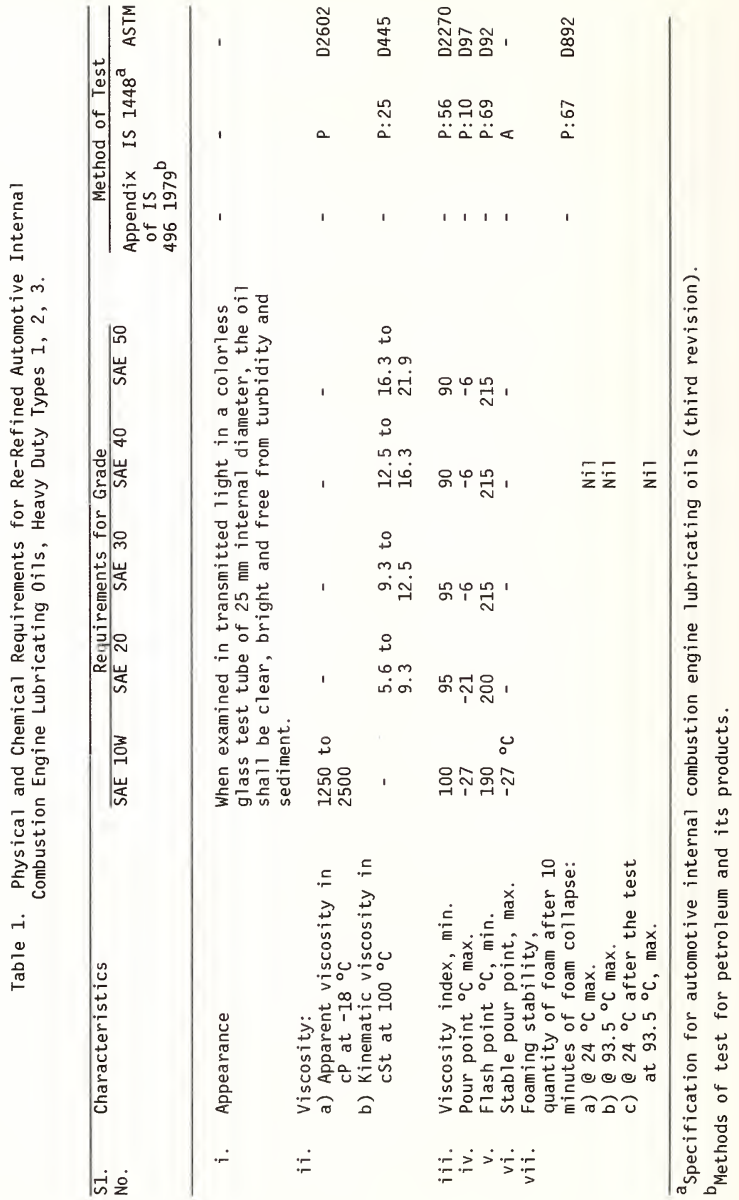




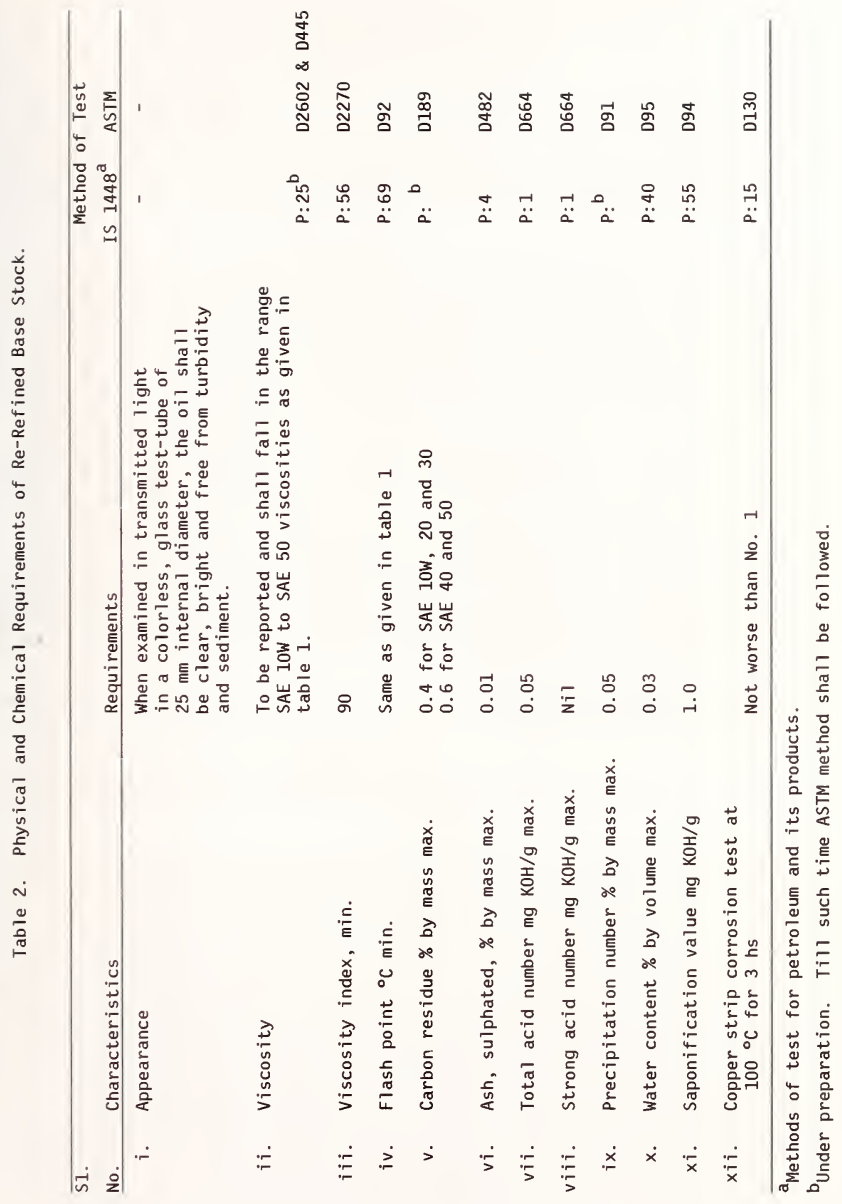


Government of India Ministry of Petroleum and Chemicals and Fertilizers

(Department of Petroleum)

The Director of Industries

Shastri Bhavan

New Delhi

26th June 1979

Subject: Introduction of a scheme for registration of units engaged in the re-refining of used automotive lubricating oils.

Sir,

I am directed to state that Government have decided to introduce a scheme of voluntary registration of Units engaged in Re-refining of Used Automotive Internal Combustion Engine Lubricants with the objective of ensuring that the end products conform to the desired quality standards while simultaneously guarding against the possibility of circulation of off specification and poorly reclaimed lubricants which not only cause serious damage to industrial equipment and machinery but can also be potential health hazard to the persons who handle them. The scheme provides for preliminary screening of the applications received from the units intending to get registered with the Department of Petroleum, followed by physical inspection of the facilities and know-how available with them for quality re-refining of used automotive lubricating oils. Simultaneously, the units are also required to obtain ISI Certification Mark which would be a pre-condition for their registration with the Department of Petroleum. After the task of registration of rerefining units has been completed it is proposed to take measures with a view to ensure that the bulk of the available Used Automotive Lubricant is supplied only to the re-refining units registered with Department of Petroleum.

A copy of the Press Note issued in the regard together with a set of detailed guidelines which are required to be observed by the Re-refining Units seeking registration is enclosed. It is requested that this scheme may be brought to the notice of all Re-refining Units functioning under your jurisdiction.

It is further requested that immediate action may kindly be initiated to facilitate early implementation of this scheme.

V. K. Misra

Deputy Secretary to the Government of India.

Press Note

Government has been greatly concerned over the circulation of spurious/substandard lubricants in the market which cannot only cause serious damage to industrial equipment and machinery but can also be a potential health hazard to the persons who handle them. The mushroom growth of backyard re-refiners and other unauthorized units, which are neither licensed nor registered and pass off their substandard products as the genuine stuff, very often in counterfeit tins and containers of the type in which well known brands of lubricating oils are marketed, has accordingly been a source of serious anxiety to the Government. Such parties reportedly market their goods unscrupulously through bazaar traders, garage owners, repair shops and bus and truck fleet operators, etc. The Central Government has already requested all the State Government/Union Territories to arrange for surprise checks both in respect to the clandestine operators as well as any of the retail outlets of the different oil companies which are suspected to be indulging in the malpractices. It has been emphasized that firm administrative action on their part would go a long way in containing this rapidly growing menace. Simultaneously, the oil companies have been asked to intensify their supervision and control over the movement and delivery of petroleum products from the lube blending plants to the recognized outlets for lube distribution and deal severely with defaulters. The have also been advised to launch a major publicity drive in order to bring about greater consumer awareness of the pitfalls of using substandard lubricants. 
In this background, Government has considered it necessary to pay special attention to the regulation of the lube oil re-refining industry. It is not generally known that if used lubricating oil is re-refined and fortified with the appropriate additives in a scientific manner, the resulting product is comparable in every way with virgin oil and yet has a significant price advantage over it. It is obviously desirable to encourage the production of scientifically re-refined lubricating oils in the interests of conservation of scarce petroleum products as well as economy to the consumers. The Government of India has accordingly decided, after detailed consultation with the various interests concerned, to introduce a scheme of voluntary registration of the re-refining units so that their products may be marketed under ISI Certification. It should be mentioned in this connection that the ISI has already formulated a set of specifications covering the re-refining of automotive internal combustion engine lubricating oils. Units which are not in a position to come up to these ISI standards will not be permitted to be registered under this scheme.

In the first phase, the scheme will cover the re-refining of automotive internal combustion engine lubricating oils which account for the major proportion of the total lube oil consumption in the country. The re-refining of used transformer hydraulic and other industrial and secondary oils will be considered for inclusion under this scheme at a later date. It is also intended that the Re-refining Units which get registered with the Department of Petroleum under this scheme, will be automatically entitled to the grant of $\mathrm{COB}$ (Carry on Business) Licence in the event of applicability of the Industries (Development \& Regulation) Act.

Applications for registration are required to be made to the Department of Petroleum through the Director of Industries of the State/Union Territories in which the Unit is located.

All existing units engaged in the re-refining process, whether on a captive or a commercial basis, may submit their applications for registration on the prescribed proforma to the Supply Division, Department of Petroleum, Shastri Bhavan, New Delhi, within a period of 90 days from the data of announcement of this scheme. The process of registration including issuance of certificate of registration, is expected to be completed within a period of 120 days from the date of receipt of the application in the Department of Petroleum.

New entrepreneurs wishing to enter this field may approach the Indian Institute of Petroleum, Dehradun, or the National Research \& Developing Corporation, New Delhi, for acquiring the technology and know-how for the re-refining of used lubricating oils in accordance with the appropriate ISI Standards.

Government hopes that this scheme will succeed in its object of making high quality re-refined lubricating oils available to the public at reasonable prices and putting out of business the Units/Parties which are selling substandard and counterfeit oils to unsuspecting buyers.

$$
\begin{gathered}
\text { Re-Refining of Used Automotive Internal Combustion Engine Crank-Case } \\
\text { Lubricating } 0 i 1 \mathrm{~s}
\end{gathered}
$$

Guidelines for introduction of a Scheme for Registration.

\subsection{Objective}

1.1. In the interests of ensuring that the activity of re-refining of used lubricating oils is undertaken on scientific lines and of ensuring desired quality standards in the final product, the Government of India has decided, after consultations with the Ministry of Industry, DGYD, DC (SSE), Indian Standards Institutions, oil companies, Indian Institute of Petroleum, Indian 0 il Corporation ( $\&$ \& Center), and the Petroleum Re-Refiners Association, that the activity of re-refining of used lubricating oils should be brought under a scheme of registration with the Central Government. The following are the details of the scheme. 


\subsection{Eligibility for Registration}

2.1. All units, whether already existing or yet to be set up, whether captive type or commercial type, will come under the scope of the registration, regardless of the quantum of capital investment or manpower employed.

\subsection{Registering Authority}

3.1. The Department of Petroleum will be the authority for registration until otherwise notified. The re-refining units which get registered with the Department of Petroleum under this scheme will automatically be entitled to the grant of a COB License (carrying on business) in the event of applicability of the industries (development and regulation) act.

\subsection{Procedure of Applying for Registration}

4.1. Applications for registration should be made on the prescribed proforma (Annexure I) in $5^{*} \times$ (6) copies to the Department of Petroleum, Shastri Bhavan, New Delhi, through the Director of Industries of the State/Union Territory in which the unit is located or to be located. The application form must contain all the information specified in the proforma.

4.2. Since the scheme of registration is also linked with the ISI Certification Mark (relating to engine oil from re-refined base stock) applicants should simultaneously apply to the Indian Standards Institution, Manak Bhavan, 9 Bahadur Shah Zafar Marg, New Delhi 110002 , for obtaining the ISI Certification Mark. The application form for this purpose will be as prescribed by the ISI.

\subsection{Mechanism for Registration}

5.1. The Department of Petroleum will constitute a Technical Committee comprised of a representative of that Ministry, DGTD, DC (SSI), Indian Institute of Petroleum, Indian $0 i 1$ Corporation ( $R$ \& D Center) and Indian Standards Institution, entrusted with the responsibility of technical scrutiny of the application in order to determine their eligibility for registration or otherwise. The Committee would like appropriate recommendations to the Department of Petroleum who will be responsible for a final decision. The Committee would meet as often as necessary.

\subsection{Times Schedule for Application}

6.1. All existing units engaged in the re-refining process whether captive or commercial type unit may submit their application for registration on the prescribed proforma to the Department of Petroleum within a period of 90 days from the date of announcement of this scheme.

6.2. New units may apply for registration as and when they are ready with their detailed scheme.

\subsection{Time Schedule for Registration}

7.1. The process of registration including issuance of the certificate of registration will be completed within a period of 120 days from the date of receipt of the application in the Department of Petroleum.

\subsection{Time Schedule for ISI Certification Mark}

8.1. Since the scheme of registration is linked to the issue of ISI Certification Mark, the ISI formalities on this account should be completed within a period of 90 days so as to enable the Department of Petroleum to complete the registration formalities within the stipulated period of 120 days. 
9.0. Guidelines for Registration

9.1. In the case of existing re-refining units, no application for registration would be entertained unless all the information stipulated in the proforma are furnished. In the case of new units such information will be required except the portion relating to past production and past level of consumption of input oils.

9.2. The Technical Committee shall satisfy itself, through physical inspection of the plant facility, about the units technical capability for the re-refining of used oils on scientific lines. The minimum general requirements for the used lubricating oils re-refining plant are stipulated.

9.3. There will be no registration without compliance with the requirement for obtaining ISI Certification Mark scheme relating to engine oils from re-refined base stock.

9.4. After obtaining the Certificate of Registration, it will be obligatory on the part of the applicant to submit to the Department of Petroleum, at the end of each quarter, details of production. New units will comply with this formality after the commencement of production. The Department of Petroleum may withdraw the Certificate of Registration in the event of noncompliance of this formality. Such action will be taken with the simultaneous advice to the oil companies, DGTD, DC (SSI) and the Director of Industries of the State/ Union Territory in which the re-refining unit is located.

10.0. Guidelines to oil companies on supply of base oils and additives.

10.1. Supply of virgin oil and additives by the oil companies or their subsidiaries will be made to the re-refining unit only on the basis of Certificate of Registration.

11.0. Guidelines to agencies concerned with supply and disposals of used oils.

11.1. Agencies of Central and State Government as well as public and private sector industrial enterprises who are bulk consumers of lubricating oils will not, henceforth, dispose of used lubricating oils in auction system or to contractors. Instead, they would make the used lubricating oils available only to the approved and registered re-refiners on the basis of the latters' accreditation with the Ministry of Petroleum. For this purpose, the Ministry of Petroleum will periodically circulate a list of registered re-refiners. 

National Bureau of Standards Special Publication 584. Proceedings of Joint Conference on Measurements and Standards for Recycled 0il/Systems Performance and Durability held at NBS, Gaithersburg, MD, October 23-26, 1979. (Issued Nov. 1980)

\title{
RE-REFINING WASTE OILS: IMPROVING ACIO/CLAY TREATMENT BY USING ACID SLUDGES AS AN ADDITIONAL FUEL IN CEMENT KILNS
}

\author{
A. L. Rollin and L. Estaque \\ Ecole Polytechnique of Montreal \\ P 6079 "A" \\ Montreal, CANADA
}

\begin{abstract}
An experimental burning of acid sludges was performed in a cement kiln for a one week period. These acid sludges, resulting from the acid/clay process used in re-refining waste crankcase oils, were used as an additional fuel. In this report a material balance on four toxic elements contained in the acid sludges shows their retention in the produced clinker. The cement produced from the test clinker had properties acceptable for commercial uses. The results of this experimental program indicate that the burning of acid sludge blends is an attractive way to increase the economics of the re-refining process and also prevent pollution.
\end{abstract}

\section{Re-refining Waste Oils. The Acid/Clay Treatment}

E. T. Cutler recently reports in a A.P.I. publication [2] ${ }^{1}$ that "re-refining could meet 58 percent of U.S. lube oil needs while conserving oil and preventing pollution". It has been clearly stated by many other scientists $[4,6,1]$ that re-refining appears to be the best way to conserve lube oils. However, among the different industrial processes presently used, the acid/clay treatment is known as the most expensive treatment [5] with the increased costs resulting from the disposal of the residues such as acid sludge and contaminated clay. The purpose of this report is to stress that the use of these acid sludges as an additional fuel burned in a cement kiln can represent an easy way to increase the economics of the process while avoiding pollution.

\section{Experimental Program}

An experimental program of burning waste oils was done at the St-Lawrence Cement Co. in Mississauga, Ontario in collaboration with the Canadian Environmental Service [1]. It was shown that waste oils could be used as additional fuel in a cement kiln without increasing the emission of toxic products in the flue gas. In fact the results indicated that the toxic elements, metals contained in the crankcase oils, were trapped in the produced clinker.

In view of these findings, it appeared interesting to repeat a similar program using acid sludge blends from the acid/clay treatment as the additional fuel. Since these blends contained the same toxic elements as used oils a similar behavior was forecast and the program would support oil conservation. Four goals were set for this program:

1) identification of toxic elements in the fuel mixture;

2) identification of toxic elements in the emission gas in the stack;

3) identification of toxic elements in the produced clinker; and

4) determination of some physical properties of the cement.

Thus, in April 1977, an industrial testing program was planned with the coordination of an engineering team from the Chemical Engineering Department of Ecole Polytechnique of

IFigures in brackets indicate the literature references at the end of this paper. 
Montreal. Tests were performed at the Canada Cement Lafarge Co. plant at St-Constant, Quebec, Canada and the program was done with the collaboration of: 1) the Northern 0 il Co., who supplied the acid sludge blend; 2) the Canada Cement Lafarge Co., who installed the combustion system, operated the kiln and sampled and analyzed samples of crude clinker and cement; 3) the Provincial Environmental Agencies who sampled and analyzed the flue gas; and 4) the Canadian Environmental Service who financed the program. The analysis of the fuel samples were performed at Ecole Polytechnique of Montreal.

\section{Experimental Installations}

The experimental installations can be divided into three parts: 1) the combustion system; 2) the acid sludge blends' circuit; and 3) the sampling outlets.

\section{The Combustion System}

As shown in figure 1 a temporary circuit was installed near the designated kiln. The fuel blend was fed to a secondary burner installed just beside the main burner of the kiln which was fed with a Bunker $C$ fuel. The fuel blend was atomized in the flame of the main burner at an approximate ratio of fuel blend to Bunker $C$ of 1 to 20. A storage tank, a filter, two pumps, a flowmeter, high and low pressure alarms, and a safety valve completed the combustion circuit. More details of the auxiliary burner and the characteristics of the accessories are available elsewere [3].

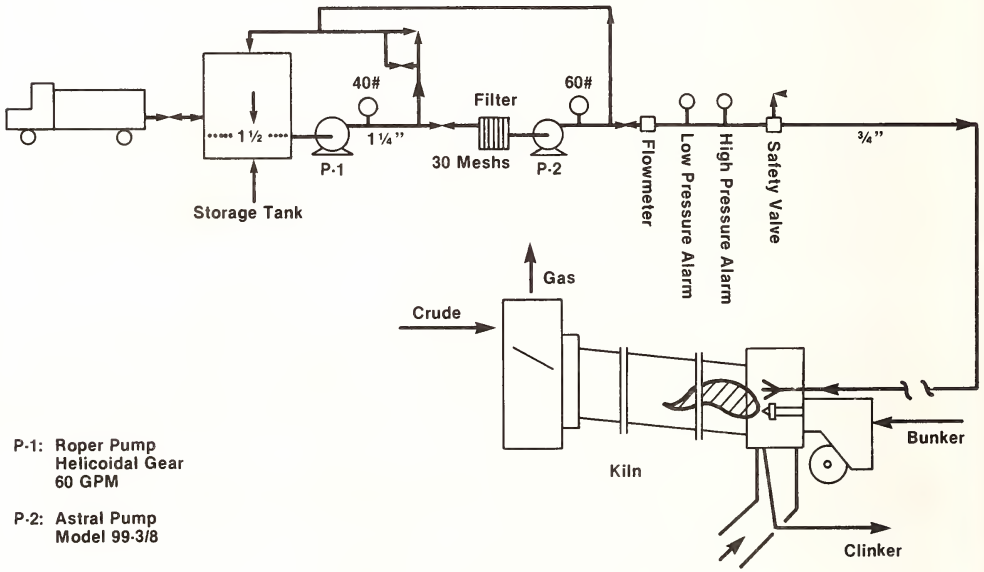

Air

Figure 1. The combustion circuit.

No modifications were made to the kiln system which operated as in normal production. The kiln was 490 feet long with a diameter of 15 feet. As shown on figure 2 , the crude ore, to which the dust residues recuperated from a dust collector and an electrostatic precipitor are added, is introduced in the kiln and caicinated. The residence time of the ore in the 
kiln is approximately eight hours. Air is preheated by passing it through the hot clinker and introduced counter currently into the kiln.

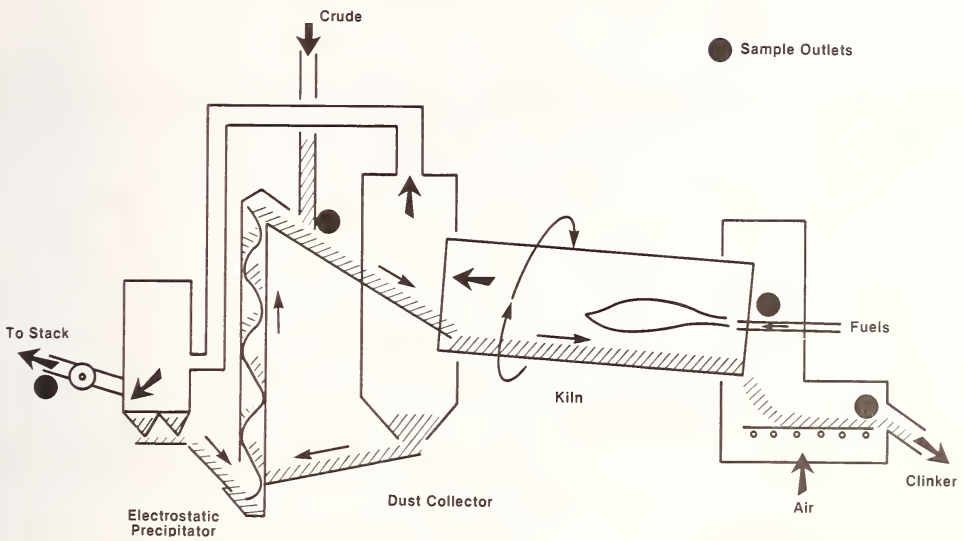

Figure 2. The kiln and the sample outlets.

5. The Acid Sludge Blend Circuit

As shown in figure 3 , the used oils are pumped into a flash tower that separates the water and the light ends from the heavier hydrocarbons. This distillate (II) is a first residue that will be used as an ingredient to the fuel blend. The bottoms oil stream is pumped to a reactor into which a sulfuric acid solution is added. Following a lengthy residence time (contact and sedimentation) an acid sludge constituted from heavy hydrocarbons, additives, sulfuric acid and most of the contaminants is collected. This stream (I) is the second available residue for the fuel blend. Finally used oils (III) and water (IV) are added into the mixing tank to provide good fluid characteristics, to lower the mixture $\mathrm{pH}$ and to ensure homogeneity of the fuel blend.

The following properties have been established after tests on blends prepared with these four streams: 20 percent (by volume) of acid sludge, 50 percent of used oils, 20 percent of distillate and 10 percent of additional water. Analyses were performed by the National Research Council of Canada [3].

\section{The Sampling outlets}

As shown in figure 2, four sampling outlets were used to collect samples during the testing period from different streams. Prior to the introduction of acid sludge blend into the kiln, samples were collected to establish the kiln operation under "normal operating conditions". The streams to be sampled and analyzed during the experimental program were: the ore fed into the kiln, the produced clinker, the fuels and the gas leaving the stack. 


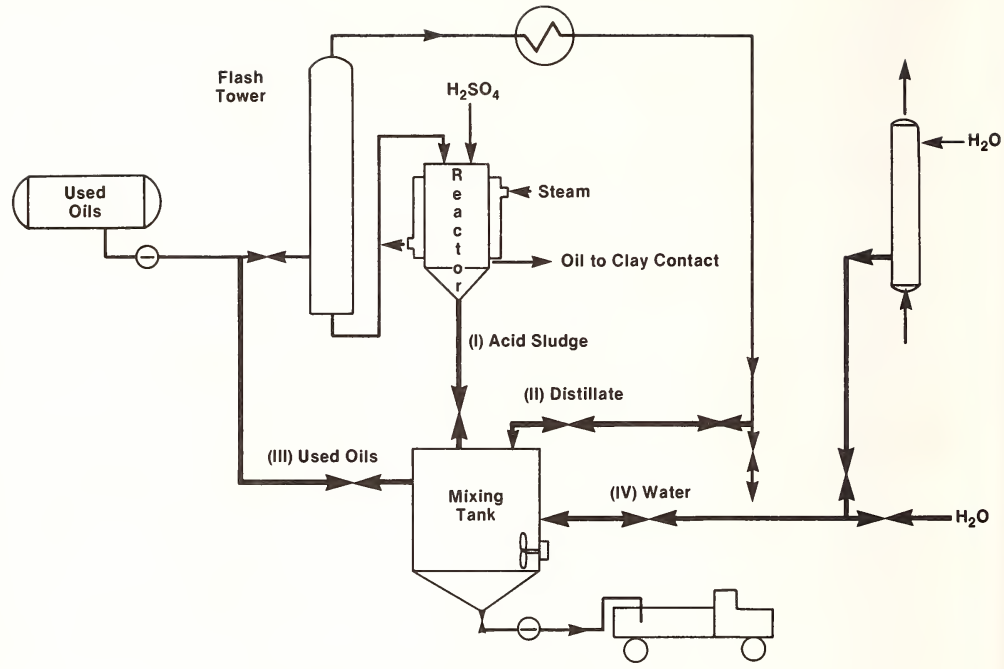

Figure 3. The acid sludge blending system.

The testing period duration was one week; however, several acid sludge blend feed interruptions were caused by pump failure and burner plugging. Coking inside the injection burner circuit (from flashing into the line) was easily overcome by cooling the atomizing circuit with air. The total feeding period of the blend was 90 hours with an average flow rate oi 1 GPM as reported in table 1 .

The feed of crude ore was $93 \mathrm{t} / \mathrm{h}$ while $19.5 \mathrm{GPM}$ of Bunker $\mathrm{C}$ was used. In spite of the fact that approximately 5 percent of acid blend was added to the Bunker $C$ as fuel, the Bunker C's flow rate remained constant during the testing period for a constant feed rate of crude ore. In total $5529 \mathrm{Gal}$. of acid sludge blend were fed into the kiln.

\section{Results}

The results from the analysis of the collected samples and from a material balance of some toxic elements are presented in this section.

\subsection{Properties of fuels}

Some physical properties and concentrations of elements in the Bunker $C$ and acid sludge blend collected during the experimental program are presented in table 2 . It should be noticed that the calorific value of the blend is approximately of $132000 \mathrm{BTU} / \mathrm{gal}$ as compared to $177000 \mathrm{BTU} / \mathrm{gal}$ for the Bunker C. The specific gravities of both fuels are similar even though the flash point of the blend is lower than that of the Bunker, being approximately 
$160^{\circ} \mathrm{F}$ and $265^{\circ} \mathrm{F}$, respectively. The water content in the blend is approximately of 20 percent and the average concentrations of $\mathrm{Pb}, \mathrm{Zn}, \mathrm{P}$ and $\mathrm{Br}$ are respectively of 6000,1150 , 850 and $1100 \mathrm{ppm}$. Finally, the sulfur concentration represents about 5 percent (by weight) of the mixture.

\subsection{Element identification in the solid samples}

The results of the analyses of some elements in the collected solid samples are presented in table 3 . One observes that the concentrations of sulfur, phosphorus, zinc and lead are higher in the clinker than in the crude ore plus the added dust collected. These data suggest that the increased concentrations results from the element content in the blend. A confirmation that these elements have been fixed in the clinker can be found in the material balance of each element which gives a retention rate of 93 percent, 89 percent and 87 percent, respectively, for the lead, zinc, phosphorus, and sulfur (see tables 5 to 8 ). These results are similar to those obtained in the Mississauga program [1]. Finally the curves representing each element input and output rates and the cumulative input and output are plotted in figures 4 to 6 .

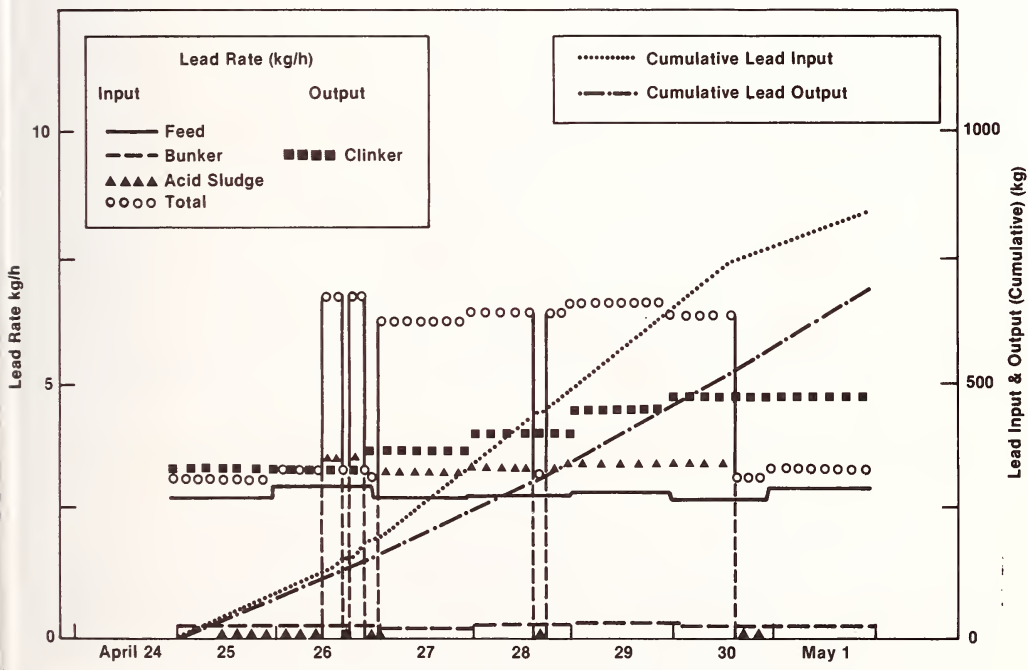

Figure 4. Lead rate and cumulative lead input and output.

Only an average retention of 12 percent of the bromine that enters the kiln is found in the clinker suggesting that the bromine appears as potassium bromide in the precipitator system. This suggestion, due to Berry [1] is corroborated by the data of table 9 .

\subsection{Analysis of flue gas}

The analyses of the samples of stack gas indicate no increase in the concentration of the toxic elements during the testing period (tabie 4). The samples collected on April 22nd 
correspond to the operation of the kiln prior to the experiment and the results of the analysis of those samples can be used for comparison. It is noted that on April 27 th the concentration of the four toxic elements were very high. This is explained by a poor performance of the electrostatic precipitator on that day. In spite of these production problems, the toxic elements' concentration in the flue gas were lower than the Environmental Protection Agency's specifications.

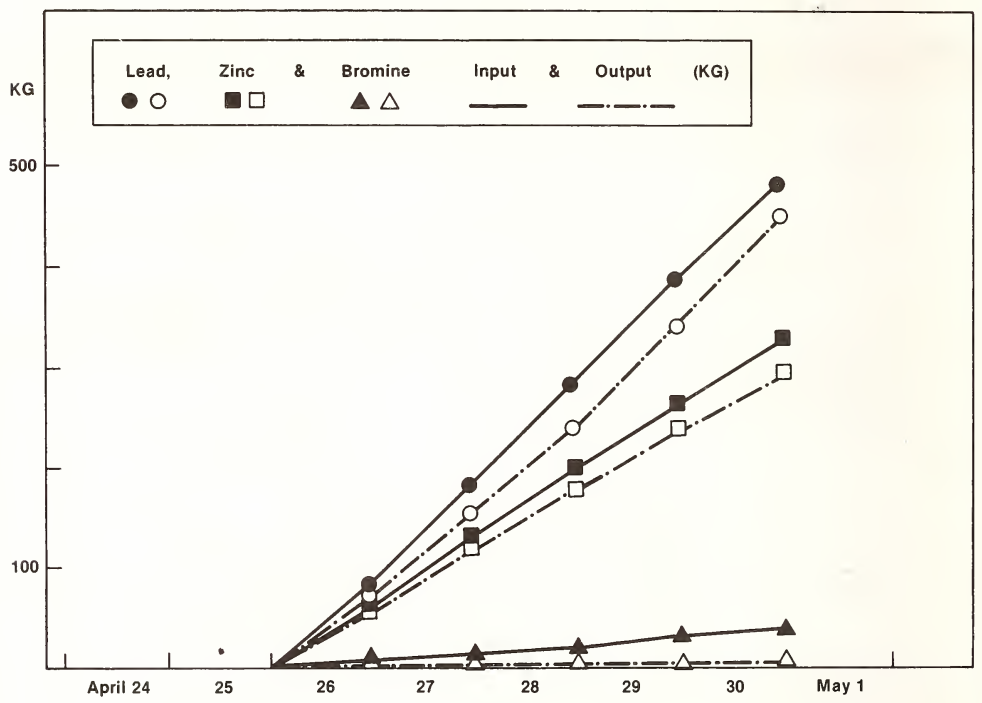

Figure 5. Cumulative lead, zinc and bromine input and output.

\subsection{Energy balance}

An accurate energy balance on operating cement kiln is very difficult to make because of lack of data on the energy losses. For that reason, and also because of fluctuations in some of the operating variables, it was impossible to close the energy balance. The energy input of the acid sludge blend was small compared to the combustion of the Bunker $C$.

\subsection{Cement properties}

The clinker produced during the program was used to make cement samples which were analyzed to insure properties acceptable for commerical uses. The results of the analysis performed by Canada Cement Lafarge Co. indicated that the setting times were faster than those of samples of cement produced prior to the experiment. However, these times were within acceptable limits. The compressive strength was better than that of the cement produced prior to the experimental period. All other properties fell into the acceptable range set by the company. 


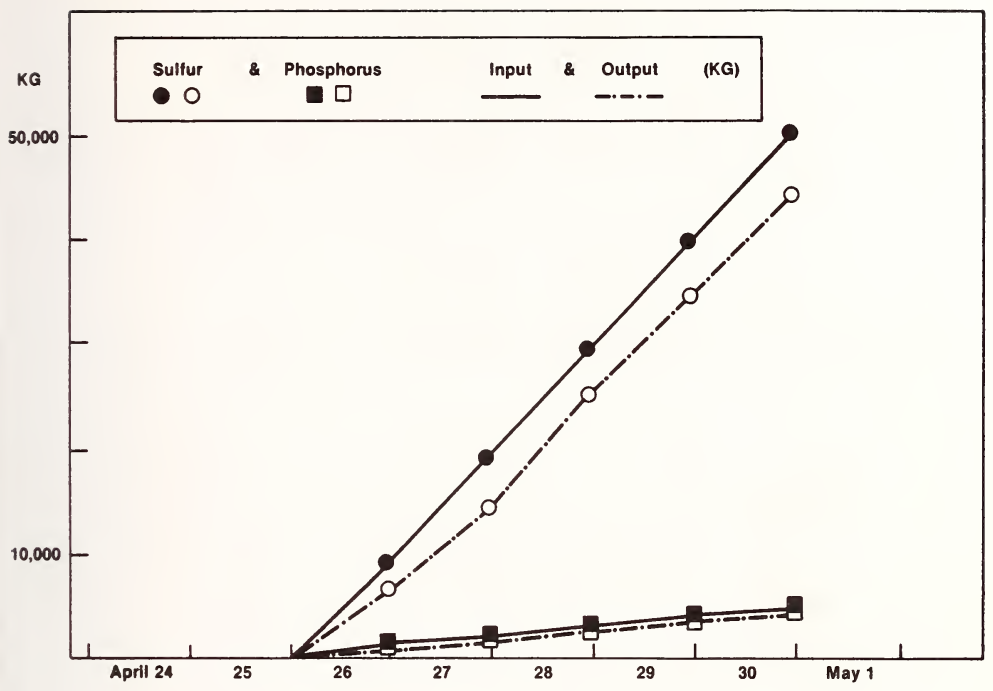

Figure 6. Cumulative sulfur and phosphorous input and output.

\section{Conclusion}

The primary conclusions of this experimental program is that the burning of an acid sludge (from an acid/clay treatment of used oils) in a cement kiln is an attractive way to increase the viability of the re-refining process and to prevent pollution. It was found that the toxic elements contained in the fuel blend are trapped in the clinker with no significant increase of toxic elements in the flue gas. Finally, the cement produced with the clinker obtained during the testing period has properties acceptable for commercial uses.

Unfortunately, this trial did not allow us to make an energy balance hence a detailed program should be considered to evaluate the real calorific contribution of the acid sludge blend. The accumulation of the bromide in the dust collector circuit should be analyzed in more detail. Finally, a study of the best acid sludge mixture should be undertaken to optimize the process. 


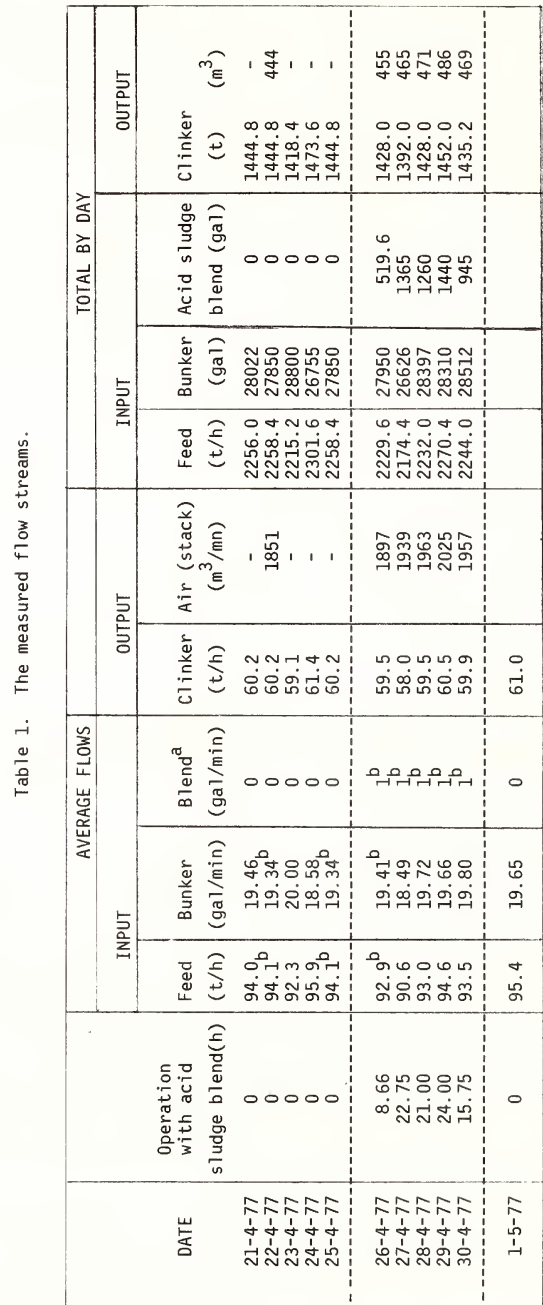

\begin{tabular}{|c|c|}
\hline 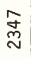 & 1 \\
\hline$\stackrel{\sim}{\stackrel{N}{ }}$ & \begin{tabular}{l}
+ \\
\multirow{N}{N}{}
\end{tabular} \\
\hline 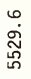 & 0 \\
\hline 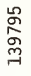 & 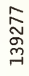 \\
\hline $\begin{array}{l}\stackrel{+}{\circ} \\
\text { 号 } \\
\text { ت̈ }\end{array}$ & 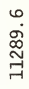 \\
\hline 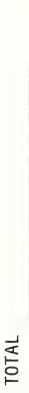 & 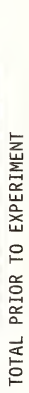 \\
\hline
\end{tabular}


Table 2. Properties of fuels.

\begin{tabular}{|c|c|c|c|c|c|c|}
\hline & BUNKER & & ACID SLUDG & BLEND & & \\
\hline Date & & $\begin{array}{l}26-4 \\
(20 h)\end{array}$ & $\begin{array}{c}27-4 \\
(7 h 30)\end{array}$ & $\begin{array}{l}28-4 \\
(14 h)\end{array}$ & $\begin{array}{c}29-4 \\
(2 h 30)\end{array}$ & $\begin{array}{r}30-4 \\
(14 \mathrm{~h})\end{array}$ \\
\hline $\begin{array}{c}\mathrm{Pb} \\
(\mathrm{ppm})\end{array}$ & $(45)$ & $6060-6400$ & $5620-6100$ & $5665-5800$ & 5950 & \\
\hline$\underset{(\mathrm{ppm})}{\mathrm{Zn}}$ & 47 & 1150 & 1130 & 1160 & 1060 & 1290 \\
\hline $\begin{array}{l}P \\
(p p m)\end{array}$ & 2.5 & 1209 & 744 & $79 ?$ & 908 & 803 \\
\hline $\begin{array}{c}\mathrm{Br} \\
(\mathrm{ppm})\end{array}$ & 8 & 1040 & 1080 & 1031 & 1070 & 1170 \\
\hline$\underset{(\%)}{S}$ & $2.97-4.2$ & 5.6 & 4.6 & 6.2 & 4.9 & 4.7 \\
\hline $\begin{array}{l}\mathrm{H}_{2} \mathrm{O} \\
(\%)\end{array}$ & .05 & 20 & 19 & 19.5 & 18 & 19.5 \\
\hline $\begin{array}{c}\mathrm{H}_{2} \mathrm{SO}_{4} \\
(\%)\end{array}$ & .05 & 6.0 & 5.63 & 5.60 & 4.58 & 5.09 \\
\hline $\begin{array}{l}\text { Calorific } \\
\text { Power } \\
\text { (BTU/gal.) }\end{array}$ & 177580 & 129613 & 134411 & 134681 & 129466 & 134078 \\
\hline $\begin{array}{l}\text { Specific } \\
\text { gravity }\end{array}$ & .966 & .967 & .961 & .960 & .963 & .957 \\
\hline $\begin{array}{l}\text { Flash } \\
\text { point } \\
\left({ }^{\circ} \mathrm{F}\right)\end{array}$ & 265 & 170 & 140 & 175 & 155 & 170 \\
\hline
\end{tabular}




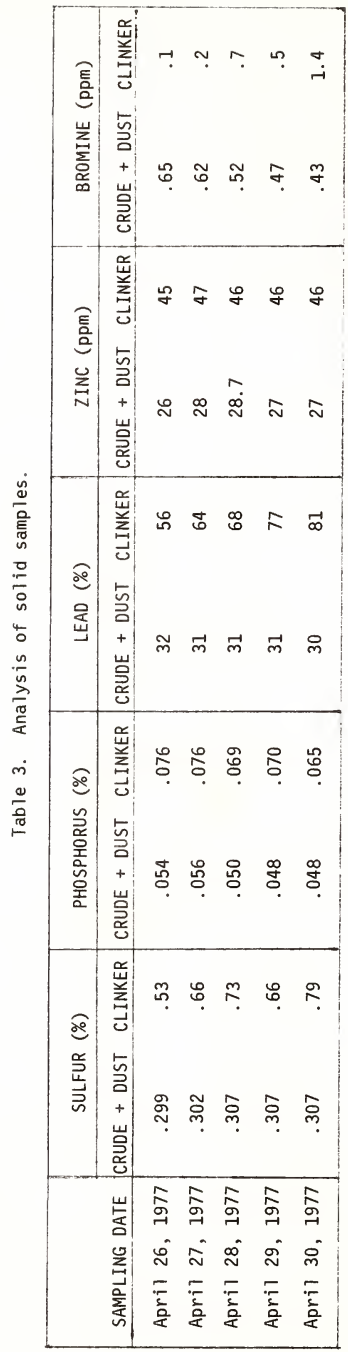


Table 4. Analysis of gas in the stack.

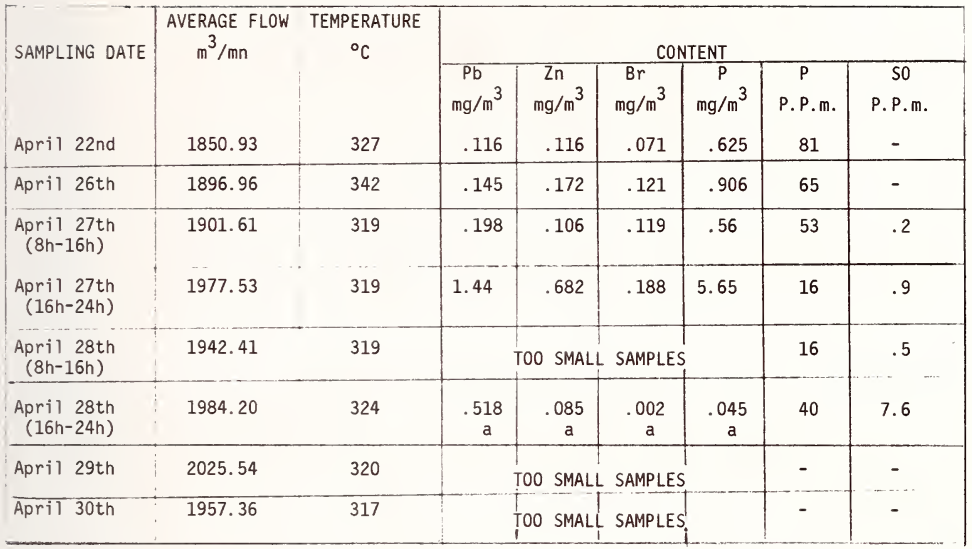

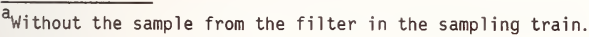

Table 5. Mass balance on lead.

\begin{tabular}{|c|c|c|c|c|c|c|c|c|}
\hline \multirow{2}{*}{ Date } & \multicolumn{4}{|c|}{ Input (1b/D) } & \multicolumn{3}{c|}{ Output (1b/D) } & \multicolumn{1}{c|}{$\begin{array}{c}\text { Retention } \\
(\%)\end{array}$} \\
\cline { 2 - 9 } & Feed & Bunker & Blend & Total & Clinker & Stack & Total & 86 \\
\hline $26-4-77$ & 142.56 & 12.2 & 30.2 & 185.1 & 159.8 & .34 & 160.1 & 81 \\
$27-4-77$ & 134.9 & 11.5 & 73.7 & 220.1 & 178.1 & .50 & 178.6 & 81 \\
$28-4-77$ & 138.2 & 12.2 & 68.5 & 219.0 & 194.2 & & 194.2 & 88 \\
$29-4-77$ & 140.6 & 12.2 & 82.3 & 235.1 & 223.7 & & 223.7 & 95 \\
$30-4-77$ & 134.6 & 12.5 & 52.9 & 200.0 & 232.6 & & 232.6 & 116 \\
\hline TOTAL(1b) & 690.9 & 60.9 & 307.7 & 1059.2 & 988.4 & & 989.2 & 93 \\
\hline
\end{tabular}


Table 6. Mass balance on zinc.

\begin{tabular}{|c|c|c|c|c|c|c|c|c|}
\hline \multirow{2}{*}{ Date } & \multicolumn{4}{|c|}{ Input (1b/D) } & \multicolumn{3}{c|}{ Output (1b/D) } & Retention \\
\cline { 2 - 8 } & Feed & Bunker & Blend & Tota1 & C1inker & Stack & Total \\
\hline $26-4-77$ & 115.9 & 12.7 & 5.7 & 134.3 & 128.4 & .7 & 128.4 & 95 \\
$27-4-77$ & 121.7 & 12.0 & 14.8 & 148.5 & 130.8 & 1.0 & 131.8 & 89 \\
$28-4-77$ & 128.2 & 13.0 & 14.05 & 153.3 & 131.3 & & 131.3 & 85 \\
$29-4-77$ & 122.6 & 12.7 & 14.6 & 149.95 & 133.4 & & 133.4 & 89 \\
$30-4-77$ & 121.2 & 13.0 & 11.7 & 145.95 & 132.0 & & 132.0 & 90 \\
\hline TOTAL(1b) & 609.6 & 63.4 & 60.95 & 733.95 & 655.9 & & 657.6 & 89 \\
\hline
\end{tabular}

Table 7. Mass balance on phosphorus.

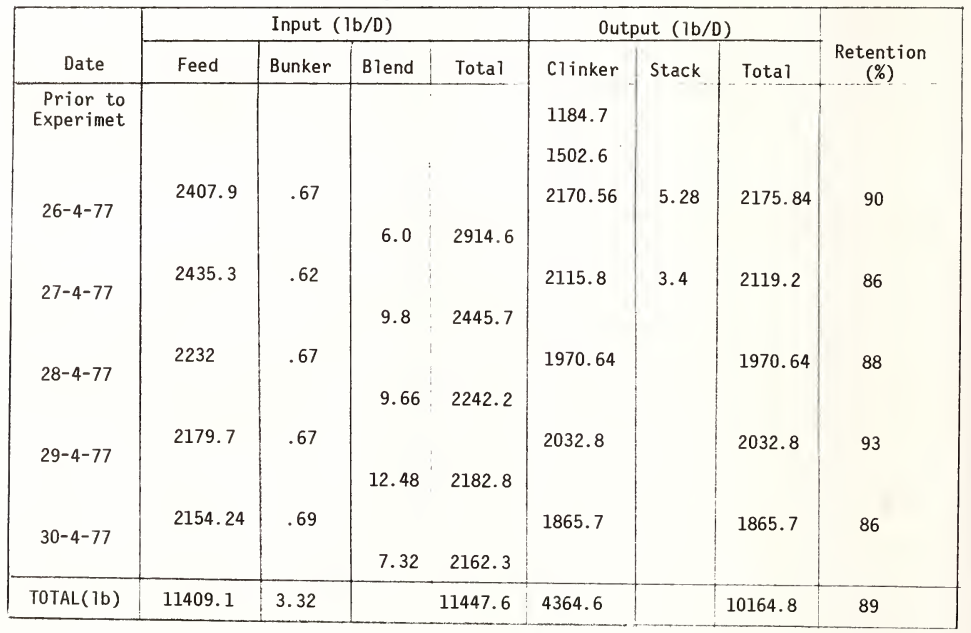


Table 8. Mass balance on sulfur.

\begin{tabular}{|c|c|c|c|c|c|c|c|c|}
\hline \multirow[b]{2}{*}{ Date } & \multicolumn{4}{|c|}{ INPUT $(1 \mathrm{~b} / \mathrm{D})$} & \multicolumn{3}{|c|}{ OUTPUT $(1 \mathrm{~b} / \mathrm{D})$} & \multirow{2}{*}{$\begin{array}{l}\text { Retention } \\
(\%)\end{array}$} \\
\hline & Feed & Bunker & Blend & Total & Clinker & Stack & Total & \\
\hline $\begin{array}{l}\text { Prior to } \\
\text { Experiment }\end{array}$ & - & 7990 & 0 & - & 20524 & - & 20524 & 91 \\
\hline $26-4-77$ & 13333 & 8019 & 283 & 21635 & 15137 & - & 15137 & 70 \\
\hline $27-4-77$ & 13133 & 7639 & 611 & 21383 & 18374 & 4.8 & 18379 & 86 \\
\hline $28-4-77$ & 13704 & 8147 & 747 & 22599 & 20849 & 32.3 & 20881 & 92 \\
\hline $29-4-77$ & 13940 & 8122 & 663 & 22728 & 19166 & - & 19166 & 84 \\
\hline $30-4-77$ & 13778 & 8180 & 484 & 22442 & 22676 & - & 22676 & 101 \\
\hline $\begin{array}{c}\text { Total } \\
\text { Experiment }\end{array}$ & 67888 & 40107 & 2791 & 110786 & 96202 & - & 96239 & - \\
\hline $\begin{array}{l}\text { Average } \\
\text { Experiment }\end{array}$ & 13578 & 8021 & 558 & 22157 & 19240 & - & 19248 & 87 \\
\hline
\end{tabular}

Table 9. Mass balance on bromine.

\begin{tabular}{|c|c|c|c|c|c|c|c|c|}
\hline \multirow[b]{2}{*}{ Date } & \multicolumn{4}{|c|}{ INPUT $(1 \mathrm{~b} / 0)$} & \multicolumn{3}{|c|}{ OUTPUT $(1 \mathrm{~b} / \mathrm{D})$} & \multirow{2}{*}{$\begin{array}{l}\text { Retention } \\
(\%)\end{array}$} \\
\hline & Feed & Bunker & Blend & Total & Clinker & Stack & Total & \\
\hline $\begin{array}{l}\text { Prior To } \\
\text { Experiment }\end{array}$ & 2.26 & 2.16 & 0 & 4.42 & & .41 & & \\
\hline $26-4-77$ & 2.66 & 2.16 & 5.20 & 10.03 & .29 & .72 & 1.01 & 10.1 \\
\hline $27-4-77$ & 2.62 & 2.06 & 14.19 & 18.88 & .55 & .72 & 1.27 & 6.7 \\
\hline $28-4-77$ & 2.23 & 2.18 & 12.49 & 16.91 & 1.44 & - & 1.99 & 11.8 \\
\hline $29-4-77$ & 2.28 & 2.18 & 15.53 & 19.99 & 1.44 & - & 1.44 & 7.2 \\
\hline $30-4-77$ & 1.80 & 2.21 & 9.81 & 13.82 & 4.01 & - & 4.01 & 29.0 \\
\hline $\begin{array}{l}\text { Total } \\
\text { Experiment }\end{array}$ & 11.59 & 10.79 & 57.23 & 79.53 & 7.73 & - & 9.72 & \\
\hline $\begin{array}{l}\text { Average } \\
\text { Experiment }\end{array}$ & 2. 32 & 2.16 & 11.44 & 15.91 & 1.55 & - & 1.94 & 12.1 \\
\hline
\end{tabular}


[1] Berry, E. E., McDonald, L. P., and Skinner, D. J., Experimental burning of waste oil as a fuel in cement manufacture, Report EPS-4-WP-75-1, Environment Canada (1975).

[2] Cutler, E. T., Conserve lube oil: re-refine, Hydrocarbon Processing, 86 (May 1976).

[3] Estaque, L. and Rollin, A. L., Essai de combustion dans un four á ciment d'un mélange constitué de résidus du procédé de régénération des huiles usagées, Technical Report CDT, Ecole Polytechnique de Montreal, 335 (November 1977).

[4] Skinner, D. J., Preliminary review of used lubricating oils in Canada, Report EPS3-WP-74-4, Environment Canada (1974).

[5] Weinstein, N. J., Re-refining schemes compared, Hydrocarbon Processing, 74, (December 1974).

[6] Whisman, M. L. and et al., Re-refining makes quality oils, Hydrocarbon Processing, 41 (October 1978).

[7] Cukor, Peter, Waste oil recycling study, Teknekron Inc., Technical Report for the Ontario Ministry of Energy (March 1976). 
Session 2

ENGINE OIL EVALUATION 

National Bureau of Standards Special Publication 584. Proceedings of Joint Conference on Measurements and Standards for Recycled 0il/Systems Performance and Durability held at NBS, Gaithersburg, MD, October 23-26, 1979. (Issued Nov. 1980)

\title{
STATUS OF THE MIL-L-46152A ENGINE OIL SPECIFICATION
}

\author{
T. Bowen
}

U.S. Army, MERADCOM

Mobility Equipment Research and Development

Ft. Belvoir, VA 22060

Over the past several years, the Department of Defense has placed considerable emphasis on the revision of military petroleum product specifications to allow the use of recycled or re-refined materials. Although this effort is not complete, significant advances have been made. One such advance has been with the MIL-L-46152 lubricating oil specification under which engine oil is procured for use in administrative vehicles. A draft revision of the specification allowing the use of re-refined materials has been prepared and forwarded to the U.S. Army Materials and Mechanics Research Center for editorial review and issuance. Also as an interim measure to expedite the procurement of these lubricants a purchase description, ME-101, covering engine oil as defined by the draft specification was issued on the 15th of October 1979. Today, I will briefly describe the requirements established by these documents.

Before entering this discussion, let me clarify one point. The draft specification has a qualification requirement which is not included in the purchase description perse. However, the purchase description does require lubricant approval; the process for which is the same as that required for qualification under the specification. In other words, both documents require prior testing and review before lubricants are purchased. Products which are approved for purchase under the purchase description will be qualified products when the specification is issued.

As with previous military engine oil specifications or purchase descriptions, the MIL-L-46152A and ME-101 documents are based on lubricant performance. As such only minimal constraints are placed on lubricant composition and properties prior to qualification or approval. Materials to be used in formulating the lubricant are defined in general terms as shown by table 1 . Note that the base stock may consist of a virgin, re-refined or a combination virgin-re-refined product. In regard to property requirements illustrated in table 2, viscosity and viscosity index are used to define lubricant grade and maximum pour and minimum flash point values are established to provide a general control of low-temperature handling and product volitality, respectively. One new requirement, a maximum 0.14 mass percent phosphorus limit, is included because of the harmful affects on emission control systems associated with phosphorus containing additives.

Table 1. Material requirements before qualification/approval.

Base stocks: petroleum, synthetic, or combination: virgin re-refined, or combination.

Additives: detergents, dispersants, oxidation inhibitors, etc. 
Table 2. Finished oil property requirements before qualification/approval.

Grade

\begin{tabular}{|c|c|c|c|c|c|}
\hline Property & $10 \mathrm{~W}$ & $\underline{30}$ & $5 W-20$ & $\underline{10 W-30}$ & $20 \mathrm{~W}-40$ \\
\hline $\begin{array}{l}\text { Viscosity } \odot 100^{\circ} \mathrm{C}, \mathrm{cSt} \\
\min \\
\max \end{array}$ & $\begin{array}{r}5.6 \\
<7.4\end{array}$ & $\begin{array}{r}9.3 \\
<12.5\end{array}$ & $\begin{array}{r}5.6 \\
<9.3\end{array}$ & $\begin{array}{r}9.3 \\
<12.5\end{array}$ & $\begin{array}{r}12.5 \\
<16.3\end{array}$ \\
\hline $\begin{array}{l}\text { Viscosity } \odot-18^{\circ} \mathrm{C}, \mathrm{cP} \\
\min \\
\max \end{array}$ & $\begin{array}{r}1250 \\
<2500\end{array}$ & -- & $<1250$ & $\begin{array}{r}1250 \\
<2500\end{array}$ & $\begin{array}{c}2500 \\
<10000\end{array}$ \\
\hline Viscosity Index (min) & -- & 75 & -- & -- & -- \\
\hline Pour Point, ${ }^{\circ} \mathrm{C}$ (max) & -32 & -18 & -40 & -32 & -23 \\
\hline Stable Pour Point, ${ }^{\circ} \mathrm{C}$ (max) & -32 & -- & -40 & -32 & -23 \\
\hline Flash Point, ${ }^{\circ} \mathrm{C}$ (min) & 205 & 220 & 200 & 205 & 215 \\
\hline Phosphorus, \%M (max) & 0.14 & 0.14 & 0.14 & 0.14 & 0.14 \\
\hline
\end{tabular}

Table 3. Engine test requirements.

Test

$\mathrm{L}-38$

Brg. Wt. Loss, Mg (max.)

Seq. IID

Avg. Rus (min)

Lifter Sticking

Seq. IIID

Visc. Inc. @ $40^{\circ} \mathrm{C}, 40 \mathrm{~h}, \%$ (max.)

Piston Varnish (min)

$0 i 1$ Land Deposit (min)

Sludge (min)

Ring Sticking

Scuffing \& Wear @ $64 \mathrm{~h}$

Cam or Lifter Scuffing

Cam + Lifter Wear $\mu \mathrm{m}$

Avg.

Max.

Seq. $V-C / V-D$

Avg. Eng. Sludge (min)

Avg. Eng. Varnish (min)

Piston Skirt Varnish (min)

0 il Screen \& Ring Clogging, \% (max.)

Comp. Ring Sticking

Cam Wear, $\mu \mathrm{m}$

Avg.

Max.
Requirement

40

8.5

None

375

9.1

4.0

9.2

None

None

102

254

9. $0 / 9.2$

$8.1 / 6.4$

8. $0 / 6.3$

$5 / 10$

None/None

$--/ 51$

$--/ 102$

Cat. ${ }^{H} \mathrm{H} 2$

Top Groove Filling, \% (max.)

Total Weighted Deposit, (max.) 
The key to both the specification and purchase description is lubricant performance as defined by a series of engine dynamometer tests. Requirements for these tests are summarized by table 3 . Note that requirements are presented for both the sequence $V-C$ and recently approved sequence $V-D$ procedure. It is envisional that use of the sequence $V-D$ procedure will be implemented as soon as possible. These requirements are the same as established for API performance classification SE--CC.

After qualification or approval, the latitude allowed in formulation is removed. As shown by table 4 , the manufacturer is restricted to the same base stock--additive combination as was used for the qualification or approval sample. Tolerances, more restrictive than the prior general requirements, are established for both the chemical and physical properties of the lubricant. In addition, the MIL-L-46152A specification provides for annual monitoring and sampling of base stock materials as shown by table 5 . It is noted that tolerances requirements are not currently assigned to the base stock properties. However, significant variation from the initial characteristics would require an explanation and could possibly necessitate partial or complete retesting of a product.

Table 4. Material and tolerance requirements after qualification/approval.

\section{Material}

- Base Stock: same source and refining treatment as used in qualification/ approval sample.

- Additive: identical as used in the qualification/approval sample.

\section{Finished $0 i 1$ Tolerances}

Gravity, ${ }^{\circ} \mathrm{API}$

Flash, Finished 0 il ${ }^{\circ} \mathrm{C}$

Viscosity

Viscosity Index

Pour Point, ${ }^{\circ} \mathrm{C}$

Stable Pour Point, ${ }^{\circ} \mathrm{C}$

Ramsbottom Carbon, \%

Sulfated Ash, \%

Elemental Constituents

Table 5. Base stock properties.

Viscosity

At $100{ }^{\circ} \mathrm{C}$, centistokes

At $40^{\circ} \mathrm{C}$, centistokes

Viscosity Index

Gravity, ${ }^{\circ} \mathrm{API}$

Pour Point, ${ }^{\circ} \mathrm{C}$

Carbon Residue, \%

Sulfated Ash, \%

Total Acid Number

Saponification Number

Elemental Content, Mass \%

Nitrogen

Chlorine

Sulfur

Color

Boiling Point Distribution, ${ }^{\circ} \mathrm{C}$

C $1,5,10,50$, and $90 \%$ Point 
Although the specific date of issue for MIL-L-46152A is not known, the specification should be available in the near future. As an interim measure, the ME-101 purchase description will allow the procurement of the quality level lubricant as defined by the proposed specification. 
National Bureau of Standards Special Publication 584. Proceedings of Joint Conference on Measurements and Standards for Recycled 0il/Systems Performance and Durability held at NBS, Gaithersburg, MD, October 23-26, 1979. (Issued Nov. 1980)

\title{
FIELD TEST OF RE-REFINED AUTOMOTIVE ENGINE OIL IN RCMP VEHICLES
}

\author{
J. Armstrong \\ Environment Canada \\ 351 St. Joseph Boulevard \\ Hul1, Quebec KIA 1C8 \\ CANADA
}

\section{Introduction}

First, I would like to thank the organizers of this conference for inviting Environment Canada to participate in it. I will be describing the re-refined oil testing program which we are presently conducting, in conjunction with a number of other agencies. The first phase of this program is now approximately 50 percent complete, and involves a comparison and evaluation, under selected field operating conditions, of the performance characteristics of a virgin base stock reference oil and a re-refined base stock test oil. I will be presenting some of the data we have obtained to date, along with some of the observations which can be made with this data.

\section{Description of Test}

The field test portion of the program was started in early March of this year, and is expected to run until December or January. Eight new, identically-equipped patrol cars were made available for use in the program by the Royal Canadian Mounted Police Force. These cars are 1979 models, Chevrolet Bel-Air sedans equipped with police-duty 305 cu in V-8 engines and automatic transmissions. They are all based in Ottawa and all experience essentially the same city-driving type patrol service. They operate on a continuous basis, $24 \mathrm{~h} /$ day, 7 days a week, and accumulate between eight to ten thousand kilometers per month. Barring accidents or other unforeseen circumstances, the test program will continue until the cars reach their normal fleet mileage of $100000 \mathrm{~km}$. At this time, all the engines will be disassembled and examined and rated for sludge and varnish accumulation. Because we did not premeasure the engines, wear comparisons will be based primarily on visual examination.

The reference oil being used is a commercially available, fully-qualified, API SE-CC multigrade 20 W40 oil prepared from virgin base stocks. The additive formulation used in the reference oil was used at the same treatment level with acid-clay re-refined base oil to prepare the test oil. This approach was taken to allow us to isolate, as much as is possible, the performance characteristics of the base oils only.

\section{Physical and Chemical Properties}

Most of the physical and chemical properties of the base and finished oils have been determined, largely through the efforts of the Fuels and Lubricants Laboratory of the National Research Council, and I will discuss a few of them today.

Some of the physical properties of the two base oils used for formulation of the finished oils are shown in table 1. Both oils are approximately an SAE 20 grade. I should point out here that the virgin base stock is a blend of approximately equal parts of SAE 10 and SAE 30 grade oil. While the specific gravity and viscosities of the virgin and re-refined oils are quite similar, the VI of the re-refined oil is somewhat higher than the virgin oil, and the flash point of the re-refined oil is about $15^{\circ} \mathrm{F}$ lower than that of the virgin oil. As would be expected, there was a color difference between the two oils. 
Table 1. Physical properties of base oils.

$\begin{array}{ll}\text { Virgin } & \text { Re-refined } \\ \text { Base Stock } & \text { Base Stock }\end{array}$

A.P.I. Gravity

Viscosity $100^{\circ} \mathrm{C}$

Viscosity @ $40^{\circ} \mathrm{C}$

Viscosity Index

Flash Point

Color
29.7

$7.30 \mathrm{cSt}$

53.43 cSt

95

$435^{\circ} \mathrm{F}$

$<1.0$
29.6

$7.51 \mathrm{cSt}$

$52.62 \mathrm{cSt}$

104.5

$420^{\circ} \mathrm{F}$

$<3.0$

Determination of the boiling point distribution showed a slight difference between the two oils. Plotting these figures (fig. 1) shows the boiling range of the re-refined base oil (the dotted line on the figure) to be about $20^{\circ} \mathrm{F}$ lower than the virgin oil boiling range. This is probably due to the presence of light ends in the re-refined oil, and this may be one of the reasons for a slightly higher oil consumption rate in the cars using the re-refined test oil.

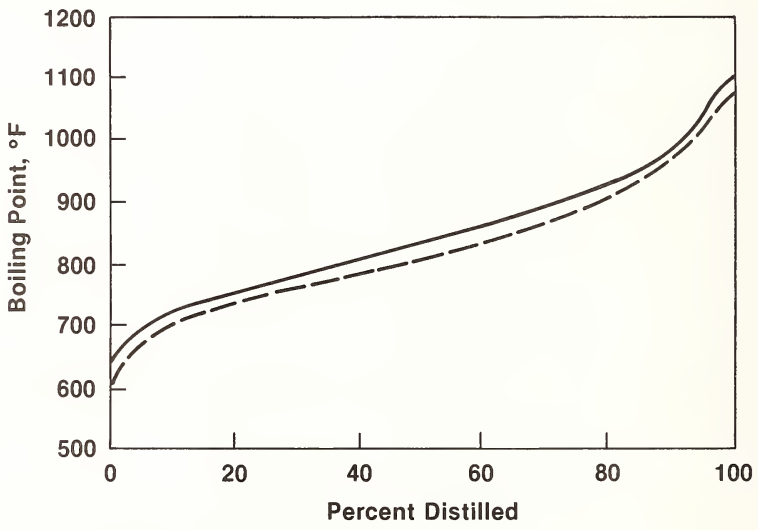

Virgin Base Oil Re-refined Base Oil

Figure 1. Boiling point distribution. 
One of the reasons we had for selecting the re-refiner we did, was that the National Research Council had previously examined samples of his re-refined oil, and therefore had a reasonably good idea of what the oil would be like. While I believe the subject of base stock consistency is being addressed later in the conference, I have prepared the following table (table 2) to show that the re-refined base oil we are using is representative of the rerefiner's production. The first column of figures in the table are the average values from ten samples of re-refined oil produced by the re-refiner during the period 1968 to 1978 . As can be seen, the properties of our test oil are quite similar to the previous sample averages, and I think it is fairly safe to say that we are using "normal" production quality oil.

Table 2. Re-refined base stock consistency.

$\begin{array}{cc}\begin{array}{c}\text { Samples } \\ 1968-1978\end{array} & \begin{array}{c}\text { Test } 0 i 1 \\ \text { Base Stock }\end{array} \\ 29.6 & 29.6 \\ 7.50 \mathrm{cSt} & 7.51 \mathrm{cSt} \\ 54.90 \mathrm{cSt} & 52.62 \mathrm{cSt} \\ 100.25 & 104.5 \\ 418^{\circ} \mathrm{F} & 420^{\circ} \mathrm{F} \\ <2.0-3.5 & <3.0\end{array}$

Some properties of the finished oils are shown in the next table (table 3 ). The oils were formulated to SAE 20 W40 grade, this being a formulation which was suitable for year-round operation, and one that would allow us to use only re-refined base stock for the test oil. As was the case with the base oils, the two finished oils are reasonably similar. Total Acid Number shows two separate determinations for each oil.

Table 3. Properties of finished oils.
A.P.I. Gravity
Viscosity $\mathrm{C} 100^{\circ} \mathrm{C}$
Viscosity @ $40^{\circ} \mathrm{C}$
Viscosity Index
Flash Point
Color

Properties of finished oils.

$\underset{0 i 1}{\operatorname{Virgin}}$

20W40

SAE Grade

A.P.I. Gravity

Viscosity Index

27.9

127.5

$445^{\circ} \mathrm{F}$

Flash Point

T.A.N.

T.B.N.
2. $24 / 2.78$

5.71
Re-refined 0 i1

$20 W 40$

28.5

132.5

$440^{\circ} \mathrm{F}$

2.5/2.64

5.74

\section{Field Test Results to Date}

As I said earlier, the field test portion of the program is approximately 50 percent (table 4). We have four patrol cars operating on each oil. Over $168000 \mathrm{~km}$ (about 105000 miles) have been accumulated on the virgin oil, and over $150000 \mathrm{~km}$ (approximately 94000 miles) on the re-refined oil. All cars are following the normal maintenance schedules and procedures practiced by the RCMP, including oil and filter changes every $5000 \mathrm{~km}$. However, because the cars are operating on a continuous basis, their availability for servicing is affected, and we are seeing oil changes occurring anywhere from about $2500 \mathrm{~km}$ to about $10000 \mathrm{~km}$, with the majority occurring around the $5000 \mathrm{~km}$ mark. For some reason, presumably chance, the vehicles using the re-refined oil are so far exhibiting about a $600 \mathrm{~km}$ longer average oil change interval than the cars using the virgin oil. 
Table 4. Field test 50 percent complete.

$\begin{array}{lcc} & \text { Virgin } & \text { Re-refined } \\ & 0 i 1 & 4 \\ \text { No. of Test Vehicles } & 4 & 154100 \mathrm{~km} \\ \text { Total Test Mileage } & 168400 \mathrm{~km} & 27 \\ \text { No. of } 0 i 1 \text { Changes } & 33 & 5720 \mathrm{~km}\end{array}$

We have been monitoring relative engine condition and used oil performance characteristics by analyzing samples of used oil taken at each oil change. These samples are being analyzed for metals, viscosity, and fuel, glycol, and water content by a private laboratory. The Fuels and Lubricants Laboratory of the National Research Council have been providing the physical and chemical analyses of the used oil, including infrared analysis. The averages of some of these properties are shown in table 5 .

Table 5. Used oil properties.

$\begin{array}{lcc} & \begin{array}{c}\text { Virgin } \\ 0 i 1\end{array} & \begin{array}{c}\text { Re-refined } \\ 0 \text { il }\end{array} \\ \text { Average Top-Up Rate } & 0.21 \frac{\text { Liter }}{1000} \mathrm{~km} & 0.25 \frac{\mathrm{Liter}}{1000 \mathrm{~km}} \\ \text { Average 0iI Age } & 979 \mathrm{~km} / \mathrm{L} & 1006 \mathrm{~km} / \mathrm{L} \\ \text { Average Iron Content } & 31 \mathrm{PPM} & 37 \mathrm{PPM} \\ \text { Viscosity Increase [ } 100^{\circ} \mathrm{F} & 15.7 \mathrm{cSt} & 29.6 \mathrm{cSt} \\ \text { Viscosity Increase 0 } 210^{\circ} \mathrm{F} & 0.6 \mathrm{cSt} & 1.76 \mathrm{cSt} \\ \text { Degree of 0xidation } & 9.5 \frac{\mathrm{ABS}}{\mathrm{CM}} & 17.3 \frac{\mathrm{ABS}}{\mathrm{CM}}\end{array}$

As I mentioned earlier, the average top-up rate for the re-refined oil $(0.251$ iter $/ 1000 \mathrm{~km})$ is somewhat higher than the virgin oil top-up rate of 0.21 liter $/ 1000 \mathrm{~km}$. However, because of the longer average oil change interval being experienced by the cars using the re-refined oil, the calculated average oil age is about the same--1006 km/liter and $979 \mathrm{~km} / 1$ iter for the group of cars using virgin oil. The average oil age at each oil change is calculated by dividing the number of kilometers driven since the last oil change by the total quantity of oil added to the crankcase, that is, the 4.5 liters initial charge plus the amount of top-up oil added during the period. Use of this figure instead of distance traveled between oil changes as an independent variable during analyses helps to account for the variations in top-up rate and length of oil change intervals.

For the remaining properties shown--iron content, viscosity increase, and degree of oxidation of the used oils--the values obtained for the re-refined used oil are consistently higher than those measured for the virgin oil.

A fair bit of information about the comparative behavior of the two oils can be obtained from looking at graphs of the used oil properties plotted against average oil age. The next few slides I will show are the graphs of iron content, viscosity increases at $100^{\circ} \mathrm{F}$ and $210^{\circ} \mathrm{F}$, and the degree of oxidation measured for the used oil samples. 
The first pair of figures show the iron content of the used oil. Interestingly, the slope of the best-fit line for the cars using virgin oil (fig. 2) is about twice as steep as the slope of the line obtained for the re-refined oil (fig. 3). As a point of interest, one of the vehicles using re-refined oil was in an accident about a week after the field test started, and while no front-end or engine damage occurred, it sat idle for about six weeks while repairs were being made. Analysis of the used oil from the first oil change after the accident resulted in the $95 \mathrm{ppm}$ iron concentration outlier on the graph. The iron concentration of the next oil sample obtained from this vehicle was $41 \mathrm{ppm}$.

The next four figures show the behavior of used oil viscosity with respect to oil age. The behavior of each oil is similar, with the best fit lines for each having essentially the same slopes but different intercepts. This was observed at both $100^{\circ} \mathrm{F}$ and $210^{\circ} \mathrm{F}$. The viscosity increases observed in the virgin oil at $100^{\circ} \mathrm{F}$ (fig. 4) are about $15 \mathrm{cSt}$ less than the viscosity increases measured for the re-refined oil (fig. 5). Similarly at $210^{\circ} \mathrm{F}$, the viscosity increases observed in the virgin oil (fig. 6) are about $1.0-1.5$ cSt less than those observed for the re-refined oil (fig. 7).

The graphs of the oxidation products present in the used oil do not indicate the parallel behavior seen with the viscosity increases. The virgin oil (fig. 8) shows a considerably less rapid increase in oxidation products with oil age than does the re-refined oil (fig. 9).

In an attempt to provide a somewhat more thorough analysis of the used oil data, we subjected the previous four properties plus copper concentration data to a more sophisticated linear regression analysis, using average oil age, vehicle odometer reading, and oil type (i.e., virgin or re-refined) as independent variables. Keeping in mind the limitations on validity of results obtained from this type of analysis on the relatively small amount of data we have, the following results were obtained at statistically significant levels:

1) In the analysis of iron concentration, oil type was not a significant contributor to the measured responses. Average oil age was by far the most significant independent variable.

2) In the analysis of copper concentration, total engine mileage (i.e., odometer reading) was the most important contributor, with both kilometer and kilometer-squared terms being more significant contributors by an order of magnitude over the other variables.

3) Both average oil age and oil type, in that order, exhibited significant effects on the measured viscosity increases in the used oil samples, both at $100^{\circ} \mathrm{F}$ and at $210^{\circ} \mathrm{F}$.

4) Analysis of oxidation products indicated that all three independent variables--average oil age, oil type, and total mileage accumulation-were significant contributors to the measured responses.

\section{Conclusions}

To conclude, I would like to repeat that the field test has been designed to isolate the performance characteristics of the virgin and re-refined base oils being studied. The conditions selected for the test are those normally experienced by RCMP vehicles in similar service. We have attempted to ensure that all test and reference vehicles are subjected to as equal treatment as possible, in both driving conditions and maintenance schedules.

The primary conclusion that can be made with the data obtained to date is that there are statistically significant differences occurring in certain measured properties of used crankcase oil from the two test groups of vehicles. These differences are no doubt attributable, at least in part, to performance differences between the two finished oils, but other factors such as the observed differences in length of oil change interval and top-up requirements are also contributing to the responses being measured.

Given the methods by which we defined and chose the test and reference oils, it might be expected that differences in performance characteristics would be observed, and also that the reference oil might exhibit "better" performance characteristics than the test oil. However, 
we will not know the final magnitudes of any differences between the oils until the field test period is completed, and the real significance of these differences, in terms of their effect on the engines, cannot be determined until the engine examinations have been completed.

\section{a/Virgin Oil}

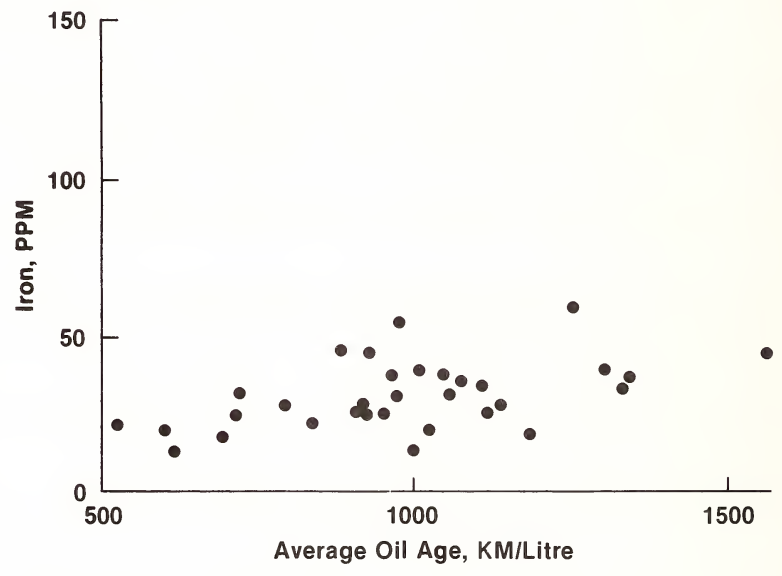

Figure 2. Iron concentration in crankcase drain samples. 


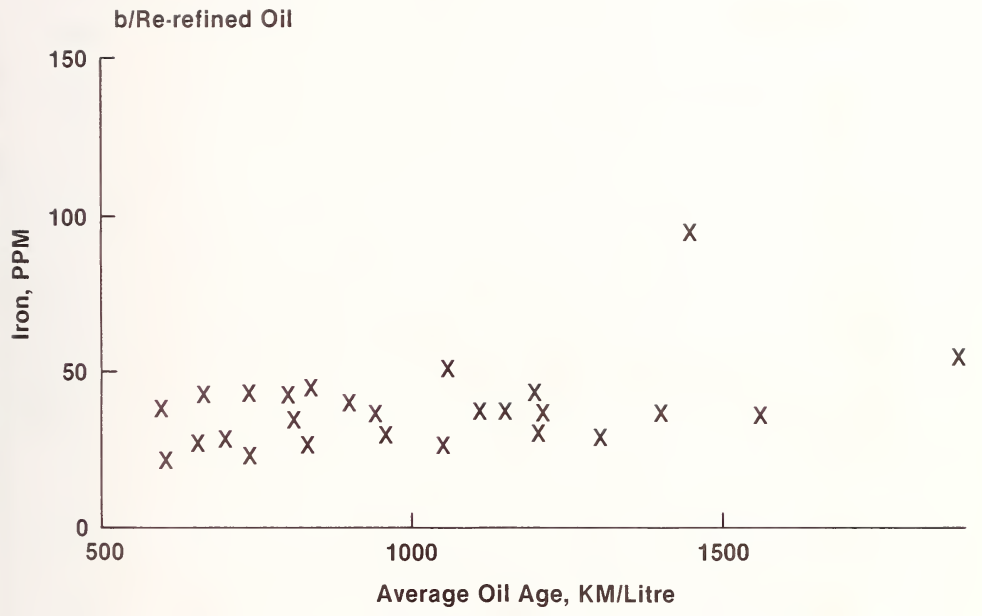

Figure 3. Iron concentration in crankcase drain samples. 
a/Virgin Oil

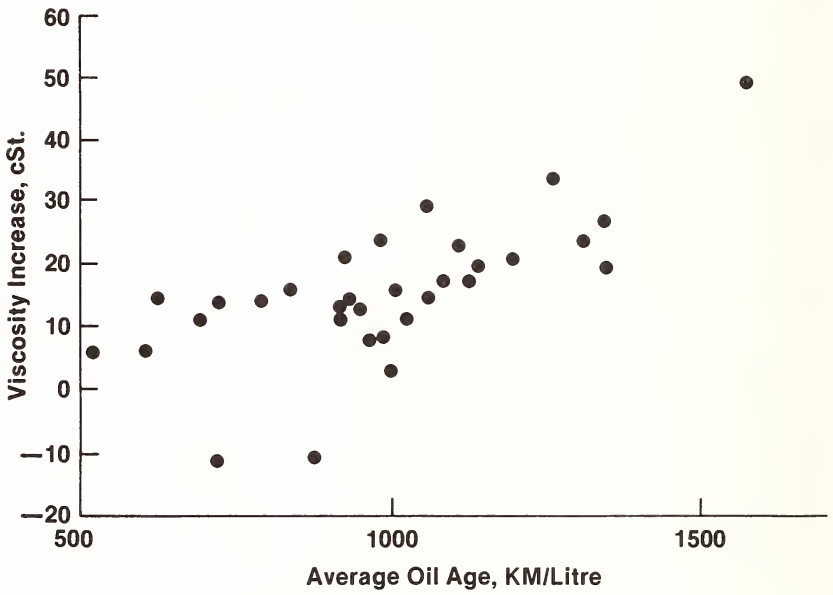

Figure 4. Viscosity increase at $100^{\circ} \mathrm{F}$. 


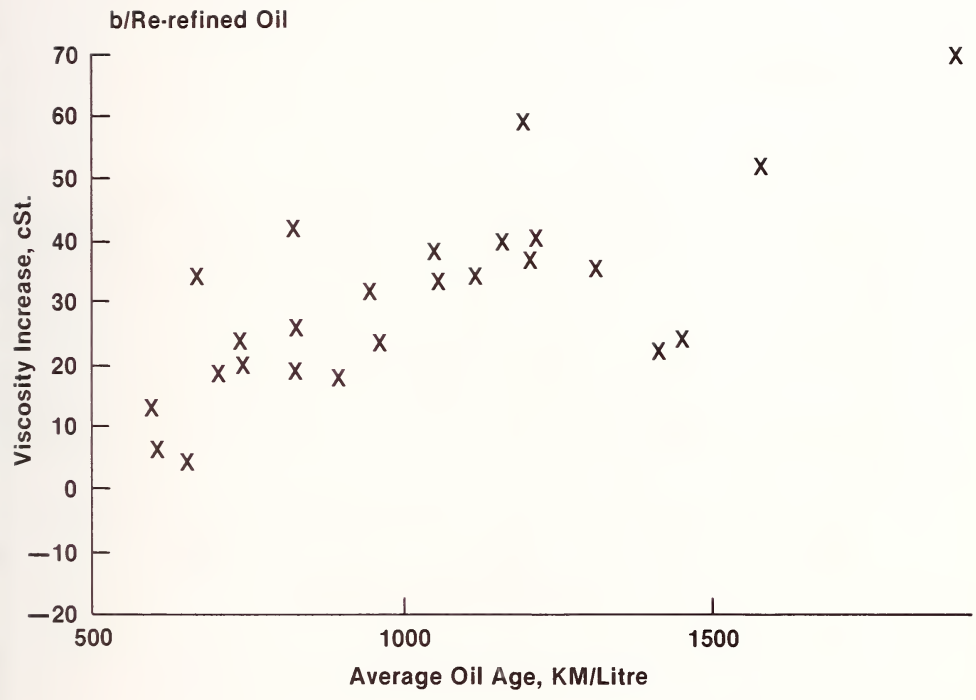

Figure 5. Viscosity increase at $100^{\circ} \mathrm{F}$. 


\section{a/Virgin Oil}

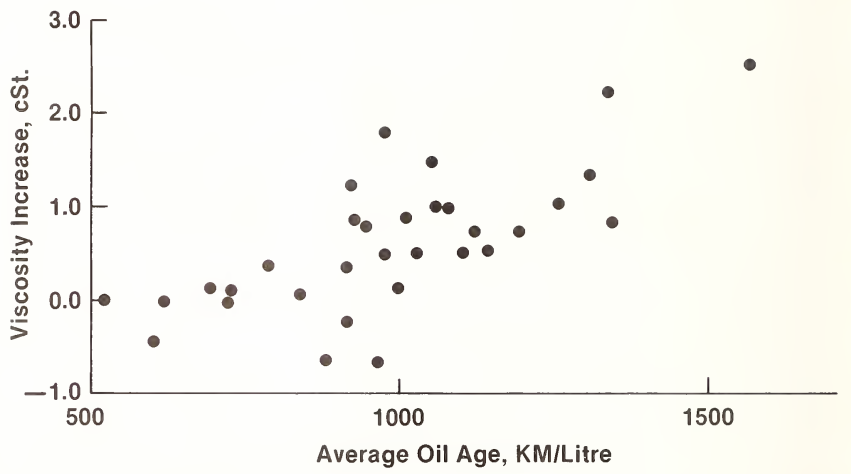

Figure 6. Viscosity increase at $210^{\circ} \mathrm{F}$ - virgin oil. 


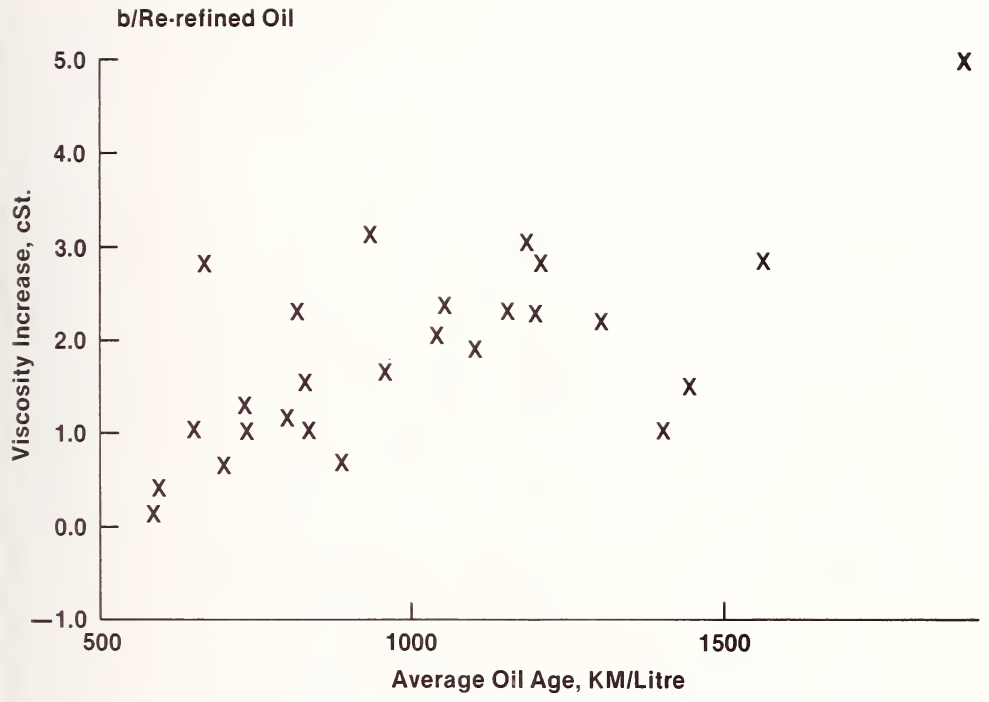

Figure 7. Viscosity increase at $210^{\circ} \mathrm{F}$ - re-refined $0 i 1$. 


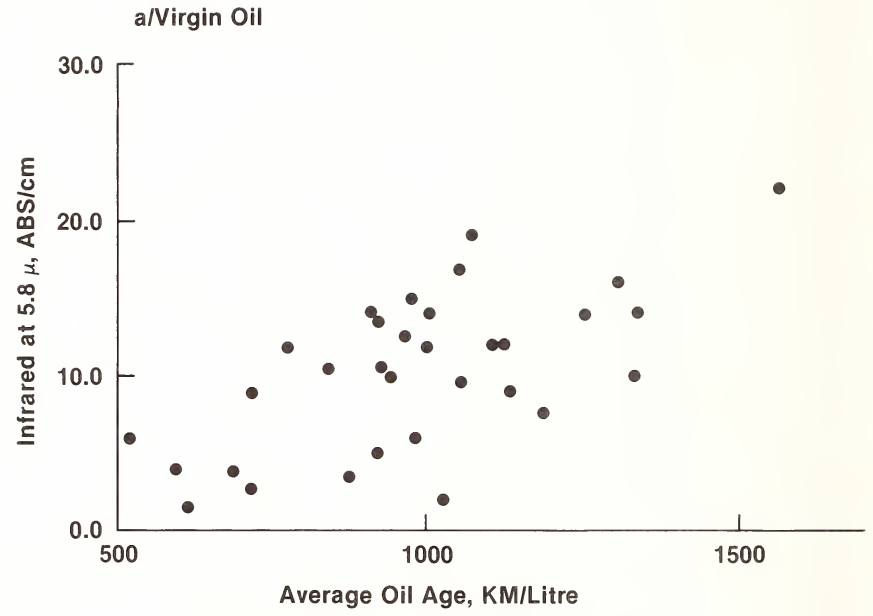

Figure 8. 0xidation products in used oil - virgin oil. 


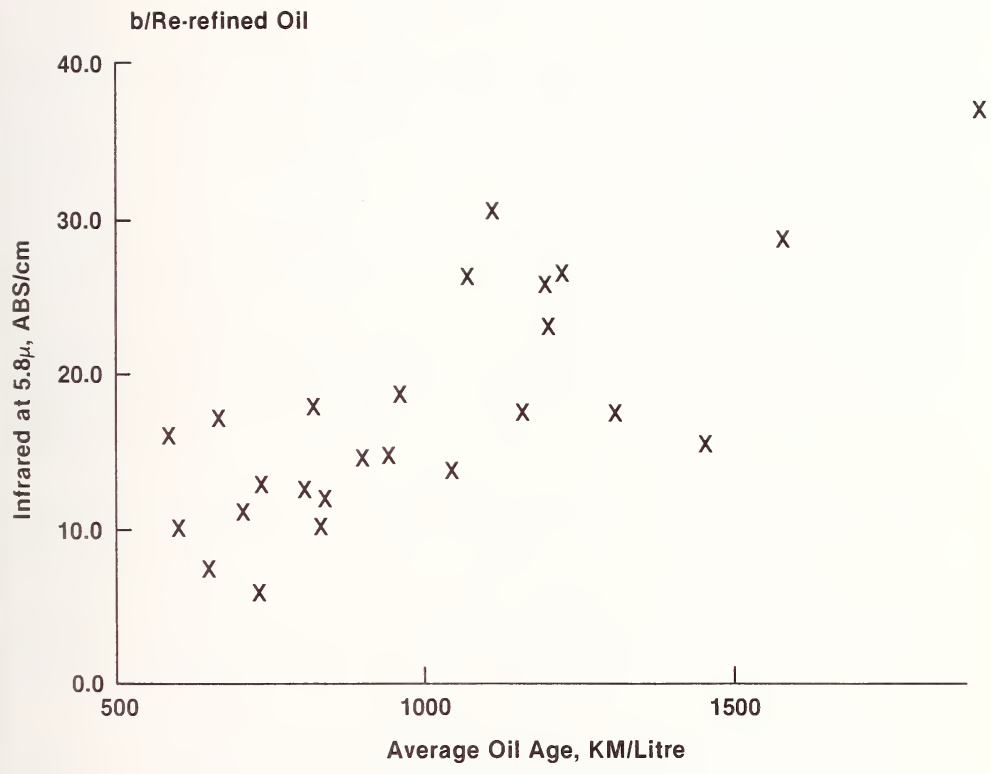

Figure 9. 0xidation products in used oil - re-refined oil. 

National Bureau of Standards Special Publication 584. Proceedings of Joint Conference on Measurements and Standards for Recycled 0il/Systems Performance and Durability held at NBS, Gaithersburg, MD, October 23-26, 1979. (Issued Nov. 1980)

\title{
PROP RE-REFINED OIL ENGINE TEST PERFORMANCE
}

\author{
R. E. Linnard \\ Phillips Petroleum Company \\ 429 TRW Building \\ Bartlesville, OK 74004
}

At the 1977 NBS-sponsored Conference on Recycled 0ils, I reported to this group on the Phillips Re-refined 0 il Process (we call it PROP ${ }^{1}$ ). At that time engineering and fabrication of the first PROP oil re-refining plant were just getting underway. While we were not then in a position to disclose details about the process (as we have subsequently done on NPRA paper AM-79-21) I did make a point of describing Phillips' intent to demonstrate the efficacy of the process in terms of the quality of its product as meeting industry recognized standards of engine test performance.

Specifically, we indicated our intent to put PROP re-refined motor oils through the same independent laboratory engine tests as are commonly undertaken with virgin oils to show compliance with the approval requirements of MIL-L-46152 and to give credible support to claims of API Service SE/CC quality.

In the intervening two years, we have not deviated from our initial approach for demonstrating product quality. Recognizing the lack of meaningful alternatives, ASTM engine tests conducted by independent laboratories continue to be used as attestations of the high quality of PROP plant-produced re-refined base oils. Using conventional, commercially-available nonproprietary (to Phillips) additive treatments, engine test programs have successfully demonstrated PROP $011 \mathrm{~s}^{1}$ compliance with the performance requirements of MIL-L-46152A and API Services SE/CC.

In the brief time allotted, I will report on our engine testing experience with PROP rerefined oils as produced in a full-scale 2 MM GPY PROP plant operating with Buyer-collected used oil feedstocks. I will also comment on the status of the first two PROP plants, one built for the State of North Carolina and the other for Mohawk 0il Company, Ltd., Vancouver B. C., Canada.

Before getting into the details of the testing programs, I want to elaborate briefly on Phillips concept of contractually demonstrating product quality to Buyer's of PROP plants. Technically credible proof of quality is essential to industry and government acceptance of lubricants blended with re-refined oils. From this base, public acceptance will evolve providing undeserved labeling requirements are lifted by FTC.

Simplistically-speaking, this requires demonstration of re-refined base oil equivalency to virgin oil blending stocks, quality-wise. For the PROP program, we are utilizing the SAE/ ASTM/API service definitions and engine test criteria to demonstrate the additive-treated re-refined oil's equivalent or "passing" performance. With the use of widely available, commercial additive packages, we view this not only as adequate verification of base oil quality, but also as being in the best interests of re-refiners and oil compounders who desire to employ re-refined base stocks in their motor oil blends.

Contractually, we are prepared to carry out such tests for each Buyer of PROP plants. Once this is successfully done, the Buyer then has the responsibility for utilizing PROP base oils in his development of a variety of specific products to meet his marketing needs. This concept is consistent with that Phillips has followed during the 30 years of operation of its solvent extraction lube oil refinery in Kansas City--namely to produce high quality paraffinic base stocks as the starting point for blending a wide range of additive-treated automotive and commercial oils.

TRegistered trademark. 
Phillips plans to continue with this format for those Buyers of PROP plants desiring this degree of quality assurance until such time as NBS is successful in coming up with the equivalency tests, as required by the EPCA Act of 1975 (PL 94-103). Hopefully, these will be less complex and less costly, but I doubt that anyone here believes this to be less of a challenge to NBS now than when discussed at the first of these conferences. Nonetheless, with ASTM now deeply involved in this effort, and with the Department of Defense' amendment to MIL-L-46152 (' $A$ ' revision) recognizing the potential equivalency of re-refined and virgin base oils, we optimistically believe real progress will be forthcoming.

Let us turn now from prognostications to facts. PROP base oils used in the blending of SE/CC motor oils for independent laboratory engine testing programs were produced in the 2 MM GPY plant built for North Carolina. The production runs were made with plant operation at its temporary site at the Phillips Research Center. (PROP oil, for the first two testing programs I will discuss, involved plant runs with used oil feedstock collected by the State of North Carolina.) The third involved base oil recovered from waste oil collected by Mohawk 0 il Company and supplied as feedstock representative of their half-million gallon storage in the Vancouver area.

Data pertaining to the oils tested and the results of their SE/CC engine tests performed by outside certified laboratories are shown in the next several tables (table 1). Programs conducted with North Carolina PROP oil contain two different additive treatments. Program A utilized a "Universal" additive treatment and a $20 \mathrm{cSt}$ @ $100{ }^{\circ} \mathrm{C}$ viscosity adjusting stock to bring the blended oil viscosity to the mid-range of the SAE 30 grade. Program $B$ was less conservative, utilizing a competitive-cost additive treatment recommended for SE/CC performance. Viscosity adjusting stock was not used in the Program B oil blend; hence its viscosity was within but near the lower limit of the SAE 30 grade.

Table 1. Prop oils for engine testing programs A \& B.

Feedstock Source: North Carolina Used 0il Collections

Processing: 2 MM GPY PROP plant

Motor 0 il Grade: SAE 30

Re-refined Neutral, \%

Viscosity Adjusting Stock, \%

$\frac{\text { Program A }}{78.9}$

9.7

Detergent-Inhibitor, \%

Pour Point Depressant, \%

11.3 (Univ.)

0.1

216

104.1

11.58

Viscosity Index

TBN

Sulfated Ash, \%

Zinc,\%
108

3.9

1. 00

0.14

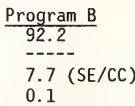

7.7 (SE/CC)
75.7

9.89

111

6.9

1.08

0.15

Sequence IID, IIID, Caterpillar 1-H2 and CLR L-38 engine tests have been successfully completed in both programs (tables 2 and 3 ). Sequence VC data complete Program A, confirming this oil's SE/CC and MIL-L-46152A. A Sequence VD test is scheduled for Program B (tables 4 and 5 ) with all other test data indicating its SE/CC performance. Contingent upon passing Sequence VD results, this program will be presented to the SAE's Lubricants Review Institute for Review Board approval as meeting the MIL-L-46152A specification. 
Table 2. Engine test results prop oil - program A.

ENGINE TEST

Ratings:

Avg. Rust

Avg. Sludge

Avg. Piston Varnish

Avg. Engine Varnish

Ring/Land Varnish

0 il Ring Clogging

0 il Screen Clogging

Ring Sticking

Lifter Sticking

Avg. Cam/Lifter Wear, in

Max. Cam/Lifter Wear, in

Cam/Lifter Scuffing

Viscosity Incr. @ $40 \mathrm{~h} \%$

Viscosity Incr. $64 \mathrm{~h} \%$

0 il Consumption, qts

Overall Rating
SEQ. IID

8.8

-.-

$---$

$---$

$---$

$\cdots$

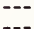

None

---

$--$

$--$

-.-

PASS
SEQ. IIID

9.6

9.4

7.8

--

None

None

None

0.0038

0.0051

None

59

92

3. 31

PASS
SEQ. VC

9. 5

8.0

8.5

$---$

None

None

None

-.-

-..

$-$

$---$

$-$

PASS

Table 3. Engine test results prop oil - program A.

\section{ENGINE TEST}

Fed. Test Method

Ratings:

Top Groove Carbon, \%

Weighted Total Deposits

Bearing Weight Loss, mg

Piston Varnish

OVERALL RATING

$$
\text { Cat. } 1-\mathrm{H}_{2}
$$

346

$\frac{\text { CLR L-38 }}{3405}$
3

139.3

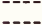

34.1

9.6
PASS

Table 4. Engine test results prop oil - program B.

ENGINE TEST

Ratings:

Avg. Rust

Avg. Sludge

Avg. Piston Varnish

Avg. Engine Varnish

Ring/Land Varnish

0 il Ring Clogging

0 il Screen Clogging

Ring Sticking

Lifter Sticking

Avg. Cam/Lifter Wear, in

Max. Cam/Lifter Wear, in

Cam/Lifter Scuffing

Viscosity Incr. e $40 \mathrm{~h} \%$

Viscosity Incr. (0) $64 \mathrm{~h} \%$

$0 i 1$ Consumption, qts.
SEQ. IID

8. 7

--

$--$

$---$

---

$-\cdots$

$--$

None

$--$

$---$

$-\cdot$

$--$

$-\cdot-$

PASS
SEQ. IIID

SEQ. VD

IN

9.5

9.2

6.8

6. 8

$-\cdot$

None

None

0.0032

0.0058

None

53

170

3. 31

OVERALL RATING

\section{PASS}


Table 5. Engine test results prop oil - program B.

Engine Test

Fed. Test Method

Ratings:

Top Groove Carbon, \%

Weighted Total Deposits

Bearing Weight Loss, mg

Piston Varnish $\frac{\text { CAT } 1-\mathrm{H} 2}{346}$

$\frac{\text { CLR L }-38}{3405}$

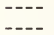

28.9

9.6

OVERALL RATING

PASS

PASS

Program $C$ results, as shown in tables 6,7 , and 8 pertain to a similar demonstration of PROP oil quality as re-refined from Mohawk-supplied Canadian waste oil feedstock. In this instance, the plant-produced 300 neutral stock $\left(62 \mathrm{cSt} @ 40{ }^{\circ} \mathrm{C}\right.$ ) was fractioned into two blending stocks--a 150 neutral and 700 neutral. This fractionation simulates the Buyer's intention to fractionate the product in his PROP plant operations. Also as an accommodation to this Buyer's specific interests, Sequence tests and the L-38 test were run with an SAE 10W-30 grade for SE performance, and the Caterpillar 1-H2 test with the SAE 30 grade.

Table 6. Prop oil for engine testing program C.

Feedstock Source: Mohawk $0 i 1$ Co. Ltd. Used $0 i 1$ Collections

Processing: 2 MM GPY PROP plant

Re-refined Light Neutra1, \%

Re-refined Heavy Neutral, \%

Detergent-Inhibitor, \%

Viscosity Index Improver

Pour Depressant Solution

Physical Properties:

Flash Point, ${ }^{\circ} \mathrm{C}$

Viscosity, cSt e $40^{\circ} \mathrm{C}$ cSt @ $100{ }^{\circ} \mathrm{C}$

Viscosity Index

TBN

Sulfated Ash, \%

Zinc, \%

\begin{tabular}{c} 
SAE $10 \mathrm{~W}-30$ \\
\hline 89.6 \\
\hdashline 7.9 \\
1.8 \\
0.6
\end{tabular}

\begin{tabular}{cc} 
& SAE 30 \\
\cline { 2 - 2 } & 22.0 \\
$\mathrm{SE} / \mathrm{CC}$ & 70.0 \\
& 7.9 \\
---- \\
0.1
\end{tabular}

213

76.0

11.40

142

6.7

1. 05

0.17
243

96.9

11.41

105

8.0

1.03

0.17

Compositional and physical characteristics for the two Mohawk oils are shown in table 6 . Both were treated with the same commercial, cost-competitive SE/CC detergent-inhibitor treatment. No virgin oil viscosity adjusting stocks were used in either Mohawk oil. Engine test results (tables 7 and 8 ) indicate full compliance with the ASTM test performance criteria for API Services SE/CC and the passing limits of MIL-L-46152A.

Our field experience with PROP re-refined oils has totalled 1.5 million miles. For the most part, this has involved PROP oils from North Carolina feedstock treated with the 'Universal' additive treatment of Program A. These field trials have been of a comparative nature, conducted in a more or less uncontrolled testing environment. One 600000 mile experience involved 19 Company-owned late model automobiles and pick-up trucks in pool service operating out of Bartlesville. Service spanning one to two years to individual vehicles was trouble-free. Examination of operating records, comparing test units to the parallel operation of more than 100 similar vehicles running with Phillips' first line quality motor oil, showed no differences in engine performance. 
Table 7. Engine test results prop oil - program C.

Engine Test

Ratings:

Avg. Rust

Avg. Sludge

Avg. Piston Varnish

Avg. Engine Varnish

Ring/Land Varnish

0i1 Ring Clogging

0il Screen Clogging

Ring Sticking

Lifter Sticking

Avg. Cam/Lifter Wear, in

Max. Cam/Lifter Wear, in

Cam/Lifter Scuffing

Viscosity Incr. ¿ $40 \mathrm{~h}$

Viscosity Incr. $64 \mathrm{~h}$

$0 i 1$ Consumption, qts.
SEQ IID

8.6

-.-

-.-

$--$

-.-

$-\cdot$

$--$

None

--

$---$

$---$

PASS
SEQ IIID

\section{7}

9.4

---

6.5

-.-

None

None

0.0023

0.0043

None

22

45

4.53

PASS

OVERALL RATING

$\underline{\text { PASS }} \quad \underline{\text { PASS }}$

Table 8. Engine test results prop oil - program C.

\section{Engine Test}

Fed. Test Method

Ratings:

Top Groove Carbon, \%

Weighted Total Deposit

Bearing Weight Loss, mg

Piston Varnish

OVERALL RATING

$$
\frac{\text { CAT } 1-\mathrm{H} 2}{346}
$$

\section{$\frac{\text { CLR L-38 }}{3405}$}

$10 \%$

133.6

----

----

PASS
9. 5

8.1

8.4

None

None

None

None

$---$

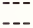

-.-

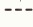

PASS

Another 925000 miles of experience has been obtained in a tire test fleet. One phase of their experience involved 30 passenger cars and light trucks (all gasoline engine-powered) with curb weights 50 percent above normal. Units in "as is" condition, with from 100000 to more than 400000 engine miles of prior service were used. 650000 miles were accrued with these cars on high speed service. No initial nor final engine inspections were involved. Notwithstanding the initial high mileage of these cars, their operation diring the five months' trial was satisfactory and typical of prior experience in the fleet.

The diesel truck experience was limited to 275000 miles total, divided among six heavily loaded tractor-trailers. Individual odometer readings ranged from 650000 to 1.1 million miles at the outset. Most were well within the fourth 250000 mile bearing changeout period. Operation with PROP oil was limited to only 35000 to 70000 miles per vehicle and realistically was not sufficiently extensive to justify a performance claim.

Presently, the State of North Carolina has several thousand gallons of SE/CC motor oils blended with PROP plant produced base oil. This SE/CC product is now being used in a variety of State-owned vehicles on an uncontrolled basis. This experience began at mid-summer. To date reports indicate good acceptance and wholly satisfactory performance.

In closing, I want to report briefly on the status of the first two PROP plants which you have read about in the press. The 2 MM GPY plant destined for North Carolina was demonstrated to and accepted by the State in late 1978. Subsequent independent laboratory engine 
testing confirmed the PROP oil's SE/CC and MIL-L-46152 quality. For several months, this plant was operated intermittently as a prototype unit at its temporary site in Bartlesville while North Carolina sought to come to a decision as to its permanent siting in the Raleigh area. The plant has been ready for shipment for several months. North Carolina's expectation is that the plant will be started up at their Garner (Raleigh suburb) site very early in 1980 . Product use will be limited to the public vehicles of state and local government as stipulated by State law to avoid competition with private enterprise. Fabrication of a 5 MM GPY PROP plant for Mohawk 0il Company, Ltd., is now complete. As I speak, final arrangements are being made for its shipment to Mohawk's North Vancouver, B.C. plant site. Start-up is scheduled during the first quarter of 1980 . Mohawk has generated extensive favorable publicity for their re-refining program during the past year. Their announced plans include marketing of PROP re-refined oils meeting SE/CC/MIL-L-46152A and other industry requirements to all segments of the Western Canada market. 
National Bureau of Standards Special Publication 584. Proceedings of Joint Conference on Measurements and Standards for Recycled 0il/Systems Performance and Durability held at NBS, Gaithersburg, MD, October 23-26, 1979. (Issued Nov. 1980)

\title{
HISTORICAL PERSPECTIVE OF LUBRICANT DEPOSIT EVALUATIONS AT SOUTHWEST RESEARCH INSTITUTE
}

\author{
J. N. Bowden and S. J. Lestz \\ Southwest Research Institute \\ P. O. Drawer 28510 \\ San Antonio, TX 78284
}

\section{Introduction}

The purpose of a lubricating oil in the crankcase of internal combustion engines, in gear trains, and in turbine engines is to separate metallic surfaces that move with respect to each other, thus minimizing friction and wear. In addition, the lubricating oil performs as a heat transfer medium, a dispersant for wear and sludge particles, and a neutralizer for acidic combustion and/or oxidation products. If the lubricant fails as a coolant, dispersant, and neutralizer, then insoluble oxidation products are formed which deposit on metallic surfaces, plug screens and filters, thus preventing the lubricant from performing its major function, that of separating sliding surfaces.

Mineral oils refined from petroleum crude provided satisfactory liquid lubricants for machinery for many years, but most modern equipment demands more from a lubricant than mineral oils alone can provide. Various additives have been developed to improve the properties of mineral oils and to give them desirable new properties. Aircraft turbine engine lubricants are subjected to large volumes of high temperature gases which flow through the engine and to comparatively high loading on gearing. Thus, good thermal and oxidative stability combined with good load carrying properties are essential, and synthetic lubricants have been found to meet these requirements more adequately than petroleum-based lubricants.

At Southwest Research Institute, many projects have been devoted to learning more about the basic mechanism of lubrication, the function of additives in lubricants, and evaluation of the qualities of piston and turbine engine oils by means of bench tests development and subsequent correlation with full-scale engine tests. This presentation describes briefly many of these projects involving piston and turbine engine lubricants.

\section{Dispersancy Mechanisms}

The basic mechanisms pertaining to the performance of oil soluble dispersants were investigated using microscopy techniques to observe sludge agglomeration at elevated temperatures and to measure the electrophoresis of the particles dispersed in the oils $[1]^{1}$. Figure 1 is a photograph of the microscope equipped with a heating stage used in this program, and figure 2 shows the parts of the electrophoresis cell. The heating stage is capable of heating the sample, under close control, to $660^{\circ} \mathrm{F}$, and contains a removable slide holder fitted with a cover glass to shield the objective lens.

These techniques proved to be effective tools for studying and evaluating oil soluble dispersants. As the dispersant concentration increases, the stability of a sludge suspension, when heat is applied, improves; and the electrophoretic mobility decreases. This mobility is nil at the maximum effective concentration for a stable sludge suspension, showing that an equilibrium between the electrically charged entities in the system has been established.

To investigate the mechanisms of ashless motor oil dispersant additives, which are mostly copolymers containing functional groups, an electron microscope technique was employed [2]. It was learned the polymeric dispersants function much like the metal-organic additives (fig. 3 ).

TFigures in brackets indicate the literature references at the end of this paper. 


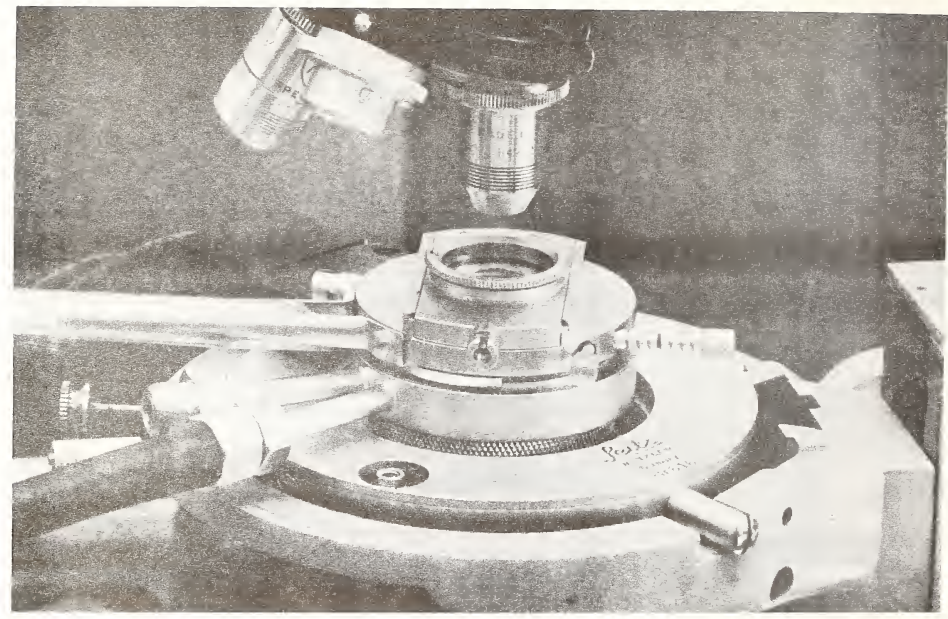

Figure 1. Heating stage on microscope.
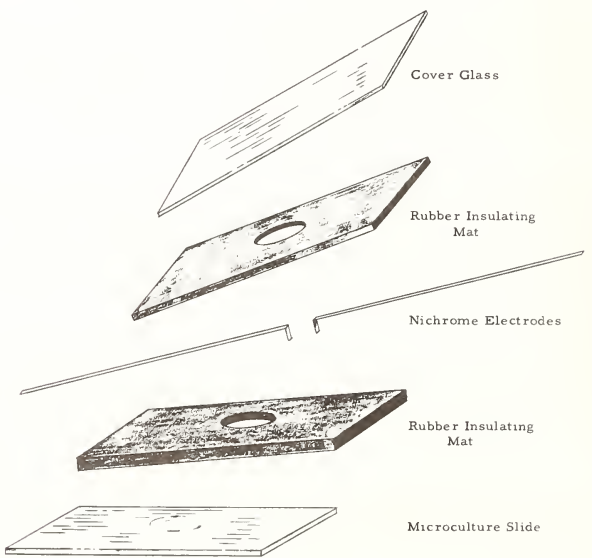

Microculture Slide

Figure 2. Electrophoresis cel1. 


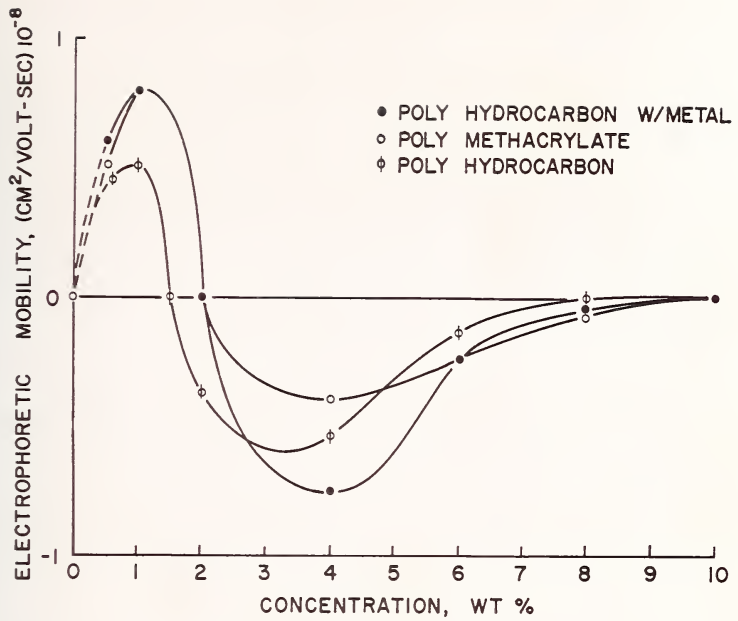

Figure 3. Effect of dispersant concentration on electrophoretic mobility.

Either the electrophoretic or sludge agglomeration techniques can be used effectively in studying the behavior of engine sludge dispersion in lubricating oils [3] (fig. 4).

A procedure was developed which permitted the prediction of sludge rating in the low temperature dispersancy (LTD) engine test [4]. This test utilizes the CLR single cylinder laboratory engine [4].

Examination of used oils with the microscope showed that high temperature was a major cause of dispersant depletion, thus permitting the sludge to agglomerate and deposit on engine parts when a given sludge particle size is reached.

Conclusions from this work were that: 1) Dispersant depletion can be studied by observing sludge agglomeration in the oil by optical microscopy. 2) $0 i 1$ contamination by sludge precursors is greater at lower engine operating temperatures. Raising the oil temperature results in larger size oil sludge agglomerates, the deposition of which is facilitated by cooling the oil. 3) The sludge agglomerate size technique can be used to predict engine sludging at any time during an LTD test without the necessity of engine disassembly. 4) The agglomeration temperature analytical technique for screening new dispersant oils correlates well with fleet and laboratory engine deposits and can predict LTD engine test ratings. 


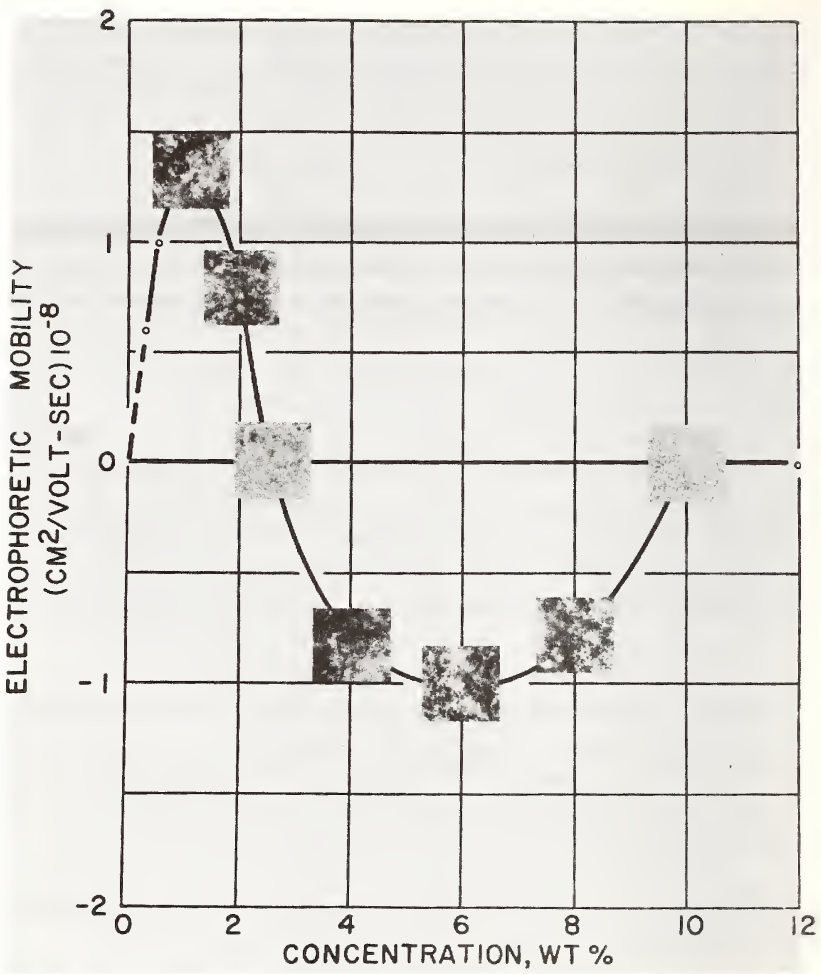

Figure 4. Effect of additive concentration on sludge mobility (basic barium sulfonate).

\section{Blowby Diversion}

When combustion products, commonly called "blowby", are prevented from reaching an engine's crankcase, sludge formation is inhibited and lubricant life extended. Blowby diversion does not reduce an engine's inherent combustion leakage but is accomplished after the blowby gases leak past the compression rings and before the gases escape into the crankcase atmosphere. Blowby, after leaking past the compression sealing zone, can be diverted from the crankcase by one, or a combination of the following (fig. 5): Basic Method No. 1- Diversion of blowby through a passage in the piston material to the combustion chamber. Basic Method No. 2 - Diversion of blowby to outside the engine by an isolated crankcase passage. Basic Method No. 3 - Diversion of blowby through the cylinder to outside the engine. Basic Method No. 4 - Diversion of blowby past the compression rings back into the combustion chamber. 
Single cylinder engine studies have demonstrated that the principle of blowby diversion is feasible and can prevent better than 90 percent of the blowby from entering the crankcase. The studies further indicated a significant reduction in sludge formation rates (increase in engine cleanliness), with decreases in ring wear and air pollution.

Use of basic method Nos. 2 and 3 permitted isolation and collection of blowby outside the engine for thorough analysis. It was learned that this material is composed not only of hydrocarbon but also a significant concentration of nitric, sulfuric, and hydrochloric acids.

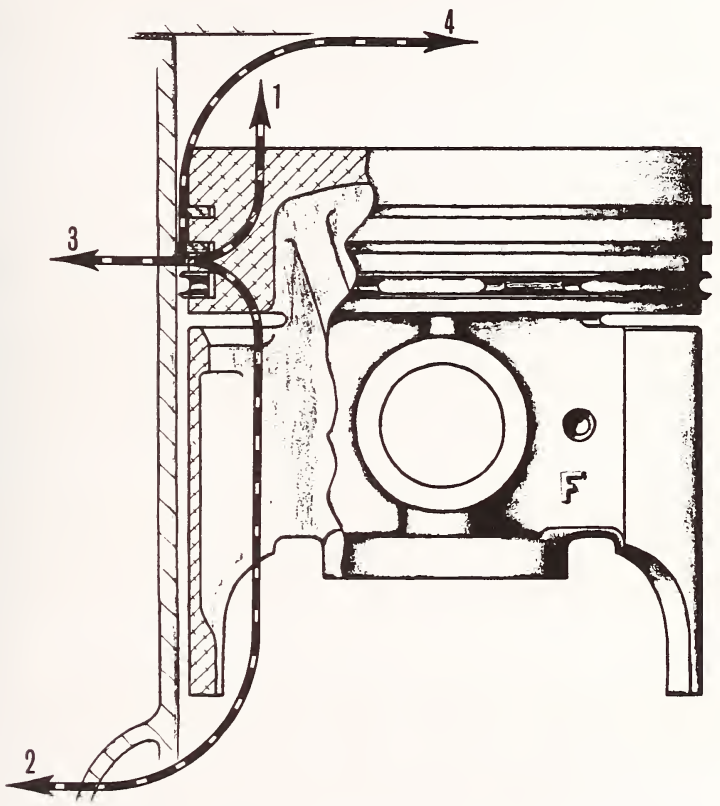

Figure 5. Four basic methods of blowby diversion.

4. Engine Sludge Analysis

At low temperature engine operating conditions, sludge is often formed which results in deposits on engine parts. A study conducted at SWRI on the mechanism of sludge formation indicated that it is initiated by liquid oxidation products, inorganic salts, and polymerized organic products that pass the piston ring zone [6]. During this work condensable blowby products were analyzed and consisted of unburned fuel, water from combustion, oil insoluble liquid oxidation products, and solid materials. Analysis of low temperature sludge generated in a laboratory engine was found to contain from 16 to 32 percent solid materials depending upon the efficiency of the dispersant additive in the oil, 60 to 80 percent oil, and small amounts of water and fuel. Inorganic salts account for half the solid content of the sludge. 


\section{Engine Varnish}

Varnish is a type of deposit that occurs on piston rubbing surfaces and can form on other surfaces in an engine. Varnish formation in spark ignition engines was investigated to determine the interrelationship between fuels, lubricants, additives, and engine operating conditions [7]. A series of engine tests were conducted with fuels of varying compositions, and different lubricants. The varnish deposits formed were removed and analyzed by nuclear magnetic resonance and infrared spectroscopy. From the data generated in this work, it was concluded that: 1) The main varnish precursors are fuel aromatic compounds. 2) Finished lubricants act as varnish inhibitors. 3) Compression ratio, jacket temperature, and engine load are the most important engine variables which affect varnish formation. 4) Nitrogen fixation $\left(\mathrm{NO}_{2}\right.$ formation) contributes to varnish formation but does not have an overriding effect. 5) Engine varnish composition is mostly alkaline in character and consists of primarily hydroxy and carbonyl organic compounds, but sulfur and nitrogen hydrocarbon derivatives are also present. In addition, lead salts are part of varnish but are not a prerequisite to varnish formation.

\section{Thermal 0xidation Stability of Gear Lubricants}

A method for measuring the thermal oxidation stability of gear lubricants was developed at the Army Fuels and Lubricants Research Laboratory, SwRI, which became a part of Federal Test Method Standard No. 791-B, and was assigned Method No. 2504. The method evaluates the deterioration of gear lubricants under severe oxidation conditions and consists of placing a sample of the lubricant in a gear case in which two spur gears and a test bearing are operated under load while heat is applied and air is bubbled through the lubricant (fig. 6). The temperature of the sample is maintained at $325^{\circ} \mathrm{F}$ and the test is continued for 50 hours. Every ten hours a sample is taken for viscosity measurement, and if 100 percent increase in viscosity is observed, the test is stopped. The lubricant sample is drained out of the gear case and tested for viscosity, acid number, pentane and benzene insolubles. Deposit on gears, various parts of the gear case and catalyst are rated for color, hardness, thickness, and type, such as lacquer or sludge. Several engine oils were evaluated by this procedure to study the high temperature oxidative effects; however, the repeatability of the test data was not good.

The apparatus was modified to evaluate the oxidation corrosion tendencies of crankcase lubricants [8]. The modification consisted of removing the test gears, copper catalyst, gear-loading mechanism, and air supply system. The lubricant compartment was modified to accommodate a driveshaft seal, and a test bearing connecting rod journal of special design was mounted on the driveshaft (fig. 7). Lubricants evaluated in this apparatus for copperlead bearing weight loss compared with results for the same lubricants evaluated in L-38 single cylinder engine tests (fig. 8).

\section{Turbine Lubricants}

As stated earlier, the requirements of aircraft turbine engine lubricants are considerably more stringent than those of automotive engine lubricants. Several procedures have been developed and investigated at SwRI to evaluate oxidation, corrosion, thermal stabilty, and depositing characteristics of synthetic turbine engine lubricants.

\section{Oxidation-Corrosion-Deposition and Thermal Stability Characteristics of Aircraft Lubricants}

A glassware test to investigate the oxidative, corrosive, depositing and thermal stability characteristics of synthetic aircraft turbine lubricants was used extensively at SwRI [10]. The procedure became a Federal Standard Method and is a required test for Military Specification, MIL-L-7808 type lubricants [11]. During the course of this work a light meter for evaluating deposits was developed which had good precision and excellent correlation with visual ratings. The effect of metal and moisture on the stability of the lubricant was found to vary considerably depending on the test lubricant (fig. 9).

Thermal stability investigation carried out in an inert $\left(\mathrm{N}_{2}\right)$ atmosphere indicated that various metals, notably magnesium, significantly reduced lubricant temperature tolerance. 


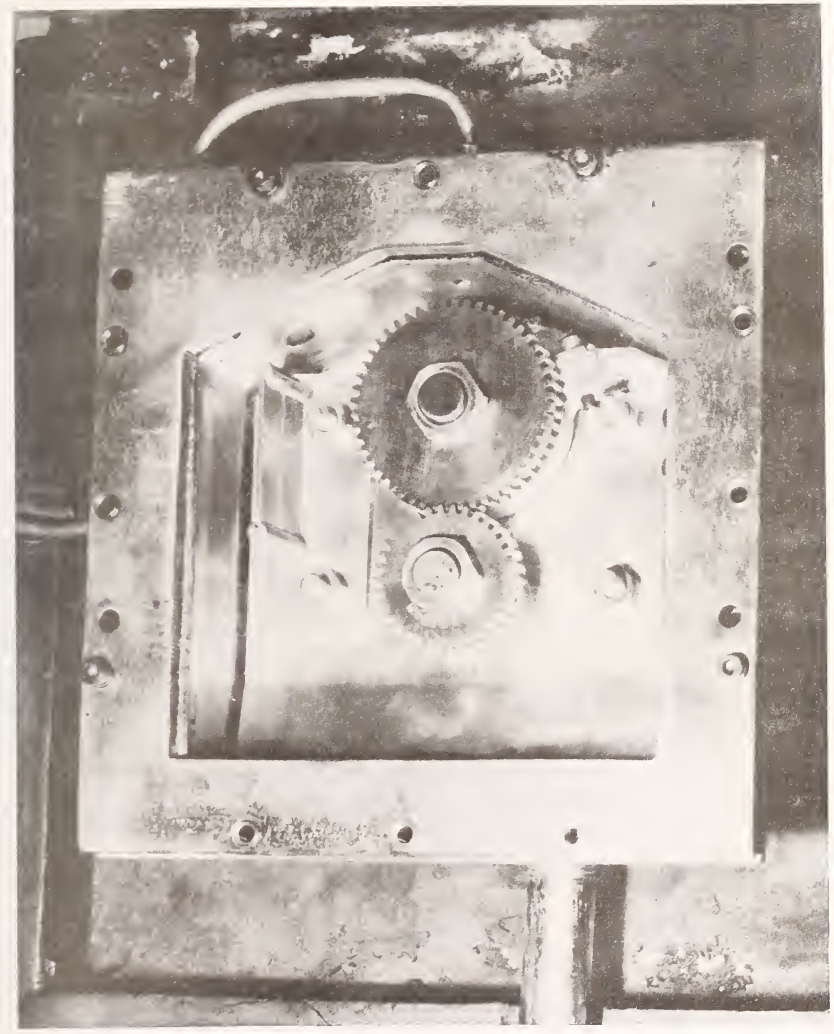

Figure 6. Apparatus for measuring the thermal oxidation of gear lubricants. 


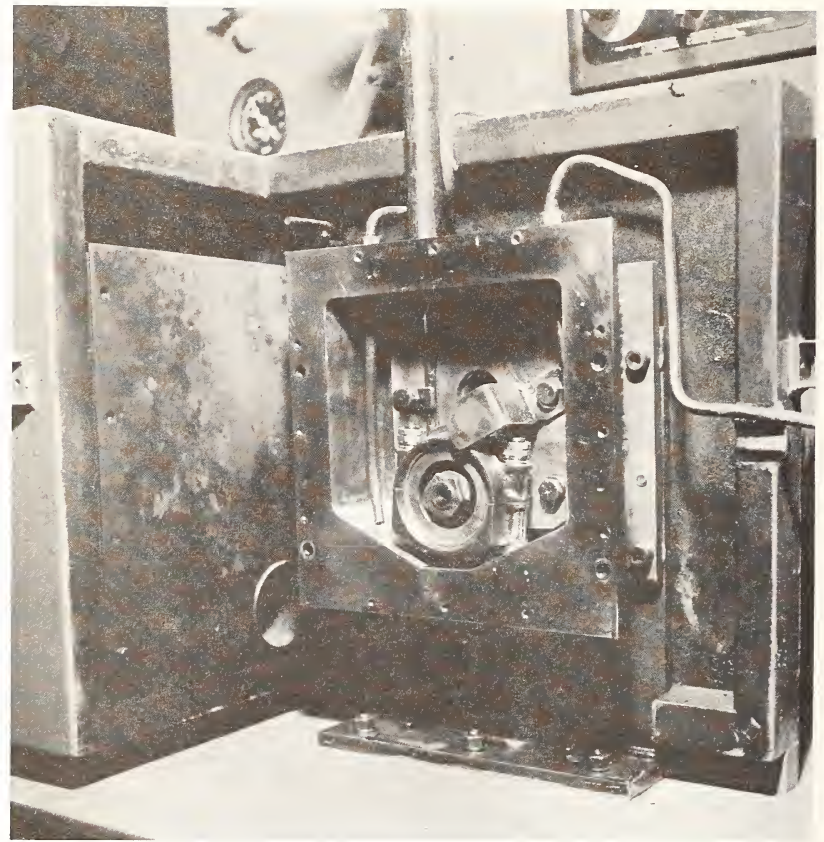

Figure 7. TOST apparatus modified for evaluation of oxidation and corrosion tendencies of crankcase lubricants.

\section{Micro Panel Coker}

Over the years, considerable attention has been devoted to the refinement and development of various bench-scale test devices intended to screen aircraft turbine engine lubricants on the basis of deposition tendencies. The thermal stress of the lubricant under such conditions results in oxidative breakdown of the fluid and the formation of deposits which impede satisfactory operation of the power plant.

A liquid-phase micro panel coker was designed and developed primarily for use in screening synthetic lubricants, on the basis of deposit formation, in instances where only researchsize sample quantities are available [12] (fig. 10). The device, which requires less than $75 \mathrm{ml}$ of sample per test, is capable of operation to $1000^{\circ} \mathrm{F}$ panel temperature and exhibited good correlation wth a full-scale, RTD "TR" panel coker which requires a sample volume of approximately $650 \mathrm{ml}$ per test (fig. 11). 


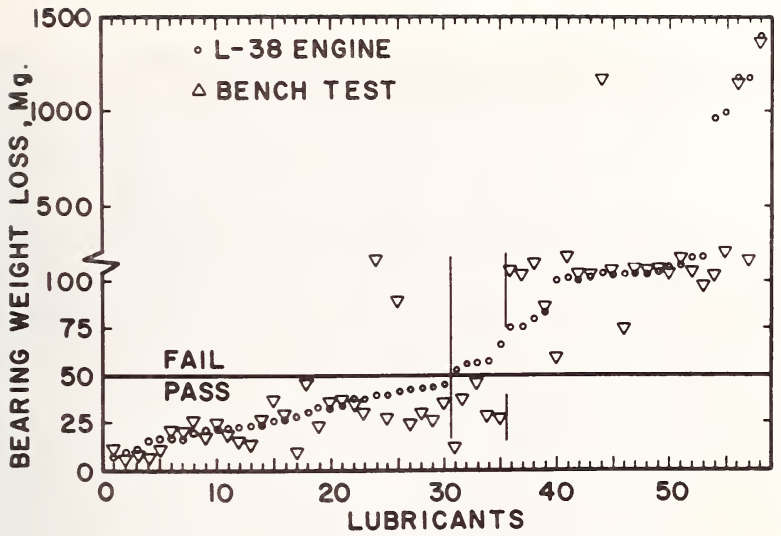

Figure 8. $L-38$ engine and bench test bearing weight loss.

A vapor-phase micro panel coker was also developed and was employed in a less extensive study of vapor-phase deposition, as opposed to the essentially liquid-phase condition found in the normal panel coker design.

Both micro panel coker models were utilized in an experimental investigation of the effect of moist air on test lubricant performance (fig. 12). A varying response to moisture was found. The performance of some fluids was unaffected, while others showed improvement, and some indicated a deleterious effect. In addition, lubricant sensitivity to moisture was dependent upon the coker type and was, in some cases, reversed between the two coker models when compared with the normal procedure using dry air.

\section{Hot Wall Deposition Rig}

An expanded program to study the deposition and degradation characteristics of aircraft turbine lubricants involved the fabrication and operation of a test rig designed to simulate the conditions of actual engine operation with regard to temperature, lubricant dispersion, and flow rate that occur in the vicinity of the No. 2 rear bearing support of a J-57 jet engine. In this test, the No. 2 rear bearing support, herein called the hot-wall, is used as the test specimen on which deposits are caused to form by subjecting the front surface of the specimen to a lubricant fog while heat is applied to the back surface (fig. 13) [13]. A schematic diagram of the hot-wall deposition rig is shown in figure 14 . The test oil sump $L$ and makeup oil reservoir $U$ are charged with 2000 and $1000 \mathrm{ml}$ of test lubricant, respectively. The lubricant is heated to $350^{\circ} \mathrm{F}$ and pumped to the test specimen $\mathrm{A}$, where it is fogged through nozzle $E$ on to the hot-wall, which is kept at the desired temperature between 500 and $560{ }^{\circ} \mathrm{F}$. Data from this test identified heating fluid temperature, atmosphere type, and test time as significant main effects of the deposition process.

A continuing investigation led to the discovery of the presence of appreciable metal (iron) content in the deposits recovered from the conventional bearing deposition tests and full-scale engine tests. The concentration of iron in the test lubricant in the principal deposits was monitored by atomic absorption spectroscopy. A direct indication of the extent of wear metal generation was provided by weight loss measurements of spring-loaded mild steel wear plates mounted within the test-lubricant sump (fig. 15). Significant deposit rating increases were found in many instances, dependent upon the test lubricant and magnitude of wear [14] (table 1). 


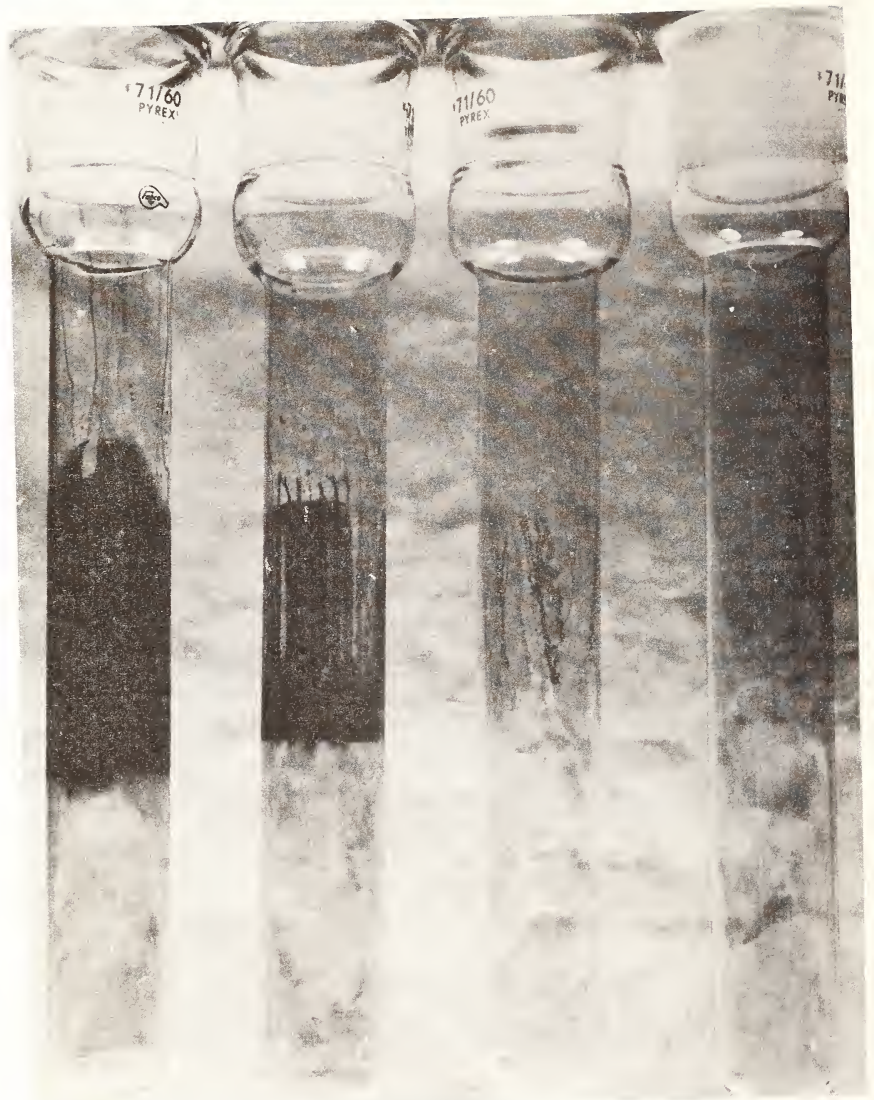

Figure 9. Typical sample tube deposits. 


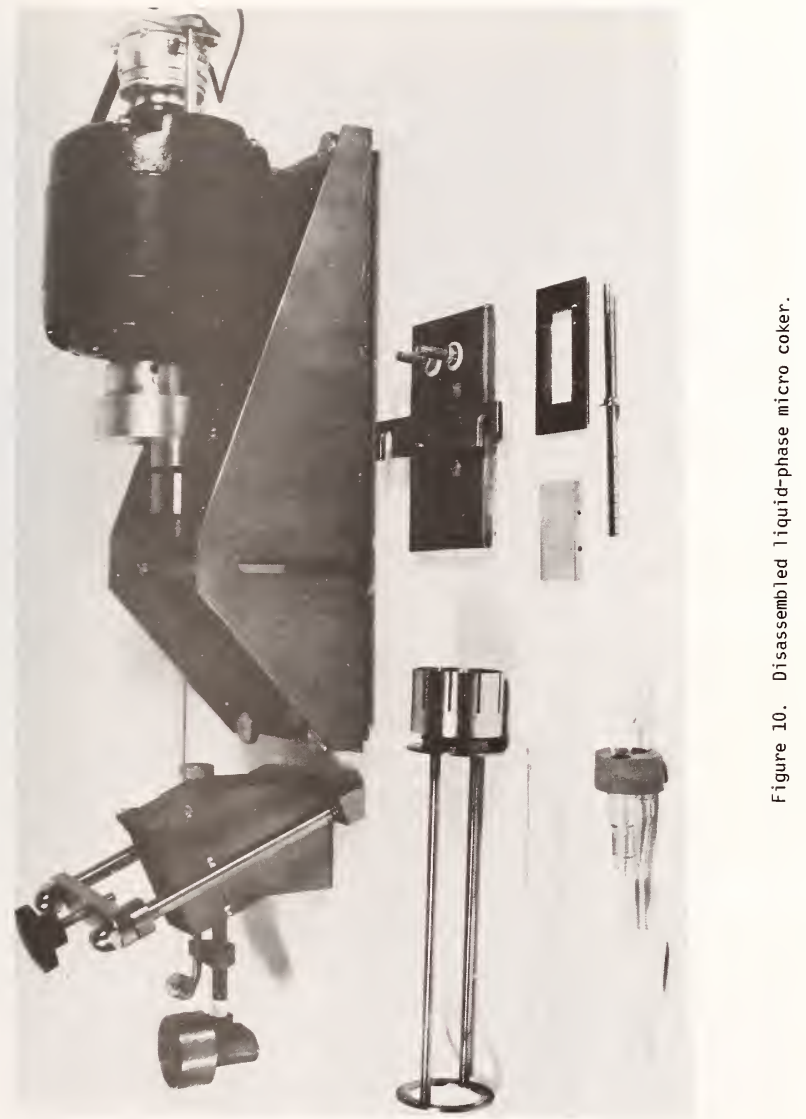




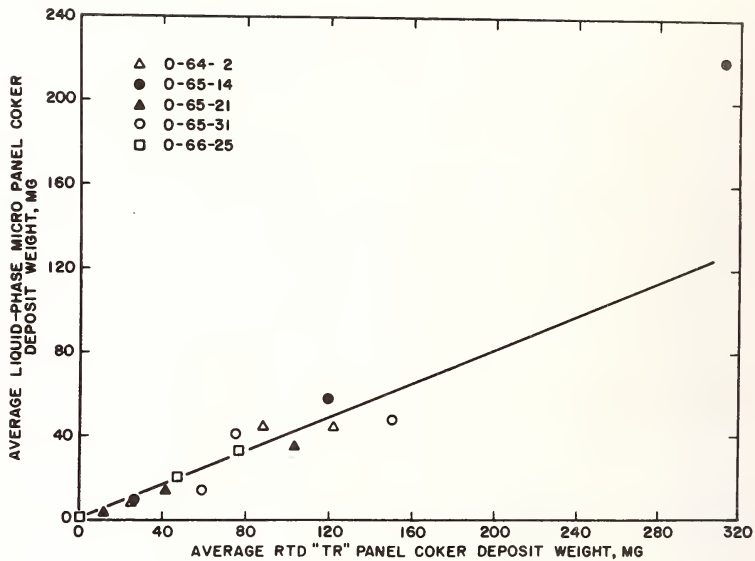

Figure 11. Correlation of deposit weight between RTD panel coker and 1iquid-phase micro panel coker.

\section{Rotating Cylinder Rig}

Experiments were conducted with a device known as the rotating cylinder rig for the formation of controlled-thickness thin films $(0.004 \mathrm{in})$ at temperatures in the range of $350^{\circ}$ to $550^{\circ} \mathrm{F}$ (fig. 16). Analytical techniques for detection of lubricant or additive consumption and degradation products included liquid chromatography and gas chromatography/ mass spectroscopy. Studies were conducted with selected polyol ester and diester base stocks, both with and without additives. Experiments showed that the antioxidants effectively retarded oxidation and deposition for both ester base stocks up to the time of complete additive consumption. A beneficial synergistic effect on deposition was noted at one concentration using the antioxidants in combination. The findings strongly suggest that an interaction between the ester oxidation products and system wear metals is a significant factor in the deposition mechanism for both ester types [15].

\section{Engine Simulator Test for Lubricant Evaluation}

The Air Force Aero Propulsion Laboratory engine simulator was designed to provide a flexible test facility with the capability of closely simulating the critical temperatures and oil flow variables experienced by the lubricant in the full-scale aircraft turbine engine. The No. 4-5 bearing compartment areas of a J-57 turbine engine are used as the basic section of the simulator (fig. 17). The simulator is driven by a 100-hp variable-speed drive system through the accessory drive gearbox, providing simulator mainshaft speeds up to $10000 \mathrm{rpm}$. Electrical resistance heaters are used to heat the air surrounding the oilwetted areas within the No. 4-5 bearing compartment areas to the controlled test temperatures. Results obtained on eight lubricants, for which full-scale engine data are available, show a 90.4 percent correlation coefficient of the deposit ratings obtained using the AFAPL engine simulator and the deposit ratings obtained from the No. 4-5 bearing compartment areas from the engine tests [16] (figs. 18 and 19). 


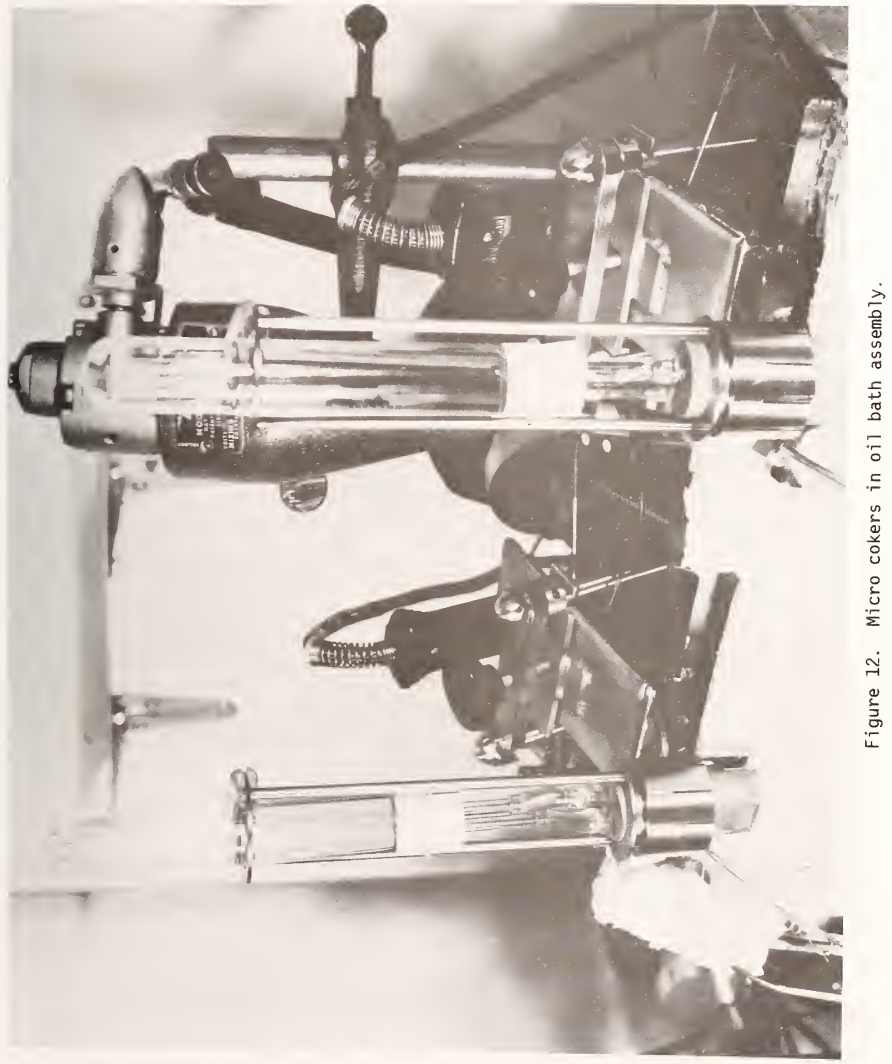




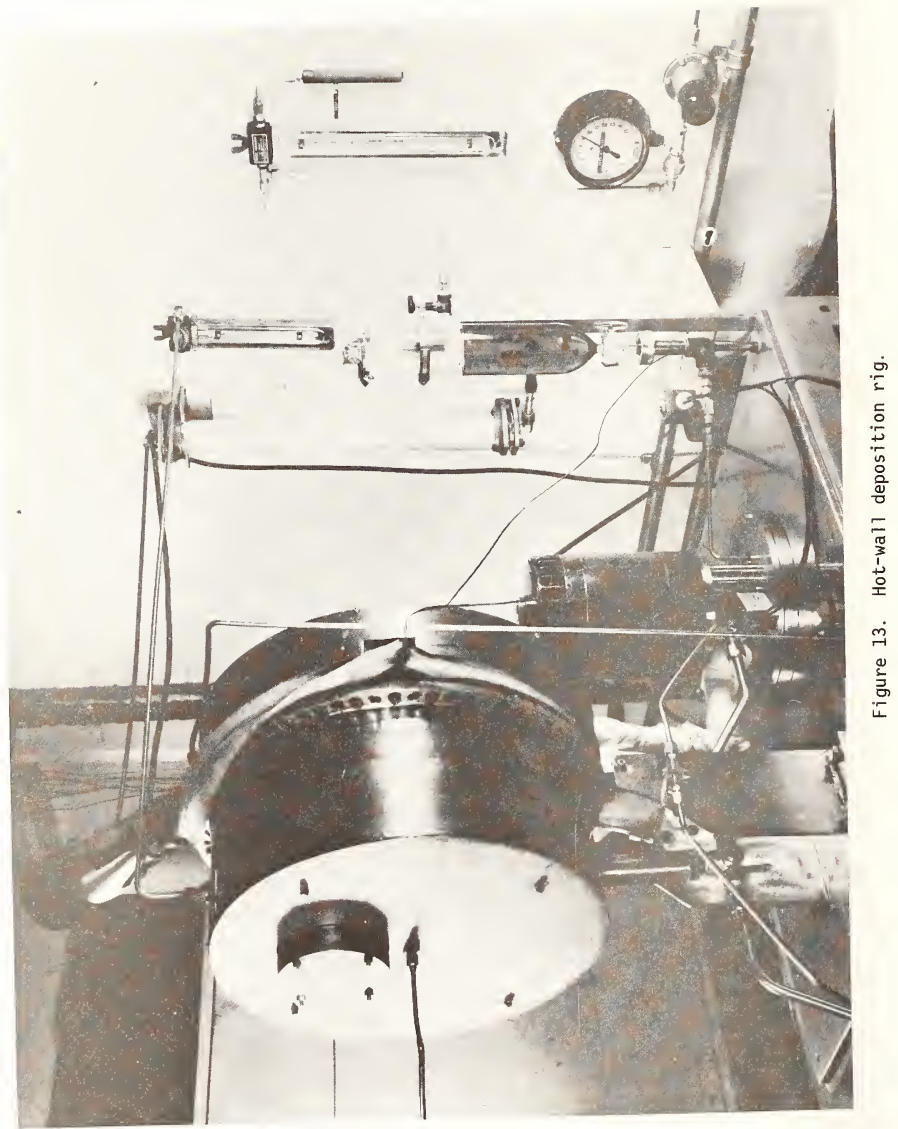




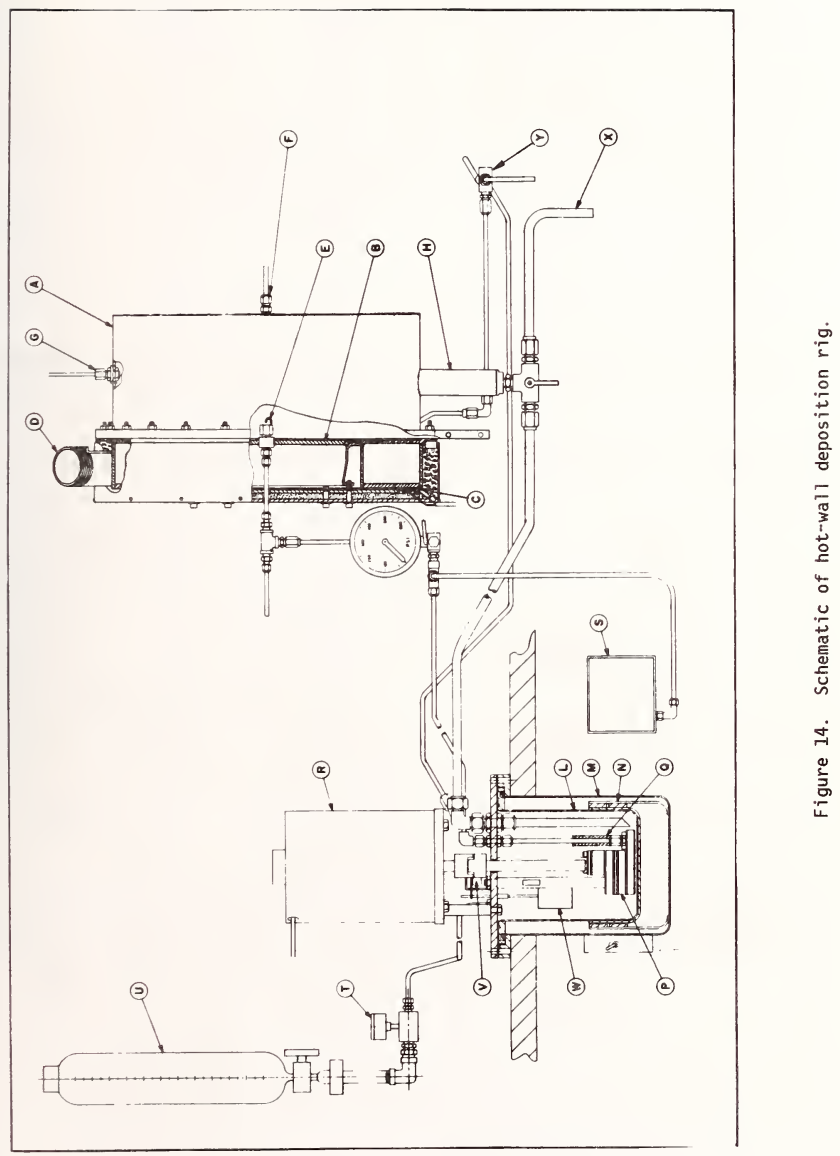




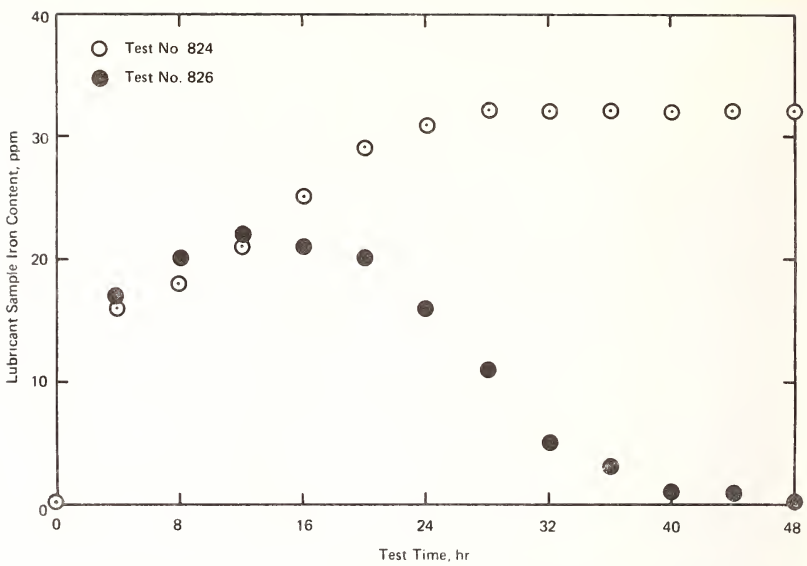

Figure 15. Typical wear metal trends in hot-wall deposition tests with wear specimens.

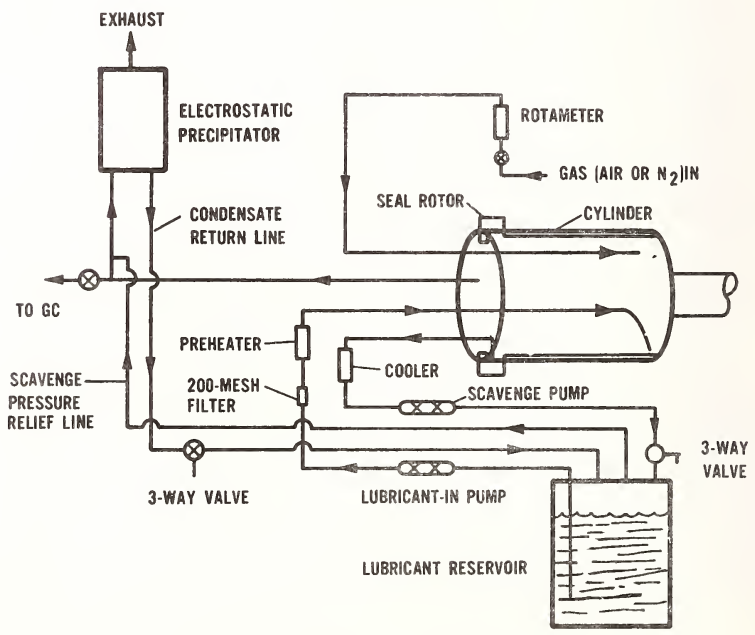

Figure 16. Rotating cylinder rig lubricant/atmosphere flow systems. 
Table 1. Summary of hot-wall deposition test results on the effect of wear metal (Fe). Mean Results

\begin{tabular}{|c|c|c|c|c|}
\hline $\begin{array}{l}\text { Lubricant } \\
\text { code }\end{array}$ & $\begin{array}{l}\text { Specimen } \\
\text { weight } \\
\text { loss, mg }\end{array}$ & $\begin{array}{l}\text { Deposit } \\
\text { rating }\end{array}$ & $\begin{array}{l}100^{\circ} \mathrm{F} \text { vis } \\
\text { change, } \%\end{array}$ & $\begin{array}{l}\text { NN change, } \\
\mathrm{mg} \mathrm{KOH} / \mathrm{g}\end{array}$ \\
\hline $0-64-2$ & $\begin{array}{l}N^{a}{ }^{a} \\
232\end{array}$ & $\begin{array}{l}36(4)^{b} \\
43(4)\end{array}$ & $\begin{array}{r}11.2 \\
9.9\end{array}$ & $\begin{array}{l}0.46 \\
0.34\end{array}$ \\
\hline $0-64-13$ & $\begin{array}{r}N P \\
389\end{array}$ & $\begin{array}{l}35(3) \\
62(3)\end{array}$ & $\begin{array}{l}7.3 \\
7.3\end{array}$ & $\begin{array}{r}-0.09 \\
0.07\end{array}$ \\
\hline $0-64-25$ & $\begin{array}{r}\text { NP } \\
806\end{array}$ & $\begin{array}{l}14(5) \\
91(3)\end{array}$ & $\begin{array}{l}98.9 \\
10.2\end{array}$ & $\begin{array}{l}9.78 \\
1.00\end{array}$ \\
\hline $0-65-16$ & $\begin{array}{r}\text { NP } \\
381\end{array}$ & $\begin{array}{l}29(5) \\
47(4)\end{array}$ & $\begin{array}{l}13.2 \\
11.2\end{array}$ & $\begin{array}{l}0.79 \\
0.54\end{array}$ \\
\hline $0-67-20$ & $\begin{array}{r}N P \\
206\end{array}$ & $\begin{array}{l}54(7) \\
81(2)\end{array}$ & $\begin{array}{l}9.3 \\
8.5\end{array}$ & $\begin{array}{l}0.34 \\
0.30\end{array}$ \\
\hline $0-67-21$ & $\begin{array}{r}N P \\
583\end{array}$ & $\begin{array}{l}31(3) \\
88(3)\end{array}$ & $\begin{array}{l}18.0 \\
20.4\end{array}$ & $\begin{array}{l}0.30 \\
0.95\end{array}$ \\
\hline $0-68-1$ & $\begin{array}{r}N P \\
437\end{array}$ & $\begin{array}{l}41(3) \\
79(3)\end{array}$ & $\begin{array}{l}14.9 \\
15.3\end{array}$ & $\begin{array}{l}0.48 \\
0.74\end{array}$ \\
\hline $0-68-7$ & $\begin{array}{r}N P \\
159\end{array}$ & $\begin{array}{l}26(2) \\
68(2)\end{array}$ & $\begin{array}{l}8.0 \\
7.5\end{array}$ & $\begin{array}{l}1.70 \\
1.68\end{array}$ \\
\hline $0-68-9$ & $\begin{array}{r}\text { NP } \\
355\end{array}$ & $\begin{array}{l}37(3) \\
62(4)\end{array}$ & $\begin{array}{l}8.9 \\
8.6\end{array}$ & $\begin{array}{l}0.32 \\
0.34\end{array}$ \\
\hline $0-68-13$ & $\begin{array}{r}\text { NP } \\
6\end{array}$ & $\begin{array}{l}22(2) \\
37(2)\end{array}$ & $\begin{array}{l}2.8 \\
0.6\end{array}$ & $\begin{array}{l}0.26 \\
0.40\end{array}$ \\
\hline $0-69-2$ & $\begin{array}{r}N P \\
124\end{array}$ & $\begin{array}{l}31(7) \\
58(4)\end{array}$ & $\begin{array}{l}12.1 \\
12.1\end{array}$ & $\begin{array}{l}0.67 \\
0.56\end{array}$ \\
\hline $0-70-2$ & $\begin{array}{r}N P \\
347\end{array}$ & $\begin{array}{r}92(2) \\
116(2)\end{array}$ & $\begin{array}{l}49.1 \\
62.7\end{array}$ & $\begin{array}{l}29.8 \\
36.1\end{array}$ \\
\hline
\end{tabular}

${ }_{\mathrm{NP}}$-wear specimens not present in system.

b Numbers in parentheses denote the number of tests run to obtain the indicated means. 







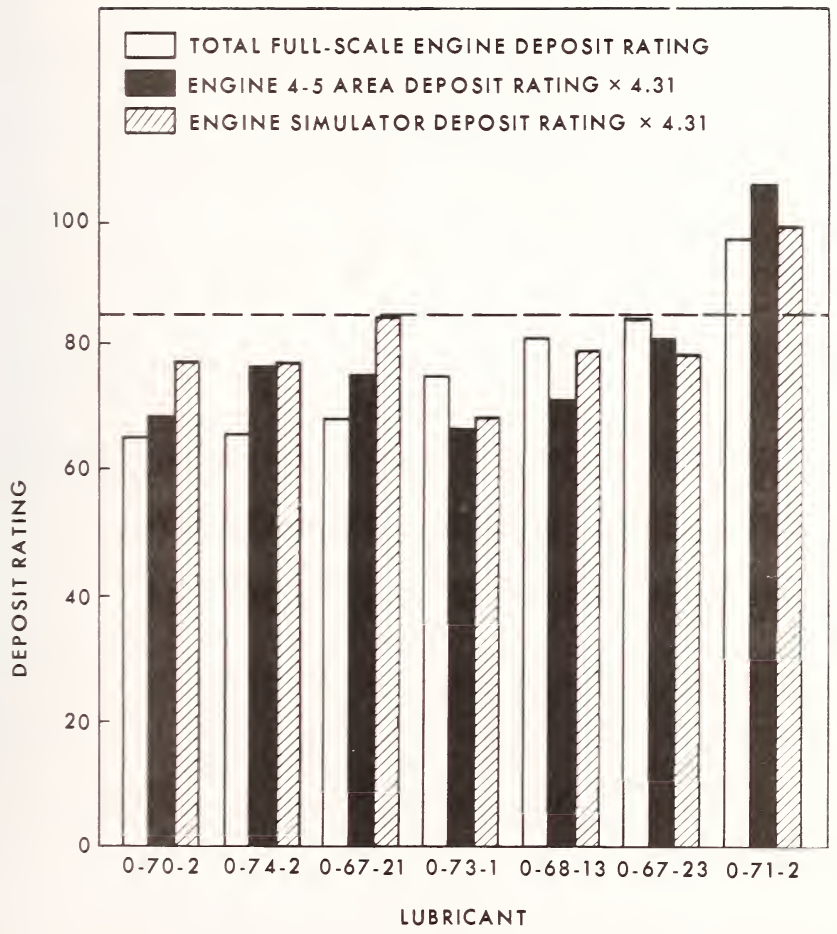

Figure 18. Comparison of estimated and actual total engine deposit ratings. 


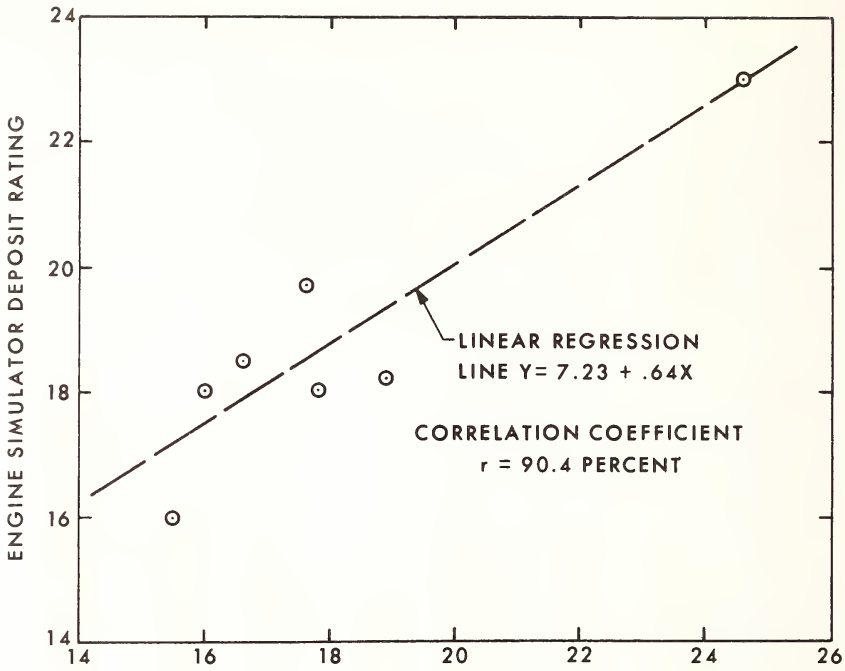

\section{4-5 AREA FULL-SCALE ENGINE DEPOSIT RATING}

Figure 19. AFAPL engine simulator deposit ratings versus deposit ratings of the 4-5 area from full-scale engine tests.

\section{Concluding Remarks}

The foregoing discussion presented numerous bench tests investigated at SwRI which were intended to evaluate the performance of automotive engine and gear oils, and aircraft turbine lubricants. In most cases the tests were designed to simulate certain aspects of the environment seen by the lubricant while performing its function, and lubricant degradation with subsequent deposit formation are the parameters measured. Although in many instances good correlation with specific engine tests were achieved, the final measure of acceptability of a finished lubricant for military applications remains the full engine tests for engine oils; automotive gear tests for gear oils, and full-scale turbine engine tests for the aircraft lubricants. The tests discussed here are excellent screening devices for new experimental lubricant formulations.

\section{References}

[1] Bowden, J. N. and Dimitroff, E., Electrophoresis of dispersant lubricating oils, paper presented at the Division of Petroleum Chemistry of the American Chemical Society, 140th National Meeting, 6, [4], B5, Chicago, I1linois (September 3-8, 1961).

[2] Bowden, J. N. and Dimitroff, E., Mechanism studies of polymeric dispersants, paper presented at American Chemical Society Symposium on Polymers in Lubricating 0ils, 7. [4], B-45, Petroleum Division, Atlantic City, New Jersey (September 1962). 
[3] Dimitroff, E. and Bowden, J. N., A theory on the mechanism of dispersancy in oil medium, paper presented at American Chemical Society Symposium on Dispersancy in $0 i 1$ Medium, Division of Colloid and Surface Chemistry, Atlantic City, New Jersey (September, 1962).

[4] Dimitroff, E., Moffitt, J. V., and Quillian, Jr., R. D., Dispersancy prediction by optical microscopy, paper presented at the Society of Automotive Engineers, National Fuels and Lubricants Meeting, Philadelphia, Pennsylvania, paper no. 600B (November, 1962).

[5] Quilitian, Jr., R. D., Meckel, N. T., and Moffitt, J. V.-, Cleaner crankcases with blowby diversion, paper presented at the Society of Automotive Engineers' Automotive Engineering Congress, Detroit, Michigan, paper no. 801B (January, 1964).

[6] Dimitroff, E. and Quillian, R. D., Jr., Low Temperature Engine Sludge, What? Where? How?, paper presented at the Society of Automotive Engineers, International Automotive Engineering Congress, Detroit, Michigan, paper no. 951A (January, 1965).

[7] Dimitroff, E., Moffitt, J. V., and Quillian, Jr., R. D., Why, what, and how: Engine varnish, Journal of Lubrication Technology, 406-416 (July, 1969).

[8] Thermal 0xidation Stability of Gear Lubricants, Federal Test Method Standard No. 791, Method 2504 (January 15, 1969).

[9] Staudt, J. J., Lepisto, P. R., and Vitkovits, J. A., A bench technique for evaluating high temperature oxidation and corrosion tendencies of automotive crankcase lubricants, paper presented at Society of Automotive Engineers, West Coast Meeting, San Francisco, California, paper no. 680538 (August, 1968).

[10] Cuellar, J. P. and Baber, B. B., Studies on the Oxidation-Corrosion-Deposition and Thermal Stability Characteristics of MIL-L-7808-Type Lubricants, Technical report AFAPL-TR-72-45, Southwest Research Institute (June, 1972).

[11] Corrosiveness and oxidation stability of aircraft turbine engine lubricants, Federal Test Method Standard No. 7918 Method 5307 (June 30, 1974).

[12] Cuellar, Jr., J. P., and Ku, P. M., Development of a Micro Lubricant Deposit Test, Technical report AFML-TR-67-438, Southwest Research Report (January, 1968).

[13] Cuellar, Jr., J. P., Montalvo, D. A., and Baber, B. B., Studies with Synthetic Lubricants in the Hot-Wall Deposition Rig, Technical Report AFAPL-TR-72-25, Southwest Research Institute (June, 1972).

[14] Cuellar, J. P. and Baber, B. B., Hot-Wall Deposition Test Results on the Effect of Wear Metal, Technical Report AFAPL-TR-73-123, Southwest Research Institute (November, 1973).

[15] Cuellar, Jr., J. P., Mechanism of Turbine Engine Lubricant Deposition, Technical Report AFAPL-TR-79-2037, Southwest Research Institute (May 1979).

[16] Baber, B. B., Tyler, J. C., and Valtierra, M. L., Development of the AFAPL Engine Simulator Test for Lubricant Evaluation, Technical Report AFAPL-TR-75-38, Southwest Research Institute (June, 1975). 

National Bureau of Standards Special Publication 584. Proceedings of Joint Conference on Measurements and Standards for Recycled 0i1/Systems Performance and Durability held at NBS, Gaithersburg, MD, October 23-26, 1979. (Issued Nov. 1980)

\title{
CURRENT ACTIVITIES OF THE NATIONAL BUREAU OF STANDARDS RECYCLED OIL PROGRAM
}

\author{
Donald A. Becker \\ Recycled 0 il Program \\ Office of Recycled Materials \\ National Bureau of Standards \\ Washington, DC 20234
}

For those of you who are not familiar with the origin or responsibilities of the National Bureau of Standards (NBS) Recycled 0il Program, the program history will be reviewed very briefly. In December of 1975, the Congress of the United States passed the Energy Policy and Conservation Act (P.L. 94-163, Section 383; 42 U.S.C. 6201 et seq.) This legislation stated that the National Bureau of Standards was to develop test procedures which could be used to establish the substantial equivalency of recycled oil products when compared to virgin oil products.

In response to this legislation, in 1976, NBS formed the Recycled 0il Program in order to develop the technical expertise necessary to address this problem. Shortly after formation, Jack Comeford joined the program, and the technical effort at that time consisted of the two of us with several part-time laboratory technicians, plus the technical expertise in specific areas around the Bureau, such as analytical chemistry, calorimetry, etc. In June of 1977, Bob Pedall of Motor 0ils Refining joined NBS as an Industrial Research Associate, sponsored by the Association of Petroleum Re-Refiners (APR). Bob was very effective in helping us learn more about the petroleum test procedures that are used with re-refined oils and recycled oils in general.

Soon after our formal organization, the goals and objectives of the Program were established. Since these help to provide insight into our efforts and responsibilities, they are included here. Our goal is "to provide the measurement methods and standards required for effective utilization of recycled petroleum products." This goal was to be carried out by achieving the following three objectives.

1) Establish the scientific and technical basis for characterization of recycled petroleum oils.

2) Develop and evaluate test procedures for establishing the substantial equivalency between recycled and virgin petroleum oils.

3) Provide technical information and data to encourage the effective utilization of recycled petroleum oils.

Note that in the second objective as shown here, the requirement for NBS as described in the legislation is not to prove equivalency, but to develop test procedures which can be used by any knowledgeable person to establish or confirm such equivalency. Many of the research efforts by other organizations which have been looking at recycled oil have established without question that a particular batch of re-refined oil is equivalent to a high quality virgin oil. The problem was, and still is, can a set of tests be developed to establish on a regular and reasonable basis that a particular re-refined oil is in fact a high quality lubricating oil.

In the development of an NBS Program, four groups of end-use products, or phases, have been identified. These phases were based on both perceived need as well as technical ability to respond. The first phase is on test procedures required to establish the equivalency of a recycled oil when used as a burner fuel. This phase has now been completed and the results 
are briefly discussed below. The second phase is on test procedures for recycled oil used as engine oils, and we are in the process of working on the first portion of this phase, engine crankcase oils. The third phase of our program is on recycled oils used as hydraulic oils, and the fourth phase is on industrial oils (e.g., cutting oils, grinding oils, rolling oils). We will address the third phase of our effort after we have completed the second phase on engine oils, and so on.

The report on Phase 1, Test Procedures for Recycled $0 i 1$ Used as Burner Fuel, was completed for the operational test procedures in September of 1978 and transmitted to the Federal Trade Commission (FTC). Several additional test procedures for potential environmental concerns were completed in August of 1979, and were transmitted to the FTC in September of 1979. In the first portion of this report, on the operational test procedures required for equivalency, 8 test procedures were recommended for modification or addition to the test procedures contained in the ASTM Specification (D396) and the Federal burner fuel oil specification (Federal Specification $W-F-815 c$ ). In the environmental section of this report, three additional test procedures have been evaluated and included, should the Environmental Protection Agency feel they are necessary. These tests procedures include analysis for polynuclear aromatics, chlorine and bromine, and lead. This entire report is available from NBS upon request.

In the fall of 1978, NBS received a Congressional appropriation which enabled this program to expand and establish the technical effort which we felt was necessary for initiating work on the difficult question of substantial equivalency for engine oils. We have now developed a rather extensive technical program, and I will describe various aspects of this program at this time.

Within the matrix management system as found in the National Measurement Laboratory of NBS, the Recycled 0il Program acts as an information source, a coordination system and a funding organization. We provide a focal point for persons both within and outside NBS, to request and obtain information on the subject of oil recycling and measurement methods and standards connected with oil recycling. In addition, the Recylced 0 il Program provides coordination and contact with many outside organizations, including the American Society for Testing and Materials (ASTM), the Society for Automotive Engineers (SAE), the American Society for Lubrication Engineers (ASLE), the Association of Petroleum Re-Refiners, and the American Petroleum Institute (API). The actual research and development work in the area of recycled oil is located within the various technical divisions in NBS, as well as in several projects located outside NBS. There are 8 major R \& D projects funded by the Recycled 0 il Program, and these will be discussed individually below.

The first research project is in the Tribochemistry Group, which was formerly the recycled oil laboratory. This group has now been expanded and transferred to the chemical Stability and Corrosion Division within the Center for Materials Science. This effort is actually a number of activities, and contains a major portion of the NBS R \& D effort directed towards recycled oil. Specific aspects of this work will be discussed in more detail later in this paper.

The second project is in the area of lubricated wear, and represents the activity taking place within the Wear Group in the Metallurgy Division, also in the Center for Materials Science. They are investigating certain aspects of lubricated wear, particularly with respect to the effect of various metallurgies and of surface topography on bench wear test procedures. Some of the activities of this group will be presented by Louis Ives later in this meeting.

Third, we have a significant effort in the Inorganic Analytical Research Division involving the development and modification of test procedures for the analysis of trace elements. In particular, the evaluation of lead analysis procedures for the environmental portion of the fuel oil tests required a great deal of effort by this Division. They are also working on the development of specific analytical methodology to support work of the Tribochemistry Group as well as the development and certification of Standard Reference Materials (SRMs) of used oil and of wear metals in oil.

The Organic Analytical Research Division was instrumental in the evaluation of a method for analysis of polynuclear aromatics in fuel oils, and at the present time is looking at 
the determination of polychlorinated biphenyls in oils. You will hear a talk on this work by Steve Chesler later in this meeting.

The fifth project is the antioxidant capacity test which was developed by the Ford Motor Company, and that we have also set up for evaluation here at the National Bureau of Standards. Dick Rebbert will discuss his work later in the meeting, and we have great hopes for this test. The sixth project is differential scanning calorimetry (DSC), and this test method will be described more fully by Jim Walker, later in the program.

The last two projects are research projects that we have initiated outside of NBS. The first is the microoxidation test that Elmer Klaus is modifying for use with petroleum oils, and he will report to you on it Thursday afternoon. The second one is a cooperative engine deposit study, an interagency agreement with the Army that we just initiated, and you heard about the historical aspects of the work that Southwest Research Institute did for the Army just a few minutes ago. This organization has had extensive experience in the evaluation of engine deposits and we look forward to a very fruitful and useful cooperative effort with them.

The NBS Recycled $0 i 1 R$ \& $D$ has been expanded considerably since the early stages of the program, and the Tribochemistry Group now has eight full time scientists working on these projects as well as five part time people working in the laboratory, plus a secretary. As many of you involved in scientific research can well appreciate, it has taken a considerable period of time to locate and bring in people with appropriate experience and background. These scientists are providing a high quality research effort in the area of petroleum testing, obtaining and modifying appropriate laboratory facilities for this work, and gaining experience with the rather extensive equipment and test procedures that are involved in petroleum oil evaluation.

The Tribochemistry Group has activities in the 4 general areas of physical properties, chemical properties, hydrocarbon type characterization, and performance test development. There is also an oil storage and blending facility to carry out the logistical requirements of the program. In the storage blending facilities, the modifications are now essentially complete and we have a storage capacity of about 150 drums plus an additional 500 gallons in one and five gallon cans. We have a blending capacity of 60 gallons, and at the present time, have 19 re-refined base stocks in our inventory. Of these, eight of them are in ten drum quantities, and these are the base stocks which we have obtained directly from a number of re-refiners and are in the process of characterizing in order to make them available to organizations requesting samples of re-refined oils for their testing. Two of these oils have already been obtained by the Army for use in their investigation of the MIL-L-2104C specification using single cylinder diesel tests. As part of this project, we are requesting that each organization which obtains samples of these oils for testing and evaluation provide the results and data to the NBS Recycled 0il Program, and this information will be compiled and published in the open literature. In addition to those initial eight re-refined oils, we have nine other re-refined oils in one drum quantities, as well as two additional re-refined oils in five - 15 gallon quantities each.

Besides the re-refined oil base stocks, we have 39 different virgin oil base stocks which we will be testing. Since the legislation requires us to investigate the "substantial equivalency" of a re-refined oil when compared to a virgin oil, we feel it is necessary to fully understand the important characteristics of virgin oils as well. Next, we currently have 56 different additive components, which have been obtained from additive companies. We will be using these additive components in our program to investigate the additive response of re-refined oils using various bench tests. Also, as part of this effort, we have 21 of the ASTM reference engine oils.

The physical properties under investigation include as a first priority: viscosity at 40 and $100{ }^{\circ} \mathrm{C}$, density, (API gravity), color, pour point, boiling point distribution using gas chromography, and flash point. In addition, the derived property, viscosity index, is of interest and will be evaluated. Some additional physical property tests that we will also be looking at, after the first priority tests have been investigated, include refractive index, average molecular weight, molecular weight distribution, and cloud point. Further, the derived physical properties of carbon distribution using the NDM method, the viscosity-gravity constant, and the refractivity intercept may be of interest. 
Chemical properties of first priority include the test procedures for carbon residue, total acid number, sulfated ash, saponification number, sulfur, nitrogen, chlorine, and infrared spectroscopy scan. With the exception of the infrared scan, these are test procedures that are included in the revised military specification MIL-L-46152A. There are a number of additional chemical properties which also may be of interest for the characterization of lubricating oils, and these are: water content, oxygen, bromine number, aniline point, coagulated insolubles (including both pentane insolubles and toluene insolubles), precipitation number, metal content (by atomic absorption spectroscopy or emission spectroscopy), ultraviolet spectroscopy, demulsibility characteristics, and a copper corrosion test to determine active sulfur.

In the hydrocarbon type characterization effort within the Tribochemistry Group, they are looking at several different methods of column chromatography to determine the various hydrocarbon components using clay and silica gel/alumina columns. At the present time, various combinations of these columns can determine the quantities of saturated hydrocarbons, aromatic hydrocarbons (including monoaromatics, diaromatics, and polynuclear aromatics), and polar hydrocarbons. The NDM carbon distribution method can be applied to lubricating oils directly, as well as to the various fractions obtained by the column chromatography procedures mentioned above. There is an effort to prepare various fractions of lubricating oils by gradient elution through an alumina column. These fractions can then be used to establish the effect of various polar fractions on some of the bench tests procedures that are being developed through the performance test R\&D. UV and IR methods will also be examined for possible use in the characterization of hydrocarbon types.

Efforts in the area of hydrocarbon type characterization which are outside the Tribochemistry Group include the application of nuclear magnetic resonance by a state-of-the-art fourier transform NMR spectrometer which is currently being set up as part of another program, and the application of high resolution mass spectrometry in cooperative efforts with several major oil companies. In addition, the Bartlesville Energy Technology Center will be running high performance liquid chromotographic separations coupled with low resolution mass spectrometry on a number of oil samples as part of the ASTM/NBS base stock consistency study that Ken Frassa will be talking about tomorrow morning, and the results from this study should be very useful in the evaluation of which of these hydrocarbon type characterization methods actually provides accurate results in terms of saturates, aromatics, naphthenics, polar compounds, etc.

The Tribochemistry Group is interested in development of performance tests for in the four general areas shown here: lubricated wear, oxidation stability, deposit formation, and rust and corrosion. However, these efforts have been largely limited at the present time until the first two areas of physical and chemical properties are completed. Instead, much of this effort is being accomplished by various research efforts outside the Tribochemistry Group, which have already been described.

One of the most important aspects of the performance test projects are evaluation of the "additive response" of lubricating oil base stocks. Since it has been stated that re-refined oil may very well have an "additive response" which varies from batch to batch, we feel it is necessary to develop test procedures which are capable of evaluating the additive response of a re-refined (or virgin) base stock. One way to do this is to use a standard additive package, perhaps at considerably smaller treat levels then would normally be used in service, and determine the effect of different batches of a particular re-refined oil on the performance of that base stock/package combination. As you can imagine, trying to establish rather or not there is a significant additive response component for re-refined oils may very well be much more difficult than monitoring such a response once it is found. I feel it is important that we establish whether or not this is a real concern, and whether or not performance tests must be developed which are capable of monitoring this characteristic in re-refined oils on a regular basis.

I now will briefly mention the various performance tests that we are involved with at the present time. In the area of lubricated wear, Lou Ives from the Metallurgy Division will be talking about their work on the ring and block tests and their evaluation of the pin and $V$ test using Falex equipment for both of these tests. The Tribochemistry Group is also involved in lubricated wear, and will be discussing their work on the 4-ball wear test. The cam and lifter test for determination of lubricated wear is one that is of great concern at the 
present time in the industry, and this type of wear is currently being monitored in several of the engine sequence tests. We are in the process of obtaining a MIRA cam and lifter bench rig, which can be used to look at this type of wear.

In the area of oxidation stability, papers on work supported by NBS will be given during this Conference on the Ford anti-oxidant capacity test, a differential scanning calorimetry test, and the microoxidation test by Elmer Klaus of Pennsylvania State University. In addition, the chemiluminescence test is currently of interest, and we hope to provide some input to this test which appears to be a very useful method for looking at oxidation stability.

Future research and development by the Tribochemistry Group will include the evaluation of oil thickening tests, the rotary bomb oxidation test, and the steam turbine test--commonly known as ASTM D943-- and comparison of these tests to other oxidation stability tests as far as reliability, precision and accuracy, and usefulness of the information obtained.

In deposit formation, much of the NBS effort will be through a cooperative research project with the U.S. Army Fuel and Lubricants Research Laboratory in San Antonio. Also, eventually we will be looking at the panel-coker test for deposits and may very well evaluate various dispersancy tests, an important characteristic of formulated lubricating oils.

Further, there are currently two engine sequence tests which are concerned with the area of rusting and corrosion. These are the L-38 Bearing corrosion test, and the II $D$ rust test. The possibility of evaluating re-refined oils for additive response to these tests will certainly be considered.

Recent progress of the NBS Recycled 0il Program include the following:

1) Transmittal of the test procedures of Phase I of our program on test procedures for recycled oil used as burner fuel to the Federal Trade Commission. (Copies of this report are available upon request.)

2) Initiation of work on Phase II of the NBS program, test procedures for engine crankcase oil, was initiated in November of 1978.

3) Proceedings of the last NBS Conference on Measurements and Standards for Recycled $0 i 1$ were recently issued as NBS Special Publication 556.

4) Consumation of an interagency agreement with the U.S. Army MERADCOM on a cooperative program for investigation of mechanisms and development of test procedures for sludge and deposit formation. This is a two year agreement and we are looking forward to continued interaction with the Army in this area, and expect that their long standing expertise in the area of sludge and deposits will provide a substantial effort on the problems of testing for sludge and deposit tendencies of lubricating oils.

5) Initiation of ASTM-NBS base stock consistancy study in March of 1980 . Ken Frassa will talk about this program in detail tomorrow morning and we look forward to this cooperative effort by many different organizations. I feel information on base stock consistency is crucial in the determination of which test procedures might be necessary to adequately characterize re-refined (and virgin) oils.

Finally, I want to describe the various mechanisms NBS uses to provide information on our work to you, the consumer. The Energy Policy and Conservation Act requires that the NBS Recycled 0 il Program provide reports on our test procedures to the Federal Trade Commission. We have taken the philosophy that everything we provide to the FTC is available to anyone who should request it. Should you be interested in receiving one or more of our reports or publications, please let me know and I will be happy to see that you will receive them. We also feel that it is important that information on what we are doing be made available to ASTM, SAE, ASLE, to the API and the APR, and I make it a point to attend at least one of these meetings each year to report on what we are doing and why.

I believe this information transfer is crucial to assuring people that our legislative requirements are being actively complied with, and on a technically defendable basis. 
Additional delivery mechanisms include conferences and workshops, publications, development of Standard Reference Materials, and providing technical advise and assistance where needed. In particular, we feel it is important to provide NBS technical assistance to other government agencies (including Federal, State and local agencies), and both the Energy Policy and Conservation Act and the Resource Conservation and Recovery Act contain specific references to support for the education of both public and private sectors on the merits of increased use of recycled oil.

In conclusion, I wish to invite all of you to provide input into the NBS Recycled 0 il Program, and to write me on what you feel the needs and the problems are in the area of oil recycling and on how NBS can help solve these problems, particularly in the area of new or improved measurement methods and standards. I always stand ready to discuss this with any of you, and feel free to discuss this with me at this meeting, by mail, or by telephone. 
Session 3

LUBE OIL BASE STOCK CHARACTERIZATION 

National Bureau of Standards Special Publication 584. Proceedings of Joint Conference on Measurements and Standards for Recycled 0il/Systems Performance and Durability held at NBS, Gaithersburg, MD, October 23-26, 1979. (Issued Nov. 1980)

\title{
ASTM/NBS BASE STOCK CONSISTENCY STUDY
}

\author{
K. A. Frassa \\ Mobil 0 il Corporation \\ 150 East 42nd Street \\ New York, NY 10017
}

This paper summarizes the scope of a cooperative ASTM/NBS program established in June 1979. The contemplated study will ascertain the batch-to-batch consistency of re-refined and virgin base stocks manufactured by various processes. This activity, which is presently being implemented, falls under ASTM Committee D-2, Technical Division P - Recycled Petroleum Products, Section II - Used $0 i 1$ and Base Stocks. A total of 12 different organizations have volunteered to participate in this study:

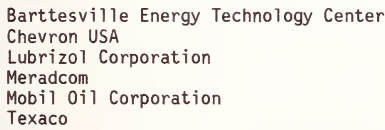

\author{
Motor 0ils Refining Co. \\ National Bureau of Standards \\ National Research Council of Canada \\ Savant, Inc. \\ Suntech, Inc. \\ Gulf Research and Development
}

For one year, approximately eight to ten different base stocks samples, table 1 , will be obtained by NBS every two weeks. One set of bi-monthly samples will be forwarded to each participant, on a coded basis monthly. As noted, seven to eight samples will be obtained from six different re-refining processes and two virgin oil samples from a similar manufacturing process.

Table 1. Base stock samples.

No. of Samples

Re-refined stocks

1
1

2

1

1

Virgin stocks $\underline{\text { Process }}$

Acid/clay

Short path vacuum dist (tentative)

Vac. dist/acid/clay

Clay

Demetalize/filter/hydrogen (tentative)

Vac. Dist/solvent ext/hydrogen

The participants will report their results on a monthly basis. The second set of samples will be retained by NBS for an interim monthly sample study, if required, based on data analysis.

Each sample's properties will be evaluated using various physical tests, table 2, chemical tests, table 3 , and bench tests, table 4. The total testing program should define the batch-to-batch base stock consistency short of engine testing. 
The first monthly samples are tentatively scheduled for shipment to participants during January 1980 and monthly thereafter for 12 consecutive months. Over 500 individual tests will be run on base stocks from each manufacturer. The total testing program will exceed 5000 tests. The results will be analyzed on a statistical basis in a report targeted for mid-1981.

Table 2. Physical property tests.

\section{Test}

Gravity, ${ }^{\circ} \mathrm{API}$

Color; foam

Viscosity e $40 \& 100^{\circ} \mathrm{C}$

$V$ iscosity Index

Pour point, ${ }^{\circ} \mathrm{C}$

Carbon residue

Boiling point dist

Cold cranking simulator $0^{\circ}$ to $-40^{\circ} \mathrm{C}$

Mini-rotary visc. $10^{\circ} \mathrm{C}$ to $-40^{\circ} \mathrm{C}$

Brookfield viscosity $0,-20,-40^{\circ} \mathrm{C}$

Refractive index

Demulsibility

Filterability
Participant

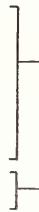

Meradcom

Savant

Suntech

NBS

Mobi1

Table 3. Chemical property tests.

\section{Test}

$\operatorname{Tan}$

Saponification

Nitrogen, chlorine, sulfur

Low resolution mass spec

(selected samples)

Liquid chromatography

Emission spectrograph

Halogens

Nitrogen, oxygen

Diff. scanning colorimeter

Differential infra-red

Sunlight stability

Additive compatibility

Glycol
Participant

Meradcom

BETC

Texaco

Motor 0 ils Ref

NBS

Mobil

Nat. Res. Canada

Lubrizol

Gulf 
Table 4. Bench tests.

Test

Engine oil additive package oxidation response

Engine oil additive package EP response

Rusting

LUBTOT

Seq III C simulator

Ford anti-oxidant response

RBOT (base stock + additive)

Turbine oil oxidation (selected samples)

\section{Participant}

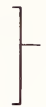

Chevron

Lubrizol

Meradcom

Suntech

NBS

Nat. Res. Canada 

National Bureau of Standards Special Publication 584. Proceedings of Joint Conference on Measurements and Standards for Recycled 0i1/Systems Performance and Durability held at NBS, Gaithersburg, MD, October 23-26, 1979. (Issued Nov. 1980)

\title{
PROPERTIES OF CANADIAN RE-REFINED BASE OILS
}

\author{
P. L. Strigner \\ National Research Council of Canada \\ Division of Mechanical Engineering \\ Ottawa, CANADA KIA OR6
}

\section{Introduction}

Owing to limited laboratory facilities, Canadian oil re-refiners employing the acid/clay process have sought aid from the Fuels and Lubricants Laboratory of the National Research Council of Canada (NRC) in the laboratory evaluation of their products, including base stocks, finished oils and waste oil feedstocks. The NRC laboratory has provided this evaluation service since 1967 even though its own facilities have not been extensive. In addition, base stocks from a number of experimental processes submitted by the re-refiners and others were evaluated. Even industrial and hydraulic reclaimed oils have been evaluated.

This presentation on properties of re-refined oils covers only the evaluation of base stocks obtained principally from used service station oil drainings by the acid/clay process (table 1). Data were condensed from a more comprehensive NRC, Division of Mechanical Engineering report MP-75 $[1]^{1}$. Since numbers by themselves of ten have little meaning, reference data were obtained on a small number of refined or virgin base stocks as well (table 2). Furthermore, the summarized Canadian data are also compared with the excellent re-refined base stock data generated by the U.S. Army for an EPA study [2], also summarized for this report. In addition, summarized data generated by NRC on three re-refined base stock samples obtained from an Indian company in 1977-79 are also compared. These base stocks were obtained from diesel engine oil drainings by the acid/clay process and are destined for reuse in re-refined diesel engine oil formulations. India has a specification standard for re-refined diesel engine oil [3].

Table 1. Canadian re-refined base stocks-acid/clay.

Evaluation period 1968-1979

\begin{tabular}{lll} 
Re-refiner & $\frac{\text { Samples }}{2}$ \\
\hline $\mathrm{A}$ and $\mathrm{C}$ & & 1 each \\
$\mathrm{D}$ & & 3 \\
$\mathrm{E}$ and $\mathrm{F}$ & & $\frac{6}{19}$ each
\end{tabular}

In addition "D" submitted an imcompletely re-refined base stock and "F" submitted a base stock obtained from used RR diesel engine oil drainings custom re-refined for reuse for the same purpose.
Table 2. Virgin base stocks-reference.

Base stock used in engine oils* - 3 samples White oil - 1 sample

base stock in MIL-L-5306 - 1 sample

*Base stocks obtained from Canadian and Mid-continent crudes by solvent refining. Summarize data from the testing of these three oils, i.e., excluding white oil and 5606 base oil data, are shown in the various tables as "virgin". White oil and 5606 base oil data are identified separately, e.g., table 17.

As might be expected, emphasis by the NRC laboratory has been placed on determining in a general way the presence of any remaining solid and liquid used oil contaminants, oil and additive deterioration products normally present in used oils, and additives. Covered as well in a general way are process contaminants, i.e., strong acid and clay. 
No attempt was made to determine the ultimate destination of the Canadian re-refined base stocks originating from used engine oil drainings. Many end up as RR car journal box oils [4], but many also are formulated, it is believed into engine oils, hydraulic oils and industrial oils. The degree of formulation is also uncertain.

\section{Test and Analytical Data}

A variety of standard ASTM and other physical and chemical tests were performed on the oils aimed at assessing (a) levels of solid and liquid contamination, and residual additive, (b) general physical and chemical properties, (c) hydrocarbon types and elements, (d) 1ight, storage and low temperature stabilities, and (e) response to anti-oxidants. Results of these tests are presented in NRC, Division of Mechanical Engineering Report ME-75. In order to keep the volume of data compact for this NBS presentation the individual results were averaged or ranges derived from the nineteen Canadian re-refined oils tested, three virgin oils and three Indian oils (tables 3 and 6 ). A number of extreme results were trimmed off to give a less misleading indication of range than by leaving them in. These trimmed off (or removed) results amounted to no more than a few in any particular property. The U.S. ranges were similarly trimmed. Because the single RR base stock sample (obtained from used naphthenic RR diesel engine oil) showed an unusually high solids level of $47 \mathrm{mg} / 100 \mathrm{~mL}$ (table 3 ) and strong acids (table 6) a repeat sample was obtained. The repeat sample showed a much lower solids level and nil strong acids, data more characteristic, it is believed, of re-refined RR diesel engine oil base stocks. It is believed that the contaminants were inadvertently picked up in the process.

During the course of the evaluations an opportunity presented itself for checking base stock consistency on two occasions: once when re-refiner "E" submitted six samples over a span of six months in 1967, and later when re-refiner " $F$ " submitted six samples over a span of 10 years. The ranges of results are given in tables 4 and 7 .

From the data generated, and based on low levels of solid and liquid contaminants as well as low levels of residual oil additive, suggested property limits were generated to represent what would probably be regarded as good quality Canadian re-refined oils from service station oil drainings (tables 5 and 8 ). These, of course, are somewhat arbitrary and not based on any end-use requirements. Bearing end-use in mind, some limits are not needed or should be relaxed while others may be needed or existing ones tightened. Some obviously would be redundant. For example, a limit for the ash content could do away with the need for limiting metallic elements, and a sulfur limit could become unrealistic as higher sulfur crudes emerge.

In tables $9,10,11,12$, and 13 some comparative data are given for partially re-refined and fully re-refined base stocks. Even though nonadditive oils, i.e. base stocks, are rarely recommended for modern machines and engines, except possibly where the oil experiences a short duration of use, it is believed that nonadditive oils are on the market. Indeed, API service classification SA for nonadditive oils still exists and so do $S A$ engine oils. Accordingly, a number of standard bench oxidation tests were performed on some of the base stocks. Results are presented in tables 10 to 13 . In addition the L-38 engine test was performed for 10 hours on a re-refined base stock. It was not possible to run the test for the standard 40 hours owing to heavy oil oxidation and high bearing weight loss even after 10 hours (table 14). From these data it is inconceivable that an SA engine oil, i.e., a base stock, could perform satisfactorily for a significant period of time in an engine. Probably the API SA category should be withdrawn unless convincing evidence can be provided to support good behavior. It is interesting to note that of the two virgin base stocks tested one showed superior bench oxidation stability at $400^{\circ} \mathrm{F}$, but inferior stability at $200^{\circ} \mathrm{F}$ while the other was vice versa (tables 10 to 13).

of more interest is the response to anti-oxidants. For this ASTM D943 was selected rather arbitrarily, because even though long in test time it does not require a disproportionate amount of operator time and does provide at least some comparative data for this study. The two additives used were zinc dialkyldithiophosphate and 2,6-ditertiary-butyl para-cresol. Averages and ranges are presented in tables 15 and 16.

Some of the other data are shown with oxidation lifetimes (D943) in table 17 in an attempt to view possible correlations with oxidation lifetime. As shown a number of properties 
of Canadian oils seem to correlate, e.g., hydrocarbon types, viscosity, sulfur, total acid number and carbon residue, although it is not known precisely which ones are operative in each instance. Furthermore, the Indian oils present some contradicting evidence, e.g. , high aromatics and high sulfur contents have not hurt the oxidation lifetime. Obviously, any real correlation would have to be based on more detailed analyses of hydrocarbon types than by ASTM D2007. For example, polar and/or sulfur compounds may enhance or inhibit the additive role. Just knowing the total amounts of one or the other is not enough; the actual active compounds may have to be identified. Suggested correlations are also shown in table 18 between demulsibility and polar constituents as measured by the general or total type tests of polar compounds, total acid number and saponification number. Here, too, better hydrocarbon, element and compound characterizations are needed for correlations.

Three storage stability tests (one year) were performed: 1) light stability in a clear glass bottle in the laboratory in sunlight, 2) room temperature stability in a dark bottle in a cupboard, and 3) low temperature stability in a dark bottle in a cold room at $40^{\circ} \mathrm{F}$. In the light stability test re-refined base stocks tended to develop flocculent precipitates after about 3 months in the sunlight; the virgin stocks tended not to even after one year (this includes the white $0 i 1$ and MIL-L-5606 base stock). This generalization has to be interpreted with care, however. Re-refined base stock from one of the re-refiners (one sample) did not precipitate; some recent samples of virgin base stocks are showing evidence of precipitates that settle. Re-refined oil flocks tended not to settle.

In respect to room temperature stability, no samples either re-refined or virgin showed flocculation even after one year. In respect to low temperature stability, the re-refined base stocks developed precipitates at $40^{\circ} \mathrm{F}$ while the virgin base stocks did not.

IR spectra of a representative number of the oils were obtained. These are presented in figure $I$ and the following observations are made about a number of the peaks:

- Peak at $1710 \mathrm{~cm}^{-1}$ due to carbonyl absorption of some engine oil additives. Barely present in Canadian re-refined engine oil base stock and RR re-refined base stock. Absent in the others. Carbonyl absorption also results from oil oxidation.

- Peaks at $1600 \mathrm{~cm}^{-1}$ and $813 \mathrm{~cm}^{-1}$ due to double bond of aromatic hydrocarbons. Absent in white oil and MIL-L-5606 base stock. Present in all others in varying degrees.

- Peak at $720 \mathrm{~cm}^{-1}$ due to saturates. Present in all samples. Cycloparaffins tend to absorb at higher wave numbers, e.g., $745 \mathrm{~cm}^{-1}$. The broader peak of the MIL-L-5606 base stock $720 \mathrm{~cm}^{1}$ and up could be characteristic of cycloparaffins.

\section{Summary}

In summary, the Fuels and Lubricants Laboratory of NRC (Canada) has been examining for over 10 years, as a service, the properties of base stocks made by Canadian re-refiners. Nineteen samples of acid/clay processed base stocks from six Canadian re-refiners were examined.

As shown, when well re-refined, the base stocks have excellent properties including a good response to anti-oxidants and a high degree of cleanliness. Since traces of additives and/or polar compounds do remain, the quality of the base stocks is judged to be slightly inferior to that of comparable virgin refined base stocks.

Some suggested specification limits for various properties and some indication of batch-to-batch consistency were obtained. Any usage of the limits should be done with caution, e.g., sulfur, bearing in mind the rapidly changing crude oil picture and engine and machine technology leading to oil products of differing compositions. Certainly modifications are in order; it may even be desirable to have grades of base stocks. 


\section{Recommendation}

ASTM standards are absent in some areas and some ASTM standards are inadequate. For example, good ASTM standards are needed for detecting metals and non-metals in low ranges. Ash (D482) and sulphated ash (D874) methods could be extended to lower levels of detectability. Qualitative tests for appearance and odor would be useful. An ASTM standard specification could even be developed for re-refined base stock quality, if only to limit the levels of used oil contaminants, additives and process materials. There could even be a number of grades.

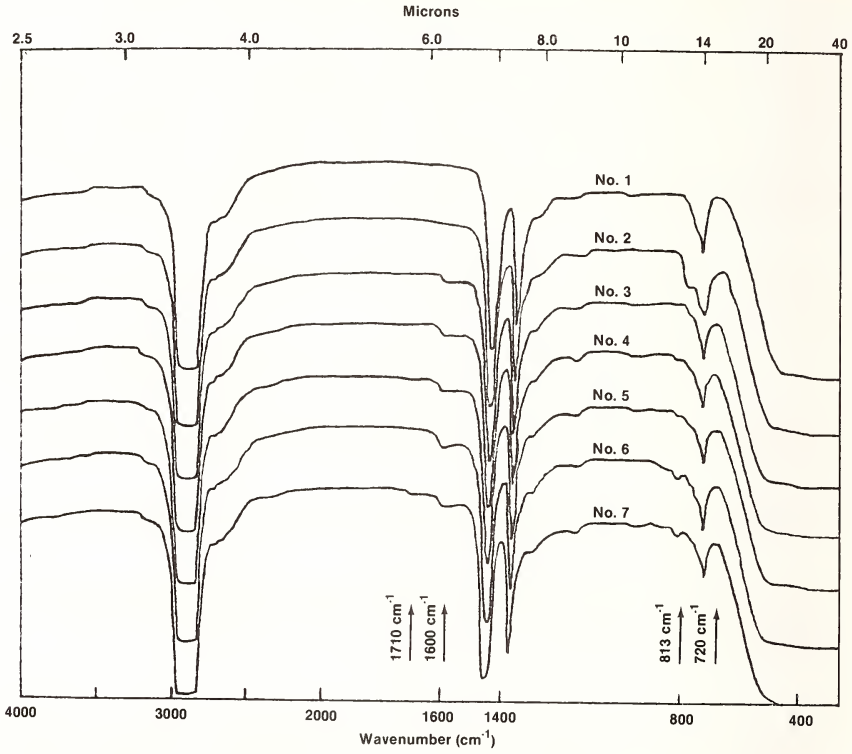

Figure 1. IR spectra of several base stocks.

No. 1 - White oil

No. 2 - MIL-L-5606 base stock

No. 3 - Virgin base stock
No. 4 - Virgin base stock

No. 5 - Canadian re-refined base stock

No. 6 - Indian re-refined base stock

No. 7 - RR re-refined base stock 
Table 3. Physical properties - ranges/averages.

Gravity \& viscosity

API gravity (D287)

Viscosity index (D2270)

Viscosity at $210^{\circ} \mathrm{F}$ (D445)

cSt

SAE

Solid contaminants \& ash

Trace sediment (D2273),\% V

Solids (D2276), $\mathrm{mg} / 100 \mathrm{~mL}$

Ash (D482), \% W

Sulfated ash (D874) \% W

Rams. carb. res (D524), \% w

Liquid contaminants

Flash point (D92), ${ }^{\circ} \mathrm{F}$

Dilution (D3525), \% V (8)

Glycol (D2982)

Water (visual)

Distillation range (3)

IBP, ${ }^{\circ} \mathrm{F}$
$5 \%,{ }^{\circ} \mathrm{F}$
$50 \%,{ }^{\circ} \mathrm{F}$
$90 \%,{ }^{\circ} \mathrm{F}$
$95 \%,{ }^{\circ} \mathrm{F}$
$\mathrm{FBP}$, $\mathrm{F}$

Miscellaneous

ASTM color (D1500)

Aniline point (D611), ${ }^{\circ} \mathrm{F}$

Copper corrosion (D130)

Odor

Appearance

Cloud point (D2500) ${ }^{\circ} \mathrm{F}$

Pour point (D97), ${ }^{\circ} \mathrm{F}$
C A N A D A

\begin{tabular}{|c|c|c|c|c|}
\hline R.R. (1) & Virgin & Re-refined & U.S. & India \\
\hline $\begin{array}{l}26.1[25.5] \\
79[79]\end{array}$ & $\begin{array}{l}29.7-32.2 \\
91-97\end{array}$ & $\begin{array}{l}29.1-30.2 \\
100-113\end{array}$ & $\begin{array}{l}28.5-30.5 \\
97-110\end{array}$ & $\begin{array}{l}27.4-27.6 \\
102-104\end{array}$ \\
\hline $\begin{array}{l}14.5[14.9] \\
40[40]\end{array}$ & $\begin{array}{l}5.2-5.8 \\
<20-20\end{array}$ & $\begin{array}{l}7.2-8.9 \\
20\end{array}$ & $\begin{array}{l}6.6-9.3 \\
20\end{array}$ & $\frac{11.2-11.4}{30}$ \\
\hline
\end{tabular}

.001

$47[6]$

.000

$.002[.000]$

$0.5-3.5$

.000

.000

$.05-.07$

.004

.27

480
$.02[.25]$
$\mathrm{Ni} 1$

$\mathrm{Nil}$

395-450

$.00-.02$

$\mathrm{Ni} 1$

$\mathrm{Ni} 1$

$.000-.005$

3. 3-5. 0

$.000-.01$

$.001-.01$

$.12-.19$

$400-450$

.03

$\mathrm{Nil}$

$\mathrm{Ni} 1$

605-675

$675-715$

785-805

860-880

875-905

910-970

540-615

655-690

780-810

860-970

875-1030

940-1080

$<0.5$

210-225

No. 1

2-5

222-226

No. 1

No. 1

(6)

(7)

(5)

(7)

-2 to +12

-5 to +10

+12 to +24

-25 to +10

520-680

$550-630$

690-725

640-725

825-870

830-920

990-1060

940-1085

(4)

(4)

$.004-.06(2)$

3. 1-6. 0

$.000-.004$

$.24-.26$

Dark

$+20$

2. 5-6. 5

3-L4. 0

220-225

No. 1

226-230

No. 1

(5)

(7)

+45 to +50

+45 to +50

Notes:

(1) Data obtained on only one sample received in December 1976. Data on another sample received in November 1979 are given in [ ].

(2) The three samples had results as follows: $.004, .004$, and $.06 \% \mathrm{~V}$.

(3) Distillation range obtained by G.C. ASTM 02887 generally followed for Canadian and Indian samples. Some difficulty was experienced at the end point when over $1000^{\circ} \mathrm{F}$. Comparisons with vacuum distillation data suggest that in this instance the G.C. end points may be low. The U.S. procedure of cutting off the distillation at $600^{\circ} \mathrm{C}\left(1112^{\circ} \mathrm{F}\right.$ ) and recording the residue at this point seems preferable.

(4) Residue range at $600{ }^{\circ} \mathrm{C}\left(1112^{\circ} \mathrm{F}\right)$ is $<1$ to $6 \% \mathrm{w}$.

(5) Odor characteristic of oils obtained by acid/clay re-refining.

(6) Odor characteristic of virgin or refined oils, i.e. slight oil odor.

(7) Clean, clear.

(8) Less than . $05 \% \mathrm{~V}$ is regarded as nil. 
Table 4. Physical properties - consistency of re-refined base stock.

Re-refiner "E"

No. of samples

Period, years

Gravity \& viscosity

API gravity (D287)

Viscosity at $210^{\circ} \mathrm{F}$ (D445) cSt.

Viscosity index (D2270)

Solid contaminants \& ash

Trace sediment (D2273), \% V

Solids (D2276), $\mathrm{mg} / 100 \mathrm{~mL}$

Ash (D482), \% W

Rams. carb. res. (D524), \% W

$\underline{\text { Liquid contaminants }}$

Flash point (D92), ${ }^{\circ} \mathrm{F}$

Dilution (D322), \% V

Glycol (D2982)

\section{Miscellaneous}

Color (D1500)

Copper strip corrosion, $3 \mathrm{~h}$ at $100^{\circ} \mathrm{C}$

Aniline point (D611), ${ }^{\circ} \mathrm{F}$
6

1/2 (1967)

28. 8-29. 5

8. $6-9.4$

101-104

$.000-.004$

$-$

$.005-.03$

$.12-.24$

440-460

$\mathrm{Ni} 1$

$\mathrm{Ni} 1$

L3. 5-L6. 5

No. 1

225-117. 5
Re-refiner "F"

6

$10(1968-78)$

29. 1-29. 9

7. $3-8.2$

97-102

$.000-.001$

.000

$.11-.17$

$390-440$

$\mathrm{Nil}$

$\mathrm{Ni} 1$

L2. 0-3. 5

No. 1

222-226 
Table 5. Suggested limits for well re-refined Canadian base oils. (Acid/clay processed from service station drainings)

\section{TEST}

Gravity \& viscosity

API gravity at $60^{\circ} \mathrm{F}$

Viscosity index

Viscosity at $100{ }^{\circ} \mathrm{C}$

Solid contaminants \& ash

Trace sediment, \% V

Solids, $\mathrm{mg} / 100 \mathrm{~mL}$

Ramsbottom carbon residue \% $\mathrm{W}$

Ash \& sulfated ash, \% $w$

Liquid contaminants

FTash point, ${ }^{\circ} \mathrm{F}$

Dilution, \% v

Dilution, \% v

Glycol

Water, \% v

Workmanship

Appearance

Odor

Color

\section{Miscellaneous}

Copper strip corrosion, $3 \mathrm{~h}$ at $100{ }^{\circ} \mathrm{C}$

Aniline point, ${ }^{\circ} \mathrm{F}$

Cloud point, ${ }^{\circ} \mathrm{F}$

Pour point, ${ }^{\circ} \mathrm{F}$

Distillation range, ${ }^{\circ} \mathrm{F}$
D2273

D2276

D91

D893/B

D524

092

Physical Tests

METHOD

D287

D2270

D445

D482/D874

D3525

D322

D2982

D95

Visual

Sme 11

D1500

D130

D611

D2500

D97

D2887

\section{SUGGESTED LIMITS}

28. $5-30.5$

95-115

9. $0-9.4$

$.001 \max$

$5 \max$

$.001 \max$

$.02 \max$

$0.20 \max$

$.005 \max$

$400 \mathrm{~min}$

$0.05 \max$

$\mathrm{NiT}$

$\mathrm{Ni} 1$

$\mathrm{Ni} 1$

Clean, clear

Characteristic

4. 0 max

No. 1

220-226

$+24 \max$

+15 max

550-1100 (1)

Note: (1) or in Tieu of $1100^{\circ} \mathrm{F}$ max. temperature, a limit on residue at $600{ }^{\circ} \mathrm{C}$ of $5 \% \mathrm{~W}$ max. 


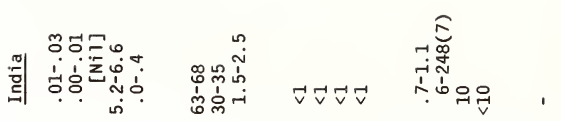

है

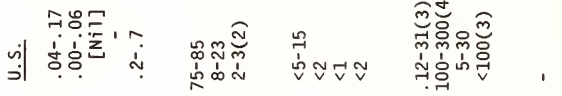

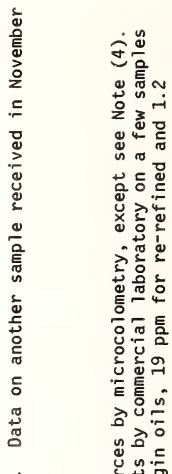

สัฐกาก

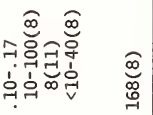

bंटरि-

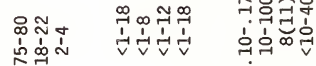

듸 동응

$\left|\begin{array}{l|}0 \\ 0 \\ \vdots \\ 4 \\ 0 \\ 0 \\ \vdots \\ 0 \\ 0\end{array}\right|$

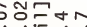

م્

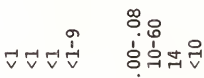

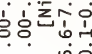

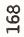

赵

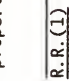

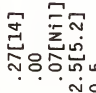

ํㅠㅁำ

षैं लंखे

守

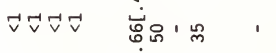

蒈 กं

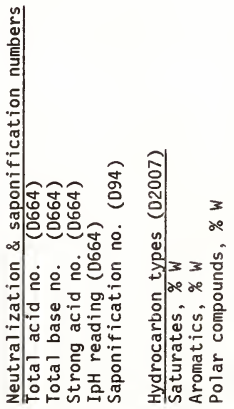

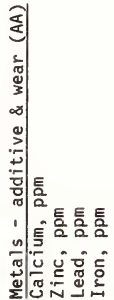

$\stackrel{\circ}{\circ}$

ம

$\frac{\sqrt{2}}{\frac{0}{\circ}}$ (n)

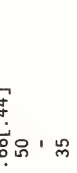


Table 7. Chemical properties - consistency of re-refined base stock.

Number of samples

Period, years

$\frac{\text { Re-refiner "E" }}{6}$

$.12-.37$ $.00-.01$

$\mathrm{Nil}$

No. (D664

No. (D94)

(D664)

-

$\frac{\text { Re-refiner " } F \text { " }}{6}$

Neutralization \& saponification numbers

\begin{tabular}{ll}
\hline Total acid & No. (D664) \\
Total base & No. (D664) \\
Strong acid & No. (D664 \\
Saponification & No. (D94) \\
Initial pH reading & (D664)
\end{tabular}

Hydrocarbon types (D2007)

Saturates, \% W

Aromatics, \% $\mathrm{W}$

Polar compounds, \% $\mathrm{w}$

$.00-.09$

$\mathrm{Ni} 1$

75. 9-78. 0

20. 3-22. 2

1. $6-2.2$

Miscellaneous

Sulfur (D129), \% W

Nitrogen, ppm (2)

Molecular weight (D2502)

Metallic elements (AA)

$.09-.22$

-
$.08-.21$

5-33

448-475

$<5$ (1)

NOTES: (1) Each element. Element tested were: $\mathrm{Al}, \mathrm{Ba}, \mathrm{Ca}, \mathrm{Cr}, \mathrm{Cu}, \mathrm{Fe}, \mathrm{Mg}, \mathrm{Pb}, \mathrm{Si}$, and $\mathrm{Zn}$. (2) Determined by Canadian Ministry of Energy, Mines \& Resources by microcoulometry.

Table 8. Suggested specification limits for well re-refined Canadian base oils. (Acid/clay processed from service station drainings)

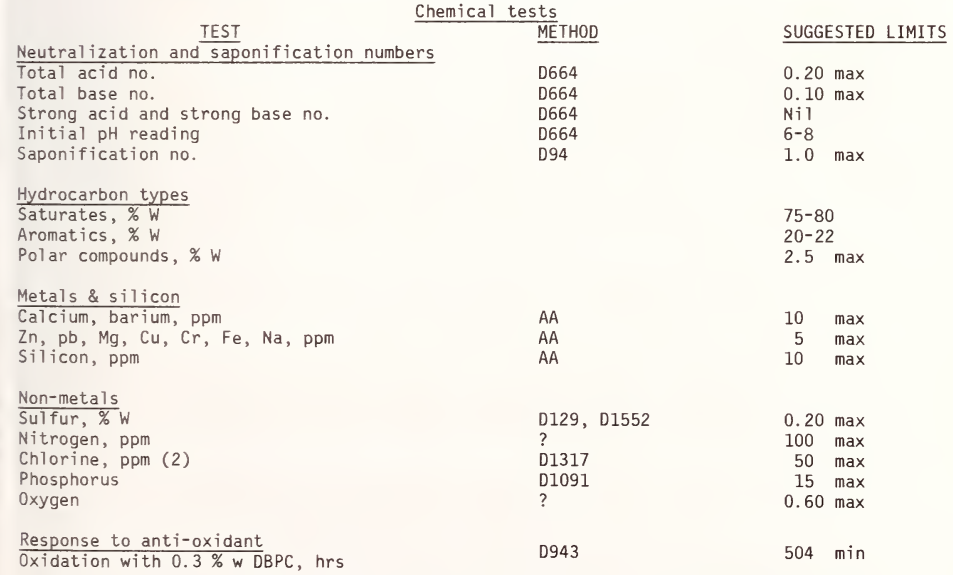

NOTES: (1) Each element.

(2) Includes bromine; ASTM D1317 measures halogens. If a standard test detecting lower limits is available the chlorine limit could be lowered to $20 \mathrm{ppm}$. 
Table 9. Properties of partially vs fully re-refined base stocks.

\begin{tabular}{|c|c|c|}
\hline & $\begin{array}{l}\text { Partial- } \\
\text { single } \\
\text { sample } \\
\end{array}$ & $\begin{array}{l}\text { Full-range of } \\
\text { results (from } \\
\text { tables } 3 \& 6 \text { ) }\end{array}$ \\
\hline Color (D1500) & D8. 0 & $2-5$ \\
\hline Trace sediment (D2273), \% v & 0.8 & $.000-.005$ \\
\hline Sulfated ash (0874), $\%$ w & .176 & $.001-.01$ \\
\hline Total acid No. (D664) & .28 & $.06-.24$ \\
\hline Polar compounds (02007), \% w & 5.1 & $2-4$ \\
\hline Saponification no. (D94) & 1.0 & $.07-1.2$ \\
\hline Zinc $(A A), p p m$ & Much & $<1-8$ \\
\hline Lead $(A A), \mathrm{ppm}$ & 350 & $<1-12$ \\
\hline Iron $(A A), \mathrm{ppm}$ & 23 & $<1-18$ \\
\hline
\end{tabular}

NOTE: (a) Submitted by re-refiner "D" (table 1).

Table 10. Oxidation of base stock at 400 of (B.A.M. ${ }^{\mathrm{a}}-$ IP 48 ).

\begin{tabular}{|c|c|}
\hline Viscosity & Carbon $^{c}$ \\
\hline Ratio $^{a}$ & Residue Increase \\
\hline
\end{tabular}

\begin{tabular}{lll} 
Re-refined (fully) & 1.4 & 0.9 \\
Re-refined (partially) & 2.0 & 1.8 \\
Virgin, base stock 1 & 1.3 & 0.4 \\
Virgin, base stock 2 & 1.9 & 1.0 \\
CGSB Specifications (old requirement) d & & \\
3-GP-51(non-heavy duty engine oil) & \\
3-GP-100(aircraft recip.engine oil) & $2.0 \max$ & $1.1 \max ^{\mathrm{g}} \mathrm{g}$ \\
\hline
\end{tabular}

NOTES: a B.A.M. is the British Air Ministry Oxidation Test IP48.

b Ratio of viscosities at $100^{\circ} \mathrm{F}$; after oxidation divided by before oxidation.

c Difference in Ramsbottom carbon residue; after oxidation minus before oxidation.

d CGSB is Canadian Government Specifications Board, Ottawa.

e 3-GP-51 was a specification for a gasoline/diesel engine oil (SAE 20). It was cancelled in 1966. No engine sequence tests were required although a performance test was indicated as "may be required".

f $3-\mathrm{GP}-100 \mathrm{~b}$ is non-detergent reciprocating aircraft engine oil comparable to MIL-L-6082. The requirement for the B.A.M. test was dropped in 1966 when 3-GP-100c was issued.

g Assuming that the new oil carbon residue is .1. The limit is stated as original +1 . 
Table 11. Oxidation of base stock at $200^{\circ} \mathrm{F}$ (ERDA-modified D943) ${ }^{\text {a }}$.

\begin{tabular}{|c|c|c|c|}
\hline & $\begin{array}{l}\text { Filterable } \\
\text { Residue } \\
\end{array}$ & $\begin{array}{c}\text { Total } \\
\text { Acid No. }\end{array}$ & $\begin{array}{l}\text { Sap. } \\
\text { No. }\end{array}$ \\
\hline Re-refined (fully) & 5.9 & 0.7 & 0.6 \\
\hline Re-refined (partially) & 53.4 & 0.4 & 1.4 \\
\hline Virgin, base stock 1 & 81.2 & 2.4 & 0.3 \\
\hline Virgin, base stock 2 & 1.5 & 5.3 & 0.0 \\
\hline
\end{tabular}

NOTE: (a) Test developed by DOE, BETC (ref. 5).

Table 12. Oxidation of base stock at $200^{\circ} \mathrm{F}$ (CIGRE-IP 306).

\begin{tabular}{|c|c|c|}
\hline $\begin{array}{l}\text { No } \\
\text { Catalyst }\end{array}$ & $\begin{array}{l}\text { Solid } \\
\text { Catalyst }\end{array}$ & $\begin{array}{l}\text { Soluble } \\
\text { Catalyst }\end{array}$ \\
\hline 0.1 & 2.4 & 1.9 \\
\hline 0.3 & 3.3 & - \\
\hline 6.6 & 17.6 & 15.7 \\
\hline 0.0 & 0.7 & 2.2 \\
\hline
\end{tabular}

Table 13. Oxidation of base stocks - comparison of data ${ }^{a}$

\begin{tabular}{|c|c|c|c|c|c|}
\hline & \multirow{2}{*}{ Temp., ${ }^{\circ} \mathrm{F}$} & \multicolumn{2}{|c|}{ Virgin } & \multicolumn{2}{|c|}{ Re-refined } \\
\hline & & Base 1 & Base 2 & Fully & Partially \\
\hline B.A.M. (Viscosity ratio) & 400 & 1.3 & 1.9 & 1.4 & 2.0 \\
\hline ERDA (Filt. res.) & 200 & 81.2 & 1.5 & 5.9 & 53.4 \\
\hline CIGRE (Tot. oxid. prod.) & 200 & & & & \\
\hline No catalyst & & 6.6 & 0.0 & 0.1 & 0.3 \\
\hline Solid catalyst & & 17.6 & 0.7 & 2.4 & 3.3 \\
\hline Soluble catalyst & & 15.7 & 2.2 & 1.9 & - \\
\hline
\end{tabular}

NOTE: (a) Data taken from tables 10 to 12.

Table 14. Oxidation of base stock - re-refined base stock. $\underline{L-38 \text { engine test (10 hours) }}$

$\begin{array}{lr}\text { Bearing weight loss, mg } & 430 \\ \text { Total acid no. (oxidized oil) } & 13 \\ \text { Viscosity increase, \% } & 62 \\ \text { Hydrocarbon types (oxidized oil) (D2007) } & 52 \\ \text { Saturates, \% W } & 19 \\ \text { Aromatic, \% W } & 28 \\ \text { Polar compounds, \% W } & \text { (a) } \\ \text { Infrared analysis (oxidized oil) } & \end{array}$

Note: (a) Strong peak at $1710 \mathrm{~cm}^{-1}$. 
Table 15. Response to anti-oxidants-ranges. ASTM D943, lifetime-hours

\begin{tabular}{lll} 
& $\frac{0.3 \% \mathrm{w} \mathrm{DBPC}}{36(168)^{\mathrm{c}}}$ & $\frac{0.5 \% \mathrm{~W} \mathrm{ZnDP}}{504(336) \mathrm{c}}$ \\
RR & $336-1512$ & $1008-2016$ \\
Re-refined & $840-2016$ & $1680-2325$ \\
Virgin (reference) & $<2016$ & $<2016$ \\
White oil & $<3024$ & $<3024$ \\
Base steck MIL-L-5606 & & 5024 \\
\hline
\end{tabular}

Notes: (a) DBPC is 2,6-ditertiary-butyl para-cresol.

(b) ZnDP is zinc dialkyldithiophosphate.

(c) Data on recent sample shown in parenthesis.

Table 16. Response to anti-oxidants-consistency ASTM D943, lifetime-hours. Re-refined base stock, supplier "F"

$0.3 \% \mathrm{wBPC}^{\mathrm{a}}$

$\underline{0.5 \% \mathrm{w} \mathrm{ZnDP}^{\mathrm{b}}}$

Sample A

504

1008

Sample B

504

840

Sample C-test 1

672

1176

Sample C-test 2

672

1008

Sample D

504

840

Notes: (a) DPBC is 2,6-ditertiary-butyl para-cresol.

(b) ZnDP is zinc dialkyldithiophosphate. 


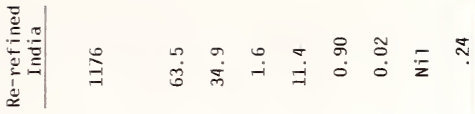

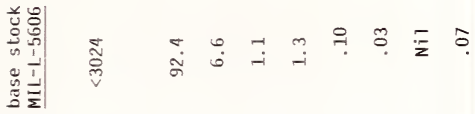

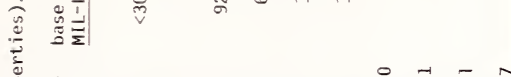



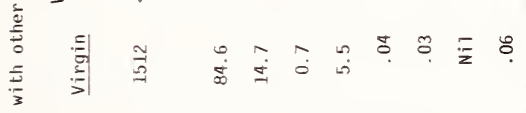

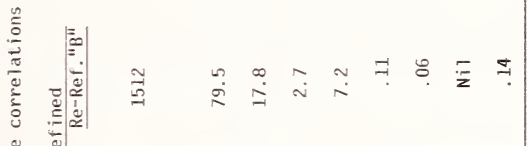

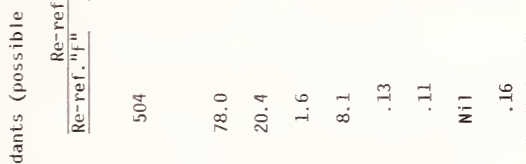

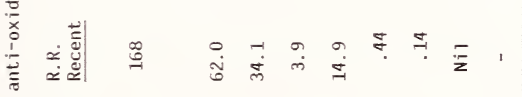

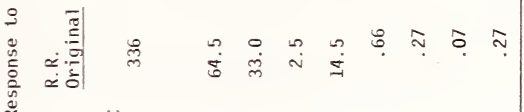

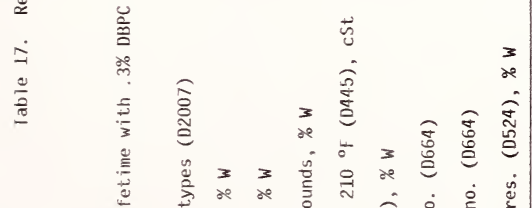

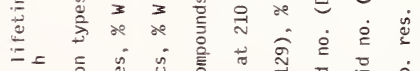

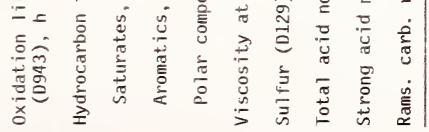


Table 18. Demulsibility (D1401) vs polar constituents.

\begin{tabular}{|c|c|c|c|c|}
\hline Base stock & $\begin{array}{c}\text { Demulsibility } \\
\text { D1401 }\end{array}$ & $\begin{array}{c}\text { Polar CPDS } \\
\text { D2007 } \\
\end{array}$ & $\begin{array}{l}\text { T.A.N. } \\
\text { S664 } \\
\end{array}$ & $\begin{array}{c}\text { Sap. No. } \\
\text { D94 }\end{array}$ \\
\hline Re-refined 1 & $40-40-0(15)$ & 1.9 & 0.11 & 0.5 \\
\hline Re-refined 2 & $40-39-1(35)$ & 1.6 & 0.11 & 0.12 \\
\hline Re-refined 3 & $40-31-9(60)$ & 1.9 & 0.12 & 0.28 \\
\hline Re-refined 4 & $22-0-58(60)$ & 2.7 & 0.06 & 0.96 \\
\hline Re-refined R.R. & $0-0-80(60)$ & 2.5 & 0.27 & 0.48 \\
\hline Virgin base stock 1 & $40-40-0(7.5)$ & 0.7 & 0.07 & 0.66 \\
\hline Virgin base stock 2 & $40-40-0(5)$ & 1.0 & 0.03 & 0.2 \\
\hline
\end{tabular}

The author gratefully acknowledges the permission granted by Mr. E. Dudgeon, Director of the Division of Mechanical Engineering and Dr. R. B. Whyte, Head, Fuels and Lubricants Section, and the efforts of the staff in performing the tests.

References

[1] Strigner, P. L., Moroz, G., Sabourin, R., Burton, G., and Bailey, T., Properties of base stocks obtained from used engine oils by acid/clay re-refining, NRC DME Report ME-75 (1980).

[2] Frame, E. A. and Bowen, T. C., Jr., U.S. Army/Environmental Protection Agency Re-refined Engine 0il Program, AFLRL Report No. 98.

[3] Indian Standard Specification for Re-refined Automotive Internal Combustion Engine Lubricating 0ils, IS: 9048-1979 (May 1979).

[4] Strigner, P. L., MacLeod, D. M., Dunn, T. R., and Shepp, L. P., Properties of USSR, U.S.A. and Canadian R.R. Car Journal Box $0 i 7 s$, ASLE No. 79-AM-6E-2, presented at 34 th Annual ASLE Meeting, St. Louis, MO (April 30-May 3, 1979).

[5] Whisman, M. L., Goetzinger, J. W., and Cotton, F. 0., Waste lubricating oil research; an investigation of several re-refining methods, Bureau of Mines Report RI 7884 (1974). 
National Bureau of Standards Special Publication 584. Proceedings of Joint Conference on Measurements and Standards for Recycled 0il/Systems Performance and Durability held at NBS, Gaithersburg, MD, October 23-26, 1979. (Issued Nov. 1980)

\title{
ASSOCIATION OF PETROLEUM RE-REFINERS STANDARDS FOR RE-REFINED BASE OILS
}

\author{
R. F. Pedal1 \\ MORCO/APR \\ 7601 W. 47th Street \\ McCook, IL 60525
}

About 1950 the members in the Association of Petroleum Re-refiners (APR) felt that they should have a set of standards or specifications for re-refined base oils which could in some way be used as a requirement for active membership. The purpose was, of course, to improve the re-refiners image, at least the image of the members of the APR. The specifications were written for oils of SAE, 10, 20, 30, and 40 grades and included viscosity limits, minimum flash points and maximum colors. They then added to the membership application a statement that those applying for active membership are regularly engaged within the United States in the business of re-refining used oil and operating a plant with the capability of meeting the technical requirements of re-refining oil in accordance with the minimum standards of APR.

In 1961 the standards were rewritten as shown in table 1. The purpose was to improve the quality of re-refined oils produced by the APR membership. The changes made included raised minimum flash points, lowered maximum colors and, in addition, the setting of maximum total acid numbers, moisture content, ash content and precipitation numbers.

Table 1. Association of Petroleum Re-Refiners standards for re-refined oil motor oil base - SAE 10 to SAE 40.

Any re-refined base oils, whether motor oils, hydraulic oils, etc., must conform to these specifications, except where customer specifications are applicable.

$$
\text { Viscosity @ } 210^{\circ} \mathrm{F} \quad \text { Minimum Flash }{ }^{\circ} \mathrm{F}
$$

SAE 10

SAE 20

SAE 30

SAE 40
$40-45$

45-58

$58-70$

70-84
365

385

430

450
Maximum Color

3.5

4.5

5

6

Minimum Viscosity Index - 90

Difference Between Flash Point and Fire Point - $40^{\circ} \mathrm{F}$ min

Neutralization Number - 0.15--Strong Acid Number - 0.0

Ash - $0.01 \%$ maximum

Moisture - trace

Precipitation number -0.0

ASTM Test Designation

Flash Point - D-92

ASTM Color - D-1500

Saybolt Viscosity - D- $88^{a}$

Viscosity Index - D-567

Neutralization Number

Strong Acid Number

D-974 or D-664

Ash - D-482

Precipitation Number - D-91

${ }^{\text {It }}$ is preferable to determine kinematic viscosity by ASTM Method D -445 and convert to Saybolt viscosity using ASTM Method D-446. 
In the fall of 1977 the APR Board of Directors asked me to revise the standards. Before making a revision, consideration was given to the areas in which re-refined oils were being discussed and studied. A partial list includes the NBS Recycled 0il Program, the NBS conferences, APR conferences, the involvement of ASTM, and the MERADCOM effort in revising the MIL L 46152 specification. These have all presented the need for more technical data about re-refined oils.

After the development of data showing adequate quality of product, there must also follow the assurance that equally good quality control will exist in the industry. In order to bring about this control, I felt that a set of test methods useful for determination of base oil quality was needed. The suggested program for control was presented to the APR for their approval as shown in tables 2, 3, and 4. The type of contaminant present in used oils is shown following its specific test method and this is followed by a suggested limit for re-refined base oil. In table 5, a typical analysis of current stock automotive crankcase drainings is shown to point out the need for each specific test method. These test methods and the limits set may need some changes to allow for the various re-refining process in existence and possible plant equipment variables not readily foreseen.

Table 2. Association of Petroleum Re-Refiners proposed quality control requirements for re-refined base oil.

The following test methods were selected to evaluate the effectiveness of re-refining process technology in removing contaminants present in used oils and to provide a testing program for base oil quality assurance.

Table 3. Proposed quality control requirements.

Test Method

Flash

Pentane insolubles

Ash, sulfated

Glycol

Sulfur

Phosphorus

Chlorine

Neutralization number

Moisture
D-893

ASTM Method

D-92

D-874

D-2982

D- 2552

D-129

-.---

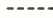

D 664
Contaminants

Fuel \& solvent

Insolubles (Dirt, process clay, etc.)

Metal

Anti-freeze

Additive

Additive

Additive

Polar materials

(acids, alkalis) $\underline{\text { Limits }}$

Same as virgin, e.g. , SAE $20=210^{\circ} \mathrm{C}\left(410^{\circ} \mathrm{F}\right)$ min

$0.01 \%$ wt. $-\max$.

$0.01 \%$ wt. $-\max$.

Negative

$0.25 \%$ wt. $-\max$.

50 PPM - max.

100 PPM - max.

Tan 0.15 - max. strong base- 0.00 max. strong acid- $0.00 \max$.

$0.01 \%$ wt. $-\max$. 
Table 4.

Test Method

Aniline point

Viscosity

$40^{\circ} \mathrm{C} / 100^{\circ} \mathrm{F}$

Viscosity

$100^{\circ} \mathrm{C} / 210^{\circ} \mathrm{F}$

Viscosity index

Gravity API
ASTM Method

D-611

D-445

$D-445$

D- 2270

D-287
Contaminants

Aromatics
Limits

$200^{\circ} \mathrm{F}-\min$

$$
\text { VI - } 90 \mathrm{~min}
$$

Total all elements $<200$ ppm

Table 5. Analytical data - used automotive crankcase oil.

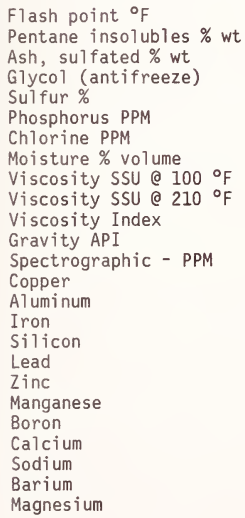

250
2.9
1.8
Present
0.55
800
3500
8.0
310
57.45
130
27.0

40
45
320
100
3950
740
35
25
1420
120
70
350

The Board of Directors of the APR has not taken a position on this proposed quality control program at this time. At the next opportunity, I will urge the APR Board of Directors and APR membership to consider the acceptance of this program as a major step forward in making the re-refiners products more readily acceptable in the marketplace. 

National Bureau of Standards Special Publication 584. Proceedings of Joint Conference on Measurements and Standards for Recycled 0il/Systems Performance and Durability held at NBS, Gaithersburg, MD, October 23-26, 1979. (Issued Nov. 1980)

\title{
THE VISCOMETRIC REQUIREMENTS FOR RE-REFINED ENGINE OILS
}

\author{
Theodore W. Selby \\ SAVANT, Inc. \\ 234 E. Larkin \\ Midland, MI 48640
}

\begin{abstract}
The following paper is intended for a reader less than familiar with: 1) the viscometric relationships between the base stock and formulated engine $0 i 1$, and 2) the demands of the modern automotive reciprocating engine on the viscometrics of the lubricant. Hopefully, the views and information to be brought forth will, to some degree, clarify a complicated area dominated by a complex property of lubricants--the viscosity.
\end{abstract}

\section{Introduction}

For as many years as the automobile has existed as a commercial device there has been some degree of cooperation between the auto manufacturers and those responsible for formulating engine oils. The level of cooperation has waxed and waned over the years but over the last twenty or thirty years such interaction has grown more intense as the automotive machine itself has grown more complex and more demands have been placed on the engine. The fact that the automobile engine is totally dependent upon its lubricant is a rather basic fact. However, the fact that the automobile engine can work reasonably well with a rather wide range of engine oil quality, at least for a limited time, is a more important fact. It is important because the differences between engine oils of high quality and those of inferior grade only become evident after a period of usage. Marked differences in engine oil may well be reflected in differences in engine performance or condition in as little as two or three months of casual driving but, of course, by then a poor choice of engine oil has left an indelible mark on the engine. Thus, it is no surprise that the automotive industry's efforts to produce higher-performance, reduced-maintenance, long-lived vehicles has focused strong attention not only on the design, metallurgy and fabrication of the engine, but also on the lubricant qualities.

At the heart of the interaction of the automotive and oil industries is the joint concern about responsibility for acceptable engine performance or the occasional engine failure. In the latter case, it is often difficult to distinguish the cause for engine failure particularly if it is sudden and catastrophic. Sharing such a burden does not necessarily make it more pleasant--particularly if there is a niggling suspicion that the other fellow has not used his technical "smarts". To meet this need for cooperative technical progress in the care and feeding of the automobile engine, the Society of Automotive Engineers (SAE), the American Petroleum Institute (API) and the American Society for Testing and Materials (ASTM) have jointly established performance limits for engine oils, called the "engine sequence tests". These tests have been, in one respect or another, on the American scene for a little over twenty years and the tests have thus far shown their value in providing the motorist with a relatively clear label of quality wherever he goes.

These tests, however, are performance-based and expensive to run. They do not tell why an oil is or is not successful in passing the test but only that it, in some way, failed to meet the test criteria. For those engineers interested in screening materials or in running preliminary tests on batch blends, other faster, less time-consuming and expensive tests are very desirable. Development of such tests are presently concerning several individual laboratories and collective groups.

Today there are two new directions that are opening for those concerned about the development and formulation of engine oils. One is the desire to produce fuel-efficient 
engine oils and the second is the desire to provide re-refined base stocks for the blending of engine oils. Related to these two areas of development, viscosity is the single most important element of the engine lubricating oil, the property easiest to measure and potentially most informative concerning performance and quality of the oil; but the property of viscosity is also most likely to cause confusion and error. This paper will examine the manifestations of formulated engine oil viscosity and relate them to re-refined base stocks.

\section{Overview of Viscometric Effects of the Engine $0 i 1$ on the Engine}

Before discussing the nature and range of viscometric properties of engine oils it is desirable to briefly and generally consider the effects of engine oil viscosity on the engine. Details will be offered later in the paper.

First of al1, the lubrication of essential operating members of the reciprocating engine is by the hydrodynamic lubrication process--a process completely dependent on the viscous properties of the engine oil. If the engine oil viscosity is, or becomes, inadequate in providing hydrodynamic lubrication, the engine becomes a basket case--usually rather quickly.

Secondly, the engine oil viscosity becomes very much higher at low temperatures and this property limits the startability of the engine.

Thirdly, at low temperatures the engine oil viscosity may become so great that it limits oil supply from the oil pump to the engine. Furthermore, the engine oil may in some cases develop a gel structure at low temperature which cavitates in the vicinity of the oil pump inlet leading to air-binding of the oil pump, again limiting lubricant flow to the engine.

Fourthly, at high temperatures the viscosity is affected by the chemical and physical changes or additions which occur to the engine oil as it is used. Changes, such as oxidation, or additives, such as ingested particulates, can cause the viscosity and gel-forming tendencies of the engine oil to increase to the extent that the engine oil is actually no longer available to the engine even at moderate temperatures.

Fifthly, the viscosity is a form of friction and absorbs energy from the engine, thus reducing the engine's efficiency.

Thus, it is evident that the viscosity of the engine oil and the conditions chosen for its measurement are very important criteria in regard to establishing the qualities of the engine oil for service. The SAE has developed and maintained the Engine 0il Viscosity Classification System since 1911 in an effort to provide a selection of viscosity grades for the engine manufacturer to recommend and the vehicle-owner to purchase to meet their needs.

This system is presently undergoing a major revision as new needs and technical insights have developed.

\section{The Viscosity and Viscometry of Engine 0ils}

\subsection{Base stocks}

At one time in the history of engine lubricants, what we now call base stocks were the finished engine oils. The increasingly demanding requirements of the engine and the automobile owner have generated the need for modern engine oils whose base stocks may contain up to 20 percent of specialized additives. Today the base stocks provide the foundation on which the quality of the finished lubricant rests and it is, thus, very important that base stock quality be adequate for the task.

\subsection{Viscometric requirements of the engine}

To restate, the engine is highly dependent on the viscometric properties of the engine $0 i 1$ for the following needs: 1) To provide hydrodynamic lubrication to the bearings and pistons, 2) to permit low-temperature starting, and 3) to permit pumping from the sump to the operating engine. 
All of these properties are dependent on the composite viscometric contributions of the base $0 i l$ and the additives. To consider these briefly:

Hydrodynamic Lubrication - To meet the hydrodynamic lubrication needs of the engine, the engine oil viscosity in the bearing areas must not drop below a certain value called the "critical viscosity". This value varies with the design and age of an engine but is in the range of 3 to 6 centipoise.

Low-Temperature Starting - Low-temperature starting is highly dependent on the design of the engine and the viscosity of the engine oil. Again, another "critical viscosity" exists which may range from 2500 to 25000 centipoise depending on the engine, the temperature, the fuel, and the battery and starter. This critical viscosity is the maximum viscosity at which a given engine will start.

Pumpability - More recently, concern has been expressed about oil pump supply to the engine at low temperatures. Standard tests are now being developed by the ASTM for the $S A E$ to assure that future engine oils will be neither "air-binding" (i.e., structure-limited) or "flow-limited" (i.e., viscosity-limited). (These terms, and others to come, will be more completely explained in following sections.)

\subsection{Viscometric properties of engine oils}

At a given temperature an engine oil may be either Newtonian or non-Newtonian in behavior. In general, single grade engine oils (i.e., SAE 20,30, 40, or 50) are Newtonian in behavior except at temperatures below the "cloud-point" (the temperature at which the wax in the oil begins to come out of solution). On the other hand, most multigrade oils (i.e., $5 w-20,10 w-30,10 w-40,20 w-50$, etc.) are non-Newtonian at any temperature if they possess a polymeric Viscosity Index Improver. (However, some multigrade oils made from synthetic oils, if they contain no polymeric additive, are likely to show Newtonian behavior.)

Newtonian Behavior - A liquid is said to be Newtonian if, at the temperature of measurement, the force causing flow is proportional to the rate of flow. Shear stress (or force per unit area under shear) can be substituted for force and shear rate (or the velocity gradient of the fluid layers) can be substituted for the rate of flow. If this is done, the constant of proportionality is the viscosity and the resulting equation and graphical expressions are shown in figure 1 .

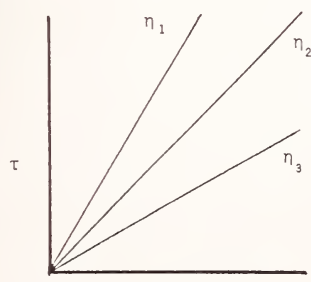

G

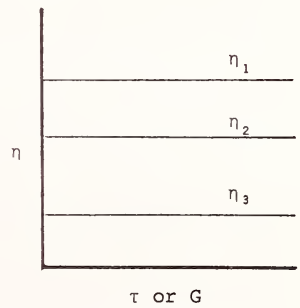
B.

A.

Figure 1. Newtonian behavior ( $\tau=\eta G$ or $\eta=\tau / G$ ) (in which $\tau$ is shear stress, $\eta$ is the viscosity, and $G$ is shear rate). 
Newtonian behavior permits predicting viscometric response of the engine oil since, at a given temperature, the oil has a constant value of viscosity at all shear reates or stresses as can be easily seen in figure $1 \mathrm{~b}$. The behavior shown in figures $1 \mathrm{a}$ and $1 \mathrm{~b}$ will provide contrast in the following discussion of non-Newtonian behavior.

Non-Newtonian Behavior - Gelation - An oil sometimes develops a structural characteristic or is said to gel when the temperature falls near or below the pour-point of the oil

(the temperature at which the oil will not flow under a mild hydrostatic head). The structure is often fairly weak and can be broken up readily at relatively low shear stresses. Still a certain amount of force is usually necessary in order to cause initial flow. This is termed the yield stress of the fluid and is shown in figure 2. Once the structure is broken, it usually will not reform or recovers only slowly and partially if the oil is held at the initial temperature. Thus, in contrast to figures $1 a$ and $1 b$, the curves of increasing and decreasing shear stress would look as in figures $2 a$ and $2 b$. This hysteresis effect is an identifying characteristic of gelled oils.

$$
\begin{aligned}
& \tau=n_{a} G+\text { yield stress } \\
& \begin{array}{l}
\tau \simeq n_{1} G \\
n_{a}: \text { apparent viscosity of oil } \\
n_{1}: \text { sheared viscosity of oil }
\end{array}
\end{aligned}
$$

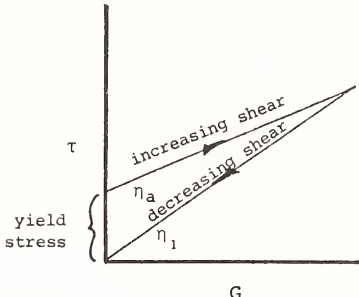

G

A.

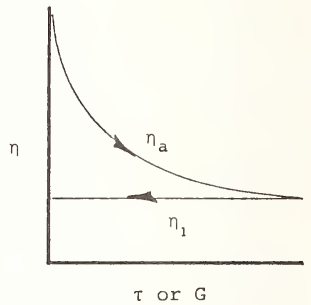

B.

Figure 2. Non-Newtonian behavior - waxy gelation.

While the oil structure will not readily reform as long as the oil is held at the temperature at which its presence is noted, if the temperature is raised and again lowered, the structure will reappear. Depending on whether or not the gelation "memory" of the oil is erased by bringing the oil to sufficiently high temperatures, the renewed structural characteristics may be equal to, less than or greater than the original structure. In fact, some oils will only show structural characteristics when they have been repeatedly cycled at temperatures somewhat above the considerably below the temperature at which the oil shows incipient gelation.

The problem created by such gelling tendencies in an engine oil is the development of "air-binding" in the oil pump; a condition created by the collapse of the fragile structure above the pump inlet which then permits the pump to "snorkel" air from the surface--effectively air-binding the pump as shown in figure 3. Depending on the strength of the structure adjacent to the air path, the oil pump may be air-bound long enough to allow serious 
damage to the engine from lack of lubrication. Even somewhat prolonged operation under such conditions may cause such damage to the bearings that they are predisposed to fail later or at least show a shorter life at operating temperatures.

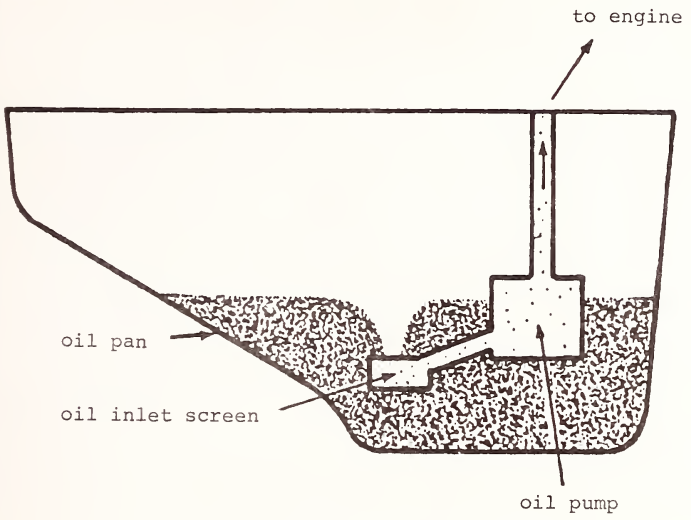

Figure 3. Air-binding limited pumpability.

To treat the problem of engine oil gelation, additives known as "pour-point depressants" have been developed to lower the temperature at which such gelation occurs. These additives are believed to, in some way, interfere with the growth of the crystalline habit of the wax present in the oil. Even polymeric additives known for their Viscosity Index improving ability can act as pour-point depressants as shown in figure 4. Other choices of Viscosity Index improving polymers may have little effect or actually create a more evident gelation as shown in figure 5. Again, these polymer effects are thought to be associated with their interaction in the development of the wax structure which in turn creates the gelled condition. In the first case it is believed to become involved in the way structure, but because of molecular dissimilarity to the wax, the polymer prevents the wax crystals from further growth. In the second case, similarity between the VI Improver and the wax crystals encourages gelation perhaps because the macromolecule is sufficiently long and flexible to serve to join two or more crystals as shown in figure 6 , thus creating a wax/polymer interaction having greater strength than the wax gel alone. In the latter case, use of pour-point depressants will control both the wax gelation and the wax/polymer effect.

As an additional point of interest regarding engine oil viscosity, gelation, and pumpability: normally, one would think that fuel dilution of an oil would lead to lower viscosity and this is true. However, fuel dilution of a diesel engine oil with a waxy diesel fuel can both decrease the viscosity and raise the yield stress as shown in figure 7 .

From the foregoing, it is evident that the gelation characteristics of the base stock, its treatment by pour-point depressants and the effect of the VI Improver all play roles in developing an engine oil with acceptable pumpability at low temperature. 

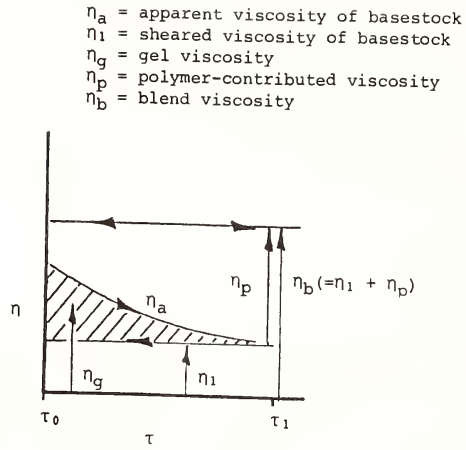

Figure 4. Gelation inhibiting polymer.

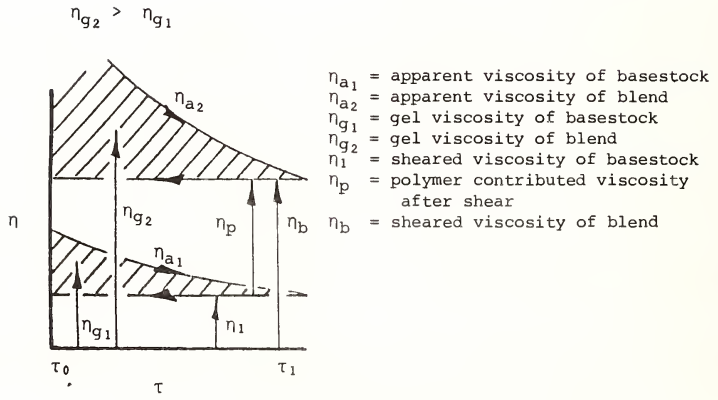

Figure 5. Gelation contributing polymer. 


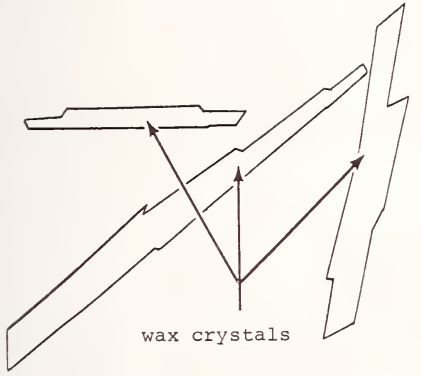

Without Polymer

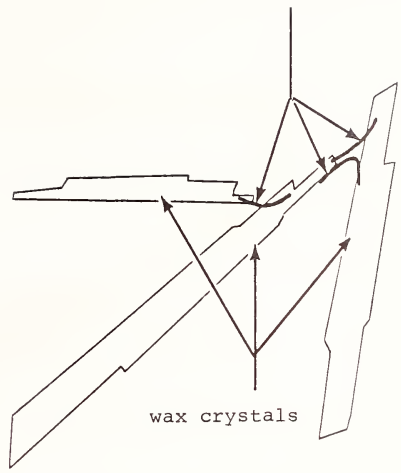

With Gel-Contributing

Polymer

Figure 6. Wax/polymer gelation effect.
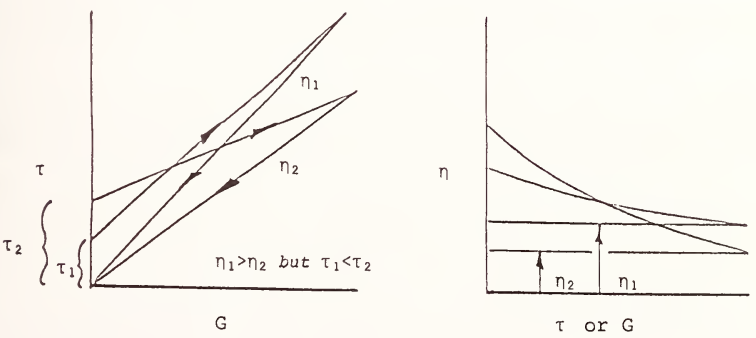

Figure 7. Effects of waxy fuel dilution on gelation of engine oil.

\subsection{Other low-temperature, low-shear effects}

There is another way in which pumpability of the engine oil may be restricted and this is by being "flow-1imited". At the very low shear stresses imposed by air pressure on the surface of the oil, the viscosity of the engine oil is simply too high to supply the oil pump with sufficient oil and the pump and engine are "starved" for lubricant. This - :: dition is shown in figure 8. The critical viscosity for a "flow-limited" condition is different for each engine but values of 30000 centipoise are being considered as an SAE limit. 


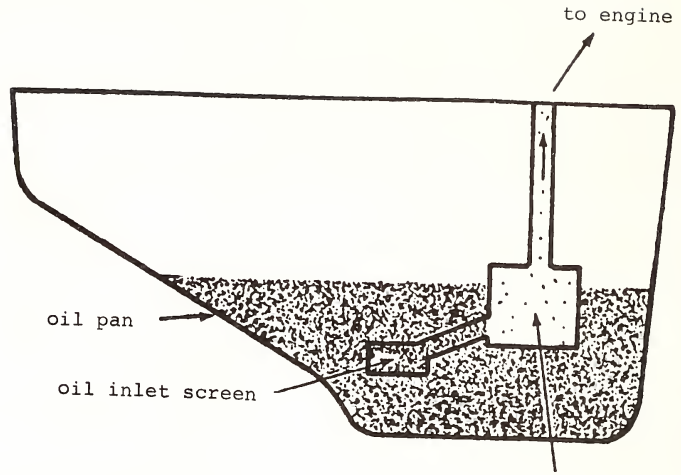

oil pump

Figure 8. Flow-limited pumpability.

The "flow-limited" characteristic of an engine oil is highly dependent on the viscositytemperature relationship of the base stock as modified by the pour-point depressant.

3.5. Non-Newtonian effects of VI improvers (and other polymeric additives)

Originally, VI Improvers were developed as engine oil additives to formulate oils of improved viscosity-temperature characteristics and this is still their most important function al though they now also serve as ashless dispersants and pour-point depressants.

A polymeric VI Improver is a long-chain macromolecule in oil solution as schematically represented in figure 9a. At low shear stresses it interferes most effectively with the molecular motion of the much smaller oil molecules, thus increasing the viscosity of the mixture by its presence. At higher shear stresses some of the polymer effectiveness is lost and the viscosity of the formulated oil decreases. Figure $9 \mathrm{~b}$ shows this form of temporary viscosity loss (TVL) caused by orientation of the polymer coil under the shearing forces. If these shear stresses grow still more intense, the polymer molecule can be ruptured, as in figure 9c, forming two more or less similarly sized macromolecules which are collectively less effective in controlling the flow of the oil molecules than their single macromolecular precursor. An oil which experiences such polymer degradation experiences an irreversible change--a permanent viscosity loss (PVL).

The effects of either temporary or permanent viscosity losses can be very significant depending on the molecular weight of the polymer and, thus, its susceptibility to distortion and rupture. This can be shown by some work by Stambaugh and Kopko in figure 10 . Here it is evident that up to 60 percent or more of the viscosity contributed by the VI Improver can be "lost" (temporarily) at the shear rates encountered in the bearings depending on the molecular weight of the polymer. Choosing to use a lower molecular weight polymer, such as VI Improver $C$ rather than $A$, can reduce the temporary viscosity loss from 60 percent to 20 percent. Moreover, in regard to permanent viscosity loss, the lower molecular weight VI 
Improvers $B$ and $C$ showed no permanent degradation in the engine while the higher molecular weight Polymer A permanently lost 20 percent of its viscosity contribution while in engine service. (The insert in figure 10 is to point out the fundamental nature of the larger plot and to thus show the form of temporary viscosity loss as opposed to the Newtonian behavior previously shown in figure 1.)

\section{B. Temporary Viscosity Loss:} (TVL)

orientation of coil under shear forces
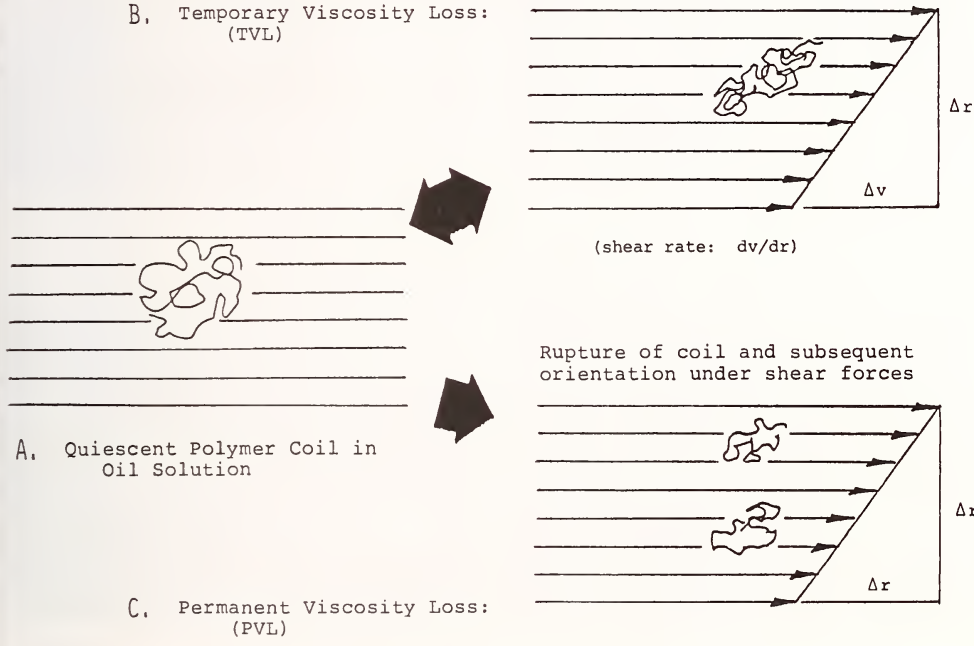

(shear rate: $d v / d r$ )

Rupture of coil and subsequent orientation under shear forces

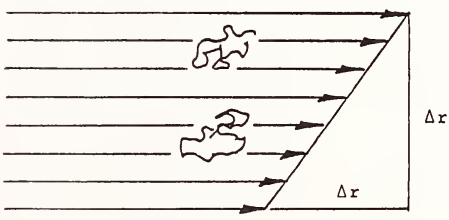

Figure 9. Temporary and permanent viscosity losses.

Obviously, the individual or combined effects of temporary and permanent viscosity loss must be considered very carefully in the formulation of an engine oil. If these effects are such as to produce an engine oil whose viscosity in the operating bearing at high temperatures is less than the critical viscosity required by that engine, which Stambaugh and Kopko further showed could be at least as high as $3.5 \mathrm{cSt}$, the engine will suffer permanent damage as shown in figure 11 for the upper two bearing sets. The lower two bearing sets represent the response to oils having an adequate combination of base stock and VI Improver and, thus, a viscosity above that which was shown critical in the engines they studied.

To restate, the degree to which the finished lubricant may, at high shear, experience either temporary or permanent viscosity loss is dependent, among other things, on the molecular weight and concentration of the polymer. These properties of the VI Improver are, in turn, dictated by the viscosity characteristics of the base stock and the SAE grade level and service desired. 


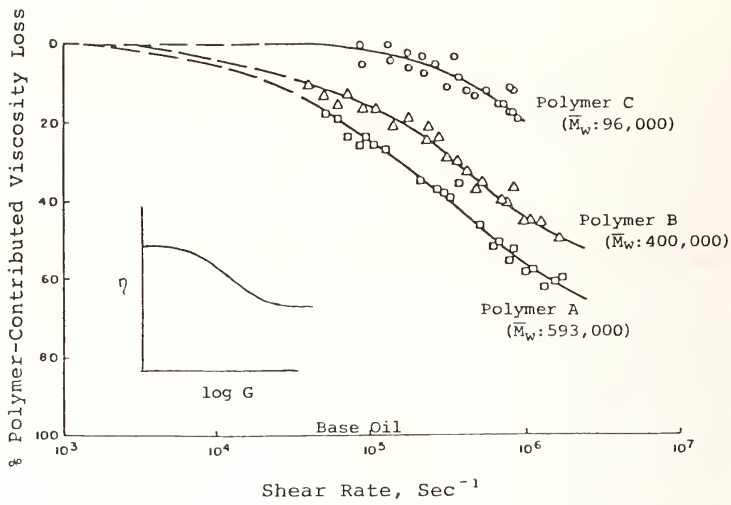

Figure 10. Relationship of molecular weight to temporary viscosity loss.

\subsection{Non-Newtonian high-shear/low-temperature characteristics}

One of the most aggravating problems plaguing the average motorist in the colder parts of the nation is a balky engine on a cold day. While there are many factors that affect cold-starting, the most critical is the engine oil viscosity. As previously mentioned, this problem was one of the primary factors leading to the development of VI Improvers, that is, to obtain an engine oil having sufficient protection for the engine bearings at highest operating temperatures while still permitting low-temperature starting.

The problem is more complex than first appears; if sufficient VI Improver is added to a base oil to give adequate bearing protection at high operating temperatures, in most cases a considerable amount of viscosity is also added by the polymer at low temperatures. This makes the proper formulation a matter of careful choice of: 1) base stock viscosity, 2) VI Improver, 3) temporary viscosity loss potential, and 4) permanent viscosity loss potential.

There are types of polymers whose coils expand as the oil becomes warmer and contract as the oil becomes colder. The mechanism by which this occurs has been explained by the solution dynamics of a polymer/oil mixture. If the oil is only a moderately good solvent for the polymer, at lower temperature the polymer cuil will contract upon itself as the solvencey of the oil decreases, at higher temperatures the coil expands since the solvent properties of the oil improves and Brownian motion further encourages such expansion. These dynamics are shown in figure 12 for such a polymer. Such polymers make it easier to obtain good high and low temperature viscometric properties. However, such VI Improvers may not be quite as efficient as the more soluble VI Improvers per unit polymer concentration in increasing the high temperature viscosity of the engine oil.

Again, it is evident that the base stock plays the major role in determining which and how much VI Improver is chosen.

\section{General Discussion and Summary}

The foregoing has been an effort to show how important the various aspects of engine oil viscosity are to the engine. Hopefully, it has also shown how important the viscometric characteristics of the base stock are to the viscosity of the formulated engine oil. 

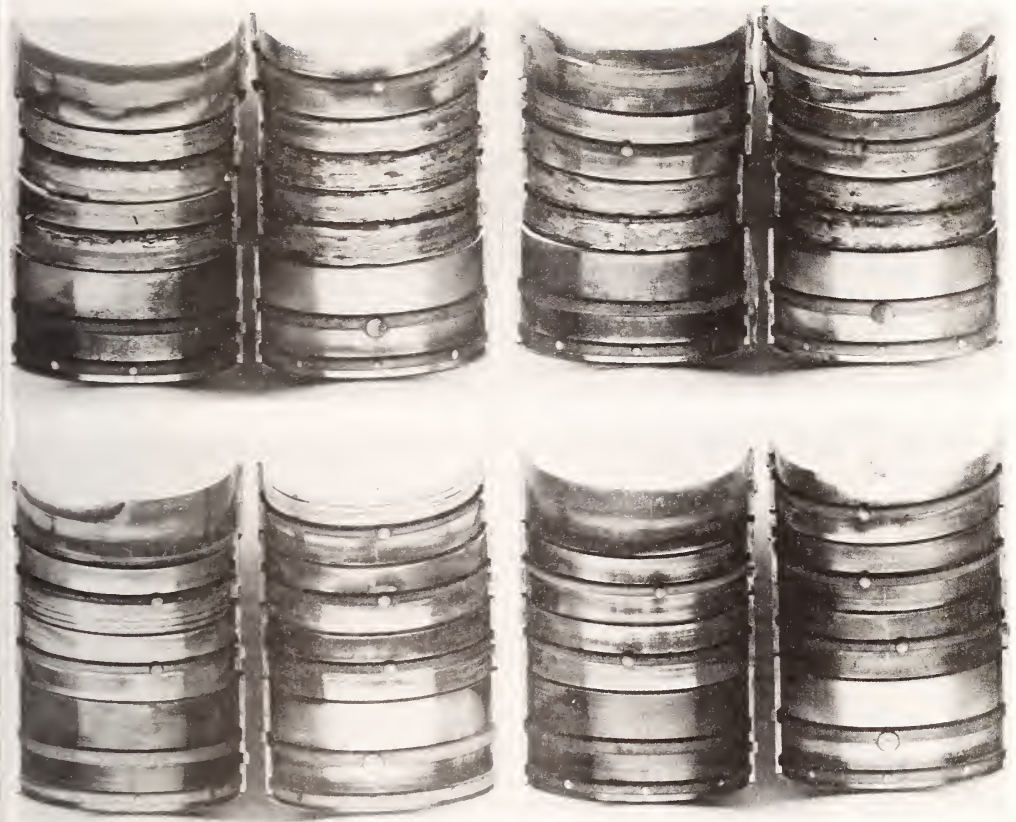

Figure 11. Condition of main bearings after 50000 miles.
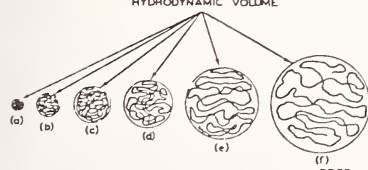

Figure 12. Expansion and contraction of a macromolecule. 
In regard to re-refined base stocks and the engine oil formulated from these re-refined stocks, viscometric analyses at both high and low temperatures with suitable instruments permit: 1) Establishment of a consistent base stock product, 2) establishment of the optimum selection of additives, and 3 ) consistency in the finished formulation.

For example, the variation which may be observed in the yield stress at a given low temperature can be related to the type and quantity of pour-point depressant. This can be a much more sensitive and technically less demanding approach than the accrual determination of the pour-point. Similarly, the effect of VI Improvers and/or various admixtures of synthetic base oils can be studied at both high and low shear stresses to determine the optimum formulations for a given SAE multigrade level.

The response of a given base stock to oxidation tests or to field performance can be very sensitively followed by viscometric measurements, particularly when coupled with other analytical techniques. (However, this area brings in a further complement of viscometric analyses which are beyond the intent of this paper.)

Thus, the formulation of an engine oil to meet the needs of today's high-performance engines requires careful understanding and close control of its viscometric properties. Base stock properties, whether from re-refined or refined sources, are the foundation of the formulated oil and the delineator or the oil's success in meeting the engines' viscometric needs. Since, of all the engine oil, and the one most easily and directly measured with proper equipment, there is no reason why any finished oil, properly compounded, should be deficient in this important property and its manifestations. 
National Bureau of Standards Special Publication 584. Proceedings of Joint Conference on Measurements and Standards for Recycled 0il/Systems Performance and Durability held at NBS, Gaithersburg, MD, October 23-26, 1979. (Issued Nov. 1980)

COMMENTS FROM A PRODUCER OF VIRGIN BASE OIL

\author{
D. G. Espey
}

Exxon Company, U.S.A.

P. 0 . Box 2180

Houston, TX 77001

In evaluating the NBS assignment against our own experiences, I am prompted to philosophize and say: "Take comfort for thy task is exceedingly difficult and don't be disheartened if you can't do the impossible."

To put your task into perspective, take a look at the massive amount of effort which recently went into the development and standardization of the PV-1 test--which is just one engine test out of the hundreds of end-use applications for lubricating oils.

Before proceeding further, let me briefly state that my company's position on recycling oil is one of support and encouragement. We see no basic problems in reclaiming or rerefining used lubes so that they may be returned to lubricant service. Our major concern is to avoid arbitrary and unnecessary constraints which could create severe problems and substantial additional costs. The processes used in refining virgin base oils and the undesirable components removed from the raw material are different from processes used in re-refining used oils and components removed from these oils. Therefore, specifications or quality criteria applied to virgin oils may not fully apply to re-refined oils (or vice versa). Careful consideration should be given to this matter. Since we are in complete agreement with the desire to conserve petroleum molecules in any way that is environmentally and economically acceptable, I hope that my comments will be received as trying to describe the real world as we see it.

I will be addressing comments to the characterization of virgin base stock quality, but before doing so, I must talk briefly about historical practices which have served consumers well for a long, long time. Prior to the 1969/70 onset of severe domestic crude short falls, most of the virgin base stocks were produced from sweet domestic crudes, and the crude sources and characteristics did not change frequently. Lube plants were designed and built to process specific crudes, frequently of local origin. Although the refining processes and the crude differed from plant to plant, each plant's production was relatively constant year after year. Products would be developed and qualified and would remain qualified until some major change occurred. But these changes did not occur overnight and requalification programs for scheduled changes might take place over a one-to-two year period.

Since about 1969, changes in crude and processing have come at increasing frequency, but they still do not come overnight, thereby giving us some time to run requalification tests. Since the 1973 embargo, we have had two major changes in our domestic lube base stock manufacture.

The first of these was the introduction of high sulfur, mid-east crude into our lube production circuit. This move was not without background and experience because we had several refineries in Europe already operating for years on these crudes with similar processing steps. Admittedly, these crudes were new to us domestically and represented a "change" which had to be addressed, but a technology base existed which said that good lubes could be produced from them. In another case, an extraction solvent was changed, but extensive pilot plant work preceded the plant modifications. Here again, the first application was in Europe, which provided us a data base for our conversion. In both these cases, programs were developed with the lubricants review board and the required engine test data were obtained, which showed performance equivalence in both cases. 
However, even before the 1973 embargo, we were concerned with the rather ponderous, time consuming, and largely empirical methods for proving out the interchangeability of crude or process changes. Therefore, we have under way some work with the objective of developing more fundamental relationships between lube base stock composition and performance relationships that would be independent of crude source or processing operations.

Needless to say, both sides of the equation have proved much more difficult than envisioned. The analytical or compositional portion of the studies has proceeded satisfactorily. But the performance side is littered with an ever changing array of performance targets--gasoline engines tests, diesel engine tests, turbine oil tests, hydraulic oils tests, etc., and the ever present issue of additive treat and response complicates matters.

A few years ago, most of us in this room would have picked a low sulfur, high viscosity index base oil as optimum for formulating automotive-type crankcase oils, and yet it "ain't necessarily so."

Many of the sulfur-containing compounds in high-sulfur base stocks are natural oxidation inhibitors--beneficial in higher temperature environments such as encountered in the sequence III D test. Therefore, arbitrary limitations should not be imposed on base oil sulfur content.

Historically, viscosity index has been used as a dual measure of quality--i.e., both viscometrics and oxidation stability. While VI obviously has valid meaning in many viscometric considerations, using VI as an index of oxidation stability can lead to incorrect conclusions. Extracting a given crude to higher VI levels will generally result in a base stock having improved response to oxidation inhibitors. However, extracting different crudes to the same VI level does not necessarily produce base stocks of the same oxidation stability--even if the sulfur levels are the same. The gross viscometric properties (VI) do not determine oxidation properties.

We surmise that many companies are attempting to quantify the relationships among all the important base stock qualities, and that new understanding will evolve from this work.

Consequently, we urge you to leave open as much room as possible in your thinking and specifications for new understanding. After all, the bottom line is adequate supplies of lubricants which will lubricate equipment--not paper specifications. 
National Bureau of Standards Special Publication 584. Proceedings of Joint Conference on Measurements and Standards for Recycled 0il/Systems Performance and Durability held at NBS, Gaithersburg, MD, October 23-26, 1979. (Issued Nov. 1980)

\title{
CHARACTERIZATION OF LUBRICATING BASE STOCKS FOR AUTOMOTIVE CRANKCASE OILS
}

\author{
Stephen M. Hsu \\ Tribochemistry Group \\ Chemical Stability and Corrosion Division \\ Center for Materials Science \\ National Bureau of Standards
}

\section{Introduction}

Lubricating base stocks are complex hydrocarbon mixtures of paraffinic, naphthenic, and aromatic molecules $[1,2]^{1}$. Typical structures are shown in figure 1 . There are very few "pure" molecules, and most molecules exist as mixed types. A small but important fraction of basestock consists of molecules containing nitrogen, sulfur, and oxygen moieties. This fraction is generally more active chemically and is "polar" in nature, and has significant influence on the performance of the lubricating oils. Some possible compounds of this class are shown in table 1 [3].

Lubricating base stocks consist of so-called neutrals and bright stocks of various viscosity grades. The neutrals are generally distillates from a fractionation tower, and the bright stocks are the bottom or residual stream. Viscosities are generally measured at $100^{\circ} \mathrm{F}$ in terms of Saybolt Universal Seconds (SUS). Therefore, a $120 \mathrm{~N}$ refers to an oil which is a distillate and has a viscosity of 120 SUS at $100^{\circ} \mathrm{F}$. Various viscosity oils are required to blend a multi-grade motor oil. Since viscosity is a function of molecular weight and molecular size, different viscosity oils represent different molecular weight and molecular size, and to some extent, different molecular structures or molecular type distributions. Table 2 presents some compositional variations of a lubricating stock refined from U.S. mid-continent crude (solvent extraction refining) as a function of viscosity grade. The differences are shown by the increase in polynuclear aromatics, sulfur, and nitrogen concentrations in the fractions as the viscosity increases. Boiling point distribution differences are shown in figure 2. The amount of sulfur, nitrogen and polynuclear aromatics are useful parameters as these compounds have a significant impact on oxidation stability, and additive response [4-7]. At the same time the structures of these compounds are also imporvant.

Therefore, measurement of the levels of sulfur, nitrogen, and oxygen is useful only when the crude source is kept constant after a pattern of performance behavior has been established.

\section{Base $0 i 1$ - Additive Interactions}

In attempting to characterize lubricating base stocks for automotive crankcase oil application, let us examine how a motor oil functions. In a typical motor oil, chemical additives, excluding the viscosity index improver, comprise about 5 percent to 10 percent of the formulated motor oils. These additives are nitrogen-containing dispersants, metal-containing detergents, rust and corrosion inhibitors, anti-wear additives, and oxidation inhibitors [8]. Generally, the additives are highly polar and functionalized molcules, which impart various qualities that the base stocks do not possess. In the final product, the effective additive concentration depends on the base stock-additive interactions (additive response) as well as additive-additive interactions. Watson [9] suggested that additives exist in oil as micelles. The critical micellar concentration (CMC) for additives is about $10^{-5}$ molar depending on molecular structure and alkyl chain length. When several different polar species are present in the same solution, the CMC could be altered by aggregation, reaction, and interactions of different species. The polar species can neutralize each other and reduce the total effective additive concentration. Components originally present in the base oil, such as the nitrogen, sulfur, and oxygen containing compounds can interfere with the micellar structures and interact

TFigures in brackets indicate the literature references at the end of this paper. 


\section{Typical Structures}

$$
C-c-c-c-c-\cdots-c-c
$$<smiles>CC(C)C(C(C)C)C(C(C)C)C(C)C</smiles><smiles>CCCCCc1cc(C)cc(C(C)C)c1</smiles><smiles>CC(C)CC1CCC2CCC(C(C)C)CC21</smiles><smiles>CCC1CC(CCC(C)C)C2C(C(C)C)=C(C)C(C)=CC12</smiles>

n-Paraffin

Iso-Paraffin

\section{Mixed}

Figure 1. Typical base oil structure. 
Table 1. Typical N, $0, \mathrm{~S}$ compounds.

Sulfur compounds

- alkyl, cyclic and aromatic thiols

- alkyl sulfides

- alkyl, cyclo-alkyl sulfides

- cyclic sulfides

Nitrogen compounds

Basic = quinolines and pyridine alkyl substituents

Non-basic $=$ pyrroles, indoles, carbozoles

Oxygen compounds

Acidic $=n$ and branched chain acids

acids containing a cyclic group

Neutral $=1-, 2-$ or 3 , and 4-methyldibenzofurans

Table 2. Base stock composition as a function of viscosity grade.

Paraffins, wt. percent

Aromatics, wt. percent

Cycloparaffins, wt. percent

Saturates, wt. percent

Aromatics, wt. percent

Polynuclear aromatics, wt. percent

Sulfur, ppm

Nitrogen, ppm

Basic nitrogen, ppm

wt. percent boiled off at

$\begin{array}{ll}360{ }^{\circ} \mathrm{C} & \left(680{ }^{\circ} \mathrm{F}\right) \\ 427{ }^{\circ} \mathrm{C} & \left(800{ }^{\circ} \mathrm{F}\right) \\ 482{ }^{\circ} \mathrm{C} & \left(900{ }^{\circ} \mathrm{F}\right) \\ 538{ }^{\circ} \mathrm{C} & \left(1000^{\circ} \mathrm{F}\right)\end{array}$

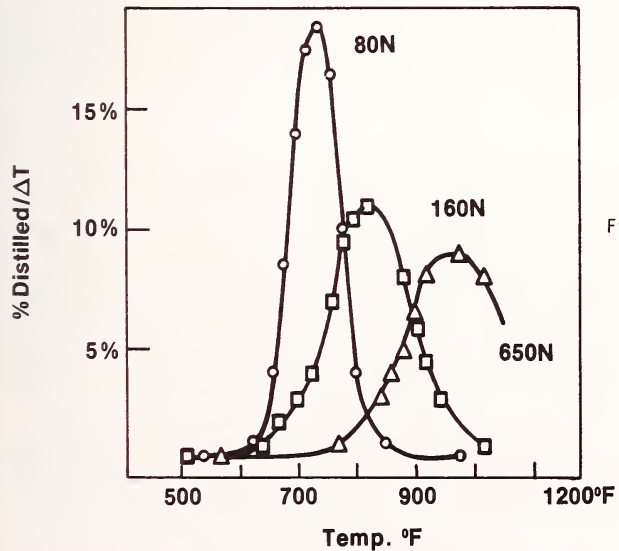

$300 \mathrm{~N}$

24

59

62

84

1.5

5.3

100

18

9

13

76

98

Figure 2. Bciling point distributions of base stocks as a function of viscosity grade. 
with the additives [10]. Some of these naturally occurring compounds have been observed to inhibit oxidation [11]. Therefore, effective characterization of lubricating base oils depends on the ability to measure and characterize the interactions between the impurities and additives, as well as the basic hydrocarbon molecules.

There are different kinds of interactions between different additives and various base oil polar molecules. The surface active additives such as anti-wear, corrosion, and rust inhibitors will interact strongly with the surface active species in the base oil (such as nitrogen- and sulfur-containing compounds). The less surface active agents like dispersants will probably react with the oil-insoluble oxidation products formed under oxidation conditions. For example, aromatics are known to form oil insoluble oxidation products through condensation reactions. Therefore, the base oil composition affects not only the initial oxidation induction behavior, but also has a significant impact during the course of oxidation/degradation. Because of this, different base oils having different chemical compositions may have different oxidation rates. In the presence of a specific additive package, different additive depletion rates may be observed from oil to $0 i 1$.

\section{Base 0 il Requirements}

There are many characteristics that are desirable in a lubricating basestock. These include the following: 1) solvency: the ability of the base oil to solubilize various chemical additives and oxidation products; 2) oxidation stability: stability of the base oil under oxidation conditions; 3 ) additive response: the extent of improvement in oxidation, corrosion, and wear characteristics from additives; 4) thermal stability: stability of the base oil due to high temperature degradation in the absence of oxygen; 5) $10 \mathrm{w}$ temperature fluidity: the ability of the base oil to maintain fluidity under low temperatures, and 6) oil consumption: the ability of the base oil to avoid excessive volatilization under normal engine operating conditions.

All of these characteristics, at least theoretically, can be defined in terms of the physical properties, chemical properties, chemical composition, and molecular structures of the base oils. In practice, detailed characterization of such a complex mixture as lubricating base oil in terms of chemical composition and structures is not feasible. This is particularly true since some of the characteristics can be altered with compounds at the ppm levels. As a result, much of the previous characterization work have used the physical and chemical properties in conjunction with bench performance tests. Recent advances in analytical techniques such as high resolution mass spectroscopy and high field nuclear magnetic resonance (NMR) offer new opportunities to accurately determine molecular structures. The remaining problem, however, is to determine which structure(s) among the thousands present affects the performance characteristic. The following sections describe each characteristic and their relations to some physical/chemical properties.

\section{Solvency}

The solvency of a base-oil frequently can be related to the aromatic content of the oil. There are two aspects of solvency: one is additive solubilization, the other is oxidation product solubilization. Since some of the chemical additives are polar, the polar molecules, such as some alkyl aromatics, in the base oil can solubilize them. In some of the linear synthetic base stocks, solvency becomes a critical problem and some diesters or other polar molecules need to be added to the base stock. In solubilizing insoluble oxidation products during use, the concept of optimum aromaticity is important [12]. During oxidation, various organic acids, alcohols and ketones are generated. The aromatics help to solubilize the oxidation products. On the other hand, aromatics, especially the polynuclear aromatics, become oil insoluble upon oxidation. Therefore, the aromatic content of base stocks should not be too high or too low. Depending on the crude source (molecular structures), processing technology, and viscosity grade, there are different optimum levels of aromatics in a base oil. Table 3 illustrates the effects of aromatics on solubilization. The solvency is measured by the spot dispersancy technique, which measures the ability of the oil to disperse sludge particles on a blotter paper and where 100 percent represents perfect dispersancy [13]. It can be seen that oil $B$ has higher aromatic content and better dispersancy. 
Table 3. Relation between aromatic content and solvency.

$\begin{array}{lrr} & \frac{0 i 1 \text { A }}{10} & \frac{0 i 1 \text { B }}{24} \\ \text { Aromatics, wt. percent } & 5 & 10 \\ \text { Monoaromatics, wt. percent } & 20 & 24 \\ \text { Paraffins, wt. percent } & 70 & 95 \\ \text { Spot dispersancy, percent } & \end{array}$

\section{Oxidation Stability}

In a complex hydrocarbon mixture, oxidation will begin when conditions for oxidation are met for the most unstable species in the mixture [2]. Oxidation is generally accepted as occurring via a free radical oxidation mechanism. Once the free radicals are generated, the oxidation processes will spread to other more stable species. The oxidation stability of a base oil may be determined by the concentration of naturally occurring chain terminating agents such as some hindered phenols, sulfur compounds, and amines. The oxidation stability of a base oil without any additive, therefore, is a measure of the level of these agents in the base 011 . Since most refining techniques such as solvent extraction, hydrotreating, and clay percolation are designed to remove the polynuclear aromatics, amines, and sulfur compounds, it should follow that the purer the base oil, the more oxidation unstable it becomes.

This, in fact, does occur as illustrated by oils $C$ and $D$ in table $4.0 i 1 \mathrm{D}$ is a white mineral oil exhaustively refined from mid-continent crude. $0 i 1 \mathrm{C}$ is the same crude but processed. In a simple air bubbling oxidation test for 6 hours at $204{ }^{\circ} \mathrm{C}\left(400^{\circ} \mathrm{F}\right.$ ) without any additives, the carbonyl concentration, $C=0$, measured by differential infrared spectroscopy, shows that the white oil has been oxidized almost twice that of the conventional oil.

Table 4. Oxidation stability as a function of base stock chemical composition.

$\begin{array}{lrr} & 0 i 1 \mathrm{C} & \frac{0 i 1 \mathrm{D}}{20} \\ \text { Paraffins, wt. percent } & 18 & 5 \\ \text { Aromatics, wt. percent } & 34 & 1 \\ \text { Poly-aromatics, wt. percent } & 8 & 5 \\ \text { Sulfur, ppm } & 700 & 20 \\ \text { Nitrogen, ppm } & 300 & 100 \\ \text { Oxidation Test } & 60 & 50 \\ \text { C=0, A/cm (w/o Add.) } & 50 & 10 \\ \text { C=0, A/cm (w/Add.) } & \\ \text { 0il Thickening Test* } & 1000 & \\ \text { Percent Viscosity Increase } & \\ \text { *Test is conducted at } 171{ }^{\circ} \mathrm{C} \text { (340 }{ }^{\circ} \mathrm{F} \text { ) for } 32 \mathrm{~h} \text { in an open test } \\ \text { tube with 7 percent wt. of a standard additive package. }\end{array}$

The same naturally occurring inhibitors, in the presence of chemical additives and antioxidants, may interfere with the effectiveness of the additives. Table 4 shows that when additives were used, oxidation of $0 i 1 \mathrm{C}$ was reduced by 17 percent. 0xidation of $0 i 1$ D was reduced by 50 percent. The same trend prevails in a more severe but longer term oxidation test where the difference in the two oils are dramatically different ( 1000 percent viscosity increase at 32 hours for 0 il $\mathrm{C}$ and only 10 percent viscosity increase for oil D).

Therefore, it may be generalized that the more stable the base oil (i.e., the higher the level of impurities), the less effective the additives will be on the final product. One caution on this generalization: the measurement of the sulfur, nitrogen, and oxygen compounds do not reliably indicate the same trend if the crude source or the processing technology changes. Unfortunately the question of which specific structures are affecting performance has not been answered at present. 


\section{Additive Response}

Additive response can be defined as the net change in performance of the lubricant which can be attributed to the additive. As has been illustrated under the section on oxidation, impurities can inhibit the oxidation process yet they can also reduce the effectiveness of additives. A similar trend in the wear performance area has also been observed [14]. The effects of the impurities ( $, \mathrm{N}, 0$ compounds) appear to be important in this regard, as well as the basic hydrocarbon structures such as: aromatic to paraffin ratio; the average alkyl chain length; and the degree and extent of branching and cyclic structures. All of these have profound effects on the additive response.

One way of looking at the additive response is that the additives represent a fixed amount of inhibition which has been determined largely by economics. Yet different molecular structures have different rates of oxidation, solvency, thermal degradation, and anti-wear characteristics, that the net effect of adding a fixed dosage of inhibitor inevitably result in different degrees of performance. 0f course, the additive package itself and/or the treat level can be adjusted to compensate for the different responses. At the current state of art, this adjustment is most often accomplished through trial and error using the engine sequence tests. This lack of basic understanding between base oil structures, additive structures, and the mechanism of their interactions is substantially impeding technological advances in lubrication.

\section{Thermal Stability}

Thermal stability refers to the degradation of hydrocarbon molecules in the absence of oxygen. The most common mechanism is carbon-carbon bond breakage under high temperatures. In heavy duty engines such as the engines used in tractors, trailers, and earth moving equipment, temperatures at the piston ring zone often reach $350-400{ }^{\circ} \mathrm{C}$ [15]. Under these conditions, the thermal stability of the oil becomes an important parameter. Information obtained from used oil analysis indicates that the concentration of nitrates and nitrites in the used oils is sometimes twice that of carbonyl compounds. It might be speculated that because of the high temperatures, the oxidation reaction rate is extremely fast. 0xygen is quickly depleted and the nitrogen in the presence of acidic components from the blowby gases $\left(\mathrm{SO}_{3}, \mathrm{SO}_{2}, \mathrm{H}_{2} \mathrm{O}, \mathrm{CO}_{2}\right.$, etc.) reacts with the oil to form nitro and nitroso compounds. The overall stability of the lubricant depends on both oxidative and thermal stability. In the absence of oxygen, linear alkyl paraffins is the most unstable, followed by cycloparaffins and aromatics. The thermal decomposition temperatures for these structures are approximately $316{ }^{\circ} \mathrm{C}\left(600^{\circ} \mathrm{F}\right)$ for straight paraffins, $427{ }^{\circ} \mathrm{C}\left(800{ }^{\circ} \mathrm{F}\right)$ for cycloparaffins and over $530^{\circ} \mathrm{C}\left(1000{ }^{\circ} \mathrm{F}\right)$ for aromatics [2]. In the presence of oxygen, the aromatics become unstable due to the ease of substitution reactions involving the aromatic hydrogen. Sulfur compounds in the base oil also appear to have a profound effect on thermal stability. High sulfur base oils, however, are almost always associated with high levels of aromatics (20-30 percent by weight), and it is unclear at the present time whether this thermal instability is actually due to the sulfur and/or the aromatics. Table 5 illustrates this situation by the use of thermal decomposition data generated with the hot tube test. In table 5 , oil $E$ is a hydrotreated base oil having the same viscosity as oil F. $0 i 1 \mathrm{~F}$ is a solvent extracted high sulfur base oil. The Hot Tube test is a bench test which simulates the ring zone conditions of a diesel engine. The same commercial additive package is added to both oils, and the difference in deposit ratings is dramatic. However, identification of which specific parameter is responsible for this difference is difficult to ascertain. Possibilities include sulfur compounds, degree of saturation, aromatic/paraffin ratio, or a combination of these factors.

Table 5. High temperature stability as a function of base stock composition.

Aromatics, wt. percent

Paraffins, wt. percent

Saturated HC, wt. percent Sulfur, ppm

Hot Tube, $495^{\circ} \mathrm{F}$ at $16 \mathrm{~h}$

$(0-10,10=$ clean $)$

$\begin{array}{rrr}\frac{0 i 1}{5} & & \frac{0 i 1 F}{24} \\ 25 & & 26 \\ & & 75 \\ 35 & & 75 \\ 300 & & 9000\end{array}$

0.5

5.0 


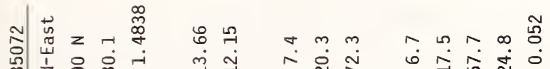

员觅

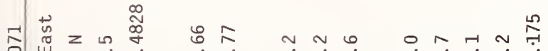

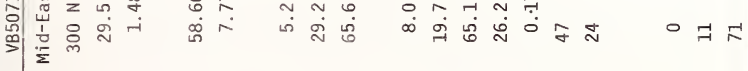

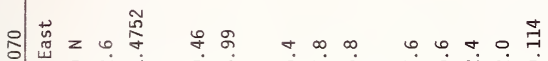

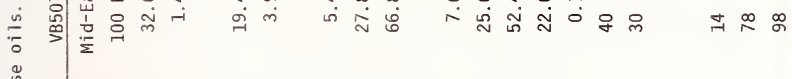

疍

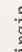

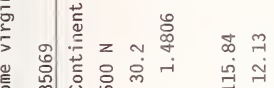

苛芹

每

告

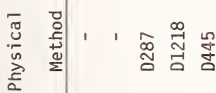

ने ने ष क न

\& $\dot{\sigma}$ लं

$m \stackrel{\infty}{N}$

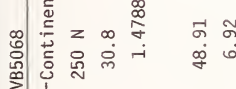

范

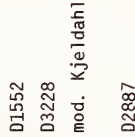

$\sim+\approx$

क ज

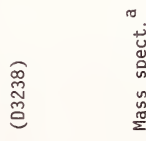

$\underset{0}{\infty}$

$\frac{\infty}{\frac{\pi}{2}}$

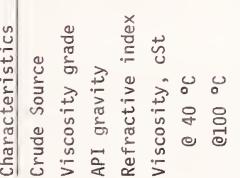

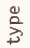

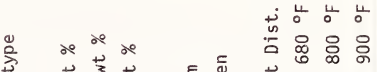

ज

으

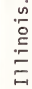

$\frac{\frac{0}{2}}{\frac{\pi}{2}}$

ᄃำ

索

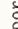




\section{Low Temperature Fluidity}

The low temperature fluidity is resistance of an oil to flow at low temperature, i.e., below $\sim-12{ }^{\circ} \mathrm{C}\left(+10^{\circ} \mathrm{F}\right)$, and is directly related to the wax content and amount of 1 inear alkyl paraffins and their molecular weights. In a new oil, this property can be modified and controlled by the addition of pour depressants. In service, the oxidation stability of the oil as well as the tendencies of the oil to polymerize and to form oil insoluble products all affect the low temperature fluidity of the oil.

\section{9. $0 i 1$ Consumption}

0 il consumption is oil "loss" during service, primarily due to volatility and molecular decomposition. $0 i 1$ consumption in an automotive engine can be related to the base stock volatility, the viscosities at engine operating temperatures $121-177{ }^{\circ} \mathrm{C}\left(250{ }^{\circ} \mathrm{F}\right.$ to $\left.350{ }^{\circ} \mathrm{F}\right)$, as well as to the engine build-up tolerance between the valve guides and the valve stems. Both the viscosity and volatility can be related to the molecular weight distribution or boiling point distribution of the base stocks. Generally, the total percentage of base stocks that boil between $343-399^{\circ} \mathrm{C}\left(650-750^{\circ} \mathrm{F}\right)$ determines the base stock volatility, and therefore the oil consumption. 0xidation stability of the base stocks also often affects oil consumption. If a base stock oxidizes rapidly, the molecular weight distribution, and therefore the viscosity, changes accordingly. Upon oxidation, most base stocks break down to smaller molecules, resulting in increased oil consumption.

\section{Methods of Characterization}

Characterization methods can be classified into two categories.: measurement of physical properties and measurement of chemical properties. Most of the test methods are ASTM standard procedures and have been used by the petroleum industry for a long time. The test methods are periodically updated and revised by ASTM.

\subsection{Physical properties}

The important tests for physical properties of a lubricating base oil consist of the following:

Viscosity at $40{ }^{\circ} \mathrm{C}$
Viscosity at $100{ }^{\circ} \mathrm{C}$
Gravity
Color
Pour point
Boiling point distribution
Flash point
Refractive index
Cloud point
Viscosity index

\author{
ASTM D-445 \\ ASTM D-445 \\ ASTM D-287 \\ ASTM D-1500 \\ ASTM D-97 \\ ASTM D-2887 \\ ASTM D-92, D-56, D-93 \\ ASTM D-1218 \\ ASTM D-2500 \\ ASTM D-2270
}

Traditionally, viscosities, viscosity index, color, and flash point are used in refineries for quality control, particularly the viscosity index. Viscosity index is an arbitrary scale measuring the change of viscosity with temperature. The scale is based on comparing an oil to a standard paraffinic oil whose assigned viscosity index (VI) is 100 , and to a standard naphthenic oil which has a VI of zero. In a way, the VI reflects the amount of paraffins in an oil. Before the advent of solvent extraction process in lube oil manufacturing which removes aromatics selectively, the amount of paraffins in a base oil was accepted as an indicator of quality for wear protection and lubrication. The VI also reflects the severity of modern day refinery processes. Generally the VI is targeted between 90 and 110, depending on the viscosity grade.

The significance of these tests relating to performance is not fully discussed in the various ASTM procedures. Generally, the test measures an average properties of many molecular species. Correlation between these physical properties and base oil performance characteristics have often not been demonstrated. 
These physical parameters have been found to correlate with some chemical structural information. Van Nes and Van Westen [1] cataloged various correlations between viscosities and molecular weight, refractive index and molecular structures, and developed the so-called $n-d-m$ method. The $n-d-m$ method correlates refractive index ( $n$ ), density (d), and molecular weight $(\mathrm{m})$, with percent carbon atoms in paraffinic, naphthenic and aromatic structures. Since these parameters can be easily measured, the method represents a convenient way to gather structural type information at low cost.

\subsection{Chemical properties}

There are many tests commonly used to measure the chemical characteristics of a lubricating base oil. Some of these are listed below:

$\begin{array}{ll}\text { Ash } & \text { ASTM D-482 } \\ \text { Sulfated ash } & \text { ASTM D-874 } \\ \text { Carbon residue } & \text { ASTM D-189, D-524 } \\ \text { Total acid number } & \text { ASTM D-664, D-974 } \\ \text { Sulfur } & \text { ASTM D-129, D-1552, D-2622 } \\ \text { Nitrogen } & \text { ASTM D-3228 } \\ \text { Chlorine } & \text { ASTM D-808, D-1317 } \\ \text { Water } & \text { ASTM D-1744, D-95 } \\ \text { Metals } & \text { ASTM D-811, Atomic absorption } \\ \text { Composition analysis } & \text { Spectrophotometry } \\ & \text { ASTM D-2007, D-2549, D-3238 }\end{array}$

Ash content of an oil refers to the content of metals and other inorganics remaining from an oil after combustion. Some metals like lead and magnesium can be lost during the combustion process due to the low boiling points of their oxides. Sulfuric acid can be added to convert the oxide to sulfates. This is then called sulfated ash. The carbon residue basically reflects the asphaltene content in the base oil. The acid number indicates the amount cf acidic species in an oil which could be important in oxidation stability and corrosion. The sulfur and nitrogen contents of a lubricating base oil provides an approximate indication of the number of molecules containing sulfur and nitrogen atoms. Depending on their molecular weight and molecular structures, they could exert different influences on oxidation stability and additive response. Chlorine and/or other halogens usually are not found in virgin base oils, but have been found in some re-refined oils. Its effect on performance is not clear at this time. Metals such as iron, zinc, calcium, magnesium, and lead are important indicators in the case of re-refined oils. The metal level reflects the completeness of the re-refining processes in removing residual additive metals and wear metals in the used oil.

\section{Results and Discussion}

Various physical property and chemical property tests were conducted on a number of re-refined and virgin base oils. Seven re-refined base oils were purchased from various re-refiners throughout the country in ten drum lots. After detailed characterization, these oils could serve as reference materials for testing by various organizations and laboratories interested in examining re-refined oils. Some data were obtained from Amoco Chemicals Corporation and some data from commercial labs. Differential scanning calorimetry $[16,17]$ and the Ford free radical titration test [18] were run on these oils by other technical divisions inside NBS. These physical and chemical data were initially collected in an attempt to look at their correlation with base oil oxidation stability as defined by the RBOT, DSC, and Ford titration tests.

In addition to the analyses on re-refined base oils, five virgin base oils of various viscosity grades were also analyzed. The data on these virgin oils is shown in table 6 . It would be noted that in some cases (e.g., the values of percent aromatic carbon between the $n-d-m$ method and low resolution mass spectrometry for the same oil) considerable variations in test results exist. This supports our view that the test procedures and test precision need to be firmly established experimentally before detailed characterization and correlation can proceed. For the virgin base oils, there also appears to be a wide range in some of the characteristics; e.g., sulfur varies from 0.034 to 0.175 percent, and aromatics from 11 percent to 26 percent. 
Table 7 shows the physical property data of the seven re-refined base oils. The indicated viscosities measured at $40^{\circ} \mathrm{C}$ show that these oils represent a range of viscosity grades. The boiling point distribution data indicate that these oils have a relatively small amount of volatile light ends (percent off at $680^{\circ} \mathrm{F}$ ). Both the refractive index and the density data suggest that these oils are very similar and uniform in their major components.

The chemical properties of the re-refined oils are presented in table 8 and their hydrocarbon type analys is data are shown in table 9 . Chemical property tests such as carbon residue, aniline point, carbon, hydrogen, and oxygen analysis all show substantial uniformity with a very narrow range among the seven re-refined base oils including oils manufactured by different processes and from different geographic areas of the country. Chemical composition analyses (i.e., hydrocarbon type analyses) also indicate the same trend, e.g., aromatics range from 19.3 percent to 22.5 percent saturates range from 73.9 percent to 77.6 percent. Even the type of hydrogen distribution by nuclear magnetic resonance (NMR) analysis of four oils sugest remarkable similarities. However, variations do exist in trace contaminant levels. This is demonstrated in the concentrations of chlorine (14 to $195 \mathrm{ppm})$, zinc $(<0.2$ to $37.9 \mathrm{ppm})$, and in the total acid number $(0.076$ to $0.81 \mathrm{mg} \mathrm{KOH})$. However, these levels are generally relatively low, and the significance of the presence of these trace compounds in a lubricating base oil needs to be determined with relation to oxidation stability.

Oxidation stability tests were run on these seven re-refined base oils and the data are shown in table 10. Three tests were conducted: the Rotary Bomb 0xidation Test (RBOT, ASTM D-2272), Ford free radical titration test, and Differential Scanning Calorimetry. The RBOT measures the time it takes the oil to absorb/react with 25 psia of oxygen in the presence of copper and water at $150{ }^{\circ} \mathrm{C}$. Usually the test is run with an additive or an additive package and it measures the oxidation and hydrolytic stability of turbine oils. The Ford Free radical titration test measures the ability of an oil to neutralize free radicals artificially released by a chemical at $60^{\circ} \mathrm{C}$. The results are expressed in molar concentration of anti-oxidant capacity. The test result reflects the amount of total anti-oxidant contributed both by additive and by naturally occurring molecules in the oil. The Differential Scanning Calorimetry test measures the oxidation onset temperatures of a small droplet of oil sample in a calorimeter under a high flow rate oxygen atmosphere. The RBOT result suggests that there are considerable variations in oxidation stability among the oils, from $27 \mathrm{~min}$ to $71 \mathrm{~min}$. However, it is generally recognized that RBOT test which are run without additive or additive package is less precise and reflects the initial oxidation rate under solid metal catalysis. It is also difficult to distinguish between oxidation stability and hydrolytic stability in this test. The free radical titration test data suggests the most stable oil to be RB007 and the least stable oil to be RB0059. In the DSC procedure, the trend of the data agree with the RBCT results. In our preliminary attempts to correlate the physical and chemical property data with these oxidation tests, there appears to be some correlation between the free radical titration data and the sulfur content of the oil. However, more data will be required to confirm this observation.

\section{Summary}

The requirements of a lubricating base oil are varied, and the ability to characterize base oils through their physical and chemical properties is felt to be important (along with appropriate engine testing) both in the acceptance of re-refined oils, as well as in evaluating virgin oils. In this paper, seven re-refined base oils have been characterized in detail and do not appear to be significantly different from virgin base oils. Further, the re-refined oils appear to be remarkably uniform in composition and characteristics. Trace contaminant levels are generally low but appear to reflect significant variations among the seven oils. Three bench oxidation tests were applied to these re-refined oils, and the results suggest relatively small variations in stability. Contaminants which appear to be potentially important include chlorine and polar components. Information of the molecular structure of sulfur, nitrogen and oxygen compounds would be helpful in any correlation studies. More study will be required to confirm and expand these initial observations. Further, any test procedure utilized for such data gathering and correlation studies must be evaluated experimentally with regard to its accuracy and precision. 


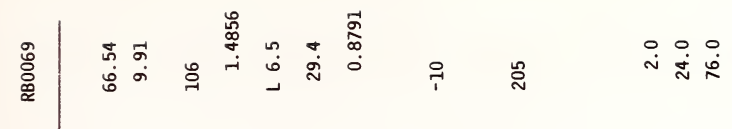

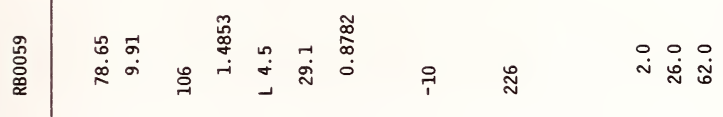

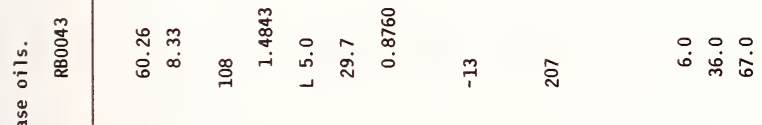



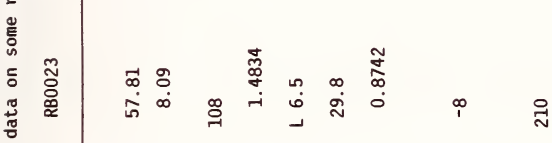

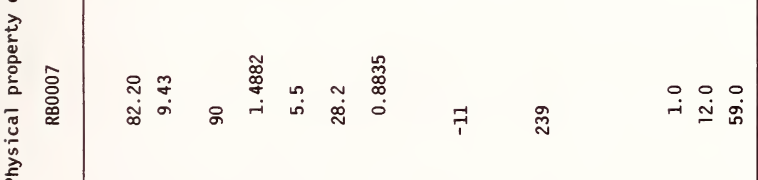

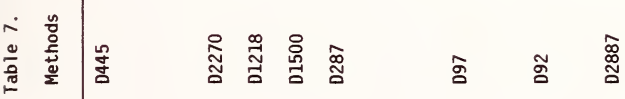

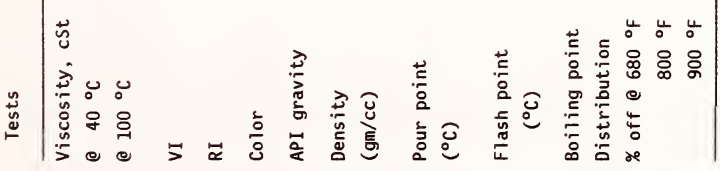




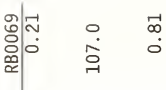

भึู๊

ก่

ํ.

অ్ำ

+
$\stackrel{्}{0}$

$\stackrel{\infty}{\sim} \quad \stackrel{\sim}{0}$

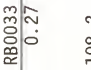

등

$\frac{\pi}{2}$

政

ㅇํㅇ

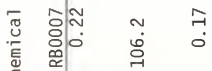



ฟN

กับับ

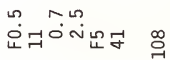

ำำ

மயํำ

ఫ్రి

$\frac{\pi}{2}$

$\sum_{\frac{1}{<}}^{山}$

站

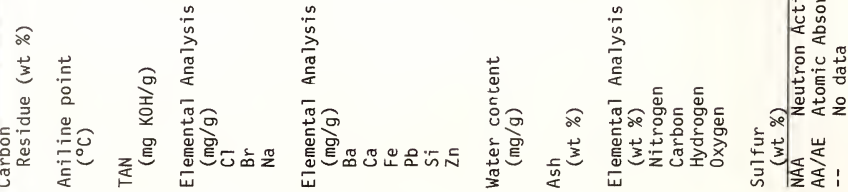

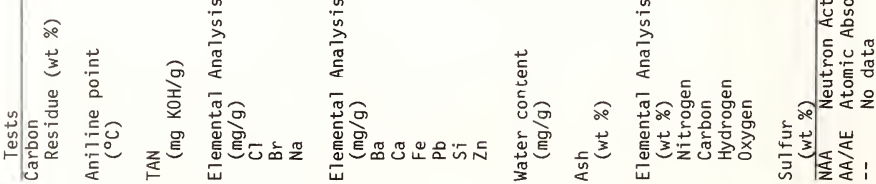

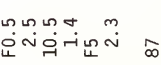

동

ஜ

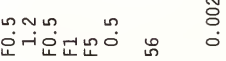

ปิ
O
0

్ㅗㅇ

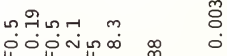

ஓ̊

$\infty$
0
0

농

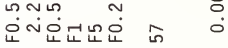

ㅎํㅇ్ㅇㅇㅛ

○மल्नं०

吉苟年

○ंल्नं०

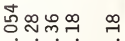

○ंल्निं

덩대유 궁

○ंग्नं०

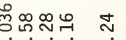
ळंர्नं०

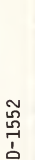

트

N.U

宅

등

$\therefore$ 듬

空

$\rightarrow 20$

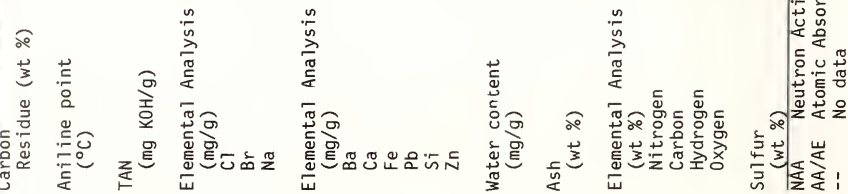




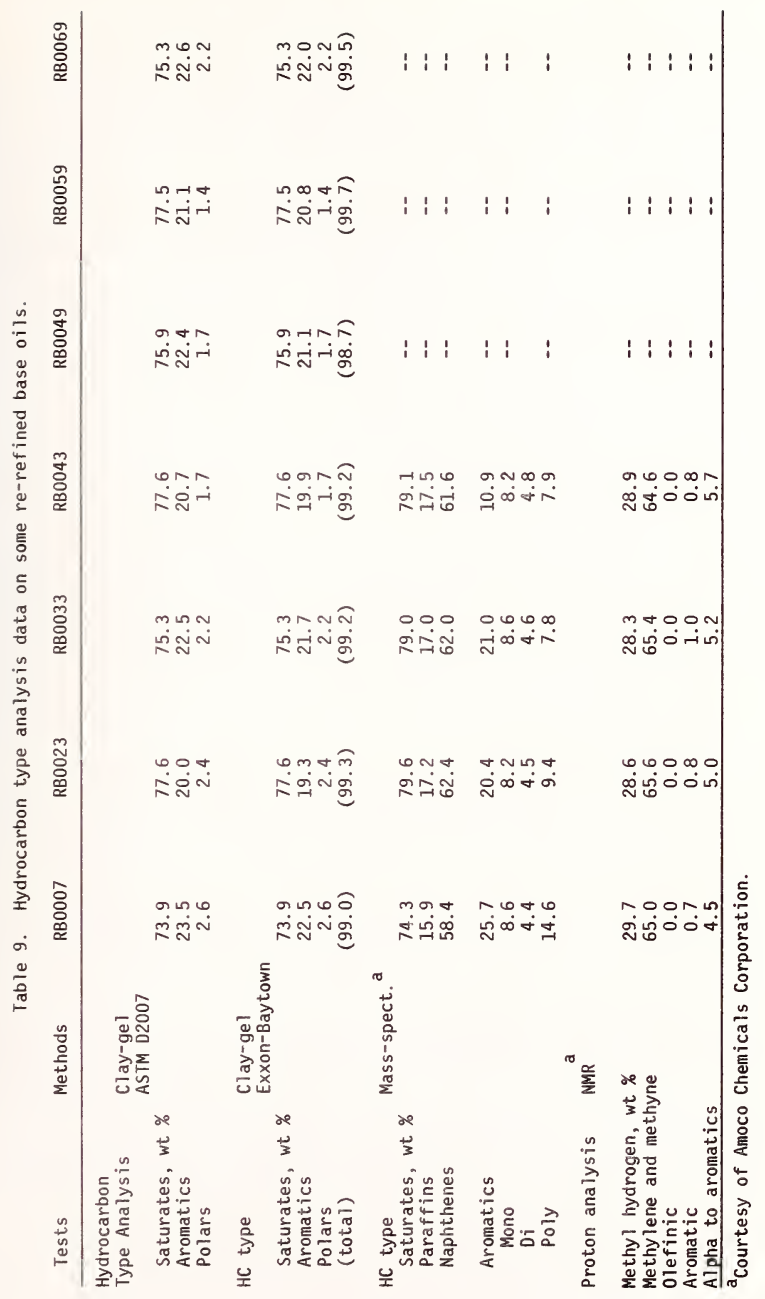




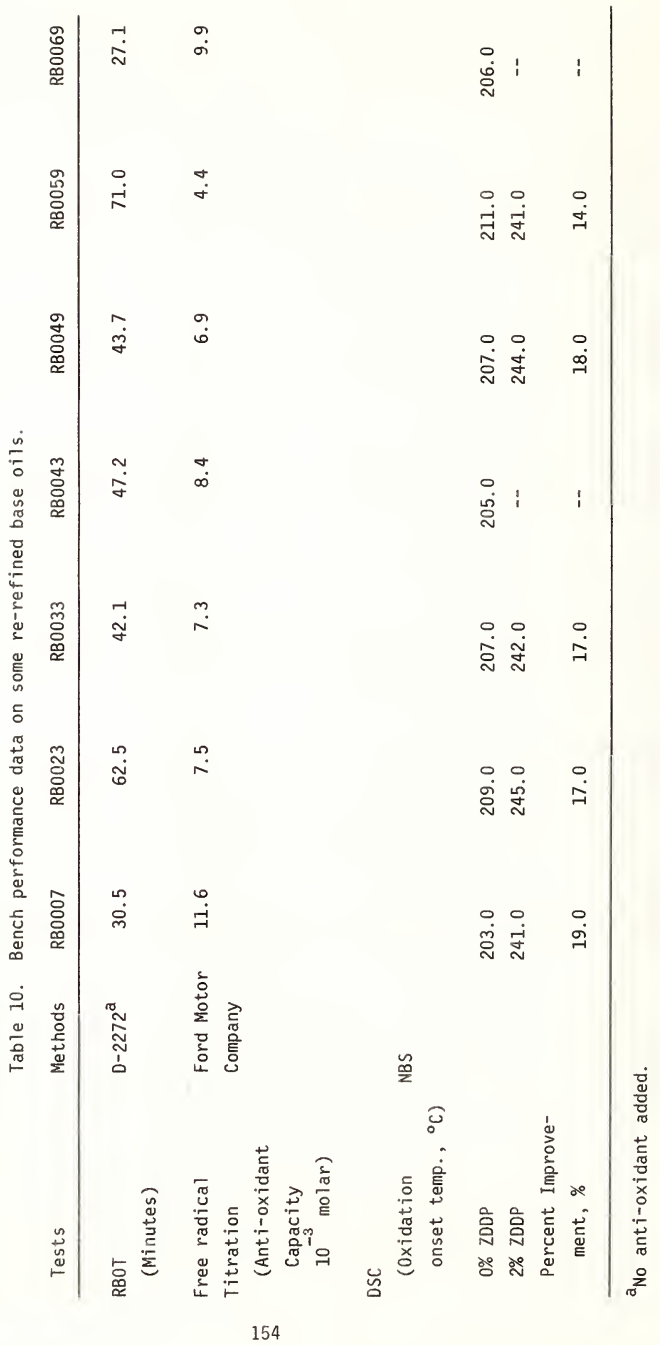


[1] Van Nes, K. and Van Westen, H. A., Aspects of the Constitution of Mineral 0ils, Elsevier Publishing Co., Amsterdam (1951).

[2] Bondi, A., Physical Chemistry of Lubricating 0ils, Reinhold Publishing Corp., New York, New York (1951).

[3] American Petroleum Institute Research Project 6 report, API, Washington, D.C. 20037.

[4] Denison Jr., G. H., Oxidation of lubricating oils. Effect of natural sulfur compounds and of peroxides, I.\&E.C., 36, 5, 477 (1944).

[5] Denison Jr., G. H. and Condit, P. C., Oxidation of lubricating oils. Mechanism of sulfur inhibition, I.\&E.C., 37, 11, 1102 (1945).

[6] Vesely, V., Resistance of lubricating oils to oxidation, Fachber Oberflaechentech, 12, 43 (1974).

[7] Von Fuchs, G. H. and Diamond, H., Oxidation characteristics of lubricating oils. Relationship between stability and chemical composition, I.\&E. C., 34, 927 (1942).

[8] Asseff, P. A., Current crankcase lubricants, Lubrication Engineering, 107 (March, 1967).

[9] Watson, R. W., Petroleum additives - the role of al kyl groups, Proceedings of Joint ASLE/JSLE Lubrication Conference, Tokyo, Japan (1975).

[10] Vesely, V., Relationship between the composition of lubricating oils and their oxidation stability, Ropa a Uhlie, 11, 297 (1969).

[11] Korcek, S. and Jensen, R. K., Relation between base oil composition and oxidation stability at increased temperatures, ASLE Trans., 19, 83 (1976).

[12] Burn, A. J. and Greig, G., Optimum aromaticity in lubricating oil oxidation, J. Inst. of Petroleum, $\underline{58}, 346$ (1972).

[13] Hsu, S. M. , Review of laboratory bench tests in assessing the performance of automotive crankcase oils, to be published in Lubrication Engineering.

[14] Hsu, S. M., Anti-wear and lubricity additives for lubricants, NBS SP. 487, Nat1. Bur. Stand., Washington, D.C. 20234, 1977.

[15] Wing, R. D. and Saunders, 0., 0 il film temperature and thickness measurements on the piston rings of a diesel engine, Proc. Inst. Mech. Engr., 186, 1 (1972).

[16] Cranton, G. E., Composition and oxidation of petroleum fractions, Thermochimica Acta, 14, 201 (1976).

[17] Tsang, W. and Walker, J., Application of differential scanning calorimetry to the characterization of lub oils, Proceedings on Measurements and Standards for Recycled 0 i1/Systems Performance and Durability, NBS SP 584, U.S. Department of Commerce, Washington, D.C., 1980.

[18] Mahoney, L. R., Korcek, S., Hoffman, S., and Willermet, P., The determination of the anti-oxidant capacity of new and used lubricants; method and applications, I.\&E.C.

Product R \& D, 17, 250 (1978). 

Session 4

OIL ANALYSIS FOR ENGINE CONDITION MONITORING 

National Bureau of Standards Special Publication 584. Proceedings of Joint Conference on Measurements and Standards for Recycled 0i1/Systems Performance and Durability held at NBS, Gaithersburg, MD, October 23-26, 1979. (Issued Nov. 1980)

\title{
WEAR PARTICLE EQUILIBRIUM MEASUREMENTS AND THEIR SIGNIFICANCE
}

\author{
R. D. Driver and E. R. Bowen
}

\author{
Foxboro Analytical \\ Burlington Center \\ 78 Blanchard Road \\ P. 0 . Box 435 \\ Burlington, MA 01803
}

Ferrography is a technique for isolating wear particle debris from lubricating and hydraulic oils, the presence of which carry with them a history of the wear processes in the machine $[1,2]^{1}$. Thus, the technique has fundamental applications in machine condition monitoring and failure prevention. The wear particles are significant in the metal types that are present in the particle distribution as an indication of the wearing machine components and in the particle size distribution and morphology which indicates the severity of wear in the system. In this paper, we shall discuss the fundamental principles which describe the working of the ferrograph, concentrating on the working of the on-line ferrograph. We shall also discuss the significance of equilibrium particle concentration in the oil system and its measurement using the ferrograph [3].

There are ferrographic instruments which provide both quantitative and qualitative information. The analytical ferrograph is a laboratory instrument which is used when a permanent record, a ferrogram, of the precipitated particles is desired [4]. Metallurgical and microscopy techniques may be used on the ferrogram to obtain a wealth of information on the wear state within a machine $[5,6]$. With this instrument, the techniques of magnetic precipitation have been extended to the precipitation of paramagnetic particles. Further, with the development of magnetic fluids, many nonmagnetic particles have been precipitated using the ferrographic technique. This has had important applications in the precipitation and separation of biological particles [7]. A second type of ferrograph in use is the direct reading ferrograph [8]. This is a self-contained unit with an optical measurement of particle density for large and small particles; large particles being those approximately $5 \mu \mathrm{m}$ or greater, and small particles being approximately $2 \mu \mathrm{m}$ or less.

The direct reading ferrograph is used as an early warning device to indicate that a more detailed investigation should be made with the analytical ferrograph. Another quantitative instrument is the on-line ferrograph. It is similar in its magnetic design to the analytical and direct reading ferrograph, but is an instrument which monitors particle wear in a purely on-line mode. This is the instrument that has been used to study particle equilibrium as described in this paper.

A photograph of the on-line ferrograph is shown in figure 1 . The machine-mounted sensor on the left contains the magnetic precipitation device and wear debris sensors. The wear debris at two different locations within the magnetic field is measured with capacitance sensors. The wear analyzer shown on the right of the photograph contains the electronics package and display which can be located up to 75 feet from the sensor. The instrument is a cyclical device which operates automatically. The time required to make the measurement varies from $30 \mathrm{~s}$ to $30 \mathrm{~min}$, depending on the concentration of debris in the fluid. At the end of each cycle, particles are cleaned from the substrate by flushing. The instrument is a linear device, since it is the fluid volume required for a set amount of wear debris to be precipitated which is measured, thus effectively removing any nonlinear response characteristics of the magnetic precipitation technique. Two measurements related to the wear mode in the system are available to the operator; the total amount of wear debris in the system per unit volume in ppm, and the percentage of large particles.

IFigures in brackets indicate the literature references at the end of this paper. 


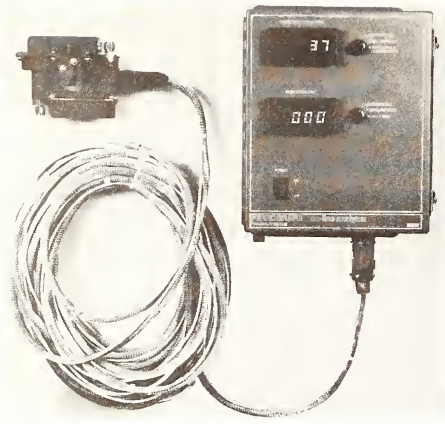

Figure 1. The on-line ferrograph sensor.

A schematic diagram showing the magnetic precipitation cell is presented in figure 2 . $0 i l$ containing the suspended magnetic particles is constrained to move along the substrate surface. The magnetic field configuration produces a force on the particles towards the substrate, with the result that large particles are precipitated near the entrance while the smaller particles are precipitated further down the substrate.

To discuss the physical principles underlying ferrography in more detail, it is instructive to consider the trajectory of a particle in the fluid as is shown schematically in figure 3 .

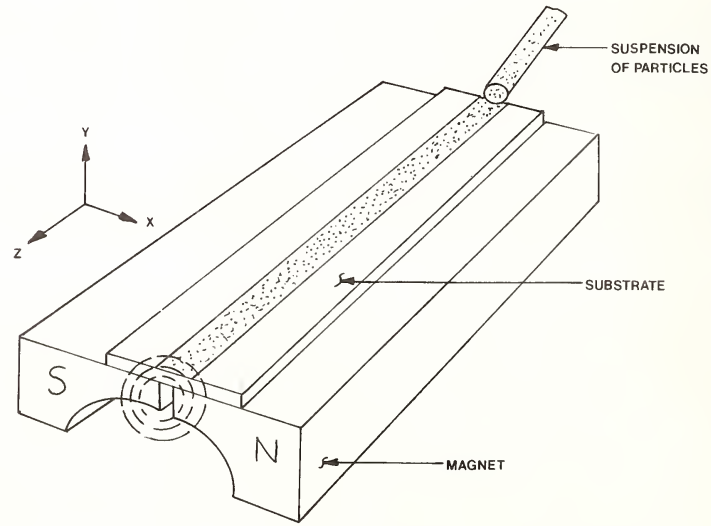

Figure 2. Schematic diagram of the magnetic precipitation cell. 


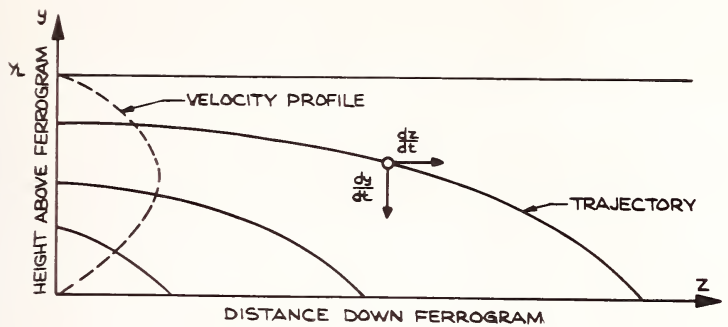

Figure 3. Schematic diagram of the fluid flow above the substrate showing the trajectory of a typical particle.

The point of precipitation of the particle on the substrate will depend on the point of entry of the particles in the fluid stream and the equations of motion which connect the velocity components. The motion of the particles in the $z$ direction is the local velocity of the fluid at a height $y$. On the assumption that the fluid flow rate is an inverse function of viscosity $\eta$, we may write,

$$
\frac{d z}{d t}(y, \eta)=\frac{g(y)}{\eta}
$$

where $g(y)$ is a geometric factor independent on the physical configuration of the fluid flow, but independent of the viscosity.

In the $y$ direction, the motion of the particle is determined by the Stokes velocity caused by the movement of the particle in the liquid under the influence of the magnetic force.

$$
6 \pi \eta \frac{d y}{d t}=\frac{2}{3} \pi a^{3} \mu H \frac{\partial H}{\partial y}
$$

where $\mu$ is the magnetic permeability of a spherical particle of radius a and the force on the particle is the standard result for a ferromagnetic particle in a high field gradient.

A differential equation for the particle connecting the $y$ and $z$ motion, independent of time, may be obtained.

$$
g(y) \frac{d y}{d z}=\frac{\pi a^{2}}{9} \mu H \frac{\partial H}{\partial y}
$$

The exact solution of this equation requires a knowledge of the $y$ dependence of $g(y)$ and the magnetic force. An extremely important property may be seen without solving the equation explicitly; namely, that the motion of the particle in the fluid is independent of viscosity.

In the case of the on-line ferrograph, we may obtain a relationship connecting the furthest distance down the substrate $Z_{L}$ that a particle of radius a will travel, namely,

$$
Z_{L}(a) \propto \frac{Y_{L}{ }^{3}}{a^{2}}
$$

where $Y_{L}$ is the thickness of the liquid layer, and the relationship does not depend on fluid viscosity. 
Another property of the ferrograph which may be deduced from the equations is that as long as the particles are randomly distributed in the fluid, and if the magnetic force on the particles is independent of the height of the particles in the fluid, the density of precipitated particles of a given radius on the substrate will be absolutely constant up to the cutoff $Z_{L}(a)$. The consequence of this is shown in figure 4 for two particle sets, one set being twice the radius of the other.

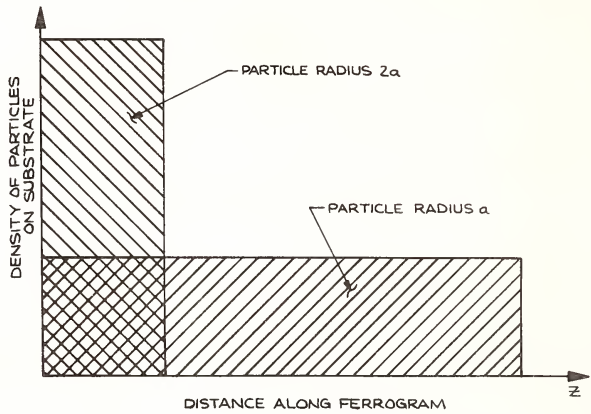

Figure 4. Idealized diagram showing the density of precipitated particles on the substrate for two different particle radii.

Now we wish to discuss the importance of the particle debris measurement and its correct interpretation in the diagnoses of the wear mode of a machine [3]. In any oil system, we may consider there to be an active element which is generating particles at some rate, $\alpha$ particles $/ \mathrm{cm}^{3} / \mathrm{s}$ for a particle radius a. The particle generation process will be one of the many wear modes that can occur in a machine. The machine will normally have a sump, an oil circulation pump, and a filter. Assume that the loss mechanism of the particles removes a fraction $\beta$ of the particle per second. A simple equation may be written connecting the rate of change of the number of particles in either of the constants $\alpha, \beta$.

$$
\frac{\mathrm{dn}(\mathrm{t})}{\mathrm{dt}}=\alpha-\beta \mathrm{n}(\mathrm{t})
$$

The loss mechanisms of the particles are generally due to filtration, settling, magnetic separation, impaction on inertial separation, and chemical dissolution in the oil. These processes can all be described by the above equation. A further mechanism may be due to the breaking up of particles of some other radius $b$ which would require an additional term of the form $\gamma \frac{\mathrm{dn}(\mathrm{b})}{\mathrm{dt}}$. However, this is not deemed to be a significant loss mechanism and is ignored. Assuming for the moment no time dependence to the constants $\alpha$ and $\beta$ we obtain a general solution for the equation of

$$
n(t)=\frac{\alpha}{\beta}\left(1-e^{-\beta t}\right)
$$

It is very important to note that the constants $\alpha$ and $\beta$ are strong functions of particle size, particularly in the influence of filters on the constant $\beta$.

Equation (6) describes the return to an equilibrium of the particle count after a change of oil in the system. The time constant to come to an equilibrium is determined exclusively by the constant $\beta$ with $1 / \beta$ being the $1 / \mathrm{e}$ time of the system. After a sufficiently long time has elapsed, the equilibrium value of the ratio $\alpha / \beta$ will be reached for the particle count. Thus, the equilibrium particle count is directly proportional to the rate of particle production $\alpha$ with any change in $\alpha$ being measurable only after a time constant of the order of $1 / \beta$. Some curves demonstrating this dependence are given in figure 5 . 


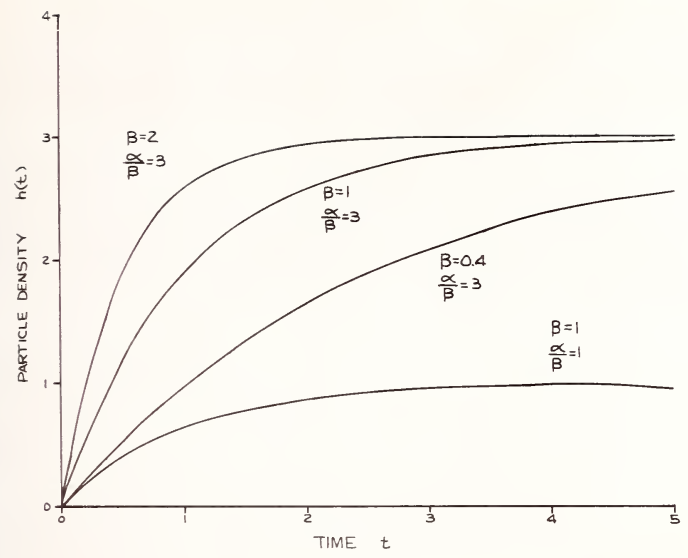

Figure 5. The tendency to equilibrium of the particle count for different values of the constants $\beta$ and $\alpha / \beta$.

It is an empirical fact that, for the most deleterious wear modes, the rate of production of large particles increases at a faster rate than for small particles as engine wear increases. Thus, the percentage of large particle readings on the on-line ferrograph is an important number in the interpretation of condition monitoring. Further, since the time constant for loss of particles is less for the large particles, they are a faster and more sensitive indication of a change in wear.

We have operated the on-line ferrograph on a test rig to monitor its ability to follow particle history in a system and test some of our basic assumptions of the particle equilibrium model. We built a test rig consisting of a 20 litre volume with a circulation pump operating at a flow rate of $20 \mathrm{l} / \mathrm{min}$. The rig has minimal dead space and no filter. Due to its configuration, the rig has a negligible rate of generation of particles, and the rate of loss of particles, mainly due to particle settling, will be long. Test particles are introduced into the system and their history followed with the on-line ferrograph. The rate of loss of particles of a given size should be given simply by the equation

$$
n=n_{0} e^{-\beta t}
$$

A plot of the decay of the total particle count in the system on a log-linear scale is shown in figure 6 . The slope of the line gives an average decay constant $\beta$. In figure 7 , we plot some data for the decrease in density of large and small particles, with time demonstrating the quite different rates of decrease on the particles. There is a slight nonlinear behavior to the data in all of these graphs, demonstrating some deviation to the dependence predicted by eq. (7). This equation is valid for a single particle size range. The experimental data, however, is the average over a finite particle size distribution. Such a weighted average of decaying exponentials with different decay constants $\beta$ will give a dependence as shown by the experimental data. The pursuit of this dependence is beyond the scope of this paper and before more sophisticated data handling techniques are attempted, much more experimental data must be taken. 
[1] Anderson, D. P., Ferrographic analysis for hydraulic fluids, topics on contamination in hydraulic systems, SP-447 (Society of Automotive Engineers, October, 1979).

[2] Bowen, E. R., Scott, D., Seifert, W. W., and Westcott, V. C., Ferrography, Tribology International, $\underline{9}, 109$ (1976).

[3] Anderson, D. P. and Driver, R. D., Equilibrium particle concentration in engine oil, Wear, 56, 415 (1979).

[4] Hofman, M. V. and Johnson, J. H., The development of ferrography as a laboratory wear measurement method for the study of engine operating conditions on diesel engine wear, Wear, 44, 183 (1977).

[5] Scott, D., Seifert, W. W., and Westcott, V. C., The particles of wear, Scientific American, 88 (May, 1974).

[6] Barwel1, F. T., Bowen, E. R., Bowen, J. P., and Westcott, V. C., The use of temper colors in ferrography, Wear, $\underline{44}, 163$ (1977).

[7] Means, D. C., Hanley, E. N., Rutkowski, R., and Westcott, V. C., Ferrographic analys is of wear particles in arthroplastic joints, Journal of Biomedical Materials Research, 12,867 (1978).

[8] Anderson, D. P. and Silva, R. S., The direct reading ferrograph - design, calibration, and a field application, Lubrication Engineering, 35, [4], 203 (1979). 

National Bureau of Standards Special Publication 584. Proceedings of Joint Conference on Measurements and Standards for Recycled 0il/Systems Performance and Durability held at NBS, Gaithersburg, MD, October 23-26, 1979. (Issued Nov. 1980)

\title{
USED OIL ANALYSIS: PAST, PRESENT AND FUTURE
}

\author{
Charles F. Schwarz
}

1025 Cromwe11 Bridge Road

Martel Laboratories, Inc.

Baltimore, MD 21204

\section{Introduction}

Engine oil analysis as a tool to monitor internal combustion engine conditions had its modest beginning over fifty years ago, and has since grown to be used worldwide. It is now recognized as a cost saving and effective method of preventive maintenance.

Commercial utilization of used oil analysis commenced in 1927 when a series of oil tests was offered to fleet operators. Engine oils of this era were basically a cut from a barrel of crude with little or no additive treatment so that oil drains were recommended every 500 to 1000 miles. Many people believed the principal purpose of oil analys is was to determine the condition of the crankcase oil and when it should be changed, and they used the service for this purpose.

However, in the days of low-cost oil, many fleet maintenance men simply felt that it was about as cheap, or cheaper, to drain oil frequently as to pay for oil analysis. This was most likely true up to the early 1950's when oil technology permitted longer engine oil drain recommendations by engine manufacturers.

"0il analysis" as it is known today is a generalized term referring to an analytical process initiated by the Denver and Rio Grand Railroad in the late 1940's and adopted by the U.S. Navy in the $1950^{\prime}$ 's. The main reason for the development of the analytical process was similar for both the railroad and the military.

After World War II most of the railroads started to use diesel power instead of steam for the locomotives and while the cost per mile decreased drastically, the problem of wear and engine oil life reared its ugly head.

Operating over the Rockies, the D\&RG started to lose engines through excessive wear and catastrophic failures. Their test department looked around for an answer and over a period of time established a procedure utilizing new spectrographic methods. During the same period of time the U.S. Navy was losing a large number of carrier aircraft due to engine failures. They looked into the work published by the D\&RG railroad and initiated a pilot program in the early 1950 's at the Pensacola Naval Base.

In a short time a number of problems on reciprocating engines was detected by oil analysis, but as can be expected in any new procedures, many falsely indicated failures were also predicted. The number of engine failures detected, and the resultant reduction in plane ditching, led the military to initiate a Joint Tri-Service program that has now been adopted by all three services.

The military oil anlaysis program has recently been renamed JOAP for "Joint 0il Analysis Program". It consists of the former Air Force, Army and Navy programs: SOAP, AOAP and NOAP, respectively. Each program varies slightly depending on the type of equipment and geographical distribution. This was brought about by new developments in instrumentation that has resulted in the establishment of two analytical methods for routine determinations of wear, and measurement of contaminant and additive metals. These are Atomic Emission Spectrography and Atomic Absorption Spectrophotometry. Both systems are in wide use and are extremely accurate in most determinations provided that the limitations of each are recognized by the laboratories, as both methods use similar principles in achieving their analysis. 
Atomic absorption ( $A A$ ) involves aspirating a diluted solution of the oil sample into a controlled air-acetylene or nitrous oxide-acetylene flame. A lamp containing a hollow cathode constructed of a specific element is used to produce a high-intensity beam of that element's emission spectrum. The beam is split in two; one half is used as a reference, and follows an uninterrupted path to a photomultiplier detector. The other half passes through the flame before reaching the detector. The detector system thereby measures any loss of intensity of the sample beam due to its passage through the flame. Atoms of the element present in the flame will absorb light of that element's characteristic wavelengths, the absorbance being proportional to the concentration of the element in the oil. 0ils containing precise amounts of the elements of interest are used as standards. Either absorbance or concentration can be read directly on modern instruments, or fed into a teleprinter or computer.

Atomic Emission (AE) is similar to AA; however, it energizes a small oil sample with a sufficiently high voltage to cause the individual metal in the sample to emit a characteristic spectrum of ultraviolet and visible light. For each element in the oil sample, the intensity of a specific characteristic wavelength will be proportional to its concentration.

The previous description of each process is highly simplified, and each oil analysis laboratory has its own reason for selecting which method is best suited to its overall operation.

\section{Basis of Spectrometric 0il Analysis}

Spectrometric oil analysis is based on the fact that movement of metallic parts in an oil-wetted system is always accompanied by friction. Consequently, some surface metal is removed, and the microscopic particles are picked up by and are circulated with the oil. Friction is the major cause of wear particle formation, but corrosion, abrasion, scuffing, scraping and spalling are also contributors; in addition, combustion by-products become trapped in the circulating system. Therefore, the circulating oil contains valuable information concerning the system's condition.

Metal flakes or particles usually found in screens, filters or detectors are not the basis of spectrometric oil analysis. Particles of this size tend to settle out and not appear in the oil sample. Their presence is important, but detection must be left to other techniques. As a general rule, the following detection techniques are used for different particle size in micrometers.

1) Visual Screen and Filter Evaluation: 45-2000 um.

2) Chip Detectors: 10-600 um.

3) Microscope Examination or Ferrography: 4-200 um.

4) Spectrometric: 0-15 um.

To be a successful preventive maintenance tool, spectrometric oil analysis must indicate the very first stages of wear, when colloidal material is being generated. Through periodic measurements of oil samples for metal composition, a normal wear trend can be established. The metallic contents of the used oil can indicate wear, contamination and additive content.

\section{Valid Sample for Valid Results}

A good sample is vital for the success of any program. The results can be no more representative than the sample. For this reason the oil should be hot and well mixed when the sample is taken. New oil samples are important in order to characterize the oil itself. Samples should be taken at least every oil change in case of severe operating conditions or extended drain periods, and at least once between every drain. For very long drain periods, i.e. 100000 miles for over-the-road service suggested by one diesel engine builder, a sample should be taken every 20000 to 25000 miles.

This paper will only cover wear metal analysis. Many laboratories offer a variety of programs depending upon the needs of the customers. No attempt will be made to list the many and varied tests offered and it is often very difficult for a fleet superintendent to decide what program he needs. 
Common sources of elements found by spectrometric oil analysis:
ELEMENT
SOURCE
Iron ( $\mathrm{Fe})$
Silver $(\mathrm{Ag})$
Aluminum ( $A 1$ )
Chromium $(\mathrm{Cr})$
Copper (Cu)
Most common wear metal. Cylinder walls, valve guides, rocker arms, piston rings, ball and roller bearing, bearing races, spring gears, safety wire, lock washers, locking nuts, locking pins, and bolts.
Bearing cages (silver plating), puddle pumps, gear teeth, shafts, and bearings in some reciprocating engines.
Spacers, shims, washers, pistons on reciprocating engines, cases on accessories, bearing cages in planetary gear, crank- cases in reciprocating engines, and some bearing surfaces. Plating metal, replacing silver in many newer engines. Seals, bearing cages, piston rings, and cylinder walls on reciprocating engines, and coolant leaks due to chromate corrosion inhibitors. Present in the form of an alloy, either bronze or brass, there- fore usually detected in conjunction with tin for bronze alloys, and zinc for brass alloys. Main or rod bearing thrust bearings, wrist pin bushings, oil coolers, gears, valves, turbocharger bushings, washers, and coolant leaking from copper radiators.
Magnesium $(\mathrm{Mg})$ Used to save weight in aircraft engines. Cases for accessories, component housings, and water in marine equipment. Also an oil additive.
Sodium $(\mathrm{Na})$
Nickel ( $\mathrm{Ni}$ )
Coolant, grease, and seawater (in marine equipment).
Lead $(\mathrm{Pb})$
Bearing metal, valve train metal, and turbine blades.
Bearing metal (generally confirming high copper or aluminum caused by bearing wear) seals, solder, paints, and greases.
Not applicable for engines using leaded gasolines.
Silicon (Si)
$\operatorname{Tin}(\mathrm{Sn})$
Titanium ( $\mathrm{Ti}$ )
Found in most oil samples owing to airborne
in some oils, from an antifoaming additive.
Bearing metal and bushing thrust metal, wrist and piston pins, pistons, rings, oils seals and solder.
In certain types of jet aircraft engines: bearing hubs, turbine blades, and compressor discs.
Boron (B)
Barium ( $\mathrm{Ba}$ )
Molybdenum (Mo)
Seals. airborne dust, water, and coolant.
$0 i 1$ additive, grease, and water leaks.
Piston rings on some diesels, electric motors, and oil additive.
Zinc $(Z n)$
Calcium ( $\mathrm{Ca}$ )
Phosphorus (P)
Antimony ( $\mathrm{Sb}$ )
Manganese $\left(\mathrm{Mn}_{\mathrm{n}}\right.$
Brass components, $0 i l$ additive, neoprene seals, grease, and coolant.
$0 i 1$ additive, grease, and some bearings.
$0 i 1$ additive and coolant leaks.
Alloys in bearings, and in grease.
Valves, blowers, and exhaust and intake systems.

Spectrometric $0 i 1$ analysis is now recognized by all major equipment manufacturers, oil companies, commercial aircraft owners, railroads, marine equipment operators, and the military.

\section{Military Equipment}

Under contract to the Army, Martel is now operating the oil analysis laboratory at Hunter Army Airfield as an integral part of the Installation Maintenance Division, DIO, Headquarters 24th Infantry Division at Fort Stewart, Georgia. At this installation we utilize a Baird-Fluid Analysis Spectrometer, FAS-2A, approved by the military under MIL-S-83129A. This laboratory receives samples from all military installations within several hundred miles of Savannah, Georgia and includes both ground vehicle and aircraft samples. In addition to the standard wear metal analysis, this laboratory is equipped and manned to perform many other tests on fuels and lubricants for the military. 


\section{Trucking Industry}

Vehicle manufacturers offer oil analysis. More than 50 million miles of Mack engine test data bolster the MaxiGard Early Warning Engine Analysis introduced in March, 1978, by Mack Trucks, Inc., Allentown, PA. The MaxiGard service program is an outgrowth of many years of monitoring actual engine performance both in the laboratory and in fleet operation. The MaxiGard oil analysis includes both physical measurements and wear metal analysis using a Perkin-Elmer Model 603 atomic absorption spectrophometer. This method was chosen because of the precise readings and background data base information available at Mack Trucks.

The program is believed to be unique in that it is the only oil analysis program in which the engine manufacturer participates in the daily recommendations and interpretations of the results obtained in the laboratory.

A key part of the MaxiGard service is the truck enrollment form. When the first sample is received for a truck being enrolled in the MaxiGard program, the form is used to record the truck owner's name, address, phone number, the emergency contact and the name of the Mack Service Center that services the customer.

This form also gives comprehensive vehicle information, including engine model and serial number, chassis model and number, transmission and rear axle model numbers, vehicle operating location, type of truck use, mileage at time of enrollment and since last overhaul (if applicable). The oil brand name, change interval, SAE grade and the crankcase capacity are included, together with the type of coolant used. All of these items are important as they are taken into account when making recommendations to the truck owner.

It is here that the value of the vast Mack experience file, and review of the suspicious oil analysis come into play. Since the test evaluation engineers are familiar with the service condition and typical wear patterns for Mack vehicles in all types of application, they can make a very prompt, accurate diagnosis of the oil analysis results that fits into the vehicle operating conditions. For example, an oil test result that would be "suspicious" in a line-haul tractor might be normal for a truck in a severe off-highway or construction application.

\section{Private Aircraft}

The AiResearch Manufacturing Company of Arizona, a Division of the Garrett Corporation, has recently designated several laboratories as approved facilities for an $0 i 1$ analysis procedure developed by them. This analysis has been specifically designed for their TPE 331 Turboprop, TSE Turboshaft and TFE 731 Turbofan engines. This procedure includes both spectrometric analysis and filter content evaluation. The value of the spectrometric analysis has been discussed in detail and we will not dwell on the merits here except to emphasize the importance of establishing a "norm" for each engine and then looking for trends in future analyses.

\subsection{Filter content evaluation}

Coarser or more rapid wear of internal engine parts results in production of larger metallic particles which are trapped in the engine oil filter. Observation under a stereoscopic microscope of the size and shape of these particles, along with a chemical analysis to determine the elements or alloys present, can provide important information as to the source of such materials. The sampling interval is taken into consideration when deciding whether the total weight of accumulated metallic particles is normal or necessitates a resample request on inspection.

\subsection{Evaluation of analysis results}

Aircraft Maintenance \& Engineering and Flight operation personnel are kept abreast of the program through Service Information Letters (SIL) on a regular basis. Both oil samples and filters are forwarded to the laboratory for analysis and the following evaluations are generally reported.

1) The oil wear trend is normal. 
2) Increases are such that a resample is recommended in order to monitor the wear trend.

3) Increases are such that an engine inspection is recommended to find source of abnormal wear.

\section{Commercial Airlines}

Spectrometric oil analysis in commercial airlines in used in an integral part of an engine maintenance program. In addition, engine performance monitors, non-destructive tests and oil screen or filter inspections are utilized. Few engines are pulled off because of oil analysis results alone; additional monitors are generally consulted for verification.

The major pitfall in the use of oil analysis by commercial airlines or the military is basing maintenance on threshold limits of wear metals. Engine removals based on a pre-set upper limit for one or several elements are frequently found to be unnecessary. A Pratt \& Whitney JT\&D turbine, for example, may exhibit a trend of $4 \mathrm{ppm}$ of iron, while another engine of the same model may perform normally at $80 \mathrm{ppm}$. An increase in the first engine to $8 \mathrm{ppm}$ would be cause for alarm since the iron concentration had doubled. The wear metal generating trends of engines are never identical and threshholds are generally meaningless.

In summary, I would like to emphasize the importance of obtaining a "norm" for each engine regardless of its type, make or model. Many people, especially those oriented towards simplifying maintenance schedules, and many new people involved in oil analysis, keep asking for the ultimate, that is, the final threshold limit for their vehicles. This is also why it is extremely difficult for a technician to evaluate the results. Computerized programs are also being used, but without the human evaluation the many pitfalls can place the program in jeopardy.

\section{A Brief Look into the Future}

1) The price of lubricating oil will continue to increase and this, sampled with larger sump capacity, will make longer oil drains more desirable. 0 il analysis can and will play an important part in reducing operating costs as additive packages are designed to permit longer drain intervals.

2) Due to noise reduction mandated by DOT and others, the internal temperature of the engine may tend to run higher and friction and wear may become a more serious problem. Again oil analysis may be helpful.

3) More on-board oil monitoring devices will be designed and built and may one day be standard equipment on large vehicles.

4) There will be new advances in instrumentation to help identify specific alloys, so that wear debris can be more readily identified, thereby pin-pointing more accurately the location of the wear.

5) Wear metal analysis will pay a very important role in developing the data necessary for evaluating the use of re-refined oils in fleet operation.

The author would like to thank Mr. James F. McCadden, Manager, Fluid Analysis Systems, Government System Division, Baird Corporation, and Mrs. Diane M. Lawrence, Atomic Spectroscopy Products Department, Perkin-Elmer Corporation for their support in supplying information for this paper and Dr. Robert Edwards, Director of Laboratory Services, Martel Laboratories, for his contribution and review of the technical information. 





National Bureau of Standards Special Publication 584. Proceedings of Joint Conference on Measurements and Standards for Recycled $0 i 1 /$ Systems Performance and Durability held at NBS, Gaithersburg, MD, October 23-26, 1979. (Issued Nov. 1980)

\title{
WEAR PARTICLE ANALYSIS FROM GREASE LUBRICATED BEARINGS
}

\author{
William Rosenlieb \\ SKF Industries, Inc. \\ 1100 First Avenue \\ King of Prussia, PA 19406 \\ and \\ Alan S. Maciejewski \\ U.S. Naval Air Engineering Center \\ Tribology Laboratory, Code 92724 \\ Lakehurst, NJ 08733

\section{Introduction}

Previously no diagnostic method had been developed for evaluating or examining samples of used grease to determine the wear state/condition of mechanical devices, in which the grease was used as the lubricant. Such mechanical devices would include gears, cams, splines, bearings, etc. The purpose of the study discussed here was to experimentally investigate the feasibility of determining the life state of one mechanical device, ball bearings, by monitoring the grease retained wear debris. The ferrography method was used to evaluate the debris and the results compared with those obtained from the physical examination of the bearing.

The development of the technique required to reduce the grease samples to a condition where they could be examined by the ferrography method and the ferrography work was performed by the Naval Air Engineering Center (NAEC). The bearing testing, grease sampling, and examination of the bearings was performed by SKF Industries, Inc.

The program consisted of the testing of three pairs of grease lubricated bearings. The first set was run continuously to a time up 1 ife of $230 \times 10^{6}$ cycles or until a grease or bearing failure occurred before the grease samples were taken and the bearings examined. In contrast, grease samples were periodically taken for wear debris analysis throughout the testing of the second set of bearings and detailed inspection of the bearing performed following test termination. During the testing of the third set of bearings, the grease samples were taken and the bearings were inspected periodically.

\section{Test Equipment and Procedures}

\subsection{Test machine}

All testing was conducted using SKF developed R2-type Bearing Endurance Testers. Each machine is comprised of a symmetrical horizontal arbor supported on two cylindrical roller bearings (load bearing) which in turn are supported in split main housings. Labyrinth seals are located on both sides of the load bearings to minimize the escape of the recirculating oil supplied to the bearing for lubrication and cooling. Two test bearings (type 6309 are press fit on the arbor, one at each end, and support a teardrop shaped housing through which the radial load is applied by a deadweight lever arm system. The test bearings are encapsulated by two rings, which form a labyrinth seal on the inboard side of the bearing, and a face plate on the outboard side. Two metal shields are located, one on each side of the bearing, to further minimize the ingestion of external debris and retain the grease and bearing wear particles in the bearing. 
The test shaft is belt driven by a 15 HP constant speed AC motor through pulleys selected to provide the desired test speed. The load bearings are splash lubricated with oil supplied from a central recirculating system at a rate sufficient to control the bearings' operating temperatures. The recirculating oil system contains a $25 \mu \mathrm{m}$ full flow filter.

The test bearings outer ring operating temperatures are sensed by shielded thermocouples and monitored by a minicomputer control system. The test bearing temperature measured at each $12 \mathrm{~min}$ interval is stored in the computer and printed out each 8 hs to provide a hard copy log of the thermal history of each test bearing.

A vibraswitch, attached to the main housing, monitors the general vibration level of the machine and turns off the drive motor when a significant increase, typical of a bearing failure, occurs.

\subsection{Testing and bearing preparation and inspection procedure}

The following procedure was used in preparing and mounting the test bearings, taking the grease samples, and inspecting the test bearings.

\subsubsection{Initial marking and cleaning of bearings}

A11 test bearings (type 6309 manufactured from carbon-vacuum-deoxidized [CVD] 52100 steel) were disassembled and the rings numbered in sequence using an electric etching pencil. The outer and inner rings, cages and shields of Set II bearings were divided in sixteen equal segments and marked with the electric etcher. Every other segment was numbered in order from 1 to 8 . Each bearing was assembled and placed in a horizontal position in a glass container partially filled with solvent and ultrasonically cleaned for 5 mins. Each bearing was then removed and flushed with petroleum ether and allowed to air dry.

\subsubsection{Greasing of bearings}

Each bearing was charged according to standard practice with approximately 12.6 grams of grease to obtain a $1 / 3$ full pack. The grease charge was inserted uniformly on both sides of the bearing between the balls using a hypodermic syringe. The shields, cleaned with solvent and petroleum ether, were placed on both sides of the bearing and the bearing wrapped in coated paper in preparation for assembly into the test rig.

\subsubsection{Assembly of bearings in rig}

Prior to the assembly of the bearings onto the shaft, the shaft bearing seats and surrounding area were washed with naphtha and wiped dry with a lint free rag. The bearings were pressed onto the shaft using the specially adapted hydraulic ram which was also cleaned with naphtha prior to use. The marked side of the bearing was located on the outboard side of the shaft. The bearing housing, following cleaning with naphtha, was assembled with the bearing type number on the outer ring located at the 12 o'clock position.

The desired radial load of 2600 lbs was applied to each bearing. This was accomplished by calculating the necessary load to be applied to the load arm and checking the weights on a spring scale before attaching. The runout between the end of the shaft and face of the bearing housing was checked and the necessary adjustments performed to assure proper alignment before starting the test.

\subsubsection{Testing}

All testing was performed at an inner ring rotational speed of 5500 rpm wth a radial load of 2600 lbs applied through the bearing housing. The bearing temperature recording computer was programmed to incorporate a subroutine (Temperature Rate of Increase Monitor) which would automatically stop the drive motor when a temperature increase rate of $1.1^{\circ} \mathrm{C}$ per minute or greater for a period resulting in an $11.7^{\circ} \mathrm{C}$ cumulative increase occurred, or when an operation temperature greater than $120^{\circ} \mathrm{C}$ was sensed. 
Bearing Set I was run in an uninterrupted manner. Testing was sustained until one of the following occurred: 1) a failure of both bearings was experienced, as indicated by an increase in bearing vibration level and/or audible noise, 2) a grease pack failure was experience, as defined by the Temperature Rate of Increase Monitor, or 3) a bearing life of $230 \times 10^{6}$ inner ring revolutions, roughly equivalent to the theoretical $L_{50}$, was achieved without failure. If testing was automatically stopped due to an excessive temperature increase rate or high temperature, the test was restarted and continued until stoppages occurred within 10 hs or less of each other.

At the conclusion of the test, the bearings were carefully removed from the rig using a special puller which was cleaned with naphtha just prior to use. The major portion of the grease was then removed from the four areas (inner ring, outer ring, cage and shields) using a small stainless steel spatula and placed in separate compartments of a clean glass container. Each bearing was then placed in a glass container with solvent and ultrasonically cleaned. Following the cleaning, the cleaning fluid and debris was placed in a glass bottle and sealed with a plastic cap using a teflon sealing disk. The grease and cleaning fluid were refrigerated until delivered to NAEC for analysis.

The bearings were disassembled and a visual inspection of all elements performed using an optical microscope with magnification up to $30 \mathrm{X}$. The inner ring surfaces were also examined with a scanning electron microscope to further determine the degree of surface damage and necessary photomicrographs were taken for documentation purposes.

Bearing Set II was tested in the same manner as Set I except grease samples were removed after $1,5,10,20,52,80,120$, and $160 \mathrm{million}$ revolutions. The grease samples were removed from the outboard side using a small stainless steel spatula from a numbered segment on the cage, inner ring, outer ring and shield starting with segment number 1 and progressing through number 8 after each progressive operating period. The removed grease was replaced by approximately the same quantity prior to restarting the bearing. Following the test termination, the same procedure was followed in removing the grease and examining the bearing as in Set $\mathrm{I}$.

Bearing Set III was tested in the same manner as Set II except at each shutdown interval the bearings were removed and the grease sampling, bearing cleaning and examination performed in the same manner as that performed at the termination of Set I testing.

\section{Test Discussion and Results}

\subsection{General discussion}

An applied radial load $(P)$ of 2600 lbs $\left(\frac{C}{P}=3.5\right)$ was selected for use during the testing. This load results in a theoretical $L_{10}$ life of 43 million revolutions for the 6309 test bearing which has a basic load rating $(C)$ of $9120 \mathrm{lbs}$. The theoretical $L_{50}$ life of the test bearings were calculated to be 230 million revolutions which was also selected to be the time up life of the test to insure the fatigue failure of several bearings.

An inner ring rotational speed or shaft speed of $5500 \mathrm{rpm}$ was selected to limit the operating test period of a given test bearing to $708 \mathrm{hs}$. Consideration in selecting the speed was also given to the expected outer ring operating temperature rise which would occur. Experience obtained in prior tests using the same load indicated that the expected temperature rise would be between $77^{\circ} \mathrm{C}$ and $90^{\circ} \mathrm{C}$. This was considered to be reasonable and would not impose excessive restrictions on the selection of the grease.

The selection of the grease was based on properties which were compatible with both the test conditions and the analysis techniques used by the NAEC to separate the debris from the grease. The grease selected meets MIL-G-23827 specifications and consists of a lithium soap base and a di-ester lubricating fluid. The specified temperature range of the grease is $-73{ }^{\circ} \mathrm{C}$ to $+120^{\circ} \mathrm{C}$. Greases meeting this military specification are reportedly one of the three most frequently used greases in naval aircraft applications and is therefore representative of what would be found in practice. 
Samples of the grease, in unopened one pound cans as received from the vendor, were sent to the NAEC. The samples were inspected and found to contain small metal particles. Therefore, grease samples removed from the bearing for NAEC examination would be expected to contain such particles in addition to metal debris generated in the operation of the bearing.

The two basic methods used to detect the initiation of a bearing failure during the testing portion of this program were vibration level monitoring and temperature rate of increase monitoring (TRIM). The vibration monitoring is a standard procedure used in bearing endurance testing and is utilized to turn off the drive motor when the vibration level increases to a value representative of that produced by a small spall in one of the bearing elements. The TRIM procedure (developed by SKF to detect early warnings of lubrication failures in grease lubricated bearings) turns off the drive motor when a bearing temperature increase rate is such that a recovery of the bearing grease system would not be expected and, thus, a catastrophic bearing failure would result if the bearing were allowed to continue running for an additional short period of time.

During the test program, grease samples were taken from four different locations (inner ring, outer ring, cage, and shield) each time samples were extracted. The grease removed from each location was stored in separate compartments of a glass petri dish to permit the determination of the most sensitive location with respect to the generated debris. The quantity of grease removed from each location was also representative of the amount of grease present and thus could be used to determine if adequate sample sizes would be present at the various locations in actual applications.

It was observed during the grease sampling that fretting material generated between the bearing housing and outer ring sometimes dropped into the grease on the bearing shields during the removal of the bearing from the shaft or during grease sample removal. Attempts were made to remove this material from all samples supplied to NAEC to eliminate confusion during evaluation. However, since there was no assurance that all fretting material was removed, a sample of the material was supplied to NAEC for examination and categorizing, thus permitting its identification if found in the grease samples. Although the presence of the fretting material was undesirable, it is also quite likely that it would be present in more applications and special care would have to be taken to minimize its presence in grease samples.

Of the six bearings tested, three experienced failures which terminated their testing before time up and a fourth experienced several TRIM shutoffs before reaching time up. Of the three failures, two were the results of inner ring spalls and the third due to TRIM shutoffs which occurred within three hours of each other.

\subsection{Testing results}

\subsubsection{Set I bearings (nos. 01 and 02 )}

After 158 hours of testing, a TRIM shutoff occurred due to a fast rise in the temperature of bearing 02 . After four additional TRIM shutoffs, with only three hours of operation between the last two, and one high temperature shutoff, the testing of bearing 02 was terminated after 302 hs or $98 \times 10^{6}$ revolutions.

The inspection of the bearing showed that advanced surface distress had occurred in both races with five bands readily detectable in the ball tracks. The two Heathcote bands were dark gray in color with only a few fine finish grinding marks still present. The center microslip band was highly glazed with some microspalling which was also present in the other two slip bands. The balls had a mottled appearance with several discoloration bands present. In general, the discoloration and high degree of surface distress indicates that inadequate lubrication had existed at some time during its operation. This finding agrees well with the testing history of several trim shutoffs.

Although the damage to this bearing was not sufficient to prevent further operation if it were regreased, the period of further operation before a surface initiated spall is likely to occur is considered to be greatly reduced when compared to an undamaged bearing. Should the bearing be continued in use without regreasing a thermal imbalance failure is likely to occur within the next few hours of operation. Thus a bearing in this condition should be replaced. 
Testing of bearing 01 was continued using a dummy bearing in place of 02 . After an additional operation of $5 \times 10^{6}$ revolutions or a total of $103 \times 10^{6}$ revolutions a TRIM shutoff occurred. After attempting to restart the test, a vibraswitch shutoff occurred indicating a spall.

The inspection of bearing 01 showed that appreciable surface distress had occurred as evidenced by the highly glazed and frosted appearance of the ball tracks which were similar to those in bearing 02. In addition a small spall had occurred in the inner ring. The surface damage and the initiation of the spall that occurred in this bearing would dictate its replacement as further running would quickly result in an inoperative bearing.

\subsubsection{Set II bearings (nos. 03 and 04)}

The testing of Set II bearings proceeded without incident with grease samples removed as scheduled after $1,5,10,20,52,80,120$, and 160 million revolutions. During the testing period from 160 million revolutions until test time up of 231 million revolutions, four TRIM shutoffs occurred due to excessive temperature increase rates in bearing 04 with no shutoffs occurring due to problems in bearing 03 .

Inspection of bearing 03 following test termination at time up showed all elements to be in excellent condition. The ball tracks in both the inner and outer races were only evident due to minor plastic flow of asperities which caused the contacted surfaces to have a slightly higher polished appearance than the uncontacted surfaces. Finish grinding lines were still present over the complete ball track further indicating minor surface wear.

The inspection of bearing 04 showed that appreciable surface distress had occurred in the races with microspalls and microcracks present in both. The ball track was evident over the full circumference of the outer ring indicating that the radial clearance had been lost for some period during the test. This condition and the surface distress both indicated that inadequate lubrication existed at some time during the test.

In general the inspection of these two bearings indicates that bearing 04 was very close to failure and should be replaced. Whereas, there was no physical evidence in bearing 03 that would suggest appreciable wear or that the bearing should be replaced due to an imminent failure.

\subsubsection{Set III bearings (nos. 05 and 06)}

The testing of Set III bearings proceeded without incident with the grease samples taken and the bearings inspected as scheduled through $20 \times 10^{6}$ revolutions. At $52 \times 10^{6}$ revolutions, a vibraswitch shutoff due to a spall failure on the inner race of bearing 06 occurred.

The inspection of the inner ring of bearing 06 after $20 \times 10^{6}$ revolutions showed the race to be in excellent condition. The presence of finish grinding lines across the complete race indicated that little wear had taken place and no surface distress had occurred. The inspection after $52 \times 10^{6}$ revolutions showed the race to be essentially in the same excellent condition except for the presence of the small spall and the appreciable denting produced by spall debris. In general, no physical evidence had been noted during any of the prior inspections which would indicate that the bearing was close to failure. The failure is considered to be a classical fatigue spall.

The testing of bearing 05 continued per schedule to a time up of $230 \times 10^{6}$ revolutions without any unscheduled shutdowns. The inspections of this bearing showed only small or subtle changes in the wear state through $160 \times 10^{6}$ revolutions. The inspection after $230 \times 10^{6}$ revolutions showed that appreciable micropitting had occurred indicating that the quality of the lubrication had worsened at some point during the final run. Although the surface distress of this bearing was not nearly as bad as that in bearings 01 and 02 , its replacement would be recommended. 


\section{Wear Particle Analysis}

\subsection{General discussion}

Prior to conducting sample analysis of the used grease samples, an effective method to dissolve the grease matrix needed to be developed. The ferrographic technique utilized, required that the grease be dissolved so as to result in a fluid type mixture capable of being passed through a narrow tube by means of a parastaltic pump onto a glass substrate. In addition to assuring a fluid-type composition, the resulting mixture would produce an acceptable ferrogram to analyze the resulting wear particulate. This would serve as aid in trending from sample to sample the wear state condition of the component.

\subsection{Solvent evaluation}

In order to dissolve the grease, a study was undertaken to evaluate various solvent combinations. Due to the various additives used in the composition of greases, a single, universal solvent could not be found. Various greases were tested, using varying amounts of grease and combinations of solvents, based upon solubility and residue of the resulting mixture. From these tests, three grease solvents were chosen based upon their wide-spread application. Solvent \#1 was composed of 50 percent toluol and 50 percent isopropanol. This solvent was found to be ineffective with lithium soap greases. Solvent $C$ was composed of 33 percent toluol, 33 percent methyl ethyl ketone and 34 percent isopropanol. This solvent showed a somewhat similar effect as solvent \#1 on lithium soap grease. Solvent \#3, composed of 30 percent toluol and 70 percent hexane, appeared to be the most universal solvent, as its solvating action is applicable over a wide selection of greases, including lithium soap grease.

\subsection{Used grease analysis}

During testing of the various solvents, it was noted that the grease being solvated was in an unused state as opposed to a "worked condition". Additionally, the unused grease samples were found to contain various metallic and nonmetallic particulate.

The metallic and nonmetallic particulate, contained in the unused grease, appears to be from the processing and packaging of the grease. Numerous ferrogram studies were conducted, in order to characterize this particulate. In addition, SEM and XDS analyses were conducted to determine shape and elemental composition. This work resulted in data which enabled the evaluator to eliminate those particulate from the grease that were observed with those from the actual wearing component.

In order to determine the difference in solvating unused and worked grease, numerous grease samples obtained from aircraft components and subjected to the various solvents stated previously. As a result of these studies, solvent \#2 was found to be more effective with worked grease. The principal reason was the ferrograms were virtually free of residual grease material as opposed to that observed using solvent \#3. Therefore, solvent \#2 was chosen for the preceding analysis.

\subsection{Sample preparation procedure}

The procedure for preparation of the grease samples for ferrographic analysis was accomplished in the following manner: 1) Ten $3 \mathrm{~mm}$ diameter glass beads were placed in a $1 / 2$ oz bottle. The use of these glass beads aided the agitation process of the grease solution. Their presence had no noticeable effect on the resulting ferrograms. 2) Varying amounts of used grease range in size by weight of between .01 to $.035 \mathrm{gm}$, were then added to the bottle. The amount used corresponded to the time of the sample extraction and the operating parameters of the specific test. 3) Five cc of solvent \#2 were poured into the bottle. The sample bottle was then closed and hand-shaken vigorously until such time that the grease became dispersed. 4) Five cc of filtered MIL-C-23699, a synthetic polyester fluid, was then added to the grease mixture. This fluid was added to increase the viscosity index of the grease mixture to aid in the delivery of the mixture to the ferrogram substrate. Additionally, the grease used (MIL-G-23827) has a di-ester lubricant additive, which makes it compatible with MIL-C-23699. 5) Sample was then recapped and 
shaken vigorously. Five cc of the grease mixture/polyester solution was then removed by pipet into another $1 / 2$ oz bottle. A ferrogram was then prepared from this mixture using filtered solvent \#2 as a washing/fixing solution.

The resulting grease samples from the bearing test were obtained from four different locations (inner ring, outer ring, cage and shield) each time samples were extracted. The quantity of grease removed was representative of the actual amount of grease present at the time of sampling. This served as an indicator as to what areas of the bearing furnished adequate amounts of grease for actual field sampling. These various sampling locations were studied to determine the sensitivity to the actual wear of the bearing surfaces by wear particle retention.

\section{Wear Particle Analysis Results}

\subsection{General discussion}

The first bearing analyzed was bearing \#1 of the endurance test. Due to the nature of the test, only one sample was taken, at the time of failure. Ferrograms were made of the resulting samples to determine the best location for sampling in terms of amount of grease available and sensitivity to wear.

Based upon the results of these ferrograms, the cage and ball sampling location seemed to reflect the actual wear state of the bearing as well as provide an adequate amount of grease for testing. The inner ring had an insignificant amount of grease, therefore it was not tested. The outer ring provided an adequate amount of grease for analysis, yet the size distribution and total number of particles were considerably less than the cage and ball sample. The shield contained an adequate amount of grease, but the size distribution and total number of particles was considerably greater than either the cage and ball and outer ring areas. Of significant note was the abnormally high percentage of large ferrous metallic particles found in the shield sample. This may suggest the need to take a closer examination of the trend in particle migration outward from the interior of the bearing.

The bearing had shut down due to a lubrication failure and a spall which had developed on the inner ring. The size distribution of particles and particle types observed indicated substantial wear had taken place and an abnormal wear mode was taking place.

The grease had a very dark brown/black appearance. This was an indication that the grease had degraded, as evidenced by the TRIM shutoff of the test. Optical and SEM inspection by SKF personnel revealed appreciable surface distress had occurred in the form of micropitting, denting and plastic deformation. Replacement of bearing would be recommended.

of the remaining five bearings, three are selected for discussion here. These bearings represent both Set II and Set III and are representative of a bearing reaching the termination point without distress, a bearing reaching termination point with some distress and a bearing experiencing failure.

\subsection{Set II bearings (no. 03)}

Bearing \#3 of Set II ran to the predetermined termination point of 230 MIL REVS. Based upon the observation made of Set I, the cage and ball sample will only be discussed.

\subsubsection{Wear in}

Wear in occurred between 1-5 million revulutions. The ratio of large to small particles was indicative of a normal wear in process. The quantity of particles was high, which is normal. Wear in particles (long, flat, narrow strips) normally associated with wear in of new surfaces were observed. The other wear particles observed revealed no other abnormalities.

\subsubsection{Normal wear}

Transition to normal wear occurred at the 10 MIL REV sampling point and continued to the 160 MIL REV point. The number of break-in type particles had diminished. The generation rate of normal rubbing wear particulate increased up to the 20 MIL REV point. From 
that point, laminar wear particles increased in number as the rubbing wear particles decreased. No other signs of abnormalities were observed. The size distribution and other particle types showed no signs of abnormality.

\subsubsection{Wear out}

After 160 MIL REV point, a somewhat accelerated wear rate had occurred. At the termination point in testing (231 MIL REV) this accelerated wear condition did not worsen significantly to any great extent. Of particular note was the increase in severe wear particles, though not in any great quantities to warrant immediate concern.

\subsubsection{Optical and SEM examination}

Optical and SEM examination by SKF personnel revealed that minimal wear and plastic flow had occurred and that the bearing was well lubricated throughout the test. The bearing wear state/condition was suitable for continued operation.

\subsection{Set III bearings (no. 05)}

Bearing \#5 of Set III ran to the predetermined termination point of 230 MIL REV with some surface distress.

\subsubsection{Wear in}

Wear in occurred between 1 and $10 \mathrm{MIL}$ REV, as opposed to 1 to $5 \mathrm{MIL}$ REV in bearing \#3. The longer wear in process may be attributed for the most part to the nature of the test (dismantle/inspect/regrease) which produced a significant lower number of wear particulate due to the lack of accumulation of wear particulate in the grease. Additionally, wear in particles appear to remain somewhat equal in number throughout the three wear in samples as opposed to the diminishing effect found in bearing \#3. This again is attributed to the nature of the test. No other signs of abnormalities were noted.

\subsubsection{Normal wear}

Transition occurred to normal wear after $10 \mathrm{MIL}$ REV point and continued to the $120 \mathrm{MIL}$ REV sampling point where an unstable wear condition initiated. The continuing presence of wear in particles indicates that the removal/dismantling/regreasing procedure reintroduces a wear in type condition momentarily after each start up. The ratio of large-to-small particles decreased somewhat from wear in, but remained high. Significant amount of cutting (abrasive) wear was observed at the 80 MIL REV sampling point. Laminar particles increased significantly in proportion to rubbing wear.

\subsubsection{Wear out}

After 120 MIL REVS sampling point, an unstable wear rate developed. The lubricant began to slightly degrade, causing problems in obtaining accurate particle analysis. An interesting observation was made, in light of the test procedure, the grease appeared to degrade as in bearing \#1, yet bearing \#5 was regreased after each sample. Severe wear particles and laminar particles increased in major dimension, yet their total numbers remained stable until the termination point in the test.

\subsubsection{Optical and SEM inspection}

Optical and SEM inspection by SKF personnel revealed excessive denting and pitting had taken place on the wearing surfaces, though no bona fide failure had occurred. Replacement of bearing would be recommended.

\subsection{Set III bearings (no. 06)}

Bearing \#6 of Set III ran to 52 MIL REVS where it developed a classical spall failure. 


\subsubsection{Wear in}

Wear in occurred between 1 and 10 MIL REV. A large number of particles were observed. A noticeable absence of wear in type particles was noted in all wear in samples. The ratio of large-to-small particles was lower than observed in other bearings, though the total number was higher than bearing \#5 despite the dismantling of the bearing. Severe wear and abrasive wear particles were observed. The increase of laminar particles was greatly accelerated as opposed to other bearings.

\subsubsection{Normal wear}

Transition to normal wear occurred after 10 MIL REV and continued to 20 MIL REVS. A dramatic increase in laminar particles occurred with a corresponding decrease in rubbing. No wear in particles were observed. The ratio of large-to-small particles decreased to within normal size.

\subsubsection{Wear out}

An unstable wear state/condition occurred after the 20 MIL REV sample point. A marked increase in total number, type, and size of all particles. The size and amount of abnormal wear particles (fatigue and severe wear) were easily detected. Slight temper coloration was noted on the severe wear particles. It was evident that on abnormal wear state/condition had or was about to occur.

\subsubsection{Optical and SEM inspection}

Optical and SEM inspection by SKF personnel revealed that a spall developed on the center tract of the inner ring. Thermal coloration occurred on the leading edge of the spall. Debris generated dents, large in size, were observed as were several pits. Replacement of bearing would be recommended.

\section{Grease Lubricated Taper Roller Bearings}

\subsection{General discussion}

Research is presently on-going in the bench-testing and analysis of the resulting used grease samples of grease lubricated taper roller bearings. The modified-for-testing taper roller bearings were tested and sampled in a manner very similar to the grease lubricated ball bearing test previously discussed. During the initial startup of the testing, a degradation problem was encountered. The grease utilized was the same as specified for the ball bearing test. A reevaluation of the grease was performed and several types of greases were tested to determine a suitable replacement. A paraffinic mineral lithium soapbased grease was selected. This grease was then implemented and performed satisfactorily. The wear particle analysis is presently being performed and preliminary indications are that the wear state/condition of the grease lubricated taper roller bearings can be ascertained in much the same manner as the ball bearings.

\section{Summary}

Ferrographic analysis has been shown to be useful in evaluating the wear/state condition of grease lubricated components. The major achievement was the successful application of dissolving the grease utilizing a solvent mixture and making ferrograms of equal quality as to that found in oil analysis. The types of wear particles found in used grease samples are comparative to those found in oil lubricated systems. Work is presently being performed on grease lubricated taper roller bearings, similar to the test conditions utilized in this study.

The analysis of the grease samples was qualitative vs quantitative. Due to the uneven distribution of wear particulate in the grease and the relatively small amount of grease used in making the ferrograms. The primary emphasis was placed upon size distribution, morphology and elemental composition. 
The results of the ferrogram analysis showed a good correlation to those of the SKF personnel in terms of monitoring the wear state/condition of the bearings throughout their life. However, the on-condition monitoring of grease lubricated components in the field, is complicated by the physical location of the components and inaccessibility by maintenance personnel to remove grease samples. Where accessibility is no problem, this technique is highly recommended. As it appears presently, this analysis technique seems best suited to the examination of grease obtained from dismantled grease lubricated components or in design applications. 
National Bureau of Standards Special Publication 584. Proceedings of Joint Conference on Measurements and Standards for Recycled 0il/Systems Performance and Durability held at NBS, Gaithersburg, MD, October 23-26, 1979. (I ssued Nov. 1980)

\title{
ENGINE CONDITION DEFINED BY OIL ANALYSIS
}

\author{
Clifford G. Salvesen \\ Mobil 0il Corporation \\ Technical Service Laboratories \\ P. 0. Box 1027 \\ Princeton, NJ 08540
}

\begin{abstract}
In this paper we discuss the technology used to monitor engines and lubricant condition. The type equipment monitored includes gasoline, diesel, dual fuel, and natural gas engines. The analytical procedures for used oil analysis include: 1) infrared spectrophotometer, 2) membrane filtration, 3 ) direct reading spectrometer, and 4) automated viscosimeter. For optimum benefit from the oil analysis data, it is necessary to have good background data on the oil being tested. Without this information, less accurate readings and interpretation of the data will result. Control limits utilized for the programs are also critical. These limits are developed from a statistical study of the data generated, field tests conducted on the oils, plus feedback from the equipment builders and users.
\end{abstract}

\section{History of 0 il Analysis}

The main objectives for any oil analysis program is to measure oil contamination, oil degradation, and wear metals. A variety of procedures may be used to define these parameters including viscosity, flash point, neutralization number, insolubles in pentane and/or toluene by centrifuge, and wet chemical or spectrographic (wet plate) measurement of metals. These tests were used for many years and served well, but were somewhat slow, for oils containing no or low additive levels. With the advent of highly dispersant engine oils it was noted that two of these tests were unreliable. These are neutralization number and insolubles. The neutralization number may be troublesome because instead of titrating for acid-oxy materials, the titrating solution may react with the additives. Insolubles results are questionable because the centrifuge procedure does not always spin out all of the insoluble materials.

\section{New Methods}

In view of the above mentioned problems, new procedures were investigated. It was found that infrared, membrane filtration, atomic absorption, or direct reading spectrometer, and automated viscosity offered better and faster means for analyzing used oils. The data obtained from these procedures follow in table 1.

Table 1.

Equipment

Infrared

Membrane filtration

Atomic absorption or direct reading spectrometer

Automated viscosimeter
For Defining

Water, oxidation, nitration, nitro compounds, glycol, gasoline fuel dilution and miscellaneous contaminants

For total insolubles and dispersancy characteristics

For key metals

For rapid viscosity measurement 
Additional information on some of these procedures and their development was given in SAE papers \#680759 and \#730745 published some years ago by personnel from the author's company.

\section{Discussion of Equipment}

\subsection{Differential infrared analysis}

The infrared equipment has been redesigned in recent years to provide more rapid, yet accurate, results. In our laboratory, we have modified various equipment to automate much of the procedure. The principal differences between our units and conventional infrared equipment are as follows:

1) Automated sample feed system -- We use a 200 position feed tray, a sample dipper, a positive displacement pump, a "self-cleaning cell" and the necessary electronic equipment to operate the system.

2) Automatic reference system -- Up to 6 different reference oils can be used and the equipment is programmed so that reference cells change as the oil types change. In practice we sequence all of the same type oil samples, and at the end of the run, the reference automatically switches to the designated product for the next series of oils. When all 200 samples are tested, the unit shuts itself down.

3) Spectrophotometer modifications -- Mechanical and electrical changes have been made to speed up the recording in wavelengths of low interest and to slow it down for key areas, and

4) Auxiliary recorder -- The output of the spectrophotometer is fed to a flat-bed recorder whose speed is adjusted to compress the spectrum so that about 360 samples are displayed on a single roll of chart paper.

In the following table we list the materials routinely tested for, and give their wavelength assignments and units of measurement.

Table 2. Identification of infrared bands

Wavelength, $\mu \mathrm{m}$

$2.9,6.05$

5.85

$6.1,7.9,11.6$

6.4

$12.4,12.8$

$9.3,9.7$

Other bands
Nature of Component

Water (bonded)

Oxidation

Organic nitrates

Nitro compounds

Gasoline dilution

Ethylene glycol

Unusual contaminants

\begin{tabular}{|c|c|c|}
\hline $\begin{array}{r}\text { Type } \\
\text { Serv } \\
\text { Diesel } \\
\end{array}$ & $\begin{array}{l}\text { of } \\
\text { ce } \\
\text { Gas } \\
\end{array}$ & $\begin{array}{c}\text { Reported } \\
\text { as } \\
\end{array}$ \\
\hline$x$ & $x$ & $\%$ Volume \\
\hline$x$ & $x$ & $\mathrm{~A} / \mathrm{cm}^{\mathrm{a}}$ \\
\hline- & $x$ & $\mathrm{~A} / \mathrm{cm}^{\mathrm{a}}$ \\
\hline - & $x$ & $\mathrm{~A} / \mathrm{cm}^{\mathrm{a}}$ \\
\hline- & $x$ & $\%$ volume \\
\hline$x$ & $x$ & $\%$ volume \\
\hline$x$ & $x$ & $\mathrm{~A} / \mathrm{cm}^{\mathrm{a}}$ \\
\hline
\end{tabular}

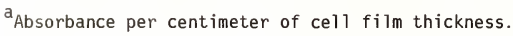

\subsection{Membrane filtration}

This procedure is used to define the amount of insoluble materials above a certain critical size, rather than total insolubles. A measure of total insolubles may be meaningless in terms of deposit drop-out or filter plugging tendencies, even at a high content, as long as their size remains well below the critical level. Through laboratory and field testing of various oils, we have defined the critical membrane size to be utilized.

The procedure for membrane filtration is to dilute the oil with pentane and filter the mixture through a preweighed membrane. The insolubles are reported as weight percent. We use a multiple sample membrane filtration apparatus for the filtration and an electrobalance with digital readout for weighing. 


\subsection{Viscosity determination}

An automated Brookfield type viscosity unit has been developed for viscosity measurement. The unit is temperature controlled for the specified test temperature, i.e., $210^{\circ} \mathrm{F}$ for most oils and $100^{\circ} \mathrm{F}$ for some. It uses an automated sample feed system similar to that described previously for the ir. A known oil is checked periodically and all torque readings are recorded on a strip chart. Calibration charts have been prepared for converting the strip chart readings to centistokes and/or SUS.

\subsection{Metals determination}

For most used oils we use a direct reading spectrometer. This unit provides a direct readout in ppm for 25 elements. Background data on the oil being tested is fed into a computer so that we minimize errors. Standard reference materials available from the National Bureau of Standards are used to calibrate the instrument.

\section{Used 0il Control Limits}

The analytical equipment described previously has the ability to accurately define the condition of a variety of oils. However, to be meaningful, accurate control limits are required for a variety of engine types and service. The procedures used to develop the control limits are as follows:

1) Compile background information on the base stocks and additives,

2) conduct field tests to stress the lubricant to a maximum degree,

3) investigate field failures where a piece of equipment has been monitored,

4) obtain feedback from equipment builders on the metallurgy of the equipmnt, and

5) statistically analyze the used oil data to establish normal and abnormal conditions.

\subsection{Base stocks and additives}

The base stock and additive chemistry must be factored into the key tests.

\subsection{Field tests}

We select a variety of equipment and applications to cover a range of operating conditions. Used oils from the units are checked periodically to follow trends; i.e., as noted by ir changes from new oil. Metals, viscosity, make-up oil, etc., are all factored into our findings.

\subsection{Field failures}

We work closely with our field engineers to obtain data on any field problems. Our laboratory supplements the field observations with deposit analyses, metallurgical examination of failed parts, etc.

\subsection{Equipment builder data}

Our field engineers work closely with equipment builders to obtain metallurgical and other key data. Furthermore, they keep us advised of any modifications, service tips, etc. , that will aid in defining equipment performance through used oil analyses.

\subsection{Statistical studies}

Periodically, the used oil results, particularly wear metals, are reviewed to define normal, borderline, and excessive ranges. Distribution curves are plotted showing total percent of samples VS Ppm of a metal. All areas below the inflection point are considered normal. This usually occurs at about the 85 percent point. The borderline area is selected as the 85-95 percent range and the excessive range covers those samples above the 95 percent range. 


\section{Typical Program in Action}

Several examples of the use of our analysis system are given below:

\subsection{Example A - cracked head}

Excessive water, glycol, copper and lead were found in an oil drain sample as noted in the following analyses.

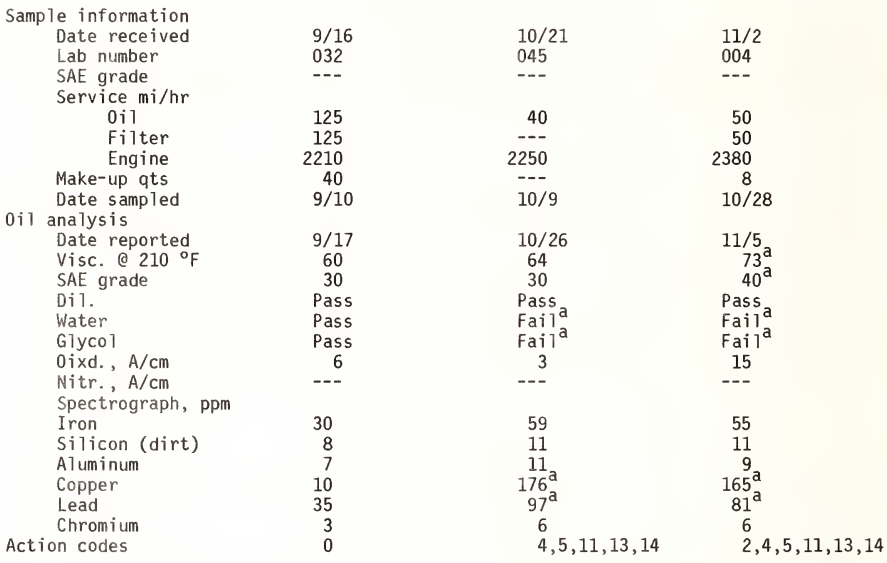

action required

After the 0ctober 9 sample results were obtained, the customer was advised by telephone. The next analysis on a sample taken three weeks later confirmed the earlier findings and the customer was again alerted.

The Maintenance Superintendent ordered the unit out of service. Inspection of the engine showed a cracked head had caused the water and glycol contamination. Repairs were made and the unit returned to service before more extensive damage had occurred.

\subsection{Example B - cracked exhaust manifold}

$0 i 1$ analyses from June through August, as noted below, showed a progressive increase in viscosity from $66 / 69 \mathrm{SSU}$ [ $210^{\circ} \mathrm{F}$ (SAE 30) to a high of 184 SSU @ $210^{\circ} \mathrm{F}$ (over SAE 50).

\section{Sample information}

$\begin{array}{lcccccc}\text { Date received } & 6 / 11 & 7 / 1 & 7 / 24 & 8 / 13 & 8 / 20 & 9 / 2 \\ \text { Lab number } & 002 & 021 & 017 & 012 & 011 & 078 \\ \text { SAE grade } & -- & -- & --- & -- & --- & -- \\ \text { Service mi/hr } & 138 & 193 & 152 & 155 & 129 & 155 \\ \quad 0 \text { il } & 138 & 193 & 152 & 155 & 129 & 155 \\ \quad \text { Filter } & 2557 & 2764 & 2879 & 3165 & 3236 & 3391 \\ \quad \text { Engine } & --- & -- & --- & -- & -- & --15 \\ \text { Make-up qts } & 6 / 6 & 6 / 28 & 7 / 18 & 8 / 10 & 8 / 15 & 8 / 27 \\ \text { Date sampled } & & & & & \end{array}$


$0 i 1$ analysis

Date reported

Visc. @ $210^{\mathrm{c}} \mathrm{F}$

SAE grade

Di1.

Water

Glycol

Oxid., $A / \mathrm{cm}$

Nitr., $A / \mathrm{cm}$

Spectrograph, ppm

Iron
Silicon (dirt)
Aluminum
Copper
Lead
Chromium

Action codes

\begin{tabular}{|c|c|c|c|c|c|}
\hline $\begin{array}{r}6 / 12 \\
81^{a} \\
40^{a}\end{array}$ & $\begin{array}{r}7 / 2 \\
97 \\
50^{a}\end{array}$ & $\begin{array}{r}7 / 27 \\
100^{a} \\
50^{a}\end{array}$ & $\begin{array}{r}8 / 14 \\
187^{\mathrm{a}} \\
50^{\mathrm{a}}\end{array}$ & $\begin{array}{r}8 / 24 \\
108^{a} \\
50^{a}\end{array}$ & $\begin{array}{r}9 / 3 \\
64 \\
30\end{array}$ \\
\hline Pass & Pass & Pass & Pass & Pass & Pass \\
\hline ass & Pass & Pass & Pass & Pass & Pas \\
\hline Pass & Pass & Pass & Pass & Pass & Pass \\
\hline 1 & 1 & 1 & 1 & 1 & 1 \\
\hline
\end{tabular}

$\begin{array}{crrrrr}53 & 50 & 37 & 43 & 37 & 47 \\ 10 & 8 & 7 & 9 & 7 & 6 \\ 28 & 20 & 16 & 23 & 19 & 19 \\ 10 & 10 & 9 & 10 & 9 & 13 \\ 26 & 21 & 33 & 31 & 22 & 23 \\ 4 & 4 & 2 & 4 & 3 & 3 \\ 2,14 & 2,14 & 2,14 & 2,14 & 2,14 & 0\end{array}$

action required

The customer's maintenance people were alerted and after several inspections, located a crack in the exhaust manifold. The lowering of exhaust pressure caused the turbocharger to slow down, starving the engine's air needs. This incomplete fuel combustion caused soot to build up, thereby boosting viscosity. After repairs were made, subsequent oil analyses showed normal viscosity levels.

\subsection{Example C - broken case gasket}

In this instance, oil analyses, as noted below, showed excessive silicon, iron and chrome. This indicated the possibility of a low pressure air leak.

Sample information

Date received

Lab number

SAE grade

Service mi/hr

Oil
Filter
Engine

Make-up qts

Date sampled

$0 i 1$ analysis

Date reported

Visc. @ $210^{\circ} \mathrm{F}$

SAE grade

Dil.

Water

Glycol

Oxid., $A / c m$

Nitr., $A / C m$

Spectrograph, ppm

$$
\text { Iron }
$$

Silicon (dirt)

Aluminum

Copper

Lead

Chromium

Action codes

$\overline{{ }^{a} \text { Action required }}$

\begin{tabular}{|c|c|c|c|c|}
\hline $\begin{array}{c}4 / 19 \\
079 \\
30\end{array}$ & $\begin{array}{r}5 / 3 \\
053 \\
30\end{array}$ & $\begin{array}{c}5 / 20 \\
027 \\
30\end{array}$ & $\begin{array}{c}6 / 18 \\
049 \\
30\end{array}$ & $\begin{array}{c}7 / 29 \\
093 \\
30\end{array}$ \\
\hline $\begin{array}{l}136 \\
136\end{array}$ & $\begin{array}{l}106 \\
106\end{array}$ & $\begin{array}{l}105 \\
105\end{array}$ & $\begin{array}{l}123 \\
123\end{array}$ & $\begin{array}{l}98 \\
98\end{array}$ \\
\hline 4794 & $\cdots$ & $\cdots$ & $\cdots$ & - \\
\hline $\begin{array}{c}72 \\
4 / 16\end{array}$ & $\begin{array}{c}20 \\
4 / 29\end{array}$ & $\begin{array}{c}32 \\
5 / 17\end{array}$ & $\begin{array}{c}40 \\
6 / 16\end{array}$ & $\begin{array}{c}32 \\
7 / 27\end{array}$ \\
\hline $\begin{array}{c}4 / 21 \\
63 \\
30\end{array}$ & $\begin{array}{r}5 / 5 \\
62 \\
30\end{array}$ & $\begin{array}{c}5 / 24 \\
64 \\
30\end{array}$ & $\begin{array}{c}6 / 22 \\
62 \\
30\end{array}$ & $\begin{array}{r}8 / 3 \\
62 \\
30\end{array}$ \\
\hline Pass & Pass & Pass & Pass & Pas \\
\hline Pass & Pass & Pass & Pass & Pas \\
\hline $\begin{array}{c}\text { Pass } \\
1\end{array}$ & $\begin{array}{c}\text { Pass } \\
6\end{array}$ & $\begin{array}{c}\text { Pass } \\
2\end{array}$ & $\begin{array}{c}\text { Pass } \\
1\end{array}$ & $\begin{array}{c}\text { Pass } \\
2\end{array}$ \\
\hline--- & $\cdots$ & -- & -- & $\cdots$ \\
\hline $\begin{array}{l}164^{\mathrm{a}} \\
99^{\mathrm{a}} \\
48 \\
11 \\
19 \\
39^{\mathrm{a}} \\
9,12,13,14\end{array}$ & $\begin{array}{c}207^{\mathrm{a}} \\
107^{\mathrm{a}} \\
50^{\mathrm{a}} \\
20 \\
22 \\
41^{\mathrm{a}} \\
8,9,10,12,13,14\end{array}$ & $\begin{array}{l}221^{\mathrm{a}} \\
58^{\mathrm{a}} \\
30 \\
14 \\
18 \\
26^{\mathrm{a}} \\
8,9,12,13,14\end{array}$ & $\begin{array}{c}165^{a} \\
45^{a} \\
29 \\
12 \\
20 \\
19 \\
7,8\end{array}$ & $\begin{array}{r}61 \\
19 \\
18 \\
9 \\
30 \\
10 \\
0\end{array}$ \\
\hline
\end{tabular}

61

18

30

10 
The customer checked all fittings, couplings, etc., between the air cleaner and turbocharger on a regular basis and they were found to be in order. Yet the silicon values remained high. It was decided to take the unit out of service until the leak could be found hoping to avoid a "major" engine failure which would have cost the customer about $\$ 6000$ to repair.

After considerable checking, a leak was discovered coming from a broken gasket between the air case and main body of the turbocharger.

Using the new procedures described herein, our laboratories are able to analyze a wide variety of lubricants from engine and nonengine applications. This is accomplished with significant reductions in manpower and oil analysis time. We find that we can handle about ten times as many samples per man hour using these new procedures compared to the older methods. Reporting time for these samples varies from the same day as the oil is received, up to ten working days, depending upon the oil application and variety of tests required. Most of the reports are issued within three to five days after sample receipt. 
Session 5

BENCH TESTS FOR OIL EVALUATION - I 

National Bureau of Standards Special Publication 584. Proceedings of Joint Conference on Measurements and Standards for Recycled 0il/Systems Performance and Durability held at NBS, Gaithersburg, MD, October 23-26, 1979. (Issued Nov. 1980)

\title{
ENGINE OIL EVALUATION THROUGH BENCH TESTING
}

\author{
S. M. Hsu \\ Tribochemistry Group \\ Chemical Stability and Corrosion Division \\ National Bureau of Standards \\ Washington, DC 20234
}

\section{Introduction}

Automotive crankcase oil performance is defined by field tests and laboratory engine sequence tests. In MIL-L-46152 specifications, passing results in five engine tests ${ }^{1}$ are required for oil qualification. These are: 1) IID - rust protection; 2) IIID - oxidation resistance, wear protection, oil consumption; 3) VD - low temperature dispersancy, wear protection, deposit forming tendencies; 4) L-38 - copper-lead bearing corrosion resistance, shear stability; and 5) 1H2 - ring sticking, wear, piston deposits in diesel engines. The engine operating conditions for some of these tests are shown in tables 1,2 , and 5 . These engine tests are generally time consuming and expensive. For this reason, various forms of small scale laboratory bench tests are developed and used to screen oils for quality and consistency. There are different opinions regarding the value of the bench tests. Some suggest the bench testing provides an effective tool to understand the underlying mechanisms of oil performance. Some suggest they are of little value because the engine test is the final judge of quality, and correlation between the engine test and bench test is difficult to develop and maintain. One contributing factor to these two opposing viewpoints is the proliferation of the number of bench tests. Some tests are developed with care and insight, some are outdated and obsolete but still in use. There are few standard procedures and even fewer published correlations. This study is the initial step to examine various kinds of bench testing against a set of criteria and to eventually provide guidance for their effective use. Within this context, this paper will examine the basic mechanisms of engine oil degradation and deposit formation. Any bench test, to be useful, must simulate some aspects of the basic mechanisms. Various bench test procedures are then described in detail.

\section{0 il Degradation Mechanisms in Gasoline Engines}

There have been a number of changes recently in engine design, fuel composition and driving patterns. As a result, the sequence engine tests have been changed from IIC, IIIC, VC, IH to IID, IIID, VD, and IH2. These changes are compared in tables 1 and 2. The following discussion on oil degradation mechanisms are based on older engine tests and operating conditions ${ }^{2}$.

Since bench tests are used to simulate engine tests, it is important to examine also how oils degrade in an operating engine. There are a limited number of studies published in the literature $[1-10]^{3}$ and basic mechanisms of oil oxidation and deposit formation are not clearly understood. In summary, the engine can be viewed as two chemical reactors in series. The first one is at the piston cylinder liner area where a thin film of oil is subjected to high temperatures, high shear stress and to hot combustion gases. The second

Detailed description of test procedures and specific engines employed are given in ASTM Publications STP 315 G and STP 509 G, 1916 Race Street, Philadelphia, PA.

2 The Army Fuels and Lubricant Laboratory at SWRI is currently in a cooperative program with the NBS Recycled 0 il Program to re-examine the degradation mechanisms in current engine and test procedures.

${ }^{3}$ Figures in brackets indicate the literature references at the end of this paper. 
reactor is the oil sump where temperatures range from climactic regime to $100{ }^{\circ} \mathrm{C}$. Here contamination by water, fuel dilution, dust, blow-by gases and the reaction products from the first reactor (referred to as the sludge and varnish precursors) occurs. Subsequently reactions take place to form sludge and varnish.

Table 1. Comparison of engine operating conditions between IIIC and IIID.

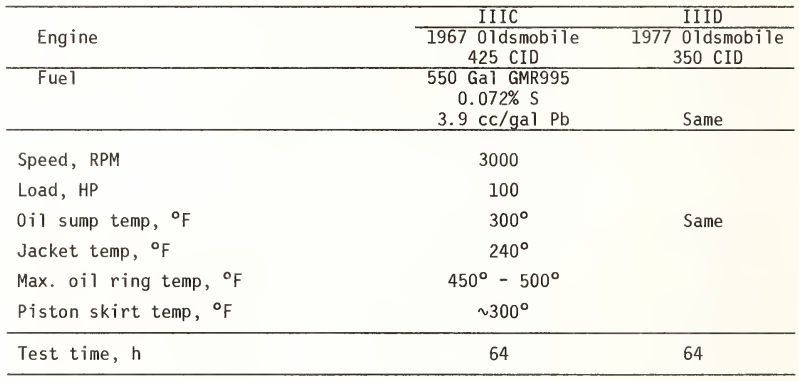

Table 2. Comparison of engine operating conditions between VC and VD.

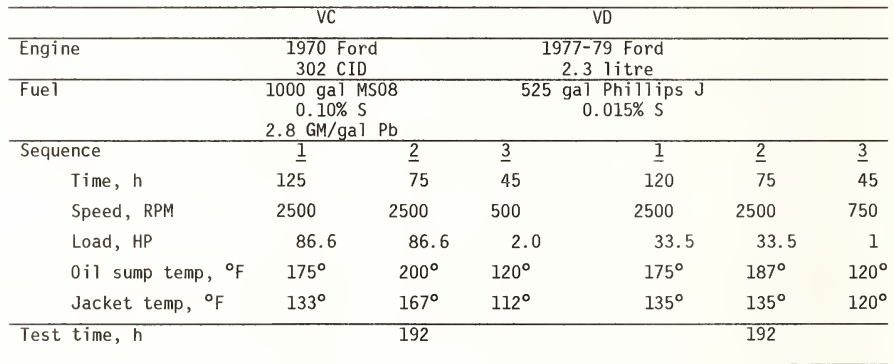

Principal oil degradation occurs in the piston ring zone and on the cylinder liner area. $0 i l$ is being pumped to the varjous parts of the engine such as rocker arms, valve train and cam and lifters where the temperature lies between 180 to $210^{\circ} \mathrm{F}$. The oil supplied to the piston and cylinder liner is subjected to far more severe conditions. Several things happen to the oils: 1) Some oil is left on the cylinder liner to face the combustion flame front (temperature of the oil $\sim 370-425^{\circ} \mathrm{C}$ ). The light ends in the oil are vaporized. Heavier fractions are oxidized and mixed with the high MW fuel components (fuel additives, lead salts, lead scavengers, soot and unburned but oxidized gasoline fractions). This oil is then scraped by the piston ring and returned to the sump. 2) Some oil is circulated through the rings. Temperatures on the order of 200 to $260{ }^{\circ} \mathrm{C}$ are possible depending on the operating conditions and the type of engine. The oil is oxidized or nitrated by the high temperatures and the blow-by gases $\left(\mathrm{NO}_{\mathrm{x}}, \mathrm{O}_{2}, \mathrm{H}_{2} \mathrm{O}, \mathrm{CO}, \mathrm{CO}_{2}, \mathrm{C}\right) . \mathrm{Polish}$ iron of the rings under these temperatures is a very good dehydrogenation catalyst. 
Fuel blow-by probably is the main cause for deposit formation. The blow-by gas is made up of combustion gases and unburned fuel components. Anderson [11] reported in a laboratory engine that out of the $1000-3000 \mathrm{ppm} \mathrm{N0}$ measured in exhaust gases (amounts vary with air/fuel ratio, compression ratio, speed), only 40 percent is left when the blow-by gas reaches the crankcase. This suggests that 60 percent of the $\mathrm{NO}_{\mathrm{x}}$ reacts with fuel components and oil in the ring zone. The resulting nitrocompounds and nitrates in the oil react with oxidized hydrocarbons to form sludge and varnish. Spindt [8] operated an engine in a nitrogen-free atmosphere and obtained essentially clean pistons.

The olefins and aromatics in the fuel have been identified as the main deposit-forming components. Several studies $[1,2,3,4,6]$ have identified that the olefins $\left(C_{2}-C_{6}\right)$ in the fuel react with $\mathrm{NO}_{x}$ to form $\alpha, \beta$ nitro-nitrates which are the sludge and varnish precursors. Radioactive tagging experiments with benzene as fuel demonstrate that 95 percent of the sludge carbon stems from fuel. Aromatic components in the fuel $\left(C_{9}-C_{11}\right.$ alkyl benzenes and alkyl indanes) have also been shown to effect varnish formation in engines.

Engine test conditions are presented in tables 1 and 2 . The chemical composition of the deposits are shown in tables 3 and 4 . Considerable fuel component influence is evident.

Table 3. Composition of gasoline engine deposits. Varnish from reference [9].

\section{Varnish}

Piston Varnish

C $\quad 20-75 \%$ Wt

$\mathrm{H} \quad 2-10$

$\mathrm{N} \quad 1-3$

S $\quad 1.5-11$

$\mathrm{Br} \quad 1-5$

C1 $1-8$

$\mathrm{Pb} \quad 5-16$

$0 \quad 11-16$

MW $\quad 300-350$
Other Varnish (Acetone Soluble)

\begin{tabular}{lc}
$\mathrm{C}$ & $67-76 \% \mathrm{Wt}$ \\
$\mathrm{H}$ & $8-10$ \\
$\mathrm{~N}$ & $1-3$ \\
$\mathrm{~S}$ & $1-2$ \\
$\mathrm{Br}$ & $2-5$ \\
$\mathrm{C} 1$ & $1-4$ \\
$\mathrm{~Pb}$ & $5-6$ \\
0 & $2-6$ \\
$\mathrm{MW}$ & $600-650$ \\
\hline
\end{tabular}

Table 4. Composition of gasoline engine deposit. Sludge from reference [5].

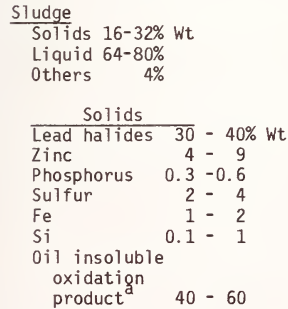

\begin{tabular}{lr}
\multicolumn{2}{c}{ Liquid } \\
\hline $\mathrm{H}_{2} \mathrm{O}$ & $0-2 \%$ \\
$0 \mathrm{il}$ & $60-80$ \\
Fuel & $4-6$
\end{tabular}

$\mathrm{a}_{0=13-15 \%, H=8-10 \%}$

$\mathrm{C}=60-70 \%, \mathrm{~N}=1.5 \%$

Certain additives play a role in forming engine varnish and sludge deposits. Sulfonates are used as rust inhibitors and detergents; under oxidizing conditions, they react with water and oil oxidation products giving rise to polymerization and gel formation. Zinc dithiophosphate (ZDDP or ZOP), while inhibiting oxidation and preventing wear and 
seizure, decomposes under a thermal and acidic environment to give oil insoluble products. Viscosity index improvers (VII) are high molecular weight polymers used to increase oil viscosity at high temperature by uncoiling their polymeric structures. At the same time, VIIs are very susceptible to oxidation and chain scission via free radical oxidation. These additives, when properly balanced, can give maximum benefits while minimizing their contribution to forming deposits. A good example is that high levels of ZDDP give excellent oxidation control but poor sludge ratings.

Summarizing, the deposit formation in gasoline engines heavily depends on the fuel composition, blow-by composition, amount of blow-by, temperature and oil oxidation. This is summarized in figure 1 . From the standpoint of bench test development, the basic mechanism can be broken down as follows: 1) High temperature oxidation (piston ring zone and cylinder liner); 2) thermal decomposition (piston ring zone and cylinder liner); 3 ) hydrolysis; 4) catalysis by: nitrated $\mathrm{C}_{2}-\mathrm{C}_{6}$ olefins; blow-by gases $\mathrm{NO}_{\mathrm{x}}$ ( $\mathrm{SO}_{\mathrm{x}}$, $\mathrm{NO}_{\mathrm{x}}$ in $\mathrm{VC}$ );

lead salts; iron and wear metal; and aromatic fuel components; and 5) absorption, adsorption and polymerization.

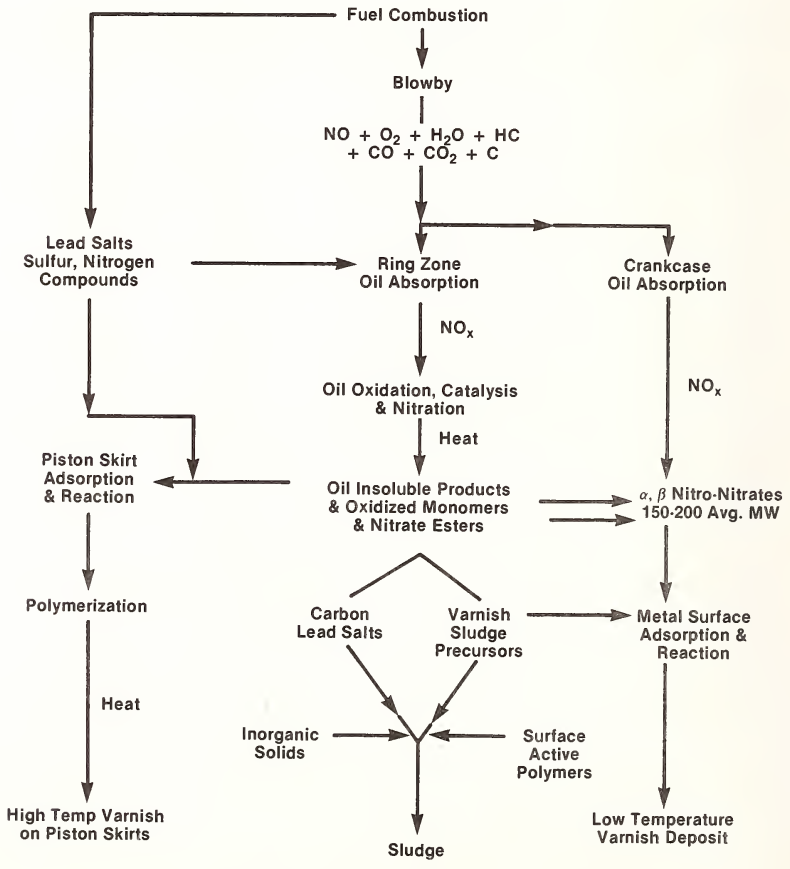

Figure 1. Deposit formation mechanism in gasoline engines. 


\section{Deposit Formation Mechanism in Diesel Engines}

The formation of diesel engine deposits can be ascribed to high temperature oil degradation in the presence of strong acid and nitrogen oxides. Most of the diesel specification engine tests are single cylinder laboratory engines as shown in table 5 . High sulfur diesel fuel is used. Significant amounts of $\mathrm{SO}_{x}$ are generated in the combustion gases in addition to $\mathrm{NO}_{x}$. There are many studies on the mechanism of deposit formation in diesel engines

[11-17]. Conclusions are: 1) diesel piston deposits contain oxyacids derived from the lubricant and 2) sulfur acid attack on the lubricant promotes deposit formation.

Table 5. Diesel engine test conditions.

\begin{tabular}{lcc}
\hline Engine & $\begin{array}{c}\text { L-38 } \\
\text { Labeco Single } \\
\text { Cylinder Engine } \\
42.5 \text { CID }\end{array}$ & $\begin{array}{c}\text { Caterpillar SC } \\
\text { Supercharged } \\
133.5 \text { CID }\end{array}$ \\
\hline Fuel & $\begin{array}{c}50 \text { gal } \\
\text { IS0-octane } \\
3.0 \text { cc/gal Pb }\end{array}$ & 1100 gal diesel \\
\hline Speed, RPM & 3150 & $0.4 \% \mathrm{~S}$ \\
Load, HP & --- & 1800 \\
0il sump temp, F & $275-290$ & Adj to 4900 \\
Jacket temp, F & 195 & BTU/min \\
Max. oil ring temp, F & --- & 180 \\
Piston skirt temp, F & -- & -- \\
\hline Test time, h & 40 & $\sim 300$ \\
\hline
\end{tabular}

Some studies showed that the degradation of oil and additives under high temperature acidic environments is the main cause for ring sticking. The temperature at the ring zone has been measured by many. Earlier studies using thermocouples revealed temperatures in the vicinity of $230^{\circ} \mathrm{C}$. Recent studies $[18,19]$ suggest much higher temperatures $\left(325-3600^{\circ} \mathrm{C}\right)$. These temperatures are tabulated in table 5 .

The overwhelming presence of combustion soot is another important factor in deposit formation. The diesel fuel, even under supercharging conditions (excess air) is only partially burned. Soot particles with sizes ranging from $100 \AA$ to $500 \AA$ are formed by condensation of $\mathrm{C}_{2}, \mathrm{C}_{3}$ and aromatic fragments in the fuel. Subsequent agglomeration increases the sizes to $0.005-2.0 \mu \mathrm{m}$. Under highly loaded conditions, the excess air is reduced and soot formation increases. In a typical used oil, the soot could range from 1 to 4 percent depending on the fuel consumption, engine conditions, load, etc. The presence of these soot particles provides a large liquid-solid interfacial area. Surface active additives such as dispersants, detergents and zinc dithiophophates agglomerate at the interface via adsorption, thus reducing the effective additive concentration.

Piston varnish formation in diesel engines is influenced heavily by $\mathrm{NO}_{x}$. As in gasoline engines, ${ }^{N O}{ }_{x}$ promotes the formation of nitrate esters which interact with oil oxidation products forming polyester and polyether type structures [17]. In diesel fuels, the small amount of light olefinic or aromatic components reduces the concentration of nitrate esters formed. 0il oxidation products play a more important role. Hydroperoxide produced from oil oxidation promotes the formation of $\mathrm{H}_{2} \mathrm{SO}_{4}$ from $\mathrm{SO}_{2}$. The sulfuric acid, in turn, promotes poly-condensation reactions of the oxidized species to higher MW resins. These resins, upon adsorption on the piston skirt, polymerize under ${ }^{N 0}{ }_{x}$ to give varnishes. The same resins also act as organic binder in the top ring groove area. Experiments with 
tritium-labeled base oil in a Petter AVI show that 90 percent of this bonding agent is derived from the oil [17]. Model hydrocarbon oxidation studies at $300-400{ }^{\circ} \mathrm{C}\left(572-752{ }^{\circ} \mathrm{C}\right)$ have yielded polymeric material similar to that found in engine piston deposits. These oxidation conditions correspond to air attack on the oil at the ring zone temperature and to preflame combustion of the fuel (cylinder liner - oil sump circulation) for a brief period. The presence of sulfur compounds and $\mathrm{NO}_{x}$ markedly increase the yield of this polymeric material which can be formed from epoxides, hydroxy acids, diols, and diacids. A schematic diagram illustrating diesel deposit formation is shown in figure 2 .

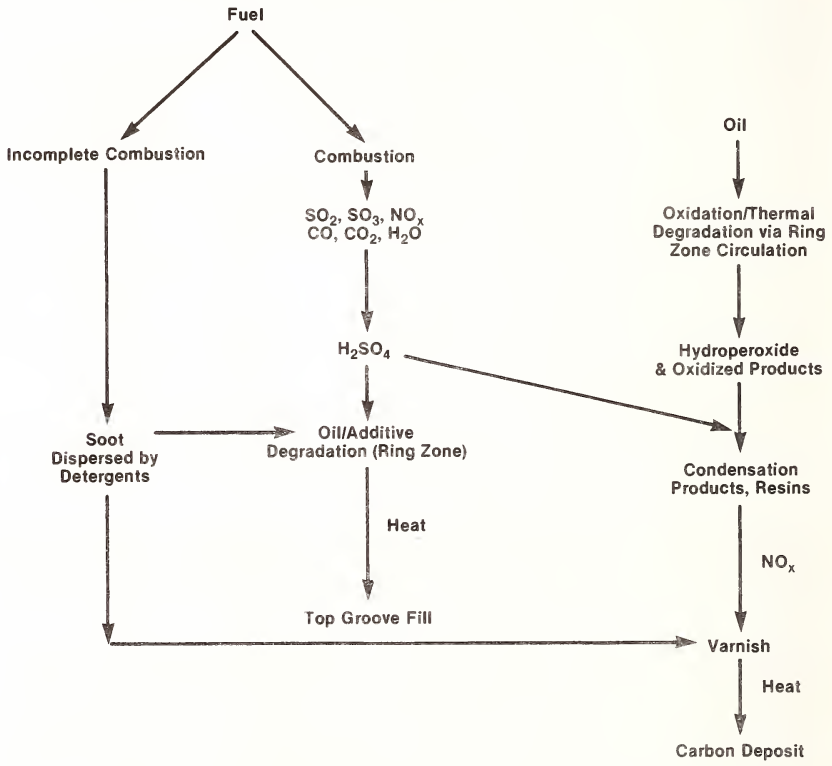

Figure 2. Diesel/engine deposit formation mechanism.

4. Bench Tests

There are many bench tests currently in use in the industry. Generally the tests address some specific aspects of oxidation, dispersancy, and deposit formation tendencies. The following sections will describe some selected bench test procedures and compare them to the engine oil degradation mechanism previously discussed.

In oxidation area, the most commonly available tests are: Rotary Bomb 0xidation Test (RBOT, ASTM D-2272), Turbine $0 i 1$ 0xidation Test (TOOT, ASTM D-943). The test procedures are shown in tables 6 and 7 . These two tests are developed for industrial oils but widely used in oil industry for other applications, sometimes with modifications. From the standpoint of chemical reaction conditions in an engine, both the RBOT and TOOT test conditions differ significantly. The data from these two tests, however, reflect the oxidation stability under 
metal catalysis and water contamination at the test temperatures. Extrapolation of data to automobile operating conditions where oxidation, nitration, fuel composition, blow-by gases and metal catalysis are important over a wide range of temperatures, is difficult and misleading. Variation of the standard RBOT and TOOT test conditions is of ten used to improve the simulation.

Table 6. Rotary bomb test.

$\begin{array}{ll}\text { Pressure } & =90 \mathrm{psig}-180 \mathrm{psig} \\ \text { Temperature } & =130^{\circ} \mathrm{C}-150^{\circ} \mathrm{C} \\ \text { Catalysts } & =\text { Copper wire }\left(154 \mathrm{~cm}^{2}\right) \\ & 5 \mathrm{cc} \text { of water } \\ 0 \text { il } & 50 \mathrm{gram} \\ \text { Water jacket } & 5 \mathrm{cc} \\ \text { Rotation } & =100 \mathrm{RPM}\end{array}$

\section{PARAMETERS MEASURED}

Time - pressure relationship

Table 7. Turbine oil oxidation test (TOOT).

$\begin{array}{ll}\text { Temperature } & =95{ }^{\circ} \mathrm{C} \\ \text { Overhead condenser } & =\text { yes } \\ \text { Catalysts } & =\text { copper \& iron wire } \\ 0 \text { i1 } & =60 \mathrm{cc} \text { of water } \\ & =300 \mathrm{cc}\end{array}$

\section{PARAMETERS MEASURED}

Number of test hours for oil to reach 2.0 TAN

Sludge

Catalyst weight

The Ford Modified 0xidation Test [20] is shown in table 8 and figure 3 . This test uses metal coupons for catalyst under vigorous stirring. The temperature is $i_{n}$ the mid-range of engine operating temperatures. The MORCO Oxidation Test [21] shown in table 9 is similar except at slower stirring speed and shorter duration. Both tests have a fixed duration. In this type of testing, the sampling frequency becomes an integral part of the test. As shown in figure 4 , if samples are taken at point $A$, the ranking of the oil will be different from point B. At point C, the two oils will not show any difference. This is an important point. Bench tests are useful only when they are used correctly. In measuring oxidation stability, it is important to plot the parameter measured as a function of time to avoid misinterpretations from discrete point comparisons.

Some new and exciting works are currently being pursued at several laboratories. Mohoney and Korcek $[22,23]$ at Ford Motor Research have published some work on free radical titration procedure by which the anti-oxidant reserve or capacity can be measured. This 
Table 8. Ford modified oxidation test.

- Beaker oxidation test

o Conditions:

$\begin{array}{ll}0 i 1 & =275 \mathrm{cC} \\ \text { Temp. } & =135{ }^{\circ} \mathrm{C} \\ \text { Catalyst } & =\text { Iron and copper strips } \\ \text { Duration } & =300 \text { hours } \\ \text { Stirring speed } & =1000 \mathrm{RPM}\end{array}$

- Parameters measured:

Viscosity increase

Pentane insoluble

TAN

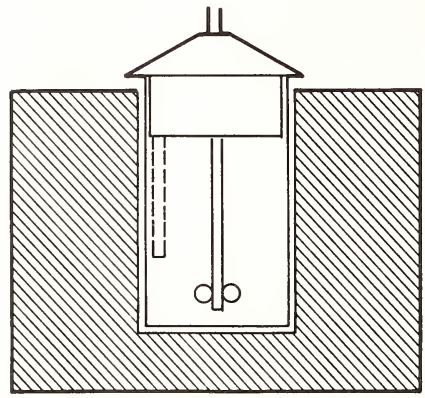

Figure 3. Ford modified oxidation test.

Table 9. Morco oxidation test.

- Open beaker type test with stirring

$\begin{array}{ll}\text { Temperature } & =135 \mathrm{C} \\ \text { Catalysts } & =\text { Copper and steel strips } \\ \text { Stirring speed } & =300 \mathrm{RPM} \\ \text { Duration } & =72 \mathrm{~h}\end{array}$

- Parameters measured

Viscosity at $100 \mathrm{~F}$ and $210 \mathrm{~F}$

Pentane insoluble

TAN

TBN 


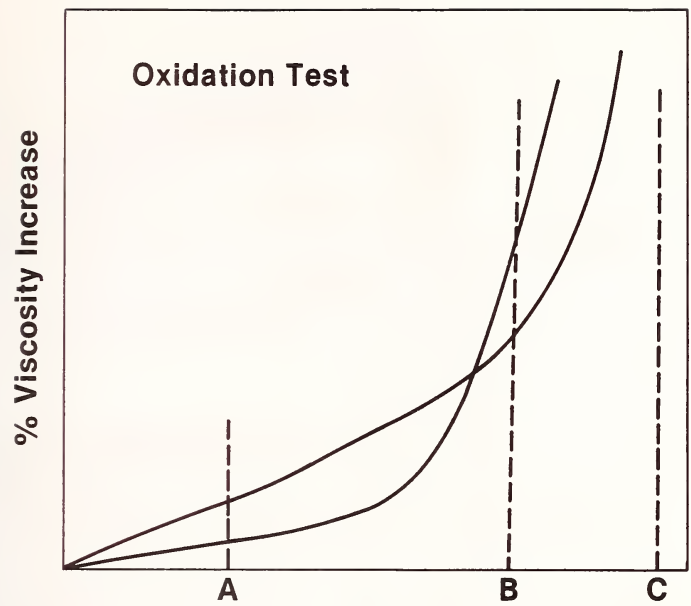

Time

Figure 4. Viscosity increase characteristics in oxidation tests.

has the advantage of measuring both the anti-oxidant present in the oil as chemical additives and the "natural inhibitors" in the oil itself. This parameter measurement in theory is much better than the carbonyl band measurement by infrared or viscosity increase, TAN etc. Klaus et al., [24] at Pennsylvania State University, under a research contract from the Recycled $0 i 1$ Program, are developing a rapid, thin-film, micro-oxidation test procedure. The oil film rests on a hot steel surface as shown in figure 5 and the molecular weight change is monitored by gel permeation chromatography. Initial results are very encouraging. Wing Tsang et al., [25] at the National Bureau of Standards, also under a research contract from the Recycled 0il Program, are examining the use of high pressure differential scanning calorimetry as a quick, precise measurement of lubricating oil oxidation stability. 0xidation induction time, heat of reaction, and the temperature under which oxidation occurs can be easily measured. This technique, if successful, could provide a sound theoretical background, as well as a practical oxidation bench test procedure.

\section{High Temperature Stability Tests}

In high temperature stability testing for automotive oils, the most prevalent tests are panel coker and hot tube. In the panel coker test small droplets of oil are continuously splashed on a hot metal panel as shown in figure 6. The panel is usually kept at $600{ }^{\circ} \mathrm{F}$ $\left(316^{\circ} \mathrm{C}\right.$ ) and after two to six hours of operation, the panel deposit is rated for lacquer deposit or the weight gain is determined. Sometimes, heated gaseous environment of $\mathrm{NO}_{2}$ and $\mathrm{SO}_{2}$ is introduced. The hot tube test [26] consists of bubbling oil with air or $\mathrm{NO}_{2}$ upward through the inside of a capillary glass tube kept at high temperatures as shown in figure 7. The test is used to simulate IIIC, $I H$, and $I G$ engine tests. For IIIC simulation, the test is run at $395^{\circ} \mathrm{F}$ with $2000 \mathrm{ppm} \mathrm{NO}$. For $1 \mathrm{H}$ simulation, the conditions are $495^{\circ} \mathrm{F}$ with air and $530^{\circ} \mathrm{F}$ for $1 \mathrm{G}$ test. The oil flowrate is kept at $1 / 3 \mathrm{cc} / \mathrm{h}$ for sixteen hours. The glass tube is then rated against standards for deposits. Generally, these two tests simulate the high temperature ring belt conditions of $1 \mathrm{H}, 1 \mathrm{G}$ engine tests. Correlation with weighted total deposits (WTD) is fair, partly because the WTD itself is not too repeatable in the engine tests. When compared to the diesel deposit mechanisms as shown 


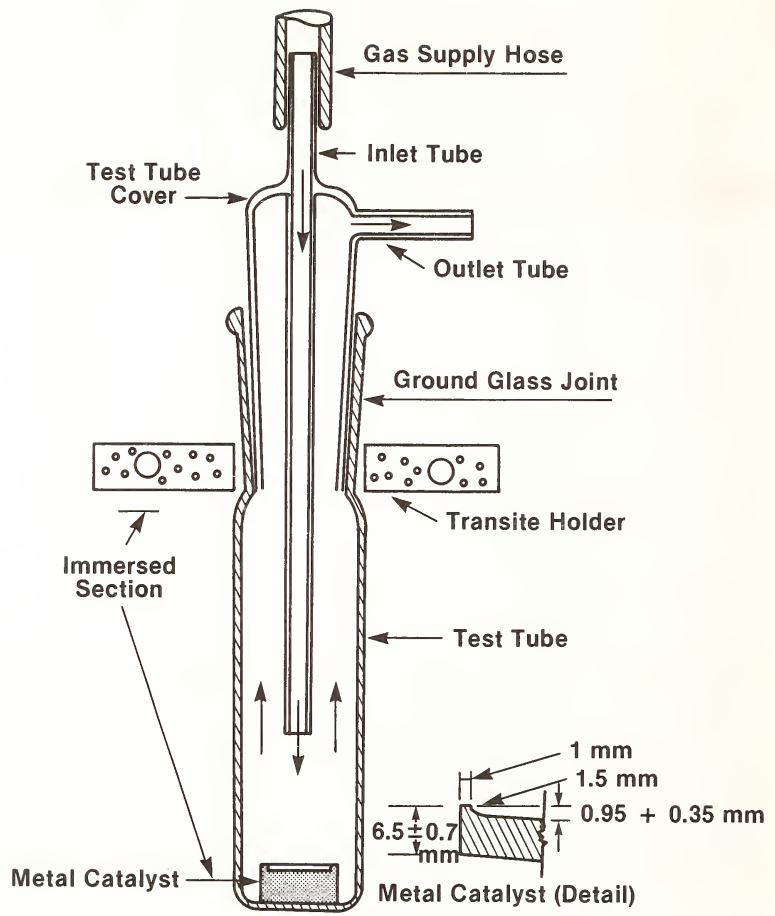

Figure 5. Pa, state micro-oxidation test apparatus.

in figure 2, the acidic environment of $\mathrm{SO}_{2}, \mathrm{SO}_{3}$, and $\mathrm{H}_{2} \mathrm{O}$ in the presence of soot is not being simulated. These two tests reflect the high temperature stability of oils under oxidizing conditions. Used oil analysis from $I H$ and $1 G$ engine tests suggests nitration is the predominant reaction path.

In the panel coker test, the cleanliness and surface roughness of the panel are important. The difference in deposits between aluminum and steel panels is also significant. Variation in operating temperatures, and the way the oil is splashed onto the panel are some of the common modifications. Some experimented with intermittent oil splashing to more closely simulate the engine operations. Detail correlation data of these tests and their modifications are not available in the public domain. 


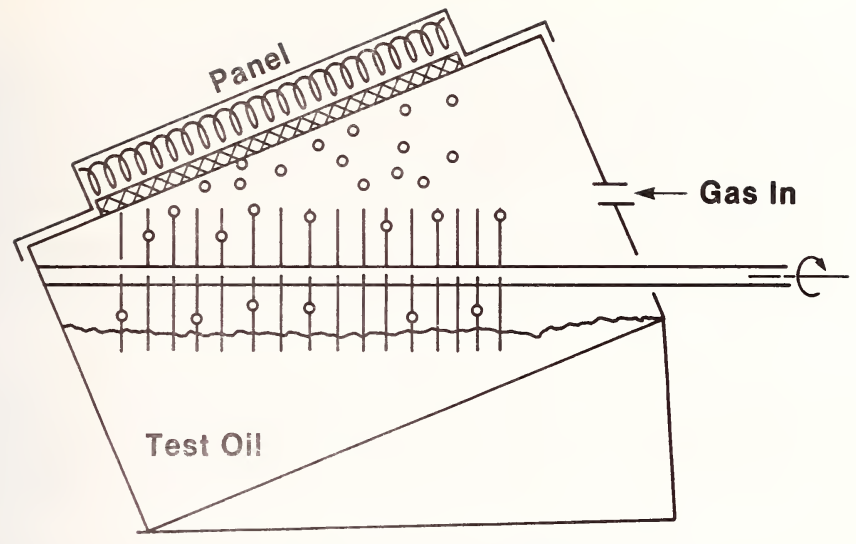

Figure 6. Panel coker equipment.

Glass Capillary

Tube

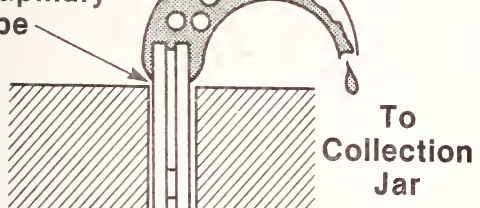

Aluminum

Thermostat

Figure 7. Hot tube apparatus.

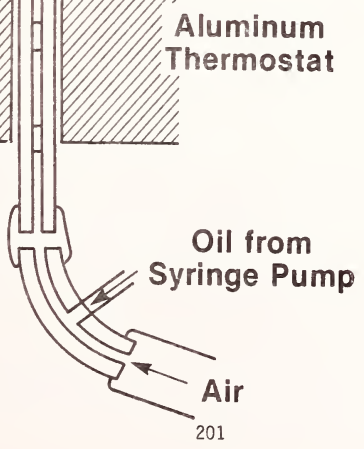




\section{Dispersancy Tests}

There are more tests on dispersancy than any other area. The most commonly used technique is the blotter spot test. It consists of either coking the oil with additives or putting some additives into a fixed amount of standardized used oil/sludge. The oil is then spotted on blotter paper or chromatograpic paper. After a fixed period of time, two concentric circles are formed as the sludge/used oil diffuses out radially. The ratio of the sludge ring (the inner black ring) over the oil ring (the outer transparent ring) indicates the degree of dispersancy, i.e., the ability to keep oil insoluble materials in suspension.

Carbon black is sometimes added to the oil and after heating at high temperatures, the oil is spotted. Some procedures use elaborate heating cycles to produce so-called "organic binder" to aggregate the fine carbon black in the oil. Generally, the spot method is sensitive to water. If used oil is used, it should either be dried or the water content adjusted to a fixed level.

The basic requirement in controlling sludge (oil insoluble oxidation products) is the ability of the oil to solubilize fine dispersions either in colloidal or micellar form. This kind of test then offers insight into the relationship between molecular structures of the additive molecules and the ability to disperse. Various forms of oil insoluble solids are employed: carbon black, pyruvic acid, rhodamine $\mathrm{C}$ dye, titanium oxide, pentane insoluble, and sludge form used oil. Generally, the ability of the additive to disperse these solids in stable form is measured. The results are often expressed in percent dispersed or in the case of acids, the amount of base used in titration. These methods are similar to blotter spot tests.

Bowden, Dimitroff et al., [26,27] used electrophoresis technique under a microscope to study the mobility of sludge particles under the influence of electric charge. Blagovidor et a1., $[28,29]$ recently developed a technique to measure the electroconductivity properties of $0 i 1 \mathrm{~s}$. He compared the electroconductivity of an oil containing the dispersant additive to an oil containing the same additive plus 2 percent lamp carbon black (specific surface of $\left.97 \mathrm{~m}^{2} / \mathrm{gm}\right)$. By plotting the ratio of the electroconductivities versus additive concentration he was able to define the critical micellar concentrations for various forms of additives. This technique holds promise to elucidate the basic mechanisms of dispersants/detergent.

\section{Discussion and Conclusions}

Bench tests are simple tools used to study a very complex phenomenon, the field test. Because of the enormous expenses and time involved in the field test, engine dynamometer "bench tests" are developed. In time, these engine bench tests become prohibitvely costly, laboratory scale bench tests are used. With each simplification step it is easy to forget the real objective of realistic simulation of field conditions. Table 10 summarizes some of the characteristics of bench, engine, and field tests.

Table 10. System comparison of bench test, engine test, and field test.

Bench Test

Closed system

Short duration

Severe condition

Single aspect

Simple

No combustion

Exaggerated difference

Low cost
Engine Test

Closed system

Short duration

Severe condition

Multiple controlled parameters

Complex

Combustion

Strong difference

Costly
Field Test

Open system

Long duration

Mild condition

Multiple parameters

Very complex

Combustion

Good difference

Expensive 
In simulation tests, the most important question may be what conditions are to be simulated? In a very complex system, the question then becomes what are the "key conditions" to be duplicated? In engine test simulation, the analysis of used oil and the understanding of the steps or conditions that lead to the final state is essential for successful simulation. Most of the commonly used bench tests, when evaluated against the engine deposit mechanisms, fail to duplicate most of the conditions. This may, in part, account for the poor reputation of bench tests as a predictive tool in oil performance evaluation.

Based on the results and discussions, the following conclusions may be drawn:

1) As a simulation model to predict performance, the existing bench tests are useful but inadequate.

2) Properly used, bench tests may be useful in checking consistency of some aspects of oil quality.

\section{References}

[1] Geyer, J., The mechanism of deposit formation and control in gasoline engines, ACS Symposium, New York (Sept. 7-12, 1969).

[2] Williams, A. L., Lacquer precursor from a paraffinic lubricant traced by Carbon 14, ACM Symposium, New York (Sept. 7-12, 1969).

[3] Vineyard, B. D. and Coran, A. Y., Gasoline engine deposit: 1. Blowby collection and the identification of deposit precursors, ACS Symposium, New York (Sept. 7-12, 1969).

[4] Coran, A. Y. and Vineyard, B. D., Gasoline engine deposit: II. Sludge binder, ACS Symposium, New York (Sept. 7-12, 1969).

[5] Dimitroff, E. and Quillian, R. D., Low temperature engine sludge - what? - where? how?, Internationa] Automotive Eng. Cong., SAE paper no. 650255, Detroit (Jan. 1965).

[6] Dimitroff, E., Moffitt, J. V., and Quillian, R. D., Aromatic compounds in fuels identified as main precursors of engine varnish, SAE Journal, 77, [7], 52-58 (1969).

[7] Berry, E. and Webster, A. B., Emulsion formation in gasoline engines, J. Inst. Petrol., 55, [544], 245-272 (1969).

[8] Spindt, R. S., Wolfe, C. L., and Stevens, D. R., Nitrogen oxides, combustion, and engine deposits, SAE Trans., 64, 797-811 (1956).

[9] Dimitroff, E., Mofitt, J. V., and Quillian, R. D., Why, what, and how: Engine varnish, ASME Trans. J. Lubr. Tech., 406-410 (July, 1969).

[10] Rogers, D. T., Rice, W. W., and Jonach, F. L., Mechanism of engine sludge formation and additive action, SAE Trans., 64, 782-811 (1956).

[11] Anderson, D. J., Mechanism of Engine Deposit and Wear. A progress report, Jap. Petrol. Inst. Meeting, Tokyo, Japan (0ct. 1968).

[12] Verley, G. M. and Ovist, E. G., The kinetics of crankcase oil contamination and piston fouling în the diesel engine, ACS Chicago Meeting (Aug. 30 - Sept. 4, 1964).

[13] Rudinger, V., A model for the deposit formation on diesel engine pistons, Erdol und Kohle, 27, [7] (1974).

[14] Spedding, H. and Noel, S. F. W., Development of techniques for the analysis of piston lacquers by infrared spectroscopy, Tribology (Feb. 1972).

[15] Denison, G. H. and $\mathrm{Clayton,} \mathrm{J.} \mathrm{0.,} \mathrm{Chemistry} \mathrm{and} \mathrm{prevention} \mathrm{of} \mathrm{piston} \mathrm{ring} \mathrm{sticking,}$ SAE Trans., 53, [5], 265-268 (1945). 
[16] Kreuz, K. L. and Love, R. F., Role of sulfur in deposit formation and lubricant degradation in diesel operation, ACS Meeting, New York (Sept. 7-12, 1969).

[17] Burgess, J. E., Morris, A. L., and Vickers, M. A., Chemistry of diesel deposits formation - a study of model processes, ACS Meeting, San Francisco, CA (Apri1 2-5, 1968).

[18] Wing, R. D. and Saunders, 0., $0 i 1 \mathrm{film}$ temperature and thickness measurements on the piston rings of a diesel engine, Proc. Inst. Mech. Engr., 186, 1-9 (1972).

[19] Deen, H. E. and Schetelich, A. A., An improved method for measuring ring zone temperatures in Caterpillar test engines explains piston deposits, SAE preprint No. 542C (1962).

[20] Manufacturing standards, MC/BJ 10-1, Ford Motor Company, Detroit, MI.

[21] MORCO Oxidation Test, Motor $0 i 1$ Refining Co., Lyons, IL.

[22] Mahoney, L. E., Korcek, S., Hoffman, S., and Willermet, P., The determination of the antioxidant capacity of new and used lubricants; method and applications, I\&EC Product $R \& D, 17,250$ (1978).

[23] Willermet, P. A., Mahoney, L. R., Kandah, S. K., and Sever, A. W., The application of antioxidant analys is to transmission fluid testing, SAE paper no. 790016, Detroit, MI, (Feb. 26 - March 2, 1979).

[24] Cvitkovic, E., Reaction rate studies on ester oxidation, M.S. Thesis, Chemical Engineering Department, Pennsylvania State University, University Park, PA (1976).

[25] Tsang, W. and Walker, J., Application of differential scanning calorimetry to the characterization of lube oils, Third Conference on Recycled 0il, NBS, Gaithersburg, MD (0ct. 23-26, 1979).

[26] Bowden, J. N. and Dimitroff, E., Electrophoresis of dispersant lubricating oils, ACS Petroleum Chemistry Preprint, 6, N4, B-5 (1961).

[27] Dimitroff, E., Moffitt, J. V., and Quillian, R. D., Dispersancy prediction by optical microscopy, SAE paper 600B presented at Philadelphia, PA (Nov. 1962).

[28] Blagovidov, I. F., Lapin, V. P., Shkolnikov, V. M., and Shor, G. I., Laboratory methods for investigation of additive oil detergency, Proc. First European Tribology Cong., Inst. Mech. Engr., London, England (Sept. 25-27 1973).

[29] Blagovidov, I. F., Lapin, V. P., and Shor, G. I., Exploitation properties of fuels and oils, Phlenum Translation from Khimiyai Tekhnologiya Topliv i Masel, 16, [1], 37-41 (1971). 
National Bureau of Standards Special Publication 584. Proceedings of Joint Conference on Measurements and Standards for Recycled 0il/Systems Performance and Durability held at NBS, Gaithersburg, MD, October 23-26, 1979. (Issued Nov. 1980)

\title{
DEVELOPMENT OF THE ARMY THERMAL OXIDATION LUBE OIL TESTER
}

\author{
Mike Valtierra and Sidney J. Lestz \\ U.S. Army Fuels and Lubricants Research Laboratory \\ Southwest Research Institute \\ San Antonio, TX
}

\section{Introduction}

The U.S. Army has a requirement to develop a bench-scale test capable of evaluating candidate military specification engine and gear lubricants. Of major concern in lubricant performance is the amount of oil deposits that is formed on hot surfaces since excessive deposits can drastically shorten the life of an engine. The Army currently has five specifications for their engine and gear oils, namely: MIL-L-2104C; MIL-L-46152; MIL-L-46167; MIL-L-21260; and MIL-L-2105. However, it is believed that these specifications may fail to provide sufficient quality control for new oil batch-to-batch variations, whether of virgin or re-refined origin. Also, quality conformance or quality assurance for new oils brings up the question, "Is our new oil buy on a current specification going to be as good as the 'original' qualified sample?" "What about re-refined oils?" An effective bench test can help answer some of these questions and can assist in new lubricant development, particularly in the area of oil deposition.

\section{Background}

Historically, the evaluation of engine and gear lubricant performance in the areas of deposition, degradation, viscosity stability, and wear has relied primarily upon data generated using single-cylinder and full-scale engine dynamometer and gear-train dynamometer tests. These tests, including the single-cylinder engine tests, are expensive and time consuming. In order to reduce dependence on costly engine tests and full-scale gear-train tests, investigation of bench-scale performance tests similar to those used in MIL-L -7808 , MIL-L-23699, and MIL-L-17331 lubricant specifications is proposed for initial screening of engine and gear lubricants.

\section{Objective}

The objective of this work is to develop a bench-scale test capable of evaluating ground vehicle engine and gear lubricant performance in the area of oil deposition. The test should be capable of providing initial screening for candidate military specification lubricants, oil base stocks, and re-refined oils and should correlate with full-scale engine tests.

\section{Test Development}

In order to meet these goals, the Army Fuels and Lubricants Research Laboratory (AFLRL) at Southwest Research Institute investigated the use of bench-scale performance tests similar to those used in Air Force and Navy MIL-L-7808, MIL-L-23699, and MIL-L-17331 lubricant specifications. The study consisted of: 1) investigating current bench-scale tests; 2) selecting two promising tests; 3 ) generating limited test data using the two testers; and 4) selecting the most promising tester and generating additional data for correlations with engine test stand data. 


\subsection{Current bench tests}

A brief study was performed to investigate existing bench tests. The following tests were considered: 1) oxidation-corrosion tests, 2) WADD gear machine, 3) Cannon shearstability test, 4) thermal oxidative test, 5) hot-wall deposition test, and 6) the AFLRL-modified Alcor Test Fuel Thermal 0xidation Tester (JFTOT) test. The study indicated that the hot-wall deposition test and the AFLRL-modified JFTOT (now called the "LUBTOT") test were the most promising.

\subsection{Hot-wall deposition test device}

The hot-wall deposition test rig was developed for the Air Force and is described in AFAPL-TR-72-25. This test rig utilizes a component of a jet engine on which oil deposits are formed. A special resistance heater was designed and attached to the jet engine component to provide a heat source. $0 i 1$ was sprayed onto the flat surface at a controlled rate. A rating technique was developed to rate the $0 i 1$ deposits formed on the hot, flat surface. Four lubricants (RE0-185, -203, -204, and CCL-L-709) were evaluated using the hot-wall deposition test rig, and the results were compared to available Caterpillar 1 G test data. The deposition data obtained from the hot-wall deposition test rig ranked the four lubricants in the same relative order as the Caterpillar 1-G mean weighted total demerit (WTD) ratings.

\subsection{Alcor Jet Fuel Thermal 0xidation Tester}

Figure 1 illustrates the unmodified Alcor Test Fuel Thermal 0xidation Tester. This device is normally used for ASTM D 3241 fuel tests, but was modified with an external recirculating oil system to study oil deposition. This tester is of interest because of several distinct advantages over the hot-wall deposition tester, namely: 1) ease of controlling test variables, 2) small oil sample required, 3) ease of cleaning between tests, 4) sample unbias deposit rating method, and 5) lower cost per sample. The test section and fuel reservoir are shown on the right side of the illustration.

\subsection{The LUBTOT tester}

Figure 2 illustrates the LUBTOT oil-air flow system that was incorporated into the JFTOT. The tester consists of a stainless steel heater tube as the test section in which deposits are formed. Heat energy is directed into the heater tube by the bus bars located at each end of the tube. A control thermocouple is placed into the hollow heater tube. $0 i 1$ and air are directed around the outside of the heater tube by a metering pump and flowmeter, respectively. The oil-air then passes from the heater tube housing and is returned to a vented reservoir. From the reservoir, the lubricant is directed to the metering pump and the cycle is repeated. An oil-in preheater maintains the oil-in temperature at a controlled value.

\subsection{Test conditions}

Table 1 illustrates the test conditions established for the LUBTOT. In this program, it was decided to vary the heater tube temperature and hold the other variables constant. A series of tests was performed at different heater tube temperatures ranging from $246{ }^{\circ} \mathrm{C}$ $\left(475{ }^{\circ} \mathrm{F}\right)$ to $371{ }^{\circ} \mathrm{C}\left(700^{\circ} \mathrm{F}\right)$ in order to establish a reasonable test temperature. An oil volume of $100 \mathrm{ml}$ was selected, while the oil-in temperature was controlled to $93^{\circ} \mathrm{C}\left(200{ }^{\circ} \mathrm{F}\right)$. The $0 i 1$ and air flowrates were set at 3 and $10 \mathrm{ml} / \mathrm{min}$, respectively. A vented reservoir was used, and a test time period of six hours was selected.

\subsection{Test lubricants}

The test lubricants selected for this work may be divided into three groups: 1) CRC Reference Engine $0 i 15,2$ ) Army Military Specification 0ils, and 3) formulated re-refined oils. Correlation work was performed using CRC Reference oils: RE0-185, RE0-191, RE0-203, RE0-204, and CCL-L-709. These oils were selected because of the available single-cylinder Caterpiliar (CAT) reference test deposition data on Weighted Total Demerits (WTD) and Top Ring Groove Fill (TGF). 


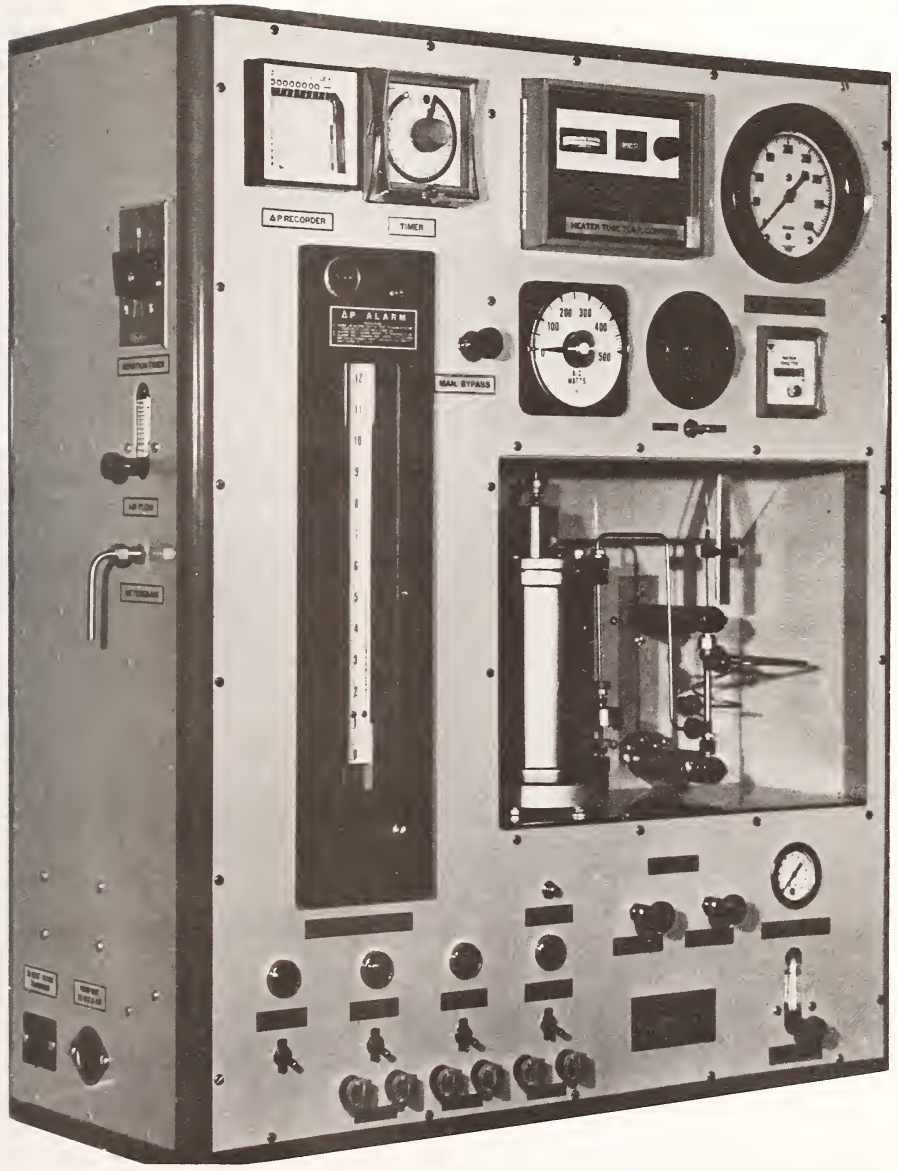

Figure 1. Alcor Jet Fuel Thermal 0xidation tester. 


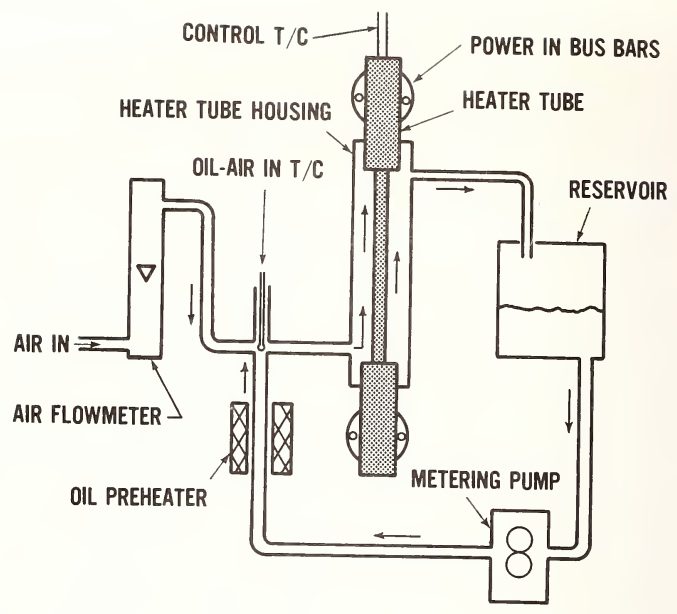

Figure 2. The LUBTOT oil-air flow system.

Table 1. Test conditions.

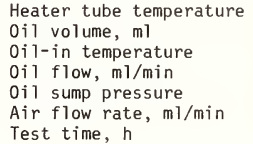

Heater tube temperature

$0 i 1$ volume, $\mathrm{ml}$

0i1-in temperature

0il flow, ml/min

Air flow rate, $\mathrm{ml} / \mathrm{min}$

Test time, $h$

Other lubricants investigated included the following Army Military Specification 0ils:

$\begin{array}{ll}\text { MIL-L-2104C } & \text { tactical/combat oil, single viscosity grade, OE/HDO } \\ \text { MIL-L-2104C } & \text { tactical/combat oil, candidate multiviscosity } \\ \text { MIL-L-46152 } & \text { commercial/administrative oil } \\ \text { MIL-L-46167 } & \text { Arctic engine oil, OEA } \\ \text { MIL-L-21260B } & \text { preservative/break-in oil }\end{array}$

A few tests were also performed using different re-refined base stock oils and formulated re-refined oils conforming to the MIL-L-46152 specification. 


\subsection{Test procedure}

Prior to starting a test, the 316 stainless steel heater tube is placed in a lathe, rotated, and polished for cleaning. The center section of the tube (where the deposits are formed) is cleaned by using metal polish ( $A-1$ metal polish, J. L. Prescott Company, Passaic, $\mathrm{NJ}$ ) with lint-free disposable tissues. After cleaning, the heater tube is placed in a calibrated Alcor Mark 8 A Tube Deposit Rater (TDR) to obtain a clean tube rating.

The tube rater subjects the heater tube to a light source of known intensity. Reflected light from the heater tube is sensed and electronically measured and displayed by an indicator needle on a 0-50 scale, depending upon the intensity of the reflected 1 ight. A low reading indicates a low deposit level while a high reading indicates a high deposit level. A clean tube provides a TDR reading of 0 .

The clean rated heater tube is installed into the tester, and the reservoir is charged with $100 \mathrm{ml}$ of test oil. The test is then performed under controlled test conditions for six hours.

Upon completion of the test, the heater tube is removed, rinsed with trichloroethylene, and placed in the Alcor Mark 8A TDR to obtain a reading of the dirty tube. As before, readings are taken at three locations on the tube (while the tube is spinning) and averaged to obtain the LUBTOT rating.

\subsection{Typical deposits}

Figure 3 illustrates typical deposits formed on the heater tube after a six-hour test. The two heater tubes at the top were tested with RE0-204 $0 i 1$ at $371{ }^{\circ} \mathrm{C}\left(700^{\circ} \mathrm{F}\right)$. These tests resulted in LUBTOT ratings of 40 and 46 for tests $4 \mathrm{~A}$ and $2 \mathrm{~A}$, respectively. 0 ther tests performed under the same test conditions using REO-185 resulted in LUBTOT ratings of 31 and 32 for tests $3 A$ and $1 A$, respectively. Compositional analysis of the deposits obtained in the LUBTOT was beyond the scope of this program, and only recently was the concept of weighing deposits introduced.

\section{Discussion of Results}

LUBTOT tests were performed under controlled test conditions at various temperature levels in order to study oil deposition characteristics of various lubricants.

\subsection{Effect of test temperature}

Figure 4 illustrates the effect that test temperature has on various lubricants. This figure represents the spread of the LUBTOT deposit ratings obtained for CRC Reference oils, MIL-L-2104C oils, and MIL-L-46167 oils subjected to $260^{\circ} \mathrm{C}\left(500{ }^{\circ} \mathrm{F}\right), 316{ }^{\circ} \mathrm{C}\left(600{ }^{\circ} \mathrm{F}\right)$, and $371{ }^{\circ} \mathrm{C}\left(700^{\circ} \mathrm{F}\right)$ temperature levels. As expected, when the heater tube test temperature was increased, a corresponding increase was obtained in the LUBTOT deposit ratings. There was some noticeable overlap in the LUBTOT deposits for the three temperature levels investigated. This overlap can be attributed to normal test scatter, lubricant effectiveness, and lubricant ineffectiveness under selected test conditions.

\subsection{Effect of deposit buildup}

A series of LUBTOT tests was performed using three reference engine oils to study the effect of deposit buildup. Figure 5 illustrates the results obtained with RE0-204, RE0-191, and REO- 185 reference engine $017 \mathrm{~s}$ at $315{ }^{\circ} \mathrm{C}\left(600^{\circ} \mathrm{F}\right)$. In these three groups of curves, the abscissa denotes the LUBTOT test time in hours with the ordinate denoting the LUBTOT deposit rating. In each of the tests, the heater tube was removed every hour and rated, then the LUBTOT test resumed for up to six hours. The dark points at the six-hour time interval indicated other uninterrupted LUBTOT tests performed on the REO oils. 


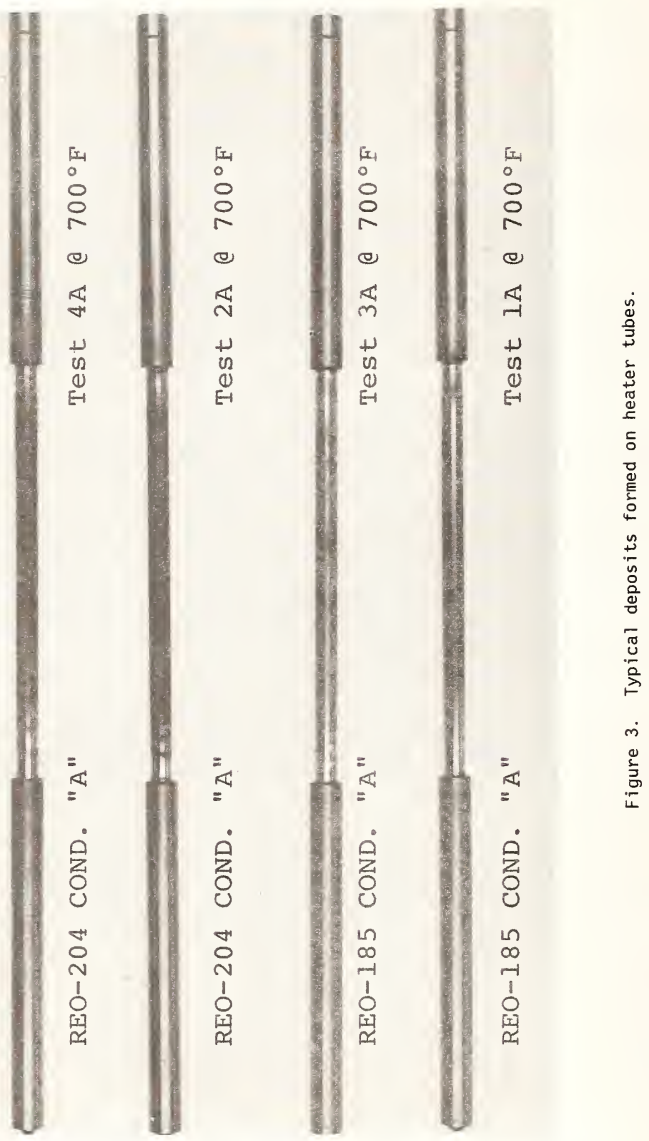




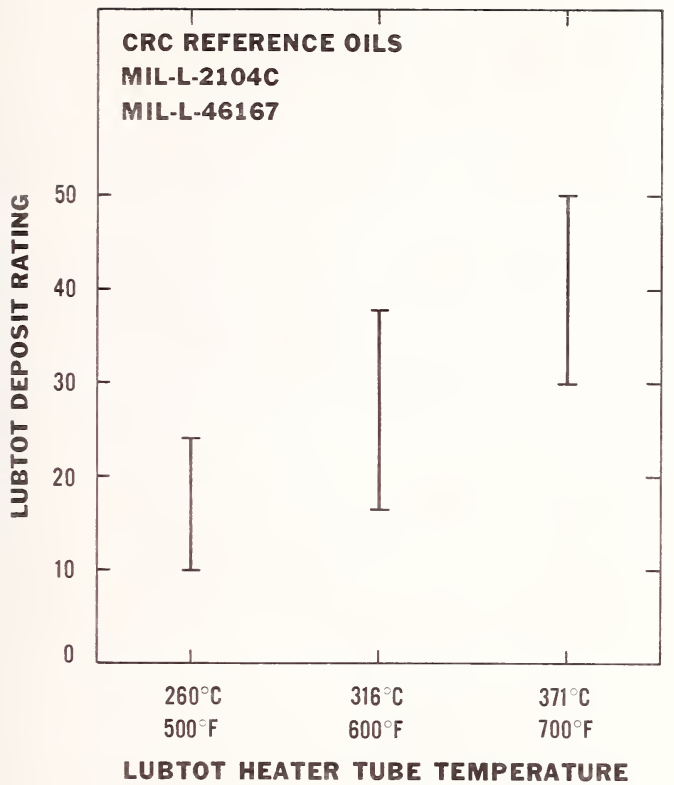

Figure 4. Effect of test temperature.

The results obtained with the REO-185 high ash, series 3 oil buildup tests showed a very low increase in deposit buildup with time. Other tests performed with the RE0-191 lubricant (a CRC Reference oil for MIL-L-2104B) resulted in a greater increase in deposit buildup with time. Three additional tests performed with the CRC Reference lubricant REO-204 (now an existing reference oil for MIL-L-2104C) resulted in an increase in buildup of deposits, with the deposits leveling out after about three hours in the tester. Test repeatability appears to be reasonable for the lubricants evaluated, while discriminating lubricant quality levels.

As noted earlier, the U.S. Army has a requirement for using various military specification lubricants for various vehicle applications. In order for these lubricants to be qualified under a specific military specification, they must pass one or more required diesel engine tests. Table 2 lists the major Army ground vehicle lubricants. LUBTOT tests were performed using these lubricants. 
Table 2. Army oils and diesel engine test.

0ils

MIL-L-2104C

MIL-L-2104C

(Proposed multivisc)

MIL-L-46152

MIL-L-46167

MIL-L-21260B
Required diesel engine tests

CAT $1-D, 1-G 2$

CAT 1-D, 1-G2, proposed 6V-53T

CAT $1-\mathrm{H}_{2}$

6V-53T Arctic procedure

CAT 1-D, CAT 1-G2
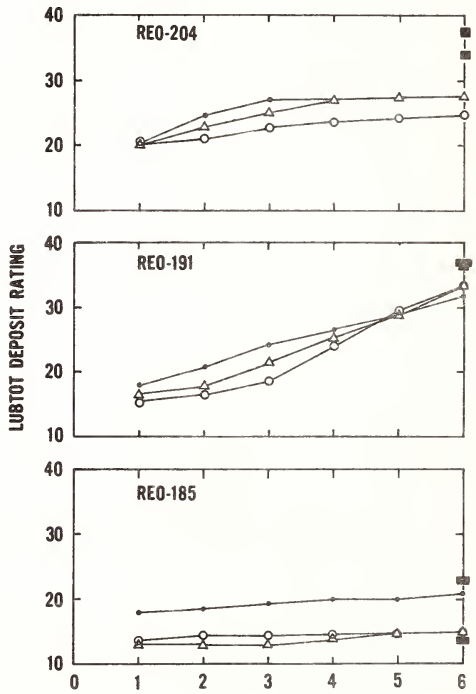

TEST TIME, HRS

Figure 5. Effect of deposit buildup.

As noted in table 2, the straight grade MIL-L-2104C, the proposed multiviscosity MIL-L-2104, and the MIL-L-21260B specifications require (Caterpillar) CAT- 10 and $1-G 2$ diesel engine tests.

The proposed multiviscosity lubricant may also require a 240-hour 6V-53T diesel engine test for lubricant qualification. The MIL-L-46152 administrative oil requires the CAT 1-H2 test while the MIL-L-46167 Arctic oil requires a $6 \mathrm{~V}-53 \mathrm{~T}$ test performed using the Arctic procedure. All of the required diesel engine tests are described by various Federal Test Methods. 


\subsection{Correlation of LUBTOT tests and engine tests}

Single-cylinder Caterpillar reference test data were obtained for most of the lubricants used in the LUBTOT program. Single test deposit information for both top ring groove fill and weighted total demerits were obtained from MERADCOM for 1-D, 1-G, I-G2, I-H, and 1-H2 Caterpillar tests performed on military specification oils. Also, single test results performed at AFLRL on 6V-53T diesel engines were collected. Other engine test results were also obtained for Caterpillar Reference Tests for REO and CCL oils.

Of prime importance in any correlation made between test devices is test repeatability. It is well known that the single-cylinder Caterpillar reference test performed on selected REO and CCL lubricants results in considerable variance in test repeatability. Reference ratings are usually tabulated and provide the number of tests performed, the mean rating, and the standard deviation calculated for the number of tests performed.

\subsection{LUBTOT and CAT $1-\mathrm{G}$ test results}

Duplicate LUBTOT tests performed using three REO oils resulted in a straight line correlation between LUBTOT results and Cat $1-G$ tests using the WTD mean ratings. In figure 6 , the abscissa denotes the LUBTOT deposit rating with the ordinate denoting the Caterpillar reference test Weighted Total Deposits. Duplicate LUBTOT tests were performed at $316{ }^{\circ} \mathrm{C}$ $\left(600^{\circ} \mathrm{F}\right)$. The test data for the REO oil tests are shown with the minimum and maximum values of the CAT I-G test data using the 80 percent confidence 1 imit range. A reasonable sample size ranging from 11 to 39 tests was available for all REO oil tests, thereby adding confidence to the reference test data and subsequent correlation. Duplicate LUBTOT tests resulted in good test repeatability. As noted by the dash line, a straight line correlation was obtained.

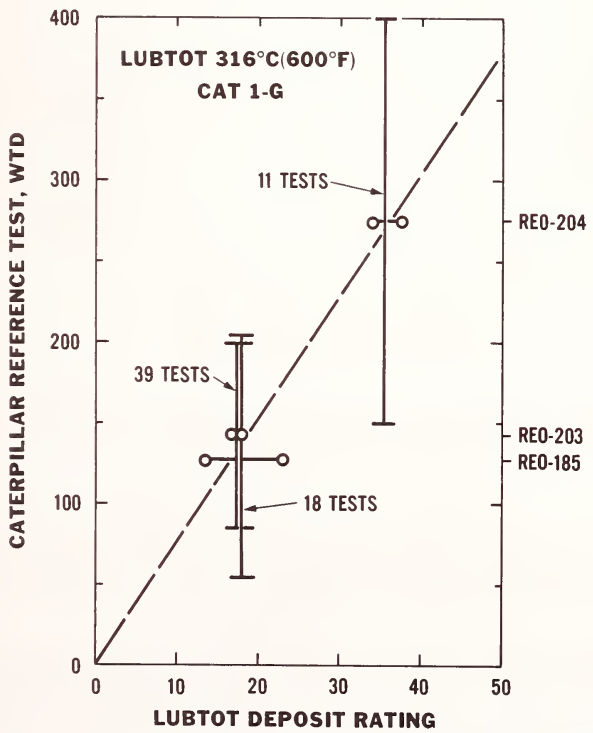

Figure 6. Correlation between LUBTOT and Caterpillar 1-G tests. 
Figure 7 illustrates the results obtained for four MIL-L-2104C lubricants evaluated at $316^{\circ} \mathrm{C}\left(600^{\circ} \mathrm{F}\right)$. The solid line represents the correlation curve obtained from figure 6 between the CAT 1-G tests and the LUBTOT results. As noted in the lower right, "AL" code numbers have been assigned to the commercial lubricants qualified under the MIL-L-2104C lubricant specification. In all cases, the single point test results fell below the correlation curve.

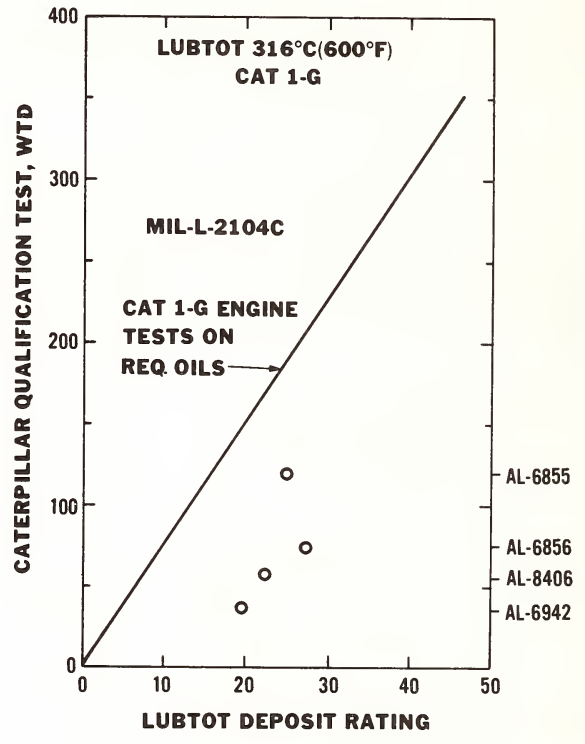

Figure 7. LUBTOT deposit ratings obtained on several MIL-L-2104C Army oils with corresponding Caterpillar qualification 1-G tests.

\subsection{LUBTOT and CAT $1-G 2$ test results}

Six LUBTOT tests were performed at $316^{\circ} \mathrm{C}\left(600^{\circ} \mathrm{F}\right)$ using REO-191, REO-204, and REO-203 reference oils. The results of these tests are plotted against the CAT 1-G2 WTD rating data and illustrated in figure 8 . As presented earlier for the CAT 1-G tests, the minimum, mean, and maximum values of the weighted total demerits are shown for each of the oils. The duplicate LUBTOT tests performed resulted in good repeatability.

The LUBTOT results for the REO-191 and REO-203 lubricants correlate well with the Caterpillar reference test WTD ratings, while the LUBTOT results obtained for the REO-204 oil were too high. 


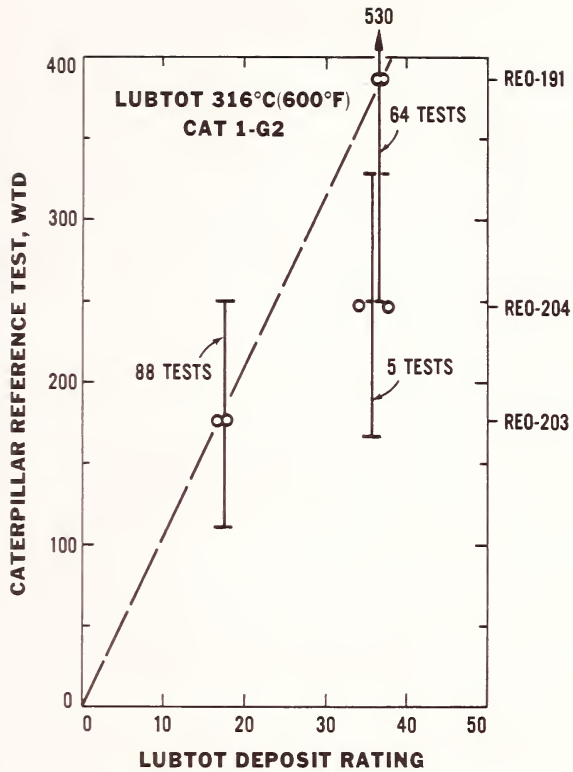

Figure 8. Correlation between LUBTOT and Caterpillar 1-G2 tests.

Figure 9 illustrates the results obtained for four military specification lubricants for which CAT 1-G2 test data were available. The solid line represents the average line for the CAT 1-G2 engine tests performed on the REO oils. The LUBTOT data obtained did not significantly differentiate deposit values for the several lubricants evaluated.

5.6. LUBTOT and CAT $1-D, 1-H$, and $1-H 2$ test results

Each of these reference tests had only two tests for comparison with LUBTOT test results. Based on the limited available data, no correlation trends could be made with either the "weighted total demerits" or the "top ring groove fill".

\subsection{LUBTOT and 6V-53T test results}

AFLRL performs 100- and 240-hour 6V-53T diesel engine tests using selected Army 1ubricants. These tests are mainly wear tests and are not specifically designed as oil deposition tests. However, ring groove carbon filling data are taken for both the 100- and the 240-hour tests. Pistons are rated for deposits in the 240-hour test only. 


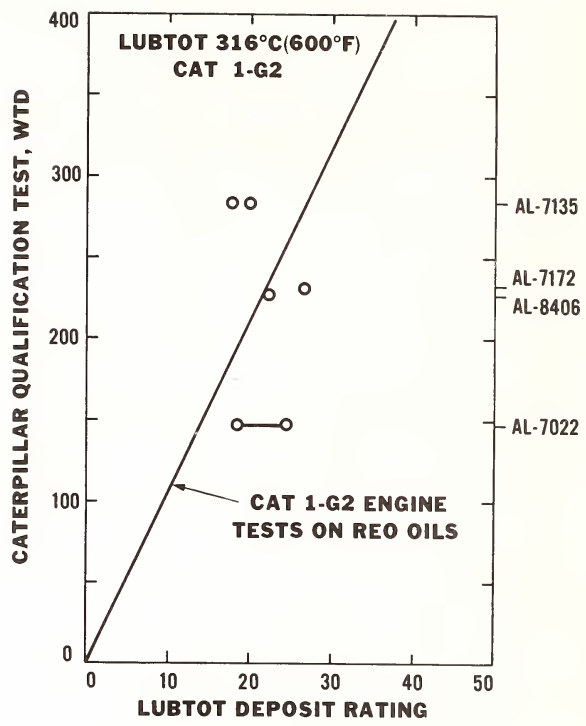

Figure 9. LUBTOT deposit ratings obtained on several Army oils with corresponding Caterpillar qualification 1-G2 tests.

An effort was made to study the piston deposits with corresponding LUBTOT tests. The results are presented in figure 10 . In this figure, the weighted total deposit data obtained for each of the six pistons were added and averaged. This average WTD rating was plotted against the LUBTOT data for the three MIL-L-2104C lubricants evaluated. The plot resulted in a correlation for $316^{\circ} \mathrm{C}\left(600{ }^{\circ} \mathrm{F}\right)$ LUBTOT tests performed. 0ther tests performed at $260^{\circ} \mathrm{C}\left(500^{\circ} \mathrm{F}\right)$ and $371{ }^{\circ} \mathrm{C}\left(700^{\circ} \mathrm{F}\right)$ resulted in more scatter in the LUBTOT data.

\subsection{Re-refined oil base stocks and formulated oils}

Of significant importance to the re-refiner is the capability to obtain a measure of consistency of base stock oils and to determine the effectiveness of formulated oils regarding oil deposition. Figure 11 illustrates the results obtained for various LUBTOT tests performed with re-refined oils. The clear bar charts represent the LUBTOT deposit data obtained for six different re-refined base stock oils. These LUBTOT tests resulted in nigh but different deposit levels for five of the six tests performed. These differences provide a measure of the consistency of the base stock oils evaluated.

Additional LUBTOT tests were performed using formulated oils (indicated by the dark bar charts) blended in accordance with MIL-L-46152 using the same six different re-refined oil base stocks, all with the same additive package. In five of the six cases, lower oil deposits were obtained, indicating the beneficial effect of the additive package as a result of the low LUBTOT deposit ratings. 


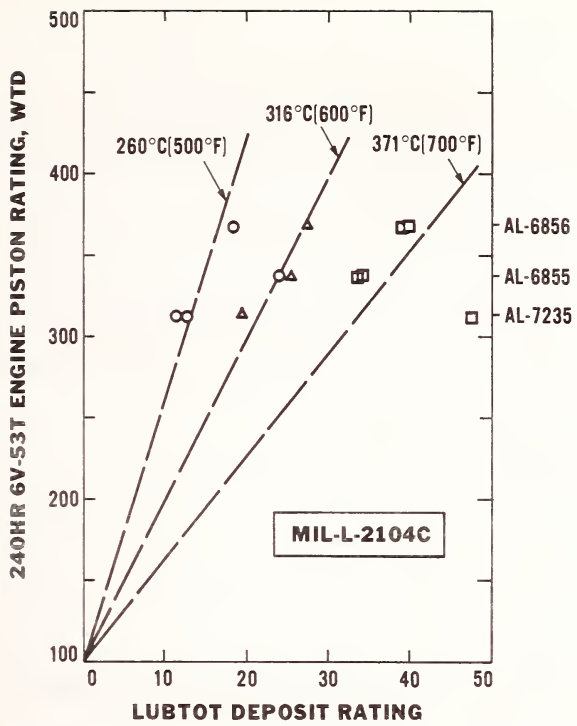

Figure 10. Correlation between LUBTOT and 6V-53T engine tests.

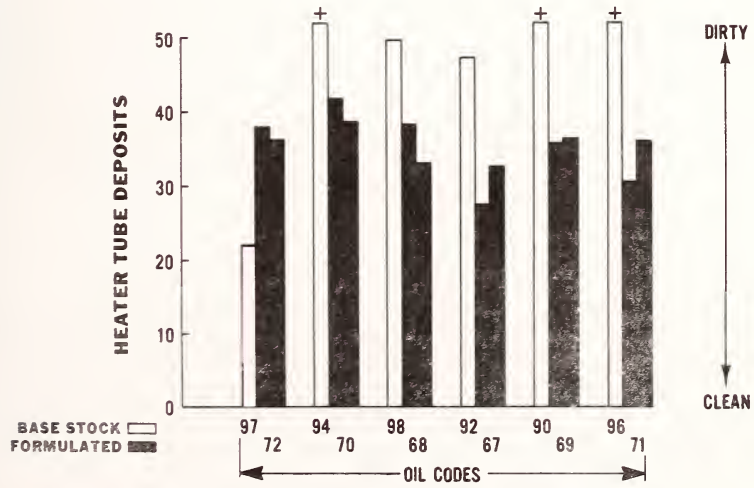

Figure 11. LUBTOT deposit ratings for re-refined base stock and formulated oils at $260^{\circ} \mathrm{C}\left(500^{\circ} \mathrm{C}\right)$. 


\subsection{Effect of base oil with feedstock}

Tests were performed with the LUBTOT tester at a test temperature of $246{ }^{\circ} \mathrm{C}\left(475{ }^{\circ} \mathrm{F}\right.$ ) to determine if the tester could identify residual contaminants in a given re-refined base oil. Figure 12 illustrates the results obtained with the percent feedstock as the abscissa and the LUBTOT Deposit Rating as the ordinate. In these tests, the test oils were contaminated with various percentages of drain oil feedstock.

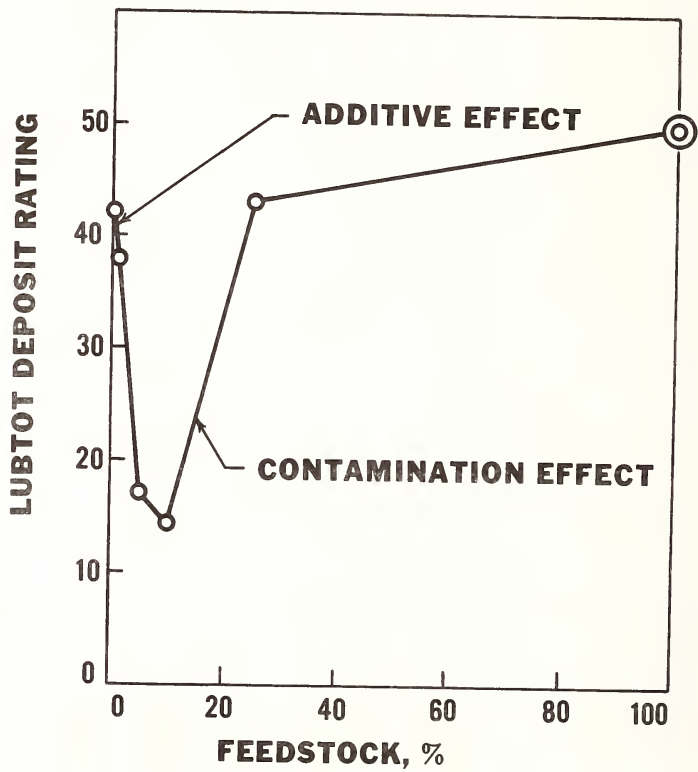

Figure 12. Effect of re-refined base oil contaminated with feedstock oil.

The test results indicated that both an additive and a contamination effect were present. Since very small quantities of feedstock were blended with the re-refined base oil, the LUBTOT produced fewer and fewer deposits down to a value of 15 . When more than 10 percent of feedstock was added to the re-refined base oil, the deposits increased drastically. Duplicate LUBTOT tests performed with 100 percent feedstock resulted in LUBTOT ratings of 50 plus. Since the LUBTOT deposits were not in direct relationship with increasing amounts of feedstock, it was not possible to identify residual contaminants in the re-refined oil. 


\section{Conclusions}

The following conclusions may be drawn from this work:

1) The AFLRL-developed LUBTOT appears to be an effective test device for evaluating lubricants regarding oil deposits that are formed under a set of controlled test conditions. The tester has several distinct advantages, namely: ease of controlling test variables, small oil sample required, ease of cleaning between tests, simple unbias deposit rating method, and low cost per test.

2) The test method developed thus far does correlate with some of the Caterpillar single-cylinder reference tests. However, the method does not correlate with the $1-D, 1-H$, and $1-\mathrm{H} 2$ test results performed on selected REO oils.

3) The LUBTOT appears to be capable of differentiating between different re-refined base stock, which can be important in identifying base stock consistency.

4) The LUBTOT can determine the effectiveness of the additive package in formulated oils regarding oil deposits caused by high-temperature operation.

\section{Recommendations}

1) Further development is needed to increase the LUBTOT's discriminating sensitivity of the deposit results.

2) Additional development work is required to improve correlation of the LUBTOT results with the two main reference tests, namely the CAT 1-G2 and the CAT 1-H2 tests.

3) Additional LUBTOT tests should be performed on oils that have failed the Caterpillar tests. This additional testing should aid in establishing a procedure for screening candidate lubricants, i.e., establishing a pass-fail criteria.

4) Consideration should also be given to studying the effect of oil-air residence time, oil volume, and greater air-to-oil ratios in an effort to further oxidize the test lubricant.

5) Additional LUBTOT tests should be performed using virgin base oils for direct comparison with virgin base oils with additives and re-refined base oils and re-refined oils with additives. 

National Bureau of Standards Special Publication 584. Proceedings of Joint Conference on Measurements and Standaris for Recycled $011 /$ Systems Performance and Durability held at N35, Gaithersburg, No, October 23-26, 1979. (Issued Nov. 1980)

\title{
PREDICTIVE TEST METHOD FOR COKING AND FOULING TENDENCY OF USED LUBRICATING OIL
}

\author{
G. L. Steele, D. W. Brinkman, and M. L. Whisman \\ United States Department of Energy \\ Bartlesville Energy Technology Center \\ Box 1398 \\ Bartlesville, OK 74003
}

\begin{abstract}
A short, reliable test has been developed to measure the coking and fouling tendency of used lubricating oils undergoing thermal stress.

The technique utilizes commercially available instrumentation and requires only $200 \mathrm{~mL}$ of sample and three hours analysis time. Correlations based on $0 i 15$ of known quality demonstrate good qualitative predictive abilities, while reproducibility studies demonstrated quantitative reliability. It is shown that ash content alone may not always be a reliable measure of fouling potential.
\end{abstract}

\section{Introduction}

The main reason for test method development in the petroleum field is to provide information that will improve processing efficiency. Heat transfer losses due to coking and fouling, and subsequent equipment downtime, can be extremely costly [3] ${ }^{1}$. Re-refining of used lubricating oil involves many processing techniques similar to those for virgin oil. However, contaminants found in used lubricating oil change its distillation characteristics, suggesting the need for a specific predictive fouling test for used crankcase oil. A process for re-refining used motor oil developed at the Bartlesville Energy Technology Center (BETC), formerly the Bartlesville Energy Research Center (BERC), includes flash and vacuum distillation steps $[8,9,10]$. Fouling of heat exchangers is a potential problem, especially in the early stages of processing an oil. Thus, a test designating the thermal stress characteristics of oil could save time and money.

The $0 i 1$ re-refining industry uses weight percent ash $[7,4]$ as an indirect measure of coking and fouling tendencies of oils. However, a more direct analysis technique is preferable, since unstable organic molecules degrade thermally and contribute to coking but are not observed in ash analysis.

Predictive methods described in the literature were developed for crude oil or finished fuel processing systems. The more familiar are the ASTM-CRC Coker Test [1], a hot-wire test [6], the Jet Fuel Thermal Oxidation Tester (JFTOT) [2], and the Erdco CFR coker [5]. These tests require considerable quantities of sample or several hours of analysis time, or both, and probably are not directly applicable to re-refining problems.

The method developed at BETC uses an apparatus with a flow-through cell containing a resistance-heated rod through the center. Except for reduced pressures, conditions within the cell can be adjusted to simulate parameters in full-size heat exchangers. Temperatures are maintained above those experienced in normal conditions in order to accelerate the appearance of problems. The increased temperature also compensates for the difference in residence time between the test section and the heat exchanger. $0 i 1 s$ of known character have shown the technique to perform well, both qualitatively and quantitatively. Because the method is based on constant flow for a fixed time period, it is adaptable to either onstream or laboratory operations.

Figures in brackets indicate the literature references at the end of this paper. 


\section{Experimental}

\subsection{Apparatus}

The Alcor Thermal Fouling Testing (JFTOT-210), used in the test, is a modified Alcor Jet Fuel Thermal Oxidation Tester. The Model 210 measures temperature change rather than pressure change as monitored by the latter unit. A $13 \mathrm{~cm}$ long, $5 \mathrm{~mm}$ i.d. test section was fitted with a 1015 carbon steel tube as shown in figure 1 . The automatic temperature control was connected to the heater tube thermocouple, instead of the temperature monitor, to more closely simulate actual heat exchanger operation. The entire unit is automated so that little operating time and attention is required.

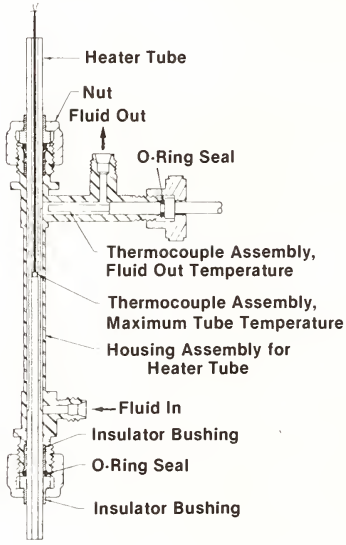

Figure 1. Heated test section.

\subsection{Procedure}

The feed pump is set so that oil passes over the resistance-heated steel tube at approximately $1 \mathrm{~mL} / \mathrm{min}$, providing a test section residence time of $100 \mathrm{~s}$. The thermocouple inside the heated tube is positioned $20 \mathrm{~mm}$ below the top of the heated section, normally, the hottest spot. This thermocouple is wired to the automatic temperature controller. Another thermocouple monitors the temperature of the oil leaving the test section. All test runs are for $180 \mathrm{~min}$ under a nitrogen pressure of $400 \mathrm{psig}$. The nitrogen pressure prevents temperature fluctuation due to vaporization.

The tube temperature was constant at $750^{\circ} \mathrm{F}$, unless otherwise noted. Thus, oil-out temperature was directly proportional to heat transfer efficiency which decreased due to coke build up on the tube surface. The difference between the original oil-out temperature at the start of the test and the final oil-out temperature was called delta T.

After each run, the tube was cleaned of excess oil by submerging it in a graduated cylinder of heptane for iwo inces, was.u with a stream of heptane, blown dry with air, and then weighed. The difference between this weight and that of the original tube is deposit weight. In addition to documenting changes in fluid temperature and deposit weight, a visual inspection of the deposits were made, including a photograph for future reference. The tube was then prepared for a subsequent run by removing the coke with abrasive cloth, 
smoothing with liquid metal polish, and rinsing with $n$-heptane. It is important to follow the procedure exactly when mixing the sample, heating, cleaning, and weighing the tube.

Deviations result in inconsistent data.

\subsection{Sample preparation}

Lubricating oils containing a range of contaminants were tested in this apparatus. These included commercial virgin-derived oils with additives, neat virgin-derived blending stocks, and used oil at various stages of re-refining. For a determination of the quantitative nature of this technique, the following mixtures of an oil known to cause heat exchanger fouling problems, (A), and a virgin-derived base stock, (B), were made: 1) 100 percent $A$; 2) 75 percent $A, 25$ percent $B$ (by volume); 3 ) 50 percent $A$, 50 percent $B$; 4) 25 percent A, 75 percent B; 5) 100 percent B. Ash analysis (ASTM D 482) confirmed the accuracy of these mixtures.

\section{Results and Discussion}

A standard requirement of any analytical method is the differentiation of qualitative variations in known samples. Utilizing the five sample mixtures described in the experimental section, the method provided good qualitative discrimination at several temperatures as shown in figure 2. A tube temperature of $750^{\circ} \mathrm{F}$ provided maximum sensitivity while permitting even problem samples to complete the 180 minute test period without plugging of the test section. Premature termination of a test because of excessive coking limits the usefulness of data obtained. By comparing the tubes from which curve 3 in figure 2 came, it can easily be seen that coke buildup increases with increasing temperature.

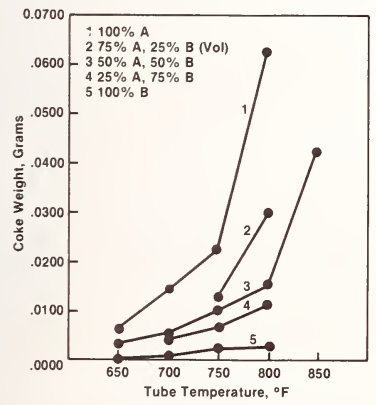

Figure 2. Gain in tube weight as a function of heated tube temperature for five lubricating oil samples.

Quantitatve precision of the method was measured in two ways. First, five runs were made with the same sample and the same tube. Then, 12 runs were made using four different tubes three times each, as would be the more normal situation. The sample was number three ( 50 percent $A, 50$ percent $B$ ) from the five standard mixtures. The change in fluid-out temperature (delta T) showed instrumental short-term instability of up to $10^{\circ} \mathrm{F}$, making the statistical significance of temperature data questionable. This problem seemingly is not correctable. However, the relative standard deviation for coke weight was only 5.4 percent for data from the same tube, and 9.5 percent for data from four different tubes. The implied difference in tubes can be partially attributed to thin areas from repeated cleaning, which become hot spots when used. The high cost of these special tubes discourages disposal after a single use. Tube weight variation was noted particularly when the oil coked significantly and the tube temperature was $750^{\circ} \mathrm{F}$ or higher. Heavy deposits showed a tendency to flake, creating another source of inconsistency. 
The weight of ash in a sample is commonly used as a measure of potential coking and fouling of an oil during thermal stress. Therefore, ash content and test results were compared for a wide variety of samples. The results are presented in figures 3 and 4 , showing coke weight versus ash, and change in fluid-out temperature (delta T) versus ash, respectively. All data were generated at a tube temperature of $750^{\circ} \mathrm{F}$. The scatter for the coke weight comparison is not nearly as large as for delta $T$. However, it is evident that ash content does not correlate well with Thermal Fouling Tester results. We attribute this lack of correlation to unstable organic components which would not show up in an ash test.

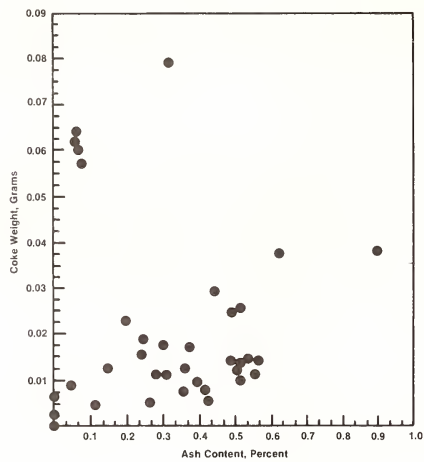

Figure 3. Coke weight vs ash content at $750^{\circ} \mathrm{F}$.

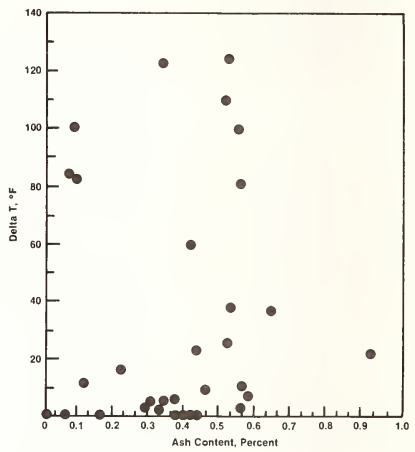

Figure 4. Delta $T$ vs ash content at $750{ }^{\circ} \mathrm{F}$.

Another problem the user must be aware of is the varying heat transfer efficiencies of different coke deposits. For example, two tubes had deposits of about $0.025 \mathrm{~g}$; yet the delta $\mathrm{T}$ for one was $110^{\circ} \mathrm{F}$, but only $6^{\circ} \mathrm{F}$ for the other. On the other hand, two tubes reflected a large difference in deposit weight, $0.017 \mathrm{~g}$ versus $0.993 \mathrm{~g}$. Yet the delta $T$ was $106{ }^{\circ} \mathrm{F}$ and $116^{\circ} \mathrm{F}$, respectively. Since the described method simulates actual conditions, both deposit weight and changes in heat transfer efficiency can help predict potential problems. Relying entirely on an indirect indication, such as ash content, may result in misleading assumptions.

Relating test results to actual heat exchanger problems is much more difficult. For example, used oil having an ash content of 0.21 percent gave a delta $T$ of $15^{\circ} \mathrm{F}$ and a coke weight of $0.0406 \mathrm{~g}$ under the described test conditions. During a pilot-scale operation, a 4.5 square foot tube and shel1 heat exchanger, with a residence time of 10.5 min, lost significant heat transfer efficiency using the same oil. While the heat exchanger temperature was held at $730^{\circ} \mathrm{F}$, oil emerging from the heat exchanger dropped in temperature by $100^{\circ} \mathrm{F}$ over a period of $72 \mathrm{~h}$. A second batch of oil with a higher ash content of 0.53 percent yielded the same delta $\mathrm{T}$ of $15^{\circ} \mathrm{F}$ and a lower coke weight of $0.0119 \mathrm{~g}$ on the Alcor test apparatus. In the pilot-scale heat exchanger, a decrease in the emerging oil temperature of only $4^{\circ} \mathrm{F}$ occurred after $80 \mathrm{~h}$ of continuous operation. This limited data implies that at least three factors must be considered in predicting coking and fouling of used lube oil. The first is temperature, since used motor oils are sensitive to thermal stress, and coking problems generally appear when the oil is raised to about $500^{\circ} \mathrm{F}$. The second is the duration or residence time at elevated temperatures. A short time (s) at temperatures above $500^{\circ} \mathrm{F}$ may prevent substantial coking especially if turbulent flow is maintained. And finally, ash must be considered as a contributing factor, although not necessarily a controlling factor in coke formation. 


\section{Conclusions}

The described test provides reproducible results if one monitors coke weight deposited on the heated tube. The method offers a relatively rapid and easy procedure for predicting coking and fouling tendencies of a lube sample, with obvious parallel application to crude oils and other similar materials. The automated instrumentation requires little operator supervision. Future use in connection with pilot- and full-scale operations should provide useful correlation data to help translate test results into predictable heat exchanger performance.

\section{References}

[1] ASTM D 1660-72, Standard Test Method for Thermal Stability of Aviation Turbine Fuels.

[2] ASTM D 3241-77, Standard Test Method for Thermal 0xidation Stability of Aviation Turbine Fuels (JFTOT Procedure).

[3] Braun, R. and Hausler, R. H., Instrument measures fouling, helps plan, $0 i 1$ and Gas J., $\underline{75}, 90-100$ (1977).

[4] Davidson, D. D. and Engesvik, B. I., Thermal treatment of used petroleum oils, U.S. Patent No. 4,033,859 (July 5, 1977).

[5] Frazier, A. W., Huddle, J. G., and Power, W. R., New, fast approach to reduced preheat-exchanger fouling, $0 i 1$ and Gas J., 63, 117-122 (1965).

[6] Hausler, R. H., New test will show fouling, $0 i 1$ and Gas J., 71, 56-63 (1973).

[7] Johnson, M. M., Reclaiming used motor oil, U.S. Patent No. 3,930,988 (January 6, 1976).

[8] Whisman, M. L., Reynolds, J. W., Goetzinger, J. W., and Cotton, F. 0., Process for preparing lubricating oil from used waste lubricating oil, U.S. Patent No. 4,073,719 (February 14, 1978).

[9] Whisman, M. L., Goetzinger, J. W., and Cotton, F. 0., Method of reclaiming waste lubricating oils, U.S. Patent No. 4,073,720 (February 14, 1978).

[10] Whisman, M. L., Reynolds, J. W., Goetzinger, J. W., Cotton, F. 0., and Brinkman, D. W., Re-refining makes quality oils, Hydrocarbon Processing, 141-145 (1978). 

National Bureau of Standards Special Publication 584. Proceedings of Joint Conference on Measurements and Standards for Recycled 0il/Systems Performance and Durability held at NBS, Gaithersburg, MD, October 23-26, 1979. (Issued Nov. 1980)

\title{
ANTIOXIDANT CONSUMPTION AND OXIDATIVE DEGRADATION OF LUBRICANTS
}

\author{
Stefan Korcek, Lee R. Mahoney, Milton D. Johnson, \\ and Klaus Otto \\ Engineering and Research Staff \\ Ford Motor Company \\ Dearborn, MI 48121
}

A general method for the determination of chain stopping antioxidants in new and used lubricants is described. The method is based upon the titration of diluted lubricant samples with peroxy radicals. In contrast to standard determinations of viscosity, acid number, and insolubles, the method provides information on lubricant oxidative degradation in the earliest periods of testing.

Examples of the application of the method in various correlation and mechanistic studies of engine oil deterioration in spark ignited internal combustion engines are given.

\section{Introduction}

Current engine oil formulations contain antioxidant additives which retard oxidative degradation in the early periods of oil usage. When these antioxidant species are depleted, oxidative degradation of the oil occurs at an accelerated rate. Thus, information on the antioxidant concentration and its decay during use is an important indicator of lubricant performance.

We have developed a method for the determination of the antioxidant capacity in new and used 0 ils. The method and its theoretical basis has been reported previously [1] ${ }^{1}$. This paper reviews the main features of the method and describes some of its most recent applications in various correlation and mechanistic studies of engine oil deterioration.

\section{Method}

The antioxidant species present in an oil sample are measured by titration with peroxy radicals

$$
\mathrm{AH}+\mathrm{nRO}_{2} . \quad \text { inactive products }
$$

The titration is performed in the oxidation apparatus shown schematically in figure 1 . A detailed description of the apparatus and procedure is given in the Appendix.

Peroxy radicals for the titration are formed at a known and constant rate from the thermal decomposition of a free radical initiator, azobisiobutyronitrile, in a model hydrocarbon oxidation system containing cyclohexene as an oxidizing substrate and $n$-hexadecane as a hydrocarbon solvent ${ }^{2}$. In the absence of antioxidants the formation of peroxy radicals from the initiator leads to rapid oxidation of cyclohexene. The resulting oxygen consumption is

\footnotetext{
TFigures in brackets indicate the literature references at the end of this paper.

${ }^{2}$ Note, the model hydrocarbon oxidation system is used here not for evaluation of the oxidation stability of the lubricant, but only for the determination of antioxidants in it.
} 
monitored by recording the pressure change in the closed oxidation system. If, however, a small diluted sample of the $0 i 1(0.1-0.5 \mathrm{ml})$ is added into the system the oxidation of cyclohexene is suppressed until all antioxidant species present in the oil are consumed by the reaction with peroxy radicals. The length of the time before the rapid oxidation of cyclohexene occurs, $\tau$, is directly proportional to the antioxidant capacity of the oil, $n(A H)^{3}$. Typical peroxy radical titration curves for a new engine oil and used oil samples from fleet testing of the same oil in a $5.0 \mathrm{~L}$ engine are presented in figure 2.

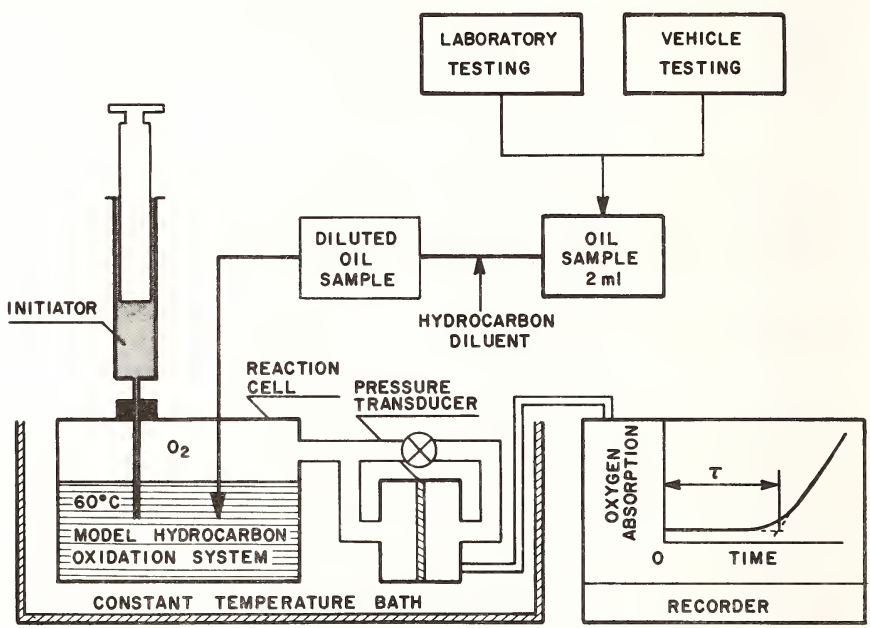

Figure 1. Peroxy radical titration of antioxidants.

The peroxy titration method measures antioxidant additives which stop oxidation by reaction with peroxy radicals, i.e., chain stopping inhibitors, such as hindered phenols, amines, and zinc dialkyl or diaryldithiophosphates. This method measures "natural inhibitors" and antioxidant species generated in the lubricant during use, but does not measure additives which stop oxidation by other mechanisms, such as peroxide decomposers and metal deactivators.

The antioxidant capacity of the oil is defined as a sum of the products of antioxidant concentrations in the oil, (AH), and stoichiometric factors, $\underline{n}$, given by the number of peroxy radicals terminated per molecule of a given antioxidan $\bar{t}$ [2]. 


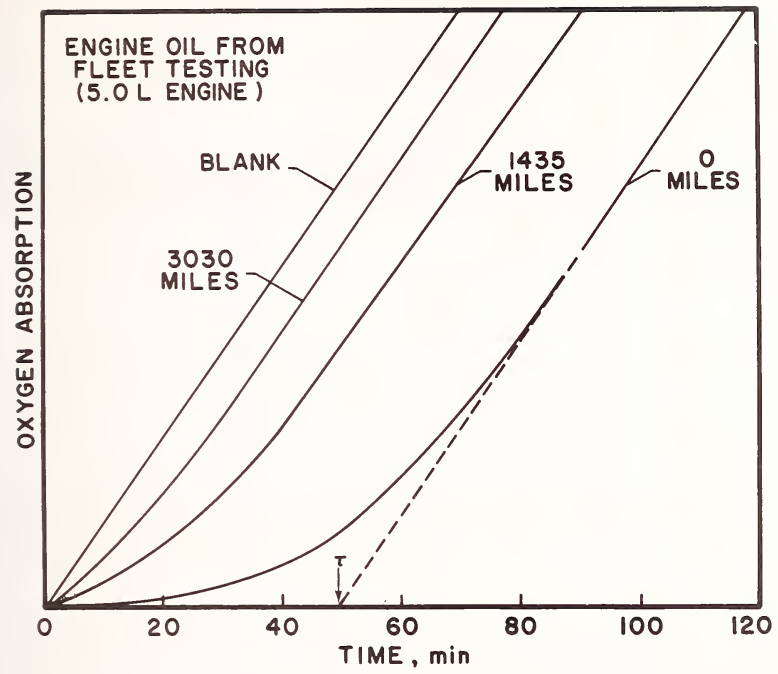

Figure 2. Peroxy radical titration curves.

\section{Applications}

The peroxy titration method has been successfully used for monitoring the decay of antioxidant capacity in engine oils during laboratory, Sequence IIIC, and fleet testing Results of these studies show clearly that the method provides important information on oxidative degradation in the early periods of testing when no other currently used performance characteristics show appreciable changes.

\section{Engine Testing}

A typical antioxidant decay curve for a synthetic hydrocarbon engine oil subjected to Sequence IIIC testing is given in figure 3. During such engine testing and service use periodic oil additions lead to periodic increases in the antioxidant capacity of the oil. In the initial periods of engine testing or service use, while the antioxidant capacity is still above its minimum effective leve $1^{4}$, small changes in viscosity may be observed. These changes are due to evaporative loss of lighter engine oil components and to shear down of VI improvers and other polymeric additives. Major changes in oil properties are observed only after antioxidant capacity drops below its minimum effective level.

${ }^{4}$ The critical level of antioxidant capacity at which an oxidative degradation of the oil begins is designated as the minimum effective antioxidant capacity [2]. 


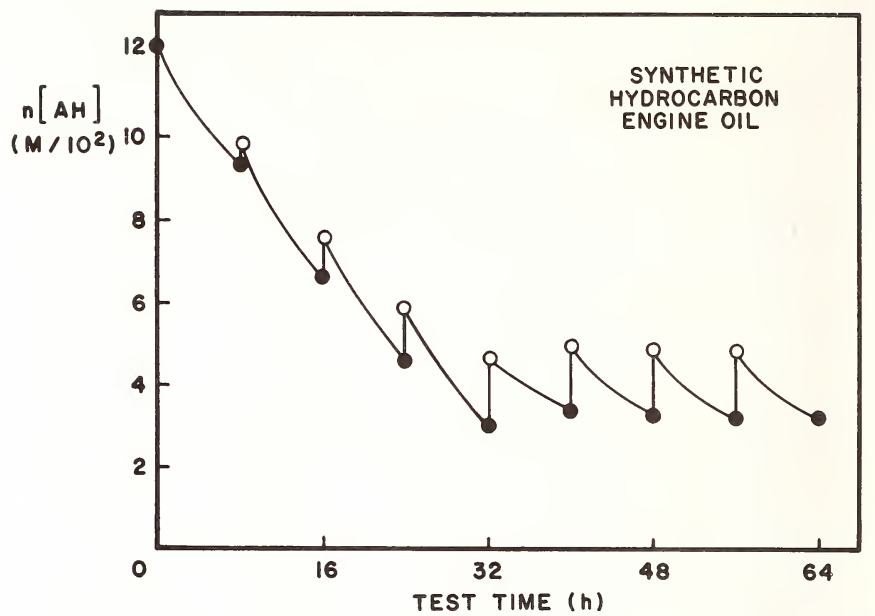

Figure 3. Antioxidant decay during Sequence IIIC testing.

The mileage at which the minimum effective antioxidant capacity is reached was found to depend not only on engine oil formulation and oil consumption but also on the size of engine used [2]. Results from fleet testing showed that the rate of antioxidant decay in the initial periods of testing was in $2.3 \mathrm{~L}$ engines about 20 percent lower than in $5.0 \mathrm{~L}$ engines.

\section{Mechanism of the Initial Antioxidant Decay}

Antioxidant decay data from various engines were found to be normalized when plotted versus an "oil surface parameter" instead of mileage [3]. This parameter is defined as a product of the number of firing events and the surface area of the oil film per cyclinder. The data from Sequence IIIC testing also fitted this correlation. This is particularly noteworthy since test conditions in the Sequence IIIC test are much more severe than those encountered in fleet service. The results of this correlation study suggest that the processes responsible for the antioxidant consumption in an engine are those occurring in the piston-cylinder area (fig. 4). There are numerous processes, however, which could account for such consumption. They may include mechanochemical and thermal decomposition of zinc dithiophosphates and chemical interactions of fuel combustion products with the oil.

In order to isolate specific effects of combustion products on the decay of antioxidants, we utilized a reaction system in which the combustion products of isooctane generated by a pulse flame were transpired through a small sample of engine oil [3]. The rate of antioxidant consumption was followed as a function of flame-oil distance and the concentrations of nitric oxide, carbon monoxide, and unburned hydrocarbons in the combustion products. The results of these studies suggest that the main mechanism of antioxidant consumption in an engine involves interactions of the oil film with combustion-derived free radicals, other than nitric oxide. 


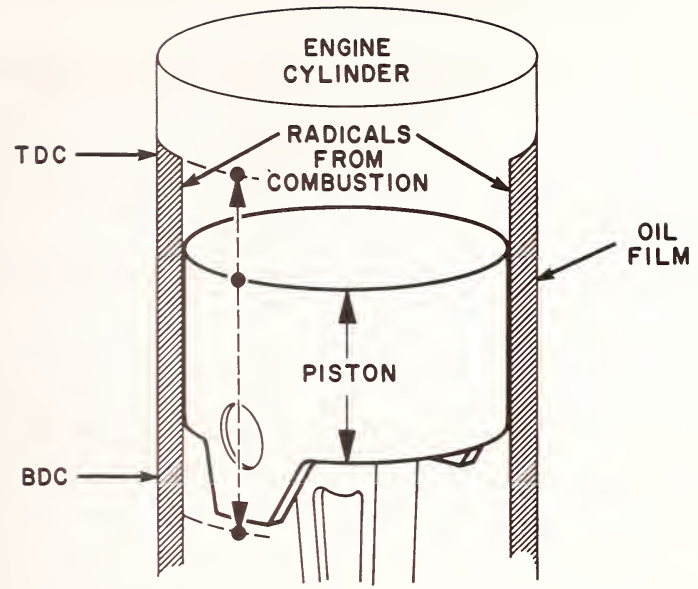

\section{$\Delta(n[A H]) \propto \underset{\substack{\text { ENGINE } \\ \text { FIRINGS }}}{\substack{\text { UMBER OF } \\ \text { OILFILM }}} \times$ SURFACE AREA}

Figure 4. Reactions of combustion derived free radicals with the oil film.

6. Implications of the Antioxidant Consumption Mechanism

The antioxidant consumption mechanism suggested previously implies that the initial antioxidant decay in an engine should be: 1) dependent on mode of combustion, 2) dependent on type of fuel used, and 3) approximately independent of base oil composition. Implications 1 and 2 are currently being investigated in our laboratory.

The approximate independence of antioxidant decay in engines on base oil composition is supported by the results from an earlier study [2]. In that study, an oil thickening characteristic in the Sequence IIIC test, the time to reach 400 percent viscosity increase, was found to be approximately directly related to the initial antioxidant capacity of the 0il. All the oils having initial antioxidant capacity greater than $5.0 \times 10^{2} \mathrm{M}$, regardless of oil formulation, passed the oil thickening requirement of the Sequence IIIC test.

Six re-refined engine oils of different base oil quality were also analyzed (table 1 ). Their initial antioxidant capacities were in the range $4.9-5.6 \times 10^{2} \mathrm{M}$. All of these oils passed the oil thickening requirement of Sequence IIIC.

A further implication of this mechanism is that conventional laboratory oxidation tests of engine oils may be qualitatively useful but will not show, in general, good correlation 
with service. The reason for this has to do with the autocatalytic formation of free radicals in laboratory test methods. The autocatalysis will depend strongly on base stock composition. This behavior contrasts with the apparent constant flux of radicals from combustion in engine tests.

Table 1. Sequence IIIC oil thickening and initial antioxidant capacity of re-refined engine oils.

Seq. IIIC 0 il

Thickening ${ }^{\mathrm{b}}$

Engine

$0 i 1$

1

2

3

4

5

6
Base 0 il

Quality ${ }^{a}$

Good

Lesser

Good

Good

Excellent

Excellent

\begin{tabular}{lll}
$S E$ & & $S E^{+C}$ \\
\cline { 1 - 1 }$M$ & & $M$ \\
$M$ & & $M$ \\
$M$ & & $F$ \\
$M$ & & $M$ \\
$M$ & & $M$ \\
$M$ & & $M$
\end{tabular}

\begin{tabular}{|c|c|}
\hline \multicolumn{2}{|c|}{$10^{2}[\mathrm{n}(\mathrm{AH})]$} \\
\hline & (M) \\
\hline Base & Finished \\
\hline $0 i 1$ & $0 i 1$ \\
\hline 1.0 & 5.6 \\
\hline 0.9 & 5.6 \\
\hline 0.8 & 5.2 \\
\hline 0.5 & 5.0 \\
\hline 0.6 & 5.4 \\
\hline 0.6 & 4.9 \\
\hline
\end{tabular}

${ }^{a}$ Rating of base oil quality made by the ASTM Task Force on Re-refined 0ils.

${ }^{b} F=$ failed to meet requirements.

$M=$ met requirements.

$\mathrm{C}_{\text {Defined as } \Delta v}$ @64 $\mathrm{hr}$. $<400 \%$.

\section{References}

[1] Mahoney, L. R., Korcek, S., Hoffman, S., and Willermet, P. A., Ind. Eng. Chem. Prod. Res. Dev., 17, 250 (1978).

[2] Korcek, S., Mahoney, L. R., Johnson, M. D., and Hoffman, S., SAE Trans., 87, 3588 (1979).

[3] Mahoney, L. R., 0tto, K., Korcek, S., and Johnson, M. D., Preprints, Div. Petrol. Chem., ACS, 24, [3], 802 (1979); Ind. Eng. Prod. Res. Dev., in press. 


\section{DETERMINATION OF THE ANTIOXIDANT CAPACITY OF NEW AND USED LUBRICANTS: APPARATUS AND DETAILED PROCEDURE}

Apparatus and Equipment. The apparatus, shown schematically in figure Al, consists of the following components.

1. Glass reaction cell consisting of a sample area $(28 \mathrm{~mm}$ i.d. $\times 30 \mathrm{~mm})$, 1 , an inlet closeable with serum cap, 2, and a side arm connected to the measuring system by a coupling (Cajon \#SS-4-UT-1-2).

2. Measuring system constructed with coiled $1 / 8$ in stainless steel tubing, 5 , and handle, 6 , which allows the reaction cell to be raised above the bath and removed for cleaning; a set of valves (Corning Stopcock \#7500), $\mathrm{S}_{7}-\mathrm{S}_{9}$, and (Corning Stopcock $\# 7540), S_{6}$; and a differential pressure transducer, 7, (Validyne Model DP15) range \pm 1 psi, connected via transducer indicator (Validyne Model CD12), 8, to a strip chart recorder (Hewlett Packard Model 7100B), 9.

3. Vacuum and gas supply system which includes stopcocks $S_{1}-S_{5}$ and $S_{10}$, a reservoir, 10 , mercury pressure relief valve, 11, mercury manometer, 12, and an outlet for a capillary pipet, 13, used for flushing the reaction cell.

4. Submersible magnetic stirrer (Troemner Model 700), 14, and stirrer controller, 15, for stirring the reactant mixture in the reaction cell.

5. Constant temperature bath, 16, with stirrer, 17, and temperature control system (Lauda Model WB20D equipped with a duplex pump for external circulation and Lauda R10 and R20 controllers), 18.

\section{Procedure}

1. Flushing and filling the system with oxygen.

a. Close $S_{1}$ and $S_{9}$; open $S_{2}$ and $S_{4}, S_{5}$ (close to relief valve), and $S_{6}-S_{8}$.

b. Open $\mathrm{S}_{3}$ and evacuate the system up to $\mathrm{S}_{9}$.

c. Close $S_{3}$, open $S_{1}$ and fill the system with oxygen. Keep the pressure in the oxygen supply line only slightly higher than atmospheric pressure. Open $S_{5}$ to the relief valve.

d. Open $\mathrm{S}_{9}$ and flush the coil and cell with oxygen having the inlet, 2, open.

e. Open $\mathrm{S}_{10}$, flush and insert the capillary pipet, 13, through inlet 2 all the way to the bottom of the cell in order to flush the sample area, 1.

f. Close $S_{6}$ and $S_{9}$ and maintain flushing through the capillary (close $S_{1}$, keep $\mathrm{S}_{10}$ open).

2. Charging the reactants to the cell.

a. Charge the required amounts of hexadecane, cyclohexene and sample into the cell using syringes with long needles $(20 \mathrm{~cm})$; maintain oxygen flushing near the top of the reaction cell.

b. Start magnetic stirring in the cell.

c. Remove the flushing capillary and quickly close the inlet, 2, with a serum cap.

d. Open $S_{9}$, close $S_{7}$ and $S_{8}$.

e. Allow the temperature to equilibrate for about 15 minutes. 
3. Adding the initiator.

a. Start the recorder (chart speed $-0.25 \mathrm{~cm} / \mathrm{min}$; full scale - $1 \mathrm{~V}$ ).

b. Inject $0.5 \mathrm{ml}$ of $A I B N$ in chlorobenzene $(0.2 \mathrm{M})$ through the serum cap using a $1 \mathrm{~m} 7$ syringe with a long needle.

c. Open $S_{7}$ and $S_{8}$ momentarily to allow equilibration of pressure on both sides of the transducer; reclose.

4. Measurement.

a. Open the measuring side of the transducer - open $S_{7}$ or $S_{8}$.

b. Record oxygen uptake, i.e., pressure decrease, versus time until the final linear portion of the curve is sufficiently long to determine the final rate of oxygen uptake.

c. Open $\mathrm{S}_{7}$, stop recording, close $\mathrm{S}_{9}$; discontinue stirring, lift up, disconnect and $\mathrm{clean}$ the reaction cell.

d. Determine the inhibition time, $\tau$, graphically.

5. Typical Charge.

a. $9.0 \mathrm{ml}$ hexadecane.

b. $1.0 \mathrm{ml}$ cyclohexene.

c. $\quad 0.5 \mathrm{~m} 1$ sample, diluted in hexadecane such that $\mathrm{n}(\mathrm{AH})$ is approximately $3.5 \times 10^{-3}$. This will give a final $\mathrm{n}(\mathrm{AH})$ in the cel1 of about $1.6 \times 10^{-4}$ and an inhibition time of approximately 45 minutes.

d. $\quad 0.5 \mathrm{ml}$ of $\mathrm{AIBN}$ in chlorobenzene (0.2M). 


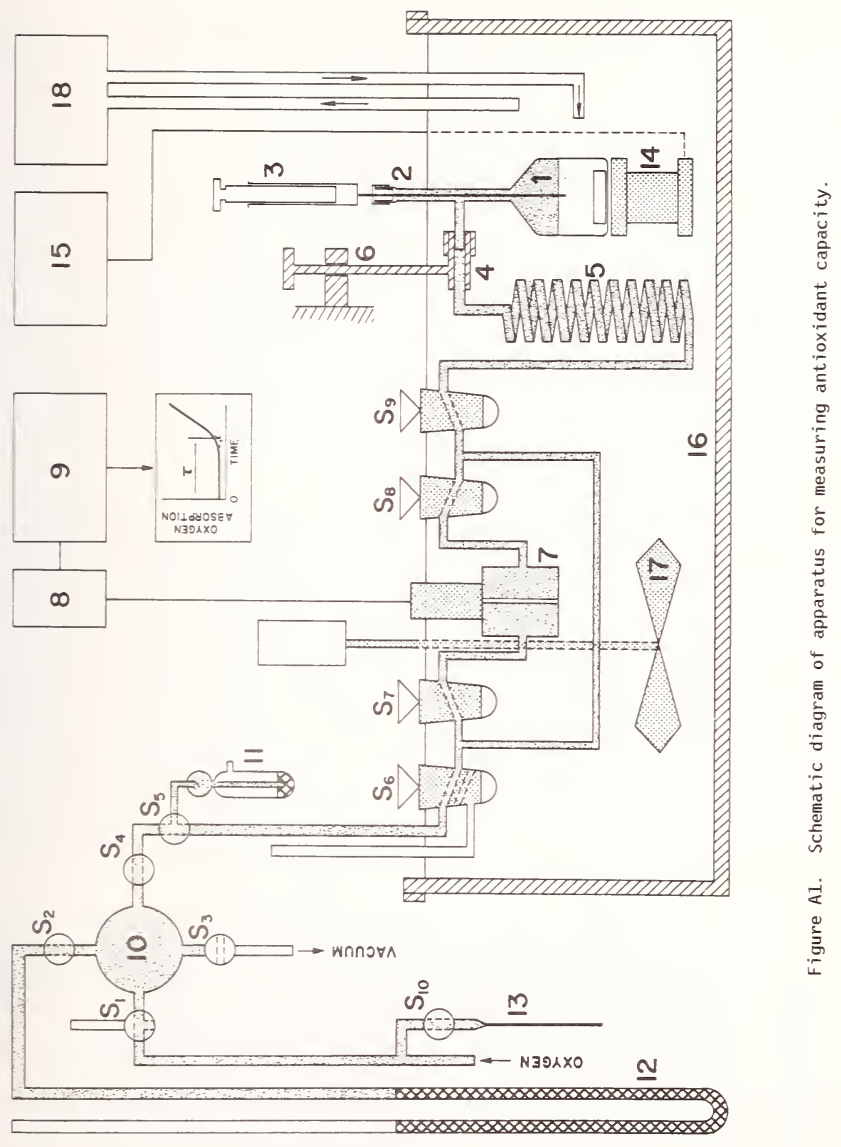



National Bureau of Standards Special Publication 584. Proceedings of Joint Conference on Measurements and Standards for Recycled 0i1/Systems Performance and Durability held at NBS, Gaithersburg, MD, October 23-26, 1979. (Is sued Nov. 1980)

\title{
APPLICATION OF THE ANTIOXIDANT CAPACITY TEST TO RE-REFINED AND VIRGIN BASE STOCK OILS
}

\author{
R. E. Rebbert \\ Chemical Thermodynamics Division \\ National Bureau of Standards \\ Washington, DC 20234
}

\begin{abstract}
The antioxidant capacity test test developed by the Ford Motor Company has been set up and is being examined for applicability to evaluate the relative free radical oxidation stability of various re-refined and virgin base stock oils. This test will also be used in the ASTM/NBS base stock consistency study which w11 begin in March 1980 . The test method determines the antioxidant capacity of a lube oil by measuring the length of an induction period which preceeds the rapid uptake of oxygen by the test solution. This paper describes the work to data on the antioxidant capacity test as applied to commercially available oils, reference oils, rerefined base stock oils and virgin base stock oils.
\end{abstract}

\section{Introduction}

In the past six months, as part of the recycled oil program here at the National Bureau of Standards, we have used the method just described by Korcek et al. $[1,2]^{1}$ to determine the antioxidant capacity of a number of different motor oils, including fully formulated commercially available oils, reference oils, unformulated re-refined base stock oils, and virgin base stock oils. Our purpose in using this method is to determine the antioxidant capacity of various oils is two-fold. First, we intend to use this property of the oil, i.e., the antioxidant concentration, as one of a number of physical and chemical properties that will be determined and tabulated for several re-refined and virgin base stock oils over a period of 12 months as part of the ASTM/NBS Base Stock Consistency study that Dr. Frassa discussed earlier [3]. These results will give us some idea of the constancy or variability of specific base oils from different refiners or re-refiners. We should also be able to investigate the additive response of each base stock oil. Secondly, by measuring the antioxidant capacity of various oils under a variety of conditions, we hope to develop a test procedure that will give, at least to some degree, an indication of the quality of the oil insofar as free radical oxidation stability is concerned. Both of these goals are relatively long term and this paper will be more of an initial progress report about the very preliminary work done so far.

\section{Results: Antioxidant Capacity}

In table 1 are shown the results of the measurement of antioxidant concentration for eight commercially available motor oils. All were labeled as multigrade SE quality and the first five are $10 \mathrm{~W}-40$ grade. These results are presented to show the range in antioxidant concentrations that can be expected in the various commercial oils using this procedure. These data also provide an indication of our reproducibility which, depending on the concentration, and probably also on the nature of the antioxidant in the oil, varies from about 3 to 10 percent. Note that even for the five $10 \mathrm{~W}-40$ 0ils there is a $21 / 2$ fold range in the apparent antioxidant concentration and a five-fold range when all eight oils are included.

Table 2 lists the antioxidant capacities of what were originally thought to be ten reference oils as supplied by the Recycled $0 i 1$ Program at NBS. It turned out to be five pairs of reference oils. The agreement between the results for each pair again indicates our reproducibility. In general, the agreement between duplicate oils is excellent, except for the last pair which, although within the experimental error, shows a larger deviation

TFigures in brackets indicate the literature references at the end of this paper. 
than the others. The correlation of the apparent antioxidant concentration with the results of the III-C engine sequence test is only fair. In particular, the failure of the last reference oil 70P (No. 5292 or 5298) is somewhat surprising in view of the relatively high antioxidant capacity of this oil. There may be some significance to the fact that our reproducibility was also worst for this oil. If the particular antioxidant present in this oil is not as effective in preventing oxidation as other antioxidants of similar concentration, this may result in both the engine sequence failure and our irreproducibility. It may also be a poor quality oil.

Table 1. Antioxidant capacity of commercial oils.

$\underline{0 i 1}$

$A(10 W-40)$

C $(10 W-40)$

D(10W-40)

$\mathrm{E}(10 \mathrm{~W}-40)$

$\mathrm{H}(10 \mathrm{~W}-40)$

$\mathrm{B}(10 \mathrm{~W}-30)$

$\mathrm{G}(10 \mathrm{~W}-20)$

$\mathrm{F}(5 \mathrm{~W}-20)$
Measured

Antioxidant Concentration

(Moles/l)

$$
\begin{aligned}
& .048 \pm .003 \\
& .051 \pm .002 \\
& .020 \pm .001 \\
& .033 \pm .002 \\
& .035 \pm .002 \\
& .038 \pm .004 \\
& .029 \pm .003 \\
& .109 \pm .003
\end{aligned}
$$

Table 2. Antioxidant capacity of reference oils.

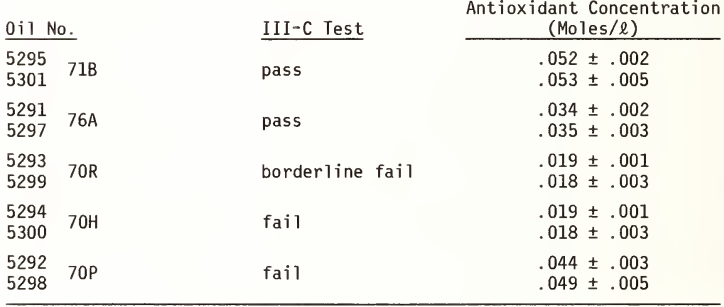

In a very real sense there is no reason to expect an exact correlation between the amount of antioxidant present in an oil and the quality of the oil. Although for a given oil as the antioxidant capacity of the oil increases, the oxidation stability would be expected to increase, yet for different oils with the same concentration of antioxidant, the oxidation stability may be drastically different--depending on the quality of the base oil and also perhaps on the efficiency of the particular antioxidant used to inhibit the chain oxidation steps, or even the thermal stability or instability of the antioxidant itself.

In table 3 are the results for the determination of antioxidant capacity of unformulated re-refined base stock oils. As expected, there is very little antioxidant remaining in any of these seven oils. In general, as it has previously been pointed out by Korcek and the Ford Group [4], the effectiveness of the antioxidant is drastically reduced when the concentration goes below a certain minimum value. This value is somewhat dependent on the type of oil used and may also be dependent on the particular antioxidant used. For the values shown here, very little residual antioxidant is expected in any of these oils. 
Table 3. Antioxidant capacity of re-refined base oils.

\begin{tabular}{ll}
$0 i 1$ No. & $\begin{array}{c}\text { Antioxidant Concentration } \\
(\text { Moles/l) }\end{array}$ \\
\hline 5026 & $.012 \pm .001$ \\
5027 & .008 \\
5028 & .007 \\
5029 & .008 \\
5030 & .007 \\
5031 & .004 \\
5032 & .010 \\
\hline
\end{tabular}

Measured

These results can now be compared with those given in table 4 where the antioxidant concentration of some twelve virgin base stock oils are listed. As expected, these values are even lower than those for the re-refined base stock oils. For these oils we appear to be reaching the limit of the test procedure and as can be seen, the antioxidant concentration is approaching zero. Table 5 briefly summarizes the results for all the different oils.

Table 4. Antioxidant capacity of virgin base oils.

\begin{tabular}{lc}
$0 i 1$ No. & $\begin{array}{c}\text { Measured } \\
\text { Antioxidant Concentration } \\
(\text { Moles/l) }\end{array}$ \\
\hline 5037 & $.003 \pm .001$ \\
5038 & .004 \\
5039 & .004 \\
5040 & .003 \\
5041 & .004 \\
5042 & .003 \\
5043 & .001 \\
5044 & .001 \\
5045 & .001 \\
5046 & .002 \\
5047 & .003 \\
5048 & .002 \\
\hline
\end{tabular}

Table 5. Summary of antioxidant concentrations.

\begin{tabular}{lcc} 
Commercial oils .. IFI & Range & Average \\
$\quad$ SE Classification (8) & $.020-.110 \mathrm{M}$ & $.045 \mathrm{M}$ \\
ASTM IIIC Reference eng- & $.018-.053 \mathrm{M}$ & $.034 \mathrm{M}$ \\
$\quad$ ine oils (5) & $0.034-0.053$ & - \\
Pass (2) & 0.018 & - \\
Borderline Foil (1) & $0.018-0.049$ & - \\
Foil (2) & $.004-.012 \mathrm{M}$ & $.008 \mathrm{M}$ \\
Re-refined base oils (7) & $.001-.004 \mathrm{M}$ & $.003 \mathrm{M}$ \\
Virgin base oils (12) & \\
\hline
\end{tabular}


As mentioned previously, the antioxidant capacity of an oil does not by itself give a measure of the relative oxidation stability of the oil. However, following in the footsteps of the Ford group, it would seem that this method of determining the antioxidant capacity of the oil could be used along with an accelerated bench type oxidation test to determine the rate of decay of the antioxidant in the oil. It is anticipated that this rate of decay of the antioxidant in the oil could be used, especially with unformulated re-refined and virgin base stock oil, to determine the relative free radical oxidation stability of the various base oils.

If we assume, as a first approximation, that for each oil at a given temperature the concentration of free radicals in the oil (which eventually would react with oxygen and lead to the oxidation of the oil) is essentially constant with time, i.e., a steady state assumption, then it is expected that the rate of decay of the antioxidant should follow a pseudo-first order rate law since the antioxidant in the oil is eventually depleted by reacting with these radicals. If this is true, then it means that a plot of the logarithm of the antioxidant concentrations versus time should be a straight line whose slope should depend on the relative concentration of free radicals in the oil and consequently on the free radical oxidation stability of the oil. Thus, a good quality oil with a high free radical oxidation stability would be expected to give a decay curve with a shallow slope, while an oil with low free radical oxidation stability would be expected to give a steep decay curve.

The experiments to check on the feasibility of this approach were just recently begun and our results, at this time, are preliminary and few. In this work, we added an antioxidant, 2,6 di-t-buty1-4-methyl phenol to each oil so that the concentration of added antioxidant was $0.1 \mathrm{~mol}$ in each case (the total antioxidant capacity was 0.1 plus the original concentration). Then, $350 \mathrm{ml}$ of this solution was placed in a $500 \mathrm{ml}$ Erlenmeyer flask at a constant temperature of $150{ }^{\circ} \mathrm{C}$ with a fixed rate of stirring. Strips of copper, steel, and aluminum were added to each sample and at approximately $24 \mathrm{~h}$ intervals $10 \mathrm{ml}$ portions were removed and the concentration of antioxidant determined. After about 120 hours the test was terminated. The results of this test for three of the reference oils and two re-refined base stock oils are shown in figure 1 . This is the antioxidant decay curve in which the logarithm of the antioxidant capacity is plotted as the ordinate versus time on the abscissa. For these five samples, straight lines are obtained over a period of three to four days in which about 80 percent of the antioxidants were used. After that time there is a considerable deviation from a linear plot. The slopes of these lines were determined and they are shown in table 6 .

\begin{tabular}{|c|c|c|c|}
\hline$\frac{0 i 1 \text { No. }}{\text { R05295-71B }}$ & $\begin{array}{c}\text { Measured } \\
\begin{array}{c}\text { Antioxidant Capacity } \\
(\text { Moles/l) }\end{array} \\
.053\end{array}$ & $\frac{\text { III-C Test }}{\text { pass }}$ & $\begin{array}{l}\text { Slope }_{1} \\
\frac{\left(\mathrm{hr}^{-1}\right)}{.0067}\end{array}$ \\
\hline$R 05291-76 A$ & .035 & pass & .0087 \\
\hline$R 05293-70 R$ & .019 & borderline fail & .0116 \\
\hline RB5027 & .008 & --- & .0088 \\
\hline RB5026 & .012 & -- & .0128 \\
\hline
\end{tabular}

There are too few samples from which to draw any firm conclusions as yet, but at least the slopes do appear to follow the IIC-C engine sequence test results for the three reference oils. We hope to extend this work to more reference oils, re-refined oils, and virgin base oils in the near future.

The author expresses his sincere appreciation to Miss Enid Porrata Doria who conducted most of the experiments reported in this paper. This work was supported by the Recycled 0 il Program at the National Bureau of Standards, Washington, DC. 


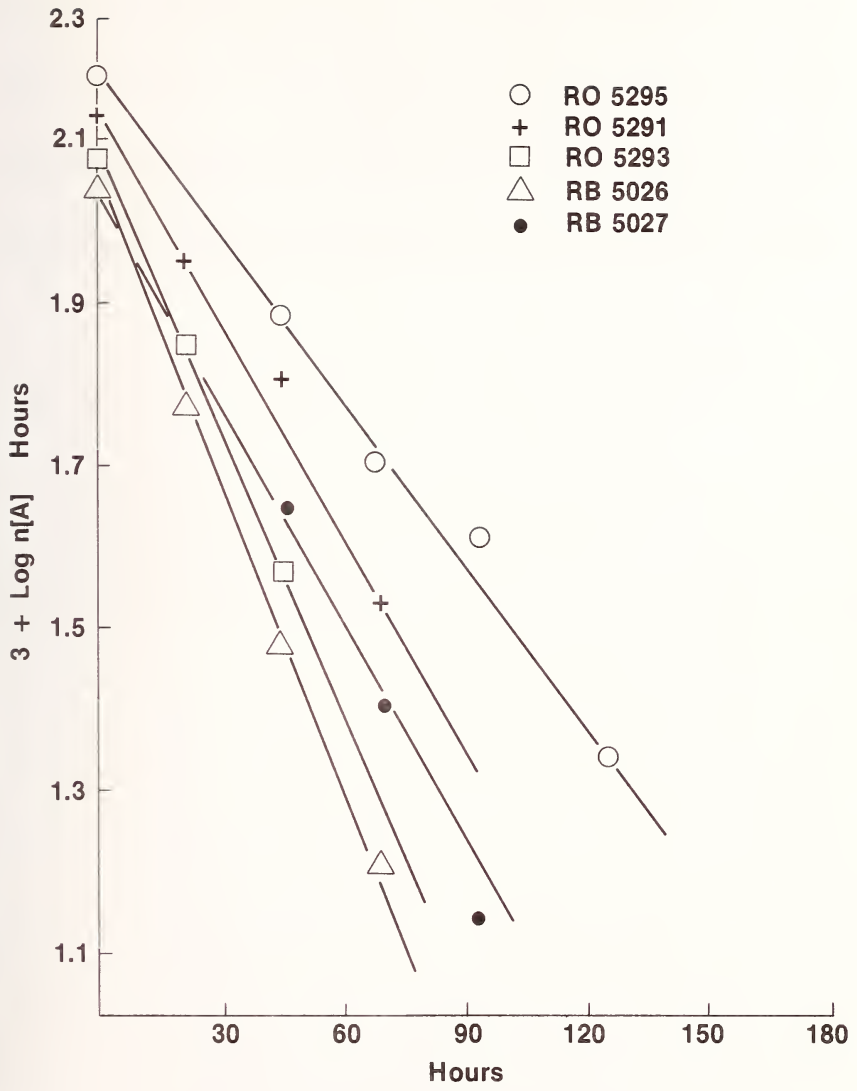

Figure 1. A plot of the logarithm of the antioxidant capacity, $n[A]$, versus time for the accelerated oxidation test. ORO-5295 (71B), + RO-5291 (76A), ๑R0-5293 (70R), RB-5026 and $-\mathrm{RB}-5027$. 
[1] Korcek, S., Mahoney, L. R., Johnson, M. D., and 0tto, K., Antioxidant consumption and oxidative degradation of lubricants, Proc. Conf. on Measurements and Standards for Recycled 0i1, NBS Special Publication 584, NBS (Gaithersburg, MD, Oct. 23, 1979).

[2] Mahoney, L. R., Korcek, S., Hoffman, S., and Willermet, P. A., Determination of the antioxidant capacity of new and used lubricants; method and applications, Ind. Eng. Chem., Product Research and Development 17, 250 (1978).

[3] Frassa, K., ASTM/NBS Base Stock Consistency Study, Proc. Cong. on Measurements and Standards for Recycled 0i1, NBS Special Publication 584, NBS (Gaithersburg, MD, 1980).

[4] Korcek, S., Mahoney, L. R., Johnson, M. D., and Hoffman, S., Antioxidant decay in engine oils during laboratory tests and long drain internal service, International Fuels and Lubricants Meeting, paper number 780955 (Toronto, Canada, Nov. 13, 1978). 
Session 6

BENCH TESTS FOR OIL EVALUATION - II 

National Bureau of Standards Special Publication 584. Proceedings of Joint Conference on Measurements and Standards for Recycled 0il/Systems Performance and Durability held at NBS, Gaithersburg, MD, October 23-26, 1979. (Issued Nov. 1980)

\title{
PIN-AND-V-BLOCK AND RING-AND-BLOCK BENCH WEAR TESTS FOR ENGINE OIL EVALUATION
}

\author{
L. K. Ives and P. A. Boyer \\ National Bureau of Standards \\ Washington, DC 20234
}

\section{Introduction}

As part of a National Bureau of Standards program to evaluate and develop methods to characterize re-refined lubricating oils, wear test procedures employing different specimen configurations are being studied. Two of these, the pin and V-block and the ring and block configurations are the subject of this investigation. A third configuration, the four ball, is the topic of a companion article $[1]^{1}$. Machines employing these configurations are among the most widely used for general purpose lubricant evaluation. All are commercially available and are designated in ASTM standard test methods. The principal focus of this investigation has been the evaluation of existing ASTM standard test methods. However, additional procedures were also examined. In this report, some aspects of the evaluation method as well as test results will be presented.

The use of laboratory bench wear testing to evaluate the service performance of lubricants is often the source of considerable controversy. This is particularly the case for engine oils where the conditions are complex and the lubricant must serve a variety of functions in addition to controlling friction and wear. However, it is this complexity as well as the prolonged nature and significant expense of service testing that makes laboratory wear testing desirable. The need for rapid and relatively inexpensive bench tests becomes especially important with the prospect of small batch processing and potential source variations that may accompany extensive recycling of lubricant products. Under these conditions, tests to determine batch-to-batch consistency and the continued adequacy of a given additive package will become most important.

\section{Evaluation Criteria}

Three criteria were used in judging the value of a particular test procedure. They were: 1) precision, 2) sensitivity, and 3) correlative capacity. Precision refers to the degree of agreement among repeated measurements of a given quantity. When the measurements are made in a single laboratory by the same operator without a perceived change in conditions, the term repeatability is also used to describe precision. Most ASTM test methods for which round robin data have been obtained contain statements indicating the expected repeatability. For example, D2670 [2] which utilizes the pin and V-block machine to measure wear characteristics of fluid lubricants states that duplicate results are suspect if they differ by more than 22 percent of the mean value.

Whether or not a satisfactory level of precision has been obtained may depend on the "sensitivity" of the test to the particular property being measured. For example, a test that is highly repeatable but is insensitive to changes in the property being measured is of little value. While precision may be determined by comparing measured values obtained from a series of duplicate tests, sensitivity requires the application of the test to lubricants having known incremental differences in the characteristic being measured.

${ }^{1}$ Figures in brackets indicate the literature references at the end of this paper. 
Table 1. Test oils

1. Paraffinic White Mineral 0 il $335 / 350$ SUS @ $378{ }^{\circ} \mathrm{C}$

2. Re-refined Base $0 i 1$

Viscosity Index $=90$

3. Virgin Base $0 i 1$

600 second solvent extracted neutral

Viscosity index $=94$

4. Sequence IIIC Reference 0ils:

$70 \mathrm{~A}-64 \mathrm{~h}$ without excess viscosity increase

$71 \mathrm{~B}-$ Viscosity break-point $=40 \mathrm{~h}$

$70 \mathrm{R}$ - Viscosity break-point $=32 \mathrm{~h}$

$70 \mathrm{H}-$ Viscosity break-point $=16 \mathrm{~h}$

$70 \mathrm{P}$ - Viscosity break-point $=16 \mathrm{~h}$

5. Sequence IIID Reference 0ils:

$76 \mathrm{~A}-1$ - $64 \mathrm{~h}$ without excess viscosity increase Average cam and lifter wear $=19 \pm 9 \times 10^{-4}$ in

$\left(48 \pm 23 \times 10^{-4} \mathrm{~cm}\right)$ from 17 tests)

$77 \mathrm{~B}-1$ - Viscosity break-point $=24 \mathrm{~h}$

Average cam and lifter wear $=113 \pm 74 \times 10^{-4}$ in

$\left(287 \pm 188 \times 10^{-4} \mathrm{~cm}\right)$ from 22 tests

Correlative capacity is used here to describe the extent to which test results correlate with service performance. Good correlation with service behavior is perhaps the most difficult objective to achieve and demonstrate in a bench wear test. This is particularly true for engine oils where service performance depends on a variety of interdependent lubricant functions and a wide range of service conditions. In this investigation, IIIC reference oils and the more recently available IIID reference oils, which will eventually supplant the IIIC oils, were employed to assess correlative capacity. The IIIC reference oils are designed primarily to determine high speed, high load oxidation resistance. Cam and lifter wear are measured as part of the sequence test procedure; however, the behavior of the IIIC oils does not vary greatly with respect to wear and the scatter in data is large. These oils are not designed to assess wear behavior. On the other hand, if oxidation or thermal degradation are experienced during the tests, an accompanying depletion of anti-wear additive may lead to severe wear. The wear test may then serve as a measure of thermal and oxidative stability. The IIID sequence test procedure is similar to the IIIC procedure, but wear is a more important component of the test. Several IIID reference oils are now available having significantly different wear characteristics. (The IIID oils were not secured in time to play an important role in the present effort but will be used extensively in the future.) A measure of the correlative capacity exhibited by a particular bench test procedure can, therefore, be obtained by comparing bench test results on a series of different reference oils with their known performance. If the bench test procedure ranks the reference oils in their known order of performance, then a high degree of correlation may be said to exist. This method also serves to calibrate the test procedure for application to oils of unknown behavior.

\section{Test 0ils}

0ils to which the various test procedures were applied are listed in table 1 . The virgin base and re-refined base stocks were selected on the basis of their in-house availability and were not chosen to demonstrate a particular quality. A widely used and highly effective antioxidant - antiwear additive, zinc dialkyldithiophosphate (ZDDP) was mixed with the base oils in concentrations ranging from 0.01 to $1.0 \mathrm{wt}$. percent to demonstrate the sensitivity of a given test procedure to a change in oil properties. Five IIIC and two IIID sequence test reference oils were employed mainly to examine the extent to which results from a given test procedure could be correlated with oils having a known service performance, as is described in the previous section. 


\section{Pin and V-Block Test Procedures}

\subsection{Test machine}

The pin and V-block test machine employed in this investigation was manufactured by the Faville-LeVally Corporation. This machine which is often referred to as the Falex machine (now designated the Falex \#0 machine by its manufacturer) has been widely used for lubricated testing for approximately 50 years. Only a brief description of the machine will be given since detailed descriptions are available in several ASTM standards including D2670 and D3233 [2] and in numerous articles, for example Crowley and Faville [3] and Faville and Faville [4]. The test specimen configuration is shown in figure 1; two opposite V-blocks are squeezed against a rotating pin. Force is transmitted to the $V$-blocks through a lever arm system and is applied by a detachable load application assembly. This assembly contains a spring that is compressed against the lever arms by means of a threaded screw. Displacement of the spring is indicated on a dial gage which is calibrated in force units. The load can be applied manually or automatically by turning a ratchet wheel fixed to the threaded screw. Automatic advance is by means of an arm attached eccentrically to the specimen pin spindle. As wear of the specimen occurs, the load decreases. The original load can be recovered by advancing the ratchet wheel. The number of ratchet teeth advanced provides a relative measure of the amount of wear during the test. The entire loading assembly and jaws holding the $\mathrm{V}$-blocks is free to rotate about the axis of the pin spindle but is held in place by a load cell. The latter gives an indication of the friction force. The standard machine is equipped for a single speed of operation, $290 \mathrm{rpm}$, and has provisions for heating the oil sample.

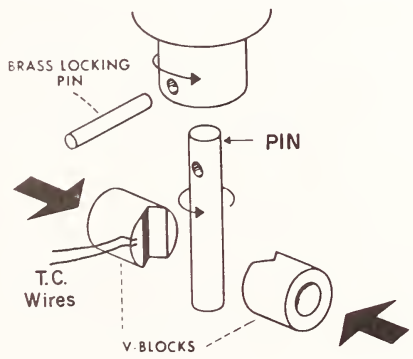

Figure 1. Pin and V-block specimen configuration.

Several modifications were made in the machine during the course of this investigation. These modifications did not impair or alter the basic function of the machine but were introduced to provide better control and to facilitate the monitoring of test conditions. The modifications included adapting a strain gage load cell to the load application mechanism to permit electronic recording of the applied load, and replacement of hydraulic load cell and recording system that was supplied for indicating friction torque which was found to be insensitive and subject to severe thermal drift by a strain gage load cell system. Finally, the simple oil bath heater control was replaced by a temperature controller with thermocouple temperature sensing. During elevated temperature operation, heat is supplied both by the built-in heater adjusted to provide a set temperature at the beginning of the test and by friction. Without a temperature sensing controller, the temperature of the oil will rise as a result of the frictional component. This may still happen under some test conditions even with the temperature controller if the heat supplied by friction is greater than that dissipated to the surroundings. Under these circumstances, to maintain a constant temperature, it would be necessary to cool the oil bath. 
Temperatures at the specimen contact regions were in general higher than the oil bath temperature. One method [5] for obtaining a measure of the contact temperature is by means of a thermocouple clamped at the bottom of the $V$-groove in one $V$-block. In this investigation, chromel-alumel thermocouple wires were spot welded to one $V$-block as illustrated in figure 1 in order to obtain a relative measure of the temperature in the contact region.

With the pin and $V$-block machine equipped as described previously, it was possible to obtain a simultaneous recording of applied load, friction force, and temperature.

\subsection{Applied load}

Three different kinds of load gage assembly are currently available for the Falex \#0 machine. They are referred to as the $800 \mathrm{lbf}(3550 \mathrm{~N}), 3000 \mathrm{lbf}(13300 \mathrm{~N})$ and the $45001 \mathrm{bf}$ $(20000 \mathrm{~N})$ gages according to the maximum indicated load value. The $800 \mathrm{lbf}$ and $3000 \mathrm{lbf}$ gages are designed to cover two different ranges of applied load but are otherwise essentially similar. The 4500 lbf gage, however, does not represent a further extension to a higher load range but is calibrated on an entirely different scale. The 800 lbf and 3000 lbf gages, sometimes referred to as direct reading gages, indicate the force applied directly to the V-blocks. This force corresponds to the test load $L$ shown in figure 2 . The $45001 \mathrm{bf}$ gage was originally designed to indicate the normal force at the pin and V-block contact junction ( $N$ in fig. 2). A change in V-block angle from $90^{\circ}$ to the currently used $96^{\circ}$, together with other modifications, has altered this relationship making the direct gage rending invalid.

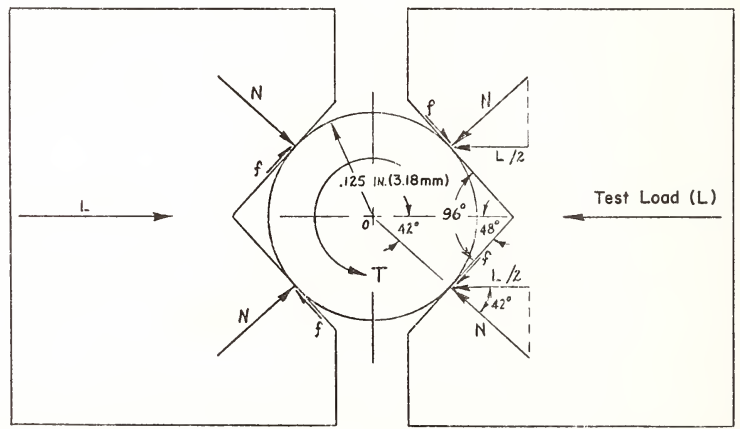

Figure 2. Diagram showing resolution of forces at pin and V-block contact junctions.

A11 gages are subject to calibration according to a procedure outlined in the various ASTM Standards (D2670, D3233, D2625) employing the Falex \#0 machine. The procedure consists of replacing the pin and V-block test specimens with a $10 \mathrm{~mm}$ Brinell ball and copper coupon of hardness 37-39 BHN. On application of a load an impression is made in the copper coupon. It is assumed that the Meyer law [6] is obeyed. The Meyer law is an empirical relationship which states that the load is proportional to the impression diameter raised to a constant 
power and would therefore yield a straight line on a logarithmic plot. Such a graph of log "true" load vs log impression diameter for copper test coupons of the prescribed hardness is part of the relevant ASTM Standards (D2670, D3233, and D2625). The accuracy of the methods depends on how well the response of the copper calibration coupon agrees with the graph published by ASTM. No recommendations are made for calibrating the test coupon itself--a step which should be taken to be assured of an accurate determination of load using this method.

The $4500 \mathrm{lbf}$ gage is calibrated on a scale that is related arbitrarily to the test load $\mathrm{L}$ on the $\mathrm{V}$-blocks. This relationship is also plotted on the true load vs impression diameter graph published by ASTM. It should be noted that the load indicated by the $45001 \mathrm{bf}$ gage is not linearly related to the true load L. The 4500 lbf gage was not used here and all loads specified correspond to $L$ indicated in figure 2.

According to the force diagram shown in figure 2, the normal force $\mathrm{N}$ at each contact is equal to $L /\left(2 \cos 42^{\circ}\right)$. Mecklenburg [7] has shown, however, that when frictional forces are included in the analysis the normal force on the incoming face of each V-block is larger than that on the outgoing face. Depending on the friction force, the difference may be 30 percent or larger. For this reason, considerable caution must be exercised in attempting to develop quantitative relationships to describe lubricant performance with the pin and $V$-block configuration.

\subsection{Test specimens}

The pin and V-block test specimens were obtained from Faville-LeVally Corp. and were manufactured to meet specifications given in ASTM standards D2670 and D3233. These specifications require that the V-blocks be of AISI C-1137 steel with a hardness of HRC 20 to 24 , that the surface roughness be 0.13 to $0.25 \mu \mathrm{m} \mathrm{rms}$, and that the $V$-angle be $96^{\circ} \pm 1^{\circ}$. The pins are to be of AISI 3315 steel with a hardness of HRB $87-91$ and surface roughness of 0.13 to $0.25 \mu \mathrm{m}$ rms. With the exception of the $V$-block angle, no tolerances are given on specimen dimensions. Thus, the degree of flatness of V-block faces was found to vary considerably and this led to the formation of uneven wear scars. Another factor that had a significant effect on test behavior was the method of finishing the $V$-block faces. $V$-blocks that were prepared by surface grinding gave results that differed from those that were obtained from blocks produced by a coining operation. Only coined blocks were used here.

Finally, variations in microstructure among different $v$-blocks were found to be the most likely and perhaps serious source of data scatter. The V-blocks, it was discovered, had two rather different microstructures. Some had a ferritic-pearlitic structure typical of annealed medium carbon steel while others had a spheroidized structure apparently arising from a different heat treatment. The hardnesses did not differ. Since these two block microstructures were found to yield considerably different results, care was taken, insofar as was possible, not to mix the different microstructures in a given test series.

\section{Pin and $V-B l o c k$ Procedures and Results}

There are two ASTM standard methods applicable to fluid lubricants that employ the Falex \#0 machine. They are: 1) D2670 Standard Method for Measuring Wear Properties of Fluid Lubricants (Falex Method), and 2) 03233 Standard Methods for Measurement of Extreme Pressure Properties of Fluid Lubricants (Falex Methods). These two tests are, in general, characteristic of tests that are designed to measure the wear rate and load carrying capacity characteristics of lubricants, respectively. In the following discussion, results obtained using D2670 will be considered first, together with some alternative procedures for determining wear rate behavior of lubricants. D3233 and other tests for measuring load carrying capacity will then be examined.

\subsection{D2670 and wear rate measurement methods}

Briefly, the procedure specified in D2670 consists of a run-in at 250 lbf (1100N) for 5 minutes followed by a 15 minute test at $700 \mathrm{lbf}(3100 \mathrm{~N})$. The number of teeth by which the ratchet wheel must be advanced to maintain the load at $7001 \mathrm{bf}(3100 \mathrm{~N})$ is taken as a measure of the amount of wear occurring during the test. The specified initial oil temperature is $24 \pm 3{ }^{\circ} \mathrm{C}$ with no requirement that it be maintained at that value during the test. As a result of frictional heating, the oil temperature may increase during the test. 
Typical test results obtained with several different oils are shown in table 2 . Each entry represents the average of 5 repeat tests. The first two oils, mineral oil with 0.1 w/o sulfur and mineral oil with 0.2 w/o sulfur, are calibration oils specified by D2670. The amount of wear, $60 \pm 5$ teeth and $107 \pm 6$ teeth, respectively, falls well within the range specified by $\mathrm{D} 2670$ for these oils. When the test procedure was applied to mineral oil without additives (see table 1) seizure occurred during the run-in period at $2501 \mathrm{bf}$ (1100N) load. Similarly, when applied to two IIIC reference oils seizure occurred during the test period at $700 \mathrm{lbf}(3100 \mathrm{~N})$, well before 15 minutes was reached. Prior to seizure, there was relatively little wear.

Table 2. ASTM D2670 test results.

\section{$\underline{0 i 1}$}

Mineral $0 i 1+0.1 \%$ Sulfur Mineral $0 i 1+0.2 \%$ Sulfur Mineral 0 il IIIC Sequence Test 0 i1 - 70A (Pass) IIIC Sequence Test $0 \mathrm{il}$ - 70H (Fail)

\author{
Teeth Wear \\ $60 \pm 5$ teeth $( \pm 8 \%)$ \\ $107 \pm 6$ teeth ( $\pm 5 \%)$ \\ Seizure during run-in e 250 lbf (1100N) \\ Seizure during test 700 lbf (3100N) \\ Seizure during test a 700 lbf (3100N)
}

The procedure specified in D2670 is clearly too severe, not only for unformulated base stocks but also for fully formulated SE grade engine oils. D2670 is apparently better suited for lubricants having relatively high entreme pressure characteristics such as cutting oils.

A number of tests were conducted at much lower loads and for longer periods of time than those specified in D2670. It was found that the load had to be reduced to as low as $501 \mathrm{bf}$ (220N) before long term (several hours) tests could be conducted on mineral oil without the occurrence of seizure. Repeatability for these tests was relatively poor.

A test procedure that has gained some support among users of the Falex \#0 machine is one that involves measurement of wear at a series of increasing load increments. Thus a characteristic curve relating wear to load is obtained. When a sufficiently high load is reached, seizure may occur so that, in addition, this method may also provide a measure of the load carrying capacity of the lubricant. Several variants of the procedure have been described $[3,4,8]$. Because the Falex \#0 machine provides for measurement of wear during operation, the wear rate vs load curve, in principle, may be developed in a single test run without changing specimens. A disadvantage of this approach is the fact that at each successive load the specimens have been worn at the preceding levels. It has been suggested that this method may be employed with relatively short time periods at each load to obtain a rapid estimate of behavior [8]. A sounder method consists of using a new set of specimens at each load level $[4,8]$. The latter procedure was applied to two IIIC reference oils and two IIID reference oils. The results are shown in figure $3 a$ and $b$, respectively. For these tests, the initial oil temperature was $60{ }^{\circ} \mathrm{C}$. A 5 minute run-in period at 50 lbf (220N) was followed by automatic advance of the load to the desired test level. The load was maintained for 30 minutes at each level before terminating that test increment and determining the amount of wear. Wear was measured in terms of the mass lost from the pin. The teeth wear measurement method was not suitable because of the very small loss experienced during these tests. Wear of the harder V-block was much less than from the pin but varied in about the same way. The wear behavior of the two IIIC reference oils shown in figure $3 a$ is essentially identical according to this test procedure. Wear at $300 \mathrm{lbf}$ (1330N) and below is relatively low. A sharp increase, by nearly an order of magnitude, is observed at $4001 \mathrm{bf}$ ( $1800 \mathrm{~N}$ ). Seizure occurred within the first few minutes at a load of 500 lbf $(2200 \mathrm{~N})$.

In contrast, the two IIID reference oils which exhibit considerably different cam and lifter wear behavior (table 1) also differ according to this test as shown in figure $3 \mathrm{~b}$. Reference oil 77B-1 gives a relatively low wear rate at loads of $100 \mathrm{lbf}$ ( $440 \mathrm{~N}$ ) and $2001 \mathrm{bf}$ $(890 \mathrm{~N})$, accelerates at $300 \mathrm{lbf}(1800 \mathrm{~N})$ and fails at $400 \mathrm{lbf}(1800 \mathrm{~N})$. A somewhat higher wear rate is obtained with reference oil $76 \mathrm{~A}-1$ at low loads. A drop is observed at $4001 \mathrm{bf}$ $(1800 \mathrm{~N})$ followed by an accelerating wear rate until failure occurred at 600 lbf (2700N). Failure for both IIID oils was associated wth severe galling of the test specimens. If, in fact, resistance to galling is the critical factor in preventing cam and lifter wear, then the test results in this example can be said to exhibit good correlation. 

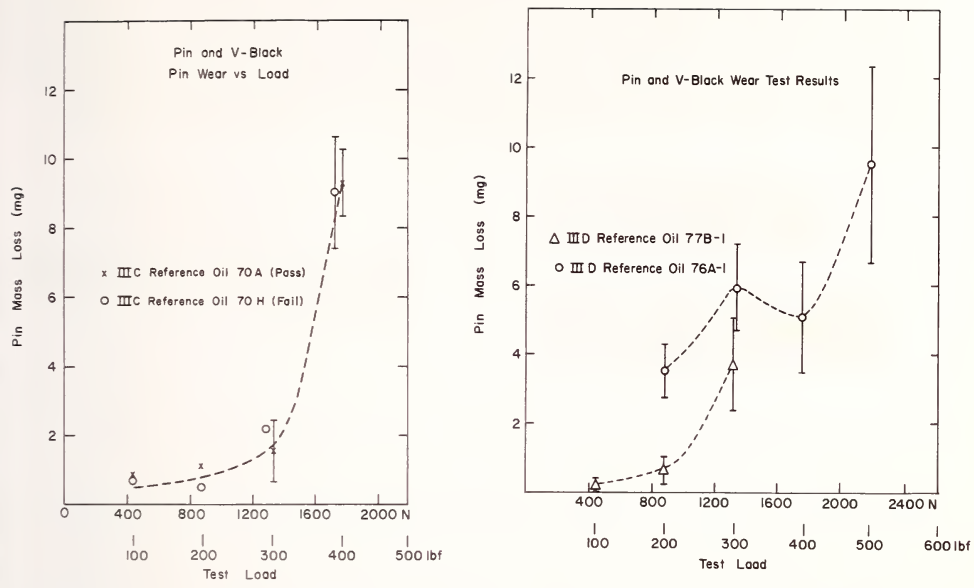

Figure 3. Pin wear as a function of load. Procedure consisted of a 5 min run-in at 50 lbs followed by $30 \mathrm{~min}$ at the test load. reference oils.

a) IIIC reference oils. b) IIID

\subsection{ASTM D3233 and other load carrying capacity methods}

Standard test method 03233 describes two methods for determining the load carrying capacity of a lubricant. In Method A, following a run-in period of five minutes at $2631 \mathrm{bf}$ $(1170 \mathrm{~N})$, the load is advanced automatically until failure occurs or the maximum capacity of the machine is reached. Method B employs the same run-in step but the load is increased in increments and held one minute at each increment, first at $4121 \mathrm{bf}(1830 \mathrm{~N})$ and then 589 , $759,924,1085 \mathrm{lbf},(2620,3380,4110,4830 \mathrm{~N})$ etc., until failure occurs. (With the $4500 \mathrm{lbf}$ load gage, run-in takes place at an indicated 300 ibf (1300N) and the load is advanced to $500 \mathrm{lbf}(2200 \mathrm{~N})$ followed by equal increments of $250 \mathrm{lbf}(1100 \mathrm{~N})$. As pointed out earlier, these equal increments of gage indicated load do not represent equal increments of force applied to the V-blocks.) The starting lubricant temperature for both methods is $51.7 \pm 3{ }^{\circ} \mathrm{C}$. Failure is caused by excessive friction which results in fracture of the pin or of the shear pin. Severe adhesive wear, galling or seizure at the specimen wear zone are observed. Extrusion of the pin without macroscopic evidence of severe adhesive wear occurs with some lubricants having high load carrying capacities. Examples of galled and extruded pins are shown in figure 4.

The rather high run-in load of 263 lbf (1170N) renders the application of D3233 to base oils and engine oils having load carrying capacities lower then SE grade oils of marginal value. In order to extend D3233, Method A to lubricants ranging from mineral oil without additives to fully formulated SE grade engine oils, a procedure employing a run-in at 50 lbf (220N) followed by automatic advance of load to failure was investigated. The run-in step included 2 hours with mineral oil followed by $1 / 2$ hour with the oil to be tested. This run-in step produced a small amount of wear and generally led to full contact with the pin across the slightly non-flat V-block faces. The initial oil temperature for this test was 
$60{ }^{\circ} \mathrm{C}$. Figure 5 shows a typical simultaneous recording of $\mathrm{V}$-block temperature, applied load and friction force obtained during the automatic load advance portion of the test. The steady state temperature of the V-block at $50 \mathrm{lbf}(220 \mathrm{~N})$ is higher than the bulk oil temperature due to frictional heating. The increase in friction force with load is approximately linear until just prior to failure when a rapid rise in friction force occurs. The point at which this sharp departure from linearity occurs is taken as the failure load. Good agreement is obtained between the failure load determined from chart recordings and visual observation of the load gage.
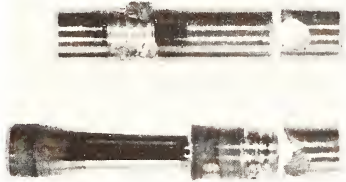

Figure 4. a) Pin that has failed due to galling and seizure. b) Pin that was extruded without evidence of severe adhesive wear.

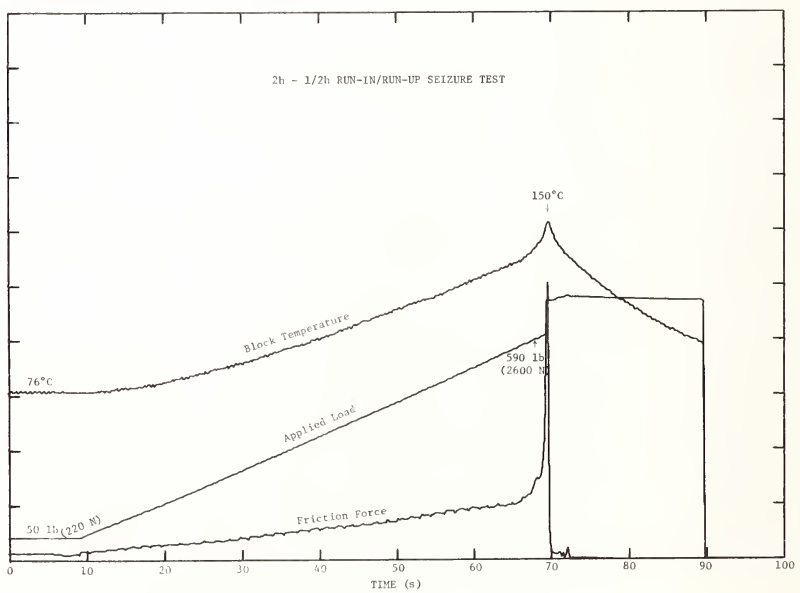

Figure 5. Typical chart traces of friction force and temperature during automatic load advance portion of load carrying capacity test.

Results obtained by applying this procedure to three different base oils with 0 to 1.0 W/o ZDDP are shown in figure 6. Each point is the average of five repeat tests. Error bars represent the \pm 10 limits. The response of the three base oils to the addition of ZDDP varies considerably. Mineral oil enhibits the most marked response. The load at seizure is multiplied three times by increasing the concentration of ZDDP from 0 to $0.03 \mathrm{w} / \mathrm{o}$. At concentrations greater than $0.07 \mathrm{w} / \mathrm{o}$, the pins were extruded without seizure. The response of the 
virgin base and re-refined base oils is not as great. When $0.05 \mathrm{w} / \mathrm{o}$ ZDDP is added to the virgin base oil, the seizure load is nearly doubled while there is only a slight increase for the re-refined base oil at this concentration. Increasing the concentration of ZDDP from $0.05 \mathrm{w} / 0$ to $1.0 \mathrm{w} / 0$ led to almost no change in seizure load for the virgin base and rerefined base oils, within the observed scatter. The latter observation suggests a saturation condition at concentrations of ZDDP higher than 0.05 percent.

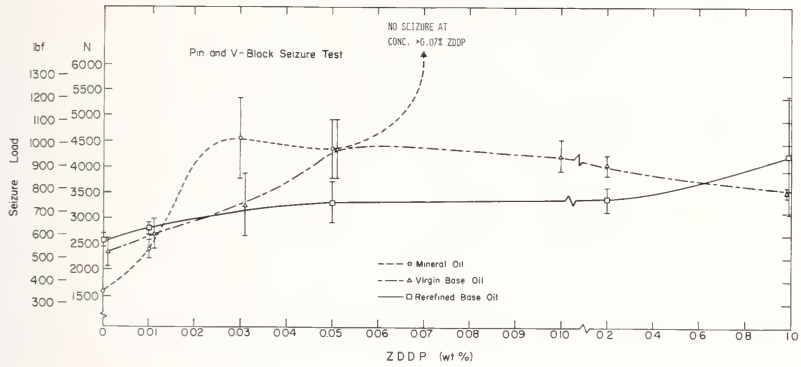

Figure 6. Load carrying capacity test results for three base oils with concentrations of ZDDP ranging from 0 to $1.0 \mathrm{w} / 0$. Each point represents the average of five or more replicate tests. Error bars give the standard deviations.

The seizure test was also applied to five IIIC reference oils. The results are shown in figure 7. As might be expected, there is relatively little difference in their response to this test. The IIIC oils are optimized for the purpose of evaluating high speed, high load thermal degradation behavior.

Finally, it should be noted that the seizure test procedures were found to be especially sensitive to metallurgical factors. V-blocks with an annealed pearlite-ferrite structure were found to exhibit seizure loads that were sometimes as much as 50 percent less than those obtained with V-blocks having a spheroidized structure.

6. Ring and Block Test Procedures

\subsection{Test machines}

The ring and block specimen configuration is shown in figure 8 . The contact geometry is that of a cylinder on flat as was the pin and V-block configuration; however, the complicated load distribution that arose as a result of multiple contacts is avoided here. There are several different machine designs utilizing the ring and block configuration. Among the most widely used are the Timken and Alpha Model LFW-1 machines. Descriptions of these machines can be found in [9] and in the ASTM standard methods which are referred to below. Both machines employ dead weight loading through a lever system but differ in design detail. The block is positioned above the ring as in figure 8 for the Alpha Model LFW-1 machine, while it is below the ring in the Timken machine. In normal operation of the Timken machine, the lubricant is supplied through a nozzle to the ring and recirculated. With the Alpha Model LFW-1 machine, the ring is dipped into a reservoir of oil. A major difference between the two machines concerns the size of the specimens used. The Timken design utilizes a ring having an outside diameter of $49.22 \mathrm{~mm}$ and width of $13.06 \mathrm{~mm}$. The block is wider $(19.05 \mathrm{~mm})$ than the ring. The Alpha Model LFW-1 ring is $35.00 \mathrm{~mm}$ in diameter and $8.15 \mathrm{~mm}$ wide, while the block is $6.35 \mathrm{~mm}$ wide and therefore narrower than the ring. The Faville-LeVally Corp. has recently redesigned the Alpha Model LFW-1 machine and renamed it the Falex \#1 machine. The Falex \#1 machine was used in this investigation. Optional components are available to permit the Falex \#1 machine to accept the Timken specimens and carry out tests designed for the Timken machine. 


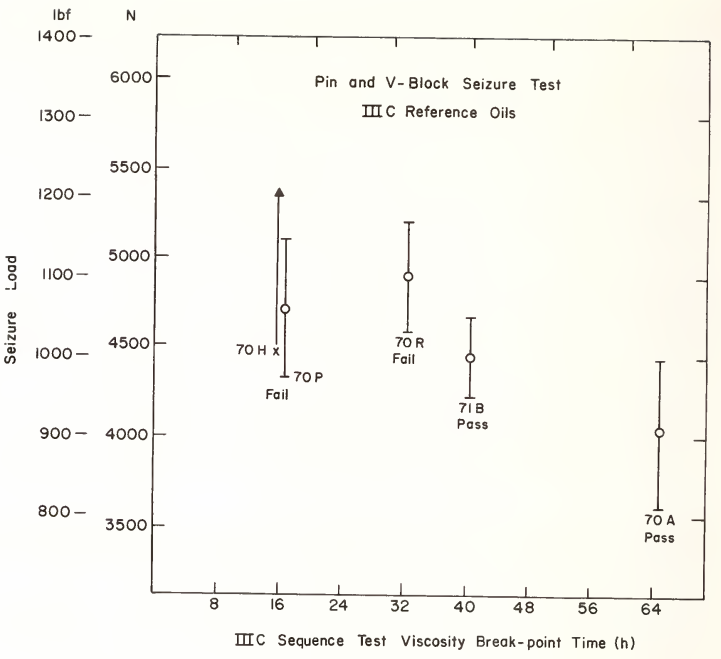

Figure 7. Load carrying capacity test results for five IIIC reference oils. Each point represents the average of five replicate tests. Error bars give the standard deviations.

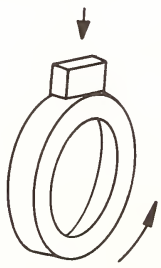

Figure 8. Block-on-ring test specimen configuration.

\subsection{Test specimens}

The test specimens employed were those that meet specifications given in ASTM D2714 (Alpha Model LFW-1 size) and D2782 (Timken design).

\subsection{Test procedures}

There are two ASTM standard test methods applicable to fluid lubricants that employ the ring and block configuration. They are: D2714 Calibration and Operation of the Alpha Model LFW-1 Friction and Wear Testing Machine and D2782 Measurement of Extreme-Pressure Properties of Lubricating Fluids (Timken Method). The evaluation of D2714 will be discussed below. 
Evaluation of $\mathbf{D} 2782$ has not yet been undertaken, however a modification of this method has been examined. The modified method is one that has been employed by the Suntech Corp. [10] for the evaluation of engine oils and some preliminary results will be presented.

\subsection{ASTM 02714}

The scope statement accompanying 02714 indicates that the method provides a procedure for calibrating and operating the Alpha Model LFW-1 machine (or the Falex \#1 machine with appropriate adjustments to accommodate the slightly different design). No guidelines are given concerning the properties of the lubricant for which the method is applicable. The test procedure is limited to a single set of operating conditions: $72 \mathrm{rpm}, 150 \mathrm{lbf}$ (3300N) load, $43^{\circ} \mathrm{C}$ oil temperature, 4500 revolutions. Calibration is established by applying the method to white mineral oil having a viscosity of 63 to $65 \mathrm{cSt}$ at $37.8^{\circ} \mathrm{C}$. The machine is judged to be calibrated if the block wear scar width falls between 1.70 and $2.90 \mathrm{~mm}$ with a repeatability range of $0.73 \mathrm{~mm}$, and the friction force after 4500 revolutions is 66.7 to $87.8 \mathrm{~N}$ with a repeatability of $29.3 \mathrm{~N}$. Figure 9 gives results obtained by applying the test procedure to mineral oil, the virgin base $0 i 1$ and the re-refined base oil all with concentrations of ZDDP ranging from 0 to $1.0 \mathrm{w} / \mathrm{o}$. In a single departure from ASTM 02714 , the oil temperature was maintained at $60^{\circ} \mathrm{C}$ rather than the prescribed $43.3{ }^{\circ} \mathrm{C}$. Each point in figure 9 represents the average wear scar width for at least five repeat tests. Error bars give the \pm lo limits. The percent standard deviation is somewhat less for oils without ZDDP ( \pm 6 to \pm 8 percent) than for oils with ZDDP ( \pm 9 percent to \pm 19 percent). Although there is a significant difference in wear among the oils without ZDDP, that difference is essentially eliminated with the addition of $0.05 \mathrm{w} / 0$ ZDDP. In fact, within the observed scatter, there is little difference in wear behavior for all oils with ZDDP. Since the amount of wear is brought to about the same level in all cases by concentrations of ZDDP equal to or greater than $0.05 \mathrm{w} / 0$, it appears that the presence of the additive dominates the wear process. In effect, the test does not discriminate between these oils at concentrations of ZDDP $\geq 0.05 \mathrm{w} / 0$.

\subsection{Suntech modification of $\mathbf{D} 2782$}

ASTM D2782 is designed to determine the load carrying capacity of fluid lubricants. The measured quantities are the minimum load at which scoring or seizure occurs, maximum load (OK value that can be applied without scoring or seizure) and the pressure at the maximum load. The pressure determination is based on the measured size of the wear scar. The amount of wear is not one of the quantities designated for determination, however, this quantity is implicitly contained in the pressure measurement. Although seizure and scoring may be evidenced by noise and vibration during the test, a final determination is made by visual examination of the wear scar on the test block without the aid of a microscope. The test conditions prescribed by 02782 are summarized in table 3 . Although ASTM D2782 has not yet been evaluated in this program, a modification referred to as the Suntech Timken test has been examined. F. E. Didot of the Suntech Corp. reports good correlation with this test and IIIC sequence test results. The Suntech Timken procedure is outlined in table 3 for

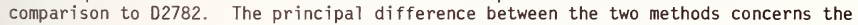
quantity of oil that is supplied to the test pieces. A continuous flow of oil (rate not specified) is supplied in the case of D2782 while for the Suntech method the test pieces are only wet with a film of oil at the start of the tests. Excess oil is thrown off during the test. Since a supply of oil is not available for cooling, frictional heating may cause a significant rise in temperature. This, in turn, may lead to an accelerated decomposition of the oil as was evidenced during tests by the generation of smoke and appearance of deposits on the test pieces.

Results obtained by applying the Suntech method to five IIIC reference oils, two IIID reference oils and two unformulated oils are given in table 4 . The values listed were obtained through application of a single series of tests to each oil. That is, loads were applied in increasing increments of $20 \mathrm{lbf}(89 \mathrm{~N})$ for each trial until failure occurred (or decrements if failure was obtained in the first trial). In order to narrow the limits, increments of 5 or $10 \mathrm{lbf}(22$ or $44 \mathrm{~N})$ were then used. Replicate tests have not yet been run to determine repeatability. Both friction force and block temperature were recorded simultaneously for each trial. A relative measure of block temperature was obtained by means of chromel-alumel thermocouple wires spot welded at a point about $1 \mathrm{~mm}$ distant from the 
contact junction. Although failure was determined by examination of the block wear scar, it was also indicated by the friction force trace. Examples of friction force and block temperature traces for three tests are shown in figure 10 . Figure 10a shows a typical example where failure did not occur. The friction force trace exhibits a sharp but brief initial peak on application of the load and remains nearly constant thereafter. The block temperature rises continuously during the test. The load was increased by $101 \mathrm{bf}$ (44N) in figure 10b. The behavior was similar to figure 10a until near the end of the test when sharp fluxuations in the friction force indicated the onset of seizure. Failure also occurred in the example shown in figure 10c. With this oil, however, rapid wear was experienced on initial application of the $80 \mathrm{lbf}(360 \mathrm{~N})$ test load; this is indicated by the broad peak in the friction force trace. A corresponding peak also occurs in the block temperature trace. As a result of the rapid initial wear, the junction area is increased and the contact stress is reduced. The remainder of the test was then completed without further evidence of failure. These results suggest that failure occurred in figure $10 \mathrm{~b}$ because of thermal degradation effects while in figure 10c the load carrying capacity was exceeded initially.

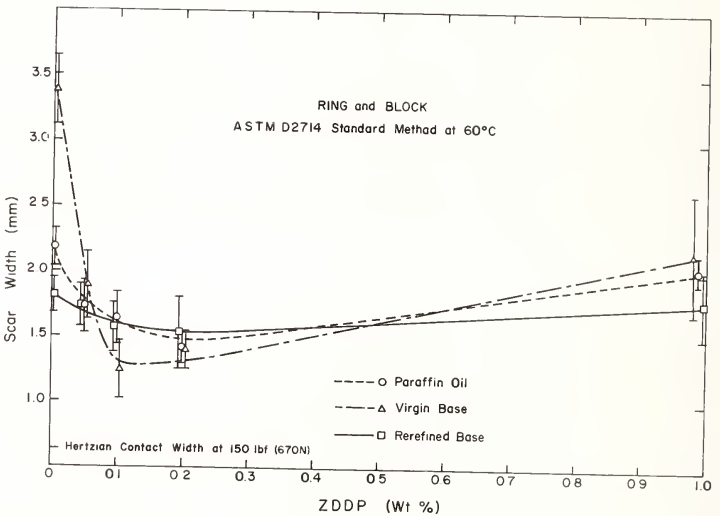

Figure 9. Results obtained by applying 02714 to three base oils with concentrations of ZDDP ranging from 0 to $1.0 \mathrm{w} / \mathrm{o}$.

Table 3. Summary of conditions and procedure for ASTM D2782 and Suntech modification.

ASTM D2782

Quantity of oil

0il temperature

Break-in

Load increments

Time per increment Speed

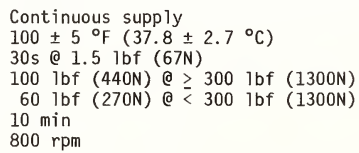

Suntech 
Table 4. Results obtained with Suntech modifications of ASTM D2782.

Test $0 i 1$

IIIC

$\left[\begin{array}{ll}R 0 & 70 A \\ R 0 & 71 B \\ \text { RO } & 70 R \\ \text { RO } & 70 H \\ R 0 & 70 P\end{array}\right.$

$64 h$ pass

$40 \mathrm{~h}$ pass

$32 \mathrm{~h}$ borderline fail

$16 \mathrm{~h}$ fail

16h fail

IIID $\quad\left[\begin{array}{lll}\text { RO } & 76 \mathrm{~A}-1 & \text { pass } \\ \text { RO } & 77 \mathrm{~B}-1 & \text { fail }\end{array}\right.$

Re-refined base stock

Paraffinic mineral oil

\author{
Max. Pass Load \\ $1301 \mathrm{bf}(580 \mathrm{~N})$ \\ $1251 \mathrm{bf}(560 \mathrm{~N})$ \\ $155 \mathrm{lbf}(690 \mathrm{~N})$ \\ $85 \mathrm{lbf}(380 \mathrm{~N})$ \\ $75 \mathrm{lbf}(330 \mathrm{~N})$ \\ 120 lbf (530N) \\ $601 \mathrm{bf}(270 \mathrm{~N})$ \\ $40 \mathrm{lbf}(180 \mathrm{~N})$ \\ $30 \mathrm{lbf}(130 \mathrm{~N})$
}

Min. Fail Load

140 lbf $(620 N)$
130 lbf $(580 N)$
120 lbf $(530 N)$
$951 \mathrm{bf}(420 \mathrm{~N})$
$80 \mathrm{lbf}(360 \mathrm{~N})$
$130 \mathrm{lbf}(580 \mathrm{~N})$
$80 \mathrm{lbf}(360 \mathrm{~N})$
$45 \mathrm{lbf}(200 \mathrm{~N})$
$40 \mathrm{lbf}(180 \mathrm{~N})$

With one exception, the IIIC and IIID reference oils are ranked approximately in the same order as in the sequence tests. The exception, reference oil 70R, gave an exceptionally high pass load. The results were inconsistent, however, in that the minimum fail load was lower than the maximum pass load. Additional tests and study are clearly warranted. It should also be noted that the two unformulated base oils were ranked decidedly lower than the formulated oils in table 5. According to the criteria set forth earlier for judging the value of a test method, the Suntech Timken test exhibits a high degree of sensitivity to different oils and shows a high degree of correlation with service performance. The repeatability has not yet been established.

\section{Conclusions}

\subsection{Pin and V-block test methods}

1) The Falex \#0 machine is compact and easy to operate. These features, however, belie complexities that are connected with load calibration and effects associated with the multiple contact specimen configuration. 2) ASTM 02670 is, in general, too severe for application to unformulated and formulated engine oils. 3) Applicable wear rate tests may be developed using lower loads. A procedure designed to measure wear at a series of increasing load steps which gives a wear rate vs load characteristic curve for the lubricant may be more useful than measurement of wear at a single load. 4) ASTM D3233 can be applied to measure the load carrying capacity of some formulated engine oils. A procedure utilizing a run-in load of $50 \mathrm{lbf}$ can be applied to base oils and formulated engine oils. 5) Specimens which met specifications described in ASTM D2670 and D3233 were found to yield different results because of differences in microstructure. 6) The extent to which pin and V-block test procedures can be used to demonstrate consistency and evaluate service performance has not yet been fully evaluated, however, the existing ASTM test methods do not appear to offer much promise in this regard.

\subsection{Ring and block methods}

1) ASTM D2714 can be applied to base oils and formulated SE engine oils. Repeatabilities ranged from 6 percent to 20 percent (standard deviation as percent of average). There was little discrimination among the base oils and formulated oils to which the test was applied. 2) A modification of ASTM 02782, the Suntech Timken test, appears to offer some interesting promise in discriminating among and ranking IIIC and IIID reference oils.

The authors wish to express their thanks to Dr. A. W. Ruff and Dr. S. M. Hsu for helpful discussion and valuable advice. 

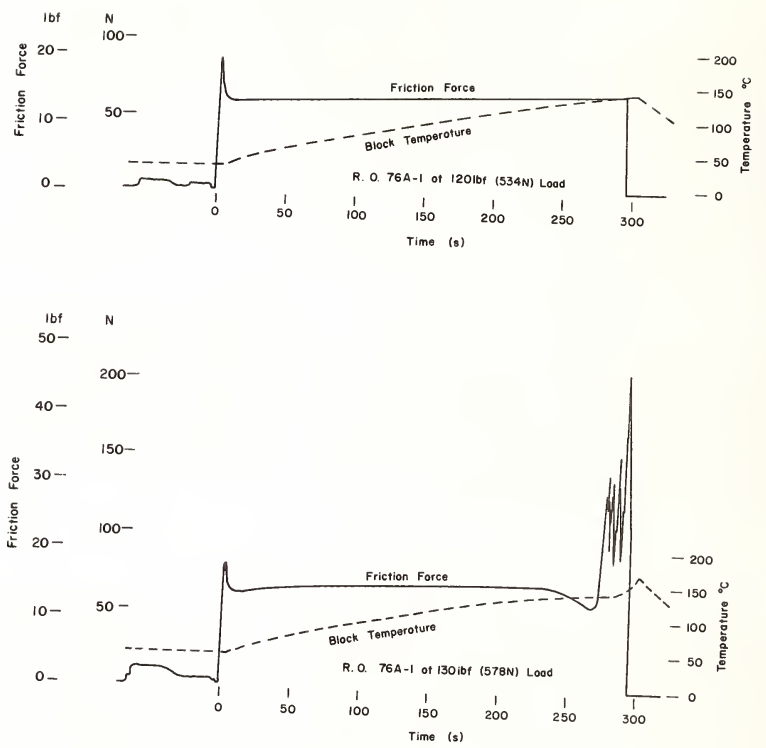

\section{(b)}

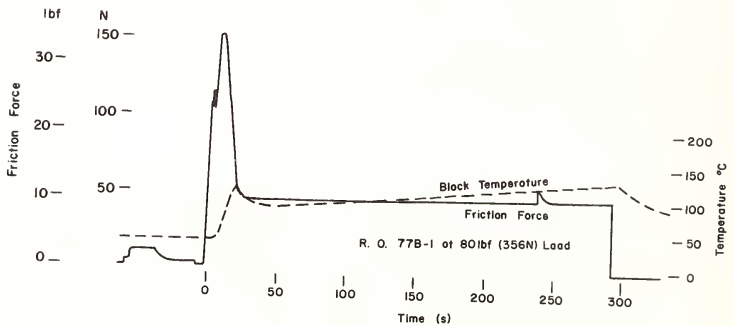
Figure 10. Simultaneous friction force and block temperature traces from tests
employing the Suntech modifications of D2782. (a) Typical "pass" behavior.
A condition of severe wear developed near end of the the curred during early stage of test near end of the test. (c) Severe wear. (b) 


\section{References}

[1] Gates, R. and Hsu, S., The four-ball wear test for engine oil evaluation (these proceedings).

[2] 1979 Annual Book of ASTM Standards, Part 24, Petroleum Products and Lubricants (II), American Society for Testing and Materials, Philadelphia, PA (1979).

[3] Crowley, C. A. and Faville, F. A., Evaluation of extreme pressure lubricants, SAE Regional Transportation Meeting, Chicago, IL (October 1937).

[4] Faville, F. A. and Faville, W. A., Falex procedures for evaluation lubricants, 23rd ASLE Annual Meeting, Cleveland, $\mathrm{OH}$ (May 1968).

[5] Pin and V-block Machine Instruction Manual, Faville-LeVally Corp., Downers Grove, IL.

[6] Tabor, D., The Hardness of Metals, Clarendon Press, Oxford (1951).

[7] Mecklenburg, K. R., The Effect of Wear on Compressive Stress in the Sphere-on-Plane and Multiple-Flat-on-Curve Configurations, Technical Report AFML-TR-73-39 (February 1973).

[8] Ryan, V. A., Measurement of lubricant film strength in the region of boundary friction, Lubrication Engineering, p. 101 (1946).

[9] Friction and Wear Devices, 2nd edition, American Society of Lubrication Engineers, Park Ridge, IL $\overline{(19} \overline{76) \text {. }}$

[10] F. E. Didot, Suntech Corp., private communication. 

National Bureau of Standards Special Publication 584. Proceedings of Joint Conference on Measurements and Standards for Recycled 0il/Systems Performance and Durability held at NBS, Gaithersburg, MD, October 23-26, 1979. (Issued Nov. 1980)

THE FOUR-BALL WEAR TEST FOR ENGINE OIL EVALUATION

Richard S. Gates and Stephen M. Hsu

Tribochemistry Group

Chemical Stability and Corrosion Division

National Bureau of Standards

Washington, DC 20234

\section{Introduction}

Bench tests are an attractive approach to wear testing. Their low cost, short duration, and ease of operation make them a desirable research tool. The commonly used engine sequence tests have been established based on actual field performance $[1]^{1}$, but they are complicated and depend on so many parameters that chemical effects are often masked. Laboratory bench tests can be tightly controlled to show differences existing in base stocks or additives. A simple bench test that correlates with performance and has the sensitivity to measure chemical effects would be invaluable in determining the effects of possible contaminants on engine oil performance, and also effects on additive response. The object of this study is to evaluate various test procedures for evaluating the wear characteristics of engine oils. The test procedures are being evaluated on the basis of sensitivity, repeatability and correlation with engine wear data.

The four-ball wear tester was chosen for this study for several reasons. The test apparatus is available commercially and used extensively in industry for wear testing. The test is easy to conduct, well controlled, and uniform test specimens are available at low cost. In any wear testing, the specimens basically undergo a destructive evaluation process. Test repeatibility, therefore, depends heavily on the uniformity of the test specimen. In the four-ball test, extra polish ball bearings with roundness specification of 0.00001 in are readily available at low cost.

Several workers have examined various procedures associated with four-ball test [2-8]. Generally these are: 1) slow speed sliding vs load, 2) fast speed sliding vs load, 3) step loading seizure test, 4) sequential testing.

These procedures, except for the sequential testing, will be examined in this study. The sequential testing is not possible on our 4-Ball machine due to equipment design.

\section{Experimental Apparatus and Procedures}

The apparatus used in this study is a Falex \#6 machine manufactured by Faville LeVally corp. It consists of three balls clamped in a planar configuration in an oil cup, with the fourth ball rotating on top of the other three. The load on the contact points was controlled by weights on a lever arm arrangement capable of giving vertical loads of over 500 lbs. The temperature of the bulk oil was controlled by a heater located in the wall of the test cup. The torque produced by the contact was measured by a force transducer which gave a continuous readout to a strip chart recorder. The original design had a test cup that called for $85 \mathrm{ml}$ of lubricant for each test. A modified test cup was constructed that required only $10 \mathrm{ml}$ of lubricant for each test. This gave more tests for a limited amount of sample and also allowed for easy sample retrieval for wear debris analysis. Wear was evaluated by measuring the diameter of the wear scars on each of the three stationary balls. The average of the three wear scar diameters was then used to calculate the wear scar volumes according to the work by Feng [9].

Figures in brackets indicate the literature references at the end of this paper. 


\section{Test Specimen Preparation}

Since thorough cleaning is important in ensuring test precision, the following procedures were used.

\subsection{Initial batch cleaning of ball bearings}

The balls were agitated ultrasonically for 2 minutes in successive baths of hexane, Stoddard solvent, and acetone. The acetone was drained off completely and the balls were kept under hexane until ready for testing.

\subsection{Test cup and top ball holder cleaning}

After removing all excess oil with a tissue, the parts were rinsed in successive solutions of hexane, Stoddard solvent, and acetone. After cleaning with a clean dry lintless tissue, the parts were dried with nitrogen gas.

\subsection{Final cleaning of ball bearings}

Just prior to testing, 4 balls were selected from the initially cleaned batch and agitated ultrasonically for 1 minute in successive baths of hexane with 10 percent Stoddard solvent, and acetone. The balls were wiped with a clean dry lintless tissue and dried with nitrogen gas.

Three of the clean balls were placed in the text cup and clamped in place. The 4 th ball was placed on top of the other three and $10 \mathrm{ml}$ of lubricant were added to the cup.

The ball holder assembly was then ready to be placed onto the loading assembly for testing. Upon completion of a test, wear scar measurements were made using a $100 \times$ microscope with a calibrated graduated reticle reading to the nearest $0.01 \mathrm{~mm}$.

\section{Criterion for Correlation}

The comparison between bench test performance and actual engine performance was made using ASTM engine test standard reference oils. The current reference oils on M.S. sequence IIID engine test were used. Data from IIID Engine Sequence Tests taken from ASTM Sequence IIID Surveillance Panel Reports, showed that it was possible to group the oils into two categories with respect to wear as shown in table 1 and figure 1 . Reference 0 ils $76 \mathrm{~A}, 75 \mathrm{~B}$, and $79 \mathrm{~A}$ were classified as $10 \mathrm{w}$ wear oils while $77 \mathrm{~B}$ and $77 \mathrm{C}$ could be classified as relatively high wear oils. The performance of the reference oils in the bench tests as compared to the wear classifications to determine if there was a correlation.

Table 1. IIID engine sequence data-reference oils.

\begin{tabular}{|c|c|c|c|c|c|}
\hline $\begin{array}{c}\text { Reference } \\
\text { 0il } \\
\text { REO } \\
\end{array}$ & $\begin{array}{l}\text { SAE Viscosity } \\
\text { Grade } \\
\end{array}$ & $\begin{array}{l}\text { Average Cam } \\
\text { and Lifter Wear } \\
\mathrm{cm} \times 10^{4} \\
\end{array}$ & $\begin{array}{l}\text { Standard } \\
\text { Deviation } \\
\mathrm{Cm} \times 10^{4} \\
\end{array}$ & $\begin{array}{l}\text { Engine } \\
\text { Test } \\
\text { Ranking } \\
\end{array}$ & $\begin{array}{r}\text { \# of } \\
\text { Tests } \\
\end{array}$ \\
\hline $76 \mathrm{~A}$ & $10 w-40$ & 48 & 23 & Low & 17 \\
\hline $75 B$ & $10 w-30$ & 46 & 25 & Low & 10 \\
\hline $79 A$ & $10 w-30$ & 48 & 15 & Low & 7 \\
\hline $77 \mathrm{~B}$ & $10 w-40$ & 287 & 188 & High & 22 \\
\hline $77 C$ & $10 w-30$ & 277 & 130 & High & 22 \\
\hline
\end{tabular}

5. Results and Discussions

5.1. Procedure evaluation

Two reference oils REO 76A and REO 77B were selected for initial screening of the speed setting. Since reference [10] showed ZDDP is an effective anti-wear agent in this load range, all of the reference oils contain zinc dithiophosphate (ZDDP) as the antiwear agent, the load is set at $23 \mathrm{~kg}$ machine loading (50 1bs). 


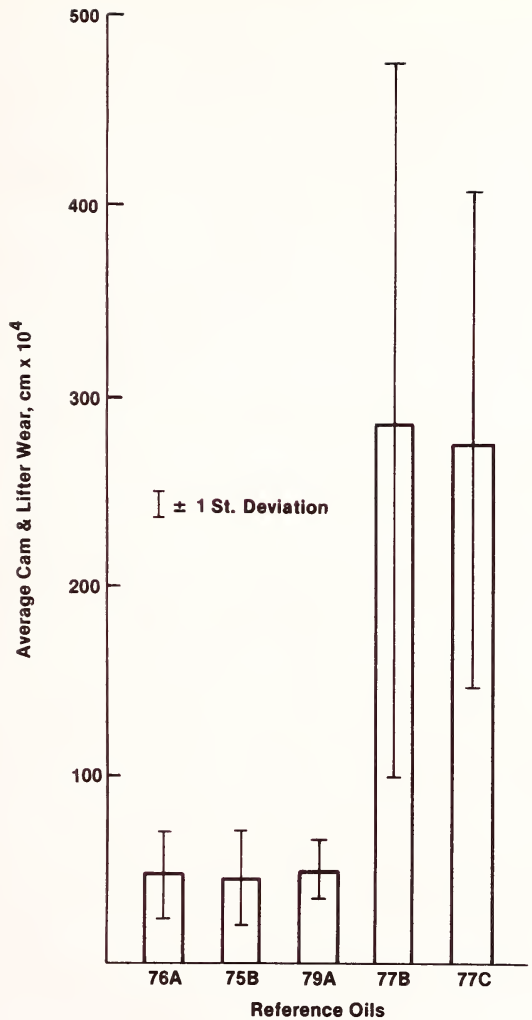

Figure 1. Engine sequence test wear ranking of reference oils.

Figure 2 shows the relationship between wear volume and speed on a log-log plot. At about 800-850 rpm, the data suggest a transition point. To examine this more closely, the data are replotted in figure 3 as wear rate (wear volume/unit linear distance traveled) versus speed. This shows that the rate of wear is actually higher at slow speed (100 to $800 \mathrm{rpm}$ ) and levels off from 800 to $2000 \mathrm{rpm}$. This may be explained as follows. As speed increases, the viscosity effect or hydrodynamic component increases as the wear process proceeds during each run. In other words, this also represents the transition of boundary lubrication into the elastohydrodynamic lubrication regime. Using this information, two speeds were selected to represent the predominant boundary lubrication ( $200 \mathrm{rpm}$ ) and elastohydrodynamic (EHD) lubrication ( $1500 \mathrm{rpm})$ modes. It should be recognized that each mode contains a component of the other in it. 


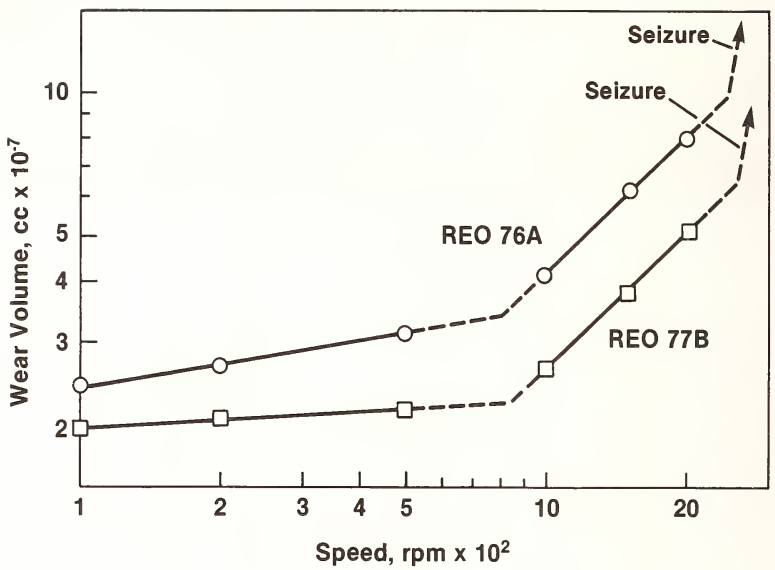

Figure 2. Wear volume as a function of speed.

Using these sets of conditions, tests were run using the entire set of Sequence IIID engine test reference oils. Table 2 shows that there was no correlation with engine sequence wear data for either mode.

\subsection{Oxidation-wear coupled test procedure}

The effectiveness of a boundary lubrication film is primarily a function of the chemical composition of the lubricant. Zinc dialkyl dithiophosphate (ZDDP) is the antiwear additive of most crankcase lubricants. ZDDP functions not only as an antiwear agent, but also as an anti-oxidant.

Table 2. Basic 4-Ball wear test data - reference oils.

$$
\begin{aligned}
\text { Common Conditions: } & \text { Load: } 23 \mathrm{~kg} \\
& \text { Temperature: } 75{ }^{\circ} \mathrm{C} \\
& \text { Duration: } 60 \mathrm{~min} \\
& \text { Fluid: } 10 \mathrm{~m} 7 \text { REO }
\end{aligned}
$$

\begin{tabular}{|c|c|c|c|c|c|}
\hline \multirow[b]{2}{*}{ REO } & \multirow[b]{2}{*}{$\begin{array}{l}\text { Engine Test } \\
\text { Wear Ranking }\end{array}$} & \multicolumn{2}{|c|}{200 RPM } & \multicolumn{2}{|c|}{1500 RPM } \\
\hline & & $\begin{array}{l}\text { Wear Volume } \\
\text { cc } \times 10^{-7} \\
\end{array}$ & Ranking & $\begin{array}{r}\text { Wear Volume } \\
\text { cc } \times 10^{-7} \\
\end{array}$ & Ranking \\
\hline $79 A$ & Low & 2.6 & 5 & 6.1 & 4 \\
\hline $75 B$ & Low & 2.5 & 4 & 5.8 & 3 \\
\hline $76 A$ & Low & 2.2 & 3 & 6.6 & 5 \\
\hline $77 \mathrm{~B}$ & $\mathrm{High}$ & 2.1 & 2 & 3.8 & 2 \\
\hline $77 C$ & $\mathrm{High}$ & 1.6 & 1 & 2.4 & 1 \\
\hline
\end{tabular}




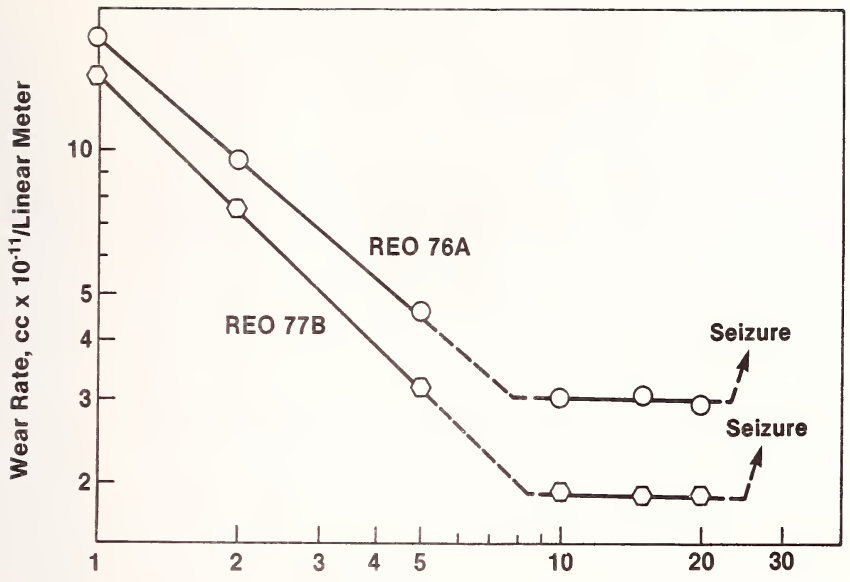

Speed, $\mathrm{rpm} \times 10^{2}$

Figure 3. Wear rate as a function of speed.

In the engine test, the oil undergoes oxidation/thermal degradation and metal cataTysis. ZDDP functions as an anti-oxidant by forming coordination complexes with the peroxide radical which initiates the oxidation process [11]. As oxidation progresses, ZDDP is used up as anti-oxidant leaving little or no ZDDP to function as the anti-wear agent. A point will be reached at which both oxidation and wear would proceed at an accelerated rate due to loss of protection because of additive depletion. If this hypothesis is true, then a wear test coupled with an oxidation procedure could reverse the ranking observed in the slow sliding experiments. The oxidation was introduced by way of an open tube oil thickening test prior to the wear test. The oil thickening test consisted of bubbling air through a $100 \mathrm{ml}$ sample of oil $10 \mathrm{ml}$ used oil from a batch of automotive crankcase used oil was added as catalyst. The tube was kept at $177^{\circ} \mathrm{C}\left(350^{\circ} \mathrm{F}\right)$ and the thickening of the oil was monitored with a capillary micro viscometer. The capillary micro viscometer constructed for these measurements required only $2 \mathrm{ml}$ of sample. The data are calibrated with reference oils of known viscosity at $40{ }^{\circ} \mathrm{C}$. The set of 5 IIID reference oils were oxidized under identical conditions using the open tube apparatus. The oil thickening rates did not correlate with the results of the IIID Engine Sequence Tests as shown in figure 4 and table 3 . This may be due to the absence of several conditions that were present during the engine sequence test - fuel dilution, constant addition of wear particles and fresh metal surfaces, water, and $\mathrm{NO}_{\mathrm{x}}$ and other blow-by gasses. Wear tests were run to observe the effects of oxidation on the antiwear characteristics of the reference oils. Again $200 \mathrm{rpm}$ and $1500 \mathrm{rpm}$ were chosen. The $200 \mathrm{rpm}$ runs showed the greatest change in ranking, as shown in table 4 . The $77 \mathrm{~B}$ oil has the highest wear just as in the engine sequence tests. The other high wear oil $77 \mathrm{C}$, also moved up in the ranking so that it was no longer the lowest wearing $0 i 1$ as shown in table 5 . The results are encouraging and show that the oxidation is affecting the antiwear properties of the oils, and that it affects the antiwear properties of the high wear reference oils more than the low wear reference oils. 


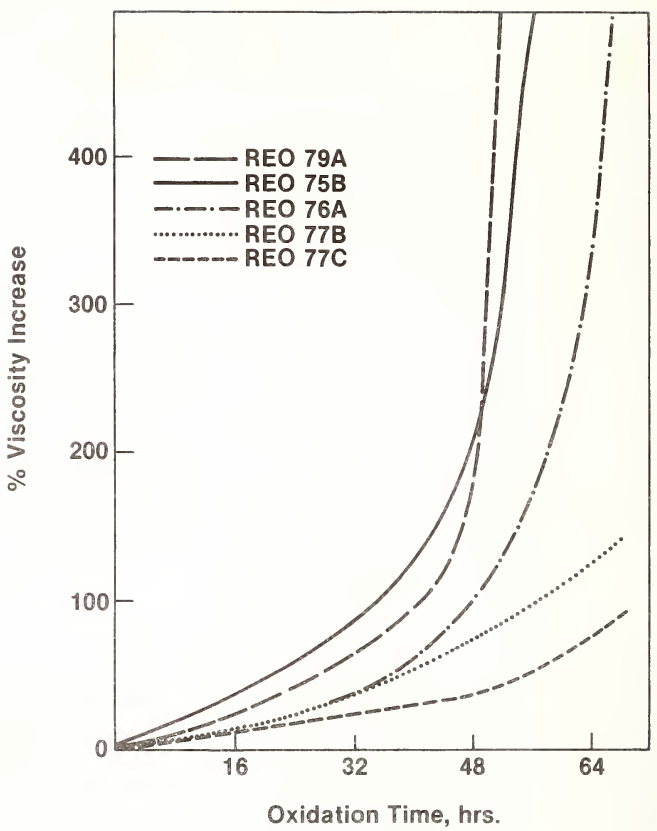

Figure 4. Viscosity increase in oil thickening test.

Table 3. 0xidation break point of reference oils.

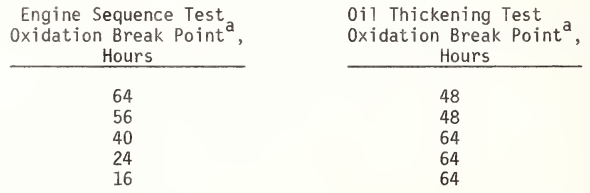

axidative break point was determined according to ASTM IIID Engine Sequence Test Method ( $375 \%$ viscosity increase). 
Table 4. 4-Ball wear test data - oxidized reference oils

$$
\begin{aligned}
\text { Common Conditions: } & \text { Load: } 23 \mathrm{~kg} \\
& \text { Temperature: } 75{ }^{\circ} \mathrm{C} \\
& \text { Deviation: } 60 \mathrm{~min} \\
& \text { Fluid: } 10 \mathrm{~m} 1 \mathrm{REO} \text { 0xidized } 48 \mathrm{~h}
\end{aligned}
$$

\begin{tabular}{|c|c|c|c|c|c|}
\hline \multirow[b]{2}{*}{ REO } & \multirow[b]{2}{*}{$\begin{array}{c}\text { Engine Test } \\
\text { Ranking } \\
\end{array}$} & \multicolumn{2}{|c|}{200 RPM } & \multicolumn{2}{|c|}{$1500 \mathrm{RPM}$} \\
\hline & & $\begin{array}{l}\text { Wear Volume } \\
\mathrm{cm}^{3} \times 10^{-7} \\
\end{array}$ & Ranking & $\begin{array}{l}\text { Wear Volume } \\
\mathrm{cm}^{3} \times 10^{-7} \\
\end{array}$ & $\underline{\text { Ranking }}$ \\
\hline $79 A$ & Low & 3.8 & 4 & 5.4 & 3 \\
\hline $75 B$ & Low & 3.2 & 1 & 5.8 & 4 \\
\hline $76 \mathrm{~A}$ & Low & 3.5 & 2 & 5.4 & 2 \\
\hline $77 B$ & $\mathrm{High}$ & 4.9 & 5 & 7.4 & 5 \\
\hline $77 \mathrm{C}$ & High & 3.6 & 3 & 4.5 & 1 \\
\hline
\end{tabular}

\begin{tabular}{|c|c|c|c|c|c|}
\hline REO & $\begin{array}{c}\text { Engine Test } \\
\text { Ranking } \\
\end{array}$ & $\begin{array}{l}\text { Unoxidized } \\
\text { Wear Volume } \\
\mathrm{cm}^{3} \times 10^{-7} \\
\end{array}$ & rence $0 i 1$ & $\begin{array}{l}\text { 0xidized Refe } \\
\text { Wear Volume } \\
\mathrm{cm}^{3} \times 10^{-7}\end{array}$ & Ranking \\
\hline $\begin{array}{l}79 A \\
75 B \\
76 A\end{array}$ & $\begin{array}{l}\text { Low } \\
\text { Low } \\
\text { Low }\end{array}$ & $\begin{array}{l}2.6 \\
2.5 \\
2.2\end{array}$ & $\begin{array}{l}5 \\
4 \\
3\end{array}$ & $\begin{array}{l}3.8 \\
3.2 \\
3.5\end{array}$ & $\begin{array}{l}4 \\
1 \\
2\end{array}$ \\
\hline $\begin{array}{l}77 \mathrm{~B} \\
77 \mathrm{C}\end{array}$ & $\begin{array}{l}\text { High } \\
\text { High }\end{array}$ & $\begin{array}{l}2.1 \\
1.6\end{array}$ & $\begin{array}{l}2 \\
1\end{array}$ & $\begin{array}{l}4.9 \\
3.6\end{array}$ & $\begin{array}{l}5 \\
3\end{array}$ \\
\hline
\end{tabular}

Table 5. Comparison of 200 RPM basic wear test data reference oil vs oxidized reference oil.

$$
\begin{aligned}
\text { Common Conditions: } & \text { Load: } 23 \mathrm{~kg} \\
& \text { Temperature: } 75{ }^{\circ} \mathrm{C} \\
& \text { Duration: } 60 \mathrm{~min} \\
& \text { Speed: } 200 \mathrm{RPM}
\end{aligned}
$$

\subsection{Step-loading seizure test}

There are several variations of seizure tests using a four-ball configuration. One method is to run wear tests at different loads with the results plotted on $\log -10 \mathrm{l}$ paper. This is the classical load capacity test. It defines the transition point between the low wear and the high wear region. 0ils can be compared either by the transition load or the final seizure load. This procedure is time consuming. The method examined in this study is a variation of the above mentioned procedure. It uses the friction characteristic to define seizure point in discrete steps of increasing loads. One typical friction trace is shown in figure 5. At point $A$, the friction force as represented by the torque increases dramatically. This load, therefore, is defined as the seizure load.

Initial testing was done using a candidate oil from each of the high wear (77B) and the low wear (76A) groups. A step loading increment of 20 lbs was selected because increments of 100, and 50 lbs lacked sensitivity, and increments of 5 or 10 lbs were impractical due to time and equipment limitations. A speed of $200 \mathrm{rpm}$ was selected for the tests based on the results of preliminary testing shown in figures 6 and 7 .

The seizure point, depicted here as a rapid increase in the coefficient of friction, shows that at $600 \mathrm{rpm}$, the difference in the seizure loads of the two oils was only $9 \mathrm{~kg}$. At $200 \mathrm{rpm}$ the difference was enhanced to $54 \mathrm{~kg}$. Slower speeds were not selected because the seizure load would have been too close to the $227 \mathrm{~kg}$ load limit of the equipment. The seizure tests were run therefore at room temperature, $200 \mathrm{rpm}$, and with $9 \mathrm{~kg}$ increments until seizure occurred. The load at which seizure occurred was used to rank the oils. 


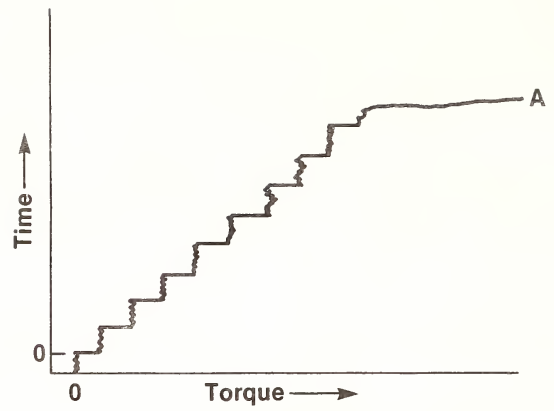

Figure 5. Typical friction trace for step-loading four-Ball seizure test.

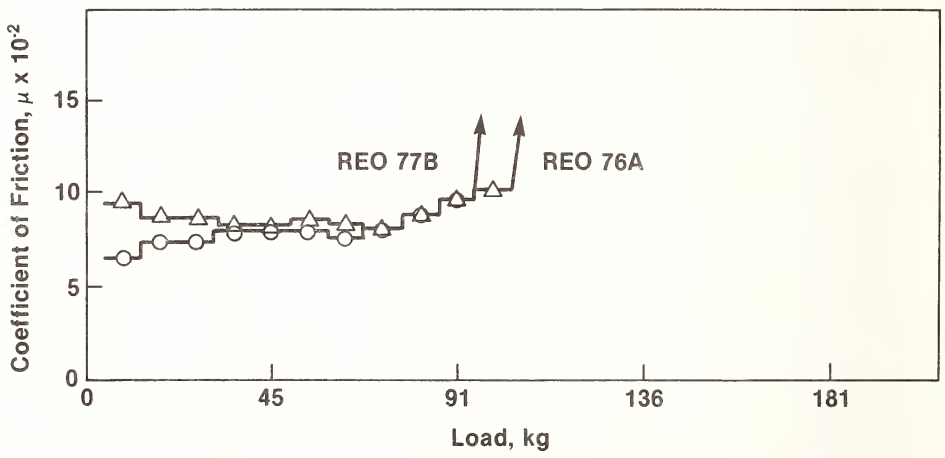

Figure 6. Step-loading seizure test at 600 RPM.

Table 6. 4-Ball step loading seizure test data - reference oils.

Common Conditions: Speed: 200 RPM

Temperature: Ambient

Duration: 5 minutes/load

Loading Increment: $9 \mathrm{~kg} / \mathrm{level}$

$\begin{array}{lcc}\text { RE0 } & \text { \# of Tests } & \begin{array}{c}\text { Seizure Load } \\ \text { kg }\end{array} \\ 77 \mathrm{C} & 1 & \underline{1} \\ 77 \mathrm{~B} & 2 & 145,163 \\ 76 \mathrm{~A} & 2 & 200,200 \\ 79 \mathrm{~A} & 1 & 218 \\ 75 \mathrm{~B} & 1 & 227\end{array}$

\begin{tabular}{cc} 
Seizure Test & $\begin{array}{c}\text { Engine Seque } \\
\text { Wear Rank }\end{array}$ \\
\cline { 3 - 3 } 5 & High \\
4 & High \\
3 & Low \\
2 & Low \\
1 & Low
\end{tabular}




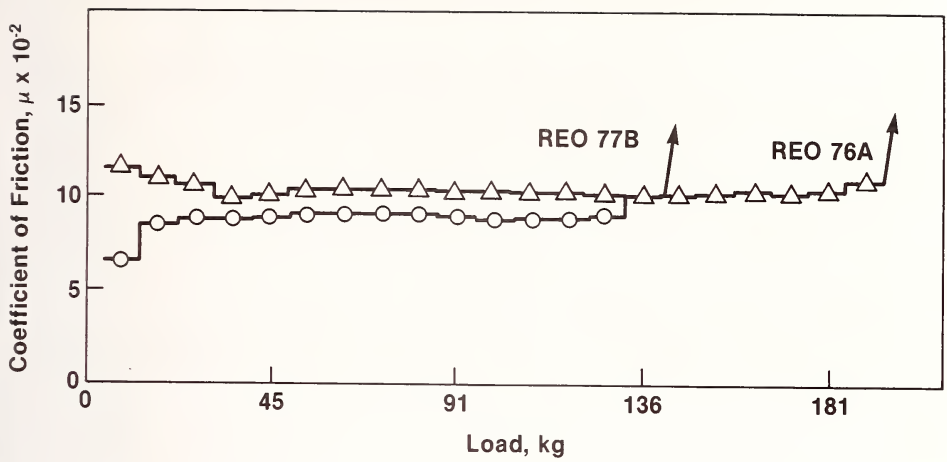

Figure 7. Step-loading seizure at 200 RPM.

The results obtained from the entire set of five reference oils shown in table 6 , had a good correlation with the Engine Sequence Ranking and shows that the step loading seizure test appears to have the capability and sensitivity to distinguish between the two groups of oils.

\section{Conclusions}

In this study, several procedures using the four-ball wear tester have been evaluated using the ASTM engine reference oils. Based on the experimental results the following conclusions can be reached:

1) The normally used slow-sliding and fast-sliding 4-Ball wear procedures did not rank the reference oils correctly.

2) The oxidation coupled slow-sliding wear test procedure gave encouraging results to correlate with engine tests.

3) The step-loading seizure procedure correlated the five reference oils correctly.

Both the oxidation-wear coupled and seizure test procedures will be examined further. Wear debris analysis and differential infrared spectroscopy will be used to investigate the mechanism in these procedures.

\section{References}

[1] Groff, W. P. Jr., Roberts, C. E., and Lepisto, P. R., New lubricant test procedures for gasoline engines from the viewpoint of an independent research lab, ASLE Preprint No. 79AM-1c-1, pp. 1-13 (1979).

[2] Brown, E. D., Friction and wear testing with the modern four-ball apparatus, Wear, 17, 381 (1971).

[3] Miller, A. H., Considerations in interpreting four-ball data, Wear, 23, 121 (1973).

[4] Feng, I. M., A new approach in interpreting the four-ball wear results, Wear, $\underline{5}$, 275 (1962). 
[5] Fein, R. S., Measurement of wear volume and interpretation of results with four-ball machines, Proc. 2nd Annual Conference of ASME Lubrication Division, Philadelphia, PA (1959).

[6] Clinton, W. C., A Study of the Four-Ball Machine, NRL Report 3709 (Sept. 1950).

[7] Klauss, E. E. and Bieber, H. E., Effects of some physical \& chemical properties of lubricants on boundary lubrication," ASLE Trans., ㄱ. 1, 1964.

[8] Fein, R. S., Transition temperatures with four-ball machine," ASLE Trans., $\underline{3}, 34$ (1960).

[9] Feng, I. M., A new approach in interpreting the four-ball wear results, Wear, $\underline{5}$, 295-288 (1962).

[10] Hsu, S. M., Anti-wear \& lubricity additives for lubricants, Proc. of the MFPG Symposium on Engineering Design, NBS SP 487, pp. 172-180 (1977).

[11] Willermet, P. A., Mahoney, L. R., and Bishop, C. M., Lubricant degradation and wear II. Antioxidant capacity and ir - spectra in systems containing zinc dialkyldithiophosphates, ASLE Reprint No. 79-AM-1B-3, pp. 1-6 (1979). 
National Bureau of Standards Special Publication 584. Proceedings of Joint Conference on Measurements and Standards for Recycled 0i1/Systems Performance and Durability held at NBS, Gaithersburg, MD, October 23-26, 1979. (Issued Nov. 1980)

\title{
APPLICATON OF DIFFERENTIAL SCANNING CALORIMETRY
}

TO THE CHARACTERIZATION OF LUBRICATING OILS

\author{
James A. Walker and Wing Tsang \\ Chemical Kinetics Division \\ Center for Thermodynamics and Molecular Sciences \\ National Measurement Laboratory \\ Washington, DC 20234
}

\begin{abstract}
High pressure differential scanning calorimetry (DSC) has been used to characterize the oxidative stability of formulated as well as virgin and recycled lubricating base stocks. At pressures of 0.7-3.4 MPa (100-500 psig) air or $\mathrm{O}_{2}$ and temperature near $200{ }^{\circ} \mathrm{C}$, degradation occurs with significant generation of heat. Experiments conducted in the temperature programmed mode give recognizably different thermograms as well as onset temperatures for various lubricating oils. In the isothermal mode induction time measurements were carried out with ASTM Engine Test Standard Reference 0 ils (RO) which contain antioxidants and appear to correlate with multicyclinder engine sequence test results. Under the same experimental conditions virgin base (VB) and recycled base (RB) stocks degradate too quickly to measure the induction time.
\end{abstract}

The dependence of induction time and peak width on pressure and temperature as well as measurements of heat output are described. The speed, accuracy and experimental configuration of DSC measurements suggest its use not only for elucidating fundamentals on the mechanism of hydrocarbon oxidation but also as a standard test method.

\section{Introduction}

Thermal analysis $[1]^{1}$ is today increasingly used as an important method for the characterization of complex organic systems. The technique involves monitoring a particular property of the system with the change of temperature or, in the isothermal mode, with time. The thermograms provide a "fingerprint" of the material similar to and as unique as an infrared spectra or a boiling point range. Proper interpretation of this characteristic can yield important information on the physicochemical processes that are actually occurring in the sample. Thermal analysis requires only a small volume of sample and this has made heats of reaction an increasingly attractive parameter for measurement. Thus differential scanning calorimetry (DSC) has become one of the most popular methods for carrying out thermal analysis.

Noel and co-workers $[2,3,4]$ were among the first to realize the potentialities of DSC for characterizing complex lubricating oils. The highly specific techniques such as mass spectroscopy or infra-red spectroscopy sometime yield too much information, with the result that interpretation becomes difficult. On the other hand, some of the ASTM tests measure gross properties or are carried out under conditions vastly different from actual in-service environment. In DSC, the use of small samples $(<2 \mathrm{mg})$ suggests that experiments are carried out under thin film conditions, thus simulating in this respect actual engine conditions. Furthermore, the test temperatures are quite high and thus again approach use conditions. The salient result of Noel [2,3] was the demonstration of the capability of carrying out such studies above ambient pressures. This is manifested by an exothermic reaction at about $200^{\circ} \mathrm{C}$. More specifically, he demonstrated (a) increased induction time with increasing inhibitor concentration up to a maximum value; (b) the effect of metal additives in lowering threshold temperatures; and (c) different threshold temperature and induction times for various types of additives.

TFigures in brackets indicate the literature references at the end of this paper. 
The present studies are aimed at exploring the possibility of using DSC as a standard test method for evaluating the oxidative stability of lubricating oil, and further to use the technique to study the basic mechanisms involved in hydrocarbon oxidation processes.

\section{Experimental}

A11 experiments were made using a DuPont Model 990 Thermal Analyzer with a model 910 high pressure differential scanning calorimeter module. A schematic of the reaction cell can be seen in figure 1 . The experimental procedure involves placing a 1 to $2 \mathrm{mg}$ sample in an open aluminum pan, setting the pressure and flow rate of the purge gas - air, oxygen, or nitrogen and then commencing the experiment either by running the temperature up to a preselected value, holding it at this point and observing the reaction heat as a function of time (isothermal experiment), or by scanning at a programmed temperature rate and measuring the incremental heat change as a function of temperature (oxidation onset experiment). For some of the isothermal experiments where induction times are very short the cell was charged to the operating pressure with $\mathrm{N}_{2}$ at the desired flow rate, and the temperature rapidly raised to the isothermal temperature. At that time $\mathrm{O}_{2}$ was introduced and the time scan started simultaneously.

\section{PRESSURE DSC CELL}

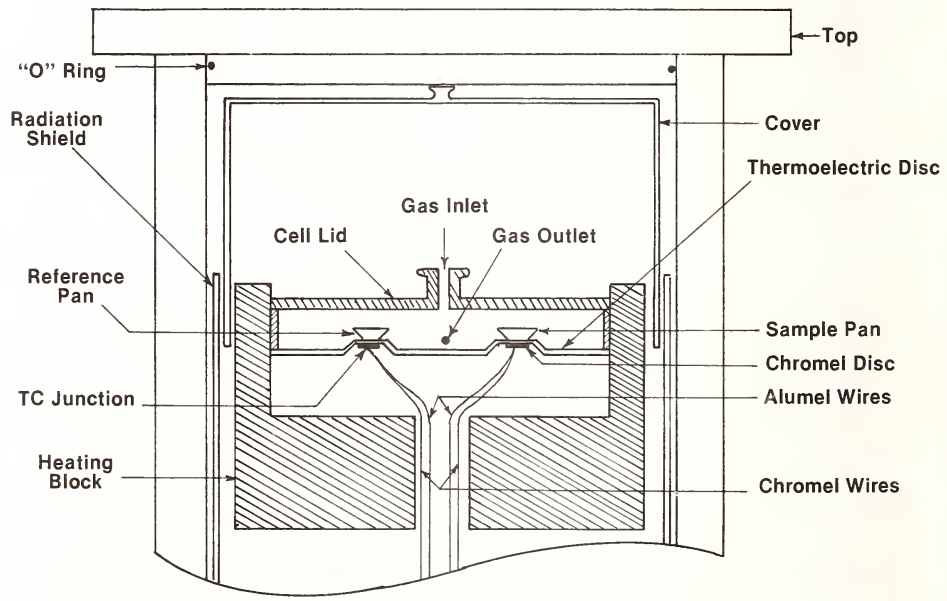

Figure 1. Schematic of DSC cell. 
A great deal of attention was given to finding the conditions that yielded an optimum amount of reproducible information and indeed it proved to be possible to increase the precision by an order of magnitude in comparison with the earlier work. The conditions that were used for most of these studies were $3.4 \mathrm{MPa}$ (500 psig) oxygen [6] for isothermal experiments and $0.7 \mathrm{MPa}(100 \mathrm{psig})$ air and $20^{\circ} \mathrm{C} / \mathrm{min}$ heating rate for oxidation onset temperature studies. All experiments were carried out with flow rates of $50-120 \mathrm{~cm}^{3} / \mathrm{min}$ (NTP). This was necessary to continually remove reaction products and to assure maximum contact between the sample and the reactive gas. The pressures used in these experiments are a reflection of the need to obtain sharp onsets as well as maintaining details in the thermograms.

\section{Results and Discussion}

Examination of the samples subsequent to DSC analysis indicates that the process that is observed is mainly one of progressive oxidation. The former undoubtedly involved both degradation as well as polymerization. Evidence of degradation can be seen at the end of the temperature programmed runs at $\sim 360^{\circ} \mathrm{C}$ where we obtained a shiny black enamel. From the isothermal experiments with reference oils one obtains somewhat darkened samples of increased viscosity and a sticky consistency. For the virgin and recycled base oils there were only changes in color.

Figures 2 through 4 represent thermograms of experiments carried out in the programmed temperature mode for the three types of oils under consideration. It is clear that there are definitive and generic differences with regard to the oils. As perhaps could be expected and in conformity with the observation of Noel and Cranton [4], the reference oils show the sharpest and latest onsets. Note that in some of these figures replicate runs are displayed, but with varying sample sizes and the results are indicative of the reproducibility of the data. It demonstrates that for this measurement sample size is not a controlling variable. The virgin base oils on the other hand display the slowest onset and a corresponding low threshold temperature. Finally, the recycled base oils appear to belong in an intermediate category. The simplest explanation for these observations is that the basic process is that of free radical polymerization. In the reference oils this process cannot occur until the inhibitor is destroyed. Since the rate of polymerization has an Arrhenius dependence on temperature, the higher temperatures which bring about the demise of the inhibitor also means that the initially observed rate must be much faster than in the case where additive is not used. For the virgin base oils there appears to be a reactive component which is apparently not present in the recycled base oils. One can well visualize that through use this reactive portion of the substrate will be destroyed. Alternatively, it is possible that the recycled base may still contain some of the additive and thus the higher onset temperatures.

Quantitative results on the onset temperatures are summarized in table 1 . The uncertainties $\left( \pm 1.7^{\circ} \mathrm{C}\right.$ ) listed in the table give a good indication of the precision of these tests. In the case of the reference oils it should be noted that while the onset

temperatures are in agreement with respect to the best and worst of the lot (compared to ASTM III-C engine sequence tests) [5] there is confusion at the intermediate levels.

In particular one notes the inversion of the order between the fail and borderline classification from the engine tests and the DSC measurements. Note that these results are confirmed by induction time measurements to be described subsequently. Of course, an engine test represents an integration of all factors and there is no reason why a test for oxidative stability should display an exact correlation.

We now come to induction time measurements. Typical results for ASTM III-C Reference 0 ils can be found in figure 5. Under identical experimental conditions for the virgin base stocks and the recycled base stocks, there is an immeasurable short induction period. Unless conditions are very carefully set, oxidation occurs during the run-up to the desired isothermal temperature. Results of experiments at $0.4 \mathrm{MPa}$ (50 psig) $\mathrm{N}_{2} / 0_{2}$ and $185^{\circ} \mathrm{C}$ give curves as seen in figure 6 . For comparison we show results for a similar experiment with a reference oil sample in figure 7. Shapes and sizes are completely different. This clearly indicates that different processes are at work. One suspects that under these conditions the recycled and virgin base oils are in an inherently unstable regime just prior to "explosion". It should be pointed out that Noel and Cranton [4] were apparently able to obtain an isothermal curve for a virgin base oil that was very similar to what they obtained for the case where inhibitors were added. 


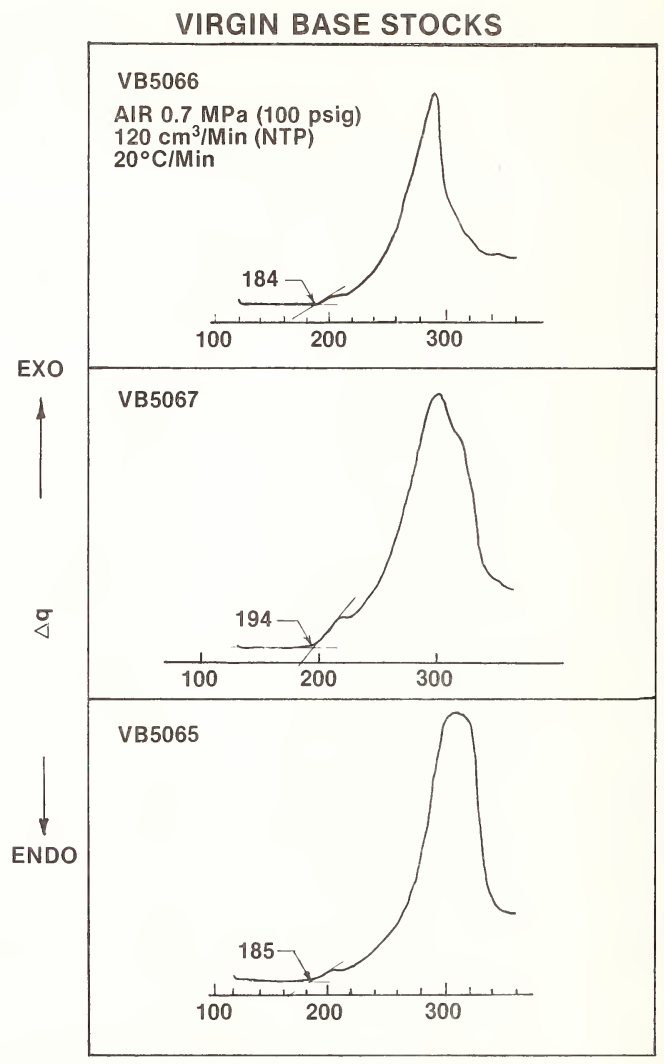

Temperature, ${ }^{\circ} \mathrm{C}$

Figure 2. Virgin base oil (VB). Oxidation onset temperature vs. $\Delta \mathrm{q}$. 
RECYCLED BASE STOCKS

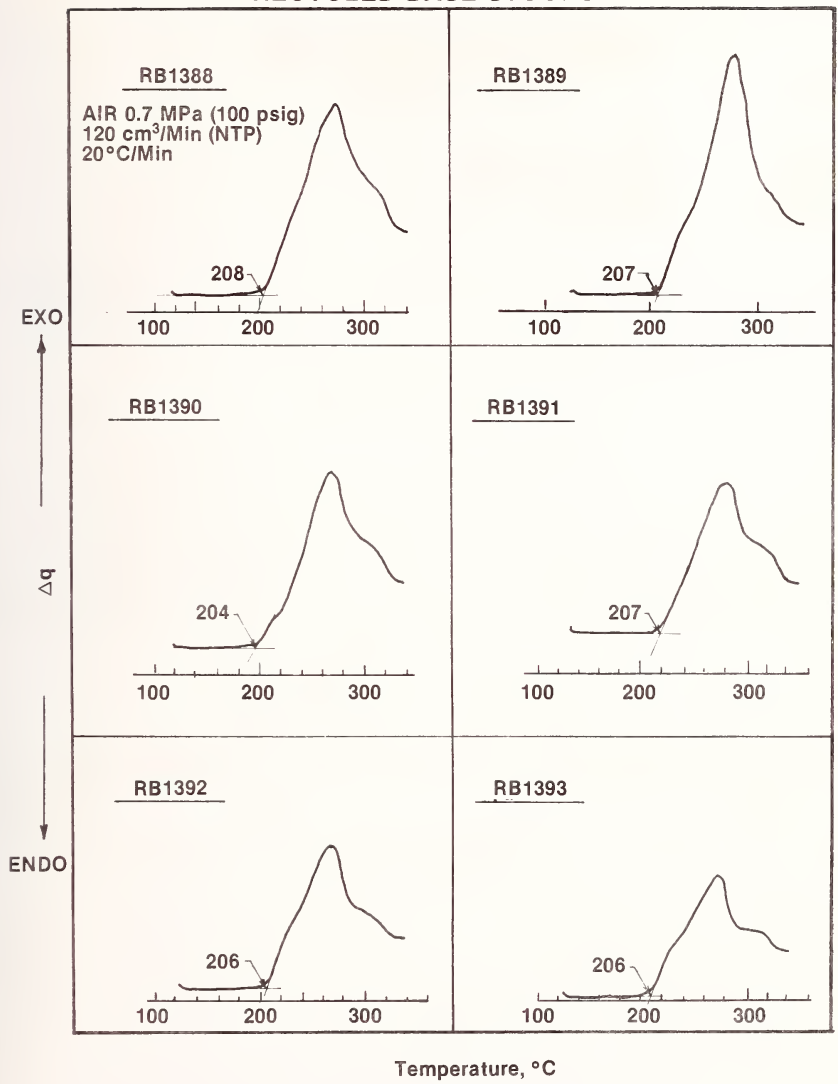

Figure 3. Recycled base oil (RB). Oxidation onset temperature vs. $\Delta \mathrm{q}$. 


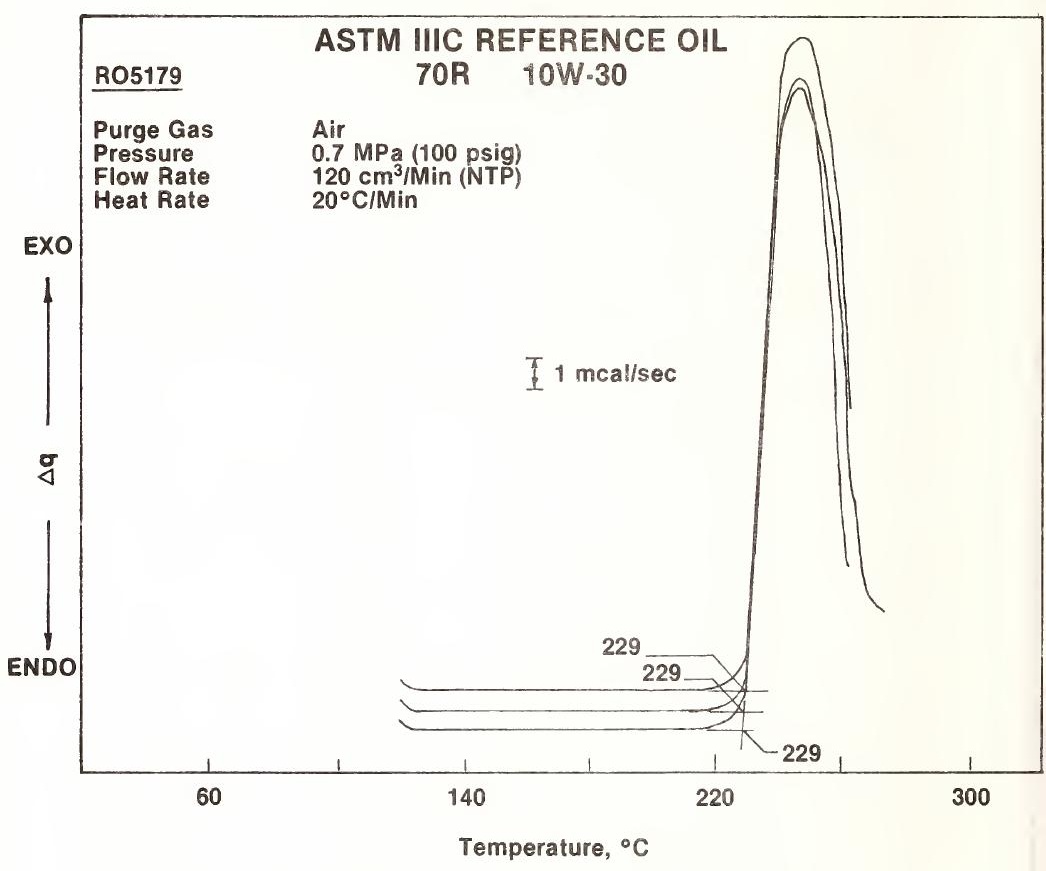

Figure 4. Typical ASTM III-C reference oil. Oxidation onset temperature vs. $\Delta \mathrm{q}$. 


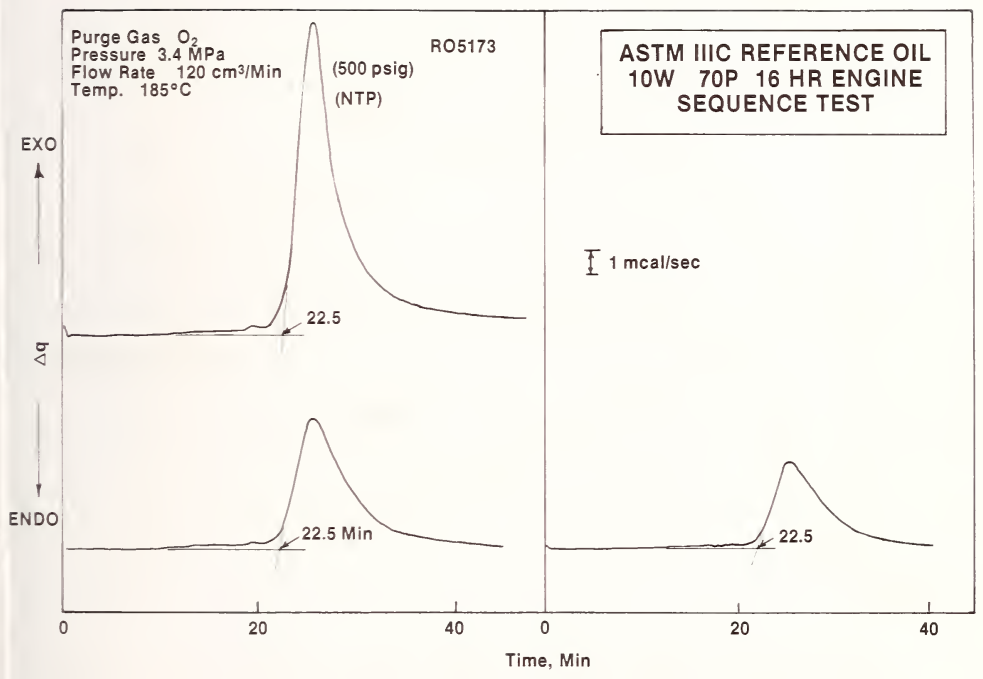

Figure 5. Induction time vs. $\Delta \mathrm{q}$ for typical ASTM III-C reference oil for three runs with different sample sizes $(0.5 \mathrm{mg}, 0.75 \mathrm{mg}$, and $1.5 \mathrm{mg})$. 


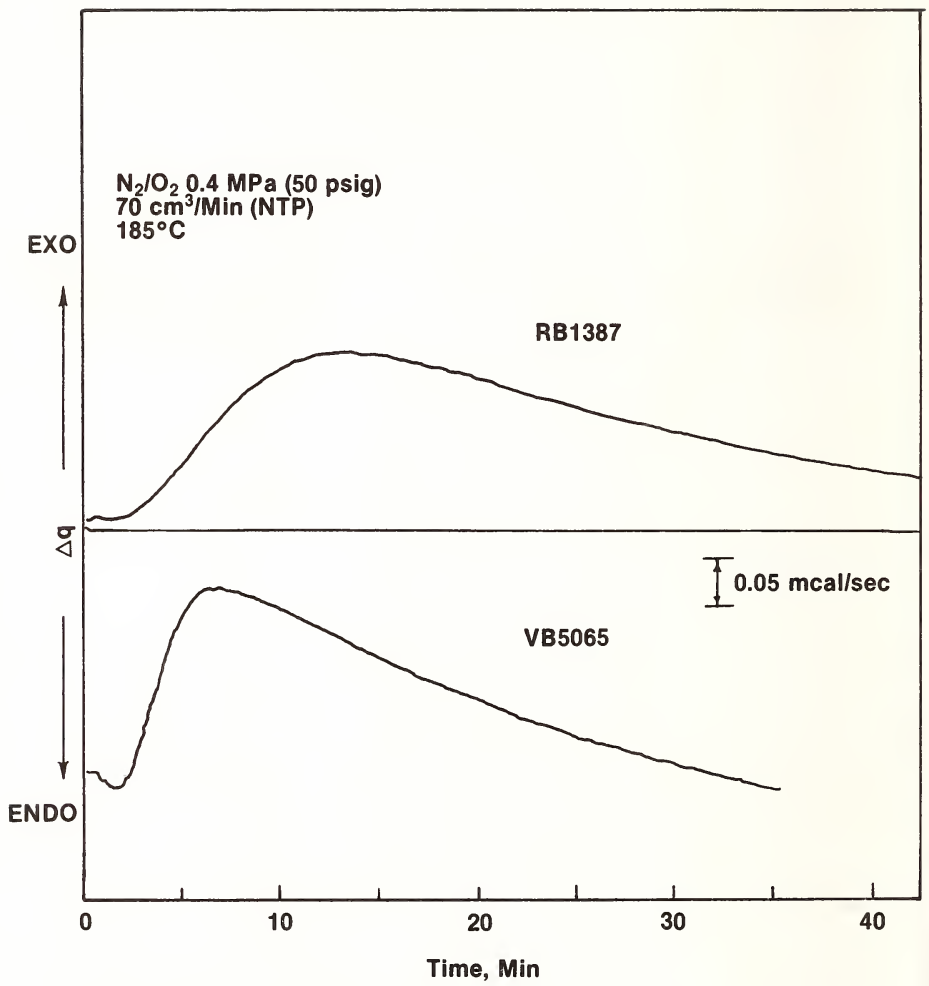

Figure 6. Induction time vs. $\Delta q$ for a virgin base and a recycled base oil e $185^{\circ} \mathrm{C}$ and $0.4 \mathrm{MPa}$ (50 psig) $\mathrm{N}_{2} / \mathrm{O}_{2}$. 
Table 1. Compilation of oxidation onset temperature data for virgin base, recycled base, and ASTM III-C reference oils.

ASTM III-C $\mathrm{C}^{\mathrm{a}}$

Reference $0 \mathrm{il}$

Samples

ASTM $\quad{ }^{\circ} \mathrm{C} \quad$ Std. Dev.

Code

ASTM III-C Engine

R05170/5171

$71 B$

260.5

1.4

Pass

R05174/5175

$76 \mathrm{~A}$

254.7

.6

Pass

R05173/5176

$70 P$

254.2

.7

Fail

R05172/5179

$70 R$

228.9

.2

Borderline

R05177/5178

$70 \mathrm{H}$

224.4

1.5

Fail

Recycled Base Stocks

RB1387

202.6

2.4

RB1388

208.0

1.8

RB1389

206.8

1. 3

RB1390

204.0

2.5

RB1391

206.7

2. 1

RB1392

206.2

1.6

RB1393

206.3

2.5

Virgin Base Stocks

VB5065

184.6

2.7

VB5066

183.5

1.5

VB5067

193.8

2.2

Purge Gas

Heating Rate

Pressure

Flow Rate
Air

$20{ }^{\circ} \mathrm{C} / \mathrm{min}$

$0.7 \mathrm{MPa}$ (100 psig)

$120 \mathrm{~cm}^{3} / \mathrm{min}$ (NTP)

$\overline{a_{B 1} \text { ind dupl }}$ icate samples.

Table 2 summarizes the results of induction time measurements on the reference oils. The uncertainties are of the order of 4.5 percent and permits a clearer discrimination between the reference oils than onset temperature measurements. It should be noted that induction time data in table 2 track the onset temperature data in table 1 exactly and thus also show the discordance in the middle range between the ASTM III-C engine and DSC tests. 
Table 2. Compilation of induction time data for

ASTM III-C reference oils.

STM III-C

eference $0 i 1$

amples

$05170 / 5171$

$35174 / 5175$

$05173 / 5176$

J5172/5179

$05177 / 5178$
ASTM

Code

$71 B$

$76 \mathrm{~A}$

$70 \mathrm{P}$

$70 R$

$70 \mathrm{H}$
Time, Min.

43. 2

31.0

23.0

13.9

8.7
Std. Dev.

1.85

2.58

.82

.56

.22
ASTM III-C Engine

Sequence Tests

Pass

Pass

Fail

Borderline

$\mathrm{Fail}$

$\begin{array}{ll}\text { Purge Gas } & \text { Oxygen } \\ \text { Pressure } & 3.4 \mathrm{MPa} \text { (500 psig) } \\ \text { Flow Rates } & 50-120 \mathrm{cc} / \mathrm{min} \text { (NTP) } \\ \text { Isothermal Temp. } & 185^{\circ} \mathrm{C}\end{array}$

Figure 8 indicates the effect of oxygen pressure on induction time as well as the shape f the exothermic polymerization process. The induction time is roughly linearly dependent $\mathrm{n} \mathrm{O}_{2}$ and is indicative of the fact that the inhibitor is being destroyed by a reaction raceable to the presence of oxygen. This is opposed to the claim of Noel and Cranton [4] nat it is the thermal stability of the inhibitor that controls anti-oxidant behavior. We snclude that it is the resistance of the inhibitor to oxidation that is the controlling actor. This in turn raises an interesting point. The actual gas encountered by the ubricating oil in an engine is more like a NO mixture, and thus may well have different ehavior patterns, especially since nitration must also be important. Clearly experiments ith more realistic gas mixtures are called for. It is possible that the disagreement etween engine test results and the present DSC tests may be due to this artifact. The shape f the reaction exotherm is a reflection of the complex chemical kinetic processes that are zcurring during the oxidation process. One notes the expected dependence as manifested by ncreasing peak width with decreasing oxygen concentration.

Figure 9 represents the effect of temperature on induction time and peak shape (half idth). These results are in accord with activation energies of about $84 \mathrm{~kJ}$, in accord with hat one expects of auto-oxidation reactions. Finally, table 3 summarizes the data on the eat released during the exothermic reaction from the present study on the reference oils. hese numbers are in the expected range for polymerization processes. They do not correlate ith oxidative stability data. Similar results have been observed by Noel and Cranton [4], no have in fact separated different fractions of lubricating oil and have shown that they re characterized by differing heats of reaction. The variation in the heats of reaction are trongly indicative of the differences in the polymerization process as it occurred in each i1.

Overa11, we believe that DSC has interesting potential as a test method for total xidation resistance. This is of course dependent on the quantity of inhibitor present, but s also sensitive to different types of inhibitors. It should also be dependent on other roperties related to rates of oxidation, such as dispersant concentration and viscosity. he precision and accuracy of our experimental results suggest the possibility of an xtremely fine scale. We note that the differential nature of these measurements make it articularly suitable for tests with an internal standard. Thus, if we use a designated ompound as a borderline reference we can simultaneously measure the exothermicity of eference and unknown in the same experiment with results that should be quite free from ossible operator errors. With regard to properties as such, it is quite clear that recycled 
base oils and virgin base oils differ in the amount and nature of some of the constituents.

However, it is unclear at present what effect, if any, this may have on performance since the additives have such great effects.

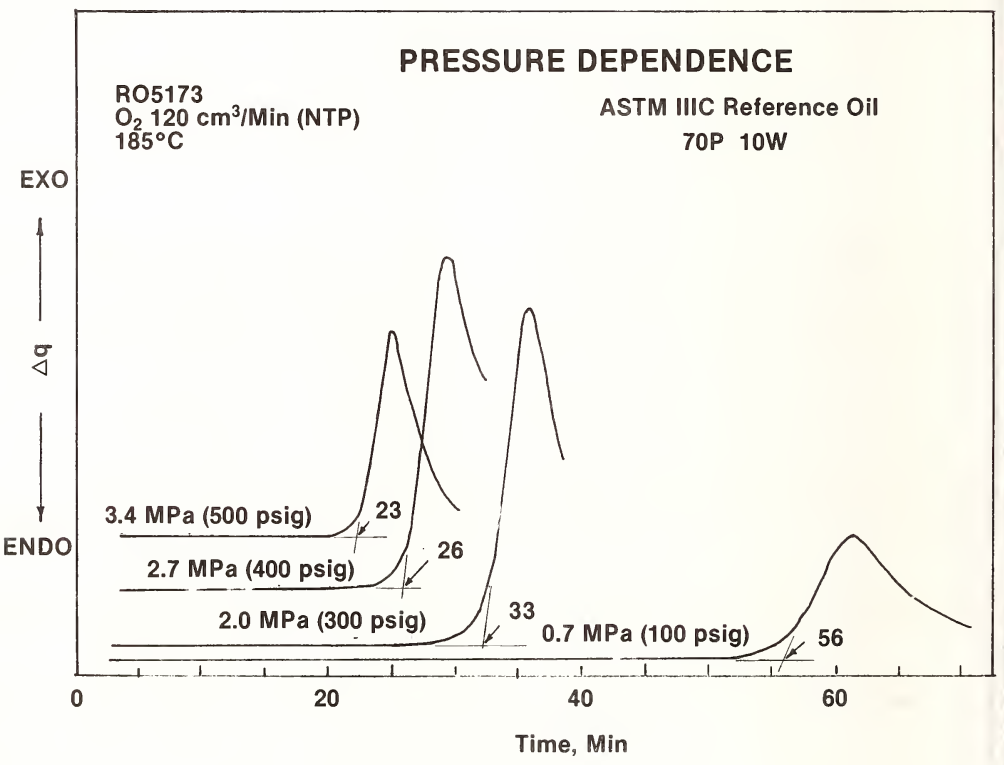

Figure 8. The effect of $\mathrm{O}_{2}$ pressure at $185{ }^{\circ} \mathrm{C}$ on the induction time of an ASTM III-C reference oil. 


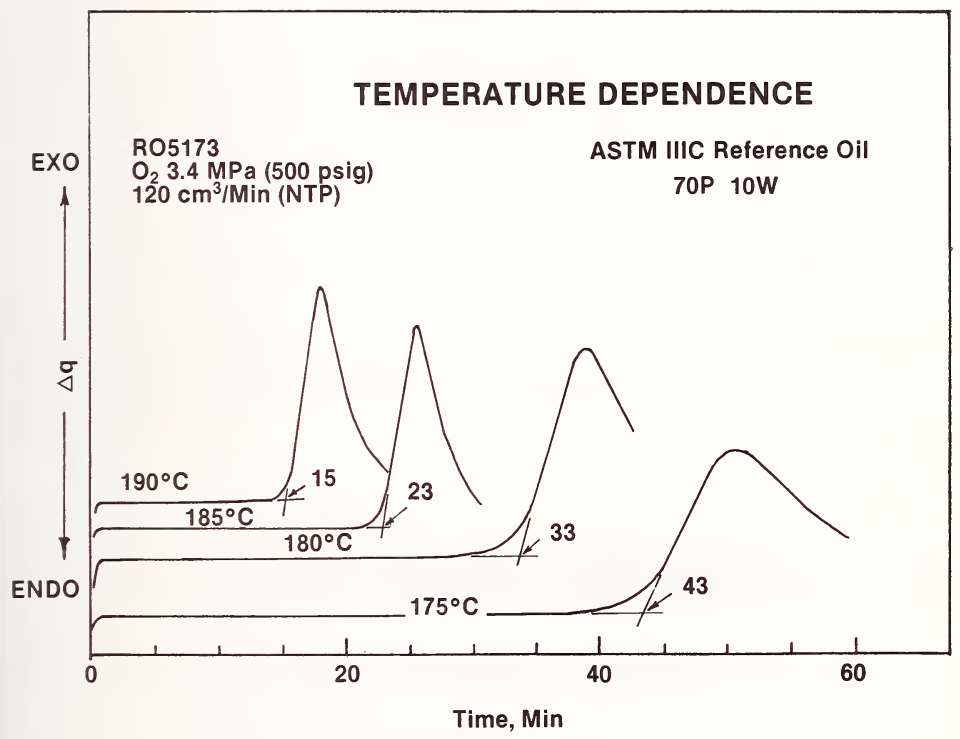

Figure 9. The effect of temperature at $3.4 \mathrm{MPa}(500 \mathrm{psig}) \mathrm{O}_{2}$ on the induction time of an ASTM III-C reference oil. 
Table 3. Compilation of heat output data for ASTM III-C reference oils.

ASTM III-C

Reference 0 il

Samples

R05170/5171

R05172/5179

R05173/5176

R05174/5175

R05177/5178

\begin{tabular}{|c|c|c|c|}
\hline & $\begin{array}{l}\text { ASTM } \\
\text { Code }\end{array}$ & $\mathrm{kJ} / \mathrm{Gram}$ & Std. Dev \\
\hline & $71 B$ & 7.1 & 0.11 \\
\hline & $76 \mathrm{~A}$ & 7.4 & 0.23 \\
\hline & $70 P$ & 6.9 & 0.11 \\
\hline & $70 R$ & 4.7 & 0.19 \\
\hline & $70 \mathrm{H}$ & 5.3 & 0.22 \\
\hline Purge Gas & & Oxygen & \\
\hline Pressure & & $3.4 \mathrm{MPa}$ (500 psig) & \\
\hline Flow Rate & & $50-120 \mathrm{~cm}^{3} / \mathrm{min}$ (NTP) & \\
\hline Isothermal & Temp. & $185^{\circ} \mathrm{C}$ & \\
\hline
\end{tabular}

[1] Porter, R. S. and Johnson, J. F., Analytical Calorimetry, $\underline{3}$ (Plenum Publishing Company, New York, 1974).

[2] Noel, F., J. Inst. Petroleum, 57, 354 (1971).

[3] Noel, F., Thermochemica Acta, 4, 377 (1972).

[4] Noel, F. and Cranton, G. E., Analytical Calorimetry, 3, 305, R. S. Porter and J. F. Johnson, eds. (Plenum Publishing Company, New York, 19 $\overline{7} 4$ ).

[5] Private communication from Dr. S. Hsu, Tribochemistry Group, NBS.

[6] R. 0. Blaine, DuPont Instruments Applications Brief Number TA 41. 
National Bureau of Standards Special Publication 584. Proceedings of Joint Conference on Measurements and Standards for Recycled 0il/Systems Performance and Durability held at NBS, Gaithersburg, MD, October 23-26, 1979. (Issued Nov. 1980)

\title{
EVALUATION OF BASESTOCK AND FORMULATED LUBES USING THE PENN STATE MICROOXIDATION TEST
}

\author{
E. Klaus, V. Krishnamachar, and H. Dang \\ Pennsylvania State University \\ 133 Chemical Engineering Building \\ University Park, PA 16802
}

\begin{abstract}
The microoxidation test has been developed at Penn State and used successfully for the evaluation of new and used ester based aircraft gas turbine lubricants. This system combines a simple thin film oxidation test with two analytical systems for primary analysis. First, the oxidized fluid is evaluated in a Gel Permeation Chromatograph with both refractive index and $U-V$ detectors. The second analysis utilizes an atomic absorption spectrometer. In addition, samples prepared from GPC analysis can be used for infrared, ultraviolet, and NMR analyses.

This presentation will discuss current efforts to adapt this microoxidation test for use with petroleum lubricating oils, and to evaluate both base stocks and formulated lubricating oils.
\end{abstract}

\section{Introduction}

A new thin-film oxidation test has been developed for the quantitative evaluation of aircraft gas turbine (ester) lubricants $[1]^{1}$. Problems associated with diffusion limitation are minimized by the use of a small sample $(20-200 \mu l)$ with a relatively large fixed area of fluid-gas contact.

Analysis with gel permeation chromatography (GPC) gives a semi-quantitative measurement of additive depletion, and measures the quantity of original fluid reacted and the quantities of oxidized products formed. By a careful calibration under a nitrogen atmosphere, the volatility loss is measured and calculated independently of the oxidation reaction. Test repeatability is excellent. The system is adaptable for a wide range of time-temperature studies and allows the duplication of system conditions in equipment, such as in the aircraft gas turbine lubrication system. A wide variety of catalytic surfaces typical of those found in structural and bearing portions of the lubrication system can be duplicated. The overall test system is simple to construct and easy to control. In many cases, significant data profiles on a single lubricant can be determined in oxidation tests of 2 to 60 minutes duration. The additional time for fluid analysis adds only 40 minutes to the oxidation test time. The GPC analysis is preparative in nature, thereby providing samples of various fractions for further spectrographic analysis [2]. The effectiveness of the test system has been illustrated with dibasic acid ester and polyol ester fluids oxidized on a steel catalyst, with and without oxidation inhibitors.

This basic test technique and analytical procedure has been modified and extended for use with mineral oils and automotive lubricant formulations. The principal modification for mineral formulations is necessary to identify the oxidation products that are formed in the same molecular weight range as the virgin lubricant.

\section{Test Procedure}

The oxidation test equipment is shown in figure 1 . This unit has been described in detail by Cvitkovic et al. [1] for use with ester lubricants. The basic microoxidation test procedure for esters and mineral oils is the same. The analysis from this test procedure is

TFigures in brackets indicate the literature references at the end of this paper. 
designed to show: (a) evaporation of the fluid as a function of molecular weight; (b) the oxidation product as a function of molecular weight; and (c) the remaining virgin mineral oil as a function of molecular weight.

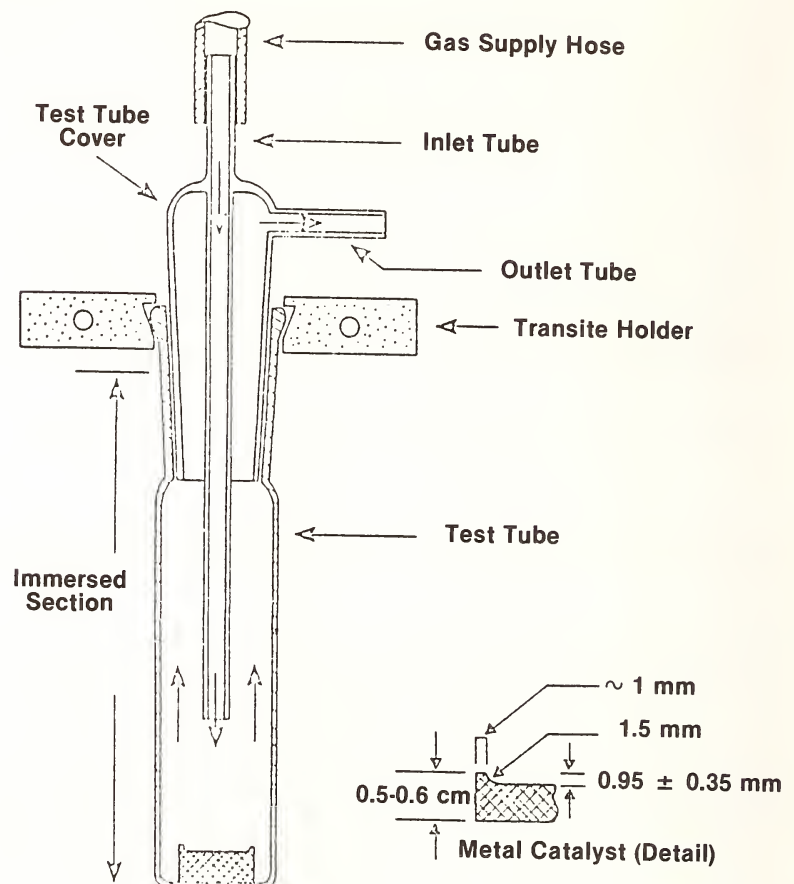

Figure 1. The microtest oxidation apparatus.

The value of evaporation is determined by the difference in the GPC chromatographs for the original formulation and an evaporation test under nitrogen flow in the same timetemperature conditions used in the microoxidation. The products of the microoxidation test are separated into two equal aliquots. One fraction is percolated through a clay column [3] to remove all the oxidation products leaving only the virgin hydrocarbon molecules from the initial formulation. The difference between the evaporation chromatograph and the clay percolation chromatograph shows the amount of the original fluid that is oxidized. The area between the chromatograph for the overall oxidized product and the clay percolated chromatograph represents the oxidized material as a function of molecular weight. As tests become more severe, some of the high molecular weight product becomes insoluble in the tetrahydrofuran solvent and can be measured as a deposit weight gain of the test cup. 
Microoxidation tests for a super refined virgin mineral oil MLO 7828 have been conducted to 11 lustrate quantitative analysis by spectrum difference. The effect of additive response in this MLO 7828 base oil is shown by similar differential chromatographic analysis for three additive concentrations and/or combinations. The additives used are zinc dialkyldithiophosphate at 0.05 percent and 0.15 percent phosphorous and 0.5 percent phenylalphanaphthylamine. This sequence of tests are shown in figures $2,3,4$, and 5 . The evaporation data are essentially the same for all four fluids. In all cases evaporation appears to resemble equilibrium flash vaporization as opposed to an efficient distillation separation. The amount of oxidized product shows a dramatic decrease as a function of ZDP additive concentration. The ZDP-PAN combination tends to show the synergistic effect of additives that control metal coating and oxidation inhibition. In the case of more effective additive response the amount of oxidized product is reduced substantially. The amount of high molecular weight oxidation product is reduced by a larger percentage than the overall oxidation product as the inhibitor package becomes more effective.

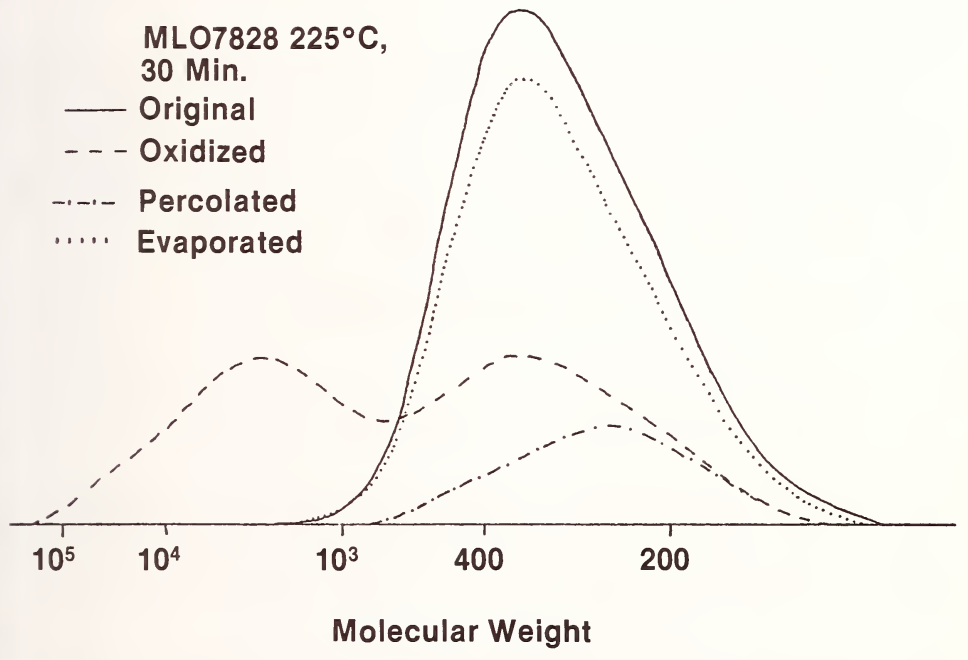

Figure 2. Analysis by GPC for oxidation and evaporation of a super refined virgin base stock. 


\section{MLO7828 + $0.625 \%$ ZDP $225^{\circ} \mathrm{C}$,}

30 Min.

Original

-.. Oxidized

-...-- Percolated

..... Evaporated

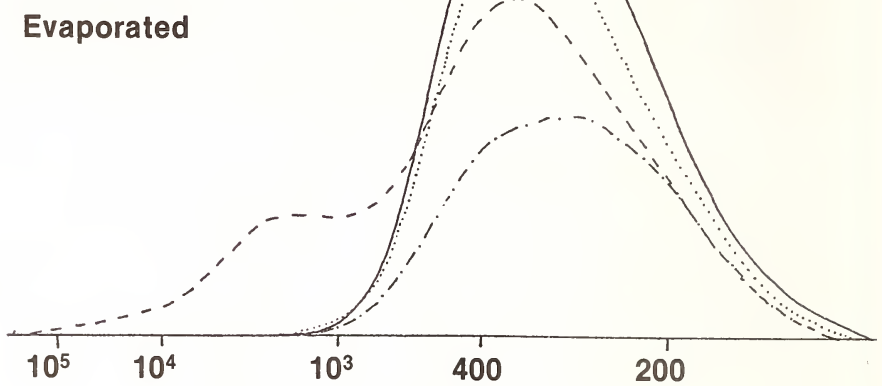

Molecular Weight

Figure 3. Additive response of 0.05 weight percent phosphorous as zinc dialkyldithio phosphate.

To establish creditability for the microoxidation test conditions, correlation with lubricant behavior in a $3 \mathrm{C}$ engine test is another goal of this program. The time-temperature relationship for the microoxidation test has been established for aircraft gas turbine lubricants. Tests of about equal severity are achieved at $200{ }^{\circ} \mathrm{C}$ for two hours or 30 minutes at $225{ }^{\circ} \mathrm{C}$. These two temperatures are in the range of temperatures that appear to exist in the piston ring belt zone of an automotive engine. Some data suggest that temperatures as high as $250^{\circ} \mathrm{C}$ exists in the ring belt zone.

A series of five $3 C$ reference oils have been used for this test evaluation. The microoxidation test data for these fluids at $200{ }^{\circ} \mathrm{C}$ and two hours test time are tabulated on table 1. The five fluids include two that fail, one borderline case, and two fluids that pass the test. The best columns for correlation are the high molecular weight (1000-10 000 mol. wt.) and total oxidized product. The problem with the $>10000 \mathrm{~mol}$. wt. product is the apparent loss from this fraction to sludge and varnish. The correlation at $200{ }^{\circ} \mathrm{C}$ and two hours is relatively poor. 


\section{MLO7828 $+1.875 \%$ ZDP $225^{\circ} \mathrm{C}$, 30 Min.}

Original

- - Oxidized

-.-.- Percolated

...... Evaporated

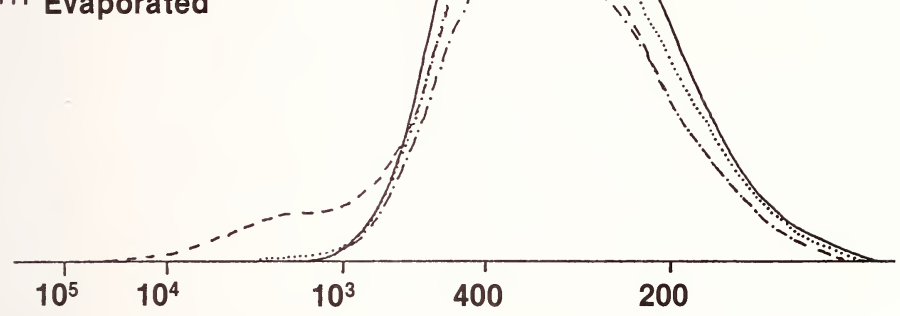

\section{Molecular Weight}

Figure 4. Additive response of 0.15 weight percent phosphorous as zinc dialkyldithio phosphate.

Table 1. Oxidized products in microoxidation tests at $200{ }^{\circ} \mathrm{C}$ and $120 \mathrm{~min}$.

3 Test

Hours

16-1

16-2

32

40

64

0x. Prod. \% of Orig. (mol. wt.)

200-1000

18.5

14.5

18.0

0.4

12.9
$1000-10000$

13.7

10.3

10.8

2.3

9.7
$>10000$

4.9

1.8

5.0

1.2

5.5
Total

37.1

26.6

33.7

3.9

28.7

At $225{ }^{\circ} \mathrm{C}$ and 30 minutes the data are presented on table 2. The correlation data look promising based on total oxidized product or oxidized product in the 1000 to 10000 molecular weight range. The principal problem fluid is the $64 \mathrm{~h} 3 \mathrm{C}$ oil. This fluid has a relatively large amount of polymeric additive which on oxidation appears to show reduced molecular weight rather than increased molecular weight. This fluid is also the most volatile of the five reference fluids. The increase in temperature from 200 to $225^{\circ} \mathrm{C}$ appears to improve correlation with the engine as shown on table 3 . 


\section{MLO7828 + 1.875\% ZDP $225^{\circ} \mathrm{C}, 30$ Min. $+0.50 \%$ PAN}

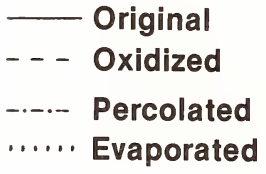

Original

Oxidized

Percolated



Molecular Weight

Figure 5. Synergistic response to pan - zinc dialkyldithio phosphate additive combinations.

A preliminary test procedure has been conducted at $245^{\circ} \mathrm{C}$ to determine the general trend. This preliminary test is a $30 \mathrm{~min}$ test at $245^{\circ} \mathrm{C}$ with only $20 \mu 2$ of fluid. The tetrahydrofuran insoluble sludge and varnish is the only property measured as shown on table 4. Additional test times of 40 and $60 \mathrm{~min}$ were also conducted. The 30 minute tests show an excellent correlation between sludge and varnish forming tendencies and the $3 \mathrm{C}$ engine ratings. The trend with increasing test time is to approach the same level of varnish asymptotically. From these data it appears that perhaps a larger difference (better correlation) would be achieved in a 20 minute test.

Eleven samples of re-refined base stock have been evaluated at $225^{\circ} \mathrm{C}$ for 30 min. Total oxidation products as shown in table 5 range from 35.7 percent to 61.6 percent. The amount of oxidation product in the 1000 to 10000 molecular weight range differs by more than a factor of two from the best to the worst case. Additive response in the two re-refined base stocks 5100 and 5101 are shown on figures 7 and 8 respectively. In general, the two re-refined base stocks show additive response that is similar trendwise with the additive response in a super refined virgin base stock (ML07828). The two re-refined base stocks, however, show less oxidation in comparable tests than the super refined virgin base oil and the additive response of the re-refined oils also appears to be less than for the virgin base stock. It appears that any inhibitors surviving the re-refining process or "natural inhibitors" may reduce response to synthetic inhibitors. 
Table 2. 0xidized products in microoxidation tests at $225^{\circ} \mathrm{C}$ and $30 \mathrm{~min}$.

\begin{tabular}{ccccr} 
3C Test & \multicolumn{3}{c}{ Ox. Prod. \% of Orig. (mol. wt.) } \\
Hours & $200-1000$ & $1000-10000$ & $>10000$ & Total \\
$16-1$ & 25.6 & 14.7 & 2.5 & 42.9 \\
$16-2$ & 27.2 & 9.0 & 1.9 & 38.1 \\
32 & 9.3 & 8.8 & 4.6 & 22.6 \\
40 & 6.1 & 2.7 & 2.0 & 10.7 \\
64 & 14.3 & 9.6 & 5.3 & 29.2
\end{tabular}

Table 3. Evaporation and oxidation in microoxidation test.

$\begin{array}{rrrrr}\text { 3C Test } & \begin{array}{c}200{ }^{\circ} \mathrm{C}-120 \mathrm{~min} . \\ \text { Evap. }\end{array} & \begin{array}{c}225{ }^{\circ} \mathrm{C}-30 \\ \text { Hours }\end{array} & \text { Evap. } & 0 \times \\ 16-1 & 25.3 & 37.1 & 22.2 & 42.9 \\ 16-2 & 29.8 & 26.6 & 23.4 & 38.1 \\ 32 & 29.3 & 33.7 & 31.5 & 22.6 \\ 40 & 28.7 & 3.9 & 26.9 & 10.7 \\ 64 & 38.5 & 28.7 & 32.1 & 29.2\end{array}$

Table 4. The use of the microoxidation test as a deposition tester.

\begin{tabular}{lccc}
$245{ }^{\circ} \mathrm{C}$, & $20 \mu \ell$, & Steel Cat. & $20 \mathrm{ml} / \mathrm{min}$ Air \\
$3 \mathrm{C}$ Test & \multicolumn{2}{c}{ Microoxidation Time, Min. } \\
Hours & 30 & 40 & 60 \\
$16-1$ & 18.5 & 21.4 & 22.8 \\
$16-2$ & 16.5 & 23.6 & 23.9 \\
32 & 15.8 & 21.0 & 21.3 \\
40 & 9.5 & 17.4 & 21.6 \\
64 & 3.8 & 15.2 & 18.8
\end{tabular}

awt. \% sludge and varnish on catalyst. 
Table 5. Oxidized products in microoxidation tests at $225^{\circ} \mathrm{C}$ and $30 \mathrm{~min}$.

$\begin{array}{lcccc}\begin{array}{l}\text { Base stock } \\ \text { Sample No. }\end{array} & 200-1000 & 1000-10000 & >10000 & \text { Total } 0 \text {. } \\ 5094 & 32.5 & 24.3 & 3.2 & 60.0 \\ 5095 & 21.5 & 21.6 & 3.7 & 46.8 \\ 5096 & 25.7 & 20.5 & 3.4 & 49.6 \\ 5097 & 24.4 & 20.6 & 2.8 & 47.8 \\ 5098 & 29.0 & 19.9 & 2.5 & 51.4 \\ 5099 & 22.3 & 23.1 & 2.7 & 48.1 \\ 5100 & 28.2 & 27.8 & 5.6 & 61.6 \\ 5101 & 21.9 & 12.4 & 1.4 & 35.7 \\ 5102 & 24.2 & 16.0 & 1.3 & 41.5 \\ 5103 & 25.6 & 25.0 & 4.5 & 55.1 \\ 5104 & 26.0 & 24.6 & 4.9 & 55.5\end{array}$

${ }^{\mathrm{a}}$ Series of re-refined stocks provided by the National Bureau of Standards.

Oxidized at $225^{\circ} \mathrm{C}, 30 \mathrm{Min}$. Original MLO7828

-. - MLO 7828

-..- MLO $7828+0.625 \%$ ZDP -......- MLO $7828+1.875 \%$ ZDP

$-x-x-$ MLO $7828+1.875 \%$ ZDP $+0.5 \%$ PAN

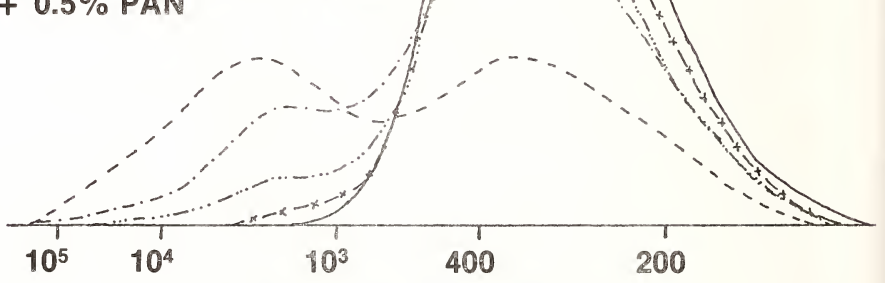

Molecular Weight

Figure 6. A comparison of additive effects on MLO 7828 super refined mineral oil. 
Oxidized at $225^{\circ} \mathrm{C}, 30 \mathrm{Min}$.

5100 Original

- - 5100

-.-. $5100+0.625 \%$ ZDP

$-\cdots-\cdots-5100+1.875 \%$ ZDP

$-x-x-5100+1.875 \%$ ZDP

$+0.5 \%$ PAN

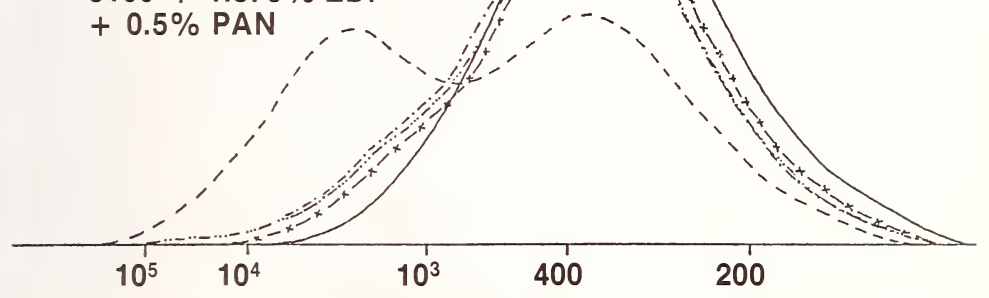

Molecular Weight

Figure 7. Microoxidation characteristics of formulated 5100 re-refined base oil. 


\section{Oxidized at $225^{\circ} \mathrm{C}, 30 \mathrm{Min}$.}

5101 Original

-. 5101

-.- $5101+0.625 \%$ ZDP

$5101+1.875 \%$ ZDP

$-x-x-5101+1.875 \%$ ZDP $+0.5 \%$ PAN

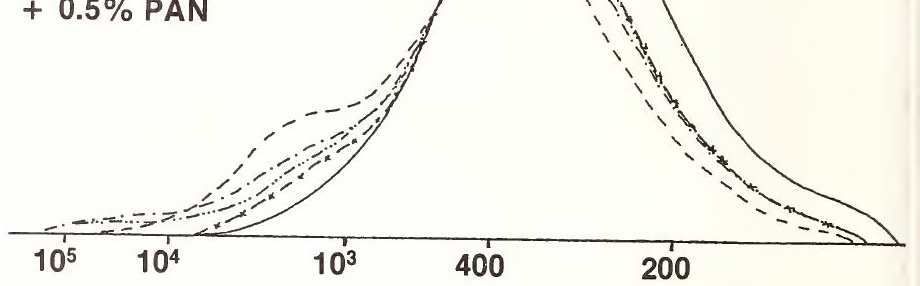

\section{Molecular Weight}

Figure 8. Microoxidation characteristics of formulated 5101 re-refined base oil.

\section{Conclusions}

A microoxidation test procedure has been adapted for use with mineral oils. This test procedure and the subsequent analysis by gel permeation chromatography show good repeatability. This test technique provides a semiquantitative measurement of evaporation, oxidation, sludge and varnish formation, oxidation products as a function of molecular weight, and additive response. Preliminary studies with a series of five $3 \mathrm{C}$ reference oils show good general correlation with microoxidation test results at 225 and $245{ }^{\circ} \mathrm{C}$.

\section{References}

[1] Cvitkovic, E., Klaus, E. E., and Lockwood, F., A thin-film test for measurement of the oxidation and evaporation of ester-type lubricants, ASLE Trans., 22, [4], 395-401 (1979).

[2] Ali, A., Lockwood, F. E., Klaus, E. E., Duda, J. L., and Tewksbury, E. J., The chemical degradation of ester lubricants, ASIF Trans., 22, [3], 267-76 (1979).

[3] Crumley, R., private communications (1976). 
National Bureau of Standards Special Publication 584. Proceedings of Joint Conference on Measurements and Standards for Recycled 0i1/Systems Performance and Durability held at NBS, Gaithersburg, MD, October 23-26, 1979. (Issued Nov. 1980)

\section{DETERMINATION OF POLYCHLORINATED BIPHENYLS IN WASTE AND LUBRICATING OILS}

S. N. Chesler, W. E. May, P. A. White, R. M. Parris, and F. R. Guenther

Center for Analytical Chemistry

National Bureau of Standards

Washington, DC 20234

Polychlorinated biphenyls (PCBs) are noxious pollutants which occur widely in our environment. They are, in themselves, moderately toxic and have been shown to have both mutagenic and carcinogenic properties. PCB-containing fluids have found widespread use as coolants in high voltage electrical components; and as these components are discarded, PCBs are introduced into the ecosystem. Due to the multitudinous methods of used motor oil collection prior to recycling, there is a real possibility of inadvertant contamination of the collected oils by PCB-containing fluids. It thus becomes necessary to develop an analytical technique to determine the presence and concentration of any PCB contaminants in waste oils.

PCB fluids are not made up from one or a few different chemical species but from the 209 possible isomers of chlorinated biphenyl (fig. 1). The preceding structure shows the possible sites for chlorination on the biphenyl nucleus. PCB fluids unfortunately have most of the same physical properties as the natural components of lubricating oils which makes it very difficult to separate out the PCB contaminants present in any oil sample.

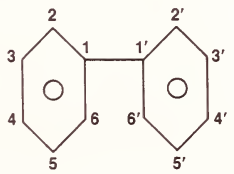

Figure 1.

A number of procedures have been developed for PCB analysis in waste and/or lubricating $0 i 1 s[1-5]^{1}$. These procedures, however, all suffer from the inability to adequately remove analytical interferences from typical waste oil samples. Most are time consuming due to the many manual operations required for sample cleanup, and all employ low resolution chromatographic procedures which can make quantitative identifications difficult. In this paper, we report a method which overcomes these deficiencies. This method first employs preparative scale high performance liquid chromatography to remove analytical interferences, and glass capillary gas chromatography to identify and quantitate any PCB contaminants in the samples analyzed.

Prior to analysis, samples are filtered and/or centrifuged to remove any extraneous materials and water. The samples are then accurately diluted in hexane to a ratio of about 8 to 1 (hexane to sample) and are ready for the liquid chromatographic cleanup procedure.

TFigures in brackets indicate the literature references at the end of this paper. 
A small amount of the diluted sample is injected upon the liquid chromatographic column and fractionated such that the PCBs in the sample can be collected separately from polar analytical inferences. The proper fractionation procedure is ascertained from column calibration by standard mixtures of pure PCBs. The details of the liquid chromatographic procedure used in this study are listed in table 1 . The sample obtained from the cleanup procedure is concentrated to $50 \mu \mathrm{L}$ under a stream of dry, filtered nitrogen gas and $0.5 \mu \mathrm{L}$ aliquots are analyzed by capillary gas chromatography. The average gas chromatographic analysis takes less than 45 minutes. The details of the gas chromatographic procedure are listed in table 2.

Table 1. Liquid chromatographic conditions for cleanup of PCB containing samples.

Pump:

Column:

Detector:

Detection wavelength:

Sample size:

Flow rate:

Mobile phase:

Fraction collected:
High pressure pulseless

Prep scale aminosilane 7.9 i.d. $\times 30 \mathrm{~cm}$

Multiwavelength ultraviolet

$205 \mathrm{~nm}$

$140 \mu \mathrm{L}$

$4.6 \mathrm{~mL} / \mathrm{min}$

$1 \%$ methylene chloride in hexane

11 to $27.5 \mathrm{~mL}$

Table 2. Gas chromatographic conditions for analysis of PCBs.

Column:

Temperature program:

Injector temperature:

Detector temperature:

Split ratio:

Column inlet pressure:

Detector:

Carrier Gas:

Sample Size:

Integrator:
SE-52 WCOT glass capillary, $0.3 \mathrm{~mm}$ i.d. $\times 20 \mathrm{~m}$ $200{ }^{\circ} \mathrm{C}$ for $2 \mathrm{~min}$, then $2{ }^{\circ} \mathrm{C} / \mathrm{min}$ to $275^{\circ} \mathrm{C}$

$300{ }^{\circ} \mathrm{C}$

$300{ }^{\circ} \mathrm{C}$

$30: 1$

$0.5 \mathrm{Kg} / \mathrm{cm}^{2}$

Electron capture - constant current, $\mathrm{Ni}^{63}$

$\mathrm{He}$

$0.5 \mu \mathrm{L}$

Digital

The above method was compared to the method of Takano et al., [2] in our laboratories. The Takano method is a classical one employing solvent extraction, column chromatography, and sulfuric acid partition, and is similar to other commonly used procedures $[1,4,5]$. In this comparison, two samples were analyzed: 1) the first was a virgin base oil deliberately contaminated with $10 \mathrm{ppm}(\mu \mathrm{g} / \mathrm{g}$ ) of Aroclor 1254 (a PCB fluid containing over 65 individual PCB isomers with an average chlorine content of 54 percent), and 2) a waste crankcase oil also with $10 \mathrm{ppm}$ Aroclor 1254 added. The complete method of Takano took over eight hours per sample with seven hours for sample cleanup and one hour for gas chromatographic analysis. The method of Takano was unable to identify the presence of Aroclor 1254 in the waste crankcase oil sample. On the other hand, the method described in this study was able to identify and measure the Aroclor 1254 in both samples with a total analysis time of less than 70 minutes per sample. 
The glass capillary gas chromatographic method yields enough separation of the individual PCB isomers so that two or more different contaminating PCB fluids can be identified and measured simultaneously. This is not possible when using the noncapillary, low resolution gas chromatographic procedures in the other methods $[1,2,4,5]$.

The quantitative determination of $P C B$ mixtures in lubricating oils can best be carried out by standard addition techniques because of the large variances in the electron capture response factors of the individual PCBs. Further, if more than one PCB fluid is found as a contaminant in the sample, a matrix algebra technique such as that proposed by Eder [6] must be employed to determine the ratio of the individual fluids. This method requires both tedious calibration with accurately known PCB mixtures and sophisticated data acquisition and reduction instrumentation.

In conclusion, we feel that we have devised a useful, quick, and accurate method for determining PCBs in lubricating and/or waste oils and that this method is superior to any existing methods.

\section{References}

[1] Bauer, U., Vom Wasser, 38, 49-62 (1971).

[2] Takano, N., Nakano, T., Takeshita, K., and Sekiyu, Gakki Shi, 17, 159-161 (1974).

[3] Balliardo, F., Gionchiglia, E., and Nano, G. M., J. Liq. Chromato., 2, 77-83 (1979).

[4] Osborne, J., unpublished method.

[5] Phillips Petroleum Company, Method 7837-AG, Issued 6 Nov 1978.

[6] Eder, G., J. Chromato., 121, 269-277 (1976). 

Session 7

SYSTEM PERFORMANCE AND DURABILITY 
National Bureau of Standards Special Publication 584. Proceedings of Joint Conference on Measurements and Standards for Recycled 0il/Systems Performance and Durability held at NBS, Gaithersburg, MD, October 23-26, 1979. (Issued Nov. 1980)

\title{
LUBRICANT FACTORS IN ROLLING CONTACT FATIGUE
}

\author{
C. N. Rowe \\ Mobil Research and Development Corporation \\ Central Research Division \\ Box 1025 \\ Princeton, NJ 08540
}

\section{Introduction}

Although the fatigue failure of bearings and gears has been a well known phenomenon for some time, it is only relatively recent that researchers have recognized that lubricant physical and chemical properties can influence fatigue life. This new appreciation of the role of lubricant factors is due primarily to three advances in technology.

First, the use of cleaner steels with fewer imperfections in the machined components had the result of eliminating many of the early subsurface initiated microcracks, thereby not only resulting in longer fatigue life but narrowing the distribution of the fatigue lives. Shifting the point of crack initiation from subsurface to surface and increasing the fatigue life not only make it possible for chemical factors to come into play to a larger degree, but to be recognized.

Second, improvements in bearing design, surface finish, and cleaner lubricant systems decrease the chance of asperity interactions at a constant EHL film thickness. Particles of hard debris of similar size or larger than the EHL film thickness upon going through the contact zone act as stress raisers on the surfaces which can initiate surface microcracks.

The third, and probably the most significant advance, is the current development of the understanding of the role of elastonydrodynamic lubrication (EHL) film thickness and lubricant viscosity on fatigue. The EHL film thickness of the interposed lubricant in a rolling or combined rolling/sliding contact determines to what extent the high spots, or asperities, on opposing surfaces come into contact. These contacts undergo very high cyclic stresses which serve to initiate microcracks at the surface, which are the precursors to bearing failure. This also led to the knowledge that the specific film thickness, which is the ratio of EHL film thickness to a surface roughness parameter, is a critical factor. In comparing the effects of lubricant chemistry on fatigue life it is important to make the comparison at similar values of the specific film thickness. Many machine designers and bearing manufacturers are now using the specific film thickness factor in estimating bearing life.

\section{Microcrack Formation-Spalling}

All fatigue failures begin with the initiation of microcracks at the surface or subsurface. Following initiation, crack propagation, caused by the cyclic stressing, leads to a growing network of crack damage which eventually results in metal particles spalling from the surface. The fatigue spalls provide paths for lubricant to escape from the contact. This decrease in the EHL film thickness leads to metal-metal contact, metallic wear, and catastrophic surface distress followed by possible components failure. Because of the large amount of surface distress, the cause--fatigue--in a postmortem analysis is very frequently overlooked. Figure 1 consists of four photomicrographs at $80 \mathrm{X}$ showing an actual failure progression in a test rig. The top photo shows surface microcracks. The second photo shows an advancement of the initial microcrack to a small spall, while the third shows further development of cracks and more small spalls. Finally, the bottom photo shows a relatively large spall and the bearing is on its journey to failure.

IFigures in brackets indicate the literature references at the end of this paper. 


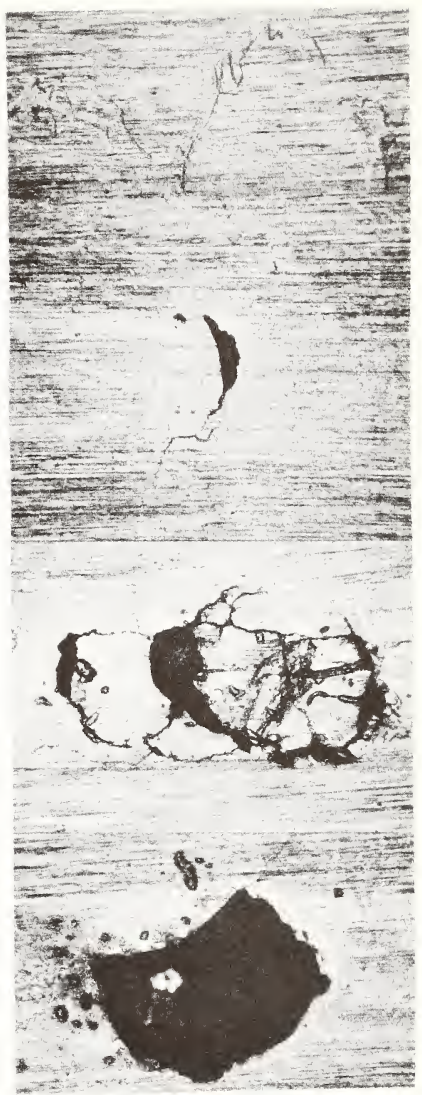

Figure 1. Fatigue crack propagation (80X). 


\section{Specific Film Thickness}

Way $[1]^{1}$ had proposed in 1935 that the lubricant under pressure enters a surface microcrack followed by sealing of the crack in the contact zone so that the developed hydraulic pressure causes propagation of the crack. The amount of lubricant penetrating the crack would decrease with increasing viscosity. Although this mechanism was favored for some time, it has since been replaced by the mechanism of shear stresses at the surfaces and their dependence on lubricant EHL film thickness. With thick lubricant films the surface asperities are sufficiently separated so that the stresses between opposing asperities will be relatively low. Under thin film conditions, the asperities can penetrate the film and the resultant high contact stresses initiate crack formation and cause crack propagation. The viscosity of the lubricant in the entrance region of the contact determines the EHL film thickness while the viscosity of the lubricant in the contact zone affects the shear stress level.

Figure 2 shows, schematically, the contact area between a ball and the inner race of a deep groove ball bearing. Although the point-to-point thickness fluctuates, the separation between the mean planes of the two surfaces defines an average film thickness, $h$. Two film-surface geometries having the same average thickness, h, but radically different surface roughnesses can provide a situation where the relatively smooth surfaces are completely separated while asperities on the rough surfaces are in contact. In recent years, a quantity called the specific film thickness, $\lambda$, has been introduced to describe the lubricant film geometry. $\lambda$ is the ratio of the oil film thickness, $h$, to the composite surface roughness, $\sigma$, where $\sigma=\left(\sigma_{1}{ }^{2}+\sigma_{2}{ }^{2}\right)^{\frac{1}{2}}$ and $\sigma_{1}$ and $\sigma_{2}$ are RMS roughness values of the two surfaces.

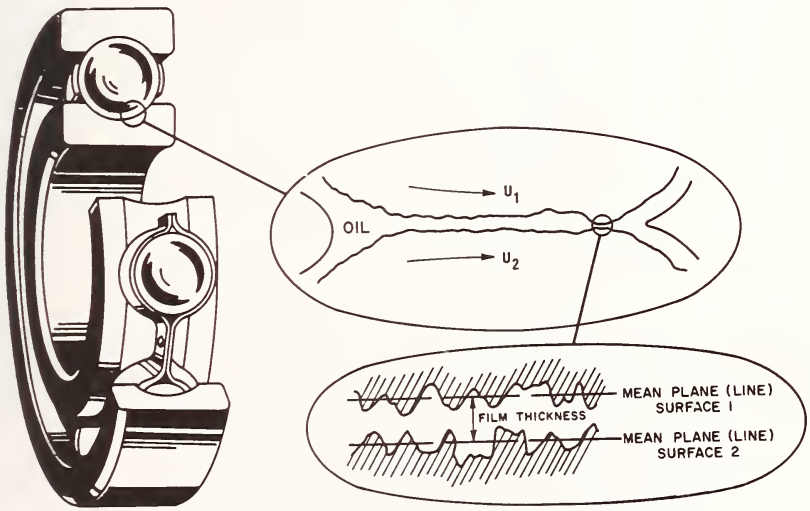

Figure 2. Schematic of contact area between ball and inner race.

Figure 3 shows relative fatigue life as a function of $\lambda$ from two separate investigations; the dashed line is a composite of the two continuous curves and is the recommended curve in the ASME Engineering Design Guide for Bearings [2]. When $\lambda$ is below 2 the fatigue life is greatly reduced. 
The evidence is convincing that specific film thickness is a critical factor in the fatigue life of bearings and gears. The EHL film thickness is proportional to the viscosity and pressure-viscosity coefficient, both to the exponent of about 0.74 . In comparing fatigue life results from research bench tests or full scale bearings it is important to know the EHL film thickness and composite roughness so that observed differences among lubricants can be related either to variation in $\lambda$ or to lubricant chemical factors.

\section{Fatigue Test Methods}

Mobil has been using four bench fatigue testers to investigate the influence of lubricant chemistry factors on fatigue life. These are: rotating-beam fatigue tester [3], rolling 4-ball fatigue tester [4], unisteel bearing fatigue machine [4], and GE rolling contact fatigue rig [5]. Description and operating conditions for the testers can be found in the indicated references.

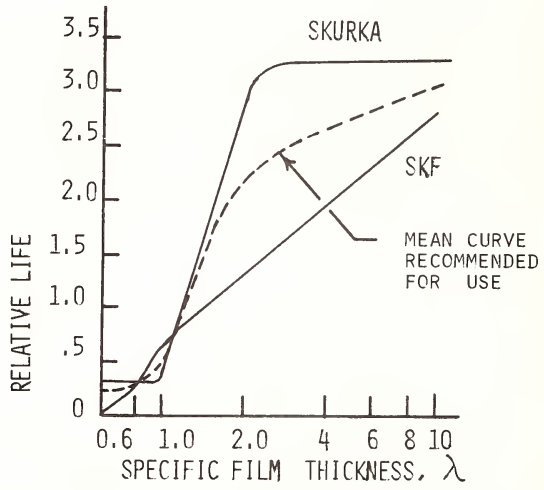

Figure 3. Relative life versus specific film thickness (ref. [2]).

5. Water-Accelerated Fatigue

The reduction of bearing fatigue life by small amounts of water in lubricants is a well known phenomenon. Cantley [6] reported the data in table 1 for the addition of water to an R\&O type SAE-20 mineral oil on the fatigue life of tapered roller bearings. Increasing the water content from 100 to $400 \mathrm{ppm}$ reduced the fatigue 1 ife by 48 percent.

Table 1. Effect of Water in R\&O SAE 200 il.

Tapered Roller Bearings

Cantley [6]

Water Content
ppm
$\mathrm{L}_{15.9}$

Normalized to $100 \mathrm{ppm}$

2. 6

1. 0

0.52 
Felson, et al. [7], determined the fatigue life of thrust loaded angular contact ball bearings with seven commercial mineral oil hydraulic fluids and determined the amount of water in the oils as received. Figure 4 shows my plot of their $L_{10}$ and $L_{50}$ life/specific film thickness ratios against concentration of water inherently present in the oils. Six of the seven oils show a clear reduction in life with increase in water concentration. Increasing the water content from 100 to $400 \mathrm{ppm}$ decreased the $L_{50}$ life 47 percent, in agreement with the 48 percent found by Cantley.

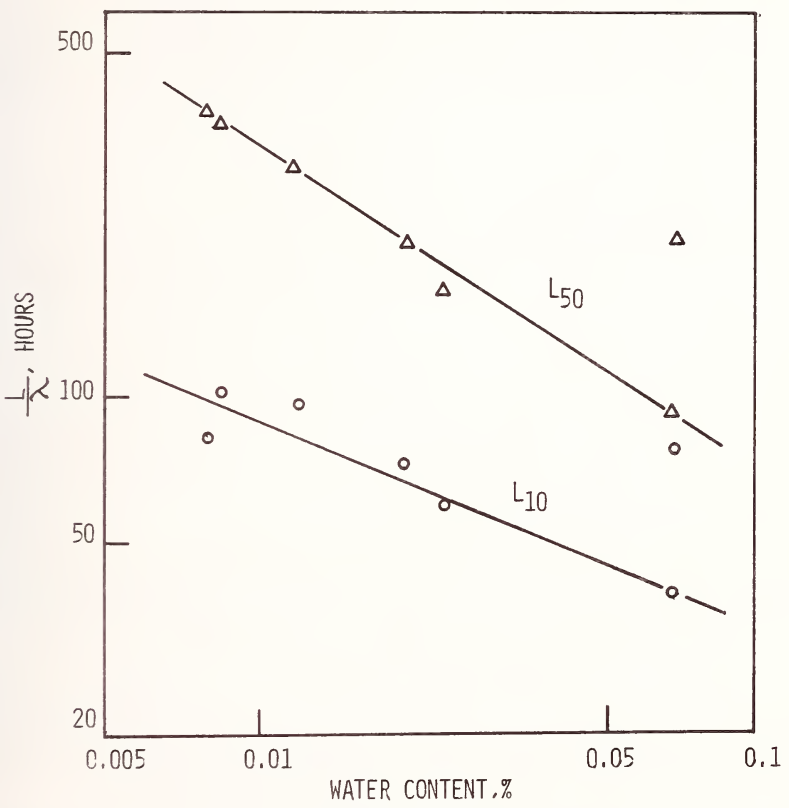

Figure 4. Effect of inherent water content in a series of hydraulic oils on fatigue life normalized to specific film thickness (data taken from ref. [7]).

Figure 5 shows $\mathrm{S} / \mathrm{N}$ plots from the rotating beam fatigue test for dry SAE 20 minteral oil $\left(\simeq 50 \mathrm{ppm} \mathrm{H} \mathrm{H}_{2} \mathrm{O}\right.$ ) and mineral oil with 0.05 percent added water [4]. Water reduced the endurance limit by 43 percent and the fatigue lives above the endurance limit by 60 percent, showing that the test is highly sensitive to water. Figure 6 shows the effect of water on a new formulated turbine/circulating oil containing an antifatigue additive (curve 2). Also shown are the results for the new oil without the antifatigue additive (curve 3 ) and without rust inhibitor (curve 4 ). These results are tabulated in table 2 . Removing the antifatigue additive from the fully formulated oil has a greater deleterious effect than removing the rust inhibitor. 
Table 2 also shows the performance of these oils in the rolling four-ball test under wet conditions at $7.52 \mathrm{GPa}\left(1.09 \times 10^{6} \mathrm{psi}\right)$ and a $\lambda$ value of 1.5 . Addition of 0.5 percent water reduces the fatigue 1 ife of the base oil from 698000 to 580000 stress cycles. The wet fully formulated oil and the wet oil without rust inhibitor are as good or better than the dry base oil. The wet formulated oil without the antifatigue additive is definitively inferior, showing that the antifatigue additive is responsible for the good result for the formulated oil. Table 3 shows confirmatory tests on the base oils and the fully formulated $0 i 1$ in the unisteel rig at a stress level of $3.90 \mathrm{GPa}(565000 \mathrm{psi})$ and a $\lambda$ of 1.6 . Both $L_{10}$ and $L_{50}$ are reduced by the water in the base $0 i 1$ and are significantly higher in the fully formulated oil under wet conditions.

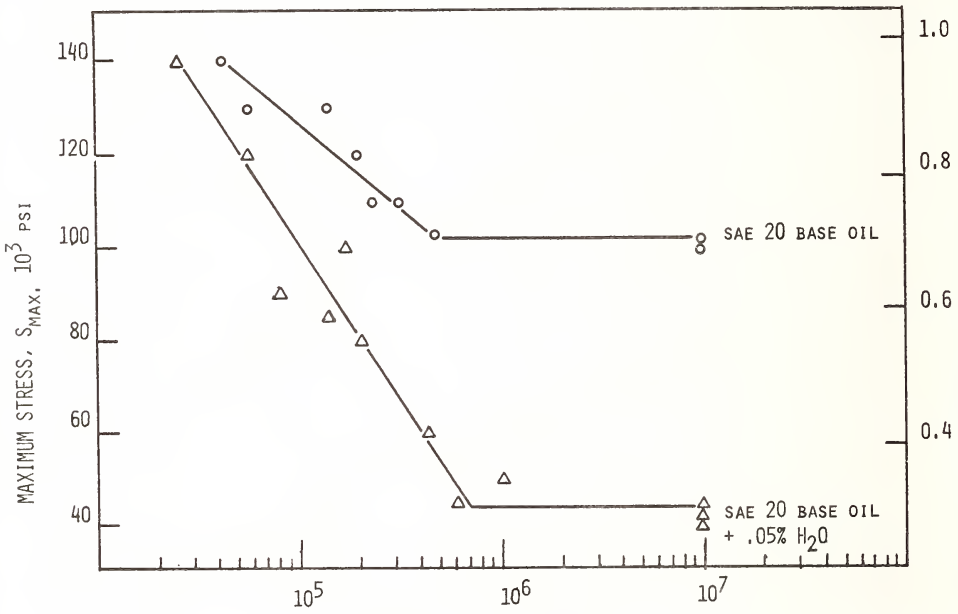

FATIGUE LIFE, $N$, CYCLES

Figure 5. S/N plots showing effect of 0.05 percent added water to SAE 20 base oil.

\section{Additive Mechanisms for Inhibiting Water Effect}

Most industrial oils contain dissolved water, in the range of 50 to 500 parts per million. In many industrial applications oils become contaminated with moisture from the operating environment. Water molecules, being extremely small in size compared to lubricant and additive molecules, readily diffuse to the tip of microcracks.

As a microcrack propagates by cyclic stressing, the newly created surface is highly reactive chemically. Water undergoes decomposition and the produced atomic hydrogen diffuses into the metal ahead of the crack, causing hydrogen embrittlement. This embrittlement not only allows the crack to propagate more rapidly, but promotes crack branching.

From Mobil's investigations of lubricant additives for preventing water acceleratedfatigue in the rotating beam apparatus, three mechanisms have evolved [ $3 \mathrm{~b}]$. The mechanisms proposed are: proton neutralization, hydrophobic surface film, and water sequestration. 
As a class of additives, amines can neutralize protons, and several amine compounds that have a high basicity and are small in size were found to counteract the deleterious effect of water [3b]. The requirement of small molecular size allows the molecule to diffuse to the tip of the crack along with the water molecule. Isopropylaminoethanol was found to be especially effective, confirming published results for the additive in a rolling four-ball tester [8].

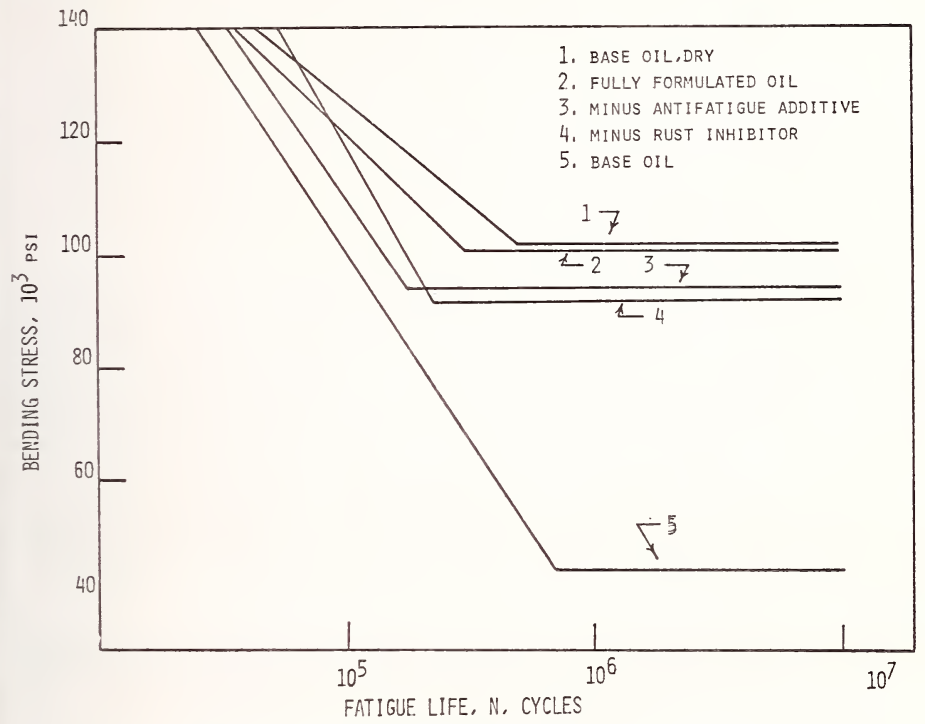

Figure 6. Comparison of $\mathrm{S} / \mathrm{N}$ plots for turbine/circulating oil containing antifatigue additive, all with 0.05 percent added water.

Table 2. Rotating beam and 4 -ball fatigue results on turbine/circulating oil components.

4-Bal1

RBF $(0.05 \%$ Water $)$ Fatigue Life e Endurance 120000 psi Limit,

Lubricant

SAE 20 Base 0il, Dry

SAE 20 Base $0 i$ ?

Fully Formulated $0 i 1$

Formulated Oil Minus

Rust Inhibitor

Formulated 0il Minus

Antifatigue Additive
(0.5\% Water)

$L_{50}$

$\left(10^{3}\right.$ Cycles)

698

580

108

44

711

100

92

722

70

94

515 
Table 3. Comparison of four-ball with unisteel results.

Rig

Four-Ba11

Unisteel

Stress Leve1, Max.

GPa $\left(10^{6}\right.$ psi)

$3.90(0.565)$

Specific Film Thickness

1.5

1.6

Specific Film Thickness

$\mathrm{L}_{50}$

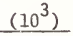

698

580

711

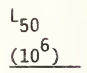

$27.0^{\mathrm{a}}$

16.4

56.3

$98 \%$

$92 \%$

$85 \%$
$95+\%$

$95+\%$

$60 \%$

Dry Base $0 i 1>$ West Base $0 i 1$

Hydrophobic surface film formation is the second mechanism. n-0ctadecanol and an amine salt of n-octadecanoic acid were found to be partially effective. Sequestering of water by microcracks is a third plausible mechanism. An amine succinate type additive is believed to function by this mechanism.

Since different additives exhibit different mechanisms in counteracting the deleterious effect of water, combinations of additives could show synergistic effects and this has been observed [3b]. This points to the potential benefits of a multiple additive system.

\section{Effect of Antiwear Additives}

The inconsistent results obtained with antiwear and EP additives suggests that the result depends on the conditions at the contacting surfaces. An additive may give a positive response at one set of test conditions, but gives a negative response under a different set of test conditions. Also, in formulated oils other additives are present, so that different additive interactions can influence how a given phosphorus or sulfur additive affects fatigue life.

Operating factors which have been shown to affect the response of EP additives are given in table 4. An apparent important factor is the specific film thickness; evidence is emerging that EP additives can be beneficial at low $\lambda$ values, but deleterious at high $\lambda$ values [9]. At low $\lambda$, the additive is forming a surface $f i l m$ and reducing the surface roughness and stresses, while at high values the additive or a reaction product is functioning by a corrosive mechanism.

Wear is of interest since without an antiwear additive present the finite amount of wear that can occur under rolling conditions can remove surface microcracks before they are able to propagate. With the antiwear additive present, the wear is greatly reduced and the surface initiated microcracks are able to propagate. This may be one mechanism by which antiwear additives reduce bearing life. A second mechanism is that wear leads to a more conforming contact with reduced contact stress. As a general statement, many factors can affect the nature of the response of an additive, and no real guidelines have yet emerged. 
Table 4. Factors affecting response of extreme pressure additives.

$\begin{array}{ll}\text { - Specific Film Thickness } \\ \text { - Metallurgy } \\ 0 \quad \text { Additive Concentration } \\ \text { - } & \text { Additive Reactivity } \\ 0 & \text { Stress Level } \\ 0 & \text { Lubricant 0xidation } \\ 0 & \text { Surface Films } \\ 0 & \text { Wear }\end{array}$

Kepple and Johnson [10] investigated the influence of rear axle lubricants on tapered roller bearings at $1.03 \mathrm{GPa}(150000 \mathrm{psi})$ Hertz stress, and the $L_{50}$ results in table 5 are normalized to a premium rust and oxidation inhibited oil. The comparison shows that the additives can reduce the $L_{50}$ fatigue 1 ife to as little as 17 percent of the life with the non-EP oil. The Weibull slopes are reasonably close except for one phosphorus-sulfur additive package in SAE 90 grade which has an unusually high slope. The EP additives, which are required to prevent wear of the hypoid gear, may lead to a reduced fatigue life of the support bearings. This could be a future problem area if lower viscosity gear oils, which minimize frictional losses and increase fuel economy, are used.

Table 5. Effect of rear axle lubricants on fatigue life of tapered roller bearings.

Kepple and Johnson [10]

$1.03 \mathrm{GPa}(150000 \mathrm{psi})$ Maximum Hertz Stress

\begin{tabular}{|c|c|c|c|}
\hline SAE Grade & $\begin{array}{c}\text { Type of } \\
\text { EP Additive Package } \\
\end{array}$ & $\begin{array}{r}\mathrm{L}_{50} \text { Life, } \\
\text { Normalized } \\
\end{array}$ & $\begin{array}{c}\text { Weibul1 } \\
\text { Slope } \\
\end{array}$ \\
\hline 90 & None & 1.00 & 1.45 \\
\hline 80 & Lead-Sulfur & 0.24 & 2.63 \\
\hline 80 & Lead-Sulfur & 0.34 & 1.26 \\
\hline 80 & Phosphorus-Sulfur & 0.32 & 1.71 \\
\hline 90 & Zinc-Phosphorus-Sulfur & 0.17 & 2.37 \\
\hline 90 & Zinc-Phosphorus-Sulfur-Chlorine & 0.40 & 2.27 \\
\hline 90 & Phosphorus-Sulfur & 0.67 & 7.69 \\
\hline
\end{tabular}

\section{Organic Phosphonate Additive}

A good example of a novel mechanism by which additive chemistry influences rolling contact fatigue is that of an organo phosphonate additive [11]. This compound cannot be used as an antifatigue component in many formulations because of the interference with other performance properties. Figure 7 illustrates the influence of the additive in a mineral oil on the GE Rolling Contact Rig. It was found that the life improved with time, indicating a 


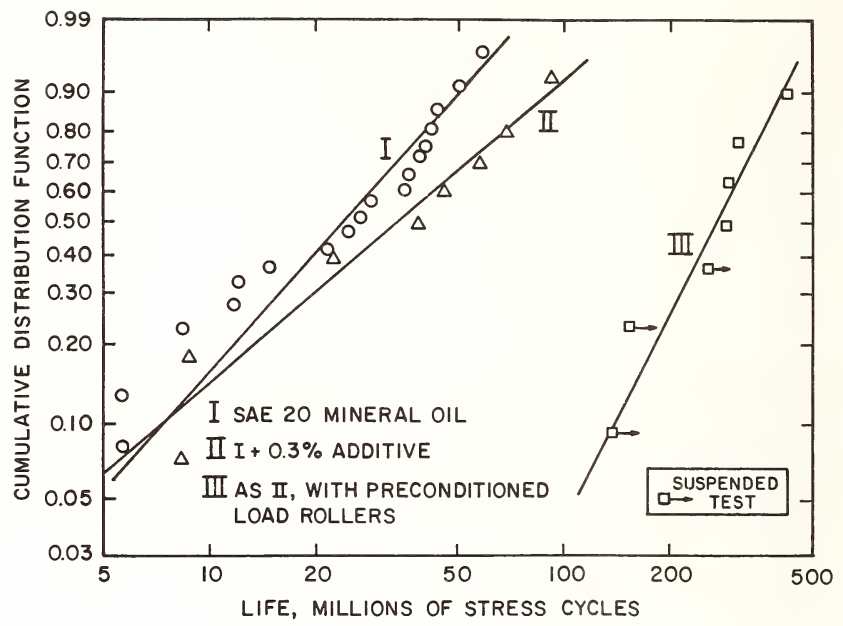

Figure 7. Effect of the organic phosphonate additive in an SAE 20 mineral oil.

build-up film on the surface of the rollers, which are not changed between tests. Electron probe analysis of the film showed that phosphorus was present and $x$-ray diffraction showed the film to be amorphous.

An optical EHL rig was operated for a period of time at $99{ }^{\circ} \mathrm{C}$ and it was found that the rolling speed required for a constant film thickness decreased with time. Calculating the generated EHL film thickness at each rolling speed and subtracting from the total film thickness, the chemical film thickness was obtained as a function of time and the results are in figure 8 . This is direct evidence, using a novel technique, that this additive forms a surface film in a concentrated contact.

These experiments demonstrate that the organic phosphonate can generate a thick chemical film within a rolling EHD contact. The rate of deposition is temperature dependent. The produced film can prolong fatigue life by one or more of the following mechanisms: 1) increasing the effective film thickness; 2 ) reducing apparent surface roughness; 3 ) inhibiting ingestion of oil into the crack, and; 4) reducing traction which will minimize tangential stresses and crack initiation and crack propagation.

\section{Summary}

In summary, we are in a learning phase on the role of lubricant and additive chemistry on the fatigue life of bearings. Much more work is needed to establish guidelines as to what type additives are detrimental and what type additives are beneficial. On the latter, work is needed to define the size of the increases to be expected. In all probability, gains in fatigue life will be seized upon by designers to operate bearings under more severe conditions. 


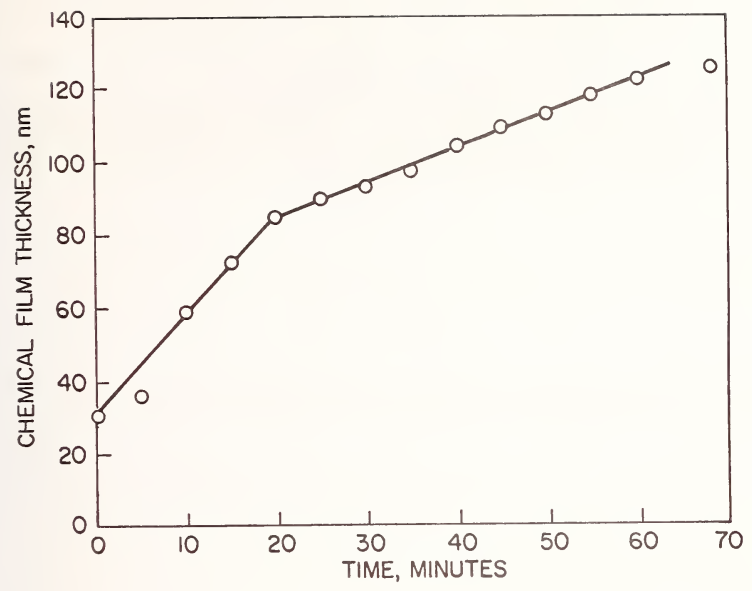

Figure 8. Growth of the chemical film thickness with time.

References

[1] Way, S., Pitting due to rolling contact, Trans., ASME, 57, A49 (1935).

[2] Life Adjustment Factors for Ball and Roller Bearings--An Engineering Guide, sponsored by the Rolling-Elements Committee, The Lubrication Division of the ASME (1971).

[3] Polk, C. J., Murphy, W. R., and Rowe, C. N., Determining fatigue crack propagation rates in lubricating environments through the application of a fracture mechanism technique, ASLE Trans., 18, 290 (1975); Murphy, W. R., Polk, C. J., and Rowe, C. N., Effect of Lubricant Additives on Water-Accelerated Fatigue, ASLE Trans., 21, 63 (1978).

[4] Armstrong, E. L., Leonardi, S. J., Murphy, W. R., and Wooding, P. S., Evaluation of water-accelerated bearing fatigue in oil-lubricated ball bearings, Lub. Engr., 34, 15 (1978).

[5] Murphy, W. R., Armstrong, E. L., and Wooding, P. S., Lubricant performance testing for water-accelerated bearing fatigue, Rolling Contact Fatigue Performance Testing of Lubricants, chap. 16, E. Tourret, and E. P. Wright, eds. (Heyden \& Son Ltd., London, 1977).

[6] Cantley, R. E., The effect of water in lubricating oil on bearing fatigue life, ASLE Trans., 20, 244 (1977).

[7] Felsen, I. M., McQuaid, R. W., and Marzani, J. A., Effect of sea-water on the fatigue life and failure distribution of flood-lubricated angular-contact ball bearings, ASLE Trans., 15, 8 (1972).

[8] Schatzberg, P., Inhibition of water-accelerated rolling contact fatigue, J. Lub. Technol., 93, 231 (1971). 
[9] Quinn, F. J. and Philips, M. R., The effect of surface roughness and lubricant film thickness upon contact fatigue, Conf. on Effects of Surface Roughness in Lubrication, Tribology International, 10, 331 (1977) (Lyon, France, Sept. 13-16, 1977).

[10] Kepple, R. K. and Johnson, M. F., Effect of Rear Axle Lubricants on the Fatigue Life of Tapered Roller Bearings, SAE Paper No. 760329 (1976).

[11] Fowles, P. E., Jackson, A., and Murphy, W. R., Lubricant Chemistry in Rolling Contact Fatigue--The Performance and Mechanism of One Antifatigue Additive, ASLE Paper 79-LC-4A-1, ASLE/ASME Lubrication Conference, Dayton, Ohio (October 16-18, 1979). 
National Bureau of Standards Special Publication 584. Proceedings of Joint Conference on Measurements and Standards for Recycled 0i1/Systems Performance and Durability held at NBS, Gaithersburg, MD, October 23-26, 1979. (Issued Nov. 1980)

\title{
THE RELATIONSHIP BETWEEN VISCOMETRIC LABORATORY MEASUREMENTS AND FIELD PERFORMANCE AND SERVICE
}

\author{
Theodore W. Selby \\ Savant, Inc. \\ 234 East Larkin \\ Midland, MI 48640
}

\section{Introduction}

It has been long known that viscosity is the heart of hydrodynamic lubrication. Stribeck's curve is a rather explicit statement of this relationship for a journal bearing. This curve is shown in figure 1 where the coefficient of friction is plotted against a parameter $n N / P$ where $\eta$ is the viscosity, $N$ is the journal speed and $P$ is the load on the journal. The straight-line portion of the curve represents the range of hydrodynamic lubrication controlled by the viscosity while the mixed lubrication and boundary lubrication regions are also indicated. All of this work in developing the information which ultimately reduced to the Stribeck curve (and other relationships) between viscosity and lubrication, was with Newtonian fluids in which the shear stress is proportional to the shear rate with the constant of proportionality defined as the viscosity by Newton.

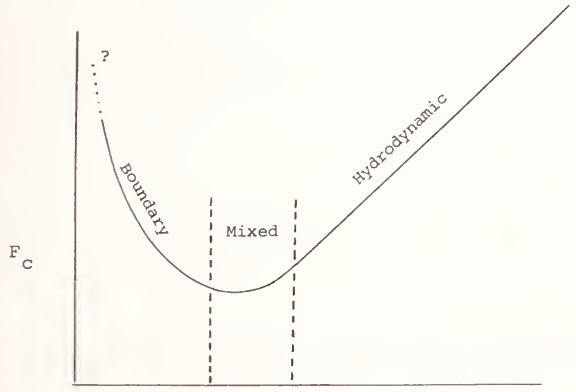

$\eta \mathrm{N} / \mathrm{P}$

Figure 1. Stribeck curve. For coaxial cylinders: $T=f[n N]$ and for the bearing equivalent: (from Stribeck) $F_{c}=f[n N / P] ; f[$ indicates a function; $T$ is torque; $N$ is speed; $\eta$ is viscosity; $F_{c}$ is the friction; and $P$ is pressure.

In the middle $40^{\prime}$ s and early $50^{\prime} s$ it was found possible to improve the range of refined basestocks capable of making suitable engine oils by adding small quantities of certain oil-soluble polymers called Viscosity Index Improvers. These polymeric additives brought about a profound change in lubricant technology. They also brought about a long period of confusion, new questions regarding the process of lubrication and new understandings regarding the role of such polymers in lubrication. That period is certainly not over yet; we are still seeking to understand the viscometric behavior of oil-soluble macromolecules in the engine as will be hopefully gathered from the following paper. 
Other lubrication needs and problems came into focus over the last 20 years and it will also be one of the objects of this paper to discuss how the viscosity of the lubricant controls these other relationships important to field performance and service.

\section{The Effect of VI Improvers on Automotive Lubrication-- A Recent History}

As previously indicated, VI Improvers were brought into the commercial world in an effort to improve the viscosity-temperature characteristics of refined basestocks and the term "multi-grade" entered into our jargon. Up to and beyond the time they were introduced it was the practice to determine the kinematic viscosity of an engine oil at 100 and $210^{\circ} \mathrm{F}$ and to extrapolate these viscosities to either higher or lower temperatures using the Walther equation or ASTM Viscosity-Temperature Charts derived from the Walther equation as in figure 2. (It had been found over the years that the Walther relationship was relatively accurate for most extrapolations concerned with mineral oils.) When this extrapolation technique was used with polymer-modified oils an anomaly occurred: the extrapolated viscosity of the polymer-modified at low temperatures (e.g. $0^{\circ} \mathrm{F}$ ) was found to be lower than that of the base oil used, as shown in figure 3. Despite their enthusiasm, it was very hard for experimentalists in those days to accept the fact that a formulated lubricant could somehow be less viscous than the base after a very viscous VI Improver was added. This apparent crossover of figure 3 caused by extrapolation was brought to measurement at the bench early in the 1950's and it was shown (fig. 4) that the crossover was an illusion of hope brought about by assuming that the extrapolation technique was appropriate. There was a crossover, but it occurred at a lower temperature where gelation affected the kinematic results.

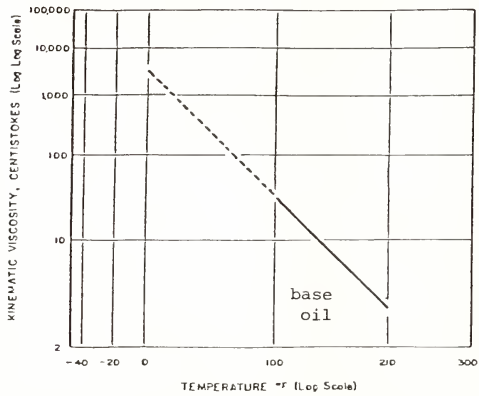

Figure 2. Extrapolated method of determining $0{ }^{\circ} \mathrm{F}$ viscosity.

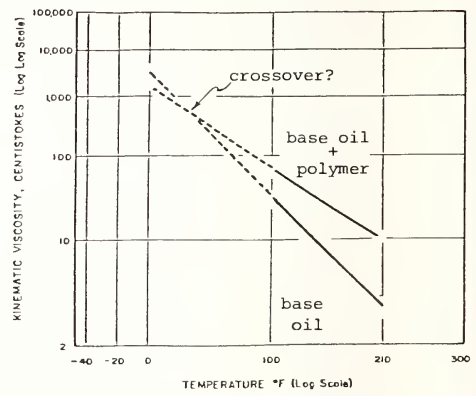

Figure 3. Comparison of extrapolation values of base stock and base stock plus polymer.

However, even this information was not entirely suitable nor sound since the measurements were still made by kinematic capillary viscometers, that is, at low shear stresses. Some of the automotive engineers and lubricant specialists from the petroleum industry claimed that since engine cranking speed was important to starting, the true measurement of response to the engine oil viscosity should first be made with the cranking engine and then extended to a suitable viscometer if, indeed, the low temperature viscosity classification system was to have significance in regard to engine starting at low temperature. So began a series of cranking experiments with the automotive engine--efforts which went on in various laboratories for about 15 years. In the process of this work, higher and higher shear stress viscometers were brought to bear on the problem to attempt to develop correlation with the information being generated by cranking engines on a number of reference engine oils. Finally, in the middle 60's the ASTM's RDD-7, which had been conducting a large part of these tests in cooperation with the CRC, finally obtained sufficient information on various viscometers to indicate that an instrument newly developed precisely for the purpose, called the Cold-Cranking Simulator (CCS), had the highest degree of precision and was the easiest of the instruments tested to use. Most important, its correlation with engine cranking data was also very good as shown in figure $5 \mathrm{a}$ at $0^{\circ} \mathrm{F}$ and figure $5 \mathrm{~b}$ at $-20^{\circ} \mathrm{F}$. 


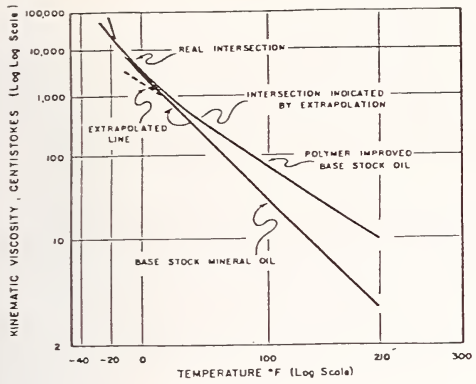

A.

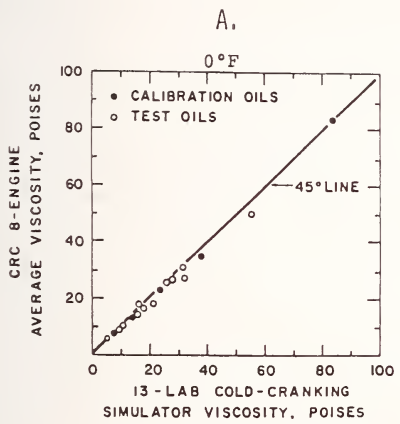

Figure 4. Extrapolated viscosity error in the comparison of a multigrade oil to its base stock.

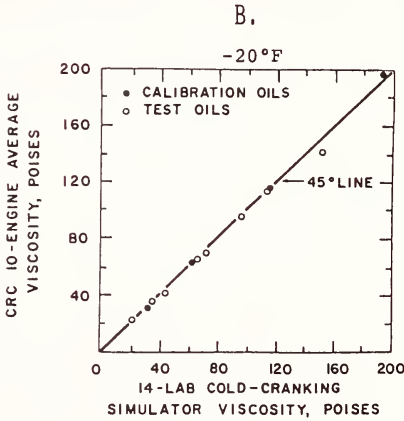

Figure 5. Correlation of the cold-cranking simulator with engine cranking speed.

However, this portion of the story is not over. Very recently, because of a new round of studies aimed at further developing the SAE Viscosity Classification System, it has been proposed that the CCS be used over a relatively broad temperature range, from 0 to $-40^{\circ} \mathrm{C}$. Preliminary information from the field indicates that the CCS still correlates quite well with the cranking speed of gasoline engines.

As a fillip to the story: It is interesting that, in the middle 60 's, work was done showing the cranking speed of a gasoline-fired engine was an effect of viscosity and not, as previously assumed, particularly important to the starting of the engine. However, the same study showed that viscosity was directly very important to the starting of the engine presumably because it was the engine oil viscosity which had to be overcome by the starting (i.e. low-speed) torque of the engine. Fortunately, the fact that the Cold-Cranking Simulator had already been developed to correlate with engine cranking speed turned out to be an acceptable relationship since the cranking speed was, after all, a measure of the viscosity experienced by the engine. 


\subsection{High temperature studies}

In the meantime, questions were being asked about the high temperature performance of Viscosity Index improved oils. Although the presence of a VI Improver in the oil contributed a considerable amount of kinematic viscosity to the basestock when the oil was new, after a certain period of use some of this viscosity contribution of the polymer seemed to be lost. This was called, appropriately, "permanent viscosity loss" (PVL). The question that developed was whether an oil experiencing such permanent viscosity loss would continue to provide sufficient lubrication to the bearings and pistons of the engine. In 1967, ASTM's RDD-7 began a study to test whether a bench test could be found to correlate with engine tests regarding the degree of PVL. Accordingly, reference fluids were established and several small fleets of cars were run on these fluids in the United States as well as in Europe. It was found, however, that the complex physical and chemical degradation of the VI Improver which took place in the engine could not be totally reproduced with tests based solely on mechanical degradation. Of the results obtained, one of the best was the correlation between the engine tests and the diesel injector, as shown in figure 6 . The exceptions were two polymer types, one of which reassociates after shear (ARO-109) and one of which was quite susceptible to oxidation (AR0-106). Work continues on the study of test methods and a diesel injector test method is presently being balloted in the ASTM. In the meantime, regarding the original concern about the lubricating function served by VI Improvers in the engine, other work on determining the viscosity of the engine oil in the bearing was already underway.

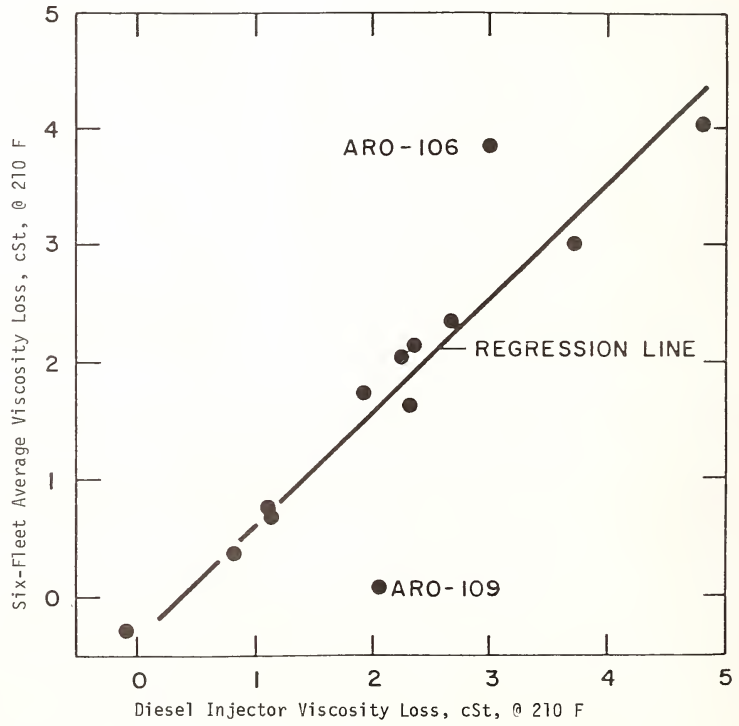

Figure 6. Correlation between the best diesel injector test data and the six-fleet average. 


\subsection{Bearing viscosity}

As previously mentioned, with the advent of multigrade engine oils, experimentalists in bearing lubrication were concerned that temporary and/or permanent viscosity loss would or could be reflected in increased bearing wear. Bearing test rig studies over the last 10 to 20 years by DeHart, Rosenberg, and others showed that polymer-modified fluids always gave less friction in the bearings than would be predicted on the basis of extrapolated viscosity at bearing operating temperature. One example is shown from work by Rosenberg in figure 7. This figure is interpreted as a section of a Stribeck curve as shown and it is quite evident that none of the polymer-modified engine oils are on the curve established by the Newtonian oils. These observations were interpreted to mean that: 1) low shear stress (kinematic) viscosities were not relevant to the bearing, 2) energy losses to polymer-modified multigrade engine oils were less than their single-grade counterparts, and 3) oil film thicknesses should be less in the bearings. Therefore, Rosenberg measured oil film thickness in the bearing for the results of the above-mentioned study and found that these were, as expected, less than predicted from low shear stress viscosities at the bearing temperature, as shown in figure 8 . However, Rosenberg also noted that there is a major difference between bearing test rigs such as his own and the bearing in a fired engine. The latter not only applies inertial loads but time-varying gas loads to the bearing. Thus, he noted a real possibility that viscoelastic effects contributed by the polymers might offer further bearing wear protection than simple viscous effects.

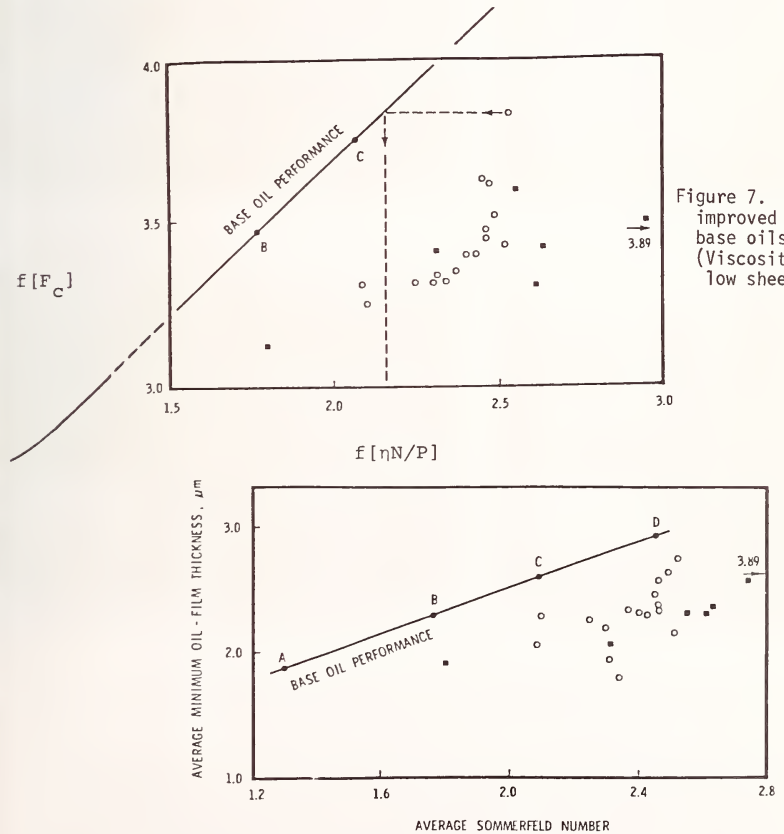

Figure 8. Film thickness of VI improved oils compared to base oil performance. 
Subsequent7y, road tests reported by Stambaugh, Kopko and Bennett showed that some polymer-modified fluids made with highly shear-susceptible VI Improvers were less than adequate to protect the bearings from catastrophic failure while other, less shearsusceptible, polymers were quite adequate. Specifically, figure 9 taken from some of their work, shows that a minimum viscosity SAE $20 \mathrm{w}-20$ oil did not protect the main bearings of the engine during 50000 miles of severe service (police "chase" cars). Use of shear-susceptible VI Improver E gave little more protection whereas shear-stable VI Improvers B and D gave quite acceptable bearing protection. As a consequence of their studies, Stambaugh and Kopko indicated that, in larger. American-made engines such as those used in their studies, a critical viscosity of about 3.3 to $3.8 \mathrm{cSt}$ would be expected.
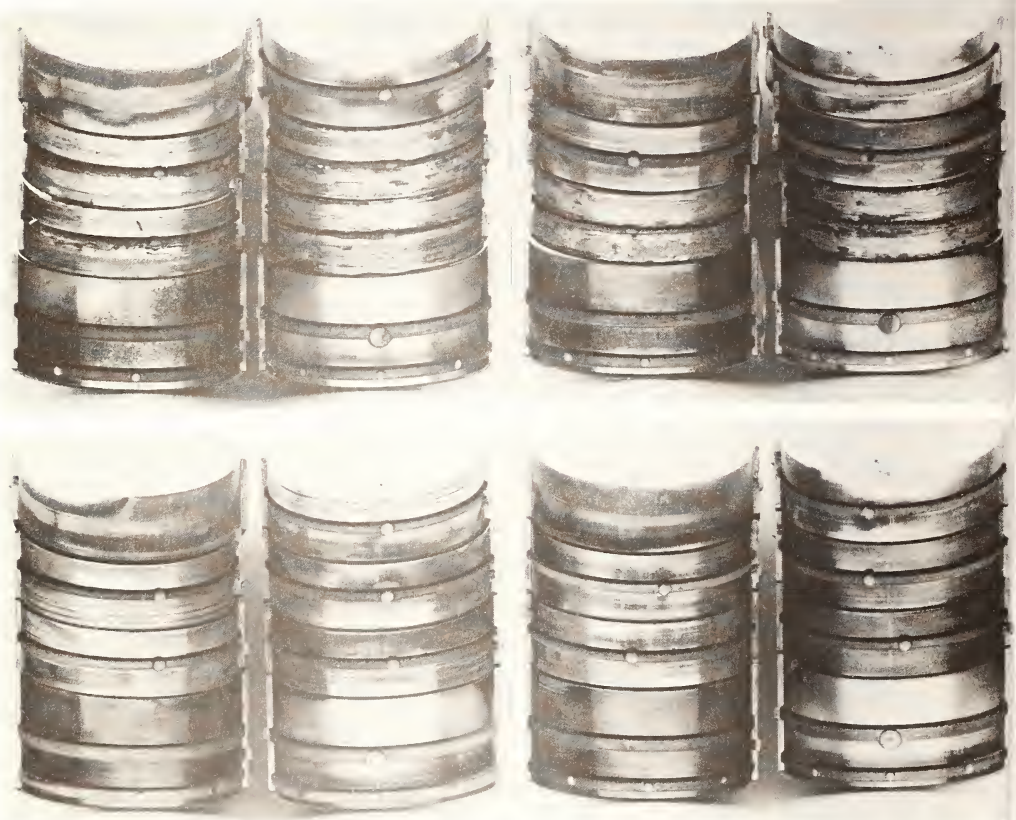

Figure 9. Illustration of main bearings and the effects of shear-susceptible VI improvers with severe service conditions.

Very recently, studies by McMillan and Rosenberg showed that even in long duration driving tests under milder but still onerous, test conditions, there was a distinct difference between shear-susceptible VI Improvers and relatively shear-stable VI Improvers. In their work, they made a head-to-head evaluation of four VI Improvers in a common basestock/additive-package through a constant high-speed ( $75 \mathrm{MPH}$ ), high-temperture $\left(300^{\circ} \mathrm{F}\right)$, $50000 \mathrm{mile}$ proving ground test. Two of the VI Improvers were from one family of polymers 
and the second two from a different family. In each pair one VI Improver was of higher molecular weight (more shear susceptible) and one of lower molecular weight (more shear stable). Thus, the total comparison was between VI Improver families and molecular weights of the polymers. Their studies show that: 1) more shear-susceptible VI Improvers give greater wear (figs. 10 and 11), and, somewhat surprisingly, 2) greater oil degradation (figs. 12 and 13 ).
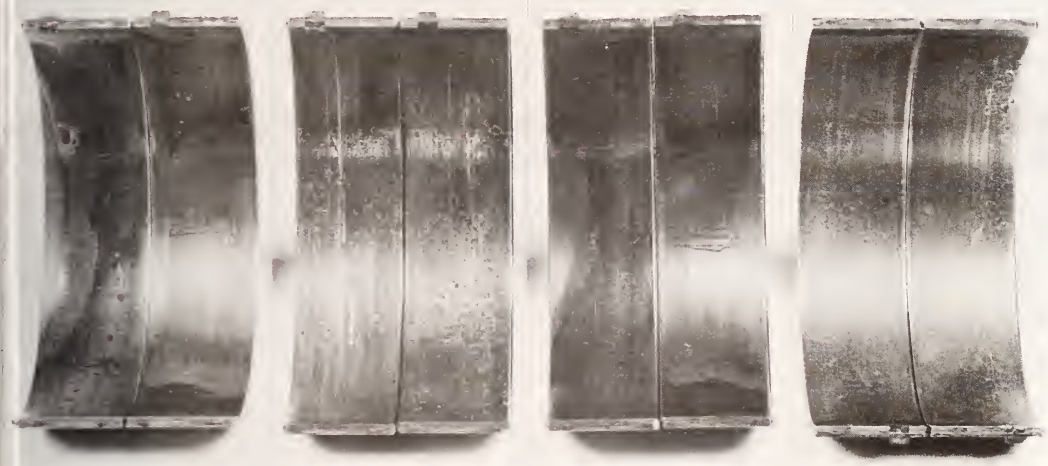

\section{Polymethacrylate}

- stable -
Polymethacrylate

- unstable -

\section{Olefin-Copolymer}

- stable -
Olefin-Copolymer

- unstable -

Figure 10. Typical rod bearings after $80000 \mathrm{~km}$ of high-speed, high-temperature service.
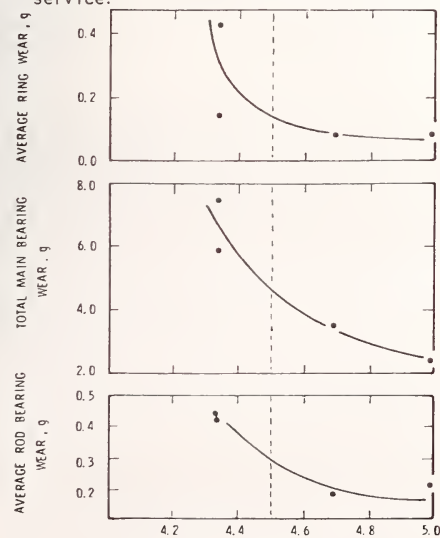

Figure 11. Relationship between wear and high-temperature, high-shear-rate viscosity.

VISCOSITY AT $6 \times 10^{5} \mathrm{~S}^{-1}$ AND $149^{\circ} \mathrm{C}$. CSt 




Figure 12. Rocker covers showing sludge deposits.

Regarding bearing wear, MCMillan and Rosenberg state that 4.5 cSt is a critical viscosity for this engine as was noted in figure 11 . Viscosity values less than this level are believed to produce the bearing wear shown in figure 10 . As a consequence of these studies and as the result of a number of changes that were anticipated in the SAE Engine $0 i 1$ Viscosity Classification System, the SAE requested ASTM's RDD-7 to develop a high shear viscometer test for engine oils. RDD-7 initiated this work about a year and a half ago and has enjoyed the cooperation of the European CEC as well.

At this point it may be instructive to contrast some engine oils from the marketplace. Very recently, and as yet unpublished, viscometric studies on the combined effects of both permanent and temporary viscosity losses on three well-known commercial $10 \mathrm{w}-40$ multigrade engine oils are shown in figure 14. The data compare the viscosities at $300^{\circ} \mathrm{F}$ on the ordinate with the permanent viscosity loss on the abscissa at two shear rates $\left(0.5 \times 10^{6}\right.$ and $1.0 \times 10^{6} \mathrm{~s}^{-1}$ ) for the three oils. Also indicated are the two critical viscosity levels of 4.5 (high wear studies) and $3.5 \mathrm{cSt}$ (catastrophic bearing failure) indicated by the previously mentioned studies. It is apparent that choosing a shear stable VI Improver and an adequate base stock such as was apparently done to obtain the properties of $0 i 11$, can prevent the engine attrition expected from $0 i 1 s 2$ and 3 when, and as, they fall into the critical viscosity zone shown by McMillan and Rosenberg's work. A reasonable conclusion from this data is that permanent and temporary viscosity losses can be very important to the life span of the engine, and thus, the selection of properly shear stable VI Improvers is a desirable adjunct to the manufacturer of quality engine oils. 


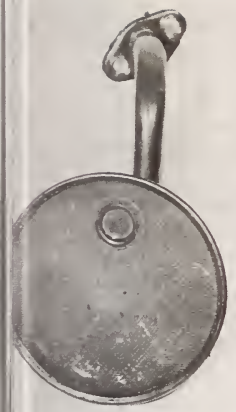

Polymethacrylate

- stable -

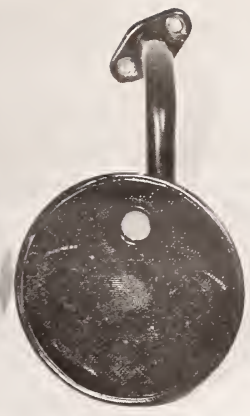

Polymethacrylate

- unstable -

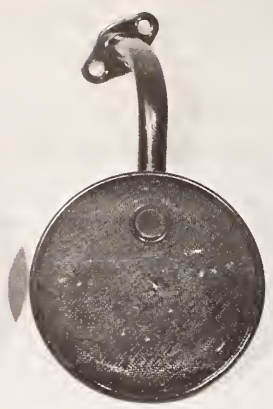

Olefin-Copolymer

- stable -

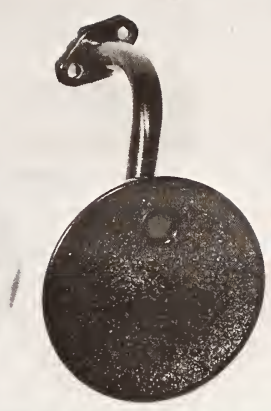

Olefin-Copolymer

- unstable -

Figure 13. $0 i 1$ pump inlet screens showing amount of screen plugging.

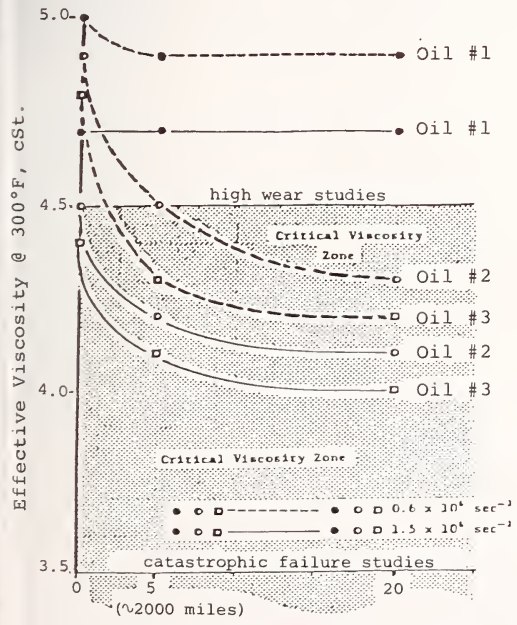

Figure 14. Comparison of three commercial 10w-40 motor oils before and after shear degradation in the fuel injector shear stability test (FISST). (Comparison made at two high shear rates.)

FISST Results, Number of Passes 


\subsection{Beyond Stribeck}

In the time since the oil embargo of 1973, and particularly with the rapid increase in oil prices, the question of improving the fuel efficiency of the engine oils has been raised. As a consequence, the further question has been raised about the role of viscous friction as a source of energy loss in the engine. That is, the same viscosity which provides hydrodynamic lubrication is also an energy sink regarding its frictional characteristics.

As previously mentioned, the Stribeck curve has long been used as an index of the relationship between viscosity and the coefficient of friction in an engine. However, the Stribeck curve of figure 1 applies to journal bearings. In the automotive engine the major source of friction (60-80 percent) is in the piston/cylinder interface as shown in figure 15 and this area must be treated as a slider bearing. For the piston/cylinder interface, the literature shows that the Stribeck curve of figure 1 no longer applies. Instead of the coefficient of friction, $F_{C}$, being proportional to $n N / P$ and the curve now appears as in figure 16. Since from 60 to 80 percent of the frictional energy expended by the engine occurs in the piston-ring/cylinder-wall interface area, in which friction is affected by only the square root of the viscosity, it is evident that decreasing the viscosity in order to gain some benefit of reduced friction will be of relatively limited benefit to fuel economy. On the other hand, such a reduction in the viscosity may very well create a condition of greater bearing vulnerability under particularly severe engine operation. In other words, on the basis of the way in which the engine absorbs energy through viscosity not much can be gained by reducing viscosity but much can be lost. Recent experiments on the reduction of friction by reducing viscosity seem to confirm this speculation--that is, little benefit in fuel economy was found.

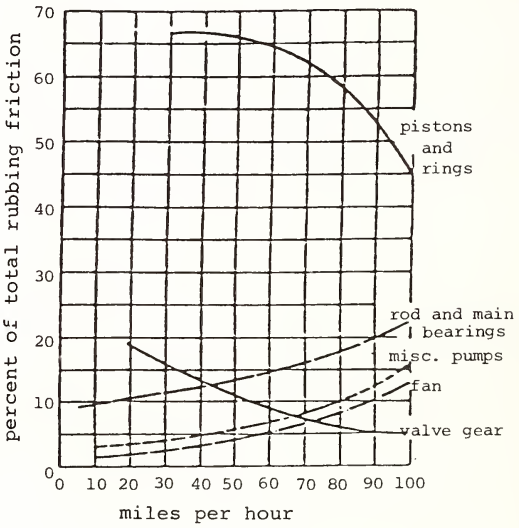

Figure 15. Percent distribution of rubbing friction. (Typical engine at road load.) 


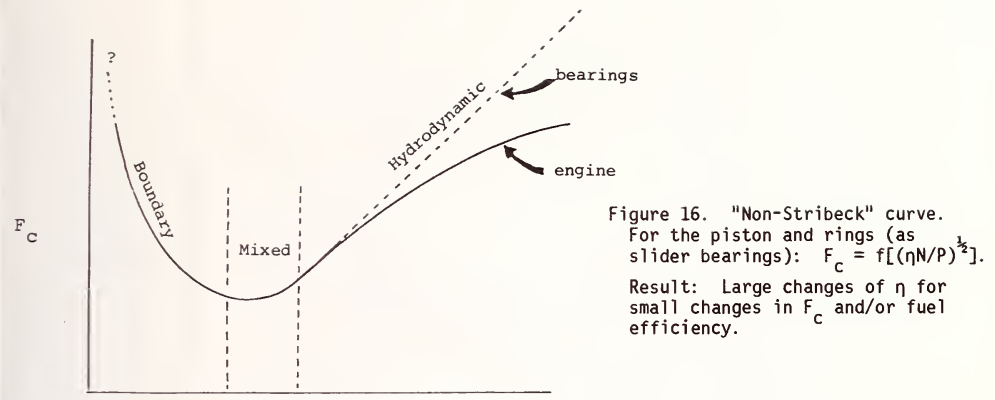

$\mathrm{nN} / \mathrm{P}$

If, then, some effective improvement in fuel efficiency of engine oils is to be made, perhaps the role of friction modifiers might be the most appropriate direction in which to go. This has been shown to be the case with certain soluble and colloidal friction modifiers. Moreover, the evidence intimates that the bottom of the Stribeck curve might be effectively extended by a friction modifier as has been suggested by McDonnell and Tempe, and Ghirla and Smith (fig. 17). This leads to the question of whether the engine can operate efficiently and with control of the bearing wear by the use of friction modifiers coupled with low viscosity fluids. Such experiments are presently being conducted.

\subsection{Other viscosity effects of the engine oil}

Within the last eight years another engine oil viscosity-related problem has become visible. This is in regard to engine oil pumpability. Engine oil pumpability is a lowtemperature phenomenon related to how adequately the oil pump can supply the lubricant to the engine. While there have been questions raised concerning engine oil pumpability for many years, the questions did not receive the support of a problem until relatively recently in Canada a certain otherwise highly qualified oil began to cause bearing failures during the winter. It was found that this oil and others had the tendency to form a gel at low temperatures. Consequently, the oils were removed from the market. However, the automotive industry took this as a serious warning that the present SAE Engine 0 il Viscosity Classification System was not adequate in protecting the engine since it did not include some means of measuring pumpability-related behavior. Accordingly, the SAE requested the ASTM'S RDD-7 to develop a pumpability test. To do this, RDD-7 first established a series of sixteen reference oils, two of which were Newtonian in character. They then mounted a series of engine and pumping rig studies to first of all determine the nature of the problem. The engine and rig studies were completed in 1975 and reported as ASTM DS 57.

During the time of engine and pumping rig testing, a series of viscometric bench tests were initiated using various low shear stress viscometers at low temperatures. Preliminary results showed a fairly strong correlation between these viscometric bench tests and the results from the engines. However, none of the first viscometric devices were simple to set up and/or use, and a new thrust of work was initiated to develop a relatively simple viscometer. Moreover, it was found during the engine tests that two different forms of oil flow restriction occurred: One form was that caused by the gel structure previously mentioned. On starting the engine, the vacuum developed by the pump caused the collapse of the gelled oil structure immediately above the oil inlet tube and this quickly developed into a hole reaching the surface as shown in figure 19. Consequently, the pump and, thus, the engine became starved for lubricant. 


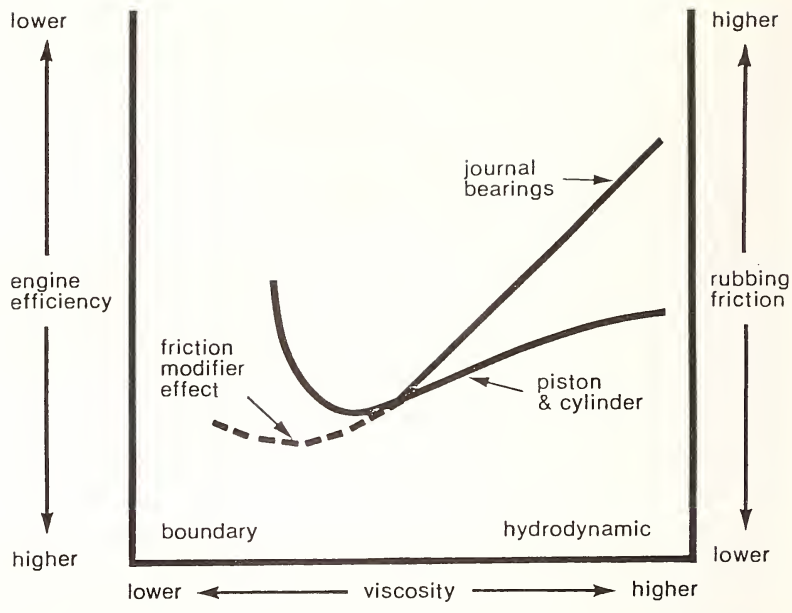

(constant speed and bearing load)

Figure 17. Engine efficiency as affected by viscosity and friction modifiers.

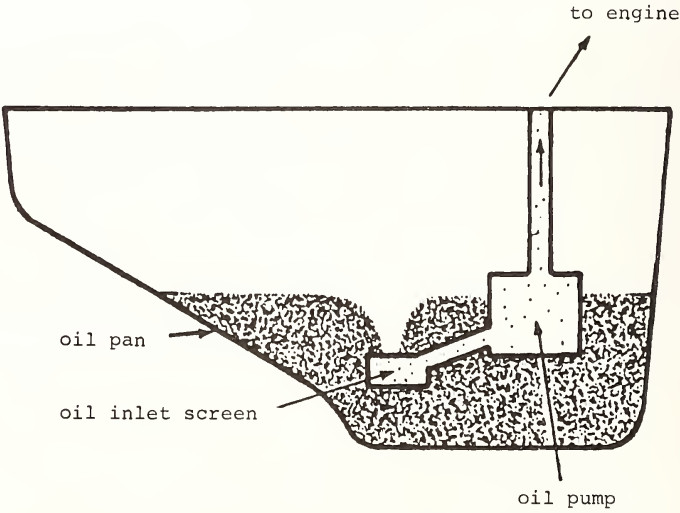

Figure 18. Air-binding limited pumpability. 


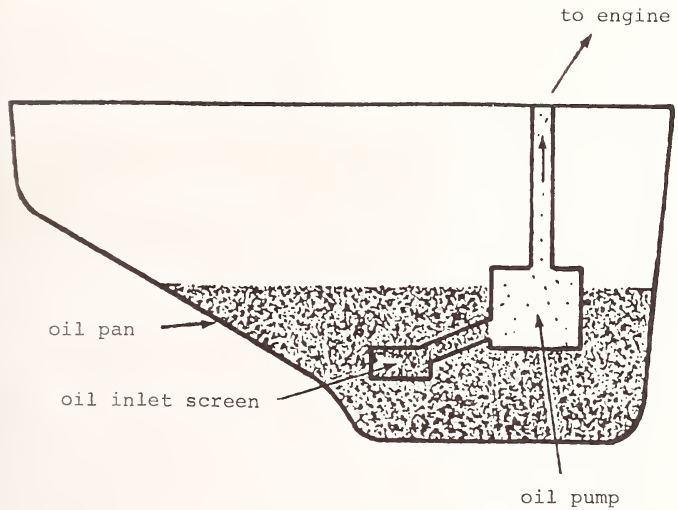

Figure 19. Flow-limited pumpability.

RDD-7 decided that an instrument acceptable for determining pumpability should, if possible, be capable of measuring both modes of pump limitation--air-binding and flowlimited. Several instruments were proposed and investigated by one or more laboratories. At this time, one ASTM Test Method has already been written around an instrument called the Mini-Rotary Viscometer (MRV) shown in figure 20 which was specifically devised to serve the purpose. The MRV has shown good correlation with the engine and rig tests in terms of the Borderline Pumping Temperature (BPT) in figure 21. (Borderline Pumping Temperature is defined as "the temperature at which the minimum gallery pressure, at any time after one minute of test, is 20 psig [138 KPa]".) RDD-7 and private investigators are continuing the investigation of other viscometers and test methods, particularly including the Brookfield viscometer which is widely used for other low-temperature, low-shear studies.

\subsection{Used oil effects}

In all of the foregoing discussion there has been very limited reference to used oil with the exception of that on permanent viscosity loss (which obviously is a used oil phenomenon). However, there are many ways in which the oil in the operating engine can be affected by its environment and, in turn, affect the engine creating a cycle of oil and engine deterioration. Some short observations are in order for an area of research which has really not been given great attention.

\subsubsection{Fuel dilution}

Fuel dilution will normally cause a reduction in viscosity which, in turn, may become harmful at high temperatures if the viscosity is reduced below the critical limit. However, and surprisingly, fuel dilution can also be deleterious at low temperatures for another reason. In diesel engines, the fuel oil may be somewhat waxy in nature. When mixed with the engine oil the wax contribution may cause an increase in the Borderline Pumpability Temperature, rather than a reduction, because of an increase in the yield stress even though the viscosity itself is reduced. This effect is diagrammed in figure 22. 


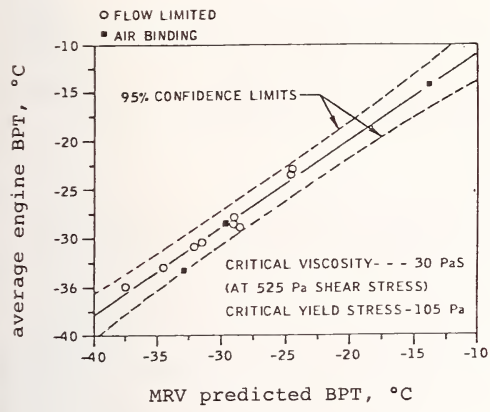

Figure 21. Correlation of MRV to average engine BPT.

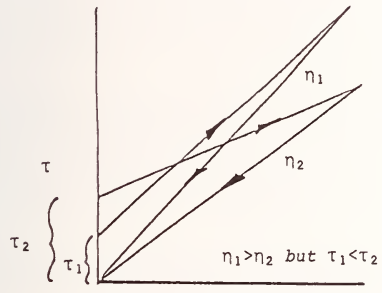

G

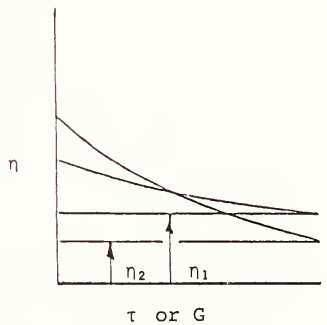

$\tau$ or $\mathrm{G}$

Figure 22. Effects of waxy fuel dilution on gelation of engine oil.

\subsubsection{Particulates}

Particulates in the engine oil come from several sources, some external to the engine and some produced by the oxidative and thermal decomposition of the oil in the operating engine. According to one of Einstein's lesser known equations and by the results of considerable viscometric studies, it can be stated that all particulates increase the engine oil viscosity in proportion to a function of their concentration. The increase is not inconsequential and may, in some cases, produce a many-fold increase in viscosity. Such increases in viscosity can deny the engine adequate lubrication.

Some of these particulates are prone to cause engine wear such as silicates and, perhaps, diesel soot, while others, such as the colloidal friction modifiers, prevent wear. It is an interesting question as to the consequences of a mixture of wear-reducing and wear-producing particulates in the engine oil. 


\subsubsection{Volatility}

One of the more obvious effects on the viscometric characteristics of engine oil is that of the volatilization of the basestock. Basestocks are usually chosen to be of sufficiently low viscosity to preserve the low temperature startability of the engine. However, such lower viscosity basestocks are by nature more volatile and in engine operations some of these volatile components are lost. This results in an increase in low temperature viscosity affecting both starting and pumpability of the engine oil.

\section{Conclusions}

Viscosity is an essential characteristic and property of the engine oil in its lubricating properties. As hopefully shown, the engine oil's viscosity has many facets and enters into many considerations connected with the protection of the engine from wear. Viscosity is also a source of energy expenditure by the engine. Taking all of this into account, it seems very important that we should maintain the effort to more closely relate the viscous properties of the engine oil to the performance of that oil in the operating engine. This is particularly true in the area of high shear viscometry which is directly related to the hydrodynamic performance of the engine's journal bearings. On the other hand it is also obvious that the proper utilization of friction modifiers may conceivably extend the range of protection where hydrodynamic lubrication is no longer sufficient. It seems obvious that we still have much to learn about the lubricating process even at such an apparently simple level as viscosity. 
National Bureau of Standards Special Publication 584. Proceedings of Joint Conference on Measurements and Standards for Recycled 0il/Systems Performance and Durability held at NBS, Gaithersburg, MD, October 23-26, 1979. (Issued Nov. 1980)

\title{
SYSTEM HEALTH MONITORING THROUGH WEAR PARTICLE ANALYSIS
}

\author{
P. B. Senholzi \\ Mechanical Technology Inc./Marine Systems \\ 1656 Homewood Landing Road \\ Annapolis, MD 21401
}

\section{Introduction}

Mechanical system reliability and life are a function of both structural integrity and wear integrity. Emphasis to date, has been placed on structural integrity with a "throw away" philosophy accommodating the consequences of wear integrity. Recent resource limitations however, have promoted substantial interest into the area of equipment wear integrity optimization. The optimization process is approached from the aspects of wear prevention and wear control. Wear prevention occurs primarily in the equipment design process while wear control is instituted in the operational arena.

Wear particle technology is a relatively recent development in the equipinent wear field. This technology utilizes the analysis of wear debris as a nondestructive reflection of the wear condition of the respective monitored process. It is currently establishing itself as a valuable tool in both the wear prevention and wear control arenas.

\section{Technology Description}

Wear particle analysis technology is based on the premise that debris generated during a wear process can serve to reflect surface conditions present in the respective process. As a result, the analysis of wear debris can be utilized as a nondestructive indicator of system/process surface wear condition. In the case of lubricated components, this debris is picked up and carried by the lubricant thus wear particle analysis is sometimes referred to as oil analysis.

Based on test performed under the Department of Defense $0 i 1$ Analys is Program, four critical wear debris characteristics have been identified as reflecting surface wear conditions. These characteristics are debris quantity, size distribution, composition, and morphology.

\subsection{Debris quantity}

Systems containing interacting components in relative motion will exhibit wear throughout their lives. The rate of system wear is affected by such aspects as operating parameters, operating environment, and the respective system surface wear conditions. By monitoring the changes in total wear debris in a system, one can assess the wear rate of a system. This total debris quantity monitoring can thus serve to reflect system operating parameters, operating environment, and surface wear conditions. In the case of oil lubricated systems, wear abnormalities will result in an increase in total oil borne wear debris. As an example, total debris quantity increased during testing of oil lubricated ball bearings containing fatigue spalls by a factor of 3-7 over that quantity exhibited during a normal wear condition.

\subsection{Debris size distribution}

As a system wears, a certain characteristic size distribution of wear debris is generated. The presence of system wear abnormalities will result in the generation of relatively large wear debris particles. These abnormalities will, in turn, cause a detectable shift in the size distribution of total wear debris. This shift in debris distribution can thus be utilized as an indicator of the severity of wear in a system. The greater the portion of large debris particles, the more severe the wear situation. 


\subsection{Debris composition}

A wearing system is usually composed of more than one wearing component. In the case of complicated systems, the wear components can number well over one hundred. These components are manufactured from a variety of materials, thus debris generated in a system is composed of numerous material types.

By determining the composition of the wear debris, the source of the debris can be clarified. For example, selective debris elemental analysis of large wear particles will provide information as to what component is exhibiting an abnormal wear condition.

\subsection{Debris morphology}

The last and possibly the most unique wear particle characteristic, is particle morphology or particle shape. It has been determined experimentally, that particle morphology can be related to the wearing component, the wear condition present, and the wear severity. A certain particular component operating in a certain wear mode will produce a unique signature with respect to the shape of the wear debris that is generated. For example, it has been determined that spherical particles present in oil lubricated systems, have been related to the presence of rolling contact fatigue within the respective monitored system. This wear debris parameter is the most difficult to monitor and relies heavily on interpretation due to its qualitative nature.

By monitoring the above four parameters, wear particle analysis technology can provide information as to system wear rate, wear severity, wear components, and active wear modes as shown in figure 1 . In the analysis process, it is impossible to assign quantitative assessment criteria for each parameter, for every system. As alluded to above, analysis determinations have to be based on a comparison criteria. Parameter readings must be compared with "normal" readings for a particular system. An effective implementation method is the trending of each parameter. Trending will reflect pertinent shifts in parameter readings thus, reflecting a system wear abnormality.

\begin{tabular}{lcccc}
\hline Wear parameters & Wear rate & Wear severity & Wear source & Wear type \\
\hline Quantity & $X$ & $X$ & & $x$ \\
Distribution & $X$ & $X$ & $X$ & $x$ \\
Composition & & & $X$ & $X$ \\
Morphology & & $X$ & & $x$ \\
\hline
\end{tabular}

Figure 1. Critical wear particle analysis parameters.

\section{Applications}

As mentioned in the introductory paragraphs of this discussion, a systematic attack on the problem of machinery wear involves both wear prevention and wear control. Wear prevention is implemented by optimizing the wear resistance of an equipment design. This design effort impacts such aspects as materials, lubricants, additives, tolerances, filtration, and surface finish. Wear control is concerned with the minimization of equipment wear rate (i.e., extension of wear $1 \mathrm{ife}$ ). This control approach is implemented during equipment manufacture, operation, and maintenance.

Wear particle analysis technology exhibits numerous effective applications within this systematic wear attack. The five major applications of wear particle analysis are as a research tool, a design tool, a quality assurance tool, a trouble shooting tool, and a nealth monitoring technique.

\subsection{Research tool}

A prime application of wear particle analysis is utilization as a research tool in basic wear mechanism studies. Once an understanding of fundamental wear mechanisms has been achieved, optimization of equipment wear prevention will be enhanced. 


\subsection{Design tool}

Wear particle analysis can be applied in several different facets of the equipment design process. It can be utilized to categorize different wear variables (i.e., materials, lubricants, etc.) with respect to their relative wear rates. This categorization can be used as a guide in the selection of equipment wear variables.

Wear particle analysis can also be applied in the assessment of the wear integrity of a new equipment design. Wear design problems can be identified during breadboard or prototype design testing. The application of wear particle analysis as a design tool serves to promote equipment wear prevention.

\subsection{Quality assurance tool}

A third application of wear particle analysis is utilization as a quality assurance tool. This application involves the wear integrity assessment of both production and overhauled/rebuilt equipment, through wear particle analysis. Such equipment problems as misassembly, and out-of-tolerance will be addressed under this application. Quality assurance efforts focus on equipment wear control.

\subsection{Trouble shooting tool}

Wear particle analysis can also be applied as a trouble shooting tool for field operating equipment. Recurring field wear related problems can be addressed utilizing particle analysis as a nondestructive reflection of pertinent components wear conditions. This application involves equipment wear control.

\subsection{Health monitoring technique}

The last, and one of the most important, applications of wear particle analysis is utilization as an equipment health monitoring technique. By the monitoring of wear debris characteristics as a reflection of surface wear condition, one can assess the "health" of a wearing system. Debris monitoring is a powerful maintenance technique aimed at equipment wear control. This technique is a step toward realization of the on-condition maintenance concept.

The five aforementioned applications can be utilized for oil, hydraulic fluid and grease lubricated systems. In some cases, these applications can also be utilized for dry wear. Although these areas represent fertile areas of wear particle analysis utilization, applications are not restricted solely to those mentioned.

This following discussion will center on the application of wear particle analysis as a wear control approach or as an equipment health monitoring technique.

\section{Health Monitoring Decision Process}

In order to effectively implement any health monitoring technique, a viable decision process must be developed. The following discussion will summarize a projected wear particle analysis decision process.

\subsection{Elements}

The projected decision process required for wear particle analys is implementation, consists of four elements; detection, diagnosis, prognosis, and prescription.

\subsubsection{Detection}

The detection elements provides a first cut or preliminary determination as to the health of a machine (i.e., is the machine wearing normally or abnormally?) If no abnormalities are detected, no further analys is is required until the next detection sampling interval. If an abnormality is suspect, the next step of the decision process is pursued. 


\subsubsection{Diagnosis}

The second element or diagnosis element of the decision process, serves to further clarify the machinery wear abnormality. It provides a determination as to what machine component/components are wearing and proceeds to define what wear mode/modes are present. Based on these determinations the analysis process is transitioned to the next decision element.

\subsubsection{Prognosis}

The prognosis element of the decision process serves to define the course of the machinery wear abnormality. It provides a prediction of residual life (time until failure) based on wear severity, wear component and respective wear mode.

\subsubsection{Prescription}

The last element of the analysis process serves to define a course of corrective action. It provides maintenance recommendations based on residual life, wearing component, and respective wear modes.

\subsection{Parameters}

Technical feasibility of this decision process relies on the ability of wear particle parameters to reflect wear abnormalities and abnormality ramifications. Based on wear particle analysis research, the following marriage of decision elements and wear particle parameters has been developed.

\subsubsection{Detection}

As indicated above, the purpose of the detection element is to provide an initial determination as to the health of a machine. Based on technology research, abnormal wear can be effectively detected by monitoring both wear particle quantity and size distribution.

\subsubsection{Diagnosis}

Once an abnormality has been detected, it is the purpose of the diagnosis element to provide information as to the source and type of the respective wear abnormality. Again, based on pertinent technology research, abnormal wear condition clarification can be accomplished by performing an elemental analysis and a morphology classification of the respective wear debris.

\subsubsection{Prognosis}

Prognosis determinations are based on the analysis and interpretation of the monitored parameters already cited. Analysis criteria developed through knowledge, experience and parameter trending of individual equipment types, serve to drive these determinations.

\subsubsection{Prescription}

As in the prognosis decision element, prescription determinations are based on the analysis and interpretation of previously mentioned parameters. Analysis criteria developed through individual equipment experience and parameter trending, also drives the prescription determinations.

\subsection{Maintenance level}

Implementation of the health monitoring decision process, requires the assignment of monitoring responsibility to pertinent maintenance levels. The detection decision element should be implemented at the first line or organizational level of maintenance. Abnormal wear detection capability will be applied either in-line with respect to the equipment lubrication system, or off-line in the general vicinity of the equipment. Determination 
as to in-line or off-line application will be based on equipment cost and criticality considerations. Front line assignment of the detection element serves to provide diagnostic capability to the first line maintenance community, provides real time wear condition monitoring, minimizes existing sampling problems, eliminates a substantial portion of the existing oil sampling workload (i.e., samples are only submitted when an abnormality is detected) and will thus result in a decrease in the number of required centralized oil analysis laboratory facility.

The diagnosis, prognosis and prescription decision elements should be implemented at a centralized facility, located either at the intermediate or depot maintenance levels. These element implementations require relatively advanced analys is equipment, advanced operator training and a developed equipment wear expertise. Assignment of these decision elements to a centralized location will serve to promote these requirements as well as optimize facility utilization, and amortize facility costs over numerous supported operating facilities. The total particle health monitoring decision process as described, is summarized in figure 2.

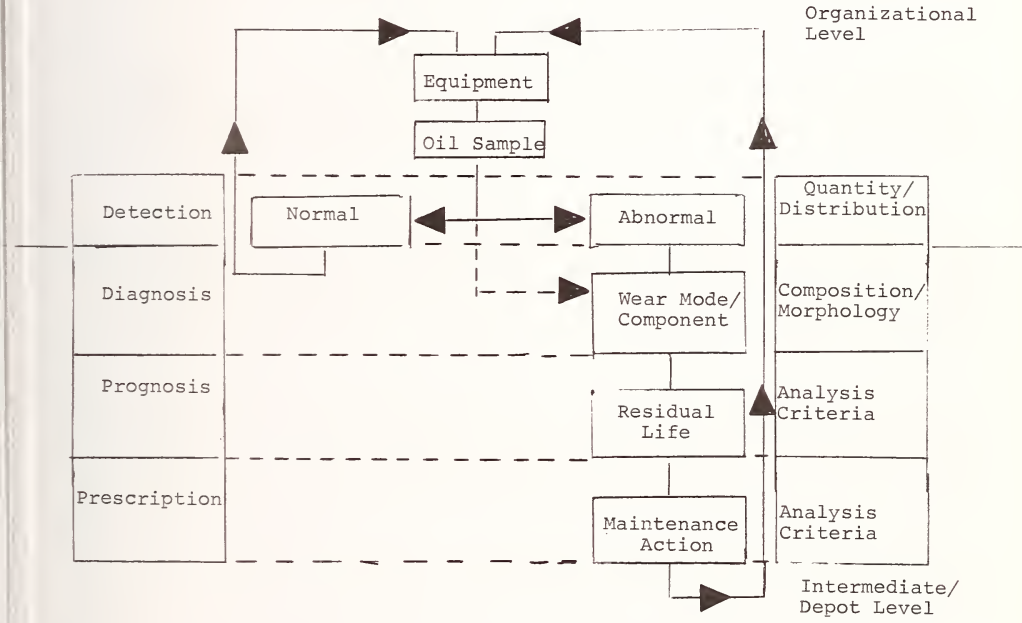

Figure 2. Wear particle analysis health monitoring decision process.

\section{Proposed Health Monitoring Equipment}

Full implementation of the health monitoring decision process requires identification of specific wear particle analysis equipment capable of effectively monitoring the pertinent parameters at the specified maintenance levels. Since the decision elements of prognosis and prescription involve no required monitoring equipment, this discussion will focus on the elements of detection and diagnosis. A proposed equipment approach for these elements, is suggested in the following paragraphs. 


\subsection{Detection}

Detection element analysis equipment has to be capable of monitoring wear debris quantity and size distribution at the first-line maintenance level. In the case of high cost and/or critical equipment, this monitoring capability would preferably be performed in-line in the respective equipment lubricant system. A particle counter would serve to meet these requirements. This application is not as simple as it appears, however. No present particle counter has thoroughly demonstrated required operational and sensitivity capability.

\subsection{Diagnosis}

Diagnosis element analysis equipment has to be capable of monitoring all wear debris critical parameters; quantity, size distribution, composition, and morphology. This monitoring effort will be implemented at the intermediate or depot maintenance level. No one analysis technique will provide this total required capability, thus a combination of techniques need to be identified. Three types of analysis equipment, utilized collectively, will provide necessary capability. These equipments are a particle counter, a spectrometer and a ferrograph.

\subsubsection{Particle counter}

The particle counter would provide information as to wear debris quantity and size distribution and would be the laboratory equivalent of the detection unit described under the above subparagraph. Laboratory counters are presently available which surpass necessary sensitivity and operational requirements dictated by this application.

\subsubsection{Spectrometer}

Spectrometric analysis provides data as to the concentration levels of present wear debris elements. This information would obviously apply to the wear debris analysis parameters of quantity and composition. Laboratory spectrometers are presently available which satisfy capability requirements of this application with one exception. Present instruments exhibit an insensitivity to the analysis of large debris particles. This insensitivity, although undesirable, does not present a major shortcoming when the spectrometer is utilized in conjunction with the other two proposed analysis equipments.

\subsubsection{Ferrograph}

The ferrograph is a relatively new wear debris analysis technique. It provides a combination of qualitative and quantitative assessments of wear debris quantity, size distribution, composition and morphology. This technique, however, is primarily attuned to the analysis of ferrous wear debris. The exhibited attunement is a result of the magnetic separation principles that are employed by ferrography. This technique is presently available for laboratory application.

Data generated from the above three equipments is analyzed collectively. Each input serves to reinforce and/or complement the other inputs. Diagnostic decisions will be based on this collective data analysis. A summary of the proposed equipments vs parameter capability is provided in figure 3 .

The equipment proposed in this discussion serves to represent one approach to wear particle analysis. It is not meant to infer that these equipments cannot be substituted for or supplemented by other types of pertinent analysis equipment.

\begin{tabular}{lcccc}
\hline Particle parameters & Quantity & Distribution & Composition & Morphology \\
\hline Particle counter & $X$ & $X$ & & \\
Spectrometer & $X$ & & $x$ & $X$ \\
Ferrograph & $X$ & $X$ & $x$ & \\
\hline
\end{tabular}

Figure 3. Wear particle analysis equipment capability. 


\section{Wear Debris Sampling}

A critical aspect in the wear particle analysis approach is the wear debris sample. Care must be taken to ensure that the analyzed wear debris sample is representative of the total wear debris being generated in the monitored system.

In the case of oil lubrication components, the generated wear debris is picked up by the 0 il and circulated throughout the lubricant system. Sampling of oil borne wear debris can be accomplished by either an in-line or off-line technique.

In-line sampling involves the monitoring of debris parameters directly in the lubrication system. This approach provides a real time indication of the monitored parameters. In order to implement this approach, the monitoring equipment must be tied directly into the monitored equipment. lubricant system. In-line monitoring of wear debris quantity and size distribution parameters, is proposed for the detection health monitoring element of high cost and/or critical application machinery.

In-line sampling, although simple in theory, presents several practical implementation problems. A major portion of these problems result from the operating parameters dictated by the direct lubrication system tie in. Such parameters as flow, pressure, and temperature, as seen in a lubrication system, are not conducive to effective debris monitoring.

Off-line sampling involves the withdrawal of a lubricant sample containing wear debris, from a lubrication system. Samples can then be transported to a laboratory for analysis. This approach provides more analysis versatility than the in-line sampling approach. Off-line sampling is proposed for the diagnosis health monitoring element. This element requires parameter analysis that presently can only be practically applied in a laboratory environment.

Although more versatile than the in-line approach, off-line sampling is very dependent on sampling technique. Such factors as sampling interval, time after shutdown, and sampling location can drastically effect sample wear debris quantity and distribution.

The above two sampling approaches rely heavily on the fact that significant wear debris is picked by the lubricant and circulated throughout the lubrication system. A prime factor affecting this debris circulation is the lubricant filter. This filter is designed to remove debris from the lubricant. Traditionally, lubricant filtration has been relatively coarse thus ineffective in removing significant wear debris from the lubricant. Recently, however, equipment lubricant filtration has been improving. This improvement is being driven by the realization of the deleterious accelerating effects of lubricant borne debris, on the system wear rate. Improved filtration will eventually lead to the condition where significant wear debris will no longer be circulating in the system, it will be for the most part, entrapped in the filter. This condition will tend to nullify the effectiveness of both present in-line and off-line sampling approaches. Drastic modifications of present sampling techniques will have to be developed in order to obtain a representative wear debris sample from a highly filtered system.

\section{Health Monitoring Equipment}

A second critical aspect in the wear particle analysis approach, is the analysis equipment. The equipment proposed under previous sections include an in-line particle counter, a laboratory particle counter, a spectrometer, and a ferrograph.

In order to fully implement this proposed equipment approach, several problems have to be overcome. These problems fall into two categories; equipment development and procedural development.

Equipment development problems involve the in-line particle counter and the spectrometer. Lack of a demonstrated in-line particle counter with required application durability and sensitivity, creates a major void in the proposed analysis approach. Spectrometer insensitivity to large wear debris particles, although a short-coming, presents itself as less of a severe problem. Both of these problem areas are receiving research emphasis and should be resolved in the near future. 
Equipment procedural problems involve analysis equipment repeatability. Necessary standardization and calibration procedures have not been developed for the total equipment package. This situation hinders quantitative wear debris analysis as well as interlaboratory joint monitoring efforts. Although some standardization efforts are presently being implemented, the equipment calibration area requires further investigation.

\section{Wear Particle Analysis Interpretation}

The third and final critical wear particle analysis aspect is analysis interpretation. Assuming a valid sample has been obtained and a pertinent equipment analysis has been performed, one must then proceed to relate generated data to the respective equipment wear condition. This process involves considerable interpretation and is complicated by equipment characteristics, operating parameters, and operating environment.

Equipment characteristics will have a decided effect on the four critical monitored parameters. Such characteristics as number of wearing components, equipment materials, lubricant, lubricant capacity, and filtration level will all tend to complicate wear debris analysis results.

Equipment operating parameters will also effect wear debris parameters thus, wear debris analysis. Parameters such as load, speed, and operating cycle have to be considered in the wear particle interpretation process.

The third factor, operating environment, can affect the wear rate of the respective equipment as well as directly contribute to the oil borne debris circulated by the equipment. These effects will further tend to distort/complicate wear debris analysis results. In order to counter these interpretation challenges, one must rely on a combination of trending techniques, equipment knowledge, and monitoring experience. Trending of monitored parameters will serve to highlight pertinent parameter changes with respect to a particular equipment. Parameter trending as opposed to parameter standard comparisons, will tend to minimize the distorting effects of equipment operating parameters and operating environment.

An in-depth technical knowledge of the monitored equipment is very advantageous with respect to wear particle analysis. This knowledge is especially useful in minimizing the complicating effects of equipment characteristics.

Finally, monitoring experience serves to fine-tune wear particle analysis interpretation. The experience factor tends to minimize all three of the interpretation distortion elements. This factor is the most critical in any wear particle analysis application.

In order to implement the above discussion and thus complete the wear particle analysis application process, the following approach is proposed. To effectively develop interpretation capability, an in-depth knowledge of the monitored equipment must first be acquired. Once acquired, control groups of respective equipment must be established and monitored on a trial basis. This trial program will serve to establish wear trends and analysis criteria. Once developed, these trends and criteria can be applied to the total inventory of equipment of the respective type.

\section{Wear Particle Analysis Health Monitoring Payoff}

The application of wear particle analysis as a health monitoring technique, exhibits numerous potential advantages over present oil analysis techniques (i.e., spectrometric oil analysis). These advantages are composed of both general and specific elements directed at the operation and maintenance of mechanical equipment. General advantages include increased availability, decreased maintenance cost, increased life, and increased safety.

Specific advantages are an increased monitoring effectiveness with a decreased sample workload. It is projected that monitoring effectiveness can be raised from the present level of 60 percent to an oil wetted component wear abnormality detection efficiency of $90+$ percent. By utilization of the detection approach, laboratory sample analysis workload will be cut down by approximately 75 percent. This decreased sample workload, although somewhat offset by increased individual sample analysis requirements, will tend to decease the number of required laboratories. 
A less obvious payoff of wear particle analysis is the potential expanded application of the technology. Hydraulic and grease lubricated component diagnostics, design assistance, quality assurance, and trouble shooting are a few of the potential expanded areas. These general and specific wear particle analysis payoffs will result in substantial time, cost, manpower, energy, and material savings for both the governmental and industrial communities.

\section{Summary}

Recent resource limitations have prompted considerable interest into the area of mechanical equipment wear integrity optimization. A prime consideration under this optimization effort, is the application of wear particle analysis technology to equipment health monitoring. This technology relates the wear debris parameters of quantity, size distribution, composition, and morphology to system wear rate, wear severity, wear source, and wear type. Monitoring of these critical wear debris parameters, through a specific decision process, uilizing pertinent analysis equipment, will serve as a viable health monitoring approach.

This wear particle analysis health monitoring approach requires special attention to the critical application areas of sampling, analysis equipment operation, and analysis interpretation. These areas can easily distort the effectiveness of wear particle analysis.

The potential payoff of wear particle analysis health monitoring is substantial. It impacts the areas of manpower, materials, energy, time, and cost savings. These potential savings are applicable to both the governmental and industrial communities.

\section{References}

[1] Dalal, H., et al., Progression of Surface Damage and Oil Wear Debris Accumulation in Rolling Contact Fatigue, U.S. Naval Air Engineering Center, final report on contract number N00156-74-C-1634, SKF Report A175T007 (1975).

[2] Leonard, L., et a1., Analysis of Sliding Wear in a Test Diesel Engine, U.S. Naval Air Engineering Center, final report on contract number N00156-73-C-0764.

[3] Wescott, V.C., et al., 0 il Analysis Program, U.S. Naval Air Engineering Center, final report on contract number N00156-74-C-1682, Foxboro-Trans Sonics Report (1975).

[4] Bowne, C. R. and Siefert, W. , Ferrography - a new tool for analyzing wear conditions, Fluid Power Testing Symposium (1976).

[5] Scott, D. and Seifert, W.W., Ferrography - a new tool for analyzing wear conditions, Fluid Power Testing Symposium (1976).

[6] Dalal, H. and Senholzi, P.B., Characteristics of wear particles generated during failure progression of roller bearings, ASLE paper presented at ASLE Annual Meeting (1976).

[7] Senholzi, P. B., Tri service R\&D oil analysis program - background, description, and results, Fluid Power Research Conference (Oct. 1975).

[8] Senholzi, P.B., Tri service oil analysis R\&D program, Mechanical Failures Prevention Group (1975).

[9] Senholzi, P.B., Technical approach to the exploratory development oil analysis program, U.S. Naval Air Engineering Center.

[10] Senholzi, P.B. and Bowen, C.R., $0 i 1$ analys is research, National Conference on Fluid Power (0ct. 1976).

[11] Senholzi, P.B., Oil analysis/wear particle analysis, Mechanical Failures Prevention Group (1977). 
[12] Senholzi, P.B., 0il analysis/wear particle analysis II, Institute of Mechanical Engineers, (1978).

[13] Maciejewski, A., 0il analysis aspects of tribology, Fluid Power Research Conference, (1979). 
National Bureau of Standards Special Publication 584. Proceedings of Joint Conference on Measurements and Standards for Recycled 0il/Systems Performance and Durability held at NBS, Gaithersburg, MD, October 23-26, 1979. (Issued Nov. 1980)

\title{
MECHANICAL FAILURES AND LUBRICATION PERFORMANCE
}

\author{
Marshall B. Peterson \\ Wear Sciences, Inc. \\ 925 Mallard Circle \\ Arnold, MD 21012
}

\section{Introduction}

In order to assure a consistent system performance it is necessary to understand the causes and the processes by which mechanical failures occur. If one tries to understand mechanical failures he reaches a certain dilemma illustrated by the list of bearing failures shown in table 1 . The difficulty with the list is that it is a mixed bag of mistakes (design, manufacturing and service related), processes (fatigue, wear, corrosion), causes (low on oil, improper crush), and results (scoring). This same situation applies to almost all components. An early task of MFPG was an attempt to collect and organize the technical literature in the area of mechanical failures $[1]^{1}$. Forty thousand abstracts were reviewed. Chapters were prepared which covered failures of various components. If one summarizes the failures listed for each component, a list of "component malfunctions" can be identified as shown in table 2. These "component malfunctions" are the reasons why a component is removed, replaced, or repaired; they are the end results of various failure processes. These failure processes are considered in the following sections.

Table 1. Causes of bearing failure.

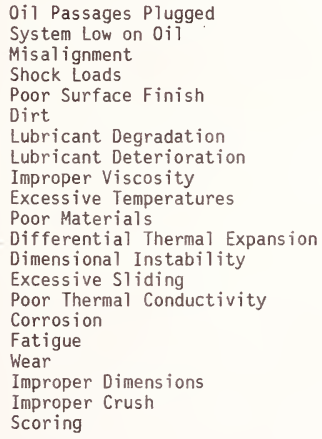

${ }^{1}$ Figures in brackets indicate the literature references at the end of this paper. 
Table 2. Component malfunctions

\begin{tabular}{|c|c|c|c|c|c|}
\hline $\begin{array}{l}\text { Component } \\
\text { Malfunction }\end{array}$ & Seal & Brake & $\begin{array}{l}\text { Rolling } \\
\text { Contract } \\
\text { Bearing }\end{array}$ & Gear & $\begin{array}{l}\text { Sliding } \\
\text { Bearing }\end{array}$ \\
\hline Inadequate Friction & High Friction & Fade & & & High Torque \\
\hline Noisy & & Squeal & & & \\
\hline Vibration/Unstable & Instability & & & & Whirl \\
\hline Distortion/Deform & Deformation & & Plastic Flow & Plastic Flow & \\
\hline Fracture & & & Fracture & Fracture & \\
\hline Surface Damage & & & $\begin{array}{l}\text { Loss of Lube- } \\
\text { Smearing }\end{array}$ & Scoring & $\begin{array}{l}\text { Loss of Lube- } \\
\text { Seizure }\end{array}$ \\
\hline Worn & Wear & High Wear & $\begin{array}{l}\text { Cage Wear- } \\
\text { Bearing Wear }\end{array}$ & Wear & $\begin{array}{l}\text { Dirt- } \\
\text { Loss of Lube }\end{array}$ \\
\hline Fatigued & & Heat Check & Fatigue & $\begin{array}{l}\text { Pitting- } \\
\text { Spalling }\end{array}$ & Fatigue \\
\hline Corroded & & & Corrosion & & Corrosion \\
\hline
\end{tabular}

2. Failure Processes - Lubrication

The failure process is illustrated in figure 1 using tribology (lubrication) as an example. In any component where there is rolling or sliding, a variety of dissipative processes are going on. These processes can lead to a variety of malfunctions depending upon the specific component and application in question. These malfunctions will be classified as failures if they interfere with the system requirements. Either they prevent the component from fulfilling its function or the performance has deteriorated to some preestablished limits. The dissipative processes are universal in that they apply to all components; malfunctions are specific in that they depend upon the circumstances to which they are applied. What may be a failure in one bearing in one application may not be considered a failure in the same bearing in another application.

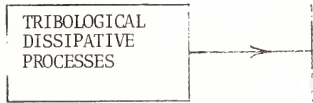

IEATING \& HEAT CYCLING PLASTIC DEFORMATION CRACK FORMATION \& PROPAGATION CUTTING \& TEARING ADHESION \& TRANSFER MATERIAL DIFFUSION OR REACTION MATERIAL REACTION WITH ENVIORNMNT

THERMAL EXPANSION/

CONTRACTION

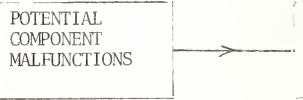
SYSTEM OR
COMPONENT
REQUIREMENT

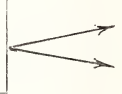
ADEQUATE BEHAVIOR

INADEQUAT BEHAVIOR

Figure 1. Failure processes.

INADEQUATE FRICTION NOISY

VIBRATION/UNSTABLE DISTORTED/DEFORMED

FRACTURE

SURFACE DAMAGE

WORN

FATIGUE

CORRODED
OPERATION MALFUNCTION LIMITS
FUNCTIONAL REQUIREMENTS

TRANSMIT MOTION DISSIPATE ENERGY LOCATE

SEAL MOTION INTERFACE 
In the component the operating conditions will determine which dissipative process predominates and what the role of the lubricant will be. The better these processes are understood the more they can be taken into account in the component design. This is described in more detail in the following section.

\section{Causes of Failure}

The various stages in the life of a component are described in figure 2 . In the conceptual stage the designer knows the system requirements, and the desired life he is trying to achieve. Based upon his knowledge of the dissipative processes the various components are designed or selected. Basically, this design sets the operating conditions. Each component is manufactured, assembled, started up, and "run in". These processes lead to an operating tribological contact which, because of imperfections in the manufacture and assembly and because of changes during "run in", lead to a new set of operating conditions.

In the operating contact the dissipative processes are initiated and will continue until a malfunction occurs. All of the dissipative processes act simultaneously and it is a race to see which can destroy the contact first. "Which one wins" is a function of operating variables and the limits set on the malfunctions. However, some major changes occur with time. These changes also influence the dissipative process. As far as lubrication is concerned, the system changes of significance are the area, misalignment, and the occurrence of overloads and excessive temperatures, not anticipated in the design. Even more important are changes in the lubricant. These changes are usually the cause of failure, not the design.

\section{Malfunction Limits}

In the design or operation of a component, certain limits are set on the malfunctions. We will tolerate a certain amount of friction or a certain amount of noise before the component is replaced or repaired. If the malfunctions are not expected they are called "failures". If they are expected we say the component is "worn out".

The condition of the lubricant can lead to all of the malfunctions listed in figure 2. In fact, exactly the same lubricant could lead to all of those malfunctions in the same component. Different applications are more sensitive to certain malfunctions. However, the most frequent malfunction associated with the lubricant is wear and fatigue. Fatigue has been addressed in a previous paper by Rowe.

The affect of the lubricant and changes in the lubricant can be seen in figure 3 . Here the life of a typical bushing is plotted against the wear coefficient where

$$
W=\frac{K L V t}{H} \quad \begin{array}{ll}
W & =\text { Wear volume }=.001 \mathrm{in} . \\
H & =\text { Hardness } \\
L & =\text { Load } \\
V & =\text { Velocity } \\
t & =\text { time }
\end{array}
$$

K's are collected from the literature for the stated conditions. A typical bushing designed for fluid film lubrication will give an exceedingly long 1 ife ( $10000 \mathrm{yr}$ ) under the operating conditions selected. If there is a transition to boundary lubrication that life will be cut to one year. The addition of improved additives would increase the life to maybe five years. If the lubricant becomes contaminated with water or becomes acidic, corrosive wear will result and 1 ife will be cut to one day. If the lubricant cannot reach the contact surface, usually the results of deposits or lack of lubrication, the life would be approximately two hours. If the lubricant becomes severely contaminated with dirt, the life will be a matter of minutes. Our favorite approach to wear problems, changing hardness, has a minor effect on life.

Lubrication performance is determined primarily by the condition of the system and the lubricant. Design efforts should be directed toward those factors affecting the condition of the lubricant. 


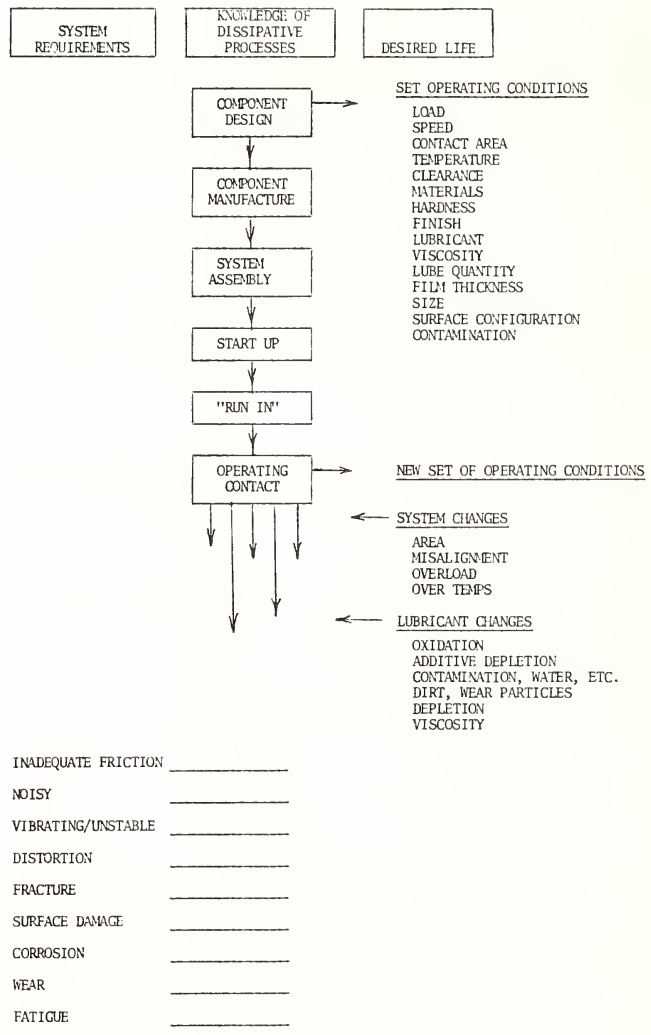

Figure 2. Causes of failure. 


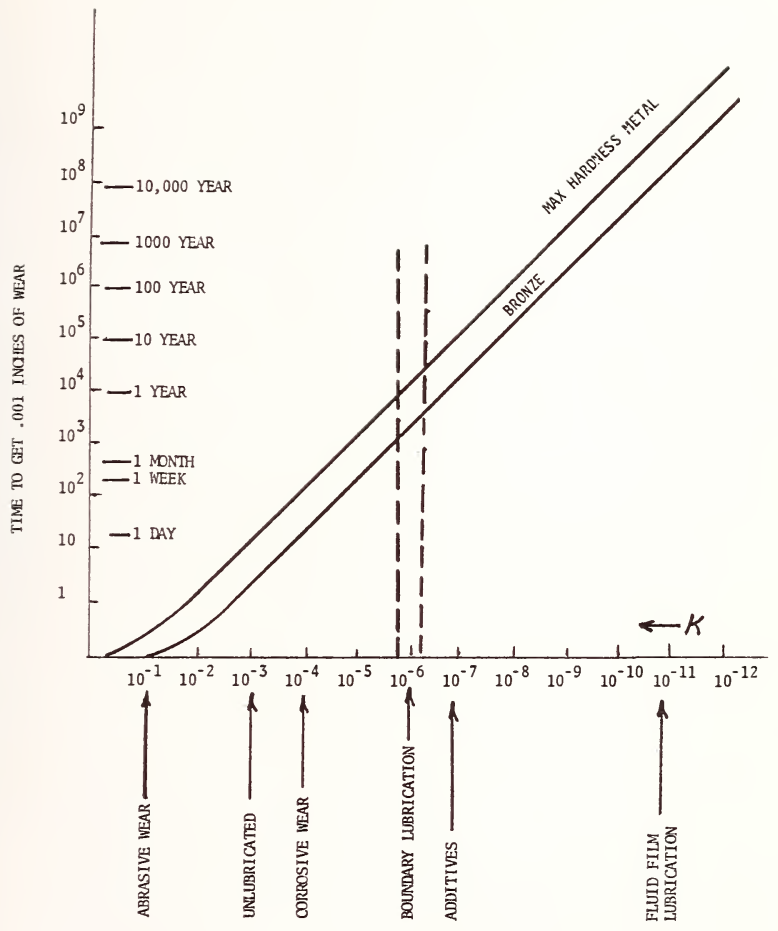

Figure 3. Effect of lubricant condition on life. 


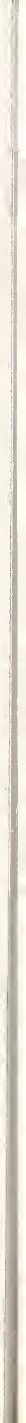


LIST OF ATTENDEES 


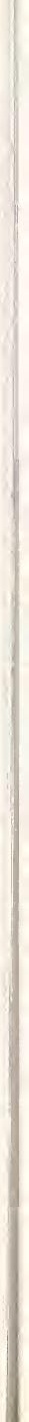


JOINT CONFERENCE ON MEASUREMENTS AND STANDARDS FOR RECYCLED OIL/SYSTEMS PERFORMANCE AND DURABILITY

\author{
National Bureau of Standards \\ Washington, DC 20234 \\ October 23-26, 1979 \\ Final Registration List
}

C. E. Aldhizer

Federal Trade Commission

6 th \& $\mathrm{Pa}$. Avenue $\mathrm{NW}$

Washington, DC 20580

M. Alphandary

Exxon Co.

USA (Research Centre)

Linden Ave.

Linden, NJ 07036

Dean Arlidge

Pfaudler

Division of Sybron

Rochester, NY 14603

James A. Armstrong

Environment Canada

351 St. Joseph Blvd.

Hul1, Quebec KIA IC8

CANADA

Carol M. Ashley

Consumer Standards Div.

North Carolina Dept. of Ag.

P. 0. Box 26056

Raleigh, NC 27611

Dan Barber

Baumgardner $0 i 1 \mathrm{Co}$., Inc.

R. R. \#I Box 611

Fayetteville, PA 17222

David B. Barton

Mobil Research \& Development Corp.

Paulsboro, NJ 08066

Donald A. Becker

National Bureau of Standards

Office of Recycled Materials

Washington, DC 20234

Siegfried Bellinger

Dentsche BP - Hamburg

Hamburg, GERMANY

Joseph G. Berke

National Bureau of Standards

Office of Recycled Materials

Washington, DC 20234
M. K. Bhargava

Chemoleums Private Limited

Thiruneermalai Road

Chromepet Madras 44

MADRAS

S. Bhattacharyya

IIT Res. Inst.

10 W. 35

Chicago, IL 60616

Mary Jo Bieberich

Code 2832

David Taylor Naval Ship

$R$ \& D Center

Annapolis, MD 21402

Stephen Bonifazi

Pratt \& Whitney Aircraft

Box 2691

West Palm Beach, FL 33402

George T. Booth III

Booth 0 il Co., Inc.

76 Robinson Street

N. Tonawanda, NY 14120

John N. Bowden

Southwest Research Institute

P. 0. Drawer 28510

San Antonio, TX 78284

Thomas Bowen

U.S. Army

Mobility Equip. Res. \&

Devlp.

Ft. Belvoir, VA 22060

Lyle Bowman

Chevron USA

555 Market Street

San Francisco, CA 94105

P. Brassart

President Syndicat Fraucais

des $R e$-roffuiranic

44 rue Ca Boetie

Paris

FRANCE 
James Breece

Safety Kleen Corp.

655 Big Timber Rd

Elgin, IL 60120

Richard F. Bridges

0 il Savings, Inc.

Suite 403

2480 Windy Hill Rd.

Marietta, GA 30067

Fred E. Brinckman

National Bureau of Standards

Washington, DC 20234

Dennis W. Brinkman

DOE/Bartlesville Energy Tech. Ctr.

Box 1398

Bartlesville, OK 74003

Lee Brodsky

Exxon Chemical Company

P. 0. Box 536

Linden, NJ 07036

Henrietta Brown

National Bureau of Standards

Washington, DC 20234

Alex D. Bull

Imperial 0i1 Limited

111 St. Clair Ave. W.

Toronto, Ontario

CANADA

Harry C. Burnett

National Bureau of Standards

Materials Bldg. Room B-264

Washington, DC 20234

M. Tylor Burton

Key Petroleum, Inc.

Skywater Road

Gibson Island, MD 21056

Douglas M. Cameron

Turbo Refineries Ltd.

Box 5827 Station L

Edmonton, Alberta,

CANADA

Norma Cameron

State Dept. of Administration

50 Sherburne Avenue

St. Paul, MN 55155

Andrew Carson

Westville 0 il \& Mfg. Co.

Box 587

Westville, IN 46391
Ken Cashmore

Gulf Canada Ltd.

2489 North Sheridan Way

Sheridan Park, Ontario L5K 1 A8 CANADA

Tai S. Chao

Atlantic Richfield Co.

400 E. Sibley Blvd.

Harvey, IL 60426

Stephen Chesler

National Bureau of Standards

Washington, DC 20234

Rustam Chinoy

Mechanical Technology, Inc.

968 Albany/Shaker Road

Latham, NY 12110

Barbara Clark

Catepillar Tractor

100 Northeast Adams St.

Peoria, IL 61629

Jack Comeford

National Bureau of Standards

Recycled 0il Program

Washington, DC 20234

Phillip Cowan

Husky 0 il Co.

P. 0. Box 380

Cody, WY 82414

Thomas D. Coyle

National Bureau of Standards

Washington, DC 20234

Stanley R. Craft

Chromaspec Labs, Inc.

P. 0. Box 71

716 D Montana

South Houston, TX 77587

James A. Creedon

The Lubrizol Corporation

29400 Lakeland Blvd.

Wickliffe, $\mathrm{OH} 44092$

R. G. Crumley

National Bureau of Standards

Washington, DC 20234

Art Cummings

National Bureau of Standards

Recycled $0 i 1$ Program

Washington, DC 20234 
George I. Davis

David Refining Corporation

P. 0. Box 6089

Tallahassee, FL 32301

James Ed Davis

Arkansas Dept. of Energy

300 Kavanaugh

Little Rock, AR 72205

Jack M. Deaton

Cummins Engine Co.

1900 Mckinley Ave.

Columbus, IN 47201

Peter R. DeBruyn

National Bureau of Standards

Industrial Liaison

Washington, DC 20234

Charlie Donaldson

Federal Trade Commission

6th \& Pennsylvania Ave., NW

Washington, DC 20580

R. W. Drexler

Lubricants, Inc.

P. 0 . Box 46

Pewaukee, WI 53072

Dic Driver

Foxboro/Analytical Inc.

P. 0. Box 435

Burlington, MA 01803

Don Eastep

Illinois Institute of Natural

Resources

Springfield, IL 62706

Rolf Eder

AMMRA Arbeitsgemeinschaft

Mittelstandischer Mineralol-

Raffinerien e.V.

200 Hamburg 1 Gurlittstraße 31

Donald J. Edwards

Mobil 0 il Corp.

150 E. 42nd St.

New York, NY 10017

Donald G. Espey

Exxon USA

P. 0. Box 2180

Houston, TX 77001

L. Estaque

Ecole Polytechnique Montreal

P 6079 "A"

Montreal, CANADA
Daniel Fairchild

Fram Corp.

55 Pawtucket Avenue

E. Providence, RI 02916

Jim Fay

ALM, Inc.

1745 Jefferson Davis Hwy

Arlington, VA 22202

Edward Forgeron

Analysts Inc.

655 Deep Valley

Rolling Mills Estate, CA 90274

Kenneth A. Frassa

Mobil 0il Corporation

150 E. 42nd Street

New York, NY 10017

Werner Fries

Fed. Office for Military

Technol. \& Procurem.

K. Adenauer UFER 2-6

D54 Koblenz

GERMANY

D. R. Gardner

Shell Canada Lab

505 University Ave.

Toronto M5G IX4

CANADA

Richard Gates

National Bureau of Standards

Office of Recycled Materials

Washington, DC 20234

A. Gianni

Stauffer Chemical Co.

Nyala Farm Road

Westport, CT 06880

C. F. Goeking, Jr.

She11 Development Company

P. 0. Box 1380

Houston, TX 77001

H. S. Golinkin

Amoco Chemicals Corporation

P. 0. Box 400

Naperville, IL 60540

Elizabeth Gorecki

Edwards 0 il Service, Inc.

530 Rouge

Detroit, MI 48217

Richard Gorecki

Edwards 0 il Service, Inc.

530 Rouge

Detroit, MI 48217 
C. C. Gravatt

National Bureau of Standards

National Measurement Lab.

Washington, DC 20234

L. H. Handler

Suntech, Inc.

P. 0. Box 1135

Marcus Hook, PA 19061

Wildrick Hart

Witco Chemical Corp.

77 N. Kendall Ave.

Bradford, PA 16701

Rudolf Havemann

Haberland \& Co.

Mineralol-Raffinerie

Bahnofstr. 82

Dol1bergen, 3161

WEST GERMANY

J. H. 0. Hazewinkel

Kinetics Tech. International

26 Vredewater

2700 A. B. Zoetermeer

THE NETHERLANDS

Leslie R. Heerdt

Faville-LeValley Corp.

2753 Curtiss Street

Downers Grove, IL 60515

Henry R. Hegner

ManTech of New Jersey Corp.

2341 Jefferson Davis Highway

Arlington, VA 22202

Walter W. Hellmuth

Texaco Inc.

P. 0. Box 509

Beacon, NY 12508

Jacque D. Heyen

Petroleum Recycling Corp.

P. 0. Box 10713

Knoxville, TN 37919

Robert R. Holden

Hughes Aircraft Co.

Bldg. 117 Mail Sta. 1

P. 0. Box 90515

Los Angeles, CA 90009

Paul Howard

E\&MR Co.

964 Sweresford Road

Exton, PA 19341
Stephen Hsu

National Bureau of Standards Office of Recycled Materials Washington, DC 20234

Conrod B. Johnson

Turbo Refineries

94 Ave. \& 34 St.

Edmonton, Alberta, CANADA

Donald R. Johnson

National Bureau of Standards

National Measurement Laboratory

Washington, DC 20234

Walter B. Johnson

Technical Center

Deere \& Co.

3300 River Drive

Moline, IL 61265

G. Kelkar

Caltex Petroleum Corp.

380 Madison Ave.

New York, NY 10017

Warren C. Kelliher

Viking Project Office

NASA

Hampton, VA 23665

Vicki L. Ketvirtis

Div. of $0 i 1$, Gas, \& Minining State of Utah

1588 W. No. Temple

Salt Lake City, UT 84116

Robert L. Kincaid

Spectron Caribe, Inc.

Cond. Las Lomas \#1

Caparra Heights, PR

E. E. Klaus

Pennsylvania State University

133 Chemical Eng. B1dg.

University Park, PA 16802

Michael Klinkhammer

D. T. Naval Ship R\&D Ctr.

Code 2832

Annapolis, MD 21402

R. L. Klug

Caterpillar Tractor Co.

Serv. Development

Pioneer Park

East Peoria, IL 61630 
Hans O.A. Koehn

Mineralo1-Raffinerie Weiss Co.

Schmidts Breite 3

Hamburg 93, 2102

WEST GERMANY

M. Kolobielski

US Army Meradcom

6710 Sherwood Rd.

Baltimore, MD 21239

Stefan Korcek

Ford Motor Company

P. 0. Box 2053

Dearborn, MI 48121

Richard L. Kornmann

Amoco Chemicals Corp.

200 E. Randolph Drive

Chicago, IL 60601

Tom Kosh

Edwards 0il Service, Inc.

530 Rouge

Detroit, MI 48217

A. J. Koury

Naval Air Systems Command

AIR-4114C

Washington, DC 20360

Sharon H. Kneiss

Gulf Research \& Dev. Co.

P. 0. Drawer 2038

Pittsburgh, PA 15230

Chia-Soon Ku

National Bureau of Standards

Washington, DC 20234

Christian LaFrenz

Fa. Haberland \& Co.

Mineralol-Raffinerie

Bahnhofst. 82

Dollbergen, 3161

WEST GERMANY

Richard Lee

US Army/JOAP-TSC

5950 Keystone Rd.

Pensacola, FL 32504

Leonard $H$. Lemon

Energy \& Minerals Research Co.

964 E. Swedesford Road

P. 0. Box 389

Exton, PA 19341
Robert Lindquist

I11. Institute of Natural

Resources

325 W. Adams - Rm 300

Springfield, IL 62558

R. E. Linnard

Phillips Petroleum Co.

429 TRW Building

Bartlesville, OK 74004

Donald A. Littlefield

ATC Petroleum, Inc.

01d Dover Road

Newington, NH 03801

Eugene S. Lubarsky

A. Johnson \& Co.

110 E. 59th Street

New York, NY 10022

John A. Ludquist

Quaker State 0il Refining Corp. Research Center

P. 0. Box 989

$0 i 1$ City, PA 16301

James A. McBain

Association of Petroleum Re-refiners - Suite 700

1101 Connecticut Avenue, NW

Washington, DC 20036

James F. McCadden

Baird Corp.

125 Middlesex Turnpike

Bedford, MA 01730

Edward W. McCrary

Louisiana 0 il \& Re-refining

2156 Scenic Highway

Baton Rouge, LA 70802

Alan Maciejewski

Naval Air Engineering Ctr.

Code 92724

Lakehurst, NJ 08733

H. P. Martin

Office of Naval Research

Code 211

Arlington, VA 22217

Peter M. Mehiel

EkoTek Lube, Inc.

7901 0akport St., 140 So.

0akland, CA 94621

David Mentzer

Exxon Research \& Engineering Co.

P. 0. Box 101

Florham Park, NJ 07932 
Louis A. Mileto

Systems Engineering Test

Directorate

Naval Air Test Center

Patuxent River, MD 20670

Thomas Myers

Booz, Allen \& Hamilton

4330 East West Highway

Bethesda, MD 20014

Christian D. Nelson

Armco

4805 Longford $\mathrm{Dr}$.

Middletown, $\mathrm{OH} 45042$

Ray Nye

Wills 0 il Co. Ltd.

533 Powell Street

Vancouver, BC V6A-1GA

CANADA

John P. O'Connell

Estech 0il Company

7601 West 47 th Street

McCook, IL 60525

David H. Parent

3400 Custer Road, Apt. 2040

Plano, TX 75023

E. Passaglia

National Bureau of Standards

Materials Bldg. Room B-308

Washington, DC 20234

Robert F. Pedall

Motor 0ils Refg. Co.

Estech 0 il Co.

7601 W 47th St.

McCook, IL 60525

Patrick Pei

National Bureau of Standards

Office of Recycled Materials

Washington, DC 20234

Glen A. Peters

AT\&SF Railway Company

P. 0. Box 536

Barstow, CA 92311

I. C. Peterson

Hydromatic Division

General Motors

Ypsilanti, MI 48197

Marshall Peterson

Wear Sciences

925 Mallard Circle

Arnold, MD 21012
D. G. Phillips

Md. Environmental Service

60 West St.

Annapolis, MD 21401

Jack Poley

Lubricon

30 Horseneck

Montville, NJ 07045

John S. Poupore

Consulting Engineer Contact

Work on 0 il Refining

Government of Canada

ottawa, CANADA KIN 8MI

R. Rebbert

National Bureau of Standards

Washington, DC 20234

Richard L. Riedel

The Standard 0 il Co.

3092 Broadway

Cleveland, $\mathrm{OH} \quad 44115$

A. L. Rollin

Ecole Polytechnique

Chem. Eng. Dept.

CP 6079

Montreal, CANADA

Carleton Rowe

Mobil Research and Development

Box 1025

Princeton, NJ 08540

J. Rowland

BP Trading, Ltd.

Britannic House, Moor Lane

London, ENGLAND EC2Y 9BU

A. W. Ruff

National Bureau of Standards

Materials B1dg., Room B-114

Washington, DC 20234

C. Salvesen

Mobil Research \& Development

Box 1025

Princeton, NJ 08540

Eugene W. Sanders

Cities Service Company

P. 0. Drawer \#2

Cranbury, NJ 08512

Lowrie B. Sargent, Jr.

Aluminum Co. of America

Alcoa Laboratories

Alcoa Technical Center

Alcoa Center, PA 15069 
John W. Schulte

The Lubrizol Corp.

Wickliffe, OH 44092

Charles Schwarz

Martel Laboratories

1025 Cromwe 11 Bridge Rd.

Baltimore, MD 21204

Adam Scott

North Carolina Dept. of Ag.

Consumer Standards Div.

P. 0. Box 26056

Raleigh, NC 27611

Morton Segal

Petrocon Corporation

Union Street

P. 0. Box 96

Modena, PA 19358

Theodore W. Selby

Savant, Inc.

234 E. Larkin

Midland, MI 48640

Peter Senholzi

Mechanical Technology Inc.

1745 Jefferson Davis Highway

Crystal Square 4, Suite 301

Arlington, VA 22202

E. J. Shalling

The Torrington Co.

59 Field Street

Torrington, CT 06790

W. A. Shelton

Union Carbide Corp. Tech. Ctr.

P. 0. Box 8361

South Charleston, WV 25303

T. R. Shives

National Bureau of Standards

Materials Bldg., Room A-111

Washington, DC 20234

John B. Skiba

Pennzoil Company

P. 0. Box 8989

Richmond, VA 23225

Richard Slocum

Ministry of Transportation

\& Communications

1201 Wilson

Downsview, Onatrio

CANADA
R. A. Smucker

Gulf Research \& Dev. Co.

P. 0. Drawer 2038

Pittsburgh, PA 15230

Ernest F. Spano

US Army Aviation Ctr. \& Ft. Rucker

ATTN: ATZQ-DI-S/S (0il Analysis Sec)

Ft. Rucker, AL 36362

Ilgvars J. Spilners

Gulf Science \& Tech.

P. 0. Drawer 2038

Pittsburgh, PA 15230

Leon Stallings

Naval Air Develop. Center

Code 60612

Warmiasler, PA 18042

William C. Starr

Mobil Research \& Dev. Corp.

Research Dept.

Paulsboro, NJ 08066

David M. Stehouwer

Fuels and Lubricants Dept.

General Motors Res. Labs.

Warren, MI 48090

J. E. Stern

NASA/Goddard

Code 721

Greenbelt, MD 20771

Roy J. Street

MoHawk Lubricants Ltd.

6400 Roberts Street

Burnaby, BC V5G 4G2

Paul Strigner

National Research Council of Canada

Div. of Mechanical Eng.

Ottawa, CANADA KIA OR6

John W. Swain, Jr.

Swain Associates

40 Denton Road

Wellesleg, MA 02181

E. S. Swanson, Jr.

Exxon Corporation

P. 0. Box 389

Florham Park, NJ 07932

H. Ed Taber

Taber 0 il Co.

835 Madison St.

Port Clinton, $\mathrm{OH} 43452$ 
Thomas A. Tagliamonte

The Lubrizol Corporation

29400 Lakeland B Tvd.

wickliffe, $\mathrm{OH} 44092$

Jerry L. Thompson

Amoco 0 il

P. 0. Box 400

Naperville, IL 60540

Harold E. Tiffany

American Petroleum Institute

2101 L Street

Washington, DC 20037

W. Tsang

National Bureau of Standards

Washington, D. C. 20234

Mike Valtierra

Army Fuels \& Lubricants Res. Lab.

P. 0. Box 28510

6220 Culebra Road

San Antonio, TX 78284

John T. Vrombaut

Technical Center

Deere \& Co.

3300 River Drive

Moline, IL 61265

James Walker

National Bureau of Standards

Washington, DC 20234

John G. Walsh

Husky 0 il Co.

600 S. Cherry St.

Denver, C0 80222

Michael S. Ward

Tennessee $0 i 1$ \& Refining, Inc.

Highway 109

Portland, TN 37148

Stephen Weeks

National Bureau of Standards

office of Recycled Materials

Washington, DC 20234

Ken Weinstein

Booz, Allen \& Hamilton

4330 East West Highway

Bethesda, MD 20014

Norman J. Weinstein

Recon Systems, Inc.

P. 0. Box 842

Somerville, NJ 08876
Jerry Wilkins

Suntech Inc.

1608 Walnut Street

Philadelphia, PA 19103

W. A. Willard

National Bureau of Standards

Materials B1dg. Room B-128

Washington, DC 20234

T. A. Wilson

Dalton \& Company Limited

Silkolene 0 il Refinery

Belper, Derbyshire DE5 IWF

ENGLAND

Keith L. Winegar

Intermountain 0 il Co.

Woods Cross, UT 84087

Harvey Yakowitz

National Bureau of Standards

Recycled $0 i 1$ Program

Washington, DC 20234 
Joint Conference on Measurements and Standards for Recycled 0i1/Systems Performance and Durability held at the National Bureau of Standards on October 23-26, 1979.

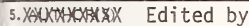

Donald A. Becker

\begin{tabular}{l|c|}
\hline 6. PERFORMING ORGANIZATION (If joint or other thon NBS, see instructions) & 7. Contract/Grant No. \\
NATIONAL BUREAU OF STANDARDS & \\
$\begin{array}{l}\text { DEPARTMENT OF COMMERCE } \\
\text { WASHINGTON, D.C. } 20234\end{array}$ & 8. Type of Report \& Period Covered \\
\end{tabular}

9. SPONSORING ORGANIZATION NAME AND COMPLETE ADDRESS (Street, City, State, ZIP)

Recycled 0il Program, NBS; ASTM Technical Division P, on Recycled Petroleum Products; Mechanical Failure Prevention Group (MFPG); Center for Materials Science, NBS; Office of Naval Research; Department of Energy; NASA/Goddard Space Flight Center; Naval Air Systems Command.

10. SUPPLEMENTARY NOTES

Library of Congress Catalog Card Number: 80-600159

Document describes a computer program; SF-185, FIPS Software Summary, is attached.

11. ABSTRACT (A 200-word or less foctual summary of most significant informotion. If document includes a significant bibliography or literoture survey. mention it here)

This publication is a formal report of the Joint Conference on Measurements and Standards for Recycled 0il/Systems Performance and Durability held at the National Bureau of Standards on October 23 through 26, 1979. There were seven sessions on specific areas, with a total of 32 technical presentations. The subject areas were as follows: (I) Recent Developments in Recycled 0il, (II) Engine 0il Evaluation, (III) Lube 0il Base Stock Characterization, (IV) 011 Analysis for Engine Condition Monitoring, (V) Bench Tests for 0il Evaluation - I, (VI) Bench Tests for $0 i 1$ Evaluation - II, and (VII) Systems Performance and Durability. Included in this report are the entire texts of the various presentations, including figures and tables.

12. KEY WORDS (Six to twelve entries; alphabetical order; capitalize only proper names; and separate key words by semicolons) Engine oil; hydraulic oil; industrial oil; lubricating oil; oil specifications; petroleum standards; petroleum test methods; recycled oil; re-refined oil; used oil; waste $0 i 1$.

13. AVAILABIL!TY

XX Unlimited

For Official Distribution. Do Not Release to NTIS

XX Order From Superintendent of Documents, U.S. Government Printing Office, Washington, D.C. 20402.

Order From National Technical Information Service (NTIS), Springfield, VA. 2216I

14. NO. OF

PRINTED PAGES

334

15. Price

$\$ 8.00$ 


\section{NBS TECHNICAL PUBLICATIONS}

\section{PERIODICALS}

JOURNAL OF RESEARCH-The Journal of Research of the National Bureau of Standards reports NBS research and development in those disciplines of the physical and engineering sciences in which the Bureau is active. These include physics, chemistry, engineering, mathematics, and computer sciences. Papers cover a broad range of subjects, with major emphasis on measurement methodology and the basic technology underlying standardization. Also included from time to time are survey articles on topics closely related to the Bureau's technical and scientific programs. As a special service to subscribers each issue contains complete citations to all recent Bureau publications in both NBS and nonNBS media. Issued six times a year. Annual subscription: domestic \$13: foreign \$16.25. Single cony. \$3 domestic: \$3.75 loreign.

NOTE: The Journal was formerly published in two sections: Section A "Physics and Chemistry" and Section B "Mathematical Sciences."

DIMENSIONS/NBS-This monthly magazine is published to inform scientists, engineers, business and industry leaders, teachers, students, and consumers of the latest advances in science and technology, with primary emphasis on work at NBS. The magazine highlights and reviews such issues as energy research, fire protection, building technology, metric conversion, pollution abatement, health and safety, and consumer product performance. In addition, it reports the results of Bureau programs in measurement standards and techniques, properties of matter and materials. engineering standards and services, instrumentation, and automatic data processing. Annual subscription: domestic SII; foreign $\$ 13,75$.

\section{NONPERIODICALS}

Monographs-Major contributions to the technical literature on various subjects related to the Bureau's scientific and technical activities.

Handbooks-Recommended codes of engineering and industrial practice (including safety codes) developed in cosperation with interested industries, professional organizations, and regulatory bodies.

Special Publications-Include proceedings of conferences sponsored by NBS, NBS annual reports, and other special publications appropriate to this grouping such as wall charts, pocket cards, and bibliographies.

Applied Mathematics Series-Mathematical tables, manuals, and studies of special interest to physicists, engineers, chemists, biologists, mathematicians, computer programmers, and others engaged in scientific and technical work.

National Standard Reference Data Series-Provides quantitative data on the physical and chemical properties of materials, compiled from the world's literature and critically evaluated. Developed under a worldwide program coordinated by NBS under the authority of the National Standard Data Act (Public Law 90-396).
NOTE: The principal publication outlet for the foregoing data is the Journal of Physical and Chemical Reference Data (JPCRD) published quarterly for NBS by the American Chemical Society (ACS) and the American Institute of Physics (AIP). Subscriptions, reprints, and supplements available from ACS, 1155 Sixteenth St. NW, Washington, DC 20056.

Building Science Series-Disseminates technical information developed at the Bureau on building materials, components, systems, and whole structures. The series presents research results, test methods, and performance criteria related to the structural and environmental functions and the durability and safety characteristics of building elements and systems.

Technical Notes-Studies or reports which are complete in themselves but restrictive in their treatment of a subject. Analogous to monographs but not so comprehensive in scope or definitive in treatment of the subject area. Often serve as a vehicle for final reports of work performed at NBS under the sponsorship of other government agencies.

Voluntary Product Standards-Developed under procedures published by the Department of Commerce in Part 10, Title 15, of the Code of Federal Regulations. The standards establish nationally recognized requirements for products, and provide all concerned interests with a basis for common understanding of the characteristics of the products. NBS administers this program as a supplement to the activities of the private sector standardizing organizations.

Consumer Information Series-Practical information, based on NBS research and experience, covering areas of interest to the consumer. Easily understandable language and illustrations provide useful background knowledge for shopping in today's technological marketplace.

Order the above NBS publications from: Superintendent of Documents, Government Printing Office, Washington, DC 20402

Order the following NBS publications-FIPS and NBSIR's-from the Vational Technical Information Services, Springfield. VA 22161.

Federal Information Processing Standards Publications (FIPS PUB)-Publications in this series collectively constitute the Federal Information Processing Standards Register. The Register serves as the official source of information in the Federal Government regarding standards issued by NBS pursuant to the Federal Property and Administrative Services Act of 1949 as amended, Public Law 89-306 (79 Stat. 1127), and as implemented by Executive Order 11717 (38 FR 12315, dated May 11, 1973) and Part 6 of Title 15 CFR (Code of Federal Regulations).

NBS Interagency Reports (NBSIR)-A special series of interim or final reports on work performed by NBS for outside sponsors (both government and non-government). In general, initial distribution is handled by the sponsor; public distribution is by the National Technical Information Services, Springfield, VA 22161, in paper copy or microfiche form.

\section{BIBLIOGRAPHIC SUBSCRIPTION SERVICES}

The following current-awareness and literature-survey bibliographies are issued periodically by the Bureau:

Cryogenic Data Center Current Awareness Service. A literature survey issued biweckly. Annual subscription: domestic \$35; foreign $\$ 45$

Liquefied Jatural Gas. A literature survey issued quarterly. Annual subscription: $\$ 30$.
Superconducting Devices and Materials. A literature survey issued quarterly. Annual subscription: \$45. Please send subscription orders and remittances for the preceding bibliographic services to the National Bureau of Standards, Cryogenic Data Center (736) Boulder, CO 80303 . 
POSTAGE ANO FEES PAIO

OFFICIAL BUSINESS U.S. OEPARTMENT OF COMMERCE COM-215

Penalty for Private Use, \$300 